\title{
A Unified Representation of Gas-Phase Element Depletions in the Interstellar Medium ${ }^{1}$
}

\author{
Edward B. Jenkins \\ Princeton University Observatory \\ Princeton, NJ 08544-1001 \\ ebj@astro.princeton.edu
}

\begin{abstract}
A study of gas-phase element abundances reported in the literature for 17 different elements sampled over 243 sight lines in the local part of our Galaxy reveals that the depletions into solid form (dust grains) are extremely well characterized by trends that employ only three kinds of parameters. One is an index that describes the overall level of depletion applicable to the gas in any particular sight line, and the other two represent linear coefficients that describe how to derive each element's depletion from this sight-line parameter. The information from this study reveals the relative proportions of different elements that are incorporated into dust at different stages of grain growth. An extremely simple scheme is proposed for deriving the dust contents and metallicities of absorption-line systems that are seen in the spectra of distant quasars or the optical afterglows of gamma-ray bursts. Contrary to presently accepted thinking, the elements sulfur and krypton appear to show measurable changes in their depletions as the general levels of depletions of other elements increase, although more data are needed to ascertain whether or not these findings truly compelling. Nitrogen appears to show no such increase. The incorporation of oxygen into solid form in the densest gas regions far exceeds the amounts that can take the form of silicates or metallic oxides; this conclusion is based on differential measurements of depletion and thus is unaffected by uncertainties in the solar abundance reference scale.
\end{abstract}

Subject headings: ISM: abundances ISM: atoms - ultraviolet: ISM

\footnotetext{
${ }^{1}$ Based in large part on published observations from (1) the NASA/ESA Hubble Space Telescope obtained at the Space Telescope Science Institute, which is operated by the Association of Universities for Research in Astronomy, Inc., under NASA contract NAS 5-26555 (2) the Far Ultraviolet Spectroscopic Explorer (FUSE) mission operated by Johns Hopkins University, supported by NASA contract NAS5-32985 and (3) The Copernicus satellite, supported by NASA grant NAGW-77 to Princeton University.
} 


\section{Introduction}

\subsection{Brief History}

For atomic species in the neutral interstellar medium (ISM), nearly all of the transitions out of the ground electronic state of the preferred ionization stages for H I regions occur in the ultraviolet part of the electromagnetic spectrum. While the elements Be and Ti have such transitions at visible wavelengths (Dunham 1939; Spitzer \& Field 1955; Habing 1969), only those from singly-ionized titanium are strong enough to yield detectable absorption features in the spectra of background stars, leaving this element as the only one that has been successfully surveyed from ground-based observatories to derive the atomic abundances in the ISM (Wallerstein \& Goldsmith 1974; Stokes 1978; Wallerstein \& Gilroy 1992; Welsh et al. 1997; Prochaska, Tripp, \& Howk 2005; Ellison, Prochaska, \& Lopez 2007). Attempts even with powerful telescopes of the present era have failed to show measurable amounts of Be II in the ISM (Boesgaard 1985; Hébrard et al. 1997). Useful kinematic information could be derived from the strong visible absorption features from atomic species in stages below the preferred ones, e.g., Na I and Ca II (Merrill et al. 1937; Adams 1949; Münch 1957; Münch \& Zirin 1961), but quantitative abundances were difficult to obtain owing to uncertainties in our knowledge of the physical conditions and atomic physics parameters that govern the ionization balances (Strömgren 1948; Herbig 1968).

In large part, for investigations of the abundances of gas-phase atomic constituents in the ISM of our Galaxy, it is essential that this research be conducted by observatories above the Earth's atmosphere 2 The earliest observations of UV stellar spectra at moderate resolution were carried out using small photographic spectrographs on sounding rockets, but the spectra were only good enough to sense the presence of interstellar features (Morton \& Spitzer 1966; Morton, Jenkins, \& Bohlin 1968), without permitting derivations any column densities except for that of atomic hydrogen based on L $\alpha$ absorption (Jenkins 1970, 1971). The first satellite to provide stellar spectra was the second Orbiting Astronomical Observatory (OAO-2) that was launched in 1968, but once again only L $\alpha$ absorption features provided any useful information on the ISM (Savage \& Jenkins 1972; Jenkins \& Savage 1974).

The era of investigations of UV interstellar absorption features from heavy elements began in earnest with a series of observations with the far-UV spectrometer (Rogerson et al. 1973a) aboard the Copernicus satellite, a facility that provided stellar spectra of high precision over a decade that started 37 years ago (Jenkins et al. 1973; Morton et al. 1973; Rogerson et al. 1973b; Spitzer et al. 1973); see an early review of highlights by Spitzer \& Jenkins (1975). Among the principal findings that emerged from these studies was that, to varying degrees, the abundances of heavy elements in atomic form relative to that of hydrogen were below the solar abundance ratios, which are presumed to approximate the true total element abundances for the ISM in our part of the

\footnotetext{
${ }^{2}$ An exception was the BUSS balloon-borne payload which could observe over limited wavelength intervals in the near-UV (de Boer et al. 1986).
} 
Galaxy. The differences in these two abundances were taken to represent the loss of atoms into solid form within dust grains, a picture that was reinforced by the approximate trend in the strengths of depletions relative to measures of chemical affinity, such as condensation temperatures in a chemical equilibrium of an extended stellar atmosphere (Field 1974) or atomic sticking probabilities that can govern how rapidly different elements are incorporated into the grains as they grow in the ISM (or, conversely, how easily they are returned to the gas phase by sputtering).

The International Ultraviolet Explorer (IUE) extended our reach to stars that were fainter than those observable with Copernicus and allowed a far greater number of features and stars to be observed [e.g., Van Steenberg \& Shull (1988)], but the accuracies of the line measurements were not as good as those that were obtained previously with Copernicus. Later, several new instrumental developments brought about considerable progress in the study of atomic absorption lines. First, after the launch of the Hubble Space Telescope (HST) in 1992, we experienced substantial improvements in wavelength resolution and the ability to observe faint stars, which in turn broadened our knowledge of depletion trends over more elements and sightlines (Savage \& Sembach 1996a). This facility, in conjunction with the Far Ultraviolet Spectroscopic Explorer (FUSE) satellite that came later, also increased our coverage to systems outside our galaxy, such as the Small and Large Magellanic Clouds (Roth \& Blades 1997; Welty et al. 1997, 2001; Mallouris 2003; Sofia et al. 2006), NGC 1705 (Sahu \& Blades 1997), I Zw18 (Aloisi et al. 2003), NGC 625 (Cannon et al. 2005) and SBS1543+593 (Bowen et al. 2005). Second, large aperture telescopes on the ground with high resolution echelle spectrographs extended our reach to gas systems in front of bright quasars at high redshift, where the UV transitions could be viewed at visible wavelengths. In recent years, new opportunities have arisen to view gases within or in front of the host galaxies of gamma ray bursts (GRBs), whose optical afterglows are often bright enough to permit observations to be performed at high wavelength resolution. With the study of these new systems came a higher level of complexity, since the results could be influenced by not only dust depletion but also intrinsic abundance differences of these objects, many of which are less chemically evolved than our Galaxy (Pettini et al. 1994, 1997, 1999, 2002; Lu et al. 1996; Prochaska \& Wolfe 2002; Pettini 2003; Khare et al. 2004; Prochaska 2004; Kulkarni et al. 2005; Wolfe, Gawiser, \& Prochaska 2005; Péroux et al. 2006a,b, 2008; Vladilo et al. 2006; Prochaska et al. 2007; Vladilo, J. 2008; Calura et al. 2009). One of the aims of the present paper is to give some guidance on how these two effects can be separated from each other (\$10.4).

\subsection{General Findings on Depletions}

Aside from the differences in depletions from one element to the next, it has been noted that the overall strengths of depletions of many elements collectively show large changes over different lines of sight. Attempts to understand these variations have been moderately successful, but not without some ambiguity. For instance, Savage \& Bohlin (1979), Harris, et al. (1984), Jenkins et al. (1986) Jenkins (1987) and Crinklaw et al. (1994) showed that the depletion strengths correlated 
well with the average density of hydrogen along each sight line. This measure is admittedly a crude indication of local conditions, since one cannot distinguish a uniform density over a long extent from strongly clumped, denser material with a low filling factor. Nevertheless Spitzer (1985) created a simple model for explaining the observations in terms of random mixtures of three different kinds of clouds with different densities and depletion strengths. A slightly different tactic was adopted by Savage \& Sembach (1996a), who summarized element depletions in terms of averages of warm (presumably low density) gas and cool (denser) gas, with some recognition of the differences between gas in the disk of the Galaxy and gas in the lower part of the halo. In their study that compared column densities of Si III and Al III, Howk \& Savage (1999) showed that even fully ionized regions exhibited depletions onto dust grains.

Other ways of characterizing depletions for different lines of sight included simply comparing them to the hydrogen column density, i.e., not divided by the length of the sight line to obtain an average density (Wakker \& Mathis 2000) or, alternatively, comparing them to the fraction of hydrogen atoms that are in molecular form (Cardelli 1994; Snow, Rachford, \& Figoski 2002; Jensen, Rachford, \& Snow 2005; Jensen, \& Snow 2007a,b). The former of the two methods is one that is useful for lines of sight that extend out far from the Galactic plane, where the effective length is of order of the scale height times the cosecant of the Galactic latitude. The latter represents an attempt to obtain a more accurate index for sight-line conditions, but it has the drawback of not factoring in variables other than local density that govern the molecular fraction, such as the strength of dissociating radiation field, the self shielding of the $\mathrm{H}_{2}$ transitions, or the finite amount of time needed to reach an equilibrium state.

All of the above comparisons with external sight-line variables were carried out for each element independently, with the recognition that the characters of the trends would differ from one case to the next but ultimately could be compared with each other. A shortcoming of this approach is that the individual investigations are weakened by two factors that are difficult to control: (1) errors in the individual measurements (for both the depletions of single elements and the external variables) and (2) a lack of fidelity between the external variables and whatever real depletion processes that they are supposed to represent.

\subsection{New Approach}

The approach of the present study is to concentrate on how the depletions of different elements are found to relate to each other, irrespective of any external factors, but with the recognition that the severity of the depletions generally differ in a systematic way from one location to another and from one element to the next. Our objective is to build a framework that describes the depletions in terms of a set of simple parameters that form an abstract model that can be used later to investigate some important issues on the formation and destruction of dust grains. The general protocol is developed in $\$ 2.2$ based on an exposition of some empirical findings about element depletions; we demonstrate this by using two comparisons for three different elements that were chosen to give 
the most instructive examples. On the basis of these findings, assuming they apply generally, one can develop an equation with a few free parameters that offers an acceptable fit to the observations (\$3) and then use a comprehensive survey of depletions gathered from measurements that have already been published (\$4) to derive the best solutions for the parameter values (\$5]). In $₫ 6$ we explore how these parameters offer insights on the elemental compositions of dust grains and how the mix in the buildup of these grains changes as the overall severity of depletions increase. Here, we supply the basic information that can be used to build upon the earlier interpretations by Spitzer \& Fitzpatrick (1993), Fitzpatrick \& Spitzer (1994), Sofia, Cardelli \& Savage (1994), Sembach \& Savage (1996), Mathis (1996) and Draine (2004) on some plausible mixtures of grain compounds that are consistent with the amounts of missing gas atoms.

The conclusions presented here on the highly predictable patterns of element depletions open the way for investigations of intrinsic abundances in Damped Lyman Alpha (DLA) and other gas systems that are seen in absorption in the spectra of distant QSOs or the optical afterglows of gamma-ray bursts (GRBs). A straightforward method of compensating for the loss of material into dust grains in such systems is presented in \$10.4, based on a simple least-squares fit to a linear equation (\$7), which then allows the total elemental abundances to be derived from the measured gas-phase column densities. This approach is also useful for the determinations of depletions in our Galaxy for which measures of hydrogen are not available, such as surveys of matter in front of white dwarf stars that are at distances up to about 100 pc from the Sun (88).

\section{Concept}

The depletion of an element $X$ in the ISM is defined in terms of (a logarithm of) its reduction factor below the expected abundance relative to that of hydrogen if all of the atoms were in the gas phase,

$$
\left[X_{\text {gas }} / \mathrm{H}\right]=\log \{N(X) / N(\mathrm{H})\}-\log (X / \mathrm{H})_{\odot},
$$

which is based on the assumption that solar abundances $(X / H) \odot$ are good reference values that truly reflect the underlying total abundances. In this formula, $N(X)$ is the column density of element $X$ and $N(\mathrm{H})$ represents the column density of hydrogen in both atomic and molecular form, i.e., $N(\mathrm{H} \mathrm{I})+2 N\left(\mathrm{H}_{2}\right)$. The missing atoms of element $X$ are presumed to be locked up in solids within dust grains or large molecules that are difficult to identify spectroscopically, with fractional amounts (again relative to $\mathrm{H}$ ) given by

$$
\left(X_{\text {dust }} / \mathrm{H}\right)=(X / \mathrm{H}) \odot\left(1-10^{\left[X_{\text {gas }} / \mathrm{H}\right]}\right) .
$$

\subsection{Reference Abundances}

One issue that has bedeviled investigators of interstellar depletions has been the mutually inconsistent results from reasonable sources of information on the "cosmic reference abundances," 
which, as stated above, are taken here to be $(X / \mathrm{H}) \odot$. Viewpoints on these abundance scales have changed through the years due either to different opinions on how they should be linked to the abundances in different types of stars (or H II regions) or, alternatively, to actual changes in some of the measurement outcomes themselves (Mathis 1996; Savage \& Sembach 1996a; Snow \& Witt 1996; Sofia \& Meyer 2001; Li 2005). The most dramatic revisions in the recent past (and some of the most important ones for the ISM) have been for the solar abundances of the elements $\mathrm{C}, \mathrm{N}$ and $\mathrm{O}$ relative to $\mathrm{H}$, where the values have decreased by about -0.2 dex from previously accepted scales (Grevesse \& Sauval 1998), but which still exhibit disquieting fluctuations from one determination to the next (Holweger 2001; Allende Prieto, Lambert, \& Asplund 2002; Asplund et al. 2004, 2005; Socas-Navarro \& Norton 2007; Allende Prieto 2008; Centeno \& Socas-Navarro 2008; Meléndez \& Asplund 2008; Caffau et al. 2009). These newer abundances now seem to be in accord with recent studies of B-star abundances (Daflon et al. 2003; Nieva \& Przybilla 2008a,b) but are inconsistent with the results from helioseismological studies of the sound speed and depth of the convection zone inside the Sun (Bahcall et al. 2005a,b; Antia \& Basu 2005, 2006), which favor the earlier abundances when the opacities are computed (Badnell et al. 2005).

For the study of interstellar depletions presented here, we adopt the abundances compiled by Lodders (2003) for the proto-Sun, which she estimates to have been higher by 0.07 dex than the current abundances in the solar photosphere (due to the fact that some gravitational settling may have occurred, thus depleting the photospheric abundances by this amount). These abundances will be adopted to represent our view of the expected atomic densities relative to that of hydrogen when there are no dust grains or molecules present. However, they are somewhat higher than the abundances of nearby B-type stars determined by Przybilla, Nieva \& Butler (2008), suggesting that the 0.07 dex upward corrections may be too large.

One unique aspect of the study here will be the development of a way to learn about the depletion of atoms onto dust grains that does not depend on the correctness of the reference abundances. This approach, which looks at differential changes in element atomic gas abundances instead of absolute depletions, will be presented in 6 .

\subsection{Underlying Strategy}

To gain an understanding of how depletions behave under different conditions, it is helpful to compare the trends for pairs of elements over different lines of sight. This comparison will lay the groundwork for the analysis that will be developed in later sections of this paper. Figure 1 shows two such comparisons, using depletions extracted from the data discussed in 4 . The depletions of $\mathrm{Mg}$ and $\mathrm{P}$ shown in the upper panel of the figure for a collection of individual sight lines exhibit an approximately linear relationship with respect to each other, with a slope slightly steeper than unity and with an intercept at the axis representing zero $\mathrm{P}$ depletion being about 0.5 dex below the zero axis for the $\mathrm{Mg}$ depletion. This displacement of the zero point indicates that $\mathrm{Mg}$ shows a small amount of depletion when $\mathrm{P}$ is undepleted, but this conclusion is dependent on the accuracy 


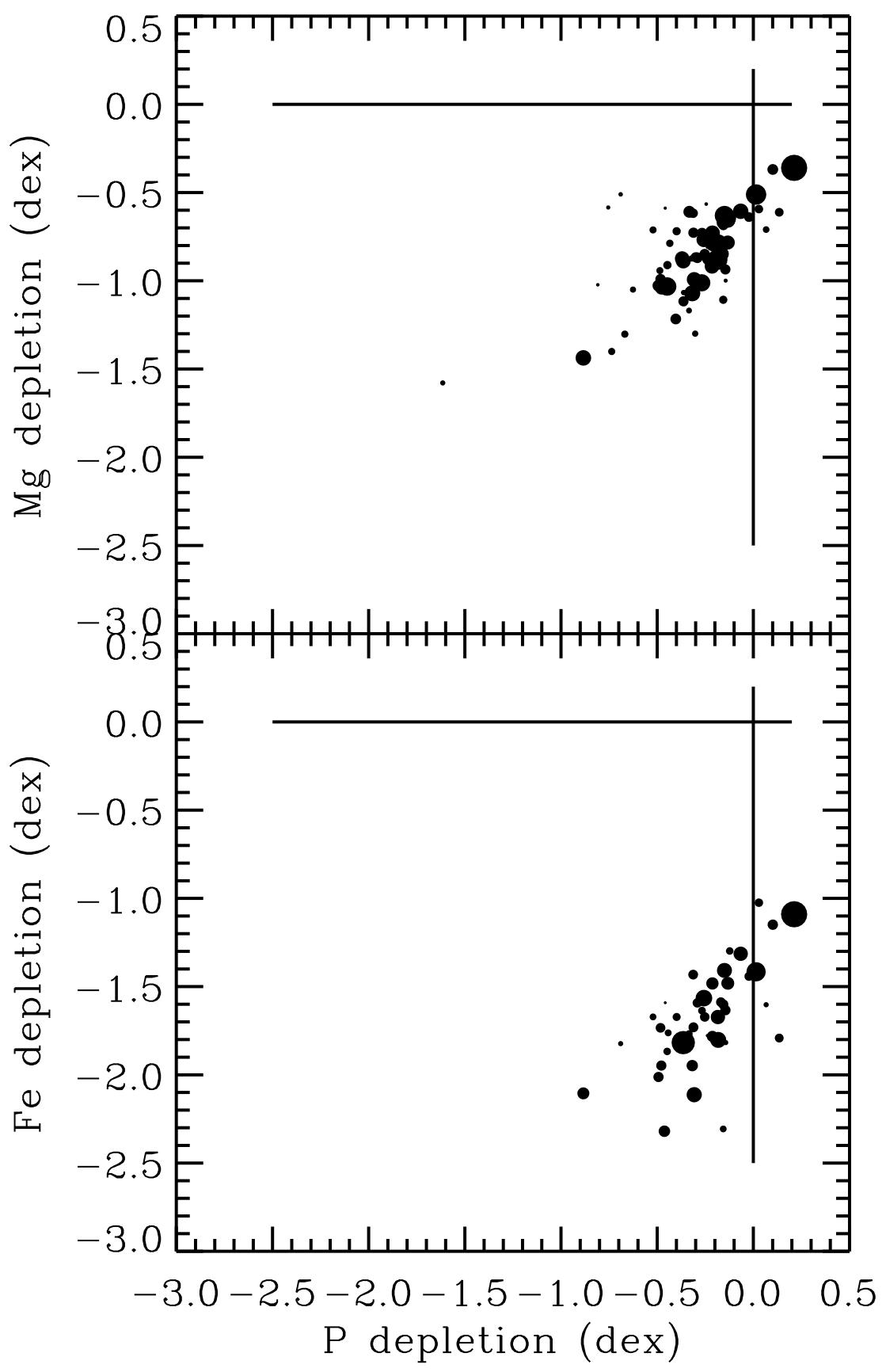

Fig. 1. - Interstellar atomic depletion factors $\left[\mathrm{Mg}_{\text {gas }} / \mathrm{H}\right]\left(\right.$ top panel) and $\left[\mathrm{Fe}_{\text {gas }} / \mathrm{H}\right]$ (bottom panel) vs. $\left[\mathrm{P}_{\text {gas }} / \mathrm{H}\right]$. Measurements with small errors are depicted with disks that have large diameters, while those with large errors are more point-like. 
of both the respective solar abundances of these two elements and the $f$-values of the transitions used to measure their interstellar abundances, together with the applicability of the assumption that solar abundances are a correct standard to apply to elements in the ISM 3 While this may be so, the slope of the line has no sensitivity to these uncertainties; it depends only on the correctness of the derived column densities. The lower panel of the figure shows that the same behavior is seen when the depletions of $\mathrm{Fe}$ and $\mathrm{P}$ are compared; it is important to note that the slope and intercept of a best fit to these points are larger in magnitude than for $\mathrm{Mg}$ and $\mathrm{P}$. A diagram similar to these two has been presented earlier by Fitzpatrick (1996) for the elements Fe and Si vs. S (see his Fig. 2), and the qualitative features are fundamentally similar.

By extension from these two examples, one can anticipate that there could be a linear relationship between all depletions; that is, in the hyperspace whose axes represent the strengths of depletions of all the different elements, an acceptable fit to the data for different sight lines will approximately conform to a single straight line. An alternative to this representation is to describe the depletion of each element in terms of a linear relationship against a generalized depletion parameter that is common to all elements through some linear relations, but which can change from one line of sight to the next. This approach will be adopted for this paper.

\section{Definitions 4 and Derivations of Parameters}

The line-of-sight depletion strength factor, which we denote as $F_{*}$, represents how far the depletion processes have progressed collectively for all elements for any given case, i.e., a larger $F_{*}$ implies a stronger depletion for all elements. Aside from a few exceptions discussed in 4.3 we are generally not able to sense true local depletions for different regions along any sight line, but only the results in the form of a single value for each element that represents a composite view of such depletions taken from samples seen in projection. We examine the consequences of this kind of blend in a later section ( $\$ 7.2)$, where an example with kinematically distinct parcels of gas with different depletions is analyzed as a single unit.

The slope of a best-fit line for the observed depletions $\left[X_{\text {gas }} / \mathrm{H}\right]_{\text {obs }}$ for any given element $X$ against $F_{*}$ may be called $A_{X}$, and this parameter represents the propensity of that element to increase (the absolute value of) its particular depletion level as $F_{*}$ becomes larger. For even the smallest observed values of $F_{*}$, most elements still show some depletion, as we learned from Fig. 1,

\footnotetext{
${ }^{3}$ The fact that some measurements of the abundances of $\mathrm{P}$ seem to be above the solar value demonstrates that depletion measurements are subject to these three types of systematic errors. However, the $f$-value adopted for the strongest $\mathrm{P}$ line, a line that is most influential in measuring the abundance of $\mathrm{P}$ for sightlines with low column densities, has recently been re-examined by Federman et al. (2007), and their new measurements show that the earlier value of the line strength is essentially correct.

${ }^{4}$ Throughout this paper, symbols with asterisk subscripts pertain to different sight lines (mnemonic aid: think of "*” representing a target star), and $X$ subscripts denote different elements.
} 
We denote this level of depletion as $\left[X_{\text {gas }} / \mathrm{H}\right]_{0}$.

While the nature of $F_{*}$ has been defined, its numerical scale has not. That is, the values of $A_{X}$ and $\left[X_{\text {gas }} / \mathrm{H}\right]_{0}$ are dependent on this scale, which is arbitrary. We assign a value of 0 for $F_{*}$ to be that which corresponds to a sight line with the lowest collective depletions observed in our sample. At the opposite extreme, we define $F_{*}=1.0$ to conform approximately to the strength of depletions for the low velocity component $\left(v_{\odot}=-15 \mathrm{~km} \mathrm{~s}^{-1}\right)$ seen toward the star $\zeta$ Oph (HD149757), for which the best studied and most detailed information is available for the depletions of many different elements (Savage, Cardelli, \& Sofia 1992). The sight line toward this star has been generally regarded as a prototype of the strong depletions that are seen in the cold, neutral medium (Savage \& Sembach 1996a).

\subsection{Determinations of $\boldsymbol{F}_{*}$}

Now that we have defined two fiducial values of $F_{*}$, we can state that a best fit of the experimental data to differing values of this depletion parameter is given by the simple linear relation

$$
\left[X_{\text {gas }} / \mathrm{H}\right]_{\text {fit }}=\left[X_{\text {gas }} / \mathrm{H}\right]_{0}+A_{X} F_{*}
$$

subject to the normalization conditions for $F_{*}$ stated earlier. Unfortunately, the observations of depletions that are needed to define the parameters $\left[X_{\text {gas }} / \mathrm{H}\right]_{0}, A_{X}$ and $F_{*}$ are sparse. All elements have only a partial coverage of the sight lines, and many sight lines have only a few column density determinations. For this reason, coupled with the fact that each quantity is linked to the adopted values for the others, solutions for the values of $F_{*}$ for each of the sight lines had to be derived using a series of iterations, described in the next paragraph, for converging upon successively more accurate values of this quantity based on a set of provisional values $A_{X}^{\prime}$ of the fundamental parameters $A_{X}$ (which will be derived more accurately in a later calculation). The values for $A_{X}^{\prime}$ are continually adjusted to make them more realistically follow the element depletions during the iteration cycles that improve upon the $F_{*}$ solution set. We must also employ provisional values for the zero-point offsets $\left[X_{\text {gas }} / \mathrm{H}\right]_{0}$, which we denote as $\left[X_{\text {gas }} / \mathrm{H}\right]_{0}^{\prime}$. New values of $\left[X_{\text {gas }} / \mathrm{H}\right]_{0}^{\prime}$ are not derived in successive iteration steps because the accuracy of this parameter is not critical in defining $F_{*}$. The convergence of these iterations was monitored and found to be quite rapid and not dependent on the initial values input to the first iteration (except for small, uniform increases or decreases in all of the $A_{X}^{\prime}$ values from one trial case to the next, which are compensated by uniform changes in the opposite sense for the $F_{*}$ set).

The calculations begin with an evaluation of a weighted average of the available observed depletions $\left[X_{\text {gas }} / \mathrm{H}\right]_{\text {obs }}$ for a given line of sight, after they have had their respective zero-point depletions subtracted and have been normalized to the values of $A_{X}^{\prime}$,

$$
F_{*}=\frac{\sum_{X}\left\{W_{X}\left(\left[X_{\mathrm{gas}} / \mathrm{H}\right]_{\mathrm{obs}}-\left[X_{\mathrm{gas}} / \mathrm{H}\right]_{0}^{\prime}\right) / A_{X}^{\prime}\right\}}{\sum_{X} W_{X}},
$$


where the weight factors $W_{X}$ are set equal to the inverse squares of the combined uncertainties of the other terms in the sum, i.e.,

$$
W_{X}=\left(\sigma\left\{\left(\left[X_{\text {gas }} / \mathrm{H}\right]_{\mathrm{obs}}-\left[X_{\text {gas }} / \mathrm{H}\right]_{0}^{\prime}\right) / A_{X}^{\prime}\right\}\right)^{-2}
$$

( $W_{X}=0$ if the observation is unavailable for element $X$.) For the initial evaluation of Eq. 4, values of $A_{X}^{\prime}$ were set to the depletions of elements measured toward $\zeta$ Oph $\left(-15 \mathrm{~km} \mathrm{~s}^{-1}\right.$ velocity component) less the respective values of $\left[X_{\text {gas }} / \mathrm{H}\right]_{0}^{\prime}$, thus insuring that the scale for $F_{*}$ is approximately consistent with the definition stated earlier. The uncertainties in our derived values for $F_{*}$ are given simply by the relation

$$
\sigma\left(F_{*}\right)=\left(\sum_{X} W_{X}\right)^{-\frac{1}{2}} .
$$

The weights $W_{X}$ in Eq. 4 guarantee that depletion measurements with large relative errors have a weak influence in the outcome. These weights make use of error estimates for the quotients of the two terms that appear in Eq. 5, $\left[X_{\text {gas }} / \mathrm{H}\right]_{\text {obs }}-\left[X_{\text {gas }} / \mathrm{H}\right]_{0}^{\prime}$ and $A_{X}^{\prime}$. A conventional approach to evaluating these errors is to add in quadrature the relative errors of the two terms, yielding the relative error of the quotient. However, this scheme breaks down when the error of the denominator $\sigma\left(A_{X}^{\prime}\right)$ is not very much less than the denominator's value $A_{X}^{\prime}$. Appendix $\mathrm{A}$ shows how one may compute errors in the quotients when the errors of the two terms are moderately large.

At the point that an initial solution set for $F_{*}$ is obtained, revised values for $A_{X}^{\prime}$ can be evaluated from a counterpart to Eq. 4 with summations $\sum_{*}$ over applicable lines of sight,

$$
A_{X}^{\prime}=\frac{\sum_{*}\left\{W_{*}\left(\left[X_{\text {gas }} / \mathrm{H}\right]_{\text {obs }}-\left[X_{\text {gas }} / \mathrm{H}\right]_{0}^{\prime}\right) / F_{*}\right\}}{\sum_{*} W_{*}},
$$

which, as with Eq. 6, has an uncertainty

$$
\sigma\left(A_{X}^{\prime}\right)=\left(\sum_{*} W_{*}\right)^{-\frac{1}{2}}
$$

for

$$
W_{*}=\left(\sigma\left\{\left(\left[X_{\text {gas }} / \mathrm{H}\right]_{\text {obs }}-\left[X_{\text {gas }} / \mathrm{H}\right]_{0}^{\prime}\right) / F_{*}\right\}\right)^{-2} .
$$

Again, the scheme for deriving the errors of quotients is invoked to evaluate the error term that appears within the weight factor in Eq. 9. Once we have defined the improved values for $A_{X}^{\prime}$ and their associated errors using Eqs. 7[19, we start over by repeating the evaluations of $F_{*}$. We cycle through Eqs. 4 and 7 until the values of $F_{*}$ and $A_{X}^{\prime}$ stabilize.

\subsection{Determinations of $A_{X}, B_{X}$ and $z_{X}$}

Now that values of $F_{*}$ and their associated uncertainties for all lines of sight have been established, we can improve upon the earlier representations of element depletions that made use of the 
provisional parameters $\left[X_{\text {gas }} / \mathrm{H}\right]_{0}^{\prime}$ and $A_{X}^{\prime}$. We accomplish this by using a more direct (noniterative) approach for determining new parameters that describe how the gas-phase abundances of element $X$ should be depleted for different values of $F_{*}$. An improved linear form

$$
\left[X_{\text {gas }} / \mathrm{H}\right]_{\text {fit }}=B_{X}+A_{X}\left(F_{*}-z_{X}\right)
$$

is a modification of Eq. 3. where the zero-point reference in $F_{*}$ is displaced to an intermediate value $z_{X}$, which is unique to element $X$ (instead of being at $F_{*}$ equal to 0 ), and the depletion at this point is called $B_{X}$. For each element we can solve for values of the two coefficients $A_{X}$ and $B_{X}$ through the evaluation of a least-squares fit [using the routine FITEXY described by Press et al. (2007)] that properly accounts for differing errors in both the dependent and independent measurement variables that are being fitted, $\left[X_{\text {gas }} / \mathrm{H}\right]_{\text {obs }}$ and $F_{*}$. The reason for replacing $\left[X_{\text {gas }} / \mathrm{H}\right]_{0}$ (i.e., the expected depletion for $F_{*}=0$ ) in the earlier equation with $B_{X}-A_{X} z_{X}$ is that for a choice

$$
z_{X}=\frac{\sum_{*} W_{*} F_{*}}{\sum_{*} W_{*}},
$$

where in this case

$$
W_{*}=\left\{\left[\sigma\left(\left[X_{\text {gas }} / \mathrm{H}\right]_{\mathrm{obs}}\right)\right]^{2}+\left[\sigma\left(F_{*}\right) A_{X}^{\prime}\right]^{2}\right\}^{-1}
$$

there is a near zero covariance between the formal fitting errors for the solutions of $B_{X}$ and $A_{X}$. This independence for the uncertainties in the derived parameters makes them easier to state and comprehend, and it allows the errors in quantities that arise from linear combinations of $A_{X}$ and $B_{X}$ to be calculated in a straightforward fashion (see Eqs. 14 and 16 below). The $W_{*}$ factors derived in Eq. 12 account for errors in the individual observations which can be compounded by the effect of the uncertainties in $F_{*}$ (which become worse if $A_{X}^{\prime}$ is large).

In practical circumstances, one must add in quadrature an uncertainty in the reference solar abundance $\sigma(X / \mathrm{H}) \odot$ to the formal error $\sigma\left(B_{X}\right)$ that arises from the least-squares fit. This is done in the listing of $B_{X}$ values for different elements (Table 4 that appears in 95 ) because the contents of this table are of general practical use, but deviations in the fit for each element shown much later in Tables 7 to 23 of Appendix $\mathrm{B}$ do not include the $\sigma(X / \mathrm{H}) \odot$ term so that one can judge better how well individual observations fit the general trend irrespective of any overall systematic errors in the solar abundances. Some of the column density measurements were not included in the least-squares fitting; these cases are discussed in 4.2 . Results for the fit parameters and their errors will be presented in $\$ 5$,

While the formulation given in Eq. 10 allows us to use parameters that have more straightforward errors, it is nevertheless still useful to know what the values of $\left[X_{\text {gas }} / \mathrm{H}\right]_{\text {fit }}$ are for two fidicial values of $F_{*}$, one representing the smallest depletions $\left(F_{*}=0\right)$ and the other representing heavy depletions $\left(F_{*}=1\right)$. These two quantities are evaluated from the simple relations,

$$
\left[X_{\text {gas }} / \mathrm{H}\right]_{0}=B_{X}-A_{X} z_{X}
$$

with an error

$$
\sigma\left(\left[X_{\text {gas }} / \mathrm{H}\right]_{0}\right)=\sqrt{\sigma\left(B_{X}\right)^{2}+\left[z_{X} \sigma\left(A_{X}\right)\right]^{2}}
$$


and

$$
\left[X_{\text {gas }} / \mathrm{H}\right]_{1}=B_{X}+A_{X}\left(1-z_{X}\right)
$$

with an error

$$
\sigma\left(\left[X_{\text {gas }} / \mathrm{H}\right]_{1}\right)=\sqrt{\sigma\left(B_{X}\right)^{2}+\left[\left(1-z_{X}\right) \sigma\left(A_{X}\right)\right]^{2}}
$$

\section{Accumulation and Processing of Data from the Literature}

The depletion study can draw upon a substantial and diverse accumulation of atomic column density measurements that have been published in the astronomical literature over several decades. One challenge in making use of these results is the creation of a good balance between two extremes in selecting the data: one being a strong discrimination in favor of the best quality results at the expense of obtaining a broad coverage of elements and sight lines, as opposed to the alternative of accepting nearly everything, good and bad, in an effort to lessen the perturbing effects of natural variations and to obtain a fuller representation of conditions in the ISM. By necessity, any reasonable compromise between these extremes will still entail the use of a very inhomogeneous mixture of data from different investigations that had different measurement methodologies and error estimation techniques.

To some extent, differences in data quality can be recognized in a proper fashion by using the stated uncertainties to govern the weighting of the terms used in the parameter estimations, as described earlier in $\S \S 3.1$ and 3.2 . A weakness of this approach is that different authors employ different standards for estimating errors, which is an effect that may partly undermine the validity of the weighting process. It would be a monumental task to attempt to scrutinize each investigator's means of estimating errors and then adjust them according to some uniform standard. Some papers did not state any errors in the column densities. For these situations, conservative estimates were made for these works, and they are noted in the notes section of Table 1. This section also states some special considerations that applied to our treatment of the investigation in question.

Elements covered in the present study include carbon, nitrogen, magnesium, silicon, phosphorus, sulfur, chlorine, titanium, chromium, manganese, iron, nickel, copper, zinc, germanium, and krypton. Argon was initially included in the compilation process, but there were too few reliable measurements taken to produce meaningful results, so this element was not considered further. Moreover, the apparent abundance of Ar, as traced by its neutral form, is strongly susceptible to being altered in partially ionized regions (Sofia \& Jenkins 1998).

\subsection{Special Treatment of Uncertainties Listed in one Survey}

The results shown by Jenkins, Savage \& Spitzer (1986) (hereafter JSS86) were processed in a special manner. These investigators quoted limits for the column densities at the $2 \sigma$ level of 
significance, which had to be replaced by reasonable estimates for the $1 \sigma$ results to be consistent with the limits expressed by other investigators. For lower limits based on the strengths of weak lines that had a strong random noise contribution, JSS86 found it appropriate to quote formal results that were negative in situations where a chance positive intensity fluctuation created a negative equivalent width. This tactic was carried out to allow anyone to overcome an upward bias in any general average that would arise from blindly setting these lower limits to zero. The following rules were adopted for converting the $2 \sigma$ lower limits to approximate representations of the $1 \sigma$ values: if the lower limit was positive, the logarithm of the adopted new value would be a mean of the stated lower limit for $\log N$ and the logarithm of the best value, on the presumption that most of the time the relative likelihoods are symmetric in the logarithms. By contrast, for very weak detections these likelihoods are governed by nearly linear processes, so that if the stated lower limit was negative (and the best value was stated as a positive number), the mean would be evaluated in terms of the linear representations of these values and would then be converted into logarithmic form. If, after evaluating this average, the linear form was still negative, then the logarithm of the lower limit was set to a very low (out of range) number so that subsequent processing would recognize the best value as really an upper limit, even at the $1 \sigma$ level.

For upper limits, the new limit was simply an average of the logarithms of the stated best and upper limits, except when the best value was stated as a negative (logarithmic) number and a linear average was used instead. As an exception, when JSS86 stated that the upper limit corresponded to a situation where the weakest line had a central optical depth greater than 2 (designated by an asterisk in their tables), the old upper limit based on the $2 \sigma$ level of confidence was retained as a hedge against possible errors arising from such saturations. Finally, in the interest of following guideline nr. 2 stated in 4.2 below, any of the best values that had special notations (or a negative number) given in the tables of JSS86 were not considered for any of the values of generalized element depletions, but positive values were retained for expositions in tables and figures.

\subsection{Criteria for Rejection}

In recognition of the fact that error estimates in various works have their shortcomings, we invoke some quality control measures by implementing a few simple rules to bypass observations that may be of questionable validity. Moreover, in some cases, we must also reject investigations that include data that for good reasons probably misrepresent the trends that are under study here.

The following censorship rules were adopted for the selection and use of data incorporated in the current study:

1. Data on atomic column densities from observations using the International Ultraviolet Explorer (IUE) were not accepted, except for measurements of $N(\mathrm{H} \mathrm{I})$ from the $\mathrm{L} \alpha$ absorption feature. The limitations of wavelength resolution and the maximum achievable $\mathrm{S} / \mathrm{N}$ of this fa- 
cility decrease the likelihood that, with the usual small velocity dispersions found in the ISM5, proper corrections for saturation can be made for absorption features that have large enough equivalent widths to be measured accurately. Moreover, Massa et al. (1998) concluded that the IUE NEWSIPS reductions had serious photometric inconsistencies. The BUSS balloonborne payload (de Boer et al. 1986) recorded spectra of quality similar to those of $I U E$, and thus they likewise were not included in the current study.

2. There has been a persistent problem with investigators being overconfident about the reliability of column density measurements based exclusively on the equivalent widths of features on or very near the flat portion of the curve of growth. For this reason, grounds for rejecting individual element abundances along any of the sight lines included determinations that did not have at least one absorption line that was clearly on the linear portion of the curve of growth, or alternatively at least 2 lines that were either on or not far above the linear part. For instance, a low resolution observation of a doublet with a 2:1 strength ratio was deemed to be acceptable only if the ratio of the two equivalent widths was greater than 1.56 However, mildly saturated single lines were accepted if the curve of growth was established by multiple lines of other species that were expected to behave in a similar fashion 7 Deviations in the standards of leniency in accepting such results varied from one study to the next, driven by perceptions on how well the velocity structures were determined from the other species. Cases based on saturated lines that were measured using the apparent optical depth method (Savage \& Sembach 1991; Jenkins 1996) for lines recorded with sufficiently high resolution were deemed to be acceptable as long as the apparent central optical depths were not too large. The application of this rule may have not been fully rigorous in all cases, since for some investigations it was difficult to determine if saturation effects created problems. In some cases, results from saturated lines were reported as lower limits for the column density; these values are recorded as such and appear in Tables 7 to 23 and Figs 5 - 8 , but they are not included in the analyses of depletions. Once in a while, very saturated lines could yield column densities through the measurement of weak damping wings, and these cases were accepted.

\footnotetext{
${ }^{5}$ Exceptions to this are the lines of highly ionized species such as Al III, Si IV and C IV (Savage, Meade, \& Sembach 2001), which have large enough $b$-values to permit reliable determinations of column densities. These species are not relevant to the present study however.

${ }^{6}$ Even though we are aware of the fact that a typical line of sight exhibits many separate velocity components, each with different column densities and velocity dispersions, a standard curve of growth analysis of the complete features that make up such an ensemble still yields an answer for the aggregate column density that is remarkably close to the correct answer, provided the features are not badly saturated. An analysis by Jenkins (1986) indicates that our adopted lower cutoff for the doublet ratio is a very conservative choice.

${ }^{7}$ As shown originally by Routly \& Spitzer (1952), highly depleted species (Ca II) have more broadly distributed velocities than less depleted ones (Na I). Hence using one element as a velocity surrogate for another when multiple components are considered collectively must be done with caution. See also Jenkins (2009).
} 
3. If any particular line of sight shows $\log N(\mathrm{H})<19.5$, there is a reasonable possibility that a nonnegligible fraction of the atoms of any element is in a stage (or stages) of ionization above the preferred one (i.e., the lowest level with an ionization potential greater than $13.6 \mathrm{eV}$ ), because the gas is not well shielded from ionizing photons that have energies well above that of the Lyman limit of hydrogen; see a discussion of this topic by Jenkins (2004). Aside from this possibility, there is also a chance that contributions from fully ionized gas could contribute to the column density of an ion in its expected preferred stage for an $\mathrm{H}$ I region. If $N(\mathrm{H} \mathrm{I})$ is small, the relative level of contamination from one or more $\mathrm{H}$ II regions (including the one surrounding the target star) could be large. Such regions, of course, do not make any contribution to the $\mathrm{L} \alpha$ absorption that is used to measure $N(\mathrm{H} \mathrm{I})$. While it is true that in principle one can estimate the probable contamination from partially or fully ionized regions by comparing the amounts of more highly ionized forms of some elements to their singly-ionized stages (Cardelli, Sembach, \& Savage 1995; Sembach \& Savage 1996; Howk \& Savage 1999; Howk \& Sembach 1999; Prochaska et al. 2002; Howk, Sembach, \& Savage 2003), a uniform application of any corrections for ionization is not feasible in a generalized study such as this one, where varying degrees of coverage of various ions emerge from diverse sources in the literature. Aside from ionization corrections, for low column density cases there is also a possibility that material very close to the star, in the form of either a shell or disk, could have its own resonance absorption features (Snow, Peters, \& Mathieu 1979; Oegerle \& Polidan 1984) that could distort the results for the ISM. The imposition of a single column density threshold for all cases may seem like a blunt instrument, given the large variations of conditions encountered in this survey. Indeed, we argue later ( $(\sqrt{8})$ that the criterion $\log N(\mathrm{H})>19.5$ is probably too conservative for short sight lines $(d \lesssim 100 \mathrm{pc})$. While this may be so, there is evidence that over much longer sight lines that could hold multiple absorbing clouds a higher threshold for $N(\mathrm{H})$ may be more appropriate. For instance, Howk, Sembach \& Savage (2006) show an example where small systematic abundance shifts caused by ionization along an extended line of sight can arise even for $N(\mathrm{H} \mathrm{I})=10^{20} \mathrm{~cm}^{-2}$. While lines of sight that had $\log N(\mathrm{H})<19.5$ were not used for determining the parameters $A_{X}^{\prime}$, $A_{X}, B_{X}$ and $z_{X}$, their values of $F_{*}$ were still evaluated so that the results could be shown in the figures and be tabulated. The reader is advised to consider these results with some caution however. Figure 2 shows the distribution of total hydrogen column densities $N(\mathrm{H})$ covered in this study.

4. Stars for which only one or two elements were observed were not included in the analysis, since they were of little or no value in constraining the comparisons of depletions for different elements. Nevertheless, as with stars that had $\log N(\mathrm{H})<19.5$, their $F_{*}$ values were computed and entries appear in the tables and figures.

5. Any absorbing systems well outside the disk of our Galaxy are excluded (e.g., those in either of the Magellanic Clouds or the Magellenic Stream), since their intrinsic element abundances are not known. Stars in the lower halo of the Galaxy are included, but the analysis is restricted 


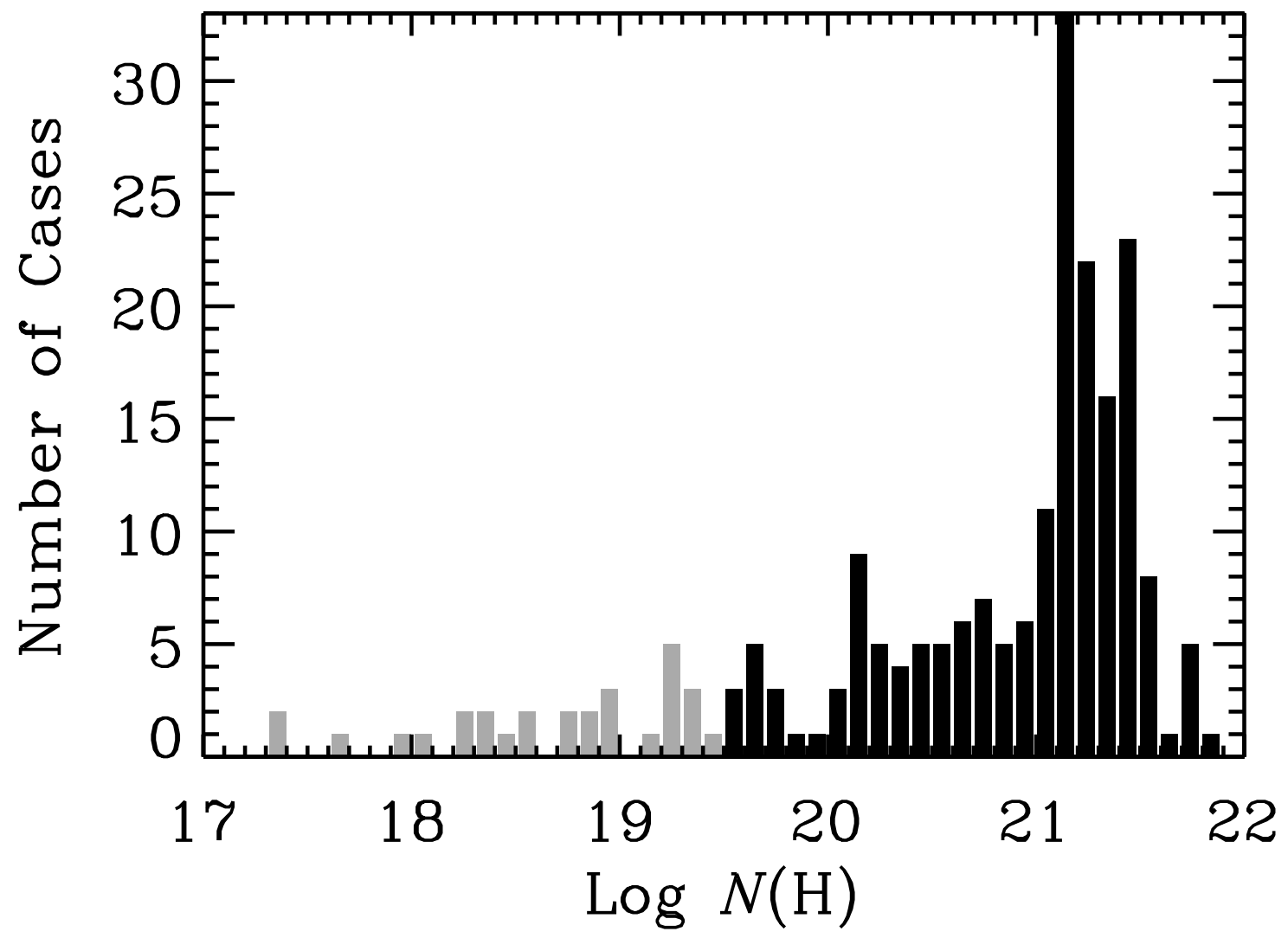

Fig. 2. - The distribution of total hydrogen column densities (atomic and molecular) for the sightlines studied in this survey. The gray bars represent cases below the cutoff $N(\mathrm{H})=10^{19.5} \mathrm{~cm}^{-2}$ established for defining the best-fit element parameters. 
to gas at low and intermediate velocities. Infalling gas at high velocities (Wakker 2001) is not included in this study, since the kinematics of this material point to an origin outside the Galactic disk, and the intrinsic abundances of the heavy elements are low (Wakker et al. 1999; Murphy et al. 2000; Gibson et al. 2001; Richter et al. 2001; Collins, Shull, \& Giroux 2003; Tripp et al. 2003).

6. Gas that is explicitly identified to be in shocks at extraordinarily high velocity are not included. (Such clouds generally have $\log N(\mathrm{H} \mathrm{I})<19.5$ anyway, as indicated by their abundances of S II). Grains are usually destroyed in such gas (Jenkins, Silk, \& Wallerstein 1976), and photons generated in the shock front (Shull \& McKee 1979) can raise the ionization level of the post-shock material (Jenkins et al. 1998).

7. A diverse set of observations has revealed that the intrinsic abundances of the elements show a gradient with galactocentric distance $R_{\mathrm{GC}}$ that ranges from about -0.03 to -0.10 dex $\mathrm{kpc}^{-1}$ (Shaver et al. 1983; Afflerbach, Churchwell, \& Werner 1997; Gummershach et al. 1998; Deharveng et al. 2000; Martins \& Viegas 2000; Rolleston et al. 2000; Giveon et al. 2002; Martín-Hernández et al. 2002; Luck, Kovtyukh, \& Andrievsky 2006). To limit the influence of these changes on our results, we do not consider stars outside the range $7<R_{\mathrm{GC}}<10 \mathrm{kpc}$ (projected onto the plane of the Galaxy) for the determinations of $A_{X}, B_{X}$ and $z_{X}$, however they are plotted in Figs. [5-8 and appear in Tables 5] and 7- 23, (Later, in \$10.3, we show that an abundance gradient does not seem to be evident within the entire collection of sight lines studied here.)

Figure 3 summarizes the distributions of distances and heights above or below the Galactic plane for all of the sight lines covered in this study. The absence of stars with distances much below $0.1 \mathrm{kpc}$ arises from the fact that the survey was almost completely restricted to data recorded for O- and B-type stars. A good coverage of distances below this limit has been provided by surveys of limited selections of elements toward late-type stars (Redfield \& Linsky 2004a) and white dwarf stars (Friedman et al. 2002; Kruk et al. 2002; Lehner et al. 2003; Oliveira et al. 2003). A special discussion of interstellar depletions toward the white dwarf stars will appear in 98 ,

\subsection{Other Considerations}

Comparisons of element column densities are made with respect to $N(\mathrm{H} \mathrm{I})$ derived from $\mathrm{L} \alpha$ absorptions and $N\left(\mathrm{H}_{2}\right)$ derived from Lyman band absorptions. Hence these measurements apply to gas at all velocities. Thus, even for investigations that revealed separate column densities of heavy elements over different radial velocity ranges, the results had to be combined over all velocities. However, there are five special lines of sight where this consolidation of the column densities over all velocities was not applied. First, Spitzer \& Fitzpatrick (1993) and Fitzpatrick \& Spitzer (1997) analyzed exceptionally good observations of the stars HD 93521 and HD 215733 taken with the highest resolution mode of the GHRS instrument on HST, and they went to great 

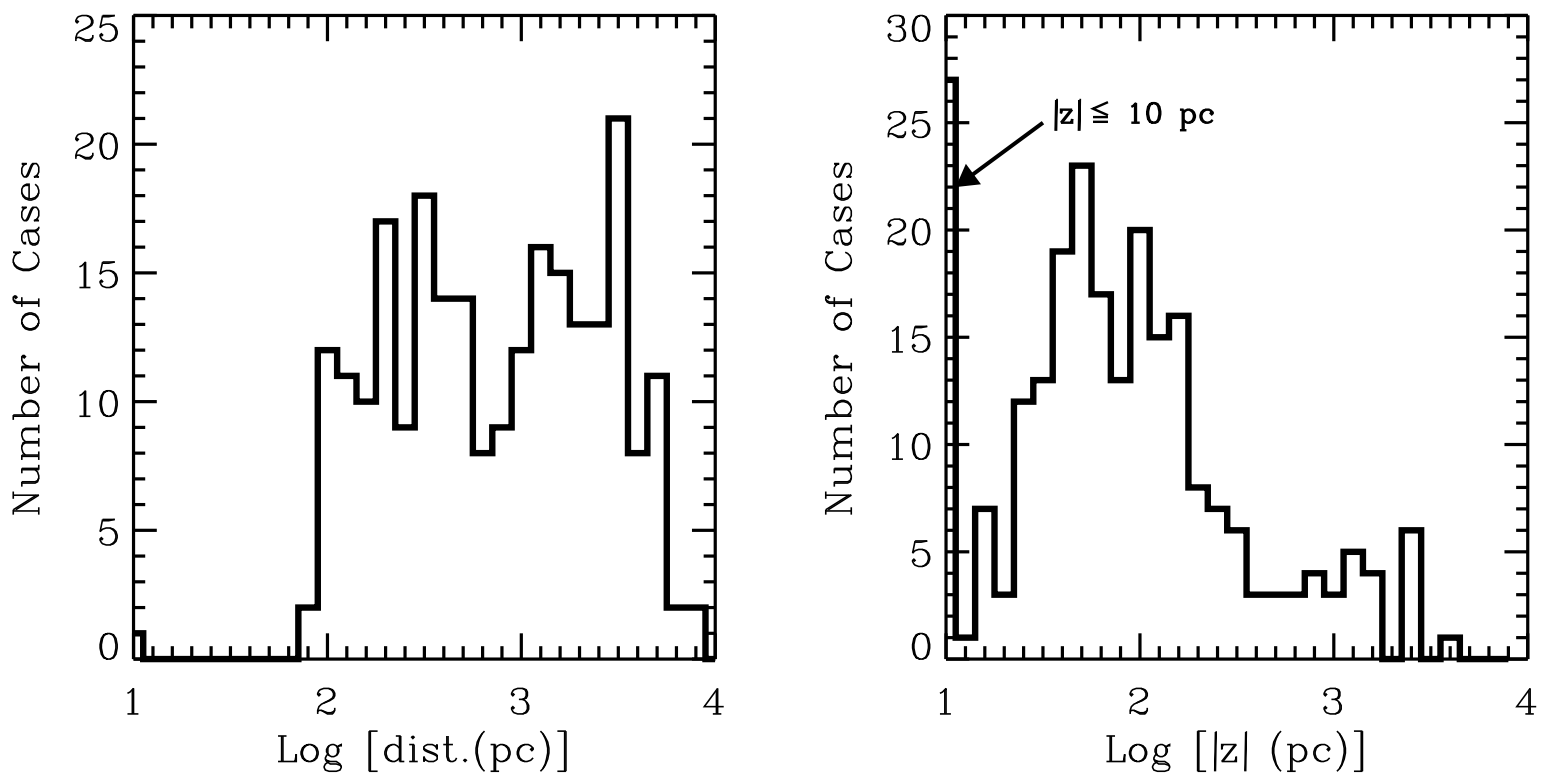

Fig. 3.- The distributions of distances to the target stars considered in this survey (left-hand panel), and their separations away from the Galactic plane (right-hand panel).

effort to decompose their profiles into separate velocity components. A principal motivation for studying the separate components of these stars for the present study is to gain information on the depletions of sulfur, which is a difficult element to study because the features are usually strongly saturated. These two stars are at large distances from the Galactic plane $(z=1.56$ and $-1.65 \mathrm{pc}$, respectively), and the sulfur profiles were sufficiently spread out in velocity that their saturation was not a problem when observed at a good velocity resolution. Also, since there is not much $\mathrm{H}$ I behind these stars, we can in principle rely on 21-cm observations to indicate the amount of hydrogen at each velocity (while this is true, there is a better method to find $N(\mathrm{H})$ that will be outlined later in (77). Second, for the line of sight toward $\gamma^{2}$ Vel, Fitzpatrick \& Spitzer (1994) showed that a significant fraction of all of the gas is fully ionized, and they could identify which velocity components were ionized and which were neutral. (This star has a foreground neutral hydrogen column density just barely above the adopted threshold of $10^{19.5} \mathrm{~cm}^{-2}$ ). Thus, for this star, only column densities associated with H I regions were included. Other stars [e.g. $\lambda$ Sco (York 1983) and 23 Ori (Welty et al. 1999) had components that were identified with H II regions, but their contributions were small compared to those from the neutral gas components. Finally, the star $\zeta$ Oph had specific velocity components identified separately because the highly depleted one at $-15 \mathrm{~km} \mathrm{~s}^{-1}$ serves as a standard for establishing the scale of $F_{*}[N(\mathrm{H})$ for the other component is small enough to neglect - see the discussion in $\$ 7.2$, and $\alpha \mathrm{CMa}$ had small enough $\mathrm{H}$ column densities that the L $\alpha$ absorption could be decomposed into two principal components by Hébrard et al (1999). 


\subsection{Renormalization to Recent $f$-values}

Many of the earlier determinations of atomic column densities were reported using transition $f$ values that have since been revised. The current analysis now includes adjustments to compensate for the differences between the old and new values. In many situations we must acknowledge that this is an inexact process since the column densities in the earlier studies were determined from several transitions, not all of which may have been revised (or had different changes).

When multiple lines were measured, the task of making the proper correction was made easier when the investigator indicated which line was the primary source of information for determining a column density. However, most authors did not provide such guidance. Usually, one can count on the weakest lines being the ones that constrain the column density outcome, while strong ones

only define the velocity dispersion parameter $b$. However, these weakest lines sometimes had to be overlooked if the relative errors in the equivalent widths were large.

When two or more lines with different $f$-value corrections were considered to be about equally influential in the column density determination, their logarithmic corrections were averaged together. This can be a potentially hazardous approach, as illustrated by the following example. The weaker of the two P II lines analyzed by JSS86 has now had its $f$-value revised downwards by 0.127 dex, while the stronger line has remained virtually unchanged. As a result, any new determination of the curve of growth would make the new $b$ value lower, the inferred saturation of both lines would increase, and $N$ (P II) would need to be revised in an upward direction by more than 0.127 dex. However, this will happen only if indeed the weak line is perceived to be saturated, and it is deemed to be well enough measured to be useful (i.e., it is not dominated by noise). If the strong line dominates in the determination of $N(\mathrm{P}$ II) because its errors are so much smaller than those of the weak line and a $\chi^{2}$ minimization is used (as was the case with JSS86), the column density should remain unchanged. In the particular case of P II in the study by JSS86, the overall distortion of the P II $b$ values is probably small, since there seems to be no systematic offset from the $b$ values measured for Fe II toward the same stars (see their Fig. 1).

All column density adjustments were made on the basis of correcting to the $f$-values published in a compilation by Morton (2003). While there have been some newer determinations for a few species that have appeared in the literature since 2003, we retain Morton's values in the interest in having a single standard list that could be consulted in the future. The only new result that was accepted was an $f$-value for the Ni II transition at $1317 \AA$ reported by Jenkins \& Tripp (2006), for which no line strength was listed by Morton. A summary of the $f$-value correction factors for different investigations, presented in logarithmic form, is shown in Table 1. These numbers represent the amounts by which the originally reported values of $\log N$ were increased for this study. 
Table 1. Column Density Corrections for Revised $f$-Values

\begin{tabular}{|c|c|c|c|c|c|c|c|c|c|c|c|c|c|c|c|c|c|c|c|}
\hline \multirow[b]{2}{*}{$\begin{array}{l}\operatorname{Code}^{\mathrm{a}} \\
(1)\end{array}$} & \multirow[b]{2}{*}{$\begin{array}{c}\text { Reference } \\
\quad(2)\end{array}$} & \multicolumn{17}{|c|}{ Correction Factors (dex) } & \multirow[b]{2}{*}{$\begin{array}{c}\text { Notes } \\
(20)\end{array}$} \\
\hline & & $\begin{array}{c}\mathrm{C} \\
(3)\end{array}$ & $\begin{array}{l}\mathrm{N} \\
(4)\end{array}$ & $\begin{array}{l}\mathrm{O} \\
(5)\end{array}$ & $\begin{array}{l}\mathrm{Mg} \\
(6)\end{array}$ & $\begin{array}{l}\mathrm{Si} \\
(7)\end{array}$ & $\begin{array}{l}\mathrm{P} \\
(8)\end{array}$ & $\begin{array}{c}\mathrm{S} \\
(9)\end{array}$ & $\begin{array}{c}\mathrm{Cl} \\
(10)\end{array}$ & $\begin{array}{c}\mathrm{Ti} \\
(11)\end{array}$ & $\begin{array}{c}\mathrm{Cr} \\
(12)\end{array}$ & $\begin{array}{l}\mathrm{Mn} \\
(13)\end{array}$ & $\begin{array}{c}\mathrm{Fe} \\
(14)\end{array}$ & $\begin{array}{c}\mathrm{Ni} \\
(15)\end{array}$ & $\begin{array}{c}\mathrm{Cu} \\
(16)\end{array}$ & $\begin{array}{l}\mathrm{Zn} \\
(17)\end{array}$ & $\begin{array}{l}\mathrm{Ge} \\
(18)\end{array}$ & $\begin{array}{c}\mathrm{Kr} \\
(19)\end{array}$ & \\
\hline $\mathrm{A}++03$ & $\begin{array}{l}\text { André et al. } \\
2003\end{array}$ & $\cdots$ & $\cdots$ & 0 & $\cdots$ & $\cdots$ & $\cdots$ & $\cdots$ & $\cdots$ & $\cdots$ & $\cdots$ & $\cdots$ & $\cdots$ & $\cdots$ & $\cdots$ & $\cdots$ & $\cdots$ & 0 & \\
\hline $\mathrm{A}++93$ & $\begin{array}{l}\text { Albert et al. } \\
1993\end{array}$ & $\cdots$ & $\cdots$ & $\cdots$ & $\cdots$ & $\cdots$ & $\cdots$ & $\cdots$ & $\cdots$ & -0.022 & $\cdots$ & $\cdots$ & $\cdots$ & $\cdots$ & $\cdots$ & $\cdots$ & $\cdots$ & $\cdots$ & \\
\hline AJS92 & $\begin{array}{l}\text { Allen, Jenkins, } \\
\text { \& Snow } 1992\end{array}$ & $\ldots$ & $\cdots$ & -0.035 & -0.356 & $\cdots$ & 0.134 & $\ldots$ & 0.025 & $\ldots$ & $\ldots$ & -0.257 & 0.039 & $\cdots$ & $\cdots$ & $\ldots$ & $\cdots$ & $\cdots$ & \\
\hline $\mathrm{B}++83$ & $\begin{array}{l}\text { Bohlin et al. } \\
1983\end{array}$ & $\cdots$ & $\cdots$ & $\cdots$ & $\cdots$ & $\cdots$ & $\cdots$ & $\cdots$ & $\cdots$ & $\cdots$ & $\cdots$ & $\cdots$ & $\cdots$ & $\cdots$ & $\cdots$ & $\cdots$ & $\cdots$ & $\cdots$ & 1 \\
\hline BFM07 & $\begin{array}{l}\text { Burgh, France, } \\
\& \text { McCandliss } \\
2007\end{array}$ & $\cdots$ & $\cdots$ & $\cdots$ & $\cdots$ & $\cdots$ & $\cdots$ & $\cdots$ & $\cdots$ & $\cdots$ & $\cdots$ & $\cdots$ & $\cdots$ & $\cdots$ & $\ldots$ & $\ldots$ & $\cdots$ & $\cdots$ & 2 \\
\hline BLWY84 & $\begin{array}{l}\text { Barker et al. } \\
1984\end{array}$ & & $\cdots$ & $\ldots$ & $\ldots$ & 0.251 & $\ldots$ & $\ldots$ & $\ldots$ & $\ldots$ & $\ldots$ & $\ldots$ & $\ldots$ & $\ldots$ & $\ldots$ & $\ldots$ & $\cdots$ & $\ldots$ & \\
\hline BSD78 & $\begin{array}{l}\text { Bohlin, Savage, } \\
\text { \& Drake } 1978\end{array}$ & $\ldots$ & $\ldots$ & $\ldots$ & $\ldots$ & $\ldots$ & $\ldots$ & $\ldots$ & $\ldots$ & $\ldots$ & $\ldots$ & $\ldots$ & $\ldots$ & $\ldots$ & $\ldots$ & $\ldots$ & $\cdot 0$ & $\ldots$ & 1 \\
\hline $\mathrm{C}++91$ & $\begin{array}{l}\text { Cardelli et al. } \\
1991\end{array}$ & -0.028 & $\ldots$ & 0.033 & -0.399 & $\ldots$ & 0.266 & $\ldots$ & $\ldots$ & $\ldots$ & 0.143 & 0.011 & 0.161 & 0.231 & -0.342 & 0.011 & $\ldots$ & $\ldots$ & 3 \\
\hline $\mathrm{C}++94$ & $\begin{array}{l}\text { Cardelli et al. } \\
1994\end{array}$ & $\ldots$ & $\ldots$ & $\cdots$ & $\ldots$ & 0.001 & $\cdots$ & $\ldots$ & $\ldots$ & $\ldots$ & $\ldots$ & $\ldots$ & $\ldots$ & $\ldots$ & $\cdots$ & $\ldots$ & $\ldots$ & $\cdots$ & 4 \\
\hline $\mathrm{C}++95$ & $\begin{array}{l}\text { Cassinelli et al. } \\
1995\end{array}$ & $\ldots$ & $\ldots$ & $\ldots$ & $\ldots$ & $\ldots$ & $\ldots$ & $\ldots$ & $\ldots$ & $\ldots$ & $\ldots$ & $\ldots$ & $\ldots$ & $\ldots$ & $\ldots$ & $\ldots$ & $\ldots$ & $\ldots$ & 5 \\
\hline $\mathrm{C}++96$ & $\begin{array}{l}\text { Cassinelli et al. } \\
1996\end{array}$ & $\ldots$ & $\ldots$ & $\ldots$ & $\ldots$ & $\cdots$ & $\cdots$ & $\ldots$ & $\ldots$ & $\cdots$ & $\cdots$ & $\cdots$ & $\cdots$ & $\cdots$ & $\ldots$ & $\cdots$ & $\cdots$ & $\ldots$ & \\
\hline $\mathrm{C}++08$ & $\begin{array}{l}\text { Cartledge et al. } \\
2008\end{array}$ & $\ldots$ & $\ldots$ & 0 & $\ldots$ & $\ldots$ & $\ldots$ & $\ldots$ & $\ldots$ & $\ldots$ & $\ldots$ & $\ldots$ & $\ldots$ & $\ldots$ & $\ldots$ & $\ldots$ & $\ldots$ & 0 & \\
\hline CLMS04 & $\begin{array}{l}\text { Cartledge et al. } \\
2004\end{array}$ & $\ldots$ & $\ldots$ & 0 & $\ldots$ & $\ldots$ & $\ldots$ & $\ldots$ & $\ldots$ & $\ldots$ & $\ldots$ & $\ldots$ & $\ldots$ & $\ldots$ & $\ldots$ & $\ldots$ & $\cdots$ & $\cdots$ & \\
\hline CLMS06 & $\begin{array}{l}\text { Cartledge et al. } \\
2006\end{array}$ & $\cdots$ & $\cdots$ & $\cdots$ & 0 & $\cdots$ & 0.133 & $\cdots$ & $\ldots$ & $\cdots$ & $\cdots$ & -0.142 & $\cdots$ & 0.106 & 0.16 & $\cdots$ & 0 & 0 & \\
\hline CM97 & $\begin{array}{l}\text { Cardelli \& } \\
\text { Meyer } 1997\end{array}$ & $\ldots$ & $\ldots$ & $\ldots$ & $\ldots$ & $\ldots$ & $\ldots$ & $\ldots$ & $\ldots$ & $\ldots$ & $\ldots$ & $\ldots$ & $\ldots$ & $\ldots$ & $\ldots$ & $\ldots$ & $\ldots$ & -0.009 & \\
\hline CMES93 & $\begin{array}{l}\text { Cardelli et al. } \\
1993\end{array}$ & 0.101 & $\ldots$ & $\ldots$ & $\ldots$ & $\ldots$ & $\ldots$ & $\ldots$ & $\ldots$ & $\ldots$ & $\ldots$ & $\ldots$ & $\ldots$ & $\ldots$ & $\ldots$ & $\ldots$ & $\ldots$ & $\ldots$ & \\
\hline CMJS96 & $\begin{array}{l}\text { Cardelli et al. } \\
1996\end{array}$ & 0.084 & $\ldots$ & $\cdots$ & $\ldots$ & $\ldots$ & $\ldots$ & $\ldots$ & $\cdots$ & $\cdots$ & $\ldots$ & $\ldots$ & $\ldots$ & $\cdots$ & $\cdots$ & $\ldots$ & $\ldots$ & $\ldots$ & \\
\hline CML03 & $\begin{array}{l}\text { Cartledge, } \\
\text { Meyer, \& } \\
\text { Lauroesch 2003 }\end{array}$ & $\ldots$ & $\ldots$ & $\ldots$ & $\ldots$ & $\ldots$ & $\ldots$ & $\ldots$ & $\ldots$ & $\ldots$ & $\ldots$ & $\ldots$ & $\ldots$ & $\ldots$ & $\ldots$ & $\ldots$ & $\ldots$ & 0 & \\
\hline CMLS01 & $\begin{array}{l}\text { Cartledge et al. } \\
2001\end{array}$ & $\cdots$ & $\cdots$ & 0 & $\cdots$ & $\cdots$ & $\cdots$ & $\ldots$ & $\cdots$ & $\cdots$ & $\cdots$ & $\cdots$ & $\cdots$ & $\cdots$ & $\cdots$ & $\cdots$ & $\cdots$ & 0 & \\
\hline
\end{tabular}


Table 1-Continued

\begin{tabular}{|c|c|c|c|c|c|c|c|c|c|c|c|c|c|c|c|c|c|c|c|}
\hline \multirow[b]{2}{*}{$\begin{array}{l}\text { Code }^{\mathrm{a}} \\
(1)\end{array}$} & \multirow[b]{2}{*}{$\begin{array}{l}\text { Reference } \\
\quad(2)\end{array}$} & \multicolumn{17}{|c|}{ Correction Factors (dex) } & \multirow[b]{2}{*}{$\begin{array}{c}\text { Notes } \\
(20)\end{array}$} \\
\hline & & $\begin{array}{l}\mathrm{C} \\
(3)\end{array}$ & $\begin{array}{l}\mathrm{N} \\
(4)\end{array}$ & $\begin{array}{l}\mathrm{O} \\
(5)\end{array}$ & $\begin{array}{l}\mathrm{Mg} \\
(6)\end{array}$ & $\begin{array}{l}\mathrm{Si} \\
(7)\end{array}$ & $\begin{array}{l}\mathrm{P} \\
(8)\end{array}$ & $\begin{array}{l}\mathrm{S} \\
(9)\end{array}$ & $\begin{array}{c}\mathrm{Cl} \\
(10)\end{array}$ & $\begin{array}{c}\mathrm{Ti} \\
(11)\end{array}$ & $\begin{array}{c}\mathrm{Cr} \\
(12)\end{array}$ & $\begin{array}{l}\mathrm{Mn} \\
(13)\end{array}$ & $\begin{array}{c}\mathrm{Fe} \\
(14)\end{array}$ & $\begin{array}{c}\mathrm{Ni} \\
(15)\end{array}$ & $\begin{array}{c}\mathrm{Cu} \\
(16)\end{array}$ & $\begin{array}{c}\mathrm{Zn} \\
(17)\end{array}$ & $\begin{array}{c}\mathrm{Ge} \\
(18)\end{array}$ & $\begin{array}{l}\mathrm{Kr} \\
(19)\end{array}$ & \\
\hline CSS95 & $\begin{array}{l}\text { Cardelli, Sem- } \\
\text { bach, \& Savage } \\
1995\end{array}$ & $\cdots$ & $\cdots$ & $\cdots$ & 0.251 & 0.001 & $\cdots$ & $\cdots$ & $\cdots$ & $\cdots$ & 0.008 & $\cdots$ & -0.045 & $\cdots$ & $\cdots$ & 0.017 & $\cdots$ & $\cdots$ & \\
\hline DG98 & $\begin{array}{l}\text { Dupin \& Gry } \\
1998\end{array}$ & $\cdots$ & $\cdots$ & $\cdots$ & $\cdots$ & -0.017 & $\cdots$ & 0.006 & $\cdots$ & $\cdots$ & $\cdots$ & -0.013 & -0.048 & $\cdots$ & $\cdots$ & $\cdots$ & $\cdots$ & $\cdots$ & \\
\hline DS94 & $\begin{array}{l}\text { Diplas \& Sav- } \\
\text { age } 1994\end{array}$ & $\cdots$ & $\cdots$ & $\cdots$ & $\cdots$ & $\cdots$ & $\cdots$ & $\cdots$ & $\cdots$ & $\cdots$ & $\cdots$ & $\cdots$ & $\cdots$ & $\cdots$ & $\cdots$ & $\cdots$ & $\cdots$ & $\cdots$ & 5 \\
\hline EPL07 & $\begin{array}{l}\text { Ellison, } \\
\text { Prochaska, } \\
\text { \& Lopez } 2007\end{array}$ & $\cdots$ & $\cdots$ & $\cdots$ & $\cdots$ & $\cdots$ & $\cdots$ & $\cdots$ & $\cdots$ & 0 & $\cdots$ & $\cdots$ & $\cdots$ & $\cdots$ & $\cdots$ & $\cdots$ & $\cdots$ & $\cdots$ & 6 \\
\hline FM90 & $\begin{array}{l}\text { Fitzpatrick \& } \\
\text { Massa } 1990\end{array}$ & $\cdots$ & $\cdots$ & $\cdots$ & $\cdots$ & $\cdots$ & $\cdots$ & $\cdots$ & $\cdots$ & $\cdots$ & $\cdots$ & $\cdots$ & $\cdots$ & $\ldots$ & $\ldots$ & $\cdots$ & $\cdots$ & $\cdots$ & 7 \\
\hline FS94 & $\begin{array}{l}\text { Fitzpatrick \& } \\
\text { Spitzer } 1994\end{array}$ & $\cdots$ & $\cdots$ & $\cdots$ & -0.369 & -0.017 & 0.127 & 0.006 & $\cdots$ & $\cdots$ & $\cdots$ & -0.011 & -0.048 & $\cdots$ & $\cdots$ & $\cdots$ & $\cdots$ & , & 8,9 \\
\hline FS97 & $\begin{array}{l}\text { Fitzpatrick \& } \\
\text { Spitzer } 1997\end{array}$ & $\ldots$ & $\ldots$ & $\ldots$ & -0.403 & -0.017 & $\ldots$ & 0.006 & $\ldots$ & $\cdots$ & 0.02 & -0.018 & -0.007 & $\ldots$ & $\ldots$ & 0.007 & $\cdots$ & $\underset{1}{N} \ldots$ & \\
\hline $\mathrm{H}++03$ & $\begin{array}{l}\text { Hoopes et al. } \\
2003\end{array}$ & $\cdots$ & -0.078 & $\cdots$ & $\cdots$ & $\cdots$ & $\ldots$ & $\cdots$ & $\ldots$ & $\cdots$ & $\cdots$ & $\cdots$ & $\cdots$ & $\ldots$ & $\cdots$ & $\cdots$ & $\cdots$ & $\cdots$ & 10 \\
\hline $\mathrm{H}++03$ & $\begin{array}{l}\text { Hoopes et al. } \\
2003\end{array}$ & $\ldots$ & -0.063 & 0.002 & $\ldots$ & $\ldots$ & $\ldots$ & $\ldots$ & $\ldots$ & $\cdots$ & $\ldots$ & $\cdots$ & $\ldots$ & $\ldots$ & $\ldots$ & $\ldots$ & $\ldots$ & $\ldots$ & 11 \\
\hline $\mathrm{H}++93$ & $\begin{array}{l}\text { Hobbs et al. } \\
1993\end{array}$ & $\ldots$ & $\cdots$ & $\cdots$ & $\ldots$ & $\ldots$ & $\ldots$ & $\cdots$ & $\ldots$ & $\cdots$ & $\cdots$ & $\cdots$ & $\cdots$ & $\ldots$ & 0.16 & $\cdots$ & -0.147 & 0.021 & 12 \\
\hline $\mathrm{H}++99$ & $\begin{array}{l}\text { Hébrard et al. } \\
1999\end{array}$ & $\cdots$ & 0.007 & 0.008 & -0.001 & -0.067 & $\cdots$ & $\cdots$ & $\ldots$ & $\cdots$ & $\cdots$ & $\cdots$ & -0.028 & $\ldots$ & $\cdots$ & $\cdots$ & $\cdots$ & $\cdots$ & \\
\hline HSF99 & $\begin{array}{l}\text { Howk, Savage, } \\
\& \text { Fabian } 1999\end{array}$ & $\cdots$ & -0.027 & 0.008 & -0.02 & 0.021 & 0.132 & 0.002 & $\cdots$ & $\cdots$ & 0.008 & -0.141 & 0 & 0 & 0.16 & 0.017 & $\cdots$ & $\cdots$ & \\
\hline HYO82 & $\begin{array}{l}\text { Hobbs, York, \& } \\
\text { Oegerle } 1982\end{array}$ & 0.147 & $\ldots$ & $\ldots$ & $\cdots$ & $\ldots$ & $\ldots$ & $\cdots$ & $\cdots$ & $\cdots$ & $\cdots$ & $\cdots$ & $\cdots$ & $\cdots$ & $\cdots$ & $\ldots$ & $\cdots$ & $\ldots$ & \\
\hline $\mathrm{J}++99$ & $\begin{array}{l}\text { Jenkins et al. } \\
1999\end{array}$ & $\ldots$ & 0.064 & $\ldots$ & $\ldots$ & $\ldots$ & $\ldots$ & $\ldots$ & $\ldots$ & $\cdots$ & $\ldots$ & $\ldots$ & $\ldots$ & $\ldots$ & $\ldots$ & $\ldots$ & $\ldots$ & $\ldots$ & \\
\hline JGD00 & $\begin{array}{l}\text { Jenkins, Gry, } \\
\text { \& Dupin } 2000\end{array}$ & $\ldots$ & -0.027 & 0.006 & $\ldots$ & $\ldots$ & $\ldots$ & $\ldots$ & $\cdots$ & $\cdots$ & $\cdots$ & $\cdots$ & $\cdots$ & $\ldots$ & $\ldots$ & $\ldots$ & $\ldots$ & $\ldots$ & \\
\hline JJ91 & $\begin{array}{l}\text { Joseph \& Jenk- } \\
\text { ins } 1991\end{array}$ & $\cdots$ & $\cdots$ & $\ldots$ & -0.437 & $\cdots$ & 0.127 & $\ldots$ & $\cdots$ & $\cdots$ & $\ldots$ & -0.222 & -0.036 & $\ldots$ & $\ldots$ & $\ldots$ & $\ldots$ & $\ldots$ & 13 \\
\hline JRS05 & $\begin{array}{l}\text { Jensen, Rach- } \\
\text { ford, \& Snow } \\
2005\end{array}$ & $\ldots$ & $\cdots$ & 0 & $\ldots$ & $\ldots$ & $\ldots$ & $\ldots$ & $\ldots$ & $\cdots$ & $\ldots$ & $\ldots$ & $\ldots$ & $\ldots$ & $\ldots$ & $\ldots$ & $\ldots$ & $\ldots$ & \\
\hline JRS07 & $\begin{array}{l}\text { Jensen, Rach- } \\
\text { ford, \& Snow } \\
2007\end{array}$ & $\ldots$ & 0 & $\ldots$ & $\ldots$ & $\ldots$ & $\ldots$ & $\ldots$ & $\ldots$ & $\cdots$ & $\cdots$ & $\cdots$ & $\cdots$ & $\cdots$ & $\cdots$ & $\cdots$ & $\cdots$ & $\ldots$ & \\
\hline JS07a & $\begin{array}{l}\text { Jensen, } \quad \& \\
\text { Snow 2007a }\end{array}$ & $\cdots$ & $\cdots$ & $\ldots$ & $\cdots$ & $\cdots$ & $\cdots$ & $\cdots$ & $\cdots$ & $\cdots$ & $\cdots$ & $\ldots$ & 0.142 & $\ldots$ & $\cdots$ & $\ldots$ & $\cdots$ & $\ldots$ & \\
\hline
\end{tabular}


Table 1-Continued

\begin{tabular}{|c|c|c|c|c|c|c|c|c|c|c|c|c|c|c|c|c|c|c|c|}
\hline \multirow[b]{2}{*}{$\begin{array}{l}\text { Code }^{\mathrm{a}} \\
(1)\end{array}$} & \multirow[b]{2}{*}{$\begin{array}{c}\text { Reference } \\
\text { (2) }\end{array}$} & \multicolumn{17}{|c|}{ Correction Factors (dex) } & \multirow[b]{2}{*}{$\begin{array}{c}\text { Notes } \\
(20)\end{array}$} \\
\hline & & $\begin{array}{c}\mathrm{C} \\
(3)\end{array}$ & $\begin{array}{l}\mathrm{N} \\
(4)\end{array}$ & $\begin{array}{l}\mathrm{O} \\
(5)\end{array}$ & $\begin{array}{l}\mathrm{Mg} \\
(6)\end{array}$ & $\begin{array}{l}\mathrm{Si} \\
(7)\end{array}$ & $\begin{array}{l}\mathrm{P} \\
(8)\end{array}$ & $\begin{array}{c}\mathrm{S} \\
(9)\end{array}$ & $\begin{array}{c}\mathrm{Cl} \\
(10)\end{array}$ & $\begin{array}{c}\mathrm{Ti} \\
(11)\end{array}$ & $\begin{array}{c}\mathrm{Cr} \\
(12)\end{array}$ & $\begin{array}{l}\mathrm{Mn} \\
(13)\end{array}$ & $\begin{array}{c}\mathrm{Fe} \\
(14)\end{array}$ & $\begin{array}{c}\mathrm{Ni} \\
(15)\end{array}$ & $\begin{array}{c}\mathrm{Cu} \\
(16)\end{array}$ & $\begin{array}{c}\mathrm{Zn} \\
(17)\end{array}$ & $\begin{array}{c}\mathrm{Ge} \\
(18)\end{array}$ & $\begin{array}{c}\mathrm{Kr} \\
(19)\end{array}$ & \\
\hline $\mathrm{JS} 07 \mathrm{~b}$ & $\begin{array}{l}\text { Jensen, } \\
\text { Snow 2007b }\end{array}$ & $\cdots$ & $\cdots$ & $\cdots$ & 0 & $\cdots$ & $\cdots$ & $\cdots$ & $\cdots$ & $\cdots$ & $\cdots$ & $\cdots$ & $\cdots$ & $\cdots$ & $\cdots$ & $\cdots$ & $\cdots$ & $\cdots$ & \\
\hline JSS86 & $\begin{array}{l}\text { Jenkins, Sav- } \\
\text { age, \& Spitzer } \\
1986\end{array}$ & $\cdots$ & $\cdots$ & $\cdots$ & -0.437 & $\cdots$ & 0.127 & $\cdots$ & 0.028 & $\cdots$ & $\cdots$ & -0.222 & 0.008 & 0.114 & 0.243 & $\cdots$ & $\cdots$ & $\cdots$ & 14 \\
\hline JSS86 & $\begin{array}{l}\text { Jenkins, Sav- } \\
\text { age, \& Spitzer } \\
1986\end{array}$ & $\cdots$ & $\cdots$ & $\cdots$ & -0.369 & $\cdots$ & -0.009 & $\cdots$ & 0.028 & $\cdots$ & $\cdots$ & -0.222 & -0.009 & $\cdots$ & $\cdots$ & $\cdots$ & $\cdots$ & $\cdots$ & 15 \\
\hline JSS86 & $\begin{array}{l}\text { Jenkins, Sav- } \\
\text { age, \& Spitzer } \\
1986\end{array}$ & $\cdots$ & $\cdots$ & $\cdots$ & -0.369 & $\cdots$ & 0.059 & $\cdots$ & 0.028 & $\cdots$ & $\cdots$ & -0.222 & 0.008 & $\cdots$ & $\cdots$ & $\cdots$ & $\cdots$ & $\cdots$ & 16 \\
\hline JSS86 & $\begin{array}{l}\text { Jenkins, Sav- } \\
\text { age, \& Spitzer } \\
1986\end{array}$ & $\cdots$ & $\cdots$ & $\cdots$ & -0.369 & $\cdots$ & 0.059 & $\cdots$ & 0.028 & $\cdots$ & $\cdots$ & -0.222 & 0.008 & $\cdots$ & $\cdots$ & $\cdots$ & $\cdots$ & $\cdots$ & 17 \\
\hline JW96 & $\begin{array}{l}\text { Jenkins \& } \\
\text { Wallerstein } \\
1996\end{array}$ & $\ldots$ & $\ldots$ & 0.004 & 0.27 & 0.005 & $\ldots$ & -0.002 & $\cdots$ & -0.022 & $\ldots$ & $\cdots$ & -0.137 & 0.404 & $\ldots$ & $\ldots$ & ị & $\ldots$ & 18 \\
\hline JY78 & $\begin{array}{l}\text { Jura \& } \quad \text { York } \\
1978\end{array}$ & $\ldots$ & $\ldots$ & $\cdots$ & $\cdots$ & $\cdots$ & 0.126 & $\cdots$ & 0.025 & $\ldots$ & $\cdots$ & $\cdots$ & $\cdots$ & $\cdots$ & $\cdots$ & $\cdots$ & $\cdots$ & $\cdots$ & 19 \\
\hline KAMM03 & $\begin{array}{l}\text { Knauth et al. } \\
2003\end{array}$ & $\cdots$ & -0.063 & 0 & $\cdots$ & $\ldots$ & $\ldots$ & $\cdots$ & $\cdots$ & $\ldots$ & $\cdots$ & $\ldots$ & $\cdots$ & $\ldots$ & $\cdots$ & $\cdots$ & $\cdots$ & $\cdots$ & 20 \\
\hline KML06 & $\begin{array}{l}\text { Knauth, } \\
\text { Meyer, \& } \\
\text { Lauroesch } 2006\end{array}$ & $\ldots$ & 0 & $\ldots$ & $\ldots$ & $\ldots$ & $\ldots$ & $\cdots$ & $\ldots$ & $\ldots$ & $\ldots$ & $\ldots$ & $\ldots$ & $\ldots$ & $\ldots$ & $\ldots$ & $\ldots$ & $\ldots$ & \\
\hline $\mathrm{L}++95$ & $\begin{array}{l}\text { Linsky et al. } \\
1995\end{array}$ & $\cdots$ & $\cdots$ & $\cdots$ & 0 & $\cdots$ & $\cdots$ & $\cdots$ & $\cdots$ & $\cdots$ & $\cdots$ & $\cdots$ & -0.028 & $\cdots$ & $\cdots$ & $\cdots$ & $\cdots$ & $\cdots$ & \\
\hline $\mathrm{L}++03$ & $\begin{array}{l}\text { Lehner et al. } \\
2003\end{array}$ & $\ldots$ & $\ldots$ & 0.017 & $\cdots$ & -0.01 & 0 & $\cdots$ & $\cdots$ & $\cdots$ & $\cdots$ & $\cdots$ & 0.021 & $\cdots$ & $\cdots$ & $\cdots$ & $\cdots$ & $\cdots$ & \\
\hline LHW08 & $\begin{array}{l}\text { Lallement, } \\
\text { Hébrard, \& } \\
\text { Welsh 2008 }\end{array}$ & $\ldots$ & $\ldots$ & $\cdots$ & $\cdots$ & $\ldots$ & $\cdots$ & $\cdots$ & $\cdots$ & 0 & $\cdots$ & $\cdots$ & $\cdots$ & $\cdots$ & $\cdots$ & $\cdots$ & $\cdots$ & $\cdots$ & \\
\hline LKF05 & $\begin{array}{l}\text { Lebouteiller, } \\
\text { Kuassivi, \& } \\
\text { Ferlet } 2005\end{array}$ & $\cdots$ & $\cdots$ & 0 & $\cdots$ & $\cdots$ & 0 & $\cdots$ & $\cdots$ & $\cdots$ & $\cdots$ & $\ldots$ & $\cdots$ & $\cdots$ & $\cdots$ & $\cdots$ & $\ldots$ & $\cdots$ & \\
\hline LP95 & $\begin{array}{l}\text { Lipman \& Pet- } \\
\text { tini } 1995\end{array}$ & $\cdots$ & $\cdots$ & $\cdots$ & $\cdots$ & $\cdots$ & $\cdots$ & $\cdots$ & $\cdots$ & -0.022 & $\ldots$ & $\cdots$ & $\cdots$ & $\cdots$ & $\cdots$ & $\cdots$ & $\cdots$ & $\cdots$ & \\
\hline LVY79 & $\begin{array}{l}\text { Laurent, Vidal- } \\
\text { Madjar, \& } \\
\text { York } 1979\end{array}$ & $\cdots$ & $\cdots$ & $\cdots$ & $\ldots$ & $\ldots$ & $\cdots$ & $\cdots$ & $\cdots$ & $\ldots$ & $\ldots$ & $\ldots$ & $\cdots$ & $\cdots$ & $\ldots$ & $\cdots$ & $\ldots$ & $\ldots$ & 21 \\
\hline LYBM78 & $\begin{array}{l}\text { Lugger et al. } \\
1978\end{array}$ & $\ldots$ & -0.014 & $\ldots$ & $\ldots$ & $\cdots$ & $\ldots$ & $\cdots$ & $\ldots$ & $\ldots$ & $\ldots$ & $\cdots$ & $\cdots$ & $\ldots$ & $\cdots$ & $\cdots$ & $\cdots$ & $\ldots$ & \\
\hline$M++07$ & $\begin{array}{l}\text { Miller et al. } \\
2007\end{array}$ & $\cdots$ & $\cdots$ & $\cdots$ & $\cdots$ & 0 & $\cdots$ & $\cdots$ & $\cdots$ & $\cdots$ & $\ldots$ & $\cdots$ & 0 & $\cdots$ & $\cdots$ & $\cdots$ & $\ldots$ & $\cdots$ & 22 \\
\hline
\end{tabular}


Table 1-Continued

\begin{tabular}{|c|c|c|c|c|c|c|c|c|c|c|c|c|c|c|c|c|c|c|c|}
\hline \multirow[b]{2}{*}{$\begin{array}{l}\text { Code }^{\mathrm{a}} \\
(1)\end{array}$} & \multirow[b]{2}{*}{$\begin{array}{c}\text { Reference } \\
\quad(2)\end{array}$} & \multicolumn{17}{|c|}{ Correction Factors (dex) } & \multirow[b]{2}{*}{$\begin{array}{r}\text { Note } \\
(20)\end{array}$} \\
\hline & & $\begin{array}{c}\mathrm{C} \\
(3)\end{array}$ & $\begin{array}{l}\mathrm{N} \\
(4)\end{array}$ & $\begin{array}{l}\mathrm{O} \\
(5)\end{array}$ & $\begin{array}{l}\mathrm{Mg} \\
(6)\end{array}$ & $\begin{array}{l}\mathrm{Si} \\
(7)\end{array}$ & $\begin{array}{l}\mathrm{P} \\
(8)\end{array}$ & $\begin{array}{c}\mathrm{S} \\
(9)\end{array}$ & $\begin{array}{c}\mathrm{Cl} \\
(10)\end{array}$ & $\begin{array}{c}\mathrm{Ti} \\
(11)\end{array}$ & $\begin{array}{c}\mathrm{Cr} \\
(12)\end{array}$ & $\begin{array}{c}\mathrm{Mn} \\
(13)\end{array}$ & $\begin{array}{c}\mathrm{Fe} \\
(14)\end{array}$ & $\begin{array}{c}\mathrm{Ni} \\
(15)\end{array}$ & $\begin{array}{c}\mathrm{Cu} \\
(16)\end{array}$ & $\begin{array}{c}\mathrm{Zn} \\
(17)\end{array}$ & $\begin{array}{c}\mathrm{Ge} \\
(18)\end{array}$ & $\begin{array}{c}\mathrm{Kr} \\
(19)\end{array}$ & \\
\hline M78 & Morton 1978 & $\ldots$ & $\ldots$ & $\ldots$ & 0.159 & 0.251 & 0.134 & -0.006 & 0.025 & $\ldots$ & 0.407 & -0.199 & 0.034 & 0.202 & 0.242 & -0.086 & $\ldots$ & $\ldots$ & 23 \\
\hline MCS97 & $\begin{array}{l}\text { Meyer, } \\
\text { Cardelli, \& } \\
\text { Sofia 1997 }\end{array}$ & $\ldots$ & -0.063 & $\ldots$ & $\ldots$ & $\ldots$ & $\ldots$ & $\ldots$ & $\ldots$ & $\ldots$ & $\ldots$ & $\ldots$ & $\ldots$ & $\ldots$ & $\ldots$ & $\ldots$ & $\ldots$ & $\ldots$ & \\
\hline MD76 & $\begin{array}{l}\text { Morton \& Din- } \\
\text { erstein } 1976\end{array}$ & $\ldots$ & $\ldots$ & $\ldots$ & $\ldots$ & $\ldots$ & $\ldots$ & $\ldots$ & $\ldots$ & $\ldots$ & $\ldots$ & $\ldots$ & $\ldots$ & $\ldots$ & $\ldots$ & $\ldots$ & $\ldots$ & $\ldots$ & 2 \\
\hline MJC98 & $\begin{array}{l}\text { Meyer, Jura, \& } \\
\text { Cardelli } 1998\end{array}$ & $\ldots$ & $\ldots$ & 0.032 & $\ldots$ & $\ldots$ & $\ldots$ & $\ldots$ & $\ldots$ & $\cdots$ & $\ldots$ & $\ldots$ & $\ldots$ & $\ldots$ & $\ldots$ & $\ldots$ & $\ldots$ & $\ldots$ & \\
\hline MJHC94 & $\begin{array}{l}\text { Meyer et al. } \\
1994\end{array}$ & $\ldots$ & $\ldots$ & 0.033 & $\ldots$ & $\ldots$ & $\ldots$ & $\ldots$ & $\ldots$ & $\ldots$ & $\ldots$ & $\ldots$ & $\ldots$ & $\ldots$ & $\ldots$ & $\ldots$ & $\ldots$ & $\ldots$ & \\
\hline MY82 & $\begin{array}{l}\text { Martin \& York } \\
1982\end{array}$ & $\cdots$ & -0.015 & $\cdots$ & $\ldots$ & $\cdots$ & $\cdots$ & -0.006 & $\cdots$ & $\cdots$ & $\cdots$ & $\cdots$ & $\cdots$ & $\cdots$ & $\cdots$ & $\ldots$ & $\ldots$ & $\ldots$ & 24 \\
\hline $\mathrm{O}++03$ & $\begin{array}{l}\text { Oliveira et al. } \\
2003\end{array}$ & $\ldots$ & $\ldots$ & 0 & $\ldots$ & 0 & 0 & $\ldots$ & $\ldots$ & $\ldots$ & $\ldots$ & $\ldots$ & -0.045 & $\ldots$ & $\ldots$ & $\begin{array}{ll}\cdots & 1 \\
& N\end{array}$ & $\cdots$ & $\ldots$ & \\
\hline OH06 & $\begin{array}{l}\text { Oliveira \& } \\
\text { Hébrard } 2006\end{array}$ & $\ldots$ & 0 & 0 & 0 & $\ldots$ & 0 & $\ldots$ & 0 & $\ldots$ & $\ldots$ & $\ldots$ & 0 & $\ldots$ & $\ldots$ & ... & $\ldots$ & $\ldots$ & \\
\hline PTH05 & $\begin{array}{l}\text { Prochaska, } \\
\text { Tripp, \& Howk } \\
2005\end{array}$ & $\ldots$ & $\ldots$ & $\cdots$ & $\ldots$ & $\cdots$ & $\cdots$ & $\cdots$ & $\cdots$ & 0 & $\cdots$ & $\ldots$ & $\cdots$ & $\cdots$ & $\cdots$ & $\cdots$ & $\ldots$ & $\ldots$ & \\
\hline $\mathrm{R}++00$ & Ryu et al. 2000 & $\ldots$ & $\ldots$ & $\ldots$ & $\ldots$ & $\ldots$ & $\ldots$ & $\ldots$ & $\ldots$ & $\ldots$ & $\ldots$ & $\ldots$ & $\ldots$ & $\ldots$ & $\ldots$ & $\ldots$ & $\ldots$ & $\ldots$ & 2 \\
\hline $\mathrm{R}++01$ & $\begin{array}{l}\text { Rachford et al. } \\
2001\end{array}$ & $\cdots$ & $\cdots$ & $\cdots$ & $\cdots$ & $\cdots$ & $\cdots$ & $\cdots$ & $\cdots$ & $\cdots$ & $\cdots$ & $\cdots$ & $\cdots$ & $\cdots$ & $\cdots$ & $\cdots$ & $\cdots$ & $\cdots$ & 2 \\
\hline $\mathrm{R}++02$ & $\begin{array}{l}\text { Rachford, et al. } \\
2002\end{array}$ & $\ldots$ & $\ldots$ & $\ldots$ & $\ldots$ & $\cdots$ & $\cdots$ & $\cdots$ & $\ldots$ & $\cdots$ & $\cdots$ & $\cdots$ & $\cdots$ & $\cdots$ & $\cdots$ & $\ldots$ & $\cdots$ & $\ldots$ & \\
\hline RB95 & $\begin{array}{l}\text { Roth \& Blades } \\
1995\end{array}$ & $\ldots$ & $\ldots$ & $\ldots$ & $\ldots$ & $\ldots$ & $\ldots$ & $\ldots$ & $\ldots$ & $\ldots$ & 0.008 & $\ldots$ & $\ldots$ & $\ldots$ & $\ldots$ & 0.015 & $\ldots$ & $\ldots$ & 25 \\
\hline $\mathrm{S}++03$ & $\begin{array}{l}\text { Sonnentrucker } \\
\text { et al. } 2003\end{array}$ & $\ldots$ & -0.063 & $\cdots$ & $\ldots$ & $\ldots$ & $\cdots$ & $\cdots$ & $\cdots$ & $\cdots$ & $\cdots$ & $\cdots$ & $\cdots$ & $\cdots$ & $\cdots$ & $\cdots$ & $\ldots$ & $\cdots$ & \\
\hline $\mathrm{S}++07$ & $\begin{array}{l}\text { Sheffer et al. } \\
2007\end{array}$ & $\ldots$ & $\ldots$ & $\cdots$ & $\cdots$ & $\cdots$ & $\cdots$ & $\cdots$ & $\cdots$ & $\cdots$ & $\cdots$ & $\cdots$ & $\cdots$ & $\cdots$ & $\cdots$ & $\cdots$ & $\ldots$ & $\cdots$ & 2 \\
\hline $\mathrm{S}++08 \mathrm{a}$ & $\begin{array}{l}\text { Shull, private } \\
\text { communication }\end{array}$ & $\ldots$ & $\ldots$ & $\ldots$ & $\ldots$ & $\ldots$ & $\ldots$ & $\ldots$ & $\ldots$ & $\ldots$ & $\ldots$ & $\ldots$ & $\ldots$ & $\ldots$ & $\ldots$ & $\ldots$ & $\ldots$ & $\ldots$ & 2 \\
\hline $\mathrm{S}++08 \mathrm{~b}$ & $\begin{array}{l}\text { Sheffer et al. } \\
2008\end{array}$ & $\ldots$ & $\ldots$ & $\cdots$ & $\ldots$ & $\ldots$ & $\cdots$ & $\cdots$ & $\cdots$ & $\cdots$ & $\cdots$ & $\ldots$ & $\ldots$ & $\cdots$ & $\cdots$ & $\cdots$ & $\ldots$ & $\ldots$ & 2,26 \\
\hline $\mathrm{S}++96$ & $\begin{array}{l}\text { Snow et al. } \\
1996\end{array}$ & 0.084 & $\ldots$ & 0.032 & -0.399 & 0 & 0.386 & $\ldots$ & $\ldots$ & -0.045 & $\ldots$ & 0.032 & $\ldots$ & 0.327 & $\ldots$ & $\ldots$ & $\ldots$ & $\ldots$ & 27 \\
\hline S76 & Snow 1976 & $\ldots$ & $\ldots$ & $\ldots$ & $\ldots$ & $\ldots$ & 0.5 & $\ldots$ & $\ldots$ & $\ldots$ & $\ldots$ & -0.3 & 0.045 & 0.121 & 0.312 & $\ldots$ & $\ldots$ & $\ldots$ & 28 \\
\hline S77 & Snow 1977 & $\ldots$ & $\ldots$ & $\ldots$ & 0.159 & $\ldots$ & 0.5 & $\ldots$ & -0.025 & $\ldots$ & $\ldots$ & -0.3 & 0.18 & $\ldots$ & 0.312 & $\ldots$ & $\ldots$ & $\ldots$ & 28 \\
\hline S78 & Stokes 1978 & $\ldots$ & $\cdots$ & $\ldots$ & $\ldots$ & $\cdots$ & $\ldots$ & $\ldots$ & $\ldots$ & -0.046 & $\ldots$ & $\ldots$ & $\ldots$ & $\ldots$ & $\ldots$ & $\ldots$ & $\ldots$ & $\ldots$ & \\
\hline S98 & Sarlin 1998 & $\ldots$ & $\ldots$ & $\ldots$ & $\ldots$ & $\ldots$ & $\ldots$ & $\ldots$ & $\ldots$ & $\ldots$ & $\ldots$ & $\ldots$ & $\ldots$ & $\ldots$ & $\ldots$ & $\ldots$ & $\ldots$ & $\ldots$ & 2 \\
\hline SB79 & $\begin{array}{l}\text { Savage \& } \\
\text { Bohlin } 1979\end{array}$ & $\ldots$ & $\ldots$ & $\ldots$ & $\ldots$ & $\ldots$ & $\ldots$ & $\ldots$ & $\ldots$ & $\ldots$ & $\ldots$ & $\ldots$ & -0.018 & $\ldots$ & $\ldots$ & $\ldots$ & $\ldots$ & $\ldots$ & \\
\hline
\end{tabular}


Table 1-Continued

\begin{tabular}{|c|c|c|c|c|c|c|c|c|c|c|c|c|c|c|c|c|c|c|c|}
\hline \multirow[b]{2}{*}{$\begin{array}{l}\text { Code }^{\mathrm{a}} \\
(1)\end{array}$} & \multirow[b]{2}{*}{$\begin{array}{c}\text { Reference } \\
\quad(2)\end{array}$} & \multicolumn{17}{|c|}{ Correction Factors (dex) } & \\
\hline & & $\begin{array}{c}\mathrm{C} \\
(3)\end{array}$ & $\begin{array}{c}\mathrm{N} \\
(4)\end{array}$ & $\begin{array}{c}\mathrm{O} \\
(5)\end{array}$ & $\begin{array}{l}\mathrm{Mg} \\
(6)\end{array}$ & $\begin{array}{c}\mathrm{Si} \\
(7)\end{array}$ & $\begin{array}{c}\mathrm{P} \\
(8)\end{array}$ & $\begin{array}{c}\mathrm{S} \\
(9)\end{array}$ & $\begin{array}{c}\mathrm{Cl} \\
(10)\end{array}$ & $\begin{array}{c}\mathrm{Ti} \\
(11)\end{array}$ & $\begin{array}{l}\mathrm{Cr} \\
(12)\end{array}$ & $\begin{array}{l}\mathrm{Mn} \\
(13)\end{array}$ & $\begin{array}{c}\mathrm{Fe} \\
(14)\end{array}$ & $\begin{array}{c}\mathrm{Ni} \\
(15)\end{array}$ & $\begin{array}{c}\mathrm{Cu} \\
(16)\end{array}$ & $\begin{array}{c}\mathrm{Zn} \\
(17)\end{array}$ & $\begin{array}{c}\mathrm{Ge} \\
(18)\end{array}$ & $\begin{array}{c}\mathrm{Kr} \\
(19)\end{array}$ & $\begin{array}{r}\mathrm{No} \\
(2\end{array}$ \\
\hline SCGM97 & $\begin{array}{l}\text { Sofia et al. } \\
1997\end{array}$ & 0.084 & $\cdots$ & $\cdots$ & $\cdots$ & $\cdots$ & $\cdots$ & . & $\cdots$ & $\cdots$ & $\cdots$ & $\cdots$ & $\cdots$ & $\cdots$ & $\ldots$ & $\ldots$ & $\ldots$ & $\ldots$ & \\
\hline $\mathrm{SCH} 75$ & $\begin{array}{l}\text { Spitzer, } \\
\text { Cochran, \& } \\
\text { Hirshfeld } 1974\end{array}$ & $\ldots$ & $\ldots$ & $\ldots$ & $\ldots$ & $\ldots$ & $\ldots$ & $\ldots$ & $\cdots$ & $\cdots$ & $\cdots$ & $\cdots$ & $\ldots$ & $\ldots$ & $\ldots$ & $\cdots$ & $\cdots$ & $\cdots$ & 2 \\
\hline SCS92 & $\begin{array}{l}\text { Savage, } \\
\text { Cardelli, } \quad \& \\
\text { Sofia } 1992\end{array}$ & $\ldots$ & -0.063 & 0.033 & -0.399 & $\ldots$ & -0.016 & $\ldots$ & $\ldots$ & $\ldots$ & 0.143 & -0.161 & 0.14 & 0.314 & 0.16 & 0.011 & -0.148 & -0.014 & \\
\hline SCS94 & $\begin{array}{l}\text { Sofia, Cardelli, } \\
\text { \& Savage } 1994\end{array}$ & $\cdots$ & $\cdots$ & $\cdots$ & $\cdots$ & 0 & $\cdots$ & $\cdots$ & $\cdots$ & $\cdots$ & $\cdots$ & $\cdots$ & $\cdots$ & $\cdots$ & $\cdots$ & $\cdots$ & $\cdots$ & $\cdots$ & \\
\hline SF93 & $\begin{array}{l}\text { Spitzer \& Fitz- } \\
\text { patrick } 1993\end{array}$ & $\ldots$ & $\ldots$ & $\ldots$ & -0.369 & -0.017 & $\ldots$ & 0.006 & $\ldots$ & -0.022 & $\ldots$ & -0.011 & -0.048 & $\ldots$ & $\ldots$ & $\ldots$ & $\ldots$ & $\ldots$ & 29 \\
\hline SF95 & $\begin{array}{l}\text { Spitzer \& Fitz- } \\
\text { patrick } 1995\end{array}$ & $\ldots$ & $\ldots$ & $\ldots$ & $\ldots$ & -0.017 & $\ldots$ & 0.006 & $\ldots$ & $\ldots$ & $\ldots$ & -0.018 & -0.007 & $\ldots$ & $\ldots$ & $\ldots$ & $\left.\right|^{\cdots}$ & $\ldots$ & \\
\hline SFM98 & $\begin{array}{lr}\text { Sofia, } & \text { Fitz- } \\
\text { patrick, } & \& \\
\text { Meyer } & 1998\end{array}$ & 0.084 & $\ldots$ & $\ldots$ & $\ldots$ & $\ldots$ & $\ldots$ & $\ldots$ & $\ldots$ & $\ldots$ & $\ldots$ & $\ldots$ & $\ldots$ & $\ldots$ & $\ldots$ & $\ldots$ & I... & $\ldots$ & \\
\hline SJ98 & $\begin{array}{l}\text { Sofia \& Jenkins } \\
1998\end{array}$ & $\ldots$ & $\ldots$ & $\ldots$ & $\ldots$ & $\ldots$ & $\ldots$ & $\ldots$ & $\ldots$ & $\ldots$ & $\ldots$ & $\ldots$ & $\ldots$ & $\cdots$ & $\ldots$ & $\cdots$ & $\ldots$ & $\ldots$ & \\
\hline SLMC04 & $\begin{array}{l}\text { Sofia et al. } \\
2004\end{array}$ & 0 & $\ldots$ & $\ldots$ & $\ldots$ & $\ldots$ & $\ldots$ & $\ldots$ & $\ldots$ & $\ldots$ & $\ldots$ & $\ldots$ & $\ldots$ & $\ldots$ & $\ldots$ & $\ldots$ & $\ldots$ & $\ldots$ & \\
\hline $\mathrm{SR}++00$ & $\begin{array}{l}\text { Snow et al. } \\
2000\end{array}$ & $\ldots$ & $\ldots$ & $\ldots$ & $\ldots$ & $\ldots$ & $\ldots$ & $\ldots$ & $\ldots$ & $\ldots$ & $\cdots$ & $\ldots$ & $\ldots$ & $\ldots$ & $\ldots$ & $\ldots$ & $\ldots$ & $\ldots$ & 5 \\
\hline SRF02 & $\begin{array}{l}\text { Snow, Rach- } \\
\text { ford, \& Figoski } \\
2002\end{array}$ & $\ldots$ & $\ldots$ & $\ldots$ & $\ldots$ & $\ldots$ & $\ldots$ & $\ldots$ & $\ldots$ & $\ldots$ & $\ldots$ & $\ldots$ & 0.143 & $\ldots$ & $\ldots$ & $\ldots$ & $\ldots$ & $\ldots$ & 30 \\
\hline SS96a & $\begin{array}{l}\text { Sembach \& } \\
\text { Savage } 1996\end{array}$ & $\ldots$ & $\ldots$ & $\ldots$ & $\ldots$ & $\ldots$ & $\ldots$ & $\ldots$ & $\ldots$ & $\ldots$ & $\ldots$ & $\ldots$ & 0 & $\ldots$ & $\ldots$ & 0.002 & $\ldots$ & $\ldots$ & \\
\hline SS96b & $\begin{array}{l}\text { Savage \& Sem- } \\
\text { bach 1996b }\end{array}$ & $\ldots$ & $\ldots$ & $\ldots$ & 0.27 & 0.02 & 0.132 & $\ldots$ & $\ldots$ & $\ldots$ & 0.01 & -0.076 & 0.009 & 0.407 & $\ldots$ & 0.017 & $\ldots$ & $\ldots$ & 32 \\
\hline SS96b & $\begin{array}{l}\text { Savage \& Sem- } \\
\text { bach } 1996 \mathrm{~b}\end{array}$ & $\ldots$ & $\ldots$ & $\ldots$ & 0.27 & 0.034 & $\ldots$ & $\ldots$ & $\ldots$ & $\ldots$ & 0.01 & -0.076 & -0.004 & 0.407 & $\ldots$ & $\ldots$ & $\ldots$ & $\ldots$ & 33 \\
\hline SST97 & $\begin{array}{l}\text { Sembach, Sav- } \\
\text { age, \& Tripp } \\
1997\end{array}$ & $\ldots$ & $\ldots$ & $\ldots$ & 0.27 & $\ldots$ & $\ldots$ & $\ldots$ & $\ldots$ & $\ldots$ & $\ldots$ & $\ldots$ & $\ldots$ & $\ldots$ & $\ldots$ & $\ldots$ & $\ldots$ & $\ldots$ & 34 \\
\hline $\mathrm{ST}++00$ & $\begin{array}{l}\text { Sonneborn et } \\
\text { al. } 2000\end{array}$ & $\ldots$ & -0.029 & $\ldots$ & $\ldots$ & $\ldots$ & $\ldots$ & $\ldots$ & $\ldots$ & $\ldots$ & $\ldots$ & $\ldots$ & $\ldots$ & $\ldots$ & $\ldots$ & $\ldots$ & $\ldots$ & $\ldots$ & \\
\hline SV85 & $\begin{array}{l}\text { Shull \& Van } \\
\text { Steenberg } 1985\end{array}$ & $\ldots$ & $\ldots$ & $\ldots$ & $\ldots$ & $\ldots$ & $\ldots$ & $\ldots$ & $\ldots$ & $\ldots$ & $\ldots$ & $\ldots$ & $\ldots$ & $\ldots$ & $\ldots$ & $\ldots$ & $\ldots$ & $\ldots$ & 5 \\
\hline
\end{tabular}


Table 1-Continued

\begin{tabular}{|c|c|c|c|c|c|c|c|c|c|c|c|c|c|c|c|c|c|c|c|}
\hline \multirow[b]{2}{*}{$\begin{array}{l}\text { Code }^{\mathrm{a}} \\
(1)\end{array}$} & \multirow[b]{2}{*}{$\begin{array}{l}\text { Reference } \\
\quad(2)\end{array}$} & \multicolumn{17}{|c|}{ Correction Factors (dex) } & \multirow[b]{2}{*}{$\begin{array}{c}\text { Notes } \\
(20)\end{array}$} \\
\hline & & $\begin{array}{c}\mathrm{C} \\
(3)\end{array}$ & $\begin{array}{l}\mathrm{N} \\
(4)\end{array}$ & $\begin{array}{l}\mathrm{O} \\
(5)\end{array}$ & $\begin{array}{l}\mathrm{Mg} \\
(6)\end{array}$ & $\begin{array}{l}\mathrm{Si} \\
(7)\end{array}$ & $\begin{array}{l}\mathrm{P} \\
(8)\end{array}$ & $\begin{array}{c}\mathrm{S} \\
(9)\end{array}$ & $\begin{array}{c}\mathrm{Cl} \\
(10)\end{array}$ & $\begin{array}{c}\mathrm{Ti} \\
(11)\end{array}$ & $\begin{array}{c}\mathrm{Cr} \\
(12)\end{array}$ & $\begin{array}{l}\mathrm{Mn} \\
(13)\end{array}$ & $\begin{array}{c}\mathrm{Fe} \\
(14)\end{array}$ & $\begin{array}{c}\mathrm{Ni} \\
(15)\end{array}$ & $\begin{array}{c}\mathrm{Cu} \\
(16)\end{array}$ & $\begin{array}{c}\mathrm{Zn} \\
(17)\end{array}$ & $\begin{array}{c}\mathrm{Ge} \\
(18)\end{array}$ & $\begin{array}{c}\mathrm{Kr} \\
(19)\end{array}$ & \\
\hline SY77 & $\begin{array}{l}\text { Shull \& } \quad \text { York } \\
1977\end{array}$ & $\cdots$ & $\cdots$ & $\cdots$ & $\cdots$ & $\cdots$ & 0.5 & $\ldots$ & $\ldots$ & $\cdots$ & $\cdots$ & $\ldots$ & 0.057 & $\ldots$ & $\ldots$ & $\ldots$ & $\ldots$ & $\ldots$ & \\
\hline VF02 & $\begin{array}{l}\text { Vidal-Madjar } \\
\text { \& Ferlet } 2002\end{array}$ & $\cdots$ & $\cdots$ & $\cdots$ & $\cdots$ & $\cdots$ & $\ldots$ & $\cdots$ & $\ldots$ & $\cdots$ & $\cdots$ & $\ldots$ & $\cdots$ & $\cdots$ & $\cdots$ & $\ldots$ & $\cdots$ & $\cdots$ & \\
\hline $\mathrm{W}++97$ & $\begin{array}{l}\text { Welsh et al. } \\
1997\end{array}$ & $\cdots$ & $\cdots$ & $\cdots$ & $\cdots$ & $\cdots$ & $\cdots$ & $\cdots$ & $\ldots$ & -0.023 & $\cdots$ & $\ldots$ & $\cdots$ & $\cdots$ & $\ldots$ & $\cdots$ & $\cdots$ & $\cdots$ & 35 \\
\hline W++99 & $\begin{array}{l}\text { Welty et al. } \\
1999\end{array}$ & 0 & -0.068 & 0.002 & 0 & 0 & 0.266 & $\cdots$ & $\cdots$ & -0.023 & 0.011 & -0.14 & 0 & -0.003 & 0.16 & 0.011 & 0 & 0 & 36 \\
\hline WG92 & $\begin{array}{l}\text { Wallerstein \& } \\
\text { Gilroy } 1992\end{array}$ & $\cdots$ & $\ldots$ & $\ldots$ & $\ldots$ & $\ldots$ & $\ldots$ & $\ldots$ & $\ldots$ & -0.106 & $\ldots$ & $\cdots$ & $\ldots$ & $\ldots$ & $\ldots$ & $\ldots$ & $\cdots$ & $\cdots$ & 26 \\
\hline WRLS02 & $\begin{array}{l}\text { Wood et al. } \\
2002\end{array}$ & 0 & 0.007 & -0.013 & $\cdots$ & 0.234 & $\cdots$ & -0.01 & $\cdots$ & $\cdots$ & $\ldots$ & $\cdots$ & $\cdots$ & $\cdots$ & $\cdots$ & $\ldots$ & $\cdots$ & $\cdots$ & \\
\hline $\mathrm{Y}++83$ & $\begin{array}{l}\text { York et al. } \\
1983\end{array}$ & $\cdots$ & 0.122 & $\cdots$ & $\cdots$ & $\cdots$ & $\cdots$ & $\cdots$ & $\ldots$ & $\ldots$ & $\cdots$ & $\ldots$ & $\cdots$ & $\cdots$ & $\cdots$ & $\cdots$ & $\cdots$ & $\left.\right|^{\cdots}$ & 37 \\
\hline $\mathrm{Y}++83$ & $\begin{array}{l}\text { York et al. } \\
1983\end{array}$ & $\cdots$ & -0.014 & $\cdots$ & $\cdots$ & $\ldots$ & $\cdots$ & $\cdots$ & $\cdots$ & $\ldots$ & $\ldots$ & $\ldots$ & $\ldots$ & $\ldots$ & $\ldots$ & $\ldots$ & $\ldots$ & ? & 38 \\
\hline $\mathrm{Y}++83$ & $\begin{array}{l}\text { York et al. } \\
1983\end{array}$ & $\cdots$ & 0.211 & $\cdots$ & $\cdots$ & $\cdots$ & $\cdots$ & $\cdots$ & $\cdots$ & $\cdots$ & $\cdots$ & $\cdots$ & $\cdots$ & $\cdots$ & $\cdots$ & $\cdots$ & $\cdots$ & $\cdots$ & 39 \\
\hline
\end{tabular}


Table 1-Continued

\begin{tabular}{|c|c|c|c|c|c|c|c|c|c|c|c|c|c|c|c|c|c|c|c|}
\hline \multirow[b]{2}{*}{$\begin{array}{l}\text { Code }^{\mathrm{a}} \\
\text { (1) }\end{array}$} & \multirow[b]{2}{*}{$\begin{array}{c}\text { Reference } \\
\quad(2)\end{array}$} & \multicolumn{17}{|c|}{ Correction Factors (dex) } & \multirow[b]{2}{*}{$\begin{array}{c}\text { Notes } \\
(20)\end{array}$} \\
\hline & & $\begin{array}{c}\mathrm{C} \\
(3)\end{array}$ & $\begin{array}{l}\mathrm{N} \\
(4)\end{array}$ & $\begin{array}{l}\mathrm{O} \\
(5)\end{array}$ & $\begin{array}{l}\mathrm{Mg} \\
(6)\end{array}$ & $\begin{array}{l}\mathrm{Si} \\
(7)\end{array}$ & $\begin{array}{l}\mathrm{P} \\
(8)\end{array}$ & $\begin{array}{l}\mathrm{S} \\
(9)\end{array}$ & $\begin{array}{c}\mathrm{Cl} \\
(10)\end{array}$ & $\begin{array}{c}\mathrm{Ti} \\
(11)\end{array}$ & $\begin{array}{c}\mathrm{Cr} \\
(12)\end{array}$ & $\begin{array}{l}\mathrm{Mn} \\
(13)\end{array}$ & $\begin{array}{c}\mathrm{Fe} \\
(14)\end{array}$ & $\begin{array}{c}\mathrm{Ni} \\
(15)\end{array}$ & $\begin{array}{c}\mathrm{Cu} \\
(16)\end{array}$ & $\begin{array}{c}\mathrm{Zn} \\
(17)\end{array}$ & $\begin{array}{c}\mathrm{Ge} \\
(18)\end{array}$ & $\begin{array}{c}\mathrm{Kr} \\
(19)\end{array}$ & \\
\hline Y76 & York 1976 & $\cdots$ & $\cdots$ & $\cdots$ & $\cdots$ & $\cdots$ & $\cdots$ & $\cdots$ & $\cdots$ & $\cdots$ & $\cdots$ & $\cdots$ & $\cdots$ & $\cdots$ & $\cdots$ & $\cdots$ & $\cdots$ & $\cdots$ & 40 \\
\hline Y83 & York 1983 & $\cdots$ & -0.016 & -0.025 & $\cdots$ & 0.458 & -0.016 & -0.006 & 0.025 & $\ldots$ & $\cdots$ & $\cdots$ & 0.052 & $\ldots$ & $\cdots$ & $\cdots$ & $\ldots$ & $\ldots$ & \\
\hline YK79 & $\begin{array}{l}\text { York \& Kina- } \\
\text { han } 1979\end{array}$ & $\cdots$ & -0.027 & -0.036 & $\cdots$ & 0.456 & -0.009 & -0.006 & 0.026 & $\cdots$ & 0.218 & -0.228 & -0.012 & -0.43 & 0.312 & -0.086 & $\cdots$ & $\cdots$ & \\
\hline YR76 & $\begin{array}{l}\text { York \& Roger- } \\
\text { son } 1976\end{array}$ & $\cdots$ & $\cdots$ & $\cdots$ & $\cdots$ & $\cdots$ & $\cdots$ & $\cdots$ & $\cdots$ & $\cdots$ & $\cdots$ & $\cdots$ & $\cdots$ & $\cdots$ & $\cdots$ & $\cdots$ & $\cdots$ & $\cdots$ & 41 \\
\hline
\end{tabular}

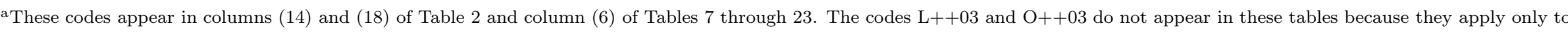
the white dwarf target stars in the Local Bubble, which are discussed separately in 8

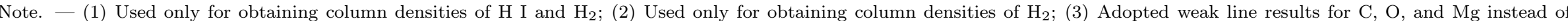

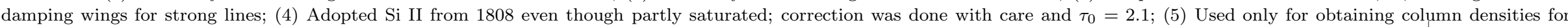

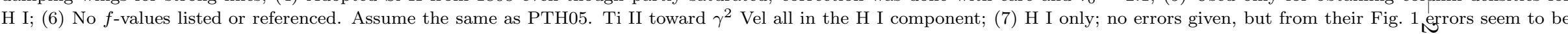

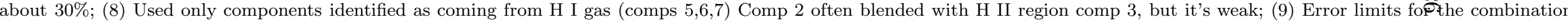

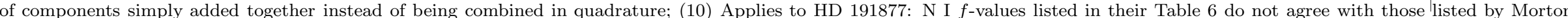

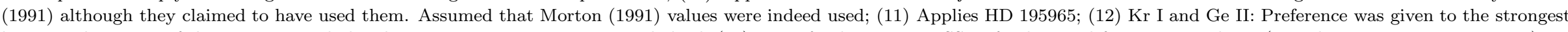

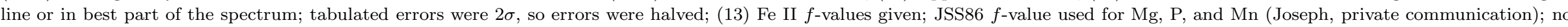

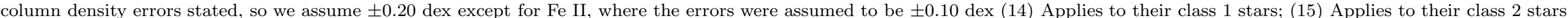

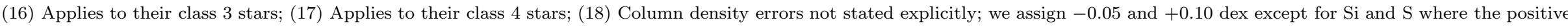

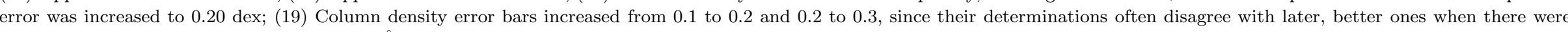

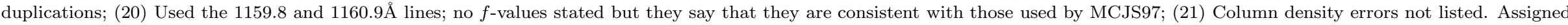

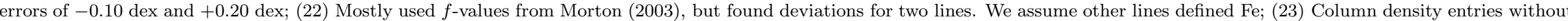

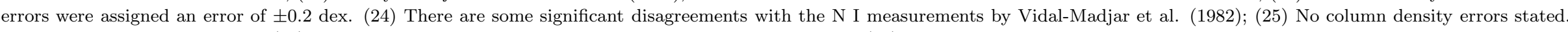

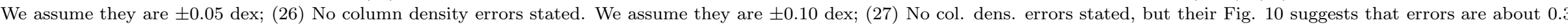

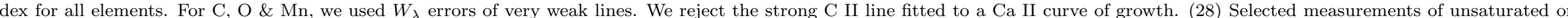

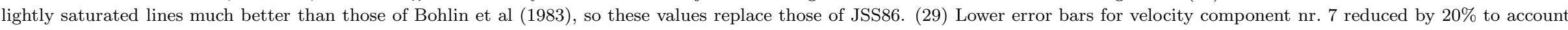

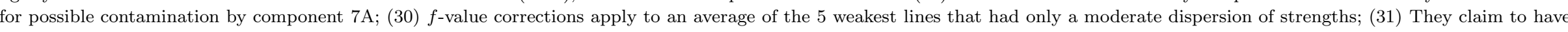

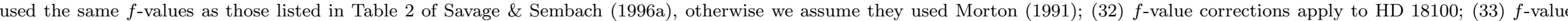

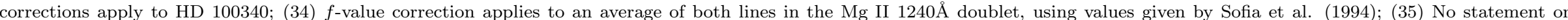

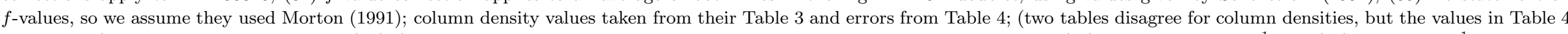

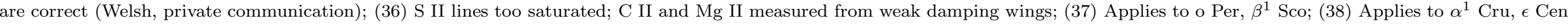

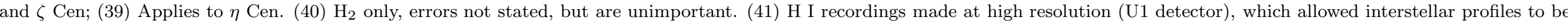
separated from stellar ones. Also, higher Lyman series lines were studied. 
Table 2. Stellar Data and Line of Sight Information

\begin{tabular}{|c|c|c|c|c|c|c|c|c|c|c|c|c|c|c|c|c|c|}
\hline \multirow[b]{2}{*}{$\begin{array}{l}\mathrm{HD} \\
(1)\end{array}$} & \multirow[b]{2}{*}{$\begin{array}{l}\text { Name } \\
(2)\end{array}$} & \multicolumn{2}{|c|}{ Gal. Coord. } & \multirow[b]{2}{*}{$\begin{array}{l}V \\
(5)\end{array}$} & \multicolumn{2}{|c|}{ Spectral Type } & \multirow[b]{2}{*}{$\begin{array}{c}E(B-V) \\
(8)\end{array}$} & \multirow{2}{*}{$\begin{array}{c}\text { dist. } \\
(\mathrm{kpc}) \\
(9)\end{array}$} & \multirow{2}{*}{$\begin{array}{c}z \\
(\mathrm{kpc}) \\
(10)\end{array}$} & \multicolumn{4}{|c|}{$\log N(\mathrm{H} \mathrm{I})$} & \multicolumn{4}{|c|}{$\log N\left(\mathrm{H}_{2}\right)$} \\
\hline & & $\begin{array}{l}\ell \\
(3)\end{array}$ & $\begin{array}{c}b \\
(4)\end{array}$ & & $\begin{array}{c}\text { Value } \\
(6)\end{array}$ & $\begin{array}{l}\text { ref. }^{a} \\
(7)\end{array}$ & & & & $\begin{array}{l}1.1 . \\
(11)\end{array}$ & $\begin{array}{l}\text { best } \\
(12)\end{array}$ & $\begin{array}{l}\text { u.l. } \\
\text { (13) }\end{array}$ & $\begin{array}{l}\text { Ref. }^{D} \\
(14)\end{array}$ & $\begin{array}{c}1.1 . \\
(15)\end{array}$ & $\begin{array}{l}\text { best } \\
\text { (16) }\end{array}$ & $\begin{array}{l}\text { u.1. } \\
(17)\end{array}$ & $\begin{array}{l}\text { Ref. }^{\text {D }} \\
\text { (18) }\end{array}$ \\
\hline 1383 & HD 1383 & 119.02 & -0.89 & 7.63 & B1 II & JM53 & 0.37 & 2.94 & -0.05 & 21.33 & 21.42 & 21.51 & CLMS04 & 20.38 & 20.45 & 20.52 & CLMS04 \\
\hline 2905 & $\kappa \mathrm{Cas}$ & 120.84 & 0.14 & 4.19 & B0.7 Ia & W72 & 0.29 & 1.18 & 0.00 & 21.05 & 21.20 & 21.32 & BSD78 & 20.09 & 20.27 & 20.45 & BSD78 \\
\hline 5394 & $\gamma \mathrm{Cas}$ & 123.58 & -2.15 & 2.39 & Bo IVe & $\mathrm{B}++08$ & 0.21 & 0.17 & -0.01 & 20.06 & 20.16 & 20.24 & BSD78 & 16.48 & 16.53 & 16.58 & S98 \\
\hline 12323 & HD 12323 & 132.91 & -5.87 & 8.92 & $09 \mathrm{~V}$ & $\mathrm{~B}++08$ & 0.21 & 4.4 & -0.45 & 21.09 & 21.18 & 21.27 & CLMS04 & 20.24 & 20.32 & 20.40 & CLMS04 \\
\hline 13268 & HD 13268 & 133.96 & -4.99 & 8.18 & O8 Vnn & $\mathrm{B}++08$ & 0.23 & 2.1 & -0.18 & 21.23 & 21.32 & 21.41 & CLMS04 & 20.35 & 20.42 & 20.49 & CLMS04 \\
\hline 13745 & HD 13745 & 134.58 & -4.96 & 7.90 & O9.7 IIn & $\mathrm{B}++08$ & 0.34 & 3.2 & -0.28 & 21.15 & 21.25 & 21.35 & DS94 & 20.42 & 20.47 & 20.52 & $\mathrm{~S}++08 \mathrm{a}$ \\
\hline 14434 & HD 14434 & 135.08 & -3.82 & 8.59 & O5.5 Vnfp & $\mathrm{B}++08$ & 0.38 & 3.5 & -0.23 & 21.28 & 21.37 & 21.46 & CLMS04 & 20.40 & 20.47 & 20.54 & CLMS04 \\
\hline 15137 & HD 15137 & 137.46 & -7.58 & 7.86 & O9.5 II-IIIn & $\mathrm{B}++08$ & 0.24 & 3.5 & -0.46 & 20.95 & 21.11 & 21.27 & DS94 & 20.24 & 20.27 & 20.30 & $\mathrm{~S}++08 \mathrm{a}$ \\
\hline 18100 & HD 18100 & 217.93 & -62.73 & 8.44 & B1 V & SMS01 & 0.02 & 1.7 & -1.48 & $20.02^{\mathrm{c}}$ & $20.15^{\mathrm{c}}$ & $20.29^{\mathrm{c}}$ & DS94 & & & 14.80 & $\mathrm{R}++00$ \\
\hline 21278 & HD 21278 & 147.52 & -6.19 & 4.97 & B5 $\mathrm{V}$ & MHG71 & 0.06 & 0.16 & -0.02 & $\ldots c$ & $20.64^{\mathrm{c}}$ & $21.07^{\mathrm{c}}$ & SV85 & 19.25 & 19.48 & 19.71 & BSD78 \\
\hline 21856 & HD 21856 & 156.32 & -16.75 & 5.90 & $\mathrm{~B} 1 \mathrm{~V}$ & L68 & 0.15 & 0.50 & -0.14 & $20.92^{\mathrm{c}}$ & $21.02^{\mathrm{c}}$ & $21.11^{\mathrm{c}}$ & BSD78 & 19.89 & 20.04 & 20.19 & BSD78 \\
\hline 22586 & HD 22586 & 264.19 & -50.36 & 8.01 & B2 III & $\mathrm{H} 70$ & 0.01 & 2.02 & -1.56 & $20.21^{\mathrm{d}}$ & $20.36^{\mathrm{d}}$ & $20.50^{\mathrm{d}}$ & DS94 & & & & Doto \\
\hline 22928 & $\delta$ Per & 150.28 & -5.77 & 2.99 & B5 III & $\mathrm{B}++08$ & 0.05 & 0.16 & -0.02 & $\ldots$ e & $\ldots$ e & $21.21^{\mathrm{e}}$ & SV85 & 19.10 & 19.30 & 19.50 & BSD78 \\
\hline 22951 & 40 Per & 158.92 & -16.70 & 4.98 & B $0.5 \mathrm{~V}$ & JM53 & 0.19 & 0.32 & -0.09 & 20.89 & 21.04 & 21.16 & BSD78 & 20.28 & 20.46 & 20.64 & BSD78 \\
\hline 23180 & o Per & 160.36 & -17.74 & 3.86 & B1 III & L68 & 0.22 & 0.38 & -0.12 & $20.72^{\mathrm{d}}$ & $20.88^{\mathrm{d}}$ & $21.01^{\mathrm{d}}$ & BSD78 & 20.45 & 20.60 & 20.75 & BSD78 \\
\hline 23408 & 20 Tau & 166.17 & -23.51 & 3.87 & B7 III & JM53 & 0.06 & 0.12 & -0.05 & & & & & 19.49 & 19.75 & 20.01 & BSD78 \\
\hline 23478 & HD 23478 & 160.76 & -17.42 & 6.69 & B3 IV & $\mathrm{H} 56 \mathrm{~b}$ & 0.20 & 0.47 & -0.14 & $20.25^{\mathrm{c}}$ & $20.71^{\mathrm{c}}$ & $20.88^{\mathrm{c}}$ & $\mathrm{C}++08$ & 20.41 & 20.48 & 20.55 & $\begin{array}{l}\mathrm{C}++08 \\
\text {. }\end{array}$ \\
\hline 23480 & $23 \mathrm{Tau}$ & 166.57 & -23.75 & 4.16 & B6 IVnn & JM53 & 0.07 & 0.12 & -0.05 & $\ldots$ & $\ldots$ & $\ldots$ & of & 19.94 & 20.12 & 20.30 & BSD78 \\
\hline 23630 & $\eta \mathrm{Tau}$ & 166.67 & -23.46 & 2.87 & B7 IIIe & $\mathrm{B}++08$ & 0.05 & 0.12 & -0.05 & $\ldots$ & .. & .. & ... & 19.36 & 19.54 & 19.72 & BSD78 \\
\hline 24190 & HD 24190 & 160.39 & -15.18 & 7.45 & $\mathrm{~B} 2 \mathrm{Vn}$ & W71 & 0.23 & 0.82 & -0.22 & 21.12 & 21.18 & 21.24 & $\mathrm{C}++08$ & 20.31 & 20.38 & 20.45 & $\mathrm{C}++08 \mathrm{~N}$ \\
\hline 24398 & $\zeta$ Per & 162.29 & -16.69 & 2.88 & B1 Ib & $\mathrm{B}++08$ & 0.27 & 0.23 & -0.07 & $20.75^{\mathrm{d}}$ & $20.80^{\mathrm{d}}$ & $20.84^{\mathrm{d}}$ & BSD78 & 20.49 & 20.67 & 20.85 & BSD78 \\
\hline 24534 & X Per & 163.08 & -17.14 & 6.10 & O9.5 III & $\mathrm{S} 82$ & 0.31 & 2.07 & -0.61 & 20.67 & 20.73 & 20.79 & DS94 & 20.88 & 20.92 & 20.96 & $\mathrm{R}++02$ \\
\hline 24760 & $\epsilon$ Per & 157.35 & -10.09 & 2.90 & B0.5 IV & $\mathrm{B}++08$ & 0.07 & 0.20 & -0.03 & 20.30 & 20.40 & 20.48 & BSD78 & 19.26 & 19.52 & 19.78 & BSD78 \\
\hline 24912 & $\xi$ Per & 160.37 & -13.11 & 4.04 & O7.5 IIInf & $\mathrm{B}++08$ & 0.26 & 0.59 & -0.13 & 21.02 & 21.11 & 21.19 & BSD78 & 20.38 & 20.53 & 20.68 & BSD78 \\
\hline 27778 & 62 Tau & 172.76 & -17.39 & 6.33 & B3V & SMS01 & 0.34 & 0.23 & -0.07 & $\ldots c$ & $20.35^{\mathrm{c}}$ & $20.89^{\mathrm{c}}$ & CLMS04 & 20.64 & 20.72 & 20.80 & CLMS04 \\
\hline 28497 & 228 Eri & 208.78 & -37.40 & 5.59 & B1.5 Ve & $\mathrm{B}++08$ & 0.02 & 0.43 & -0.26 & $\ldots{ }^{f}$ & $19.53^{\mathrm{f}}$ & $20.13^{\mathrm{f}}$ & SV85 & 15.00 & 15.11 & 15.20 & SY77 \\
\hline 29248 & $\nu$ Eri & 199.31 & -31.38 & 3.92 & B2 III & L68 & -0.02 & 0.21 & -0.11 & $20.03^{\mathrm{d}}$ & $20.35^{\mathrm{d}}$ & $20.52^{\mathrm{d}}$ & $\mathrm{B}++83$ & & & 17.41 & $\mathrm{~B}++83$ \\
\hline 30614 & $\alpha$ Cam & 144.07 & 14.04 & 4.30 & O9.5 Iae & $\mathrm{B}++08$ & 0.23 & 1.73 & 0.42 & $20.81^{\mathrm{d}}$ & $20.90^{\mathrm{d}}$ & $20.98^{\mathrm{d}}$ & BSD78 & 20.19 & 20.34 & 20.49 & BSD78 \\
\hline 31237 & $\pi^{5}$ Ori & 196.27 & -24.56 & 3.72 & B2 III & L68 & 0.03 & 0.35 & -0.14 & $19.65^{\mathrm{d}}$ & $20.16^{\mathrm{d}}$ & $20.37^{\mathrm{d}}$ & $\mathrm{B}++83$ & $\ldots$ & $\ldots$ & 17.45 & $\mathrm{~B}++83$ \\
\hline 34029 & $\alpha$ Aur & 162.59 & 4.57 & 0.08 & G1 III+K0 III & SF90 & 0.80 & 0.01 & 0.00 & 18.15 & 18.24 & 18.30 & VF02 & $\ldots$ & ( & & \\
\hline 34816 & $\lambda$ Lep & 214.83 & -26.24 & 4.27 & B0.5 IV & L68 & -0.03 & 0.26 & -0.12 & 20.08 & 20.18 & 20.26 & $\mathrm{~B}++83$ & $\ldots$ & 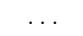 & 15.04 & $\mathrm{~B}++83$ \\
\hline 34989 & HD 34989 & 194.62 & -15.61 & 5.78 & B1 V & L68 & 0.11 & 0.49 & -0.13 & $21.00^{\mathrm{c}}$ & $21.10^{\mathrm{c}}$ & $21.18^{\mathrm{c}}$ & BSD78 & 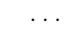 & & 18.45 & BSD78 \\
\hline 35149 & 23 Ori & 199.16 & -17.86 & 5.00 & $\mathrm{~B} 1 \mathrm{Vn}$ & L68 & 0.08 & 0.36 & -0.11 & $20.47^{\mathrm{c}}$ & $20.63^{\mathrm{c}}$ & $20.74^{\mathrm{C}}$ & BSD78 & $\ldots$ & $\ldots$ & 18.53 & BSD78 \\
\hline 35439 & 25 Ori & 200.96 & -18.29 & 4.87 & B1 Vne & $\mathrm{B}++08$ & 0.06 & 0.35 & -0.11 & 20.06 & 20.36 & 20.49 & $\mathrm{~B}++83$ & 14.63 & 14.78 & 14.93 & $\mathrm{~B}++83$ \\
\hline 35715 & $\psi$ Ori & 200.09 & -17.22 & 4.60 & B1 V & L68 & 0.03 & 0.37 & -0.11 & $20.26^{\mathrm{c}}$ & $20.49^{\mathrm{c}}$ & $20.64^{\mathrm{c}}$ & $\mathrm{B}++83$ & 14.63 & 14.78 & 14.93 & $\mathrm{~B}++83$ \\
\hline 36166 & HD 36166 & 201.67 & -17.19 & 5.74 & $\mathrm{~B} 2 \mathrm{~V}$ & L68 & 0.01 & 0.40 & -0.12 & $\ldots{ }^{c}$ & $\ldots \mathrm{c}$ & $20.11^{\mathrm{c}}$ & $\mathrm{B}++83$ & $\ldots$ & $\ldots$ & 15.00 & $\mathrm{~B}++83$ \\
\hline 36486 & $\delta$ Ori A & 203.86 & -17.74 & 2.23 & O9.5 II & $\mathrm{B}++08$ & 0.08 & 0.42 & -0.13 & 20.15 & 20.19 & 20.23 & $\mathrm{ST}++00$ & 14.42 & 14.68 & 14.94 & BSD78 \\
\hline 36822 & $\phi^{1}$ Ori & 195.40 & -12.29 & 4.40 & B0.5 IV-V & L68 & 0.07 & 0.33 & -0.07 & 20.72 & 20.81 & 20.89 & BSD78 & 19.17 & 19.32 & 19.47 & BSD78 \\
\hline 36841 & HD 36841 & 204.26 & -17.22 & 8.58 & $\mathrm{O} 8$ & SMS01 & 0.31 & 4.92 & -1.46 & 21.40 & 21.70 & 22.00 & SV 85 & $\ldots$ & $\ldots$ & $\ldots$ & $\ldots$ \\
\hline 36861 & $\lambda$ Ori A & 195.05 & -12.00 & 3.30 & O8 IIIf & $\mathrm{B}++08$ & 0.10 & 0.55 & -0.11 & 20.65 & 20.78 & 20.88 & BSD78 & 18.92 & 19.12 & 19.32 & BSD78 \\
\hline 37021 & $\theta^{1}$ Ori & 209.01 & -19.38 & 7.96 & B3 V & LA76 & 0.42 & 0.56 & -0.19 & $21.52^{\mathrm{c}}$ & $21.65^{\mathrm{c}}$ & $21.78^{\mathrm{c}}$ & CLMS04 & & & & CLMS04 \\
\hline 37043 & $\iota$ Ori & 209.52 & -19.58 & 2.77 & O9 III & $\mathrm{B}++08$ & 0.06 & 0.43 & -0.14 & 20.08 & 20.15 & 20.21 & BSD78 & 14.49 & 14.69 & 14.89 & BSD78 \\
\hline 37061 & $\nu$ Ori & 208.92 & -19.27 & 6.87 & $\mathrm{~B} 0.5 \mathrm{~V}$ & LA76 & 0.44 & 0.64 & -0.21 & 21.64 & 21.73 & 21.82 & CLMS04 & & & & \\
\hline 37128 & $\epsilon$ Ori & 205.21 & -17.24 & 1.70 & B0 Iae & $\mathrm{B}++08$ & 0.10 & 0.48 & -0.14 & 20.35 & 20.45 & 20.53 & BSD78 & 16.37 & 16.57 & 16.77 & BSD78 \\
\hline 37367 & HD 37367 & 179.04 & -1.03 & 5.99 & B2 IV-V & L68 & 0.33 & 0.34 & -0.01 & $21.02^{\mathrm{C}}$ & $21.17^{\mathrm{c}}$ & $21.29^{\mathrm{C}}$ & CLMS04 & 20.44 & 20.53 & 20.62 & CLMS04 \\
\hline 37468 & $\sigma$ Ori & 206.82 & -17.34 & 3.80 & $09.5 \mathrm{~V}$ & L68 & 0.03 & 0.37 & -0.11 & 20.42 & 20.52 & 20.60 & $\mathrm{~B}++83$ & & & 18.30 & $\mathrm{~B}++83$ \\
\hline 37742 & $\zeta$ Ori A & 206.45 & -16.59 & 1.70 & O9.5 Ib & $\mathrm{B}++08$ & 0.13 & 0.25 & -0.07 & 20.32 & 20.41 & 20.49 & BSD78 & 15.56 & 15.71 & 15.86 & $\mathrm{SCH} 75$ \\
\hline 37903 & HD 37903 & 206.85 & -16.54 & 7.84 & B1.5 V & SMS01 & 0.29 & 0.83 & -0.24 & $21.02^{\mathrm{c}}$ & $21.12^{\mathrm{c}}$ & $21.22^{\mathrm{c}}$ & CLMS04 & 20.78 & 20.85 & 20.92 & CLMS04 \\
\hline 38666 & $\mu \mathrm{Col}$ & 237.29 & -27.10 & 5.15 & $09.5 \mathrm{~V}$ & $\mathrm{~B}++08$ & 0.01 & 0.41 & -0.19 & 19.84 & 19.86 & 19.88 & HSF99 & 15.35 & 15.50 & 15.65 & SCH75 \\
\hline
\end{tabular}


Table 2-Continued

\begin{tabular}{|c|c|c|c|c|c|c|c|c|c|c|c|c|c|c|c|c|c|}
\hline \multirow[b]{2}{*}{$\begin{array}{l}\mathrm{HD} \\
(1)\end{array}$} & \multirow[b]{2}{*}{$\begin{array}{l}\text { Name } \\
(2)\end{array}$} & \multicolumn{2}{|c|}{ Gal. Coord. } & \multirow[b]{2}{*}{$\begin{array}{l}V \\
(5)\end{array}$} & \multicolumn{2}{|c|}{ Spectral Type } & \multirow[b]{2}{*}{$\begin{array}{c}E(B-V) \\
(8)\end{array}$} & \multirow{2}{*}{$\begin{array}{c}\text { dist. } \\
(\mathrm{kpc}) \\
(9)\end{array}$} & \multirow{2}{*}{$\begin{array}{c}z \\
(\mathrm{kpc}) \\
(10)\end{array}$} & \multicolumn{4}{|c|}{$\log N(\mathrm{H} \mathrm{I})$} & \multicolumn{4}{|c|}{$\log N\left(\mathrm{H}_{2}\right)$} \\
\hline & & $\begin{array}{l}\ell \\
(3)\end{array}$ & $\begin{array}{c}b \\
(4)\end{array}$ & & $\begin{array}{c}\text { Value } \\
(6)\end{array}$ & $\begin{array}{l}\text { ref. }^{a} \\
(7)\end{array}$ & & & & $\begin{array}{c}1.1 . \\
\text { (11) }\end{array}$ & $\begin{array}{l}\text { best } \\
(12)\end{array}$ & $\begin{array}{l}\text { u.l. } \\
\text { (13) }\end{array}$ & $\begin{array}{l}\text { Ref. }^{b} \\
(14)\end{array}$ & $\begin{array}{c}1.1 . \\
(15)\end{array}$ & $\begin{array}{l}\text { best } \\
(16)\end{array}$ & $\begin{array}{l}\text { u.l. } \\
(17)\end{array}$ & $\begin{array}{l}\text { Ref. }^{b} \\
\text { (18) }\end{array}$ \\
\hline 38771 & $\kappa$ Ori & 214.51 & -18.50 & 2.05 & B0.5 Ia & $\mathrm{B}++08$ & 0.09 & 0.20 & -0.06 & 20.47 & 20.52 & 20.56 & BSD78 & 15.48 & 15.68 & 15.88 & BSD78 \\
\hline 40111 & 139 Tau & 183.97 & 0.84 & 4.82 & B1 Ib & $\mathrm{B}++08$ & 0.10 & 0.48 & 0.01 & $20.81^{\mathrm{d}}$ & $20.90^{\mathrm{d}}$ & $20.98^{\mathrm{d}}$ & BSD78 & 19.53 & 19.73 & 19.93 & BSD78 \\
\hline 40893 & HD 40893 & 180.09 & 4.34 & 8.99 & B0 IV & MCW55 & 0.31 & 3.07 & 0.23 & 21.36 & 21.45 & 21.54 & $\mathrm{C}++08$ & 20.42 & 20.49 & 20.56 & $\mathrm{C}++08$ \\
\hline 41161 & HD 41161 & 164.97 & $\begin{array}{r}1.04 \\
12.89\end{array}$ & 6.76 & $\mathrm{O} 8 \mathrm{Vn}$ & $\mathrm{B}++08$ & 0.19 & 1.4 & 0.31 & 20.91 & 21.00 & 21.09 & OH06 & 19.89 & 19.98 & 19.18 & OH06 \\
\hline 42933 & $\delta$ Pic & 263.30 & -27.68 & 4.81 & B0.5 IV & $\mathrm{B}++08$ & 0.02 & 0.40 & -0.19 & 20.15 & 20.23 & 20.31 & DS94 & $\ldots$ & $\ldots$ & $\ldots$ & 年 \\
\hline 43818 & LU Gem & 188.49 & 3.87 & 6.92 & B0 II & JM53 & 0.45 & 1.85 & 0.12 & $\ldots$ & & & $\ldots$ & $\ldots$ & $\ldots$ & $\ldots$ & . \\
\hline 44506 & HD 44506 & 241.63 & -20.78 & 5.53 & B1.5 IIIn & $\mathrm{B}++08$ & 0.02 & 0.75 & -0.27 & $19.49^{\mathrm{d}}$ & $20.09^{\mathrm{d}}$ & $20.32^{\mathrm{d}}$ & $\mathrm{B}++83$ & $\ldots$ & $\ldots$ & 14.85 & $\mathrm{~B}++83$ \\
\hline 44743 & $\beta \mathrm{CMa}$ & 226.06 & -14.27 & 1.97 & B1 II-III & L68 & -0.04 & 0.15 & -0.04 & $18.26^{\mathrm{g}}$ & $18.30^{\mathrm{g}}$ & $18.34^{\mathrm{g}}$ & $\mathrm{C}++96$ & & & & \\
\hline 47839 & 15 Mon & 202.94 & 2.20 & 4.66 & $\mathrm{O} 7 \mathrm{Vf}$ & $\mathrm{B}++08$ & 0.07 & 0.86 & 0.03 & 20.21 & 20.31 & 20.41 & DS94 & 15.45 & 15.55 & 15.65 & BDS78 \\
\hline $48915(+12)$ & $\alpha \mathrm{CMa}$ & 227.23 & -8.89 & -1.47 & A0 IV & L72 & 0.00 & 0.003 & 0.00 & 17.18 & 17.40 & 17.54 & $\mathrm{H}++99$ & $\ldots$ & $\ldots$ & $\ldots$ & $\ldots$ \\
\hline$(+18)$ & & & & & & & & & & 17.48 & 17.60 & 17.74 & $\begin{array}{l}\mathrm{H}++99 \\
\end{array}$ & $\ldots$ & $\ldots$ & $\ldots$ & \\
\hline 49798 & HD 49798 & 253.71 & -19.14 & 8.29 & $\mathrm{sdO}$ & KM89 & 0.03 & 0.57 & -0.19 & $\ldots$ & $\ldots$ & $\ldots$ & $\ldots$ & $\ldots$ & $\ldots$ & $\ldots$ & .. \\
\hline 52089 & $\epsilon \mathrm{CMa}$ & 239.83 & -11.33 & 1.51 & B2 II & MR50 & -0.05 & 0.12 & -0.02 & $17.85^{\mathrm{g}}$ & $17.96^{\mathrm{g}}$ & $18.08^{\mathrm{g}}$ & $\mathrm{C}++95$ & $\ldots$ & $\ldots$ & 17.66 & BSD78 \\
\hline 52266 & HD 52266 & 219.13 & -0.68 & 7.23 & O9 IVn & W73 & 0.22 & 1.84 & -0.02 & 1900 & & 10.00 & $\ldots$ & $\ldots$ & & $\ldots$ & 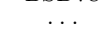 \\
\hline 52918 & 19 Mon & 218.01 & 0.61 & 4.99 & B1 IVe & $\mathrm{B}++08$ & 0.04 & 0.37 & 0.00 & 19.75 & 20.20 & 20.35 & $\mathrm{~B}++83$ & 14.63 & 14.78 & 14.93 & $\mathrm{~B}++83$ \\
\hline 53138 & $\mathrm{o}^{2} \mathrm{Cma}$ & 235.55 & -8.23 & 3.00 & B3 Ia & MR50 & 0.05 & 0.98 & -0.14 & $17.95^{\mathrm{d}}$ & $19.78^{\mathrm{d}}$ & $20.04^{\mathrm{d}}$ & BSD78 & $\ldots$ & $\ldots$ & $\ldots$ & $\ldots$ \\
\hline 53975 & HD 53975 & 225.68 & -2.32 & 6.48 & $\mathrm{O} 7.5 \mathrm{~V}$ & W72 & 0.16 & 1.40 & -0.06 & 21.07 & 21.13 & 21.19 & OH06 & 19.14 & 19.18 & 19.22 & ОH06 \\
\hline 54662 & HD 54662 & 224.17 & -0.78 & 6.23 & $06.5 \mathrm{~V}$ & W72 & 0.27 & 1.22 & -0.02 & 21.23 & 21.38 & 21.49 & BSD78 & 19.82 & 20.00 & 20.18 & BSD78 \\
\hline 55879 & HD 55879 & 224.73 & 0.35 & 6.00 & O9.5 II-III & W72 & 0.08 & 1.78 & 0.01 & 20.75 & 20.90 & 21.02 & BSD78 & 19.02 & & 18.90 & BSD78 \\
\hline 57060 & $29 \mathrm{CMa}$ & 237.82 & -5.37 & 4.98 & O7 Iabfp & $\mathrm{B}++08$ & 0.15 & 1.87 & -0.17 & 20.60 & 20.70 & 20.78 & BSD78 & 15.60 & 15.78 & 15.96 & BSR38 \\
\hline 57061 & $\tau \mathrm{CMa}$ & 238.18 & -5.54 & 4.39 & O9 II & $\mathrm{B}++08$ & 0.11 & 1.57 & -0.15 & 20.65 & 20.70 & 20.74 & BSD78 & 15.30 & 15.48 & 15.66 & BSLO 8 \\
\hline 62542 & HD 62542 & 255.92 & -9.24 & 8.03 & B5 V & FTW55 & 0.31 & 0.38 & -0.06 & & & & & 20.60 & 20.81 & 21.02 & $\mathrm{R}++\mathrm{H} 02$ \\
\hline 63005 & HD 63005 & 242.47 & -0.93 & 9.13 & $\mathrm{O} 6 \mathrm{Vf}$ & $\mathrm{B}++08$ & 0.22 & 5.4 & -0.09 & 21.18 & 21.24 & 21.30 & CLMS04 & 20.14 & 20.23 & 20.32 & CLMS04 \\
\hline 64740 & HD 64740 & 263.38 & -11.19 & 4.61 & $\mathrm{~B} 1.5 \mathrm{Vp}$ & $\mathrm{B}++08$ & 0.01 & 0.23 & -0.05 & $19.64^{\mathrm{c}}$ & $20.05^{\mathrm{c}}$ & $20.23^{\mathrm{c}}$ & $\mathrm{B}++83$ & $\ldots$ & $\ldots$ & 14.95 & $\mathrm{~B}++83$ \\
\hline 64760 & HD 64760 & 262.06 & -10.42 & 4.23 & B0.5 Ib & $\mathrm{B}++08$ & 0.05 & 0.51 & -0.09 & 20.13 & 20.26 & 20.35 & $\mathrm{~B}++83$ & $\ldots$ & $\ldots$ & 14.60 & $\mathrm{~B}++83$ \\
\hline 65575 & $\chi \mathrm{Car}$ & 266.68 & -12.32 & 3.44 & B3 IVp & HGS69 & 0.01 & 0.14 & -0.03 & & $\ldots$ e & $20.74^{\mathrm{e}}$ & $\mathrm{B}++83$ & $\ldots$ & $\ldots$ & 14.78 & $\mathrm{~B}++83$ \\
\hline 65818 & V Pup & 263.48 & -10.28 & 4.45 & $\mathrm{~B} 1 \mathrm{~V}+\mathrm{B} 3 \mathrm{~V}$ & P43 & 0.07 & 0.29 & -0.05 & $20.36^{\mathrm{c}}$ & $20.52^{\mathrm{c}}$ & $20.65^{\mathrm{c}}$ & $\mathrm{B}++83$ & 14.78 & 15.08 & 15.38 & $\mathrm{~B}++83$ \\
\hline 66788 & HD 66788 & 245.43 & 2.05 & 9.43 & O8 V & SMS01 & 0.20 & 4.85 & 0.17 & 21.13 & 21.23 & 21.33 & JS07a & 19.69 & 19.72 & 19.75 & $\mathrm{~S}++08 \mathrm{a}$ \\
\hline 66811 & $\zeta$ Pup & 255.98 & -4.71 & 2.21 & O5 Ibnf & $\mathrm{B}++08$ & 0.12 & 0.33 & -0.03 & 19.92 & 19.96 & 20.00 & $\mathrm{ST}++00$ & 14.40 & 14.45 & 14.50 & MD76 \\
\hline 68273 & $\gamma^{2}$ Vel & 262.80 & -7.69 & 1.81 & WC $8+09$ I & $\mathrm{B}++08$ & 0.00 & 0.47 & -0.06 & 19.67 & 19.71 & 19.75 & $\mathrm{ST}++00$ & 14.03 & 14.23 & 14.43 & BSD78 \\
\hline 69106 & HD 69106 & 254.52 & -1.33 & 7.13 & B0.5 IVnn & $\mathrm{B}++08$ & 0.14 & 1.5 & -0.03 & 21.00 & 21.06 & 21.12 & $\mathrm{C}++08$ & 19.57 & 19.64 & 19.71 & $\begin{array}{l}\mathrm{C}++08 \\
\text { 年 }\end{array}$ \\
\hline 71634 & HD 71634 & 273.32 & -11.52 & 6.65 & B7 IV & M61 & 0.09 & 0.32 & -0.06 & $\ldots$ & $\ldots$ & $\ldots$ & $\ldots$ & $\ldots$ & $\ldots$ & $\ldots$ & $\ldots$ \\
\hline $72089(+5)$ & HD 72089 & 263.21 & -3.89 & 8.01 & B5 II-III & MSS78 & 0.03 & 0.80 & -0.05 & $\ldots$ & $\ldots$ & $\ldots$ & $\ldots$ & $\ldots$ & $\ldots$ & $\ldots$ & . \\
\hline 72127 & HD 72127 & 262.57 & -3.36 & 4.99 & B2 IV & HGS69 & 0.03 & 0.40 & -0.02 & . & 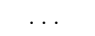 & & $\ldots$ & $\ldots$ & $\ldots$ & $\ldots$ & \\
\hline 72754 & FY Vel & 266.83 & -5.82 & 6.90 & B2 I: pe & $\mathrm{T} 71$ & 0.31 & 3.91 & -0.40 & $21.05^{\mathrm{h}}$ & $21.17^{\mathrm{h}}$ & $21.29^{\mathrm{h}}$ & CLMS04 & 20.25 & 20.35 & 20.45 & CLMS04 \\
\hline 73882 & HD 73882 & 260.18 & 0.64 & 7.27 & O8.5 Vn & W73 & 0.59 & 0.96 & 0.01 & 21.04 & 21.11 & 21.22 & FM90 & 20.98 & 21.08 & 21.18 & $\mathrm{SR}++00$ \\
\hline 74375 & HD 74375 & 275.82 & -10.86 & 4.32 & B1.5 III & HGS69 & 0.16 & 0.44 & -0.08 & $20.67^{\mathrm{d}}$ & $20.78^{\mathrm{d}}$ & $20.87^{\mathrm{d}}$ & BSD78 & $\ldots$ & $\ldots$ & 18.34 & BSD78 \\
\hline 74575 & $\alpha$ Pyx & 254.99 & 5.77 & 3.68 & B1.5 III & HGS69 & 0.04 & 0.27 & 0.03 & $20.27^{\mathrm{d}}$ & $20.46^{\mathrm{d}}$ & $20.59^{\mathrm{d}}$ & $\mathrm{B}++83$ & $\ldots$ & & 15.04 & $\mathrm{~B}++83$ \\
\hline 75309 & HD 75309 & 265.86 & -1.90 & 7.84 & B1 IIp & $\mathrm{B}++08$ & 0.18 & 2.9 & -0.10 & $20.98^{\mathrm{h}}$ & $21.07^{\mathrm{h}}$ & $21.17^{\mathrm{h}}$ & CLMSO4 & 20.08 & 20.20 & 20.32 & CLMS04 \\
\hline 79186 & GX Vel & 267.36 & 2.25 & 5.02 & B5 Ia & GHS77 & 0.23 & 1.91 & 0.07 & $21.08^{\mathrm{d}}$ & $21.18^{\mathrm{d}}$ & $21.27^{\mathrm{d}}$ & CLMS04 & 20.63 & 20.72 & 20.81 & CLMS04 \\
\hline 79351 & a Car & 277.69 & -7.37 & 3.40 & $\mathrm{~B} 2.5 \mathrm{~V}$ & $\mathrm{~S} 82$ & 0.04 & 0.14 & -0.02 & $\ldots c$ & $\ldots c$ & $20.44^{\mathrm{c}}$ & $\mathrm{B}++83$ & $\ldots$ & $\ldots$ & 17.90 & $\mathrm{~B}++83$ \\
\hline 81188 & $\kappa \mathrm{Vel}$ & 275.88 & -3.54 & 2.46 & B2 IV-V & HGS69 & 0.02 & 0.18 & -0.01 & $\ldots c$ & $\ldots c$ & $19.50^{\mathrm{c}}$ & $\mathrm{B}++83$ & $\ldots$ & $\ldots$ & 17.70 & $\mathrm{~B}++83$ \\
\hline 88115 & HD 88115 & 285.32 & -5.53 & 8.31 & B1.5 IIn & $\mathrm{B}++08$ & 0.12 & 3.7 & -0.36 & $20.86^{\mathrm{h}}$ & $20.98^{\mathrm{h}}$ & $21.06^{\mathrm{h}}$ & $\mathrm{A}++03$ & 19.00 & 19.30 & 19.48 & $\mathrm{~A}++03$ \\
\hline 91316 & $\rho$ Leo & 234.89 & 52.77 & 3.84 & B1 Iab & $\mathrm{B}++08$ & 0.04 & 1.09 & 0.87 & $20.14^{\mathrm{d}}$ & $20.25^{\mathrm{d}}$ & $20.32^{\mathrm{d}}$ & BSD78 & 15.31 & 15.61 & 15.91 & BSD78 \\
\hline 91597 & HD 91597 & 286.86 & -2.37 & 9.61 & B1 IIIne & $\mathrm{B}++08$ & 0.30 & 3.9 & -0.16 & $21.34^{\mathrm{h}}$ & $21.40^{\mathrm{h}}$ & $21.46^{\mathrm{h}}$ & DS94 & 19.65 & 19.70 & 19.75 & $\mathrm{~S}++08 \mathrm{a}$ \\
\hline 91651 & HD 91651 & 286.55 & -1.72 & 8.87 & O9 V:n & $\mathrm{B}++08$ & 0.25 & 2.8 & -0.08 & 21.09 & 21.15 & 21.21 & DS94 & 19.04 & 19.07 & 19.10 & $\mathrm{~S}++08 \mathrm{a}$ \\
\hline 91824 & HD 91824 & 285.70 & 0.07 & 8.15 & $\mathrm{O} 7 \mathrm{~V}$ & GHS77 & 0.22 & 2.99 & 0.00 & 21.06 & 21.12 & 21.18 & CLMS04 & 19.78 & 19.85 & 19.92 & CLMS04 \\
\hline 91983 & HD 91983 & 285.88 & 0.05 & 8.58 & B1 III & F58 & 0.14 & 3.03 & 0.00 & $21.07^{\mathrm{d}}$ & $21.16^{\mathrm{d}}$ & $21.26^{\mathrm{d}}$ & CLMS04 & 20.07 & 20.14 & 20.21 & CLMS04 \\
\hline 92554 & HD 92554 & 287.60 & -2.02 & 9.50 & O9.5 IIn & $\mathrm{B}++08$ & 0.34 & 6.9 & -0.24 & 21.18 & 21.28 & 21.38 & DS94 & 18.88 & 18.93 & 18.98 & $\mathrm{~S}++08 \mathrm{a}$ \\
\hline
\end{tabular}


Table 2-Continued

\begin{tabular}{|c|c|c|c|c|c|c|c|c|c|c|c|c|c|c|c|c|c|}
\hline \multirow[b]{2}{*}{$\begin{array}{l}\mathrm{HD} \\
(1)\end{array}$} & \multirow[b]{2}{*}{$\begin{array}{c}\text { Name } \\
(2)\end{array}$} & \multicolumn{2}{|c|}{ Gal. Coord. } & \multirow[b]{2}{*}{$\begin{array}{c}V \\
(5)\end{array}$} & \multicolumn{2}{|c|}{ Spectral Type } & \multirow[b]{2}{*}{$\begin{array}{c}E(B-V) \\
(8)\end{array}$} & \multirow{2}{*}{$\begin{array}{l}\text { dist. } \\
\text { (kpc) } \\
(9)\end{array}$} & \multirow{2}{*}{$\begin{array}{c}z \\
(\mathrm{kpc}) \\
(10)\end{array}$} & \multicolumn{4}{|c|}{$\log N(\mathrm{H} \mathrm{I})$} & \multicolumn{4}{|c|}{$\log N\left(\mathrm{H}_{2}\right)$} \\
\hline & & $\begin{array}{l}\ell \\
(3)\end{array}$ & $\begin{array}{c}b \\
(4)\end{array}$ & & $\begin{array}{c}\text { Value } \\
(6)\end{array}$ & $\begin{array}{l}\text { ref. }^{a} \\
(7)\end{array}$ & & & & $\begin{array}{c}1.1 . \\
(11)\end{array}$ & $\begin{array}{l}\text { best } \\
(12)\end{array}$ & $\begin{array}{l}\text { u.l. } \\
\text { (13) }\end{array}$ & $\begin{array}{l}\text { Ref. }^{\mathrm{b}} \\
(14)\end{array}$ & $\begin{array}{c}1.1 . \\
(15)\end{array}$ & $\begin{array}{l}\text { best } \\
(16)\end{array}$ & $\begin{array}{l}\text { u.l. } \\
(17)\end{array}$ & $\begin{array}{l}\text { Ref. }^{b} \\
(18)\end{array}$ \\
\hline 93030 & $\theta$ Car & 289.60 & -4.90 & 2.78 & B $0 \mathrm{~V}$ & $\mathrm{H} 56 \mathrm{a}$ & 0.04 & 0.14 & -0.01 & 20.18 & 20.26 & 20.34 & DS94 & 14.90 & 15.02 & 15.26 & AJS92 \\
\hline 93205 & V560 Car & 287.57 & -0.71 & 7.76 & $\mathrm{O} 3 \mathrm{Vf}+$ & $\mathrm{B}++08$ & 0.34 & 3.3 & -0.04 & 21.34 & 21.38 & 21.42 & $\mathrm{~A}++03$ & 19.70 & 19.78 & 19.85 & $\mathrm{~A}++03$ \\
\hline 93222 & HD 93222 & 287.74 & -1.02 & 8.11 & O7 IIIf & $\mathrm{B}++08$ & 0.32 & 3.6 & -0.06 & 21.33 & 21.40 & 21.46 & $\mathrm{~A}++03$ & 19.70 & 19.78 & 19.85 & $\mathrm{~A}++03$ \\
\hline $93521(-66)$ & HD 93521 & 183.14 & 62.15 & 7.06 & O9 Vp & $\mathrm{B}++08$ & 0.05 & 1.76 & 1.56 & 18.21 & 18.51 & 18.82 & SF93 & $\ldots$ & $\ldots$ & $\ldots$ & $\ldots$ \\
\hline$(-58)$ & & & & & & & & & & 19.28 & 19.34 & 19.40 & SF93 & $\ldots$ & $\ldots$ & .. & . \\
\hline$(-51)$ & & & & & & & & & & 19.11 & 19.20 & 19.29 & SF93 & $\ldots$ & $\ldots$ & $\ldots$ & $\ldots$ \\
\hline$(-39)$ & & & & & & & & & & 18.70 & 18.88 & 19.06 & SF93 & $\cdots$ & $\ldots$ & $\cdots$ & $\ldots$ \\
\hline$(-29)$ & & & & & & & & & & 18.06 & 18.38 & 18.70 & SF93 & $\ldots$ & $\ldots$ & $\ldots$ & $\ldots$ \\
\hline$(-18)$ & & & & & & & & & & 19.23 & 19.28 & 19.33 & SF93 & $\ldots$ & $\ldots$ & $\cdots$ & $\cdots$ \\
\hline$(-10)$ & & & & & & & & & & 19.31 & 19.36 & 19.41 & SF93 & $\ldots$ & $\ldots$ & $\ldots$ & $\ldots$ \\
\hline$(+3)$ & & & & & & & & & & 19.24 & 19.30 & 19.36 & SF93 & $\ldots$ & $\ldots$ & .. & . \\
\hline$(+7)$ & & & & & & & & & & 18.56 & 18.79 & 19.02 & SF93 & $\ldots$ & $\ldots$ & .. & $\ldots$ \\
\hline (total) & & & & & & & & & & $20.06^{\mathrm{i}}$ & $20.10^{\mathrm{i}}$ & $20.16^{\mathrm{i}}$ & DS94 & $\ldots$ & $\ldots$ & $\ldots$ & $\ldots$ \\
\hline 93843 & HD 93843 & 288.24 & -0.90 & 7.33 & O5 IIIf & $\mathrm{B}++08$ & 0.24 & 3.5 & -0.06 & 21.25 & 21.33 & 21.41 & DS94 & 19.58 & 19.61 & 19.64 & $\mathrm{~S}++08 \mathrm{a}$ \\
\hline 94493 & HD 94493 & 289.01 & -1.18 & 7.27 & B1 Ib & $\mathrm{B}++08$ & 0.15 & 3.4 & -0.07 & $21.03^{\mathrm{h}}$ & $21.08^{\mathrm{h}}$ & $21.12^{\mathrm{h}}$ & $\mathrm{A}++03$ & 20.08 & 20.15 & 20.20 & $\mathrm{~A}++03$ \\
\hline 94454 & HD 94454 & 295.69 & -14.73 & 6.70 & B8 III & $\mathrm{HC} 75$ & 0.19 & 0.30 & -0.08 & & & & & 20.66 & 20.76 & 20.86 & $\mathrm{~S}++08 \mathrm{~b}$ \\
\hline 99171 & HD 99171 & 286.33 & 17.38 & 6.11 & B2 IV-V & HGS69 & 0.03 & 0.54 & 0.16 & $\ldots \mathrm{c}$ & $20.06^{\mathrm{c}}$ & $20.43^{\mathrm{c}}$ & BSD78 & 15.10 & 15.25 & 15.40 & BSD78 \\
\hline 99857 & HD 99857 & 294.78 & -4.94 & 7.47 & $\mathrm{~B} 0.5 \mathrm{Ib}$ & $\mathrm{B}++08$ & 0.27 & 3.5 & -0.30 & 21.16 & 21.24 & 21.31 & $\mathrm{~A}++03$ & 20.36 & 20.43 & 20.49 & $\mathrm{~A}++03$ \\
\hline 99872 & HD 99872 & 296.69 & -10.62 & 6.11 & B3 V & HGS69 & 0.29 & 0.24 & -0.04 & & & & & 20.41 & 20.51 & 20.61 & $\mathrm{~S}++07$ \\
\hline 99890 & HD 99890 & 291.75 & 4.43 & 8.31 & B0 IIIn & GHS77 & 0.17 & 3.59 & 0.28 & 20.80 & 20.93 & 21.06 & DS94 & 19.42 & 19.47 & 19.52 & $\mathrm{~S}+{ }_{\mathrm{N}} 08 \mathrm{a}$ \\
\hline 100340 & HD 100340 & 258.85 & 61.23 & 10.07 & $\mathrm{~B} 1 \mathrm{~V}$ & $\mathrm{~B}++08$ & 0.00 & 3.0 & 2.63 & $20.38^{\mathrm{c}}$ & $20.46^{\mathrm{c}}$ & $20.54^{\mathrm{c}}$ & DS94 & & & & . \\
\hline 102065 & HD 102065 & 300.03 & -18.00 & 6.61 & $\mathrm{~B} 2 \mathrm{~V}$ & BFM07 & 0.28 & 0.18 & -0.05 & $\ldots$ & $\ldots$ & & & 20.53 & 20.63 & 20.73 & BFM07 \\
\hline 103779 & HD 103779 & 296.85 & -1.02 & 7.22 & B0.5 Iab & GHS77 & 0.17 & 4.34 & -0.08 & 21.06 & 21.16 & 21.26 & DS94 & 19.77 & 19.82 & 18.87 & $\mathrm{~S}++08 \mathrm{a}$ \\
\hline 104705 & DF Cru & 297.45 & -0.34 & 7.83 & B0 Ib & $\mathrm{B}++08$ & 0.17 & 5.0 & -0.03 & 21.00 & 21.10 & 21.18 & $\mathrm{~A}++03$ & 20.04 & 20.08 & 20.11 & $\mathrm{~A}++03$ \\
\hline 106490 & $\delta$ Cru & 298.23 & 3.79 & 2.78 & B2 IV & $\mathrm{B}++08$ & 0.02 & 0.11 & 0.01 & & & $19.69^{\mathrm{C}}$ & $\mathrm{B}++83$ & $\ldots$ & & 14.08 & $\mathrm{~B}++83$ \\
\hline 108248 & $\alpha^{1} \mathrm{Cru}$ & 300.13 & -0.36 & 1.40 & B0.5 IV & HGS69 & 0.22 & 0.10 & 0.00 & 19.50 & 19.60 & 19.70 & YR76 & $\ldots$ & $\ldots$ & 14.18 & $\mathrm{~B}++83$ \\
\hline 108639 & HD 108639 & 300.22 & 1.95 & 7.81 & B0.2 III & W72 & 0.26 & 2.41 & 0.08 & 21.26 & 21.35 & 21.44 & $\mathrm{C}++08$ & 19.88 & 19.95 & 20.02 & $\mathrm{C}++08$ \\
\hline 109399 & HD 109399 & 301.71 & -9.88 & 7.63 & B0.7 II & GHS77 & 0.19 & 2.94 & -0.50 & 21.05 & 21.11 & 21.17 & DS94 & 19.84 & 20.04 & 20.24 & JS07a \\
\hline 110432 & BZ Cru & 301.96 & -0.20 & 5.32 & B0.5 IIIe & $\mathrm{B}++08$ & 0.39 & 0.6 & 0.00 & 20.70 & 20.85 & 21.00 & $\mathrm{R}++01$ & 20.60 & 20.64 & 20.68 & $\mathrm{R}++02$ \\
\hline 111934 & BU Cru & 303.20 & 2.51 & 6.92 & B1.5 Ib & $\mathrm{D}++06$ & 0.32 & 2.29 & 0.10 & & & & & & & & \\
\hline 112999 & V946 Cen & 304.17 & 2.18 & 7.38 & $\mathrm{~B} 6 \mathrm{~V}$ & GHS77 & 0.17 & 0.45 & 0.02 & & & 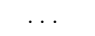 & & 20.01 & 20.11 & 20.21 & $\mathrm{~S}++08 \mathrm{~b}$ \\
\hline 113904 & $\theta$ Mus & 304.67 & -2.49 & 5.69 & $\mathrm{WC} 5+\mathrm{B} 0 \mathrm{Ia}$ & HGS69 & 0.18 & 2.66 & -0.12 & 20.98 & 21.08 & 21.16 & BSD78 & 19.72 & 19.83 & 19.94 & BSD78 \\
\hline 114886 & HD 114886 & 305.52 & -0.83 & 6.89 & O9 IIIn & GHS77 & 0.32 & 1.84 & -0.03 & 21.28 & 21.34 & 21.40 & $\mathrm{C}++08$ & 20.15 & 20.23 & 20.30 & $\mathrm{C}++08$ \\
\hline 115071 & V961 Cen & 305.76 & 0.15 & 7.97 & B0.5 Vn & GHS77 & 0.40 & 2.70 & 0.01 & 21.30 & 21.36 & 21.42 & $\mathrm{C}++08$ & 20.55 & 20.63 & 20.70 & $\mathrm{C}++08$ \\
\hline 116658 & $\alpha$ Vir & 316.11 & 50.84 & 1.04 & B1 IV & $\mathrm{B}++08$ & 0.10 & 0.08 & 0.06 & $18.90^{\mathrm{j}}$ & $19.00^{\mathrm{j}}$ & $19.10^{\mathrm{j}}$ & YR76 & 12.65 & 12.95 & 13.25 & Y76 \\
\hline 116781 & V967 Cen & 307.05 & -0.07 & 7.45 & B0 IIIne & $\mathrm{B}++08$ & 0.31 & 2.2 & 0.00 & 21.08 & 21.18 & 21.28 & JS07a & 20.03 & 20.08 & 20.13 & $\mathrm{~S}++08 \mathrm{a}$ \\
\hline 116852 & HD 116852 & 304.88 & -16.13 & 8.49 & O9 III & $\mathrm{B}++08$ & 0.14 & 4.5 & -1.25 & 20.87 & 20.96 & 21.05 & CLMS04 & 19.68 & 19.79 & 19.90 & CLMS04 \\
\hline 118716 & $\epsilon$ Cen & 310.19 & 8.72 & 2.27 & B1 III & HGS69 & 0.04 & 0.13 & 0.02 & $19.10^{\mathrm{d}}$ & $19.60^{\mathrm{d}}$ & $19.79^{\mathrm{d}}$ & $\mathrm{B}++83$ & $\ldots$ & $\ldots$ & 14.08 & $\mathrm{~B}++83$ \\
\hline 119608 & HD 119608 & 320.35 & 43.13 & 7.50 & $\mathrm{~B} 1 \mathrm{Ib}$ & SMS01 & 0.11 & 4.20 & 2.87 & $20.79^{\mathrm{d}}$ & $20.85^{\mathrm{d}}$ & $20.90^{\mathrm{d}}$ & SV85 & $\ldots$ & $\ldots$ & $\ldots$ & \\
\hline 120086 & HD 120086 & 329.61 & 57.50 & 7.82 & $\mathrm{~B} 2 \mathrm{~V}$ & SMS01 & 0.04 & 0.99 & 0.83 & $\ldots c$ & $\ldots c$ & $20.07^{\mathrm{c}}$ & SV85 & $\ldots$ & $\ldots$ & $\ldots$ & $\ldots$ \\
\hline 120324 & $\mu$ Cen & 314.24 & 19.12 & 3.46 & B2 IV-Ve & S82 & 0.04 & 0.16 & 0.05 & $4.00^{\mathrm{f}}$ & $18.76^{\mathrm{f}}$ & $20.22^{\mathrm{f}}$ & $\mathrm{B}++83$ & & & 14.78 & $\mathrm{~B}++83$ \\
\hline 121263 & $\zeta$ Cen & 314.07 & 14.19 & 2.52 & B2.5 IV & $\mathrm{B}++08$ & 0.02 & 0.12 & 0.03 & & & $20.02^{\mathrm{e}}$ & BSD78 & 12.62 & 12.80 & 12.98 & BSD78 \\
\hline 121968 & HD 121968 & 333.97 & 55.84 & 10.16 & B1 V & $\mathrm{B}++08$ & 0.11 & 3.8 & 3.14 & $20.43^{\mathrm{c}}$ & $20.58^{\mathrm{c}}$ & $20.70^{\mathrm{c}}$ & DS94 & 18.60 & 18.70 & 18.80 & BFM07 \\
\hline 122451 & $\beta$ Cen & 311.77 & 1.25 & 0.60 & B1 III & $\mathrm{B}++08$ & 0.06 & 0.12 & 0.00 & $19.49^{\mathrm{j}}$ & $19.54^{\mathrm{j}}$ & $19.59^{\mathrm{j}}$ & YR76 & 12.70 & 12.80 & 12.90 & Y76 \\
\hline 122879 & HD 122879 & 312.26 & 1.79 & 6.43 & B0 Ia & $\mathrm{B}++08$ & 0.29 & 3.3 & 0.10 & 21.14 & 21.26 & 21.38 & CLMS04 & 20.15 & 20.24 & 20.33 & CLMS04 \\
\hline 124314 & HD 124314 & 312.67 & -0.42 & 6.64 & O6 Vnf & $\mathrm{B}++08$ & 0.43 & 1.4 & -0.01 & 21.31 & 21.41 & 21.49 & $\mathrm{~A}++03$ & 20.46 & 20.52 & 20.57 & $\mathrm{~A}++03$ \\
\hline 125924 & HD 125924 & 338.16 & 48.28 & 9.66 & B2 IV & SMS01 & 0.01 & 3.51 & 2.62 & $20.47^{\mathrm{c}}$ & $20.63^{\mathrm{c}}$ & $20.74^{\mathrm{c}}$ & DS94 & $\ldots$ & $\ldots$ & $\ldots$ & \\
\hline 127972 & $\eta$ Cen & 322.77 & 16.67 & 2.32 & B2 IVe & $\mathrm{S} 82$ & 0.00 & 0.09 & 0.03 & $\ldots \mathrm{f}$ & $\ldots f$ & $19.48^{\mathrm{f}}$ & $\mathrm{B}++83$ & $\ldots$ & $\ldots$ & 14.18 & $\mathrm{~B}++83$ \\
\hline 135591 & HD 135591 & 320.13 & -2.64 & 5.43 & O7.5 IIIf & $\mathrm{B}++08$ & 0.18 & 1.25 & -0.06 & 20.92 & 21.08 & 21.19 & BSD78 & 19.66 & 19.77 & 19.88 & BSD78 \\
\hline
\end{tabular}


Table 2-Continued

\begin{tabular}{|c|c|c|c|c|c|c|c|c|c|c|c|c|c|c|c|c|c|}
\hline \multirow[b]{2}{*}{$\begin{array}{l}\mathrm{HD} \\
(1)\end{array}$} & \multirow[b]{2}{*}{$\begin{array}{c}\text { Name } \\
(2)\end{array}$} & \multicolumn{2}{|c|}{ Gal. Coord. } & \multirow[b]{2}{*}{$\begin{array}{c}V \\
(5) \\
\end{array}$} & \multicolumn{2}{|c|}{ Spectral Type } & \multirow[b]{2}{*}{$\begin{array}{c}E(B-V) \\
(8)\end{array}$} & \multirow{2}{*}{$\begin{array}{c}\text { dist. } \\
(\mathrm{kpc}) \\
(9) \\
\end{array}$} & \multirow{2}{*}{$\begin{array}{c}z \\
(\mathrm{kpc}) \\
(10)\end{array}$} & \multicolumn{4}{|c|}{$\log N(\mathrm{H} \mathrm{I})$} & \multicolumn{4}{|c|}{$\log N\left(\mathrm{H}_{2}\right)$} \\
\hline & & $\begin{array}{l}\ell \\
(3)\end{array}$ & $\begin{array}{c}b \\
(4)\end{array}$ & & $\begin{array}{c}\text { Value } \\
(6)\end{array}$ & $\begin{array}{l}\text { ref. }^{\mathrm{a}} \\
(7)\end{array}$ & & & & $\begin{array}{c}1.1 . \\
(11)\end{array}$ & $\begin{array}{l}\text { best } \\
(12)\end{array}$ & $\begin{array}{l}\text { u.l. } \\
\text { (13) }\end{array}$ & $\begin{array}{l}\text { Ref. }^{\mathrm{b}} \\
(14)\end{array}$ & $\begin{array}{l}1.1 . \\
(15)\end{array}$ & $\begin{array}{l}\text { best } \\
(16)\end{array}$ & $\begin{array}{l}\text { u.l. } \\
\text { (17) }\end{array}$ & $\begin{array}{l}\text { Ref. }^{b} \\
(18)\end{array}$ \\
\hline 136298 & $\delta$ Lup & 331.32 & 13.82 & 3.20 & B1.5 IV & $\mathrm{B}++08$ & 0.02 & 0.21 & 0.05 & c & $\ldots c$ & $19.76^{\mathrm{c}}$ & $\mathrm{B}++83$ & 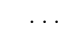 & 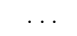 & 14.26 & $\mathrm{~B}++83$ \\
\hline 137595 & HD 137595 & 336.72 & 18.86 & 7.50 & B3 Vn & H70 & 0.18 & 0.50 & 0.16 & $20.90^{\mathrm{k}}$ & $20.97^{\mathrm{k}}$ & $21.04^{\mathrm{k}}$ & $\mathrm{C}++08$ & 20.50 & 20.56 & 20.62 & $\mathrm{C}++08$ \\
\hline 138690 & $\gamma$ Lup & 333.19 & 11.89 & 2.77 & $\mathrm{~B} 2 \mathrm{Vn}$ & B58 & 0.04 & 0.13 & 0.03 & $\ldots$ e & $\ldots$ e & $20.34^{\mathrm{e}}$ & $\mathrm{B}++83$ & & & 14.26 & $\mathrm{~B}++83$ \\
\hline 141637 & $1 \mathrm{Sco}$ & 346.10 & 21.71 & 4.64 & B2.5 Vn & B58 & 0.12 & 0.15 & 0.06 & $20.99^{\mathrm{c}}$ & $21.12^{\mathrm{c}}$ & $21.22^{\mathrm{c}}$ & BSD78 & 19.05 & 19.23 & 19.41 & BSD78 \\
\hline 143018 & $\pi$ Sco & 347.21 & 20.23 & 2.89 & B1 V & $\mathrm{B}++08$ & 0.08 & 0.18 & 0.06 & $20.58^{\mathrm{c}}$ & $20.65^{\mathrm{c}}$ & $20.71^{\mathrm{c}}$ & BSD78 & 19.12 & 19.32 & 19.52 & BSD78 \\
\hline 143118 & $\eta$ Lup A & 338.77 & 11.01 & 3.41 & B2.5 IV & $\mathrm{B}++08$ & 0.00 & 0.14 & 0.03 & $\ldots$ e & $\ldots$ e & $20.12^{\mathrm{e}}$ & $\mathrm{B}++83$ & $\ldots$ & $\ldots$ & 14.23 & $\mathrm{~B}++83$ \\
\hline 143275 & $\delta$ Sco & 350.10 & 22.49 & 2.29 & B0.3 IVe & $\mathrm{B}++08$ & 0.00 & 0.21 & 0.08 & 21.05 & 21.15 & 21.23 & BSD78 & 19.21 & 19.41 & 19.61 & BSD78 \\
\hline 144217 & $\beta^{1} \mathrm{Sco}$ & 353.19 & 23.60 & 2.62 & B $0.5 \mathrm{~V}$ & B58 & 0.18 & 0.12 & 0.05 & 21.05 & 21.09 & 21.13 & BSD78 & 19.77 & 19.83 & 19.89 & BSD78 \\
\hline 144470 & $\mathrm{o}^{1} \mathrm{Sco}$ & 352.75 & 22.77 & 3.95 & $\mathrm{~B} 1 \mathrm{~V}$ & B58 & 0.18 & 0.14 & 0.06 & $21.07^{\mathrm{c}}$ & $21.17^{\mathrm{c}}$ & $21.25^{\mathrm{c}}$ & BSD78 & 19.94 & 20.05 & 20.16 & BSD78 \\
\hline 144965 & HD 144965 & 339.04 & 8.42 & 7.12 & B2 Vne & JJ92 & 0.27 & 0.51 & 0.08 & $20.74^{\mathrm{f}}$ & $20.97^{\mathrm{f}}$ & $21.06^{\mathrm{f}}$ & $\mathrm{C}++08$ & 20.70 & 20.77 & 20.84 & $\mathrm{C}++08$ \\
\hline 145502 & $\nu \mathrm{Sco}$ & 354.61 & 22.70 & 4.13 & B2 IVp & L68 & 0.20 & 0.30 & 0.12 & $20.77^{\mathrm{C}}$ & $21.07^{\mathrm{c}}$ & $21.24^{\mathrm{c}}$ & BSD78 & 19.74 & 19.89 & 20.04 & BSD78 \\
\hline 147165 & $\sigma$ Sco & 351.31 & 17.00 & 2.91 & B1 III & B58 & 0.31 & 0.23 & 0.07 & $21.12^{\mathrm{d}}$ & $21.34^{\mathrm{d}}$ & $21.49^{\mathrm{d}}$ & BSD78 & 19.64 & 19.79 & 19.94 & BSD78 \\
\hline 147683 & V760 Sco & 344.86 & 10.09 & 7.05 & $\mathrm{~B} 4 \mathrm{~V}+\mathrm{B} 4 \mathrm{~V}$ & ACNP85 & 0.28 & 0.37 & 0.07 & $20.94^{\mathrm{c}}$ & $21.20^{\mathrm{c}}$ & $21.35^{\mathrm{c}}$ & $\mathrm{C}++08$ & 20.56 & 20.68 & 20.80 & $\mathrm{C}++08$ \\
\hline 147888 & $\rho$ Oph D & 353.65 & 17.71 & 6.78 & B3 V & B58 & 0.42 & 0.12 & 0.04 & $21.47^{1}$ & $21.69^{1}$ & $21.80^{1}$ & SV85 & 20.40 & 20.48 & 20.56 & CLMS04 \\
\hline 147933 & $\rho$ Oph A & 353.69 & 17.69 & 5.02 & $\mathrm{~B} 2 \mathrm{~V}$ & B58 & 0.37 & 0.11 & 0.03 & $21.54^{\mathrm{C}}$ & $21.63^{\mathrm{C}}$ & $21.72^{\mathrm{C}}$ & DS94 & 20.42 & 20.57 & 20.72 & BSD78 \\
\hline 148184 & $\chi \mathrm{Oph}$ & 357.93 & 20.68 & 4.42 & B1.5 Ve & $\mathrm{S} 82$ & 0.41 & 0.16 & 0.06 & $20.86^{\mathrm{f}}$ & $21.07^{\mathrm{f}}$ & $21.17^{\mathrm{f}}$ & BSD78 & 20.45 & 20.63 & 20.81 & BSD78 \\
\hline 148594 & HD 148594 & 350.93 & 13.94 & 6.90 & B8 Vnn & GG94 & 0.18 & 0.19 & 0.05 & $\ldots$ & $\ldots$ & $\ldots$ & & 19.81 & 19.88 & 19.95 & CLMS04 \\
\hline 148605 & $22 \mathrm{Sco}$ & 353.10 & 15.80 & 4.78 & $\mathrm{~B} 2 \mathrm{~V}$ & B58 & 0.09 & 0.13 & 0.03 & $20.25^{\mathrm{c}}$ & $20.68^{\mathrm{c}}$ & $20.85^{\mathrm{c}}$ & BSD78 & 18.56 & 18.74 & 18.92 & BSD78 \\
\hline 149038 & $\mu$ Nor & 339.38 & 2.51 & 4.91 & O9.7 Iab & W72 & 0.27 & 1.32 & 0.06 & 20.90 & 21.00 & 21.08 & BSD78 & 20.30 & 20.45 & 20.60 & BSD78 \\
\hline $149757(-27)$ & $\zeta \mathrm{Oph}$ & 6.28 & 23.59 & 2.58 & $09.5 \mathrm{~V}$ & $\mathrm{~S} 82$ & 0.29 & 0.11 & 0.04 & & & & & & & & \\
\hline$(-15)$ & & & & & & & & & & 20.69 & 20.72 & 20.74 & BSD78 & 20.57 & 20.65 & 20.73 & B9D 78 \\
\hline 149881 & V600 Her & 31.37 & 36.23 & 7.01 & B0.5 III & $\mathrm{B}++08$ & 0.05 & 2.85 & 1.68 & 20.43 & 20.65 & 20.80 & BSD78 & & & 19.00 & BSD78 \\
\hline 151804 & V973 Sco & 343.62 & 1.94 & 5.25 & O8 Iaf & W72 & 0.33 & 1.73 & 0.06 & 20.92 & 21.08 & 21.19 & BSD78 & 20.15 & 20.26 & 20.37 & BSD78 \\
\hline 151805 & HD 151805 & 343.20 & 1.59 & 9.01 & B1 Ib & SMM85 & 0.19 & 6.0 & 0.17 & $21.26^{\mathrm{d}}$ & $21.32^{\mathrm{d}}$ & $21.38^{\mathrm{d}}$ & $\mathrm{C}++08$ & 20.29 & 20.36 & 20.43 & $\mathrm{C}++08$ \\
\hline 151890 & $\mu^{1}$ Sco & 346.12 & 3.91 & 2.98 & B1.5 IV & $\mathrm{B}++08$ & 0.05 & 0.22 & 0.02 & $4.00^{\mathrm{c}}$ & $19.59^{\mathrm{c}}$ & $20.12^{\mathrm{c}}$ & $\mathrm{B}++83$ & $\ldots$ & & 14.26 & $\mathrm{~B}++83$ \\
\hline 152236 & $\zeta^{1}$ Sco & 343.03 & 0.87 & 4.78 & B1.5 Iap & HGS69 & 0.56 & 1.06 & 0.02 & $21.64^{\mathrm{d}}$ & $21.77^{\mathrm{d}}$ & $21.90^{\mathrm{d}}$ & DS94 & 20.61 & 20.73 & 20.85 & $\mathrm{R}++08$ \\
\hline 152590 & HD 152590 & 344.84 & 1.83 & 8.48 & $\mathrm{O} 7 \mathrm{~V}$ & GHS77 & 0.37 & 3.60 & 0.12 & 21.31 & 21.37 & 21.43 & CLMS04 & 20.40 & 20.47 & 20.54 & CLMS04 \\
\hline 154368 & V1074 Sco & 349.97 & 3.22 & 6.18 & O9 Ia & SMS01 & 0.66 & 1.67 & 0.09 & 20.95 & 21.00 & 21.02 & $\mathrm{~S}++96$ & 21.09 & 21.16 & 21.23 & $\mathrm{R}++02$ \\
\hline 155806 & V1075 Sco & 352.59 & 2.87 & 5.61 & O7.5 Ve & $\mathrm{B}++08$ & 0.23 & 0.86 & 0.04 & 20.92 & 21.08 & 21.19 & BSD78 & 19.77 & 19.92 & 20.07 & BSD78 \\
\hline 156110 & HD 156110 & 70.99 & 35.71 & 7.58 & B3 Vn & GMB77 & 0.03 & 0.62 & 0.36 & .. m & $\ldots \mathrm{m}$ & $20.23^{\mathrm{m}}$ & SV85 & $\ldots$ & $\ldots$ & $\ldots$ & $\ldots$ \\
\hline 157246 & $\gamma$ Ara & 334.64 & -11.48 & 3.31 & $\mathrm{~B} 1 \mathrm{Ib}$ & $\mathrm{B}++08$ & 0.05 & 0.34 & -0.07 & $20.57^{\mathrm{d}}$ & $20.68^{\mathrm{d}}$ & $20.76^{\mathrm{d}}$ & BSD78 & 19.00 & 19.23 & 19.46 & BSD78 \\
\hline 157857 & HD 157857 & 12.97 & 13.31 & 7.81 & O6.5 IIIf & $\mathrm{B}++08$ & 0.37 & 3.1 & 0.71 & 21.17 & 21.26 & 21.35 & CLMS04 & 20.58 & 20.68 & 20.78 & CLMS04 \\
\hline 158243 & V861 Ara & 337.59 & -10.64 & 8.15 & B1 Iab & SMS01 & 0.18 & 6.51 & -1.20 & $21.00^{\mathrm{d}}$ & $21.11^{\mathrm{d}}$ & $21.21^{\mathrm{d}}$ & DS94 & $\ldots$ & $\ldots$ & $\ldots$ & $\ldots$ \\
\hline 158408 & $v$ Sco & 351.27 & -1.84 & 2.70 & B2 IV & HGS69 & 0.03 & 0.18 & -0.01 & $\ldots$ e & $\ldots$ e & $19.26^{\mathrm{e}}$ & BSD78 & $\ldots$ & $\ldots$ & 14.11 & BSD78 \\
\hline 158926 & $\lambda$ Sco & 351.74 & -2.21 & 1.62 & B1.5 IV & $\mathrm{B}++08$ & 0.08 & 0.22 & -0.01 & $19.20^{\mathrm{j}}$ & $19.23^{\mathrm{j}}$ & $19.26^{\mathrm{j}}$ & Y83 & 12.51 & 12.70 & 12.90 & Y 83 \\
\hline 160578 & $\kappa$ Sco & 351.04 & -4.72 & 2.38 & B1.5 IIIn & HGS69 & -0.01 & 0.15 & -0.01 & $20.03^{\mathrm{d}}$ & $20.22^{\mathrm{d}}$ & $20.34^{\mathrm{d}}$ & $\mathrm{B}++83$ & & & 14.23 & $\mathrm{~B}++83$ \\
\hline 163522 & HD 163522 & 349.57 & -9.09 & 8.42 & B1 Ia & GHS77 & 0.16 & 9.92 & -1.57 & $21.01^{\mathrm{h}}$ & $21.09^{\mathrm{h}}$ & $21.17^{\mathrm{h}}$ & DS94 & .. & & & $\ldots$ \\
\hline 164284 & $66 \mathrm{Oph}$ & 30.99 & 13.37 & 4.78 & B2 IV-Ve & S 82 & 0.11 & 0.20 & 0.05 & $19.50^{\mathrm{f}}$ & $20.62^{\mathrm{f}}$ & $20.81^{\mathrm{f}}$ & $\mathrm{B}++83$ & 19.70 & 19.85 & 20.00 & $\mathrm{~B}++83$ \\
\hline 164794 & $9 \mathrm{Sgr}$ & 6.01 & -1.21 & 5.93 & $\mathrm{O} 4 \mathrm{~V}((\mathrm{f}))$ & W73 & 0.28 & 1.40 & -0.03 & 21.31 & 21.34 & 21.39 & SV85 & . & 20 & .. & (1) \\
\hline 165024 & $\theta$ Ara & 343.33 & -13.82 & 3.66 & $\mathrm{~B} 2 \mathrm{Ib}$ & $\mathrm{B}++08$ & 0.06 & 0.25 & -0.06 & $20.74^{\mathrm{d}}$ & $20.84^{\mathrm{d}}$ & $20.91^{\mathrm{d}}$ & BSD78 & .. & $\ldots$ & 18.95 & BSD78 \\
\hline 165246 & HD 165246 & 6.40 & -1.56 & 7.76 & O8 $\mathrm{Vn}$ & GHS77 & 0.33 & 1.85 & -0.05 & 20.34 & 21.41 & 21.48 & $\mathrm{C}++08$ & 20.07 & 20.15 & 20.23 & $\mathrm{C}++08$ \\
\hline 165955 & HD 165955 & 357.41 & -7.43 & 9.19 & B3 Vn & $\mathrm{B}++08$ & 0.12 & 1.3 & -0.17 & $21.04^{\mathrm{n}}$ & $21.10^{\mathrm{n}}$ & $21.16^{\mathrm{n}}$ & CLMSO4 & 16.49 & 16.53 & 16.57 & CLMS04 \\
\hline 167264 & $15 \mathrm{Sgr}$ & 10.46 & -1.74 & 5.35 & O9.7 Iab & W73 & 0.20 & 1.77 & -0.05 & 20.99 & 21.15 & 21.26 & BSD78 & 20.18 & 20.28 & 20.38 & BSD78 \\
\hline 167756 & HD 167756 & 351.47 & -12.30 & 6.29 & B0.5 Ia & GHS77 & 0.06 & 4.23 & -0.90 & 20.71 & 20.81 & 20.91 & DS94 & & & & \\
\hline 167971 & MY Ser & 18.25 & 1.68 & 7.45 & $\mathrm{O} 8 \mathrm{Ib}(\mathrm{f}) \mathrm{p}$ & W72 & 0.91 & 1.52 & 0.04 & 21.30 & 21.60 & 21.90 & $\mathrm{R}++02$ & 20.73 & 20.85 & 20.97 & $\mathrm{R}++02$ \\
\hline 168076 & HD 168076 & 16.94 & 0.84 & 8.18 & $\mathrm{O} 4 \mathrm{~V}((\mathrm{f}))$ & W73 & 0.67 & 2.31 & 0.03 & 21.42 & 21.65 & 21.88 & DS94 & 20.60 & 20.68 & 20.76 & $\mathrm{R}++02$ \\
\hline 168941 & HD 168941 & 5.82 & -6.31 & 9.37 & O9.5 IIp & GHS77 & 0.24 & 7.80 & -0.86 & 21.02 & 21.11 & 21.20 & DS94 & 20.05 & 20.10 & 21.15 & $\mathrm{~S}++08 \mathrm{a}$ \\
\hline 170740 & HD 170740 & 21.06 & -0.53 & 5.76 & B2 IV-V & L68 & 0.38 & 0.28 & 0.00 & $20.78^{\mathrm{C}}$ & $21.03^{\mathrm{c}}$ & $21.22^{\mathrm{C}}$ & DS94 & 20.78 & 20.86 & 20.94 & $\mathrm{R}++02$ \\
\hline 175360 & HD 175360 & 12.53 & -11.29 & 5.93 & B6 III & MSS88 & 0.12 & 0.24 & -0.05 & $\ldots$ & $\ldots$ & $\ldots$ & & $\ldots$ & $\ldots$ & $\ldots$ & $r_{1}$ \\
\hline
\end{tabular}


Table 2-Continued

\begin{tabular}{|c|c|c|c|c|c|c|c|c|c|c|c|c|c|c|c|c|c|}
\hline \multirow[b]{2}{*}{$\begin{array}{l}\text { HD } \\
(1)\end{array}$} & \multirow[b]{2}{*}{$\begin{array}{l}\text { Name } \\
(2)\end{array}$} & \multicolumn{2}{|c|}{ Gal. Coord. } & \multirow[b]{2}{*}{$\begin{array}{l}V \\
(5) \\
\end{array}$} & \multicolumn{2}{|c|}{ Spectral Type } & \multirow[b]{2}{*}{$\begin{array}{c}E(B-V) \\
(8)\end{array}$} & \multirow{2}{*}{$\begin{array}{c}\text { dist. } \\
(\mathrm{kpc}) \\
(9)\end{array}$} & \multirow{2}{*}{$\begin{array}{c}z \\
(\mathrm{kpc}) \\
(10)\end{array}$} & \multicolumn{4}{|c|}{$\log N(\mathrm{H} \mathrm{I})$} & \multicolumn{4}{|c|}{$\log N\left(\mathrm{H}_{2}\right)$} \\
\hline & & $\begin{array}{c}\ell \\
(3) \\
\end{array}$ & $\begin{array}{c}b \\
(4) \\
\end{array}$ & & $\begin{array}{c}\begin{array}{c}\text { Value } \\
(6)\end{array} \\
\end{array}$ & $\begin{array}{l}\text { ref. }{ }^{\mathrm{a}} \\
(7) \\
\end{array}$ & & & & $\begin{array}{c}1.1 . \\
(11) \\
\end{array}$ & $\begin{array}{l}\text { best } \\
(12) \\
\end{array}$ & $\begin{array}{c}\text { u.l. } \\
(13) \\
\end{array}$ & $\begin{array}{l}\text { Ref. }^{\mathrm{b}} \\
(14) \\
\end{array}$ & $\begin{array}{c}1.1 . \\
(15) \\
\end{array}$ & $\begin{array}{l}\text { best } \\
(16) \\
\end{array}$ & $\begin{array}{c}\text { u.l. } \\
(17)\end{array}$ & $\begin{array}{l}\begin{array}{l}\text { Ref. }^{b} \\
(18)\end{array} \\
\end{array}$ \\
\hline 177989 & HD 177989 & 17.81 & -11.88 & 9.34 & BO III & $\mathrm{B}++08$ & 0.11 & 6.0 & -1.24 & 20.86 & 20.96 & 21.04 & $\mathrm{~A}++03$ & 20.11 & 20.18 & 20.23 & $\mathrm{~A}++03$ \\
\hline 179406 & $20 \mathrm{Aql}$ & 28.23 & -8.31 & 5.36 & B3 $\mathrm{V}$ & L68 & 0.26 & 0.30 & -0.04 & $\ldots$ & $\cdots$ & $\ldots$ & $\ldots$ & 20.57 & 20.62 & 20.65 & $\mathrm{~S}++08 \mathrm{a}$ \\
\hline 179407 & HD 179407 & 24.02 & -10.40 & 9.44 & B0.5 Ib & SMS01 & 0.23 & 9.21 & -1.66 & 21.00 & 21.11 & 21.22 & DS94 & 20.16 & 20.21 & 20.27 & $\mathrm{~S}++08 \mathrm{a}$ \\
\hline 184915 & $\kappa \mathrm{Aql}$ & 31.77 & -13.29 & 4.96 & B0.5 IIIne & $\mathrm{B}++08$ & 0.17 & 0.70 & -0.16 & 20.77 & 20.85 & 20.93 & DS94 & 20.16 & 20.31 & 20.46 & BSD78 \\
\hline 185418 & HD 185418 & 53.60 & -2.17 & 7.52 & $\mathrm{~B} 0.5 \mathrm{~V}$ & $\mathrm{~B}++08$ & 0.38 & 1.2 & -0.05 & 21.10 & 21.19 & 21.28 & CLMS04 & 20.59 & 20.71 & 20.83 & CLMS04 \\
\hline 188209 & HD 188209 & 80.99 & 10.09 & 5.63 & O9.5 Iab & W72 & 0.14 & 2.21 & 0.39 & 20.75 & 20.90 & 21.02 & BSD78 & 19.90 & 20.01 & 20.12 & BSD78 \\
\hline 190918 & V1676 Cyg & 72.65 & 2.07 & 6.81 & WN4+O9.7Iab & $\mathrm{B}++08$ & 0.44 & 2.1 & 0.08 & 21.32 & 21.38 & 21.44 & CLMS04 & 19.76 & 19.84 & 19.92 & CLMS04 \\
\hline 191877 & HD 191877 & 61.57 & -6.45 & 6.27 & B1 Ib & $\mathrm{B}++08$ & 0.14 & 2.3 & -0.26 & $20.95^{\mathrm{d}}$ & $21.05^{\mathrm{d}}$ & $21.15^{\mathrm{d}}$ & $\mathrm{H}++03$ & 19.97 & 20.02 & 20.07 & $\mathrm{~S}++08 \mathrm{a}$ \\
\hline 192035 & RX Cyg & 83.33 & 7.76 & 8.22 & B0 III - IVn & $\mathrm{B}++08$ & 0.28 & 2.7 & 0.36 & 21.11 & 21.20 & 21.29 & CLMS04 & 20.55 & 20.62 & 20.69 & CLMS04 \\
\hline 192639 & HD 192639 & 74.90 & 1.48 & 7.11 & O7 Ibf & $\mathrm{B}++08$ & 0.56 & 2.1 & 0.05 & 21.20 & 21.29 & 21.38 & CLMS04 & 20.63 & 20.73 & 20.83 & CLMS04 \\
\hline 193322 & HD 193322 & 78.10 & 2.78 & 5.82 & $\mathrm{O} 9 \mathrm{~V}$ & L68 & 0.33 & 0.70 & 0.03 & 20.86 & 21.08 & 21.23 & BSD78 & 19.90 & 20.08 & 20.26 & BSD78 \\
\hline 195455 & HD 195455 & 20.27 & -32.14 & 9.20 & B0.5 III & SMS01 & 0.07 & 5.76 & -3.07 & 20.57 & 20.67 & 20.77 & DS94 & $\cdots$ & $\cdots$ & $\ldots$ & $\ldots$ \\
\hline 195965 & HD 195965 & 85.71 & 5.00 & 6.98 & B0 V & $\mathrm{B}++08$ & 0.19 & 1.1 & 0.10 & 20.92 & 20.95 & 20.98 & $\mathrm{H}++03$ & 20.34 & 20.37 & 20.40 & JS07b \\
\hline 197512 & HD 197512 & 87.89 & 4.63 & 8.55 & B0.5 V & $\mathrm{J} 78$ & 0.30 & 1.70 & 0.14 & $\ldots$ & $\ldots$ & $\ldots$ & $\ldots$ & & & & $\ldots$ \\
\hline 198478 & $55 \mathrm{Cyg}$ & 85.75 & 1.49 & 4.86 & B3 Ia & L68 & 0.43 & 1.34 & 0.03 & $21.15^{\mathrm{d}}$ & $21.31^{\mathrm{d}}$ & $21.46^{\mathrm{d}}$ & CLMS04 & 20.72 & 20.87 & 21.02 & CLMS04 \\
\hline 198781 & HD 198781 & 99.94 & 12.61 & 6.46 & B0.5 V & L68 & 0.26 & 0.69 & 0.15 & 20.82 & 20.91 & 21.00 & CLMS04 & 20.41 & 20.48 & 20.55 & CLMS04 \\
\hline 199579 & HD 199579 & 85.70 & -0.30 & 5.97 & $\mathrm{O} 6 \mathrm{Vf}$ & $\mathrm{B}++08$ & 0.31 & 1.4 & -0.01 & 20.93 & 21.04 & 21.15 & DS94 & 20.49 & 20.53 & 20.57 & $\mathrm{R}++02$ \\
\hline 200120 & $59 \mathrm{Cyg}$ & 88.03 & 0.97 & 4.74 & B1.5 Ve & $\mathrm{B}++08$ & 0.02 & 0.34 & 0.01 & $\ldots \mathrm{f}$ & $19.20^{\mathrm{f}}$ & $20.07^{\mathrm{f}}$ & BSD78 & 19.12 & 19.30 & 19.48 & BSD78 \\
\hline 201345 & HD 201345 & 78.44 & -9.54 & 7.75 & O9 V & $\mathrm{B}++08$ & 0.14 & 2.2 & -0.36 & 20.88 & 20.97 & 21.06 & CLMS04 & 19.42 & 19.55 & 19.68 & CLMS04 \\
\hline 202347 & HD 202347 & 88.22 & -2.08 & 7.50 & B1. $5 \mathrm{~V}$ & $\mathrm{~B}++08$ & 0.11 & 1.0 & -0.04 & $20.68^{\mathrm{c}}$ & $20.83^{\mathrm{c}}$ & $20.94^{\mathrm{c}}$ & $\mathrm{A}++03$ & 19.85 & 19.95 & 20.04 & $\mathrm{c}++03$ \\
\hline 202904 & $v$ Cyg & 80.98 & -10.05 & 4.43 & B2.5 Ve & S 82 & 0.09 & 0.16 & -0.03 & $\ldots \mathrm{f}$ & $20.37^{\mathrm{f}}$ & $20.65^{\mathrm{f}}$ & $\mathrm{B}++83$ & 18.97 & 19.15 & 19.33 & $\mathscr{B}++83$ \\
\hline 203064 & $68 \mathrm{Cyg}$ & 87.61 & -3.84 & 5.04 & O7.5 III: $\mathrm{n}((\mathrm{f}))$ & W72 & 0.22 & 1.28 & -0.09 & 20.85 & 21.00 & 21.11 & BSD78 & 20.15 & 20.30 & 20.45 & BSD78 \\
\hline 203374 & HD 203374 & 100.51 & 8.62 & 6.69 & B2 Vne & A 81 & 0.43 & 0.34 & 0.05 & $20.96^{\mathrm{f}}$ & $21.13^{\mathrm{f}}$ & $21.23^{\mathrm{f}}$ & $\mathrm{C}++08$ & 20.51 & 20.60 & 20.69 & $\mathrm{C}++08$ \\
\hline 203532 & HD 203532 & 309.46 & -31.74 & 6.36 & B3 IV & HGS69 & 0.24 & 0.22 & -0.11 & $\ldots{ }^{c}$ & $20.22^{\mathrm{c}}$ & $20.97^{\mathrm{c}}$ & CLMS04 & 20.56 & 20.64 & 20.72 & CLMS04 \\
\hline 203938 & HD 203938 & 90.56 & -2.23 & 7.10 & B0.5 IV & MCW55 & 0.59 & 0.79 & -0.03 & 21.33 & 21.48 & 21.63 & FM90 & 20.94 & 21.00 & 21.06 & $\mathrm{R}++02$ \\
\hline $206144^{\circ}$ & HD 206144 & 34.82 & -45.12 & 9.36 & B2 II & MSS 88 & 0.05 & 5.98 & -4.23 & $20.26^{\mathrm{d}}$ & $20.49^{\mathrm{d}}$ & $20.65^{\mathrm{d}}$ & DS94 & & & & $\cdots$ \\
\hline 206267 & HD 206267 & 99.29 & 3.74 & 5.62 & $06.5 \mathrm{~V}$ & W72 & 0.45 & 0.86 & 0.06 & 21.15 & 21.30 & 21.45 & $\mathrm{R}++02$ & 20.82 & 20.86 & 20.90 & $\mathrm{R}++02$ \\
\hline 206773 & HD 206773 & 99.80 & 3.62 & 6.93 & Bo V:nnep & GK76 & 0.39 & 0.82 & 0.05 & 21.03 & 21.09 & 21.15 & CLMS04 & 20.34 & 20.44 & 20.54 & CLMS04 \\
\hline 207198 & HD 207198 & 103.14 & 6.99 & 5.96 & O9.5 Ib-II & $\mathrm{B}++08$ & 0.47 & 1.3 & 0.16 & 21.46 & 21.53 & 21.60 & CLMS04 & 20.79 & 20.83 & 20.87 & $\mathrm{R}++02$ \\
\hline 207308 & HD 207308 & 103.11 & 6.82 & 7.49 & B0.7 III-IV(n) & W71 & 0.44 & 1.24 & 0.15 & 21.10 & 21.20 & 21.30 & JS07a & 20.71 & 20.76 & 20.81 & $\mathrm{~S}++08 \mathrm{a}$ \\
\hline 207538 & HD 207538 & 101.60 & 4.67 & 7.30 & $09.5 \mathrm{~V}$ & GK76 & 0.51 & 0.94 & 0.08 & 21.22 & 21.34 & 21.46 & DS94 & 20.85 & 20.91 & 20.97 & $\mathrm{R}++02$ \\
\hline 208440 & HD 208440 & 104.03 & 6.44 & 7.91 & B1 V & $\mathrm{S} 68$ & 0.27 & 1.05 & 0.12 & $21.12^{\mathrm{f}}$ & $21.21^{\mathrm{f}}$ & $21.31^{\mathrm{f}}$ & CLMS04 & 20.22 & 20.29 & 20.36 & CLMS04 \\
\hline 208947 & HD 208947 & 106.55 & 9.00 & 6.40 & $\mathrm{~B} 2 \mathrm{~V}$ & L68 & 0.16 & 0.56 & 0.09 & $20.72^{\mathrm{c}}$ & $20.91^{\mathrm{c}}$ & $21.03^{\mathrm{c}}$ & $\mathrm{C}++08$ & & & & \\
\hline 209339 & HD 209339 & 104.58 & 5.87 & 6.69 & BO IV & L68 & 0.24 & 1.22 & 0.13 & 21.10 & 21.17 & 21.24 & $\mathrm{C}++08$ & 20.16 & 20.24 & 20.32 & $\mathrm{C}++08$ \\
\hline 209975 & 19 Сep & 104.87 & 5.39 & 5.11 & O9.5 Ib & W72 & 0.27 & 1.23 & 0.12 & 20.96 & 21.11 & 21.23 & BSD78 & 19.90 & 20.08 & 20.26 & BSD78 \\
\hline 210809 & HD 210809 & 99.85 & -3.13 & 7.56 & O9 Iab & $\mathrm{B}++08$ & 0.28 & 4.3 & -0.23 & 21.20 & 21.29 & 21.38 & CLMS04 & 19.91 & 20.00 & 20.09 & CLMS04 \\
\hline 210839 & $\lambda$ Cep & 103.83 & 2.61 & 5.09 & O6 Infp & $\mathrm{B}++08$ & 0.49 & 1.1 & 0.05 & 21.03 & 21.15 & 21.27 & DS94 & 20.80 & 20.84 & 20.88 & $\mathrm{R}++02$ \\
\hline 212571 & $\pi$ Aqr & 66.01 & -44.74 & 4.79 & $\mathrm{~B} 1 \mathrm{~V}(\mathrm{e})$ & L68 & 0.07 & 0.24 & -0.17 & $20.32^{\mathrm{f}}$ & $20.50^{\mathrm{f}}$ & $20.62^{\mathrm{f}}$ & DS94 & & & & \\
\hline 212791 & V408 Lac & 101.64 & -4.30 & 8.02 & B3ne & KW99 & 0.18 & 0.62 & -0.05 & $20.85^{f}$ & $21.11^{\mathrm{f}}$ & $21.23^{\mathrm{f}}$ & CLMS04 & 19.31 & 19.42 & 19.53 & CLMS04 \\
\hline 214080 & HD 214080 & 44.80 & -56.92 & 6.82 & B1 Ib & $\mathrm{B}++08$ & 0.05 & 3.42 & -2.87 & $20.38^{\mathrm{d}}$ & $20.61^{\mathrm{d}}$ & $20.77^{\mathrm{d}}$ & BSD78 & & & 19.00 & BSD78 \\
\hline 214680 & $10 \mathrm{Lac}$ & 96.65 & -16.98 & 4.88 & $\mathrm{O} 9 \mathrm{~V}$ & W72 & 0.08 & 0.61 & -0.18 & 20.54 & 20.70 & 20.81 & BSD78 & 19.11 & 19.22 & 19.33 & BSD78 \\
\hline 214993 & $12 \mathrm{Lac}$ & 97.65 & -16.18 & 5.23 & B1.5 IIIn & L68 & 0.06 & 0.61 & -0.17 & $20.60^{\mathrm{d}}$ & $20.76^{\mathrm{d}}$ & $20.89^{\mathrm{d}}$ & $\mathrm{B}++83$ & 19.45 & 19.63 & 19.81 & $\mathrm{~B}++83$ \\
\hline $215733(-93)$ & HD 215733 & 85.16 & -36.35 & 7.34 & B1 II & SMS01 & 0.06 & 2.79 & -1.65 & 16.91 & 17.39 & 17.63 & FS97 & & & & \\
\hline$(-83)$ & & & & & & & & & & 17.60 & 18.40 & 18.55 & FS97 & & . & $\cdots$ & .. \\
\hline$(-61)$ & & & & & & & & & & 18.91 & 19.44 & 19.56 & FS97 & $\cdots$ & $\cdots$ & $\cdots$ & $\cdots$ \\
\hline$(-59)$ & & & & & & & & & & 18.75 & 18.95 & 19.25 & FS97 & $\ldots$ & $\cdots$ & $\ldots$ & $\ldots$ \\
\hline$(-54)$ & & & & & & & & & & 19.09 & 19.63 & 19.88 & FS97 & $\ldots$ & $\cdots$ & $\ldots$ & $\cdots$ \\
\hline$(-47)$ & & & & & & & & & & & 18.94 & 19.69 & FS97 & $\ldots$ & $\ldots$ & $\ldots$ & $\ldots$ \\
\hline$(-45)$ & & & & & & & & & & 17.37 & 18.06 & 18.38 & FS97 & & & & $\cdots$ \\
\hline
\end{tabular}


Table 2-Continued

\begin{tabular}{|c|c|c|c|c|c|c|c|c|c|c|c|c|c|c|c|c|c|}
\hline \multirow[b]{2}{*}{$\begin{array}{l}\mathrm{HD} \\
(1)\end{array}$} & \multirow[b]{2}{*}{$\begin{array}{c}\text { Name } \\
(2)\end{array}$} & \multicolumn{2}{|c|}{ Gal. Coord. } & \multirow[b]{2}{*}{$\begin{array}{l}V \\
(5)\end{array}$} & \multicolumn{2}{|c|}{ Spectral Type } & \multirow[b]{2}{*}{$\begin{array}{c}E(B-V) \\
(8)\end{array}$} & \multirow{2}{*}{$\begin{array}{l}\text { dist. } \\
(\mathrm{kpc}) \\
(9)\end{array}$} & \multirow{2}{*}{$\begin{array}{c}z \\
(\mathrm{kpc}) \\
(10)\end{array}$} & \multicolumn{4}{|c|}{$\log N(\mathrm{H} \mathrm{I})$} & \multicolumn{4}{|c|}{$\log N\left(\mathrm{H}_{2}\right)$} \\
\hline & & $\begin{array}{c}\ell \\
(3) \\
\end{array}$ & $\begin{array}{c}b \\
(4) \\
\end{array}$ & & $\begin{array}{c}\begin{array}{c}\text { Value } \\
(6)\end{array} \\
\end{array}$ & $\begin{array}{l}\text { ref. }^{a} \\
(7) \\
\end{array}$ & & & & $\begin{array}{c}1.1 . \\
(11) \\
\end{array}$ & $\begin{array}{l}\text { best } \\
(12) \\
\end{array}$ & $\begin{array}{c}\text { u.l. } \\
(13) \\
\end{array}$ & $\begin{array}{l}\begin{array}{l}\text { Ref. }^{\mathrm{D}} \\
(14)\end{array} \\
\end{array}$ & $\begin{array}{c}1.1 . \\
(15) \\
\end{array}$ & $\begin{array}{l}\text { best } \\
(16) \\
\end{array}$ & $\begin{array}{c}\text { u.l. } \\
(17) \\
\end{array}$ & $\begin{array}{l}\begin{array}{l}\text { Ref. }^{\mathrm{D}} \\
(18)\end{array} \\
\end{array}$ \\
\hline$(-42)$ & & & & & & & & & & 17.23 & 18.53 & 18.90 & FS97 & $\ldots$ & $\ldots$ & $\ldots$ & $\ldots$ \\
\hline$(-40)$ & & & & & & & & & & 18.06 & 18.81 & 19.23 & FS97 & $\cdots$ & $\ldots$ & $\ldots$ & $\ldots$ \\
\hline$(-32)$ & & & & & & & & & & 19.50 & 19.64 & 19.74 & FS97 & $\cdots$ & $\ldots$ & $\cdots$ & $\ldots$ \\
\hline$(-31)$ & & & & & & & & & & & & & $\ldots$ & & $\cdots$ & $\cdots$ & $\cdots$ \\
\hline$(-28)$ & & & & & & & & & & 18.85 & 18.91 & 19.02 & FS97 & $\cdots$ & $\cdots$ & $\cdots$ & $\cdots$ \\
\hline$(-26)$ & & & & & & & & & & 18.99 & 19.11 & 19.19 & FS97 & $\ldots$ & $\ldots$ & $\ldots$ & $\ldots$ \\
\hline$(-23)$ & & & & & & & & & & 19.21 & 19.25 & 19.29 & FS97 & $\ldots$ & $\ldots$ & $\cdots$ & $\ldots$ \\
\hline$(-21)$ & & & & & & & & & & 19.32 & 19.37 & 19.42 & FS97 & $\cdots$ & $\cdots$ & $\cdots$ & $\cdots$ \\
\hline$(-19)$ & & & & & & & & & & & & & & & & $\cdots$ & .. \\
\hline$(-16)$ & & & & & & & & & & 20.08 & 20.11 & 20.14 & FS97 & $\cdots$ & $\cdots$ & $\cdots$ & $\cdots$ \\
\hline$(-11)$ & & & & & & & & & & 19.57 & 19.60 & 19.63 & FS97 & $\cdots$ & $\ldots$ & $\cdots$ & $\cdots$ \\
\hline$(-9)$ & & & & & & & & & & 20.01 & 20.07 & 20.13 & FS97 & $\cdots$ & $\cdots$ & $\cdots$ & $\cdots$ \\
\hline$(-5)$ & & & & & & & & & & 19.50 & 19.58 & 19.66 & FS97 & $\ldots$ & $\ldots$ & $\ldots$ & $\ldots$ \\
\hline$(+1)$ & & & & & & & & & & 19.68 & 19.71 & 19.74 & FS97 & $\cdots$ & $\ldots$ & $\cdots$ & $\cdots$ \\
\hline$(+9)$ & & & & & & & & & & & & & & & $\cdots$ & $\cdots$ & . \\
\hline$(+15)$ & & & & & & & & & & 18.35 & 18.42 & 18.49 & FS97 & $\cdots$ & $\cdots$ & $\cdots$ & .. \\
\hline (total) & & & & & & & & & & $20.66^{\mathrm{P}}$ & $20.75^{\mathrm{p}}$ & $20.84^{\mathrm{p}}$ & DS94 & & & & \\
\hline 217675 & o And & 102.21 & -16.10 & 3.63 & B6 III & $\mathrm{S} 82$ & 0.05 & 0.12 & -0.03 & $\ldots$ & $\ldots$ & $\ldots$ & $\ldots$ & 19.49 & 19.67 & 19.85 & BSD78 \\
\hline 218376 & $1 \mathrm{Cas}$ & 109.95 & -0.78 & 4.84 & B0.5 III & L68 & 0.16 & 0.35 & 0.00 & 20.80 & 20.95 & 21.07 & BSD78 & 19.97 & 20.15 & 20.33 & BSD78 \\
\hline 218915 & HD 218915 & 108.06 & -6.89 & 7.20 & O9.5 Iabe & $\mathrm{B}++08$ & 0.21 & 5.0 & -0.60 & 21.13 & 21.17 & 21.21 & $\mathrm{~A}++03$ & 20.15 & 20.20 & 20.26 & $\mathrm{~A}++03$ \\
\hline 219188 & HD 219188 & 83.03 & -50.17 & 7.00 & B0.5 IIIn & $\mathrm{B}++08$ & 0.09 & 2.08 & -1.60 & 20.62 & 20.85 & 20.99 & BSD78 & 19.16 & 19.34 & 19.52 & BSD7\% \\
\hline 220057 & HD 220057 & 112.13 & 0.21 & 6.95 & B3 IV & CLMS04 & 0.17 & 0.77 & 0.00 & $20.83^{\mathrm{q}}$ & $21.02^{\mathrm{q}}$ & $21.15^{\mathrm{q}}$ & CLMSO4 & 20.21 & 20.28 & 20.35 & CLMS04 \\
\hline 224151 & V373 Cas & 115.44 & -4.64 & 6.05 & B0.5 II-III & L68 & 0.34 & 1.30 & -0.11 & 21.24 & 21.32 & 21.39 & $\mathrm{~A}++03$ & 20.54 & 20.61 & 20.67 & $\mathrm{~A}++03$ \\
\hline 224572 & $\sigma$ Cas & 115.55 & -6.36 & 5.00 & B1 V & L68 & 0.13 & 0.34 & -0.04 & $20.64^{\mathrm{c}}$ & $20.79^{\mathrm{c}}$ & $20.88^{\mathrm{c}}$ & BSD78 & 20.05 & 20.23 & 20.41 & BSD78 \\
\hline 232522 & HDE 232522 & 130.70 & -6.71 & 8.70 & B1 II & $\mathrm{B}++08$ & 0.14 & 6.1 & -0.71 & 21.02 & 21.08 & 21.14 & CLMS04 & 20.13 & 20.22 & 20.31 & CLMS04 \\
\hline 303308 & HDE 303308 & 287.59 & -0.61 & 8.21 & $\mathrm{O} 3 \mathrm{Vf}$ & $\mathrm{B}++08$ & 0.33 & 3.8 & -0.04 & 21.33 & 21.41 & 21.48 & $\mathrm{~A}++03$ & 20.26 & 20.34 & 20.41 & $\mathrm{~A}++03$ \\
\hline 308813 & HDE 308813 & 294.79 & -1.61 & 9.32 & $09.5 \mathrm{~V}$ & $\mathrm{~B}++08$ & 0.26 & 3.1 & -0.09 & 21.11 & 21.20 & 21.29 & CLMS04 & 20.18 & 20.25 & 20.32 & CLMS04 \\
\hline$\ldots$ & $\mathrm{BD}+354258$ & 77.19 & -4.74 & 9.46 & B0.5 Vn & MCW55 & 0.22 & 2.90 & -0.24 & 21.18 & 21.28 & 21.38 & JS07a & 19.53 & 19.56 & 19.59 & $\mathrm{~S}++08 \mathrm{a}$ \\
\hline$\ldots$ & $\mathrm{BD}+532820$ & 101.24 & -1.69 & 9.96 & B0 IV:n & H56b & 0.28 & 5.07 & -0.15 & 21.26 & 21.35 & 21.44 & CLMS04 & 19.90 & 20.01 & 20.12 & CLMS04 \\
\hline$\cdots$ & CPD -59 2603 & 287.59 & -0.69 & 8.75 & O5 V((f)) & W73 & 0.36 & 3.5 & -0.04 & 21.01 & 21.12 & 21.23 & DS94 & 20.05 & 20.15 & 20.25 & $\mathrm{~S}++08 \mathrm{~b}$ \\
\hline$\ldots$ & CPD -69 1743 & 303.71 & -7.35 & 9.46 & B0.5 IIIn & SMS01 & 0.19 & 5.45 & -0.70 & 21.02 & 21.11 & 21.20 & CLMS04 & 19.81 & 19.90 & 19.99 & CLMS04 \\
\hline
\end{tabular}

${ }^{a}$ Codes in this column are linked to references listed in Table 3

${ }^{\mathrm{b}}$ Codes in this column are linked to references listed in Table 1

${ }^{c}$ Published $N$ (H I) corrected for contamination by the stellar L $\alpha$ line using the prescription of Diplas \& Savage (1994) for $\log g=4$ and the [c $\left.c_{1}\right]$ value in the catalog of Hauck \& Mermilliod (1998); see 4.6 .2 for details.

${ }^{\mathrm{d}}$ Same as with note $c$ except that $\log g=3$ instead of 4

e After computing the correction for contamination by the stellar L $\alpha$ feature, the upper limit value was a negative number, so the upper limit was set equal to the upper limit for $N$ (H I) $)_{\mathrm{obs}}$,

${ }^{\mathrm{f}}$ Correction for stellar L $\alpha$ contamination was based on the stellar spectral type and a generic correction for that type with $\log g=4$, since either a measurement of $\left[c_{1}\right]$ was not available or the star had emission lines that made photometric measurements unreliable; see $\$ 4.6 .2$ for details.

${ }^{g}$ Normally this value of $N(\mathrm{H} \mathrm{I})$ would require a correction for stellar L $\alpha$ contamination, but in this case the column density was determined from the shape of the star's energy distribution in the EUV after accounting for hydrogen absorption in the star's photosphere, so the published number was accepted at face value.

${ }^{\mathrm{h}}$ Same as for note $f$ except that $\log g=3$ was used instead of 4 .

${ }^{\mathrm{i}}$ These values are taken from a measurement of the $\mathrm{L} \alpha$ feature. Numbers listed above for individual velocity components are from $21-\mathrm{cm}$ emission measurements. The sums of the $21-\mathrm{cm}$ values give 
$\log N(\mathrm{H} \mathrm{I})=19.99,20.08,20.17$

${ }^{\mathrm{j}}$ Normally this value of $N(\mathrm{H} \mathrm{I})$ would require a correction for stellar L $\alpha$ contamination, but in this case the interstellar feature could be measured at the bottom of the stellar one, so the published number was accepted at face value.

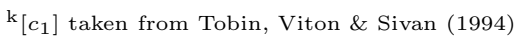

${ }^{1}[c$ 1] measurement is not available, and the spectral classification could range between B3 $\mathrm{V}$ and B5 $\mathrm{V}$. The correction for stellar L $\alpha$ contamination is based on a compromise value for the generic correction, but with an increase in the $\Delta$ uncertainty parameter to 0.54 dex (see Eq. 20.

$\mathrm{m}\left[c_{1}\right]$ taken from Tobin $(1985)$

${ }^{\mathrm{n}}\left[c_{1}\right]$ taken from Tobin \& Kaufmann $(1984)$

${ }^{\circ}$ This star was misidentified as HD 206114 by Diplas \& Savage (1994).

$\mathrm{p}$ These values are taken from a measurement of the $\mathrm{L} \alpha$ feature. Numbers listed above for individual velocity components are from $21-\mathrm{cm}$ emission measurements. The sums of the $21-\mathrm{cm}$ values give $\log N(\mathrm{H} \mathrm{I})=20.66,20.77,20.88$. [c $\left.c_{1}\right]$ taken from Tobin $(1985)$

${ }^{\mathrm{q}}\left[c_{1}\right]$ evaluated from the Vilnius photometric indices of Sudzius \& Bobinas (1992), followed by a conversion to the Strömgren system using the recipe given by Kaltcheva \& Knude (2002). 
Table 3. Refrence Codes for Spectral Types Listed in Table 2

\begin{tabular}{ll}
\hline \hline \multicolumn{1}{c}{ Code } & \multicolumn{1}{c}{ Reference } \\
\hline A81 & Abt 1981 \\
ACNP85 & Andersen et al. 1985 \\
B++08 & Bowen et al. 2008 \\
B54 & Bidelman 1954 \\
B58 & Bertiau 1958 \\
BFM07 & Burgh, France, \& McCandliss 2007 \\
CLMS04 & Cartledge et al. 2004 \\
D++06 & Dufton et al. 2006 \\
F58 & Feast 1958 \\
FTW55 & Feast, Thackeray, \& Wesselink 1955 \\
GG94 & Garrison \& Gray 1994 \\
GK76 & Garrison \& Kormendy 1976 \\
GMB77 & Golay, Mandwewala, \& Bartholdi 1977 \\
H56a & Hoffleit 1956 \\
H56b & Hiltner 1956 \\
H70 & Hill 1970 \\
HGS69 & Hiltner, Garrison, \& Schild 1969 \\
J81 & Jensen, 1981 \\
JJ92 & Jaschek \& Jaschek 1992 \\
JM53 & Johnson \& Morgan 1953 \\
KM89 & Kilkenny \& Muller 1989 \\
KW99 & Kohoutek \& Wehmeyer 1999 \\
L68 & Lesh 1968 \\
L72 & Levato 1972 \\
LA76 & Levato \& Abt 1976 \\
M61 & Morris 1961 \\
MCW55 & Morgan, Code, \& Whitford 1955 \\
MHG71 & Morgan, Hiltner, \& Garrison 1971 \\
MR50 & Morgan \& Roman 1950 \\
P43 & Popper 1943 \\
S68 & Simonson 1968 \\
S82 & Slettebak 1982 \\
SF90 & Strassmeier \& Fekel 1990 \\
&
\end{tabular}


Table 3-Continued

\begin{tabular}{ll}
\hline \hline \multicolumn{1}{c}{ Code } & \multicolumn{1}{c}{ Reference } \\
\hline SMM85 & Savage, Massa, \& Meade 1985 \\
SMS01 & Savage, Meade, \& Sembach 2001 \\
T71 & Thackeray 1971 \\
W71 & Walborn 1971 \\
W72 & Walborn 1972 \\
W73 & Walborn 1973 \\
\hline
\end{tabular}




\subsection{Characteristics of the Sight Lines and Target Stars}

Table 2 lists some fundamental information on the stars included in this investigation, along with determinations of the amount of foreground hydrogen in both atomic and molecular form. The stars are identified by both their HD numbers and their alternate representations [columns (1) and 2], followed by their Galactic coordinates [columns (3) and (4)]. Column (5) lists visual magnitudes of the stars taken from the Simbad database. Except for a few stars, these V magnitudes were not used for calculating the reddenings or spectroscopic parallaxes discussed in 4.5.1; the tabulated values are therefore of uncertain origin and meant only as an approximate guide. Column (6) lists the spectral types of the stars, followed by codes in column (7) that designate their sources in the literature according to the matches to references given in Table 3. Column (8) lists the $B-V$ color excess toward each star, which is one indication of the total amount of dust along the sight line. Column (9) shows the distances toward the stars, computed according to the principles given below in 4.5 .1 , followed by the corresponding distances $z$ from the Galactic plane [column (10)]. Columns (11) through (18) show the lower limits, best values, and upper limits for atomic and molecular hydrogen, in each case followed by codes that give the sources for these values. Note that many atomic hydrogen column densities had adjustments applied to account for stellar contamination of the $\mathrm{L} \alpha$ profile, as will be explained later in $\$ 4.6 .2$.

Figure 4 shows the distribution of $F_{*}$ values for all of the stars considered, including those which did not meet the eligibility requirements for helping to determine the element parameters $A_{X}, B_{X}$, and $z_{X}$ as outlined under point nrs. 3, 4, and 7 in 4.2 . Note that there are values of $F_{*}$ below zero, but the sightlines for these cases have $\log N(\mathrm{H})<19.5$, which violates one of the conditions needed for participation in the estimation of the element parameters. Actual numerical values of $F_{*}$ (and their uncertainties) toward the specific target stars appear later in Table 5 ,

\subsubsection{Calculations of Distances and Reddenings}

For determining the distances to early-type stars, one must make use of different sources of information, depending on the circumstances. At the most basic level, we note that trigonometric parallaxes provide the most accurate measures of distance for nearby stars, but when the errors in these parallaxes are not considerably smaller than the measured values, it is better to rely on spectroscopic parallaxes. For trigonometric parallaxes, we rely on the second reduction of the Hipparcos data (nr. I/311 in the Strasbourg CDS VizieR on-line catalog) 8 (van Leeuwen 2007), but accept the values only if $\pi / \sigma(\pi)>10$. For stars that do not meet this standard, we revert to distance derivations based on spectroscopic parallaxes, as described below.

As a part of an investigation of O VI absorptions in the Galactic disk, Bowen et al. (2008)

\footnotetext{
${ }^{8}$ The faulty version of this catalog that appeared during July to Sept 2008 was not used.
} 


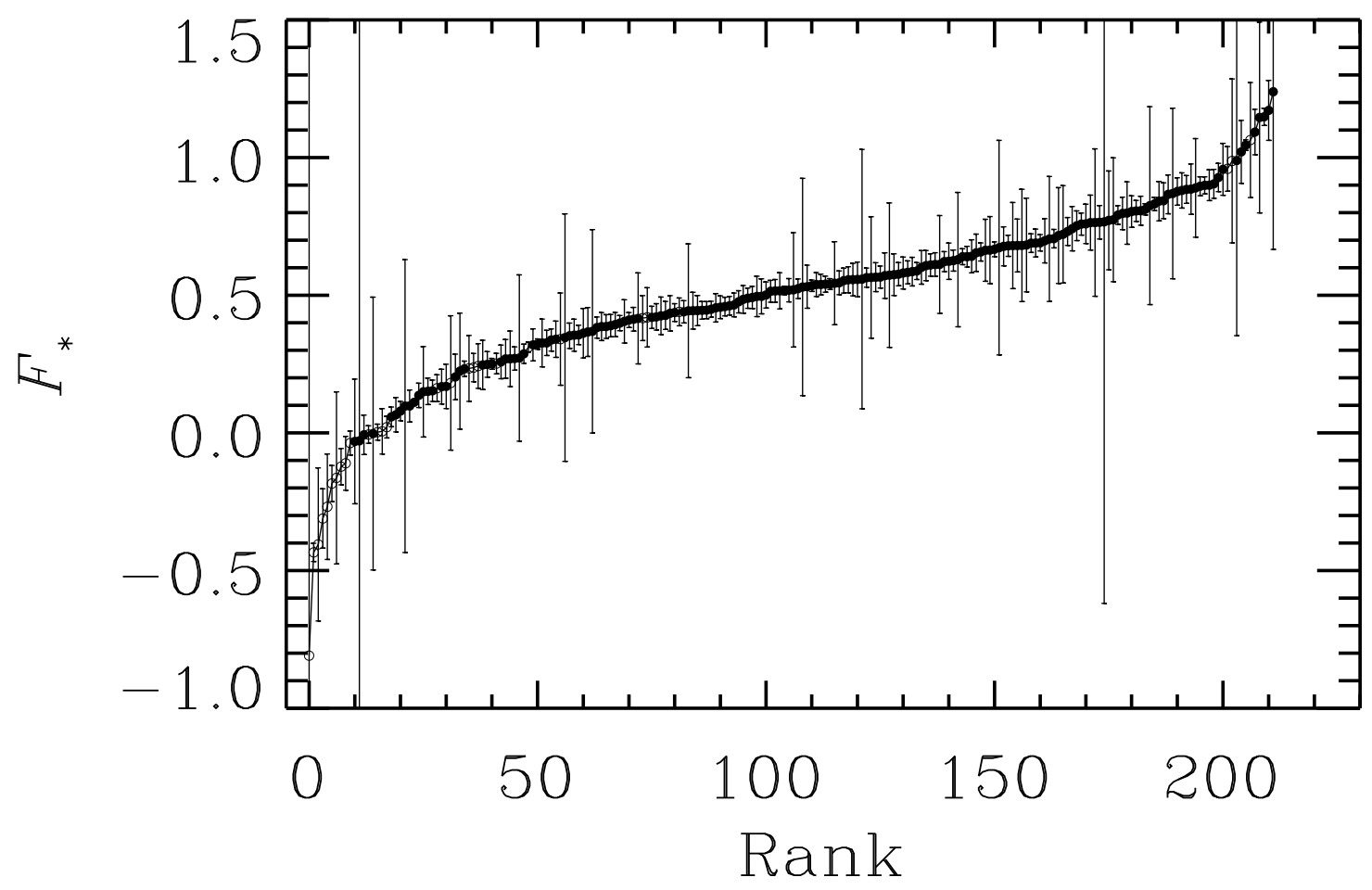

Fig. 4. - The outcomes for $F_{*}$ and their respective $1 \sigma$ errors in this study, arranged in a sequence according to their rank in value. Solid points apply to cases where $N(\mathrm{H})>10^{19.5} \mathrm{~cm}^{-2}$, and hollow ones indicate measurements below this range. 
(hereafter B08) carried out a rigorous process for determining the distances to stars based on spectroscopic parallaxes with many additional refinements, as described in Appendix B of their article. We adopt here many of the principles that they did, but with some simplifications since the standard of accuracy here is not as demanding as that for one of the objectives of the O VI survey. Some of the stars in the current survey were listed by B08. For those cases, Table 2 simply duplicates the values of distance and reddening that they listed, except for cases where they adopted Hipparcos parallaxes. The reason for rejecting their distances based on Hipparcos data is that (1) they used results from the earlier, less accurate solutions that were incorporated into the first catalog (Schrijver 1997), and (2) their acceptance threshold was set to $\pi / \sigma(\pi)>5$ instead of 10.

Stars for which neither the Hipparcos parallaxes nor the determinations by B08 were applicable had their spectroscopic parallaxes determined with the standard formula for the distance $d$ (in kpc),

$$
\log d=\left(m_{V}-A_{V}-M_{V}-10\right) / 5
$$

where $m_{V}$ is the apparent $V$ magnitude of the star, $A_{V}$ is the extinction by dust in the visible (assumed to be $3.1 E(B-V)$ ), and $M_{V}$ is the absolute $V$ magnitude of the star. We follow the recommendation of B08 in adopting, when available, the two-color photometric measurements from the Tycho Starmapper catalog (Schrijver 1997) to obtain values for the $B$ and $V$ magnitudes, after a suitable transformation from the Tycho magnitude system $B_{T}$ and $V_{T}$ (see Appendix B1 of B08). The premise here is that these magnitudes represent a uniform set of measurements where both colors were determined at a single epoch (which can be important for variable stars). If Tycho magnitudes were not available, we use values of $B$ and $V$ listed in the catalog of Johnson et al. (1966). Finally, if neither of the above two sources had listings for the stars, we used the magnitudes given by the Simbad web site.

Column (6) of Table 2 lists the adopted spectral classifications of the target stars, along with the respective sources of the assignments in the column that follows. (Many of these classifications were taken from either B08 or Savage, Meade \& Sembach (2001), who made judgments on the most reliable sources and listed them in their tables.) For these chosen spectral types, we link them to values of $M_{V}$ in the consolidation from many sources made by B08 and adopt the intrinsic colors from Wegner (1994). A fraction of the stars are recognized as spectroscopic binaries and thus must have their distances adjusted outward to compensate for the fact that their brightnesses are greater than that of the primary star alone. B08 outline a procedure for implementing this correction (see their Appendix B1.2).

\subsection{Determinations of $N(\mathrm{H})$}

For most stars, we can draw upon measurements of both $\mathrm{H} \mathrm{I}$ and $\mathrm{H}_{2}$ and evaluate the quantity $N(\mathrm{H} \mathrm{I})+2 N\left(\mathrm{H}_{2}\right)$ to find the total number of hydrogen atoms $N(\mathrm{H})$ along a given sight line. Since the errors in $N(\mathrm{H} \mathrm{I})$ and $N\left(\mathrm{H}_{2}\right)$ are uncorrelated, we can simply add them in quadrature to find 
the net uncertainty in $N(\mathrm{H})$. Unfortunately, for some of the stars of potential value for this survey, there were no measurements of the foreground $\mathrm{H} \mathrm{I}, \mathrm{H}_{2}$ (or both), or there were just upper limits thereof. For other stars, corrections had to be made for the upward shift in the apparent $N(\mathrm{H} \mathrm{I})$ caused by $\mathrm{L} \alpha$ absorption in the stellar atmospheres. The handling of these special circumstances is discussed in the following subsections.

\subsubsection{Missing Information}

At the most fundamental level, sight lines without information on both $\mathrm{H} \mathrm{I}$ and $\mathrm{H}_{2}$ were not suitable for measuring depletions directly. However, for about half of these stars $N(\mathrm{H} \mathrm{I})$ is known, and values of $N(\mathrm{H})$ could be salvaged on the premise that empirically the fraction of hydrogen in molecular form is very small $\left(f\left(\mathrm{H}_{2}\right) \equiv 2 N\left(\mathrm{H}_{2}\right) /\left[N(\mathrm{H} \mathrm{I})+2 N\left(\mathrm{H}_{2}\right)\right]<0.1\right)$ when the star's $B-V$ color excess is less than 0.05 (Savage et al. 1977); see also Rachford et al. (2009). An equivalent cutoff can be established on the basis of just the measurement of $N(\mathrm{H} \mathrm{I})$ : In a survey of stars using the Copernicus satellite, Bohlin, Savage \& Drake (1978) found that

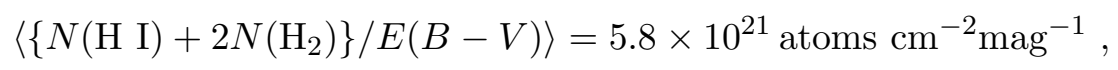

which is approximately consistent with

$$
\langle N(\mathrm{H} \mathrm{I}) / E(B-V)\rangle=5.2 \times 10^{21} \text { atoms } \mathrm{cm}^{-2} \mathrm{mag}^{-1}
$$

derived for an IUE survey conducted by Shull \& Van Steenberg (1985) for a larger number of stars. For such stars with no explicit $\mathrm{H}_{2}$ data, but which had $\log N(\mathrm{H} \mathrm{I})<20.4$ the value for $N(\mathrm{H})$ was set equal to $N(\mathrm{H} \mathrm{I})$, but with an increase in the upper error bar by 0.04 dex to allow for the fact that an unseen additional $10 \%$ of the hydrogen atoms could be in molecular form.

Many stars had no reported values for $N(\mathrm{H} \mathrm{I})$ because either the $\mathrm{L} \alpha$ absorption was not observed or the star was of a late enough spectral type that there was a good chance that the $\mathrm{L} \alpha$ feature was strongly dominated by a stellar contribution. It is important to emphasize that for such cases we did not use $E(B-V)$ to determine $N(\mathrm{H})$ on the basis of the empirical relationship given in Eq. 18. This choice makes the survey immune to possible misleading effects caused by real deviations from the general connection between selective extinction and the amount of gas present. This can be important for future studies that might attempt to relate depletions to various observable properties of the dust (i.e., $A_{V}, R_{V}$, wavelength of maximum polarization, etc.). It also avoids our being deceived by photometric errors arising from the occasional presence of emission lines in the spectra of stars.

We avoided the practice of estimating $N(\mathrm{H})$ simply by using the column density of a supposedly undepleted element and assuming a solar abundance ratio, since the lack of any depletion for that element could be subject to question. For example, we did not accept values of $N(\mathrm{H})$ listed by Cartledge et al. (2004, 2006) based on the column densities of Kr. (Later, it will be shown that Kr may exhibit some very mild depletion.) 
Ultimately, stars for which $N(\mathrm{H})$ could not be recovered from data in the literature were not useless. A means for calculating an indirect, synthetic value for this quantity is discussed in 97 , and it will be demonstrated that this outcome offers a reasonably accurate replacement for an observed value of $N(\mathrm{H})$.

\subsubsection{Corrections for Stellar L $\alpha$ Absorption}

A significant proportion of the sight lines covered in this study (102 cases) made use of stars that had spectral types B1 or cooler. In such instances, there is a danger that the equivalent width of the observed $\mathrm{L} \alpha$ absorption feature is enhanced by an underlying stellar contribution (Savage \& Panek 1974). It is important to account for this effect, since there will be a systematic shift in the measurement of $N(\mathrm{H} \mathrm{I})$, sometimes quite small, to some amount that is above the true value that belongs to the ISM. Many investigators who reported or used values of $N(\mathrm{H} \mathrm{I})$ recognized this problem and provided cautions that some of their results were probably contaminated by a stellar contribution, but they did not attempt to apply compensations (Bohlin, Savage, \& Drake 1978; Shull \& Van Steenberg 1985; André et al. 2003; Cartledge et al. 2004, 2008). However Bohlin, et al. (1983) appear to have overlooked this problem when they derived additional values of $N(\mathrm{H} \mathrm{I})$.

In a study of L $\alpha$ absorption toward a large number of stars, Diplas \& Savage (1994) devised a means for estimating the stellar L $\alpha$ absorption and corrected many of their measurements to compensate for it. Their method was based on the findings of Savage \& Panek (1974) with some additional guidance from NLTE stellar atmosphere calculations, and it used as a yardstick the reddening-corrected measure of the Balmer discontinuity based on a combination of narrow-band Strömgren photometric indices $\left[c_{1}\right]=c_{1}-0.2(b-y)$, where the uncorrected Balmer jump index $c_{1}=(u-v)-(v-b)$.

In making corrections for stellar L $\alpha$ absorption in the present study, we assume that the stellar profile is well approximated by a Lorentzian shape, as did Diplas \& Savage, so that we may simply subtract from the observed $N(\mathrm{H} \mathrm{I})$ the equivalent column density for the stellar line to obtain the interstellar value. In estimating the strength of the stellar line, we follow exactly the recipe given by Diplas \& Savage. Our only departure from their practice was that we did not exclude from consideration cases where $\log N(\mathrm{H} \mathrm{I})_{\text {obs. }}-\log N(\mathrm{H} \mathrm{I})_{\text {stellar }} \leq 0.5$ dex. We justify this action on the grounds that the larger uncertainties are well accounted for in the error estimation technique described below, which then influences the weight factors in the parameter estimations described in $\S 93.1$ and 3.2 without totally discarding the results at an arbitrary level.

After subtraction of $N(\mathrm{H} \mathrm{I})_{\text {stellar }}$ from $N(\mathrm{H} \mathrm{I})_{\text {obs. }}$ to obtain $N(\mathrm{H} \mathrm{I})_{\text {ISM }}$, we define the error in the result $\sigma[N(\mathrm{H} \mathrm{I})]_{\mathrm{ISM}}$ in terms of a combination of errors in both the observed column density and the estimate for the stellar contribution, given by the relation

$$
\sigma[N(\mathrm{H} \mathrm{I})]_{\mathrm{ISM}}=\sqrt{\sigma_{ \pm}[N(\mathrm{H} \mathrm{I})]_{\text {obs. }}^{2}+\left[N(\mathrm{H} \mathrm{I})_{\text {stellar }}\left(1-10^{\mp \Delta}\right)\right]^{2}}
$$


where $\sigma_{ \pm}[N(\mathrm{H} \mathrm{I})]_{\text {obs. }}$ represents the differences between the best values of the observed column densities and their respective upper and lower bounds, and $\Delta$ is the logarithm of the relative uncertainty in $N(\mathrm{H} \mathrm{I})_{\text {stellar }}$. We adopted a value $\Delta=0.20$ dex for all of the correction calculations 9

For most of the stars that needed an evaluation of $N(\mathrm{H} \mathrm{I})_{\text {stellar, }}$, values of the critical parameter $\left[c_{1}\right]$ could be retrieved from the catalog of Hauck \& Mermilliod (1998) 10 In a few cases, other sources were needed, as indicated in the endnotes of Table 2. The photometry for stars whose spectral classifications indicated the presence of emission lines (i.e., with an "e" appended) are probably untrustworthy. For these stars, as well as others for which no measurements of $\left[c_{1}\right]$ could be found, the estimates for $N(\mathrm{H} \mathrm{I})_{\text {stellar }}$ had to be based on the stars' spectral types, using mean values of $\left[c_{1}\right]$ found for other stars with similar classifications. From the dispersion of individual results about these means, we judge that the uncertainty of any outcome using only the spectral classification is about 0.38 dex; hence we used this value for $\Delta$ in Eq. 20 for the small number of cases where a spectral type had to be used instead of $\left[c_{1}\right]$. These stars with reduced accuracy are also identified explicitly in the table.

In a number of instances, we found that $\sigma[N(\mathrm{H} \mathrm{I})]_{\mathrm{ISM}}>N(\mathrm{H} \mathrm{I})_{\mathrm{ISM}}$, but $N(\mathrm{H} \mathrm{I})_{\mathrm{ISM}}>$ 0 . When this happened, lower limits were not stated in Table 2 and should thus be considered to be zero (the preferred values and upper limits were retained however). In other cases, $N(\mathrm{H} \mathrm{I})_{\mathrm{ISM}}<0$ but $N(\mathrm{H} \mathrm{I})_{\mathrm{ISM}}+\sigma[N(\mathrm{H} \mathrm{I})]_{\mathrm{ISM}}>0$; under these circumstances only upper limits set equal to $N(\mathrm{H} \mathrm{I})_{\text {ISM }}+\sigma[N(\mathrm{H} \mathrm{I})]_{\text {ISM }}$ were stated. Finally, there were 6 instances where $N(\mathrm{H} \mathrm{I})_{\text {ISM }}+\sigma[N(\mathrm{H} \mathrm{I})]_{\text {ISM }}<0$; when this happened, only upper limits were stated and they were simply set equal to the upper limits for $N(\mathrm{H} \mathrm{I})_{\text {obs. }}$. The fact that his occurred for only 6 out of the 95 cases considered for the correction offers a rough indication that the estimates for the $1 \sigma$ uncertainties in $N(\mathrm{H} \mathrm{I})_{\text {ISM }}$ are probably not unrealistically small.

There are a few determinations of $N(\mathrm{H} \mathrm{I})$ for the cooler stars that could be accepted at their stated values because either (1) their interstellar features could be seen as distinct absorptions at the bottoms of the photospheric features ( $\alpha$ CMa, $\alpha$ Vir, $\beta$ Cen and $\lambda$ Sco) (York \& Rogerson 1976; York 1983; Hébrard et al. 1999) or (2) the H I column density was determined by the observed shape of the star's energy distribution in the EUV after accounting for hydrogen absorption in the star's photosphere ( $\beta$ and $\epsilon$ CMa) (Cassinelli et al. 1995, 1996).

\footnotetext{
${ }^{9}$ The best value of $\Delta$, an error parameter that must include both random and systematic errors, is difficult to quantify with much precision. Our choice of $\Delta=0.20$ dex is a conservative one based on 3 considerations: (1) An estimate by Savage \& Panek (1974) that their rms errors in equivalent widths of the stellar L $\alpha$ feature are about $20 \%$, which translates into $(+0.16,-0.19)$ dex errors in $N(\mathrm{H} \mathrm{I})_{\text {stellar }},(2)$ An rms deviation of approximately 0.08 dex in $N(\mathrm{H} \mathrm{I})$ at $\left[c_{1}\right] \approx 0.3$ on either side of the theoretical line shown in Fig. 2 of Diplas \& Savage (1994) (where the stellar line probably dominates over the interstellar contribution), but with 4 outliers elsewhere that were more than three times this value in the negative direction, and (3) the size of the transition between the two discrete choices for factoring in the stellar surface gravity, one at $\log g=3$ and the other at $\log g=4$, in the recipe of Diplas \& Savage.

${ }^{10}$ The photometric data are available in the Strasbourg CDS VizieR on-line catalog nr. II/215.
} 


\section{Solutions for the Element Coefficients}

Compilations of the atomic column density measurements (corrected for $f$-value changes) and their sources in the literature appear in Appendix B with a series of tables organized according

to the different elements studied in this survey. These same tables also show the outcomes for $F_{*}$, together with information on how well the individual measurements conform to the best-fit solutions within our generalized framework.

For the depletion parameters that pertain to the just the elements, Table 4 presents the outcomes of the weighted least squares fits described in 3.2. (Sulfur is an element that presents special challenges and will be handled separately in 99 , ) Column (2) of this table lists the assumed reference abundances taken from Lodders (2003) for the proto-Sun (see 2.1 ). The fundamental parameters of the linear fits are $A_{X}, B_{X}$ and $z_{X}$ listed in columns (3) to (5), but the secondary quantities $\left[X_{\text {gas }} / \mathrm{H}\right]_{0}$ and $\left[X_{\text {gas }} / \mathrm{H}\right]_{1}$ in columns (6) and (7) allow us to understand how these parameters translate into the expected depletions near the two extremes of $F_{*}, F_{*}=0$ and 1 (values of $F_{*}$ greater than 1 do show up for a few stars however - see Figure 4). The last three columns of the table present information on how well the observations fit their respective best-fit trends. For each element, we can use the values of $\chi^{2}$ [column (8)] with their appropriate degrees of freedom $\nu$ (number of observations minus 2) listed in the next column to compute the probability shown in column (10) that the fit could have been worse than what we obtained. These probabilities are based on the assumptions that (1) the basic model for depletions expressed in Eq. 10 is correct and that (2) the errors in the observed depletions were estimated correctly. For Mn, this probability value seems rather low, which may indicate that either there are complicating factors that render the model as inappropriate for this element or that the errors in measuring column densities were underestimated (or both). Conversely, unreasonably high values for these probabilities (e.g., Mg, $\mathrm{Fe}, \mathrm{Cu}$, and $\mathrm{Ge}$ ) indicate that the measurement errors have probably been overestimated. 
Table 4. Element Depletion Parameters ${ }^{\mathrm{a}}$

\begin{tabular}{|c|c|c|c|c|c|c|c|c|c|}
\hline $\begin{array}{l}\text { Elem. } \\
\qquad X \\
(1)\end{array}$ & $\begin{array}{l}\text { Adopted } \\
(X / \mathrm{H})_{\odot}^{\mathrm{b}} \\
\quad(2)\end{array}$ & $\begin{array}{r}A_{X} \\
(3)\end{array}$ & $\begin{array}{l}B_{X}{ }^{c} \\
(4)\end{array}$ & $\begin{array}{c}z_{X} \\
(5)\end{array}$ & $\begin{array}{c}{\left[X_{\text {gas }} / \mathrm{H}\right]_{0}{ }_{0}} \\
(6)\end{array}$ & $\begin{array}{c}{\left[X_{\text {gas }} / \mathrm{H}\right]_{1}{ }^{c}} \\
(7)\end{array}$ & $\begin{array}{l}\chi^{2} \\
(8)\end{array}$ & $\begin{array}{c}\nu \\
(9)\end{array}$ & $\begin{array}{c}\text { Prob. } \\
\text { worse } \\
\text { fit } \\
(10)\end{array}$ \\
\hline $\mathrm{C}$ & $8.46 \pm 0.04$ & $-0.101 \pm 0.229$ & $-0.193 \pm 0.060$ & 0.803 & $-0.112 \pm 0.194$ & $-0.213 \pm 0.075$ & 3.7 & 8 & 0.881 \\
\hline $\mathrm{N}$ & $7.90 \pm 0.11$ & $-0.000 \pm 0.079$ & $-0.109 \pm 0.111$ & 0.550 & $-0.109 \pm 0.119$ & $-0.109 \pm 0.117$ & 28.8 & 32 & 0.628 \\
\hline $\mathrm{O}$ & $8.76 \pm 0.05$ & $-0.225 \pm 0.053$ & $-0.145 \pm 0.051$ & 0.598 & $-0.010 \pm 0.060$ & $-0.236 \pm 0.055$ & 75.0 & 64 & 0.164 \\
\hline $\mathrm{Mg}$ & $7.62 \pm 0.02$ & $-0.997 \pm 0.039$ & $-0.800 \pm 0.022$ & 0.531 & $-0.270 \pm 0.030$ & $-1.267 \pm 0.029$ & 79.0 & 103 & 0.962 \\
\hline $\mathrm{Si}$ & $7.61 \pm 0.02$ & $-1.136 \pm 0.062$ & $-0.570 \pm 0.029$ & 0.305 & $-0.223 \pm 0.035$ & $-1.359 \pm 0.052$ & 19.4 & 16 & 0.247 \\
\hline $\mathrm{P}$ & $5.54 \pm 0.04$ & $-0.945 \pm 0.051$ & $-0.166 \pm 0.042$ & 0.488 & $0.296 \pm 0.049$ & $-0.649 \pm 0.050$ & 69.5 & 65 & 0.330 \\
\hline $\mathrm{Cl}$ & $5.33 \pm 0.06$ & $-1.242 \pm 0.129$ & $-0.314 \pm 0.065$ & 0.609 & $0.442 \pm 0.102$ & $-0.800 \pm 0.082$ & 38.9 & 44 & 0.688 \\
\hline $\mathrm{Ti}$ & $5.00 \pm 0.03$ & $-2.048 \pm 0.062$ & $-1.957 \pm 0.033$ & 0.430 & $-1.077 \pm 0.043$ & $-3.125 \pm 0.049$ & 50.7 & 43 & 0.195 \\
\hline $\mathrm{Cr}$ & $5.72 \pm 0.05$ & $-1.447 \pm 0.064$ & $-1.508 \pm 0.055$ & 0.470 & $-0.827 \pm 0.062$ & $-2.274 \pm 0.064$ & 24.1 & 20 & 0.239 \\
\hline Mn & $5.58 \pm 0.03$ & $-0.857 \pm 0.041$ & $-1.354 \pm 0.032$ & 0.520 & $-0.909 \pm 0.038$ & $-1.765 \pm 0.038$ & 106.3 & 83 & 0.043 \\
\hline $\mathrm{Fe}$ & $7.54 \pm 0.03$ & $-1.285 \pm 0.044$ & $-1.513 \pm 0.033$ & 0.437 & $-0.951 \pm 0.038$ & $-2.236 \pm 0.041$ & 48.5 & 66 & 0.948 \\
\hline $\mathrm{Ni}$ & $6.29 \pm 0.03$ & $-1.490 \pm 0.062$ & $-1.829 \pm 0.035$ & 0.599 & $-0.937 \pm 0.051$ & $-2.427 \pm 0.043$ & 30.7 & 34 & 0.630 \\
\hline $\mathrm{Cu}$ & $4.34 \pm 0.06$ & $-0.710 \pm 0.088$ & $-1.102 \pm 0.063$ & 0.711 & $-0.597 \pm 0.089$ & $-1.307 \pm 0.068$ & 15.3 & 32 & 0.995 \\
\hline $\mathrm{Zn}$ & $4.70 \pm 0.04$ & $-0.610 \pm 0.066$ & $-0.279 \pm 0.045$ & 0.555 & $0.059 \pm 0.058$ & $-0.551 \pm 0.054$ & 25.6 & 19 & 0.142 \\
\hline $\mathrm{Ge}$ & $3.70 \pm 0.05$ & $-0.615 \pm 0.083$ & $-0.725 \pm 0.054$ & 0.690 & $-0.301 \pm 0.078$ & $-0.916 \pm 0.059$ & 12.4 & 24 & 0.975 \\
\hline $\mathrm{Kr}$ & $3.36 \pm 0.08$ & $-0.166 \pm 0.103$ & $-0.332 \pm 0.083$ & 0.684 & $-0.218 \pm 0.109$ & $-0.384 \pm 0.089$ & 18.9 & 26 & 0.839 \\
\hline
\end{tabular}

${ }^{a}$ As defined in Eqs. 10, 11, 13 \& 15, Coefficients for S do not appear in this table because a nonstandard approach was required. The coefficients are given in the text of 99

${ }^{\mathrm{b}} \mathrm{On}$ a logarithmic scale with $\mathrm{H}=12$. Values and their errors taken from the recommended solar abundances of Lodders 
(2003).

${ }^{\mathrm{c}}$ Unlike the convention for listing errors in the fit outcomes in Tables 7 to 23, the uncertainties with the terms listed here include both the formal errors of the fit coefficients and the error in the adopted value of $(X / \mathrm{H}) \odot$, added together in quadrature. 


\section{The Buildup of Dust Grains}

The strengths of chemical bonds for compounds that are most likely to form in dust grains vary over a large range. As a consequence, the propensity of different elements to condense into solid form, or the likelihood that they can subsequently be liberated back into the gas phase, are strongly dependent on physical conditions and time scales for creating or destroying the compounds. One popular paradigm is that the most refractory compounds are formed early in the nucleation process (possibly in the mass-loss outflows of stars or in the ejecta of supernovae), forming a core of the dust grain, and this is followed by the accumulation in dense molecular clouds of more loosely bound compounds that form a mantle around this core (Greenberg 1989; Jones, Duley, \& Williams 1990; Mathis 1990; Dwek 1998; Tielens 1998; Draine 2003a). However, in approaching the issue of relative depletions in different regions of space, we can bypass the question of how the grains are structured, i.e., whether they have a core-mantle assembly or a more amorphous configuration, and simply focus on the empirical relationships between different element abundances when the overall severity of the depletions change.

Since we define lines of sight with $F_{*}=0$ to represent the circumstances that exhibit the minimum general level of depletion, we can regard values of $\left[X_{\text {gas }} / H\right]_{0}$ to represent a "base depletion" that, by virtue of it being found everywhere, probably indicates the composition of the most durable constituents of grains (or in the parlance of the core-mantle picture, the disappearance of elements in the gas phase to make up the "core" of a grain). As the composition of the grains evolve from being dominated by refractory compounds to more volatile ones, different elements increase the absolute values of their depletions at different rates. One way to characterize the makeup of the more developed grains that have incorporated these volatile compounds might be to consider the depletions at some much larger level of depletion, say at $F_{*}=1$.

An important drawback of any declaration of an absolute level of depletion is that it depends on the assumed abundance of an element in the ISM when no grains exist at all, for which there have been some inconsistent quantitative conclusions, as discussed earlier in $\$ 2.1$. As a result, there have been conflicting views on the makeup of the grains, which in turn have created some challenges in constructing representations of the number, sizes and compositions of dust grains that had to be reconciled with the observed absorption, scattering and polarization at visible, UV and X-ray wavelengths (Mathis 1996; Smith \& Dwek 1998; Draine 2003b,c).

While our expressions of the base depletions $\left[X_{\text {gas }} / \mathrm{H}\right]_{0}$ must depend on the adopted values of the reference abundances, we can dispense with this relationship for more strongly developed depletions by not attempting to characterize the total composition of grains in the more advanced stages of growth, but instead simply by measuring the additional consumptions of different elements as they are incorporated into the newly formed grain materials. That is, by determining how rapidly

the abundances of different elements decrease as $F_{*}$ advances, we become insensitive to ambiguities that arise from uncertainties in the reference abundances.

If we substitute the right-hand side of Eq. 10 for $\left[X_{\text {gas }} / \mathrm{H}\right]$ into Eq. 2 and differentiate it with 
respect to $F_{*}$, we find that

$$
\begin{aligned}
d\left(X_{\text {dust }} / \mathrm{H}\right) / d F_{*} & =-(\ln 10)(X / \mathrm{H})_{\odot} A_{X} 10^{B_{X}+A_{X}\left(F_{*}-z_{X}\right)} \\
& =-(\ln 10) A_{X}\left(X_{\text {gas }} / \mathrm{H}\right)_{F_{*}}
\end{aligned}
$$

The first equality gives the result in terms of variables defined earlier in this paper, while the second shows that this outcome is independent of the adopted solar abundances - only the actual expectation of $\left(X_{\text {gas }} / \mathrm{H}\right)$ and its slope $\left(A_{X}\right)$ with $F_{*}$ matter. (Note that the term $\left(X_{\text {gas }} / \mathrm{H}\right)$ refers to the actual gas-phase abundance of an element $X$ relative to $\mathrm{H}$, whereas the notation used in earlier equations, $\left[X_{\text {gas }} / H\right]$, refers to the logarithm of the element's depletion factor.)

Figures 5 through 8 show two fundamental results for all of the elements except sulfur. (Again, sulfur is a difficult case that will be treated separately in 99.) For each element, the upper panel depicts the observed depletions as a function of $F_{*}$. Individual observed depletions are plotted as points with diameters that indicate their respective levels of accuracy. Dashed lines follow the linear trends with $F_{*}$ represented by the best fits defined by the parameters $A_{X}, B_{X}$, and $z_{X}$ listed in Table 4. The quantities $\left[X_{\text {gas }} / \mathrm{H}\right]_{0}$ and $\left[X_{\text {gas }} / \mathrm{H}\right]_{1}$ in columns $(6)$ and $(7)$ in that table are equal to the intercepts of these lines at $F_{*}=0$ and $F_{*}=1$, respectively; see Eqs. 13 through 16. The lower panels show the differential grain compositions, expressed in terms of the number of atoms per $\mathrm{H}$ atom that condense onto the grains per unit change in $F_{*}$. The cross-hatched regions show the allowed combinations of this differential composition for 1 and $2 \sigma$ deviations in the errors for $A_{X}$ and $B_{X}$. (Note that the portion of $\sigma\left(B_{X}\right)$ that is attributable to $\sigma(X / \mathrm{H})_{\odot}$ drops out of Eq. 21, thus leaving only the formal uncertainty in the least-squares solution for the intercept of the fit at $z_{X}$. These values of $\sigma\left(B_{X}\right)$ can be recovered by subtracting in quadrature the error values listed in column (2) of Table 4 from those listed in column (4) of the same table.)

Clearly, the slopes of the logarithms of the consumption rates of free atoms exhibit large variations from one element to the next, indicating that as the gas becomes more depleted the composition of the grains must change (or, put differently, that the material in the outer portions of the grain mantles differs from that in or near the cores). Our outlook on plausible mixtures of compounds within the grains must be constrained by not only the consumption information presented here, but also the chemical properties of the compounds themselves (Mathis 1996; Draine 2003a, 2004). 
Fig. 5.- (Shown on next page) Top row of panels: Measured depletions (points) and the linear trends defined by the parameters $A_{X}, B_{X}$ and $z_{X}$ in Eq. 10 (dashed lines), as listed in Table 4 , shown as a function of the generalized depletion parameter $F_{*}$ for the elements $\mathrm{C}, \mathrm{N}, \mathrm{O}, \mathrm{Mg}$ and Si. Solid points have $N(\mathrm{H})>10^{19.5} \mathrm{~cm}^{-2}$, while open ones have $N(\mathrm{H})$ values below this range. Gray points represent sightlines that had only 3 elements to define their $F_{*}$ parameters, while black ones represent those that had 4 or more elements. Upper and lower limit measurements are depicted with arrows (and were not included in any analysis). Sight lines that crossed the galactocentric limits $R_{\mathrm{GC}}<7 \mathrm{kpc}$ or $R_{\mathrm{GC}}>10 \mathrm{kpc}$ are overlaid with crosses $(+)$ or x's $(\times)$, respectively, to indicate that they were not used to define the linear trends for the elements. Bottom row of panels: Differential consumptions of elements by number (relative to hydrogen) by dust grains for small changes in $F_{*}$, again plotted as a function of $F_{*}$. The trend lines that follow Eq. 21 with the best values of $A_{X}$ and $B_{X}$ are shown with dark lines, while the allowable changes that can arise from the uncertainties in $A_{X}$ and $B_{X}$ are shown by the shaded regions. Uncertainties at the $1 \sigma$ level are shown by the cross-hatched areas, while the envelopes for $2 \sigma$ deviations have simple line shading in only one direction. 


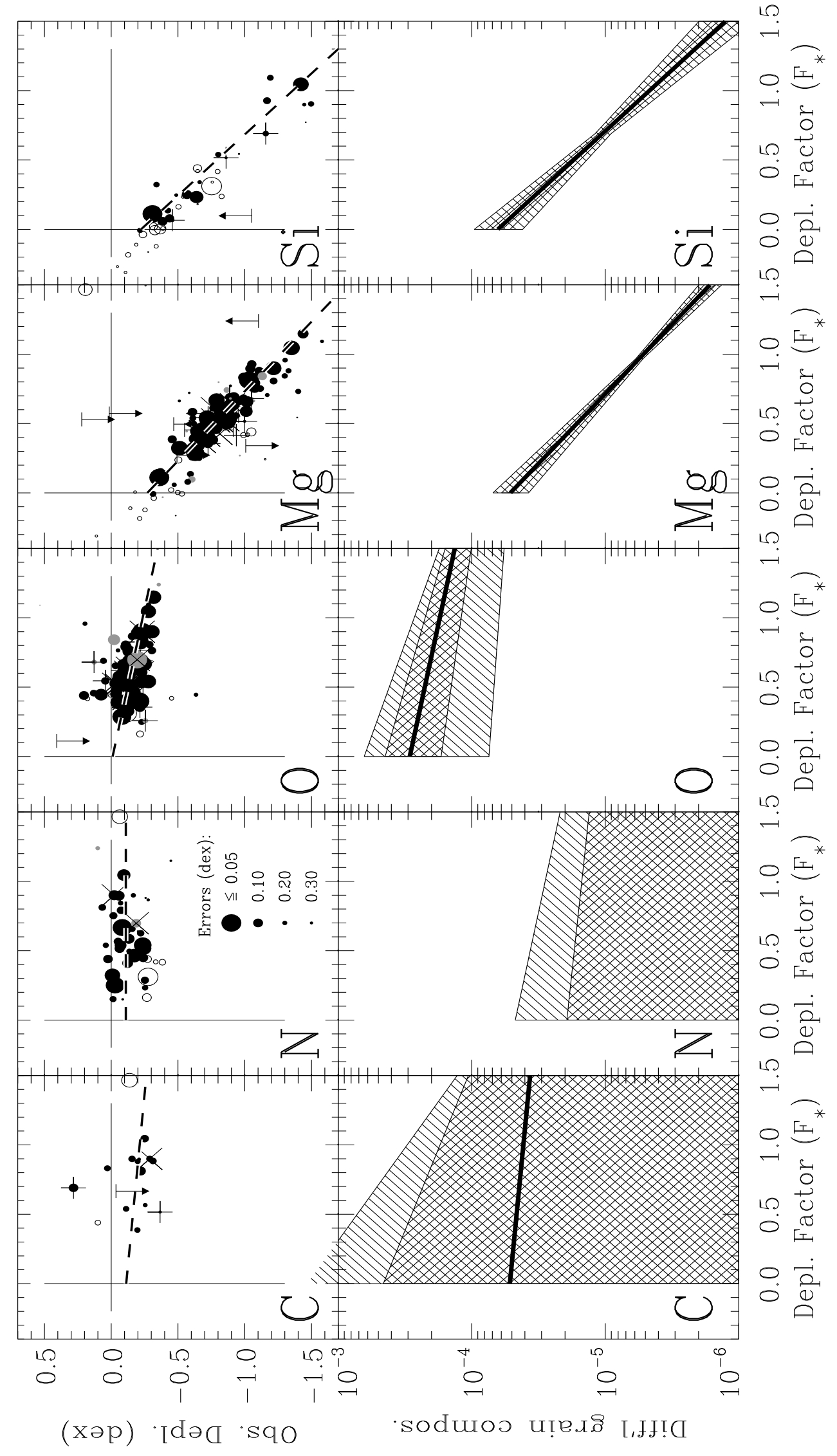

Fig. 5.- (Caption on previous page.) 


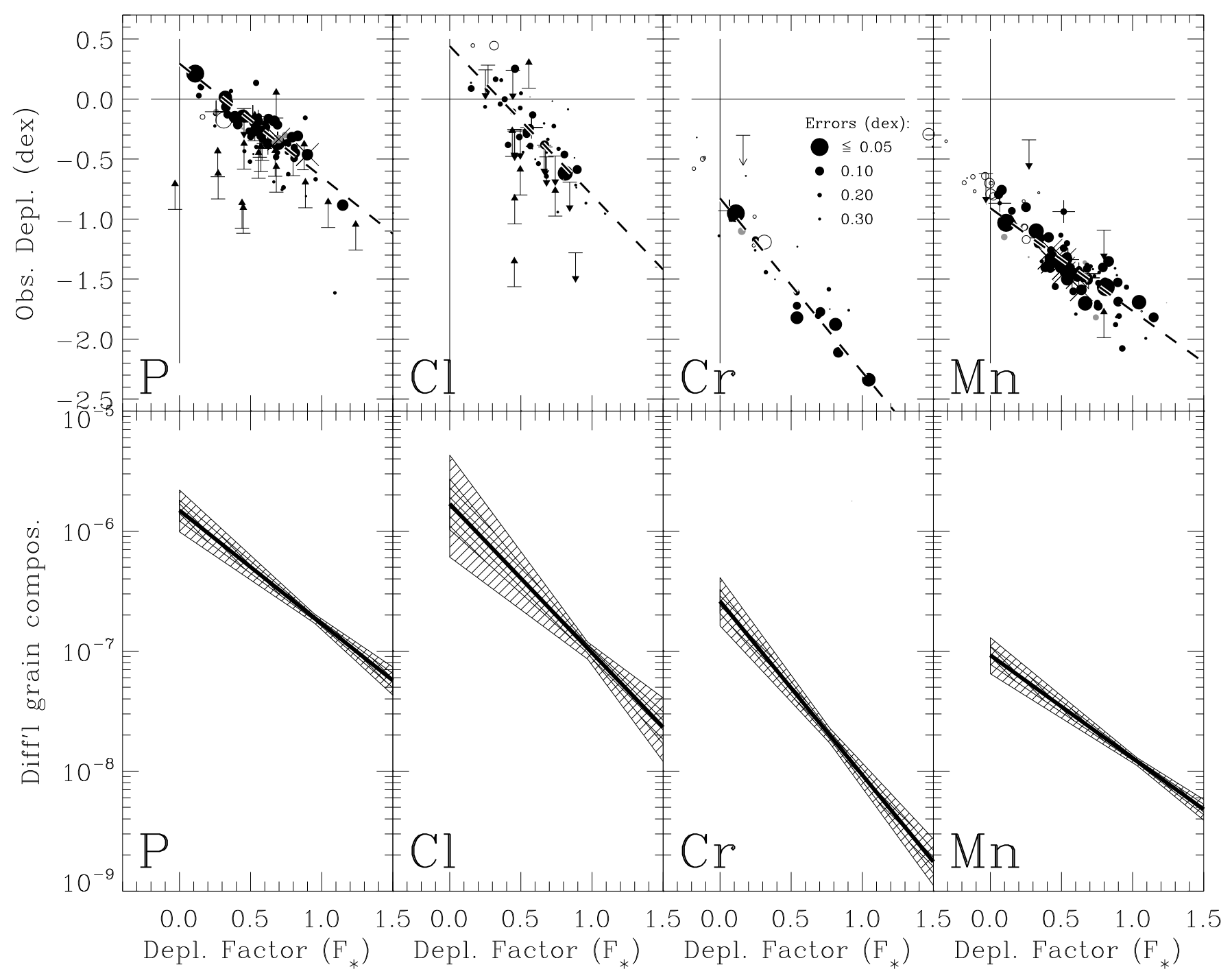

Fig. 6. - Same as for Fig. 5 for the elements P, Cl, Cr, and Mn. 


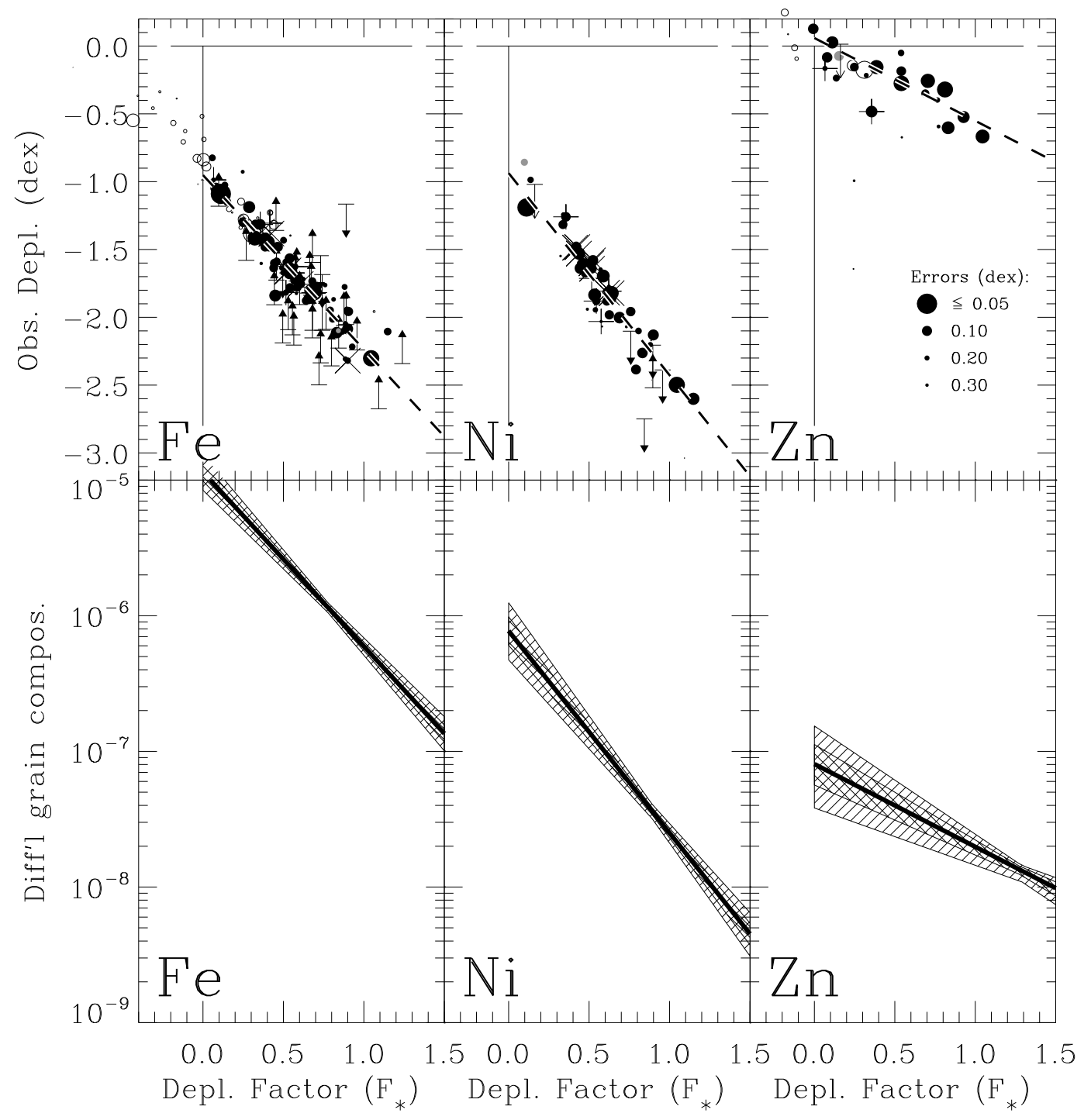

Fig. 7.- Same as for Fig. 5 for the elements Fe, Ni, and Zn. 


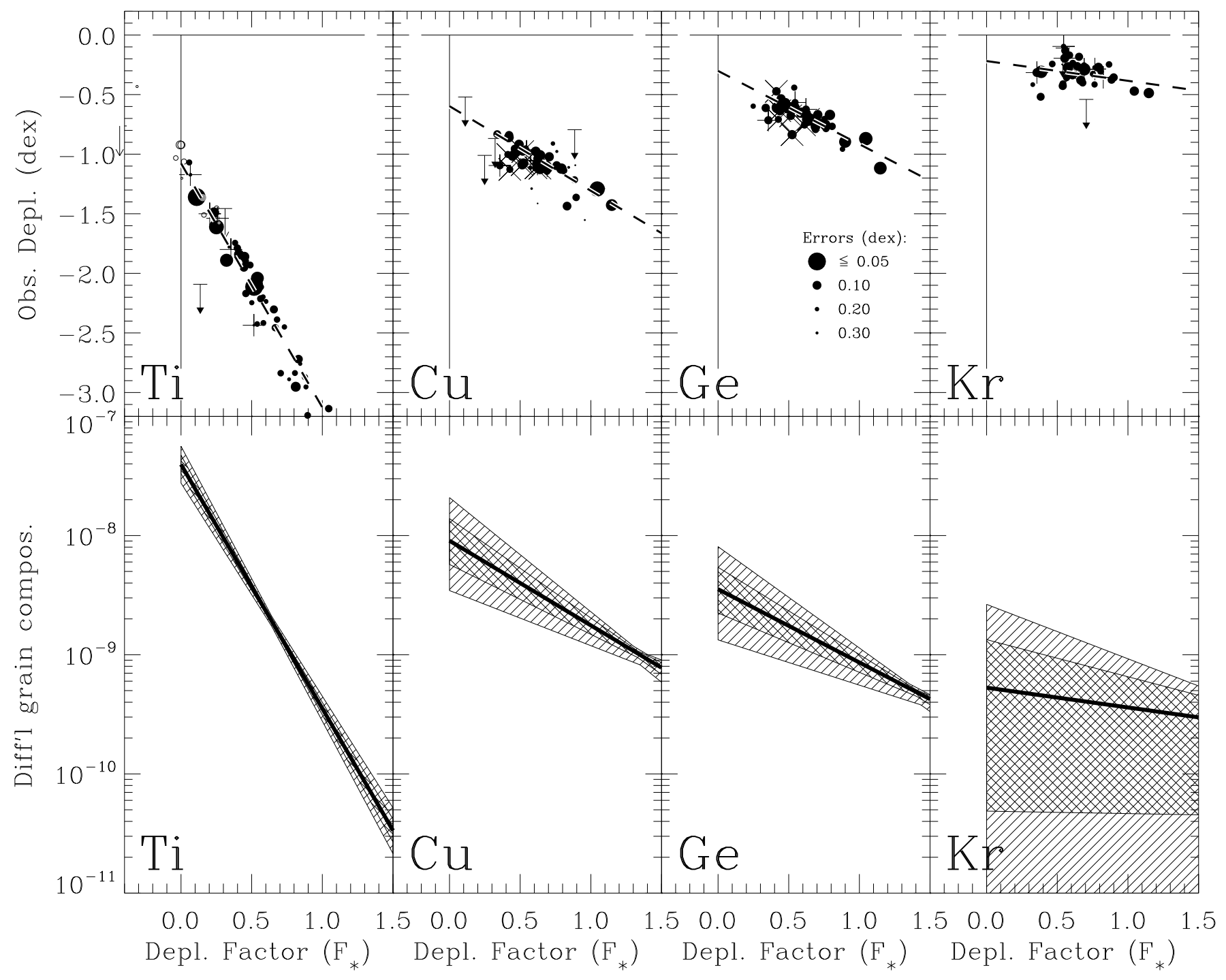

Fig. 8.- Same as for Fig. 5 for the elements Ti, Cu, Ge, and Kr. 


\section{Derivation of $N(\mathrm{H})$ and $F_{*}$ when $N(\mathrm{H})$ is not Observed}

\subsection{Method}

There are a number of applications where we can use the information on the depletion trends either to make up for the fact that $N(\mathrm{H})$ is not known, or, if it is known, to make an independent determination of the overall total abundances of heavier elements in the gas (usually referred to as the metallicity of the gas). In this section, we describe a means for processing information on the relative gas phase abundances to recover both $N(\mathrm{H})$, assuming a metallicity equal to the solar value, and the depletion strength $F_{*}$. Later, we will touch upon the relevance of this analysis for specific issues ranging from determinations of depletions of gas not far from the Sun ( $(88)$, to interpretations of the metallicity of gas out to several kpc from the Sun (\$10.3), to the general behavior of sulfur depletions ( $(9)$, and, finally to the metallicity in absorption systems at high redshifts (10.4). Even within the current survey, a reconstruction of $N(\mathrm{H})$ and $F_{*}$ is of some utility: out of all of the sightlines (or specific velocity components) studied here, there are 97 cases where information is missing on the observed column densities of $\mathrm{H} \mathrm{I}, \mathrm{H}_{2}$, or both. For 39 of them, the fact that $N\left(\mathrm{H}_{2}\right)$ was not observed did not present a problem, since $\mathrm{H}_{2}$ was unlikely to contribute much to $N(\mathrm{H})$, as discussed in 4.6.1. For the remaining 58, the lack of information on the observed $N(\mathrm{H})$ prevented

the determination of $\left[X_{\text {gas }} / H\right]_{\text {obs }}$ for any of the elements, values of which are essential for calculating $F_{*}$ through the use of Eq. 4 .

If it were true that all of the elements depleted logarithmically in unison as the general level of depletion became more severe (i.e., their values of $A_{X}$ were virtually identical), without information on $N(\mathrm{H})$ it would be impossible to distinguish between a line of sight with a modest level of depletion and a certain estimated $N(\mathrm{H})$, as opposed to a situation where the depletions were very strong and $N(\mathrm{H})$ was much higher. Fortunately, this is usually not the case. Given that many sight lines have measured abundances of elements with different $A_{X}$ values, it is possible to estimate with reasonable accuracy the quantities $N(\mathrm{H})$ and $F_{*}$, even when $N(\mathrm{H})$ is not known from the observations.

If we substitute $\left[X_{\text {gas }} / \mathrm{H}\right]_{\text {obs }}$ for $\left[X_{\text {gas }} / \mathrm{H}\right]_{\text {fit }}$ in Eq. 10, we obtain

$$
\left[X_{\text {gas }} / \mathrm{H}\right]_{\mathrm{obs}}=B_{X}+A_{X}\left(F_{*}-z_{X}\right)
$$

Noting that

$$
\left[X_{\text {gas }} / \mathrm{H}\right]_{\text {obs }}=\log N(X)-\log N(\mathrm{H})-\log (X / \mathrm{H})_{\odot}
$$

(this is simply a restatement of Eq. 1), we can rearrange the terms in this equation to obtain a simple linear expression

$$
y=a+b x
$$

where

$$
\begin{gathered}
y=\log N(X)-\log (X / \mathrm{H})_{\odot}-B_{X}+A_{X} z_{X}, \\
x=A_{X},
\end{gathered}
$$


and the coefficients of the equation have the meaning

$$
a=\log N(\mathrm{H})
$$

and

$$
b=F_{*} .
$$

This set of equations allows us to derive the most likely values of $\log N(\mathrm{H})$ and $F_{*}$ through the method of finding a (weighted) least-squares fit, once again using the routine FITEXY (Press et al. 2007) that recognizes the existence of errors in the measurements of both $x$ and $y$ when minimizing the $\chi^{2}$ of the fit. Note that the uncertainty in $\log (X / \mathrm{H})_{\odot}$ does not contribute to the errors in $y$, since excursions in this term are exactly canceled by opposing changes in the derived values of $B_{X}$. Any combination of elements that does not give large differences for the $A_{X}$ values will yield a value for $b$ (i.e., $F_{*}$ ) that is very uncertain. For this reason, lines of sight where the $A_{X}$ values span a range of less than 0.5 were not evaluated. Also, at least 3 elements were required for the analysis to proceed. (In principle, only 2 elements are needed to obtain a solution, but then we have no information on the goodness of fit.) The element sulfur was not considered. Henceforth, we will refer to the outcomes of the above set of equations as synthetic versions of $N(\mathrm{H})$ and $F_{*}$.

\subsection{Outcomes and Performance}

Table 5 allows us to compare the observed values of $\log N(\mathrm{H})$ and values of $F_{*}$ computed according to Eq. 4 in 33.1 [columns (3)-(6)] to the synthetic ones obtained from the best-fit calculations described above [columns (7) and (8)]. This table also lists synthetic values for these two quantities for the stars that had incomplete or no information on the observed $N(\mathrm{H})$. Stars for which $F_{*}$ could not be computed either from Eqs. 4 or 24a do not appear in the table.

As stated in 93 , the highly depleted velocity component at $-15 \mathrm{~km} \mathrm{~s}^{-1}$ in the direction of $\zeta \mathrm{Oph}$ was adopted as an approximate fiducial point for defining the scale of $F_{*}$. In the initial analysis, we had assumed that this component is responsible for most of the hydrogen along the sight line. We are now in a position to test this assumption. The least-squares fit outcome for Eq. 24a evaluated for the other component at $-27 \mathrm{~km} \mathrm{~s}^{-1}$ yields $\log N(\mathrm{H})_{\text {syn. }}=19.53 \pm 0.06$, which is well below $\log N(\mathrm{H})_{\text {obs. }}=21.15$ determined from the damped $\mathrm{L} \alpha$ profile and the Lyman series lines of $\mathrm{H}_{2}$ in the spectrum of this star. This value is even lower than the estimate of $\log N(\mathrm{H})=19.74$ that was adopted by Savage, Cardelli \& Sofia (1992).

For most of the determinations the trends of $y$ vs. $x$ appear to be well defined, and the scatter of $y$ values on either side of the best-fit line are consistent with the measurement errors. However, on some occasions the minimum $\chi^{2}$ values indicated that the fit was poor, as shown by small values for the probabilities of a worse fit given in column (9) of the table. When this happens, we must

be cautious about the reliability of the outcomes for the synthetic $N(\mathrm{H})$ and $F_{*}$. Two examples illustrate some common reasons for this sort of outcome. 
Table 5. Observed and Synthetic $\log N(\mathrm{H})$ and $F_{*}$

\begin{tabular}{|c|c|c|c|c|c|c|c|c|c|}
\hline \multirow[b]{3}{*}{$\begin{array}{l}\text { HD } \\
(1)\end{array}$} & \multirow[b]{3}{*}{$\begin{array}{l}\text { Name } \\
\quad(2)\end{array}$} & \multicolumn{4}{|c|}{ Observed } & \multicolumn{2}{|c|}{ Synthetic } & \multirow{3}{*}{$\begin{array}{c}\text { Prob. } \\
\text { worse } \\
\text { fit } \\
(9)\end{array}$} & \multirow[b]{3}{*}{$\begin{array}{c}\text { Elements Considered } \\
(10)\end{array}$} \\
\hline & & \multicolumn{3}{|c|}{$\log N(\mathrm{H})$} & \multirow[b]{2}{*}{$\begin{array}{l}F_{*} \\
(6)\end{array}$} & \multirow[b]{2}{*}{$\begin{array}{c}\log N(\mathrm{H}) \\
\quad(7)\end{array}$} & \multirow[b]{2}{*}{$\begin{array}{l}F_{*} \\
(8)\end{array}$} & & \\
\hline & & $\begin{array}{l}\text { l.l. } \\
(3)\end{array}$ & $\begin{array}{c}\text { best } \\
(4)\end{array}$ & $\begin{array}{l}\text { u.l. } \\
(5)\end{array}$ & & & & & \\
\hline 1383 & HD 1383 & 21.43 & 21.50 & 21.58 & $0.61 \pm 0.04$ & $21.49 \pm 0.08$ & $0.59 \pm 0.08$ & 0.510 & $\mathrm{O} \mathrm{Mg} \mathrm{Mn} \mathrm{Ni} \mathrm{Cu} \mathrm{Ge}$ \\
\hline 2905 & $\kappa$ Cas & 21.17 & 21.29 & 21.40 & $0.58 \pm 0.06$ & $21.00 \pm 0.26$ & $0.41 \pm 0.14$ & 0.989 & $\mathrm{Mg} \mathrm{Cl} \mathrm{Ti} \mathrm{Mn} \mathrm{Fe} \mathrm{Ni} \mathrm{Cu}$ \\
\hline 5394 & $\gamma \mathrm{Cas}$ & 20.06 & 20.16 & 20.24 & $0.52 \pm 0.04$ & $20.15 \pm 0.05$ & $0.51 \pm 0.05$ & 0.306 & N O Mg P Cl Ti Mn Fe \\
\hline 12323 & HD 12323 & 21.21 & 21.29 & 21.36 & $0.52 \pm 0.04$ & $21.24 \pm 0.08$ & $0.48 \pm 0.07$ & 0.011 & $\mathrm{O} \mathrm{Mg} \mathrm{Mn} \mathrm{Fe} \mathrm{Ni} \mathrm{Cu} \mathrm{Ge}$ \\
\hline 13268 & HD 13268 & 21.35 & 21.42 & 21.49 & $0.51 \pm 0.04$ & $21.38 \pm 0.07$ & $0.48 \pm 0.08$ & 0.147 & $\mathrm{O} \mathrm{Mg} \mathrm{Mn} \mathrm{Ni} \mathrm{Cu} \mathrm{Ge}$ \\
\hline 13745 & HD 13745 & 21.30 & 21.37 & 21.45 & $0.43 \pm 0.07$ & $\cdots$ & .. & $\ldots$ & $\mathrm{Mg} \mathrm{Fe}$ \\
\hline 14434 & HD 14434 & 21.40 & 21.47 & 21.54 & $0.52 \pm 0.04$ & $21.45 \pm 0.09$ & $0.51 \pm 0.09$ & 0.301 & $\mathrm{O} \mathrm{Mg} \mathrm{Mn} \mathrm{Ni} \mathrm{Cu}$ \\
\hline 15137 & HD 15137 & 21.10 & 21.22 & 21.35 & $0.37 \pm 0.09$ & $\ldots$ & $\cdots$ & $\ldots$ & $\mathrm{Mg} \mathrm{Fe}$ \\
\hline 18100 & HD 18100 & 20.02 & 20.15 & 20.29 & $0.14 \pm 0.04$ & $19.75 \pm 0.09$ & $-0.21 \pm 0.08$ & 0.000 & Mg Si P Cr Mn Fe Ni Zn \\
\hline 21856 & HD 21856 & 21.02 & 21.11 & 21.18 & $0.67 \pm 0.39$ & $\cdots$ & $\cdots$ & $\cdots$ & $\mathrm{Mg} \mathrm{Mn}$ \\
\hline 22586 & HD 22586 & 20.21 & 20.36 & 20.54 & $0.34 \pm 0.07$ & $20.24 \pm 0.35$ & $0.20 \pm 0.24$ & 0.240 & Si Ti Fe Ni \\
\hline 22928 & $\delta$ Per & 19.40 & $\ldots$ & 21.22 & $\ldots$ & $19.64 \pm 0.11$ & $0.23 \pm 0.11$ & 0.028 & N Mg P Ti Mn Fe \\
\hline 22951 & 40 Per & 21.11 & 21.22 & 21.33 & $0.73 \pm 0.05$ & $20.89 \pm 0.15$ & $0.52 \pm 0.10$ & 0.007 & $\mathrm{Mg} \mathrm{P} \mathrm{Cl} \mathrm{Ti} \mathrm{Mn} \mathrm{Ni} \mathrm{Cu}$ \\
\hline 23180 & o Per & 21.09 & 21.19 & 21.30 & $0.84 \pm 0.06$ & $21.28 \pm 0.09$ & $0.92 \pm 0.09$ & 0.362 & N O Mg P Ti Mn Cu \\
\hline 23478 & HD 23478 & 20.89 & 21.05 & 21.14 & $-0.00 \pm 0.50$ & $\ldots$ & $\ldots$ & $\ldots$ & $\mathrm{O} \mathrm{Kr}$ \\
\hline 23630 & $\eta \mathrm{Tau}$ & $\ldots$ & $\ldots$ & $\ldots$ & & $20.40 \pm 0.14$ & $0.89 \pm 0.10$ & 0.005 & Ti Cr Zn \\
\hline 24190 & HD 24190 & 21.25 & 21.30 & 21.35 & $0.63 \pm 0.24$ & $\ldots$ & $\ldots$ & $\ldots$ & $\mathrm{O} \mathrm{Kr}$ \\
\hline 24398 & $\zeta$ Per & 21.10 & 21.20 & 21.31 & $0.88 \pm 0.05$ & $21.23 \pm 0.07$ & $0.90 \pm 0.07$ & 0.163 & C O Mg P Ti Mn Fe Cu Kr \\
\hline 24534 & X Per & 21.31 & 21.34 & 21.38 & $0.90 \pm 0.06$ & $21.37 \pm 0.07$ & $0.93 \pm 0.11$ & 0.228 & $\mathrm{C} \mathrm{N} \mathrm{O} \mathrm{P} \mathrm{Fe}$ \\
\hline 24760 & $\epsilon$ Per & 20.41 & 20.50 & 20.59 & $0.68 \pm 0.04$ & $20.45 \pm 0.05$ & $0.62 \pm 0.05$ & 0.375 & N O Mg P Cl Ti Mn Fe Kr \\
\hline 24912 & $\xi$ Per & 21.22 & 21.29 & 21.37 & $0.83 \pm 0.02$ & $21.46 \pm 0.06$ & $0.95 \pm 0.05$ & 0.000 & C O Mg P Cl Ti Cr Mn Fe Ni Cu Zn \\
\hline 27778 & 62 Tau & 20.99 & $\cdots$ & 21.27 & $\cdots$ & $21.38 \pm 0.07$ & $1.19 \pm 0.07$ & 0.640 & N O Mg P Mn Fe Ni Cu Ge Kr \\
\hline 30614 & $\alpha$ Cam & 21.02 & 21.09 & 21.17 & $0.46 \pm 0.04$ & $21.02 \pm 0.09$ & $0.41 \pm 0.07$ & 0.001 & O Mg P Ti Mn \\
\hline 31237 & $\pi^{5}$ Ori & 19.65 & 20.16 & 20.37 & $0.52 \pm 0.21$ & $\ldots$ & $\ldots$ & $\ldots$ & $\mathrm{Mg} \mathrm{P}$ Mn Fe \\
\hline 34029 & $\alpha$ Aur & 18.15 & 18.24 & 18.34 & $0.44 \pm 0.05$ & $18.71 \pm 0.13$ & $0.95 \pm 0.12$ & 0.000 & $\mathrm{C} N \mathrm{O} \mathrm{Mg} \mathrm{Si} \mathrm{Fe}$ \\
\hline 34816 & $\lambda$ Lep & 20.08 & 20.18 & 20.26 & $0.45 \pm 0.05$ & $\ldots$ & & $\ldots$ & $\mathrm{Ti}$ \\
\hline
\end{tabular}


Table 5-Continued

\begin{tabular}{|c|c|c|c|c|c|c|c|c|c|}
\hline \multirow[b]{3}{*}{$\begin{array}{r}\mathrm{HD} \\
(1)\end{array}$} & \multirow[b]{3}{*}{$\begin{array}{c}\text { Name } \\
(2)\end{array}$} & \multicolumn{4}{|c|}{ Observed } & \multicolumn{2}{|c|}{ Synthetic } & \multirow{3}{*}{$\begin{array}{c}\text { Prob. } \\
\text { worse } \\
\text { fit } \\
(9)\end{array}$} & \multirow[b]{3}{*}{$\begin{array}{l}\text { Elements Considered } \\
\qquad(10)\end{array}$} \\
\hline & & \multicolumn{3}{|c|}{$\log N(\mathrm{H})$} & \multirow[b]{2}{*}{$\begin{array}{l}F_{*} \\
(6)\end{array}$} & \multirow[b]{2}{*}{$\begin{array}{c}\log N(\mathrm{H}) \\
\quad(7)\end{array}$} & \multirow[b]{2}{*}{$\begin{array}{l}F_{*} \\
(8)\end{array}$} & & \\
\hline & & $\begin{array}{l}1.1 . \\
(3)\end{array}$ & $\begin{array}{c}\text { best } \\
(4)\end{array}$ & $\begin{array}{l}\text { u.l. } \\
(5)\end{array}$ & & & & & \\
\hline 34989 & HD 34989 & 21.00 & 21.10 & 21.18 & $0.72 \pm 0.17$ & $\cdots$ & $\cdots$ & $\cdots$ & $\mathrm{Fe}$ \\
\hline 35149 & 23 Ori & 20.47 & 20.63 & 20.74 & $0.54 \pm 0.04$ & $21.03 \pm 0.05$ & $0.85 \pm 0.05$ & 0.000 & C N O Mg Si P Cl Ti Cr Mn Fe Ni Cu Zn Ge \\
\hline 35439 & 25 Ori & 20.06 & 20.36 & 20.49 & $0.72 \pm 0.18$ & $\cdots$ & $\cdots$ & $\cdots$ & $\mathrm{Mg} \mathrm{P} \mathrm{Cl} \mathrm{Mn}$ \\
\hline 35715 & $\psi$ Ori & 20.26 & 20.49 & 20.64 & $0.66 \pm 0.11$ & $\cdots$ & $\cdots$ & $\cdots$ & $\mathrm{Mg} \mathrm{P} \mathrm{Cl} \mathrm{Mn} \mathrm{Fe}$ \\
\hline 36486 & $\delta$ Ori A & 20.15 & 20.19 & 20.23 & $0.54 \pm 0.02$ & $20.07 \pm 0.04$ & $0.45 \pm 0.04$ & 0.004 & N O Mg P Cl Ti Cr Mn Fe Zn \\
\hline 36822 & $\phi^{1}$ Ori & 20.75 & 20.84 & 20.91 & $0.74 \pm 0.08$ & $\ldots$ & $\ldots$ & $\ldots$ & $\mathrm{Mg} \mathrm{P} \mathrm{Mn}$ \\
\hline 36841 & HD 36841 & $\cdots$ & $\cdots$ & $\ldots$ & $\cdots$ & $20.90 \pm 0.19$ & $0.81 \pm 0.18$ & 0.937 & $\mathrm{Mg} P \mathrm{Mn} \mathrm{Ni} \mathrm{Cu}$ \\
\hline 36861 & $\lambda$ Ori A & 20.67 & 20.80 & 20.90 & $0.57 \pm 0.04$ & $20.77 \pm 0.04$ & $0.53 \pm 0.04$ & 0.144 & C N O Mg P Cl Ti Mn Fe Kr \\
\hline 37021 & $\theta^{1}$ Ori & $\ldots$ & $\ldots$ & $\ldots$ & $\cdots$ & $21.52 \pm 0.06$ & $0.75 \pm 0.06$ & 0.000 & C O Mg Si P Fe Ni Cu Ge Kr \\
\hline 37043 & $\iota$ Ori & 20.08 & 20.15 & 20.21 & $0.41 \pm 0.03$ & $20.09 \pm 0.05$ & $0.36 \pm 0.04$ & 0.040 & N O Mg P Cl Ti Mn Fe \\
\hline 37061 & $\nu$ Ori & $\cdots$ & $\cdots$ & $\cdots$ & $\cdots$ & $21.69 \pm 0.06$ & $0.82 \pm 0.07$ & 0.000 & $\mathrm{C} \mathrm{O} \mathrm{Mg} \mathrm{Si} \mathrm{Fe} \mathrm{Cu} \mathrm{Ge} \mathrm{Kr}$ \\
\hline 37128 & $\epsilon$ Ori & 20.35 & 20.45 & 20.53 & $0.54 \pm 0.03$ & $20.40 \pm 0.05$ & $0.49 \pm 0.04$ & 0.022 & O Mg P Cl Ti Cr Mn Fe Zn Kr \\
\hline 37367 & HD 37367 & 21.23 & 21.33 & 21.42 & $0.65 \pm 0.07$ & $21.49 \pm 0.09$ & $0.86 \pm 0.12$ & 0.991 & $\mathrm{O} \mathrm{Mg} \mathrm{Mn} \mathrm{Cu} \mathrm{Ge} \mathrm{Kr}$ \\
\hline 37468 & $\sigma$ Ori & 20.42 & 20.52 & 20.60 & $0.58 \pm 0.04$ & $20.78 \pm 0.11$ & $0.78 \pm 0.11$ & 0.000 & $\mathrm{Mg} \mathrm{P} \mathrm{Cl} \mathrm{Ti} \mathrm{Mn}$ \\
\hline 37742 & $\zeta$ Ori A & 20.32 & 20.41 & 20.49 & $0.57 \pm 0.05$ & $\cdots$ & $\cdots$ & $\cdots$ & $\mathrm{Ti}$ \\
\hline 37903 & HD 37903 & 21.38 & 21.44 & 21.50 & $1.15 \pm 0.03$ & $21.34 \pm 0.06$ & $1.03 \pm 0.07$ & 0.297 & N O Mg P Mn Fe Ni Cu Ge Kr \\
\hline 38666 & $\mu \mathrm{Col}$ & 19.84 & 19.86 & 19.88 & $0.11 \pm 0.01$ & $19.92 \pm 0.04$ & $0.16 \pm 0.04$ & 0.589 & Mg Si P Ti Cr Mn Fe Ni Zn \\
\hline 38771 & $\kappa$ Ori & 20.47 & 20.52 & 20.56 & $0.67 \pm 0.03$ & $20.50 \pm 0.05$ & $0.65 \pm 0.05$ & 0.000 & N O Mg P Cl Ti Mn Fe Kr \\
\hline 40111 & 139 Tau & 20.87 & 20.95 & 21.03 & $0.49 \pm 0.04$ & $20.77 \pm 0.09$ & $0.34 \pm 0.08$ & 0.718 & Mg P Cl Ti Mn Fe Ni Cu \\
\hline 40893 & HD 40893 & 21.46 & 21.54 & 21.61 & $0.61 \pm 0.05$ & $21.47 \pm 0.06$ & $0.52 \pm 0.07$ & 0.372 & $\mathrm{O} \mathrm{Mg} \mathrm{Fe} \mathrm{Kr}$ \\
\hline 41161 & HD 41161 & 21.00 & 21.08 & 21.17 & $0.44 \pm 0.04$ & $21.30 \pm 0.06$ & $0.57 \pm 0.04$ & 0.002 & $\mathrm{NO} \mathrm{Oi} \mathrm{Fe}$ \\
\hline 42933 & $\delta \mathrm{Pic}$ & 20.15 & 20.23 & 20.35 & $0.32 \pm 0.06$ & $\cdots$ & $\cdots$ & $\cdots$ & $\mathrm{Ti}$ \\
\hline 43818 & LU Gem & $\cdots$ & $\cdots$ & $\cdots$ & $\cdots$ & $21.65 \pm 0.06$ & $0.66 \pm 0.07$ & 0.032 & $\mathrm{O} \mathrm{Mg} \mathrm{Mn} \mathrm{Ni} \mathrm{Cu} \mathrm{Ge}$ \\
\hline 44506 & HD 44506 & 19.49 & 20.09 & 20.32 & $-0.03 \pm 0.23$ & $\cdots$ & $\cdots$ & $\cdots$ & $\mathrm{Mg} \mathrm{Cl} \mathrm{Fe}$ \\
\hline 44743 & $\beta \mathrm{CMa}$ & 18.26 & 18.30 & 18.38 & $-0.43 \pm 0.03$ & $18.23 \pm 0.04$ & $-0.46 \pm 0.05$ & 0.000 & N O Si Mn Fe \\
\hline 47839 & 15 Mon & 20.21 & 20.31 & 20.41 & $0.25 \pm 0.05$ & $20.13 \pm 0.08$ & $0.12 \pm 0.06$ & 0.854 & O P Cl Ti Cr Zn Ge \\
\hline
\end{tabular}


Table 5-Continued

\begin{tabular}{|c|c|c|c|c|c|c|c|c|c|c|}
\hline \multirow[b]{3}{*}{$\begin{array}{r}\mathrm{HD} \\
(1)\end{array}$} & \multirow[b]{3}{*}{$\begin{array}{c}\text { Name } \\
(2)\end{array}$} & \multicolumn{4}{|c|}{ Observed } & \multicolumn{2}{|c|}{ Synthetic } & \multirow{3}{*}{$\begin{array}{c}\text { Prob. } \\
\text { worse } \\
\text { fit } \\
(9)\end{array}$} & \multirow{3}{*}{\multicolumn{2}{|c|}{$\begin{array}{c}\text { Elements Considered } \\
\qquad(10)\end{array}$}} \\
\hline & & \multicolumn{3}{|c|}{$\log N(\mathrm{H})$} & \multirow[b]{2}{*}{$\begin{array}{l}F_{*} \\
(6)\end{array}$} & \multirow[b]{2}{*}{$\begin{array}{c}\log N(\mathrm{H}) \\
\quad(7)\end{array}$} & \multirow[b]{2}{*}{$\begin{array}{l}F_{*} \\
(8)\end{array}$} & & & \\
\hline & & $\begin{array}{l}1.1 . \\
(3)\end{array}$ & $\begin{array}{c}\text { best } \\
(4)\end{array}$ & $\begin{array}{l}\text { u.l. } \\
(5)\end{array}$ & & & & & & \\
\hline $48915(+12)$ & $\alpha \mathrm{CMa}$ & 17.18 & 17.40 & 17.58 & $0.42 \pm 0.11$ & $16.96 \pm 0.08$ & $-0.01 \pm 0.07$ & 0.000 & $\mathrm{NO} \mathrm{Mg} \mathrm{Si} \mathrm{Fe}$ & \\
\hline$(+18)$ & & 17.48 & 17.60 & 17.78 & $0.42 \pm 0.08$ & $17.26 \pm 0.06$ & $0.06 \pm 0.05$ & 0.000 & $\mathrm{~N} \mathrm{O} \mathrm{Mg} \mathrm{Si} \mathrm{Fe}$ & \\
\hline 52266 & HD 52266 & $\cdots$ & $\cdots$ & $\cdots$ & $\ldots$ & $21.37 \pm 0.10$ & $0.65 \pm 0.10$ & 0.503 & $\mathrm{Mg} \mathrm{Mn} \mathrm{Ni} \mathrm{Cu} \mathrm{Ge}$ & \\
\hline 52918 & 19 Mon & 19.75 & 20.20 & 20.35 & $0.44 \pm 0.24$ & $\cdots$ & $\cdots$ & $\cdots$ & $\mathrm{Mg} \mathrm{P} \mathrm{Mn}$ & \\
\hline 53138 & $\mathrm{o}^{2} \mathrm{Cma}$ & 17.95 & 19.78 & 20.08 & $0.10 \pm 0.53$ & $\ldots$ & $\ldots$ & $\ldots$ & $\mathrm{Ti}$ & \\
\hline 53975 & HD 53975 & 21.08 & 21.14 & 21.20 & $0.45 \pm 0.03$ & $21.06 \pm 0.06$ & $0.41 \pm 0.05$ & 0.000 & N O Mg Ti Fe & \\
\hline 54662 & HD 54662 & 21.28 & 21.41 & 21.52 & $0.89 \pm 0.09$ & $21.17 \pm 0.66$ & $0.67 \pm 0.62$ & 0.970 & $\mathrm{Mg} \mathrm{Cl} \mathrm{Mn} \mathrm{Fe} \mathrm{Ni}$ & \\
\hline 57060 & $29 \mathrm{CMa}$ & 20.60 & 20.70 & 20.78 & $0.50 \pm 0.05$ & $20.80 \pm 0.16$ & $0.58 \pm 0.12$ & 0.063 & Mg P Cl Ti Mn Fe & \\
\hline 57061 & $\tau \mathrm{CMa}$ & 20.65 & 20.70 & 20.74 & $0.39 \pm 0.04$ & $20.67 \pm 0.06$ & $0.36 \pm 0.08$ & 0.225 & $\mathrm{C} \mathrm{O} \mathrm{Mg} \mathrm{Cl} \mathrm{Cr} \mathrm{Mn} \mathrm{Fe} \mathrm{Zn} \mathrm{Kr}$ & 1 \\
\hline 63005 & HD 63005 & 21.27 & 21.32 & 21.37 & $0.64 \pm 0.03$ & $21.28 \pm 0.06$ & $0.61 \pm 0.07$ & 0.261 & $\mathrm{O} \mathrm{Mg} \mathrm{Mn} \mathrm{Ni} \mathrm{Cu} \mathrm{Ge}$ & g] \\
\hline 64740 & HD 64740 & 19.64 & 20.05 & 20.23 & $0.27 \pm 0.30$ & $\ldots$ & $\ldots$ & $\ldots$ & $\mathrm{Cl} \mathrm{Fe}$ & \\
\hline 64760 & HD 64760 & 20.13 & 20.26 & 20.35 & $0.35 \pm 0.06$ & $\ldots$ & $\ldots$ & $\ldots$ & $\mathrm{Mg} \mathrm{P} \mathrm{Cl} \mathrm{Mn} \mathrm{Fe}$ & \\
\hline 65818 & V Pup & 20.36 & 20.52 & 20.65 & $0.36 \pm 0.09$ & $\ldots$ & $\ldots$ & $\ldots$ & $\mathrm{Mg} \mathrm{P} \mathrm{Cl} \mathrm{Mn} \mathrm{Fe}$ & \\
\hline 66788 & HD 66788 & 21.16 & 21.26 & 21.35 & $0.53 \pm 0.08$ & $\cdots$ & $\cdots$ & $\cdots$ & $\mathrm{Mg} \mathrm{Fe}$ & \\
\hline 66811 & $\zeta$ Pup & 19.92 & 19.96 & 20.00 & $0.32 \pm 0.02$ & $20.14 \pm 0.05$ & $0.47 \pm 0.04$ & 0.628 & N Mg Si P Cl Ti Cr Mn Fe Ni Zn & \\
\hline 68273 & $\gamma^{2} \mathrm{Vel}$ & 19.67 & 19.71 & 19.75 & $0.25 \pm 0.02$ & $19.80 \pm 0.05$ & $0.31 \pm 0.04$ & 0.152 & N Mg Si P Ti Mn Fe & \\
\hline 69106 & HD 69106 & 21.04 & 21.09 & 21.15 & $0.64 \pm 0.06$ & $21.10 \pm 0.08$ & $0.65 \pm 0.09$ & 0.818 & $\mathrm{O} \mathrm{Mg} \mathrm{Fe} \mathrm{Kr}$ & \\
\hline 71634 & HD 71634 & $\ldots$ & $\cdots$ & $\cdots$ & $\ldots$ & $21.34 \pm 0.16$ & $0.90 \pm 0.16$ & 0.389 & $\mathrm{Mg} P \mathrm{Mn} \mathrm{Ni} \mathrm{Cu} \mathrm{Ge}$ & \\
\hline 72127 & HD 72127 & $\cdots$ & $\cdots$ & $\cdots$ & $\cdots$ & $20.25 \pm 0.11$ & $0.40 \pm 0.08$ & 0.021 & Ti Cr Zn & \\
\hline 72754 & FY Vel & 21.19 & 21.28 & 21.38 & $0.76 \pm 0.10$ & $21.13 \pm 0.08$ & $0.54 \pm 0.12$ & 0.913 & $\mathrm{O} \mathrm{P} \mathrm{Ge} \mathrm{Kr}$ & \\
\hline 73882 & HD 73882 & 21.50 & 21.57 & 21.65 & $0.68 \pm 0.07$ & $\cdots$ & $\cdots$ & $\cdots$ & $\mathrm{N} \mathrm{Fe}$ & \\
\hline 74375 & HD 74375 & 20.67 & 20.78 & 20.87 & $0.61 \pm 0.18$ & $\cdots$ & $\cdots$ & $\cdots$ & $\mathrm{Fe}$ & \\
\hline 74575 & $\alpha \mathrm{Pyx}$ & 20.27 & 20.46 & 20.59 & $0.33 \pm 0.09$ & $\cdots$ & $\cdots$ & $\cdots$ & $\mathrm{Ti}$ & \\
\hline 75309 & HD 75309 & 21.10 & 21.18 & 21.26 & $0.63 \pm 0.04$ & $21.18 \pm 0.06$ & $0.61 \pm 0.07$ & 0.173 & N O Mg P Mn Ni Cu Ge Kr & \\
\hline 79186 & GX Vel & 21.34 & 21.41 & 21.48 & $0.69 \pm 0.03$ & $21.46 \pm 0.07$ & $0.73 \pm 0.07$ & 0.532 & $\mathrm{O} \mathrm{Mg} \mathrm{P} \mathrm{Mn} \mathrm{Ni} \mathrm{Cu} \mathrm{Ge}$ & \\
\hline 88115 & HD 88115 & 20.89 & 20.99 & 21.08 & $0.35 \pm 0.45$ & $\cdots$ & & $\cdots$ & $\mathrm{NO}$ & \\
\hline
\end{tabular}


Table 5-Continued

\begin{tabular}{|c|c|c|c|c|c|c|c|c|c|}
\hline \multirow[b]{3}{*}{$\begin{array}{l}\mathrm{HD} \\
(1)\end{array}$} & \multirow[b]{3}{*}{$\begin{array}{l}\text { Name } \\
(2)\end{array}$} & \multicolumn{4}{|c|}{ Observed } & \multicolumn{2}{|c|}{ Synthetic } & \multirow{3}{*}{$\begin{array}{c}\text { Prob. } \\
\text { worse } \\
\text { fit } \\
(9)\end{array}$} & \multirow[b]{3}{*}{$\begin{array}{l}\text { Elements Considered } \\
\qquad(10)\end{array}$} \\
\hline & & \multicolumn{3}{|c|}{$\log N(\mathrm{H})$} & \multirow[b]{2}{*}{$\begin{array}{l}F_{*} \\
(6)\end{array}$} & \multirow[b]{2}{*}{$\begin{array}{l}\log N(\mathrm{H}) \\
\quad(7)\end{array}$} & \multirow[b]{2}{*}{$\begin{array}{l}F_{*} \\
(8)\end{array}$} & & \\
\hline & & $\begin{array}{l}1.1 . \\
(3)\end{array}$ & $\begin{array}{l}\text { best } \\
(4)\end{array}$ & $\begin{array}{l}\text { u.l. } \\
(5)\end{array}$ & & & & & \\
\hline 91316 & $\rho$ Leo & 20.14 & 20.25 & 20.32 & $0.15 \pm 0.04$ & $20.16 \pm 0.09$ & $0.11 \pm 0.06$ & 0.497 & Ti Cr Zn \\
\hline 91597 & HD 91597 & 21.36 & 21.41 & 21.47 & $0.44 \pm 0.05$ & $\ldots$ & $\cdots$ & $\cdots$ & $\mathrm{Mg} \mathrm{Fe}$ \\
\hline 91651 & HD 91651 & 21.10 & 21.16 & 21.22 & $0.27 \pm 0.04$ & $\cdots$ & $\cdots$ & $\cdots$ & $\mathrm{Mg} \mathrm{Fe}$ \\
\hline 91824 & HD 91824 & 21.11 & 21.16 & 21.22 & $0.45 \pm 0.03$ & $21.34 \pm 0.07$ & $0.61 \pm 0.08$ & 0.292 & $\mathrm{O} \mathrm{Mg} P \mathrm{Mn} \mathrm{Ni} \mathrm{Cu} \mathrm{Ge}$ \\
\hline 91983 & HD 91983 & 21.16 & 21.24 & 21.32 & $0.48 \pm 0.04$ & $21.32 \pm 0.06$ & $0.55 \pm 0.07$ & 0.821 & $\mathrm{O} \mathrm{Mg} \mathrm{P} \mathrm{Mn} \mathrm{Ni} \mathrm{Cu} \mathrm{Ge}$ \\
\hline 92554 & HD 92554 & 21.18 & 21.28 & 21.38 & $0.27 \pm 0.07$ & $\cdots$ & $\cdots$ & $\cdots$ & $\mathrm{Mg} \mathrm{Fe}$ \\
\hline 93030 & $\theta$ Car & 20.18 & 20.26 & 20.34 & $0.45 \pm 0.03$ & $20.10 \pm 0.09$ & $0.34 \pm 0.05$ & 0.342 & $\mathrm{O} \mathrm{Mg} \mathrm{P} \mathrm{Cl} \mathrm{Ti} \mathrm{Mn} \mathrm{Fe}$ \\
\hline 93205 & V560 Car & 21.36 & 21.40 & 21.44 & $0.40 \pm 0.03$ & $21.26 \pm 0.05$ & $0.28 \pm 0.05$ & 0.958 & $\mathrm{O} \mathrm{Mg} \mathrm{Ti} \mathrm{Fe}$ \\
\hline 93222 & HD 93222 & 21.35 & 21.42 & 21.48 & $0.39 \pm 0.04$ & $21.48 \pm 0.06$ & $0.46 \pm 0.06$ & 0.055 & $\mathrm{O} \mathrm{Mg} \mathrm{P} \mathrm{Fe}$ \\
\hline $93521(-66)$ & HD 93521 & 18.21 & 18.51 & 18.86 & $-0.31 \pm 0.11$ & $18.79 \pm 0.14$ & $-0.14 \pm 0.11$ & 0.000 & Mg Si Ti Mn Fe \\
\hline$(-58)$ & & 19.28 & 19.34 & 19.44 & $-0.01 \pm 0.03$ & $19.36 \pm 0.08$ & $-0.04 \pm 0.06$ & 0.000 & Mg Si Ti Mn Fe \\
\hline$(-51)$ & & 19.11 & 19.20 & 19.33 & $-0.04 \pm 0.04$ & $19.61 \pm 0.12$ & $0.24 \pm 0.11$ & 0.007 & Mg Si Ti Mn Fe \\
\hline$(-39)$ & & 18.70 & 18.88 & 19.10 & $0.01 \pm 0.08$ & $18.04 \pm 0.17$ & $-0.82 \pm 0.15$ & 0.000 & Mg Si Ti Mn Fe \\
\hline$(-29)$ & & 18.06 & 18.38 & 18.74 & $0.34 \pm 0.17$ & $\cdots$ & $\cdots$ & $\cdots$ & Si Mn Fe \\
\hline$(-18)$ & & 19.23 & 19.28 & 19.37 & $0.00 \pm 0.03$ & $19.16 \pm 0.11$ & $-0.14 \pm 0.09$ & 0.000 & Mg Si Ti Mn Fe \\
\hline$(-10)$ & & 19.31 & 19.36 & 19.45 & $0.02 \pm 0.04$ & $19.38 \pm 0.17$ & $0.01 \pm 0.12$ & 0.282 & Mg Si Ti Mn Fe \\
\hline$(+3)$ & & 19.24 & 19.30 & 19.40 & $0.25 \pm 0.04$ & $19.10 \pm 0.17$ & $0.10 \pm 0.18$ & 0.948 & Mg Si Ti Mn Fe \\
\hline$(+7)$ & & 18.56 & 18.79 & 19.06 & $0.23 \pm 0.12$ & $\cdots$ & $\cdots$ & $\cdots$ & Si Mn Fe \\
\hline (total) & & 20.06 & 20.10 & 20.20 & $0.06 \pm 0.04$ & $20.14 \pm 0.13$ & $0.05 \pm 0.11$ & 0.009 & Mg Si Ti Mn Fe \\
\hline 93843 & HD 93843 & 21.27 & 21.35 & 21.42 & $0.39 \pm 0.05$ & $\cdots$ & $\cdots$ & $\cdots$ & $\mathrm{Mg} \mathrm{Fe}$ \\
\hline 94493 & HD 94493 & 21.13 & 21.17 & 21.20 & $0.29 \pm 0.03$ & $21.11 \pm 0.06$ & $0.25 \pm 0.06$ & 0.013 & $\mathrm{NO} \mathrm{Mg} \mathrm{Fe}$ \\
\hline 99857 & HD 99857 & 21.30 & 21.36 & 21.41 & $0.54 \pm 0.04$ & $21.28 \pm 0.05$ & $0.47 \pm 0.06$ & 0.357 & $\mathrm{~N} \mathrm{O} \mathrm{Mg} \mathrm{P} \mathrm{Fe} \mathrm{Kr}$ \\
\hline 99890 & HD 99890 & 20.84 & 20.96 & 21.08 & $0.17 \pm 0.08$ & $\cdots$ & $\cdots$ & $\cdots$ & $\mathrm{Mg} \mathrm{Fe}$ \\
\hline 100340 & HD 100340 & 20.38 & 20.46 & 20.58 & $0.10 \pm 0.06$ & $19.59 \pm 0.20$ & $-0.63 \pm 0.17$ & 0.118 & $\mathrm{Mg} \mathrm{Mn} \mathrm{Ni}$ \\
\hline 103779 & HD 103779 & 21.11 & 21.20 & 21.29 & $0.43 \pm 0.06$ & $\cdots$ & $\cdots$ & $\cdots$ & $\mathrm{Mg} \mathrm{Fe}$ \\
\hline 104705 & DF Cru & 21.09 & 21.18 & 21.24 & $0.33 \pm 0.05$ & $21.10 \pm 0.05$ & $0.26 \pm 0.06$ & 0.583 & $\mathrm{O} \mathrm{Mg} \mathrm{P} \mathrm{Fe} \mathrm{Kr}$ \\
\hline
\end{tabular}


Table 5-Continued

\begin{tabular}{|c|c|c|c|c|c|c|c|c|c|}
\hline \multirow[b]{3}{*}{$\begin{array}{r}\mathrm{HD} \\
(1)\end{array}$} & \multirow[b]{3}{*}{$\begin{array}{l}\text { Name } \\
(2)\end{array}$} & \multicolumn{4}{|c|}{ Observed } & \multicolumn{2}{|c|}{ Synthetic } & \multirow{3}{*}{$\begin{array}{c}\text { Prob. } \\
\text { worse } \\
\text { fit } \\
(9)\end{array}$} & \multirow[b]{3}{*}{$\begin{array}{c}\text { Elements Considered } \\
\qquad(10)\end{array}$} \\
\hline & & \multicolumn{3}{|c|}{$\log N(\mathrm{H})$} & \multirow[b]{2}{*}{$\begin{array}{l}F_{*} \\
(6)\end{array}$} & \multirow[b]{2}{*}{$\begin{array}{c}\log N(\mathrm{H}) \\
\quad(7)\end{array}$} & \multirow[b]{2}{*}{$\begin{array}{l}F_{*} \\
(8)\end{array}$} & & \\
\hline & & $\begin{array}{l}1.1 . \\
(3)\end{array}$ & $\begin{array}{c}\text { best } \\
(4)\end{array}$ & $\begin{array}{l}\text { u.l. } \\
(5)\end{array}$ & & & & & \\
\hline 108248 & $\alpha^{1} \mathrm{Cru}$ & 19.50 & 19.60 & 19.70 & $0.15 \pm 0.05$ & $19.78 \pm 0.09$ & $0.30 \pm 0.09$ & 0.240 & $\mathrm{~N} \mathrm{Mg} \mathrm{P} \mathrm{Cl} \mathrm{Mn} \mathrm{Fe}$ \\
\hline 108639 & HD 108639 & 21.30 & 21.38 & 21.47 & $0.37 \pm 0.37$ & $\ldots$ & $\ldots$ & $\ldots$ & $\mathrm{O} \mathrm{Kr}$ \\
\hline 109399 & HD 109399 & 21.12 & 21.18 & 21.24 & $0.48 \pm 0.05$ & $\cdots$ & $\ldots$ & $\cdots$ & $\mathrm{Mg} \mathrm{Fe}$ \\
\hline 110432 & BZ Cru & 21.13 & 21.20 & 21.28 & $1.17 \pm 0.11$ & $\cdots$ & $\cdots$ & $\cdots$ & $\mathrm{N} \mathrm{Fe}$ \\
\hline 111934 & BU Cru & $\ldots$ & $\ldots$ & $\ldots$ & $\ldots$ & $21.48 \pm 0.14$ & $0.57 \pm 0.15$ & 0.879 & Mg P Mn Ni Cu Ge \\
\hline 114886 & HD 114886 & 21.35 & 21.40 & 21.46 & $0.87 \pm 0.31$ & $\cdots$ & $\cdots$ & $\cdots$ & $\mathrm{O} \mathrm{Kr}$ \\
\hline 115071 & V961 Cen & 21.45 & 21.50 & 21.55 & $0.22 \pm 0.21$ & $\ldots$ & $\ldots$ & $\ldots$ & $\mathrm{O} \mathrm{Kr}$ \\
\hline 116658 & $\alpha$ Vir & 18.90 & 19.00 & 19.10 & $0.16 \pm 0.05$ & $18.84 \pm 0.06$ & $0.11 \pm 0.06$ & 0.658 & N O Si P Cl Ti Mn Fe \\
\hline 116781 & V967 Cen & 21.16 & 21.24 & 21.33 & $0.44 \pm 0.07$ & $\cdots$ & $\cdots$ & $\cdots$ & $\mathrm{Mg} \mathrm{Fe}$ \\
\hline 116852 & HD 116852 & 20.94 & 21.02 & 21.10 & $0.36 \pm 0.04$ & $20.71 \pm 0.05$ & $0.07 \pm 0.05$ & 0.000 & $\mathrm{O} \mathrm{Mg} \mathrm{Mn} \mathrm{Fe} \mathrm{Ni} \mathrm{Cu} \mathrm{Zn}$ Ge $\mathrm{Kr}$ \\
\hline 118716 & $\epsilon$ Cen & 19.10 & 19.60 & 19.79 & $0.15 \pm 0.16$ & $19.67 \pm 0.12$ & $0.20 \pm 0.12$ & 0.801 & $\mathrm{~N} \mathrm{Mg} \mathrm{P} \mathrm{Cl} \mathrm{Fe}$ \\
\hline 120086 & HD 120086 & $\cdots$ & $\ldots$ & 20.07 & $\ldots$ & $19.38 \pm 0.23$ & $-0.56 \pm 0.18$ & 0.000 & Mg Si Ti Fe Ni \\
\hline 120324 & $\mu$ Cen & $\cdots$ & 18.76 & 20.22 & $-0.81 \pm 3.74$ & $\cdots$ & $\cdots$ & $\ldots$ & $\mathrm{Mg} \mathrm{P} \mathrm{Cl} \mathrm{Fe}$ \\
\hline 121263 & $\zeta$ Cen & 12.92 & $\cdots$ & 20.02 & $\cdots$ & $19.84 \pm 0.14$ & $0.48 \pm 0.14$ & 0.295 & N Mg P Mn Fe \\
\hline 121968 & HD 121968 & 20.45 & 20.60 & 20.71 & $0.26 \pm 0.06$ & $20.31 \pm 0.09$ & $0.09 \pm 0.06$ & 0.468 & $\mathrm{OP} \mathrm{Ti}$ \\
\hline 122451 & $\beta$ Cen & 19.49 & 19.54 & 19.59 & $0.23 \pm 0.03$ & $19.23 \pm 0.10$ & $0.06 \pm 0.06$ & 0.174 & N Si Ti \\
\hline 122879 & HD 122879 & 21.24 & 21.34 & 21.44 & $0.55 \pm 0.04$ & $21.58 \pm 0.07$ & $0.75 \pm 0.07$ & 0.640 & $\mathrm{O} \mathrm{Mg} \mathrm{Mn} \mathrm{Fe} \mathrm{Ni} \mathrm{Cu}$ Ge Kr \\
\hline 124314 & HD 124314 & 21.43 & 21.51 & 21.58 & $0.59 \pm 0.05$ & $21.57 \pm 0.05$ & $0.64 \pm 0.06$ & 0.502 & $\mathrm{NO} \mathrm{Mg} \mathrm{P} \mathrm{Fe} \mathrm{Kr}$ \\
\hline 125924 & HD 125924 & 20.47 & 20.63 & 20.78 & $0.20 \pm 0.08$ & $\cdots$ & $\cdots$ & $\cdots$ & $\mathrm{Ti}$ \\
\hline 127972 & $\eta$ Cen & $\cdots$ & $\cdots$ & 19.48 & $\cdots$ & $20.23 \pm 0.10$ & $0.86 \pm 0.10$ & 0.000 & $\mathrm{~N}$ Mg P Mn Fe \\
\hline 135591 & HD 135591 & 20.98 & 21.12 & 21.22 & $0.56 \pm 0.22$ & $\cdots$ & $\cdots$ & $\cdots$ & $\mathrm{Mg} \mathrm{Cl} \mathrm{Mn}$ \\
\hline 137595 & HD 137595 & 21.18 & 21.22 & 21.27 & $0.77 \pm 0.22$ & $\cdots$ & $\cdots$ & $\cdots$ & $\mathrm{O} \mathrm{Kr}$ \\
\hline 141637 & $1 \mathrm{Sco}$ & 21.01 & 21.13 & 21.23 & $0.69 \pm 0.05$ & $21.22 \pm 0.08$ & $0.78 \pm 0.09$ & 0.762 & $\mathrm{O} \mathrm{Mg} \mathrm{P} \mathrm{Cl} \mathrm{Cr} \mathrm{Mn} \mathrm{Fe} \mathrm{Cu} \mathrm{Zn} \mathrm{Ge} \mathrm{Kr}$ \\
\hline 143018 & $\pi$ Sco & 20.62 & 20.69 & 20.74 & $0.71 \pm 0.03$ & $20.95 \pm 0.10$ & $0.91 \pm 0.08$ & 0.521 & Mg P Ti Cr Mn Fe Cu Zn Ge \\
\hline 143275 & $\delta$ Sco & 21.07 & 21.17 & 21.24 & $0.90 \pm 0.03$ & $21.34 \pm 0.06$ & $1.01 \pm 0.06$ & 0.038 & $\mathrm{C}$ N O Mg P Cl Ti Mn Fe $\mathrm{Cu}$ \\
\hline 144217 & $\beta^{1} \mathrm{Sco}$ & 21.10 & 21.14 & 21.17 & $0.81 \pm 0.02$ & $21.27 \pm 0.06$ & $0.91 \pm 0.06$ & 0.507 & C N O Mg P Cl Ti Cr Mn Fe Zn \\
\hline
\end{tabular}


Table 5-Continued

\begin{tabular}{|c|c|c|c|c|c|c|c|c|c|}
\hline \multirow[b]{3}{*}{$\begin{array}{l}\text { HD } \\
(1)\end{array}$} & \multirow[b]{3}{*}{$\begin{array}{l}\text { Name } \\
(2)\end{array}$} & \multicolumn{4}{|c|}{ Observed } & \multicolumn{2}{|c|}{ Synthetic } & \multirow{3}{*}{$\begin{array}{c}\text { Prob. } \\
\text { worse } \\
\text { fit } \\
(9)\end{array}$} & \multirow[b]{3}{*}{$\begin{array}{c}\text { Elements Considered } \\
(10)\end{array}$} \\
\hline & & \multicolumn{3}{|c|}{$\log N(\mathrm{H})$} & \multirow[b]{2}{*}{$\begin{array}{l}F_{*} \\
(6)\end{array}$} & \multirow[b]{2}{*}{$\begin{array}{c}\log N(\mathrm{H}) \\
\quad(7)\end{array}$} & \multirow[b]{2}{*}{$\begin{array}{l}F_{*} \\
(8)\end{array}$} & & \\
\hline & & $\begin{array}{l}1.1 . \\
(3)\end{array}$ & $\begin{array}{l}\text { best } \\
(4)\end{array}$ & $\begin{array}{l}\text { u.l. } \\
(5)\end{array}$ & & & & & \\
\hline 144470 & $\mathrm{o}^{1} \mathrm{Sco}$ & 21.14 & 21.23 & 21.30 & $0.81 \pm 0.04$ & $21.36 \pm 0.08$ & $0.91 \pm 0.08$ & 0.938 & O Mg P Cl Ti Mn Fe \\
\hline 144965 & HD 144965 & 21.23 & 21.32 & 21.38 & $1.15 \pm 0.35$ & & $\cdots$ & $\ldots$ & $\mathrm{O} \mathrm{Kr}$ \\
\hline 145502 & $\nu \mathrm{Sco}$ & 20.87 & 21.13 & 21.28 & $0.80 \pm 0.11$ & $21.49 \pm 0.84$ & $0.98 \pm 0.44$ & 0.707 & $\mathrm{Mg} \mathrm{Cl} \mathrm{Ti}$ \\
\hline 147165 & $\sigma$ Sco & 21.16 & 21.36 & 21.51 & $0.76 \pm 0.06$ & $21.50 \pm 0.08$ & $0.87 \pm 0.07$ & 0.000 & O Mg P Cl Ti Cr Mn Zn Kr \\
\hline 147683 & V760 Sco & 21.25 & 21.41 & 21.51 & $0.56 \pm 0.47$ & $\cdots$ & $\cdots$ & $\cdots$ & $\mathrm{O} \mathrm{Kr}$ \\
\hline 147888 & $\rho$ Oph D & 21.55 & 21.74 & 21.84 & $0.88 \pm 0.06$ & $21.59 \pm 0.05$ & $0.71 \pm 0.06$ & 0.000 & C N O Mg Mn Fe Ni Ge Kr \\
\hline 147933 & $\rho \mathrm{Oph} \mathrm{A}$ & 21.62 & 21.70 & 21.78 & $1.09 \pm 0.08$ & $21.62 \pm 0.23$ & $1.00 \pm 0.26$ & 0.001 & O Mg Si P Cl Mn Ni Cu \\
\hline 148184 & $\chi \mathrm{Oph}$ & 21.17 & 21.31 & 21.41 & $0.96 \pm 0.09$ & $21.89 \pm 0.23$ & $1.57 \pm 0.26$ & 0.739 & $\mathrm{O} \mathrm{Mg} \mathrm{P} \mathrm{Cl} \mathrm{Mn} \mathrm{Cu}$ \\
\hline 148594 & HD 148594 & $\ldots$ & & 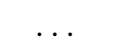 & & $21.31 \pm 0.07$ & $0.95 \pm 0.07$ & 0.382 & O Mg P Mn Ni Cu Ge Kr \\
\hline 148605 & 22 Sco & 20.28 & 20.69 & 20.86 & $0.53 \pm 0.39$ & $\ldots$ & $\ldots$ & $\ldots$ & $\mathrm{Cl} \mathrm{Mn}$ \\
\hline 149038 & $\mu$ Nor & 21.11 & 21.19 & 21.27 & $0.56 \pm 0.05$ & $\ldots$ & $\cdots$ & $\ldots$ & $\mathrm{Ti}$ \\
\hline $149757(-27)$ & $\zeta \mathrm{Oph}$ & $\ldots$ & $\cdots$ & $\cdots$ & $\ldots$ & $19.53 \pm 0.06$ & $0.11 \pm 0.05$ & 0.000 & O Mg Si P Ti Cr Mn Fe Ni Cu Zn \\
\hline$(-15)$ & & 21.10 & 21.15 & 21.20 & $1.05 \pm 0.02$ & $21.15 \pm 0.05$ & $1.04 \pm 0.05$ & 0.881 & C N O Mg Si Ti Cr Mn Fe Ni Cu Zn Ge Kr \\
\hline 149881 & V600 Her & 20.43 & 20.65 & 20.80 & $0.07 \pm 0.06$ & $20.52 \pm 0.08$ & $-0.03 \pm 0.06$ & 0.030 & Si Ti Cr Mn Fe Zn \\
\hline 151804 & V973 Sco & 21.07 & 21.19 & 21.29 & $0.57 \pm 0.08$ & $21.21 \pm 0.42$ & $0.57 \pm 0.37$ & 0.867 & $\mathrm{Mg} \mathrm{Cl} \mathrm{Mn} \mathrm{Fe} \mathrm{Ni} \mathrm{Cu}$ \\
\hline 151805 & HD 151805 & 21.36 & 21.41 & 21.46 & $0.83 \pm 0.36$ & $\ldots$ & $\ldots$ & $\ldots$ & $\mathrm{O} \mathrm{Kr}$ \\
\hline 151890 & $\mu^{1}$ Sco & $\ldots$ & 19.59 & 20.12 & $-0.03 \pm 3.47$ & $\ldots$ & $\ldots$ & $\ldots$ & $\mathrm{Mg} \mathrm{P} \mathrm{Cl} \mathrm{Mn} \mathrm{Fe}$ \\
\hline 152236 & $\zeta^{1} \mathrm{Sco}$ & 21.73 & 21.84 & 21.96 & $0.80 \pm 0.06$ & $\ldots$ & $\ldots$ & $\ldots$ & $\mathrm{Ti} \mathrm{Fe}$ \\
\hline 152590 & HD 152590 & 21.42 & 21.47 & 21.52 & $0.69 \pm 0.03$ & $21.46 \pm 0.06$ & $0.68 \pm 0.06$ & 0.669 & C O Mg Si P Mn Fe Cu Ge Kr \\
\hline 154368 & V1074 Sco & 21.54 & 21.59 & 21.64 & $0.52 \pm 0.07$ & $21.79 \pm 0.16$ & $0.69 \pm 0.16$ & 0.026 & C O Mg Si P Ti Mn Fe Ni \\
\hline 155806 & V1075 Sco & 21.00 & 21.14 & 21.24 & $0.62 \pm 0.07$ & $21.29 \pm 0.24$ & $0.73 \pm 0.25$ & 0.401 & $\mathrm{Mg} \mathrm{Cl} \mathrm{Mn} \mathrm{Fe} \mathrm{Ni} \mathrm{Cu}$ \\
\hline 157246 & $\gamma$ Ara & 20.61 & 20.71 & 20.78 & $0.46 \pm 0.03$ & $20.75 \pm 0.05$ & $0.53 \pm 0.05$ & 0.015 & $\mathrm{O}$ Mg P Cl Ti Mn Fe \\
\hline 157857 & HD 157857 & 21.38 & 21.44 & 21.51 & $0.62 \pm 0.04$ & $21.47 \pm 0.07$ & $0.65 \pm 0.07$ & 0.591 & $\mathrm{O} \mathrm{Mg} P \mathrm{Mn} \mathrm{Ni} \mathrm{Cu} \mathrm{Ge}$ \\
\hline 158926 & $\lambda \mathrm{Sco}$ & 19.20 & 19.23 & 19.26 & $0.31 \pm 0.02$ & $19.13 \pm 0.04$ & $0.28 \pm 0.04$ & 0.000 & N O Si P Cl Cr Fe Zn \\
\hline 160578 & $\kappa$ Sco & 20.03 & 20.22 & 20.34 & $0.50 \pm 0.07$ & $20.27 \pm 0.09$ & $0.52 \pm 0.09$ & 0.000 & $\mathrm{~N} \mathrm{Mg} \mathrm{P} \mathrm{Cl} \mathrm{Mn} \mathrm{Fe}$ \\
\hline 164284 & $66 \mathrm{Oph}$ & 20.23 & 20.75 & 20.90 & $0.89 \pm 0.18$ & $21.74 \pm 0.83$ & $1.88 \pm 0.88$ & 0.263 & $\mathrm{Mg} \mathrm{P} \mathrm{Cl} \mathrm{Mn} \mathrm{Ni} \mathrm{Cu}$ \\
\hline
\end{tabular}


Table 5-Continued

\begin{tabular}{|c|c|c|c|c|c|c|c|c|c|}
\hline \multirow[b]{3}{*}{$\begin{array}{r}\mathrm{HD} \\
(1)\end{array}$} & \multirow[b]{3}{*}{$\begin{array}{l}\text { Name } \\
(2)\end{array}$} & \multicolumn{4}{|c|}{ Observed } & \multicolumn{2}{|c|}{ Synthetic } & \multirow{3}{*}{$\begin{array}{c}\text { Prob. } \\
\text { worse } \\
\text { fit } \\
(9)\end{array}$} & \multirow[b]{3}{*}{$\begin{array}{c}\text { Elements Considered } \\
\qquad(10)\end{array}$} \\
\hline & & \multicolumn{3}{|c|}{$\log N(\mathrm{H})$} & \multirow[b]{2}{*}{$\begin{array}{l}F_{*} \\
(6)\end{array}$} & \multirow[b]{2}{*}{$\begin{array}{c}\log N(\mathrm{H}) \\
\quad(7)\end{array}$} & \multirow[b]{2}{*}{$\begin{array}{l}F_{*} \\
(8)\end{array}$} & & \\
\hline & & $\begin{array}{l}\text { l.l. } \\
(3)\end{array}$ & $\begin{array}{c}\text { best } \\
(4)\end{array}$ & $\begin{array}{l}\text { u.l. } \\
(5)\end{array}$ & & & & & \\
\hline 165024 & $\theta$ Ara & 20.74 & 20.84 & 20.91 & $0.56 \pm 0.03$ & $20.80 \pm 0.09$ & $0.53 \pm 0.07$ & 1.000 & $\mathrm{Mg} \mathrm{P} \mathrm{Cl} \mathrm{Ti} \mathrm{Mn} \mathrm{Fe}$ \\
\hline 165246 & HD 165246 & 20.70 & 21.46 & 21.52 & $0.77 \pm 1.39$ & $\cdots$ & $\ldots$ & $\ldots$ & $\mathrm{O} \mathrm{Kr}$ \\
\hline 165955 & HD 165955 & 21.04 & 21.10 & 21.16 & $0.42 \pm 0.04$ & $21.04 \pm 0.09$ & $0.38 \pm 0.10$ & 0.460 & $\mathrm{O} \mathrm{Mg} \mathrm{Mn} \mathrm{Ni} \mathrm{Cu} \mathrm{Ge}$ \\
\hline 167264 & $15 \mathrm{Sgr}$ & 21.13 & 21.25 & 21.34 & $0.68 \pm 0.16$ & $21.66 \pm 0.21$ & $1.17 \pm 0.28$ & 0.796 & $\mathrm{O} \mathrm{Mg} \mathrm{Mn}$ \\
\hline 167756 & HD 167756 & $\ldots$ & $\ldots$ & $\ldots$ & $\ldots$ & $20.54 \pm 0.08$ & $0.12 \pm 0.08$ & 0.061 & Mg Si Cr Zn \\
\hline 167971 & MY Ser & 21.53 & 21.73 & 21.97 & $0.70 \pm 0.23$ & $\ldots$ & $\ldots$ & $\cdots$ & $\mathrm{Fe}$ \\
\hline 168076 & HD 168076 & 21.55 & 21.73 & 21.93 & $0.68 \pm 0.17$ & $\cdots$ & $\cdots$ & $\cdots$ & $\mathrm{Fe}$ \\
\hline 168941 & HD 168941 & 21.11 & 21.19 & 21.62 & $0.42 \pm 0.17$ & $\cdots$ & $\cdots$ & $\cdots$ & $\mathrm{Mg} \mathrm{Fe}$ \\
\hline 170740 & HD 170740 & 21.30 & 21.40 & 21.50 & $1.02 \pm 0.11$ & $\cdots$ & $\cdots$ & $\cdots$ & $\mathrm{Fe}$ \\
\hline 175360 & HD 175360 & $\ldots$ & $\ldots$ & $\cdots$ & $\ldots$ & $21.00 \pm 0.07$ & $0.70 \pm 0.08$ & 0.463 & $\mathrm{O} \mathrm{Mg} \mathrm{P} \mathrm{Mn} \mathrm{Ni} \mathrm{Cu} \mathrm{Ge} \mathrm{Kr}$ \\
\hline 177989 & HD 177989 & 21.01 & 21.08 & 21.15 & $0.55 \pm 0.05$ & $21.19 \pm 0.06$ & $0.67 \pm 0.07$ & 0.623 & $\mathrm{O} \mathrm{Mg} \mathrm{P} \mathrm{Fe} \mathrm{Kr}$ \\
\hline 179406 & $20 \mathrm{Aql}$ & $\cdots$ & $\cdots$ & $\cdots$ & $\cdots$ & $21.09 \pm 0.12$ & $0.14 \pm 0.08$ & 0.000 & N Ti Fe \\
\hline 179407 & HD 179407 & 21.12 & 21.21 & 21.30 & $0.35 \pm 0.05$ & $\cdots$ & $\cdots$ & $\cdots$ & $\mathrm{Ti}$ \\
\hline 184915 & $\kappa \mathrm{Aql}$ & 20.98 & 21.05 & 21.13 & $0.88 \pm 0.05$ & $21.23 \pm 0.29$ & $0.97 \pm 0.16$ & 0.869 & Mg Cl Ti Mn \\
\hline 185418 & HD 185418 & 21.34 & 21.41 & 21.49 & $0.79 \pm 0.03$ & $21.61 \pm 0.06$ & $0.98 \pm 0.07$ & 0.046 & N O Mg P Mn Fe $\mathrm{Ni} \mathrm{Cu} \mathrm{Ge} \mathrm{Kr}$ \\
\hline 188209 & HD 188209 & 20.88 & 21.00 & 21.10 & $0.66 \pm 0.12$ & . & & $\ldots$ & $\mathrm{Mg} \mathrm{P} \mathrm{Mn}$ \\
\hline 190918 & V1676 Cyg & 21.35 & 21.40 & 21.46 & $0.46 \pm 0.03$ & $21.43 \pm 0.09$ & $0.48 \pm 0.08$ & 0.531 & $\mathrm{O} \mathrm{Mg} \mathrm{Mn} \mathrm{Ni} \mathrm{Cu}$ \\
\hline 191877 & HD 191877 & 21.04 & 21.12 & 21.21 & $0.39 \pm 0.04$ & $\cdots$ & $\cdots$ & $\cdots$ & $\mathrm{N} \mathrm{Ti}$ \\
\hline 192035 & RX Cyg & 21.32 & 21.38 & 21.45 & $0.76 \pm 0.04$ & $21.39 \pm 0.07$ & $0.78 \pm 0.08$ & 0.130 & $\mathrm{O} \mathrm{Mg} \mathrm{Mn} \mathrm{Ni} \mathrm{Cu} \mathrm{Ge}$ \\
\hline 192639 & HD 192639 & 21.41 & 21.48 & 21.55 & $0.64 \pm 0.04$ & $21.54 \pm 0.07$ & $0.70 \pm 0.07$ & 0.906 & $\mathrm{~N} O \mathrm{Og} \mathrm{Mn} \mathrm{Fe} \mathrm{Ni} \mathrm{Cu}$ \\
\hline 195965 & HD 195965 & 21.11 & 21.13 & 21.16 & $0.52 \pm 0.02$ & $21.06 \pm 0.05$ & $0.48 \pm 0.04$ & 0.297 & N O Mg Ti \\
\hline 198478 & $55 \mathrm{Cyg}$ & 21.44 & 21.55 & 21.66 & $0.81 \pm 0.05$ & $21.52 \pm 0.07$ & $0.80 \pm 0.08$ & 0.129 & $\mathrm{O} \mathrm{Mg} \mathrm{P}$ Mn $\mathrm{Ni} \mathrm{Cu} \mathrm{Ge} \mathrm{Kr}$ \\
\hline 198781 & HD 198781 & 21.09 & 21.15 & 21.21 & $0.59 \pm 0.03$ & $21.07 \pm 0.08$ & $0.53 \pm 0.08$ & 0.017 & $\mathrm{O}$ Mg P Mn Ni Ge \\
\hline 199579 & HD 199579 & 21.18 & 21.25 & 21.32 & $0.76 \pm 0.27$ & $\cdots$ & $\cdots$ & $\cdots$ & $\mathrm{N} \mathrm{Fe}$ \\
\hline 200120 & $59 \mathrm{Cyg}$ & 19.54 & $\cdots$ & 20.20 & $\cdots$ & $20.12 \pm 0.22$ & $0.27 \pm 0.14$ & 0.489 & Mg P Cl Ti Mn Fe \\
\hline 201345 & HD 201345 & 20.92 & 21.00 & 21.09 & $0.34 \pm 0.04$ & $20.89 \pm 0.07$ & $0.24 \pm 0.07$ & 0.220 & $\mathrm{O} \mathrm{Mg} P \mathrm{Mn} \mathrm{Ni} \mathrm{Cu} \mathrm{Ge}$ \\
\hline
\end{tabular}


Table 5-Continued

\begin{tabular}{|c|c|c|c|c|c|c|c|c|c|}
\hline \multirow[b]{3}{*}{$\begin{array}{l}\mathrm{HD} \\
(1)\end{array}$} & \multirow[b]{3}{*}{$\begin{array}{c}\text { Name } \\
(2)\end{array}$} & \multicolumn{4}{|c|}{ Observed } & \multicolumn{2}{|c|}{ Synthetic } & \multirow{3}{*}{$\begin{array}{c}\text { Prob. } \\
\text { worse } \\
\text { fit } \\
(9)\end{array}$} & \multirow[b]{3}{*}{$\begin{array}{l}\text { Elements Considered } \\
\qquad(10)\end{array}$} \\
\hline & & \multicolumn{3}{|c|}{$\log N(\mathrm{H})$} & \multirow[b]{2}{*}{$\begin{array}{l}F_{*} \\
(6)\end{array}$} & \multirow[b]{2}{*}{$\begin{array}{c}\log N(\mathrm{H}) \\
\quad(7)\end{array}$} & \multirow[b]{2}{*}{$\begin{array}{l}F_{*} \\
(8)\end{array}$} & & \\
\hline & & $\begin{array}{l}.1 . \\
(3)\end{array}$ & $\begin{array}{c}\text { best } \\
(4)\end{array}$ & $\begin{array}{l}\text { u.l. } \\
(5)\end{array}$ & & & & & \\
\hline 202347 & HD 202347 & 20.81 & 20.94 & 21.02 & $0.56 \pm 0.06$ & $20.93 \pm 0.09$ & $0.56 \pm 0.09$ & 0.059 & $\mathrm{O} \mathrm{Mg} \mathrm{P} \mathrm{Fe}$ \\
\hline 202904 & $v \mathrm{Cyg}$ & 19.45 & $\cdots$ & 20.67 & $\cdots$ & $20.24 \pm 0.14$ & $0.39 \pm 0.11$ & 0.431 & Mg P Cl Ti Mn Fe \\
\hline 203064 & $68 \mathrm{Cyg}$ & 21.04 & 21.15 & 21.24 & $0.68 \pm 0.20$ & $\ldots$ & & ... & $\mathrm{Mg} \mathrm{Cl} \mathrm{Mn}$ \\
\hline 203374 & HD 203374 & 21.22 & 21.33 & 21.40 & $0.56 \pm 0.06$ & $21.43 \pm 0.07$ & $0.66 \pm 0.07$ & 0.181 & $\mathrm{O} \mathrm{Mg} \mathrm{Fe} \mathrm{Kr}$ \\
\hline 203532 & HD 203532 & 20.91 & $\cdots$ & 21.26 & $\cdots$ & $21.37 \pm 0.08$ & $1.14 \pm 0.09$ & 0.907 & $\mathrm{O} \mathrm{Mg} \mathrm{P} \mathrm{Mn} \mathrm{Ni} \mathrm{Cu} \mathrm{Ge} \mathrm{Kr}$ \\
\hline 203938 & HD 203938 & 21.61 & 21.70 & 21.80 & $0.99 \pm 0.64$ & $\cdots$ & $\cdots$ & $\ldots$ & $\mathrm{Fe}$ \\
\hline 206267 & HD 206267 & 21.45 & 21.54 & 21.63 & $0.87 \pm 0.07$ & $21.60 \pm 0.09$ & $0.92 \pm 0.10$ & 0.810 & $\mathrm{~N} \mathrm{O} \mathrm{Mg} \mathrm{Fe} \mathrm{Kr}$ \\
\hline 206773 & HD 206773 & 21.20 & 21.25 & 21.30 & $0.53 \pm 0.02$ & $21.21 \pm 0.05$ & $0.51 \pm 0.04$ & 0.105 & O Mg P Ti Mn Ni Ge \\
\hline 207198 & HD 207198 & 21.63 & 21.68 & 21.73 & $0.90 \pm 0.03$ & $21.57 \pm 0.06$ & $0.81 \pm 0.07$ & 0.864 & C N O Mg Si Mn Fe Ni Ge Kr \\
\hline 207308 & HD 207308 & 21.38 & 21.44 & 21.50 & $0.80 \pm 0.06$ & $\ldots$ & $\ldots$ & $\ldots$ & $\mathrm{Mg} \mathrm{Fe}$ \\
\hline 207538 & HD 207538 & 21.51 & 21.58 & 21.66 & $0.84 \pm 0.07$ & $21.81 \pm 0.09$ & $1.09 \pm 0.11$ & 0.869 & $\mathrm{O} \mathrm{Mg} \mathrm{Fe}$ \\
\hline 208440 & HD 208440 & 21.23 & 21.31 & 21.38 & $0.61 \pm 0.04$ & $21.37 \pm 0.07$ & $0.68 \pm 0.08$ & 0.989 & $\mathrm{O} \mathrm{Mg} \mathrm{P} \mathrm{Mn} \mathrm{Ni} \mathrm{Cu} \mathrm{Ge} \mathrm{Kr}$ \\
\hline 209339 & HD 209339 & 21.20 & 21.26 & 21.32 & $0.58 \pm 0.04$ & $21.35 \pm 0.07$ & $0.66 \pm 0.07$ & 0.951 & $\mathrm{O} \mathrm{Mg} \mathrm{Fe} \mathrm{Kr}$ \\
\hline 209975 & 19 Сер & 21.06 & 21.18 & 21.29 & $0.57 \pm 0.26$ & $\ldots$ & ... & $\ldots$ & $\mathrm{Cl} \mathrm{Mn}$ \\
\hline 210809 & HD 210809 & 21.25 & 21.33 & 21.42 & $0.41 \pm 0.04$ & $21.27 \pm 0.07$ & $0.36 \pm 0.07$ & 0.359 & $\mathrm{O} \mathrm{Mg} \mathrm{Mn} \mathrm{Ni} \mathrm{Cu} \mathrm{Ge}$ \\
\hline 210839 & $\lambda$ Cep & 21.39 & 21.45 & 21.51 & $0.66 \pm 0.03$ & $21.44 \pm 0.05$ & $0.67 \pm 0.05$ & 0.035 & N O Mg Ti Fe \\
\hline 212571 & $\pi \mathrm{Aqr}$ & $\cdots$ & $\cdots$ & $\cdots$ & $\cdots$ & $20.64 \pm 0.11$ & $0.52 \pm 0.11$ & 0.045 & $\mathrm{Cr} \mathrm{Cu} \mathrm{Zn} \mathrm{Ge}$ \\
\hline 212791 & V408 Lac & 20.88 & 21.12 & 21.24 & $0.57 \pm 0.08$ & $21.13 \pm 0.08$ & $0.61 \pm 0.09$ & 0.253 & $\mathrm{O} \mathrm{Mg} \mathrm{P} \mathrm{Mn} \mathrm{Ni} \mathrm{Cu} \mathrm{Ge}$ \\
\hline 214080 & HD 214080 & 20.38 & 20.61 & 20.77 & $0.27 \pm 0.10$ & $20.06 \pm 0.55$ & $-0.03 \pm 0.20$ & 0.629 & Mg Ti Mn \\
\hline 214680 & $10 \mathrm{Lac}$ & 20.58 & 20.73 & 20.83 & $0.50 \pm 0.06$ & $\ldots$ & $\cdots$ & $\ldots$ & $\mathrm{P} \mathrm{Ti}$ \\
\hline 214993 & $12 \mathrm{Lac}$ & 20.68 & 20.82 & 20.94 & $0.68 \pm 0.10$ & $\ldots$ & $\ldots$ & $\cdots$ & $\mathrm{Mg} \mathrm{P} \mathrm{Cl} \mathrm{Mn}$ \\
\hline $215733(-93)$ & HD 215733 & 16.91 & 17.39 & 17.67 & $-0.27 \pm 0.19$ & $\cdots$ & $\cdots$ & $\cdots$ & $\mathrm{Si} \mathrm{Fe}$ \\
\hline$(-83)$ & & 17.60 & 18.40 & 18.59 & $0.99 \pm 0.30$ & $\ldots$ & $\ldots$ & $\cdots$ & $\mathrm{Si} \mathrm{Fe}$ \\
\hline$(-61)$ & & 18.91 & 19.44 & 19.60 & $1.06 \pm 0.21$ & $\cdots$ & $\cdots$ & $\cdots$ & Si Mn Fe \\
\hline$(-59)$ & & 18.75 & 18.95 & 19.29 & $-0.11 \pm 0.10$ & $18.42 \pm 0.15$ & $-0.62 \pm 0.13$ & 0.193 & Mg Si Cr Mn Fe Zn \\
\hline$(-54)$ & & 19.09 & 19.63 & 19.92 & $0.54 \pm 0.15$ & $18.63 \pm 0.15$ & $-0.40 \pm 0.13$ & 0.013 & Mg Si Cr Mn Fe Zn \\
\hline
\end{tabular}


Table 5-Continued

\begin{tabular}{|c|c|c|c|c|c|c|c|c|c|}
\hline \multirow[b]{3}{*}{$\begin{array}{l}\mathrm{HD} \\
(1)\end{array}$} & \multirow[b]{3}{*}{$\begin{array}{l}\text { Name } \\
(2)\end{array}$} & \multicolumn{4}{|c|}{ Observed } & \multicolumn{2}{|c|}{ Synthetic } & \multirow{3}{*}{$\begin{array}{c}\text { Prob. } \\
\text { worse } \\
\text { fit } \\
(9)\end{array}$} & \multirow[b]{3}{*}{$\begin{array}{l}\text { Elements Considered } \\
\qquad(10)\end{array}$} \\
\hline & & \multicolumn{3}{|c|}{$\log N(\mathrm{H})$} & \multirow[b]{2}{*}{$\begin{array}{l}F_{*} \\
(6)\end{array}$} & \multirow[b]{2}{*}{$\begin{array}{l}\log N(\mathrm{H}) \\
\quad(7)\end{array}$} & \multirow[b]{2}{*}{$\begin{array}{l}F_{*} \\
(8)\end{array}$} & & \\
\hline & & $\begin{array}{l}1.1 . \\
(3)\end{array}$ & $\begin{array}{l}\text { best } \\
(4)\end{array}$ & $\begin{array}{l}\text { u.l. } \\
(5)\end{array}$ & & & & & \\
\hline$(-47)$ & & $\ldots$ & 18.94 & 19.73 & $\ldots$ & $18.85 \pm 0.16$ & $-0.39 \pm 0.14$ & 0.199 & Mg Si Cr Mn Fe Zn \\
\hline$(-45)$ & & 17.37 & 18.06 & 18.42 & $-0.40 \pm 0.28$ & $\ldots$ & $\ldots$ & $\ldots$ & Mg Si Mn Fe \\
\hline$(-42)$ & & 17.23 & 18.53 & 18.94 & $-0.16 \pm 0.31$ & $18.08 \pm 0.33$ & $-0.72 \pm 0.29$ & 0.336 & Mg Si Cr Mn Fe Zn \\
\hline$(-40)$ & & 18.06 & 18.81 & 19.27 & $0.18 \pm 0.24$ & $18.09 \pm 0.57$ & $-0.48 \pm 0.48$ & 0.146 & $\mathrm{Si} \mathrm{Cr} \mathrm{Mn} \mathrm{Fe}$ \\
\hline$(-32)$ & & 19.50 & 19.64 & 19.78 & $0.25 \pm 0.09$ & $18.99 \pm 0.46$ & $-0.40 \pm 0.41$ & 0.057 & Mg Si Cr Mn Fe Zn \\
\hline$(-31)$ & & $\cdots$ & $\cdots$ & $\ldots$ & $\cdots$ & $18.14 \pm 0.35$ & $-0.76 \pm 0.29$ & 0.364 & Mg Si Cr Mn Fe Zn \\
\hline$(-28)$ & & 18.85 & 18.91 & 19.06 & $-0.18 \pm 0.07$ & $19.00 \pm 0.20$ & $-0.12 \pm 0.19$ & 0.643 & Mg Si Cr Mn Fe Zn \\
\hline$(-26)$ & & 18.99 & 19.11 & 19.23 & $-0.12 \pm 0.07$ & $18.83 \pm 0.21$ & $-0.39 \pm 0.20$ & 0.361 & Mg Si Cr Mn Fe Zn \\
\hline$(-23)$ & & 19.21 & 19.25 & 19.33 & $0.24 \pm 0.08$ & $19.07 \pm 0.41$ & $0.06 \pm 0.37$ & 0.389 & Mg Si Cr Mn Fe Zn \\
\hline$(-21)$ & & 19.32 & 19.37 & 19.46 & $0.24 \pm 0.05$ & $19.27 \pm 0.16$ & $0.15 \pm 0.17$ & 0.289 & Mg Si Cr Mn Fe Zn \\
\hline$(-19)$ & & $\cdots$ & $\cdots$ & $\cdots$ & $\cdots$ & $19.22 \pm 0.41$ & $0.27 \pm 0.40$ & 0.989 & $\mathrm{Si} \mathrm{Cr} \mathrm{Mn} \mathrm{Fe}$ \\
\hline$(-16)$ & & 20.08 & 20.11 & 20.18 & $0.93 \pm 0.05$ & $20.02 \pm 0.21$ & $0.83 \pm 0.22$ & 0.013 & Mg Si Cr Mn Fe Zn \\
\hline$(-11)$ & & 19.57 & 19.60 & 19.67 & $-0.01 \pm 0.07$ & $19.84 \pm 0.21$ & $0.27 \pm 0.23$ & 0.716 & Mg Si Cr Zn \\
\hline$(-9)$ & & 20.01 & 20.07 & 20.17 & $0.08 \pm 0.04$ & $20.52 \pm 0.10$ & $0.45 \pm 0.10$ & 0.000 & Mg Si Cr Mn Fe Zn \\
\hline$(-5)$ & & 19.50 & 19.58 & 19.70 & $0.77 \pm 0.18$ & $19.17 \pm 0.53$ & $0.34 \pm 0.55$ & 0.621 & Mg Si Cr Zn \\
\hline$(+1)$ & & 19.68 & 19.71 & 19.78 & $0.90 \pm 0.05$ & $18.90 \pm 0.42$ & $0.18 \pm 0.34$ & 0.251 & $\mathrm{Mg}$ Si Cr Mn Fe \\
\hline$(+15)$ & & 18.35 & 18.42 & 18.53 & $0.96 \pm 0.08$ & $\cdots$ & $\cdots$ & $\cdots$ & $\mathrm{Si} \mathrm{Fe}$ \\
\hline (total) & & $\cdots$ & $\cdots$ & $\cdots$ & $\cdots$ & $20.41 \pm 0.17$ & $-0.05 \pm 0.16$ & 0.589 & Mg Si Cr Mn Fe Zn \\
\hline 218376 & 1 Cas & 20.95 & 21.07 & 21.17 & $0.60 \pm 0.06$ & $20.66 \pm 0.27$ & $0.37 \pm 0.15$ & 0.602 & $\mathrm{Mg} \mathrm{Cl} \mathrm{Ti} \mathrm{Mn}$ \\
\hline 218915 & HD 218915 & 21.22 & 21.25 & 21.29 & $0.70 \pm 0.08$ & $21.20 \pm 0.06$ & $0.60 \pm 0.12$ & 0.809 & $\mathrm{NOP}$ \\
\hline 219188 & HD 219188 & 20.66 & 20.88 & 21.01 & $1.24 \pm 0.57$ & $20.99 \pm 0.14$ & $1.77 \pm 0.62$ & 0.268 & $\mathrm{NO} \mathrm{Mn}$ \\
\hline 220057 & HD 220057 & 21.02 & 21.16 & 21.26 & $0.75 \pm 0.05$ & $21.21 \pm 0.06$ & $0.83 \pm 0.06$ & 0.131 & N O Mg P Mn Ni Cu Ge Kr \\
\hline 224151 & V373 Cas & 21.40 & 21.46 & 21.52 & $0.46 \pm 0.04$ & $21.40 \pm 0.04$ & $0.42 \pm 0.05$ & 0.666 & $\mathrm{~N} \mathrm{O} \mathrm{Mg} \mathrm{P} \mathrm{Fe} \mathrm{Kr}$ \\
\hline 224572 & $\sigma$ Cas & 20.87 & 20.98 & 21.07 & $0.76 \pm 0.07$ & $21.09 \pm 0.39$ & $0.86 \pm 0.40$ & 0.559 & $\mathrm{Mg} \mathrm{P} \mathrm{Cl} \mathrm{Mn} \mathrm{Fe} \mathrm{Cu}$ \\
\hline 232522 & HDE 232522 & 21.14 & 21.19 & 21.24 & $0.44 \pm 0.03$ & $21.07 \pm 0.08$ & $0.33 \pm 0.08$ & 0.797 & $\mathrm{O} \mathrm{Mg} \mathrm{Mn} \mathrm{Ni} \mathrm{Ge}$ \\
\hline 303308 & HDE 303308 & 21.41 & 21.48 & 21.54 & $0.38 \pm 0.04$ & $21.37 \pm 0.05$ & $0.30 \pm 0.05$ & 0.169 & $\mathrm{O} \mathrm{Mg} \mathrm{Ti} \mathrm{Fe} \mathrm{Kr}$ \\
\hline
\end{tabular}


Table 5-Continued

\begin{tabular}{|c|c|c|c|c|c|c|c|c|c|}
\hline \multirow[b]{3}{*}{$\begin{array}{l}\mathrm{HD} \\
(1)\end{array}$} & \multirow[b]{3}{*}{$\begin{array}{l}\text { Name } \\
(2)\end{array}$} & \multicolumn{4}{|c|}{ Observed } & \multicolumn{2}{|c|}{ Synthetic } & \multirow{3}{*}{$\begin{array}{c}\text { Prob. } \\
\text { worse } \\
\text { fit } \\
(9)\end{array}$} & \multirow[b]{3}{*}{$\begin{array}{l}\text { Elements Considered } \\
\qquad(10)\end{array}$} \\
\hline & & \multicolumn{3}{|c|}{$\log N(\mathrm{H})$} & \multirow[b]{2}{*}{$\begin{array}{l}F_{*} \\
(6)\end{array}$} & \multirow[b]{2}{*}{$\begin{array}{c}\log N(\mathrm{H}) \\
\quad(7)\end{array}$} & \multirow[b]{2}{*}{$\begin{array}{l}F_{*} \\
(8)\end{array}$} & & \\
\hline & & $\begin{array}{l}1.1 . \\
(3)\end{array}$ & $\begin{array}{l}\text { best } \\
(4)\end{array}$ & $\begin{array}{l}\text { u.l. } \\
(5)\end{array}$ & & & & & \\
\hline \multirow[t]{5}{*}{308813} & HDE 308813 & 21.21 & 21.29 & 21.36 & $0.49 \pm 0.04$ & $21.22 \pm 0.08$ & $0.43 \pm 0.08$ & 0.679 & $\mathrm{O} \mathrm{Mg} \mathrm{Mn} \mathrm{Ni} \mathrm{Cu} \mathrm{Ge}$ \\
\hline & $\mathrm{BD}+354258$ & 21.20 & 21.30 & 21.39 & $0.40 \pm 0.08$ & $\cdots$ & $\cdots$ & $\cdots$ & $\mathrm{Mg} \mathrm{Fe}$ \\
\hline & $\mathrm{BD}+532820$ & 21.31 & 21.39 & 21.47 & $0.43 \pm 0.05$ & $21.23 \pm 0.10$ & $0.27 \pm 0.09$ & 0.204 & $\mathrm{O} \mathrm{Mn} \mathrm{Ni} \mathrm{Cu} \mathrm{Ge}$ \\
\hline & CPD -59 2603 & 21.11 & 21.20 & 21.30 & $0.17 \pm 0.06$ & $\ldots$ & $\ldots$ & $\ldots$ & $\mathrm{Mg} \mathrm{Fe}$ \\
\hline & CPD -69 1743 & 21.08 & 21.16 & 21.24 & $0.42 \pm 0.05$ & $21.02 \pm 0.09$ & $0.30 \pm 0.09$ & 0.113 & $\mathrm{O} \mathrm{Mn} \mathrm{Ni} \mathrm{Cu} \mathrm{Ge}$ \\
\hline
\end{tabular}


First, as the top panel of Fig. 9] shows for the star $\xi$ Per, the poor fit may simply be due to the fact that many of the observational errors for the column densities are remarkably small (Cardelli et al. 1991), which results in a large value for $\chi^{2}$ for the fit even when the overall trend seems to be reasonably well defined. Here, there is a moderate but tolerable disagreement between the intercepts and slopes of two lines, one representing the trend that conforms to $\log N(\mathrm{H})_{\mathrm{obs}}=21.29 \pm 0.08$ and $F_{*}=0.83 \pm 0.02$ derived using Eq. 4 (solid gray line) and the other arising from the best-fit solution to Eq. 24a (dashed gray line), yielding $\log N(\mathrm{H})_{\text {syn. }}=21.46 \pm 0.06$ and $F_{* \text { syn. }}=0.95 \pm 0.05$. (It is important to note that the quoted uncertainties in the results are based on only the measurement errors, with no reference to how much the points scatter about the fit line. If one repeats the analysis using just the measurements with no errors and assumes that the model is perfectly correct, the anticipated uncertainties in $\log N(\mathrm{H})_{\text {syn. }}$ and $F_{* \text { syn. }}$ increase to 0.14 and 0.12 , respectively.)

A second reason for a poor outcome is that there may be fundamental problems arising from the fact that different regions with markedly different depletion levels are being grouped together. For example, the line of sight toward the star HD 116852 in the lower halo of the Galaxy traverses regions at different radial velocities that have markedly different relative abundances (Sembach \& Savage 1996). When such a mixture is considered as a whole, the basic premise that the relative abundances should obey the simple relation given by Eq. 10 starts to break down. It is clear from the lower panel of Fig. 9 that the disagreements between the two variable pairs is far worse: $\log N(\mathrm{H})_{\text {obs }}=21.02 \pm 0.08$ vs. $\log N(\mathrm{H})_{\text {syn. }}=20.71 \pm 0.05$ (i.e., a factor of 2 in column density, which is well outside the quoted errors) and $F_{*}=0.36 \pm 0.04$ from Eq. 4 vs. $F_{* \text { syn. }}=0.07 \pm 0.05$ from Eq. 24a, The inset in the figure showing the apparent optical depths $\tau_{\mathrm{a}}$ as a function of velocity for three species shows that the small changes in depletion for the lightly depleted elements $\mathrm{O}$ and $\mathrm{Mg}$ contrast sharply with strong changes in the usually heavily depleted Ni. If we could actually see a velocity profile for $\mathrm{H}$, it would probably not look much different than the one for $\mathrm{O}$. The broad peaks seen in the Ni profile centered at $v=-10$ and $-35 \mathrm{~km} \mathrm{~s}^{-1}$ probably have a low depletion and an almost negligible amount of hydrogen associated with them, but they are conspicuous because they are seen alongside the component centered on $v=+10 \mathrm{~km} \mathrm{~s}^{-1}$ where the Ni is highly depleted. If we repeat the analysis using just the information derived from the elements $\mathrm{O}, \mathrm{Cu}, \mathrm{Zn}, \mathrm{Ge}$ and $\mathrm{Kr}$, the $y$-intercept corresponds to $\log N(\mathrm{H})_{\text {syn. }}=21.01 \pm 0.09$ (dotted line), which almost exactly (fortuitously) equals the measured value. With the analysis restricted to this subset of elements with only light to moderate depletions, which gives greater emphasis to the velocity component that has the most hydrogen, the probability of a worse fit comes out at a satisfactory value of 0.674 .

The two examples highlighted in the previous two paragraphs were carefully chosen to demonstrate two principal reasons for finding probability of worse fit outcomes at extremely low values (in these cases, lower than 0.001, as can be seen for the entries in column (9) of Table 5 for the respective stars). Other reasons for poor fits may include errors in the column densities that are well outside the quoted uncertainty limits (i.e., mistakes or poor judgment on the part of the observer) or perhaps some unusual effects that cause deviations in the element abundances so that they no longer conform to the simplified, general depletion trends among the elements being described here. 


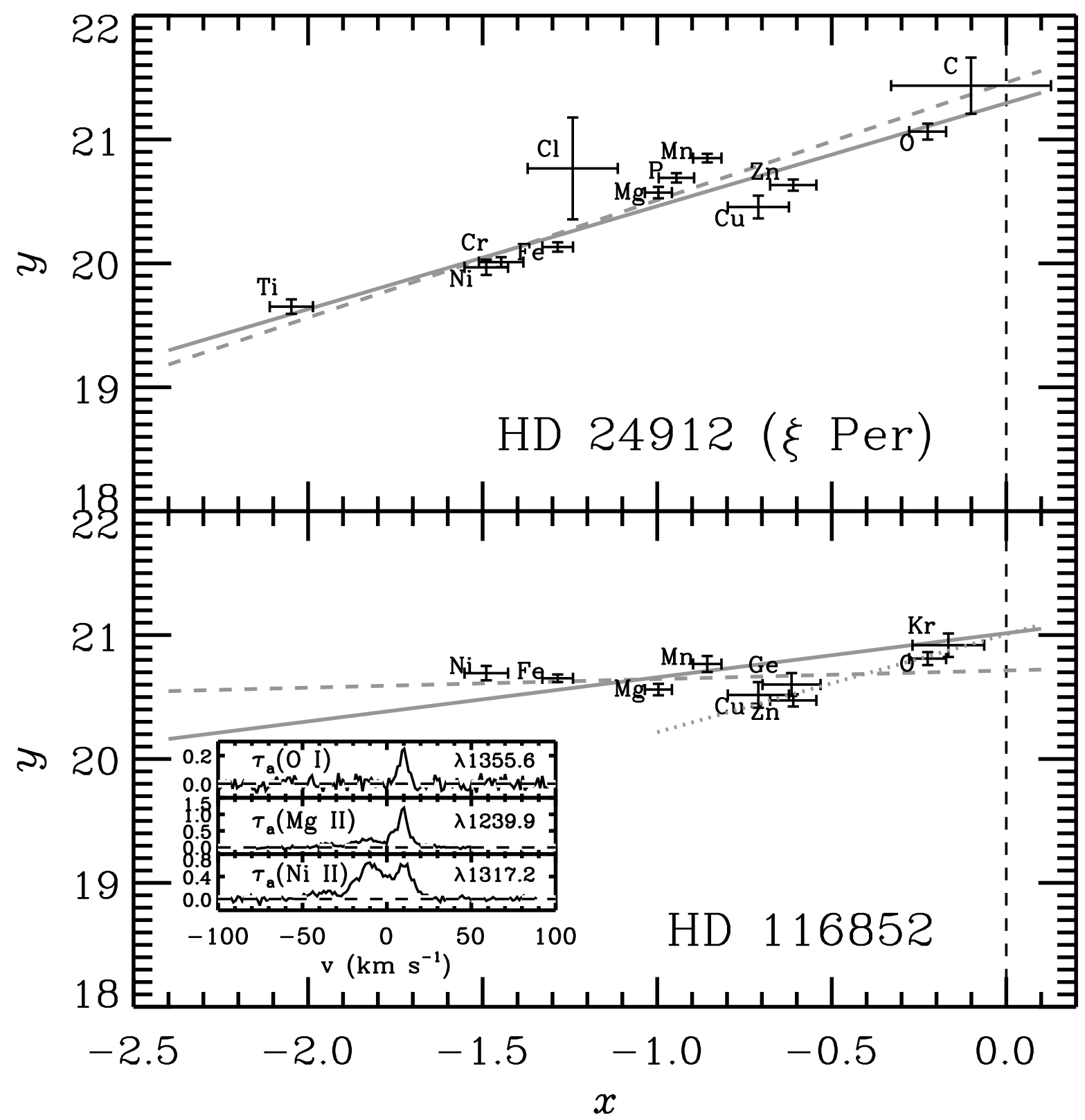

Fig. 9. - Illustrations of the fits obtained from the use of Eq. 24a, which can be used to estimate $N(\mathrm{H})$ and $F_{*}$ when $N(\mathrm{H})$ is not observed. The dashed gray line in each case shows the best fit: its slope yields $F_{*}$ and the $y$-intercept at $x=0$ yields $N(\mathrm{H})$. The solid gray line shows the slope and intercept obtained through from the observed value of $N(\mathrm{H})$ and the value of $F_{*}$ derived using the formulae given in 3.1. For HD 116852 (lower panel), a fit (dotted gray line) is also shown for just the elements $\mathrm{O}, \mathrm{Cu}, \mathrm{Zn}, \mathrm{Ge}$ and $\mathrm{Kr}$. The inset in this panel shows the shapes of the apparent optical depths vs. heliocentric radial velocity for the elements O I, Mg II, and Ni II. The two sight lines depicted in this figure highlight some special considerations that resulted in the poor fits discussed in the text. 


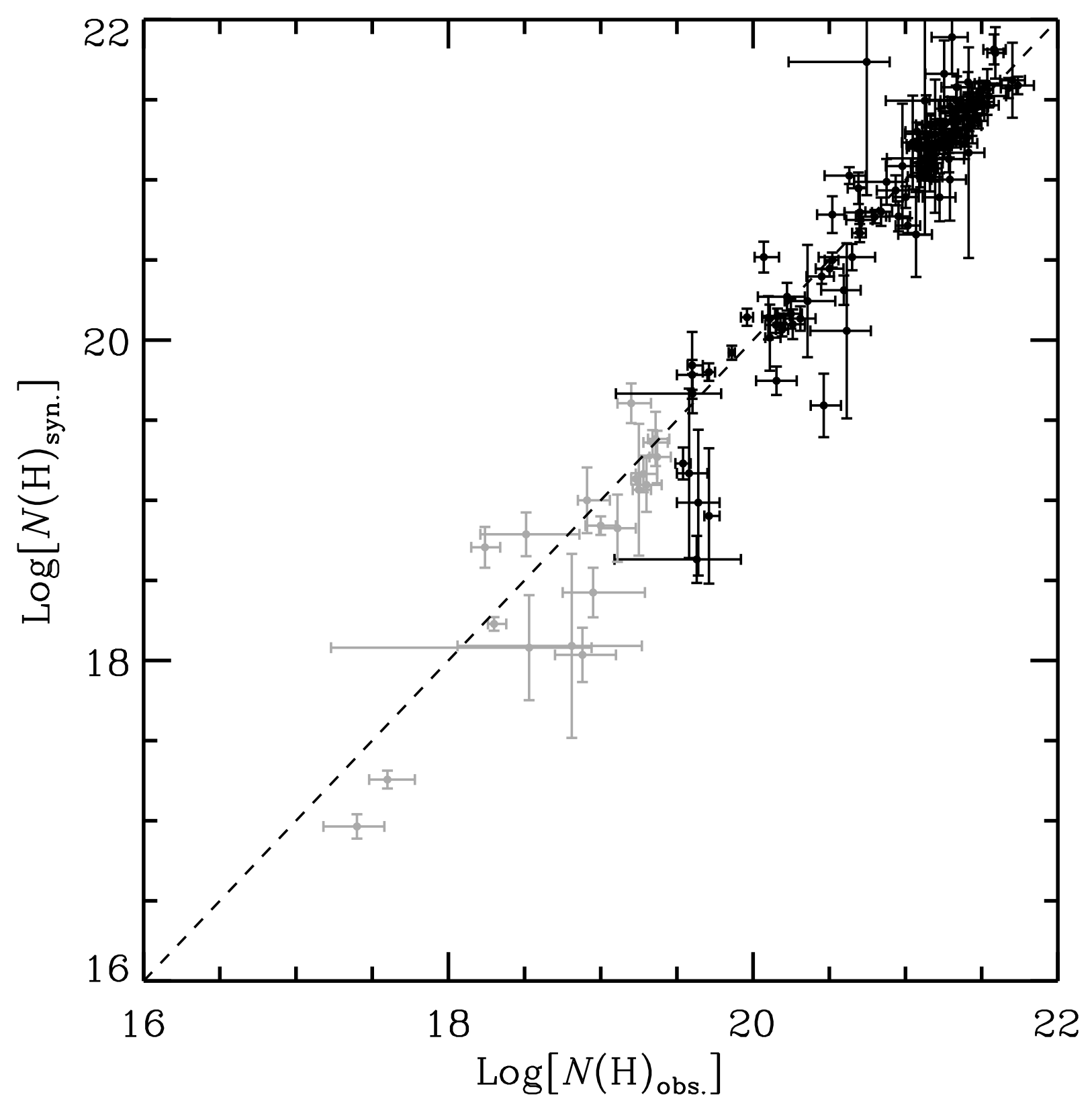

Fig. 10.- A comparison of the synthetic values of $N(\mathrm{H})$ calculated using Eq. 24a ( $y$ axis) against their actual observed values ( $x$ axis), when known. See Columns (3-5) and Column (7) of Table 5 . Gray points and error bars signify cases where $\log N(\mathrm{H})_{\text {obs. }}<19.5$ to emphasize the fact that their abundance measurements may not reliably indicate the true gas phase abundances in H I regions. 


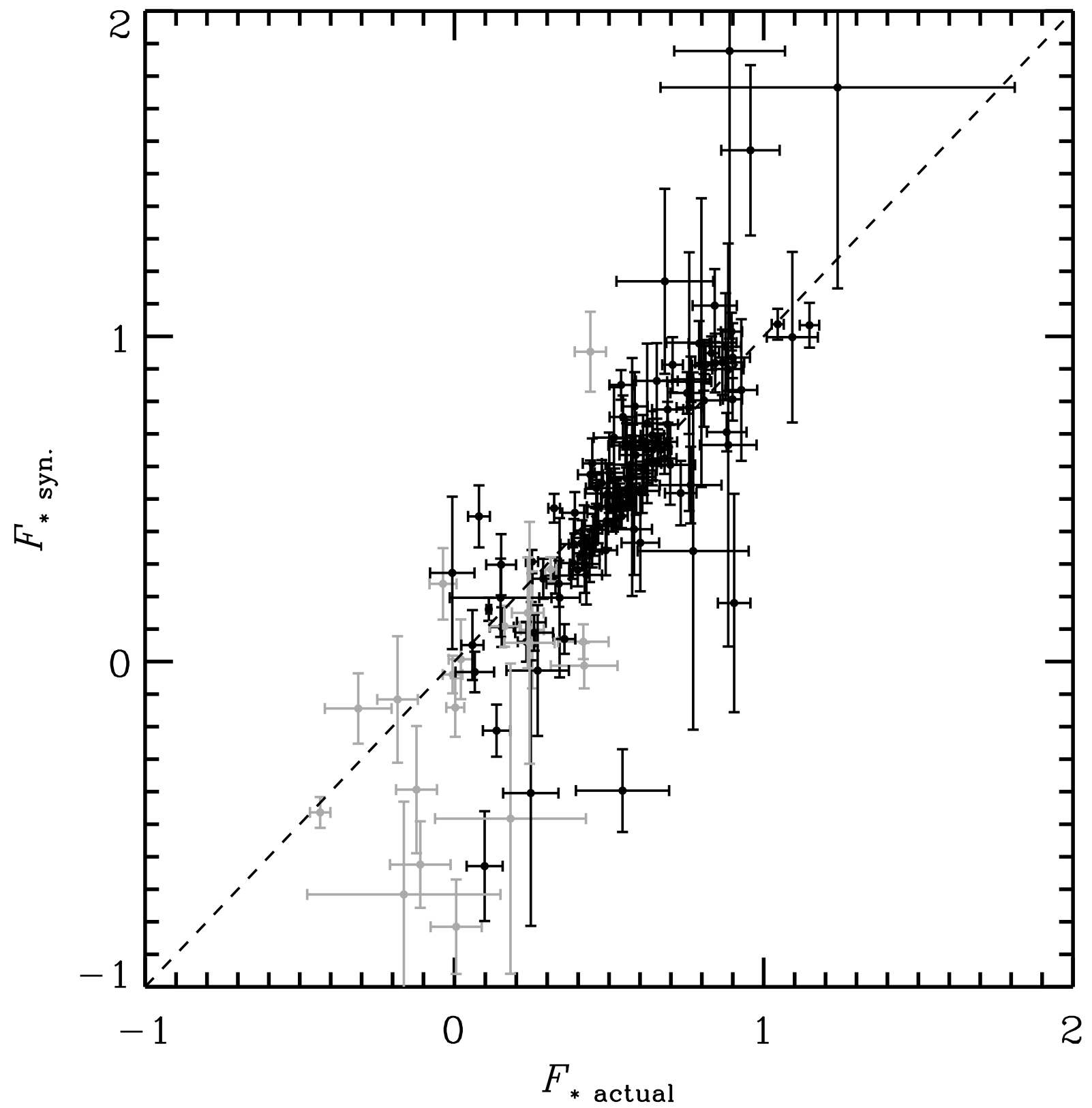

Fig. 11. - A comparison of the synthetic values of $F_{*}$ computed using Eq. 24a ( $y$ axis), which would be used if $N(\mathrm{H})$ were unknown, against computations of $F_{*}$ obtained from Eq. 4 for all cases where $N(\mathrm{H})$ has actually been observed. As in Fig. 10, gray symbols show cases where $\log N(\mathrm{H})_{\text {obs. }}<19.5$. 


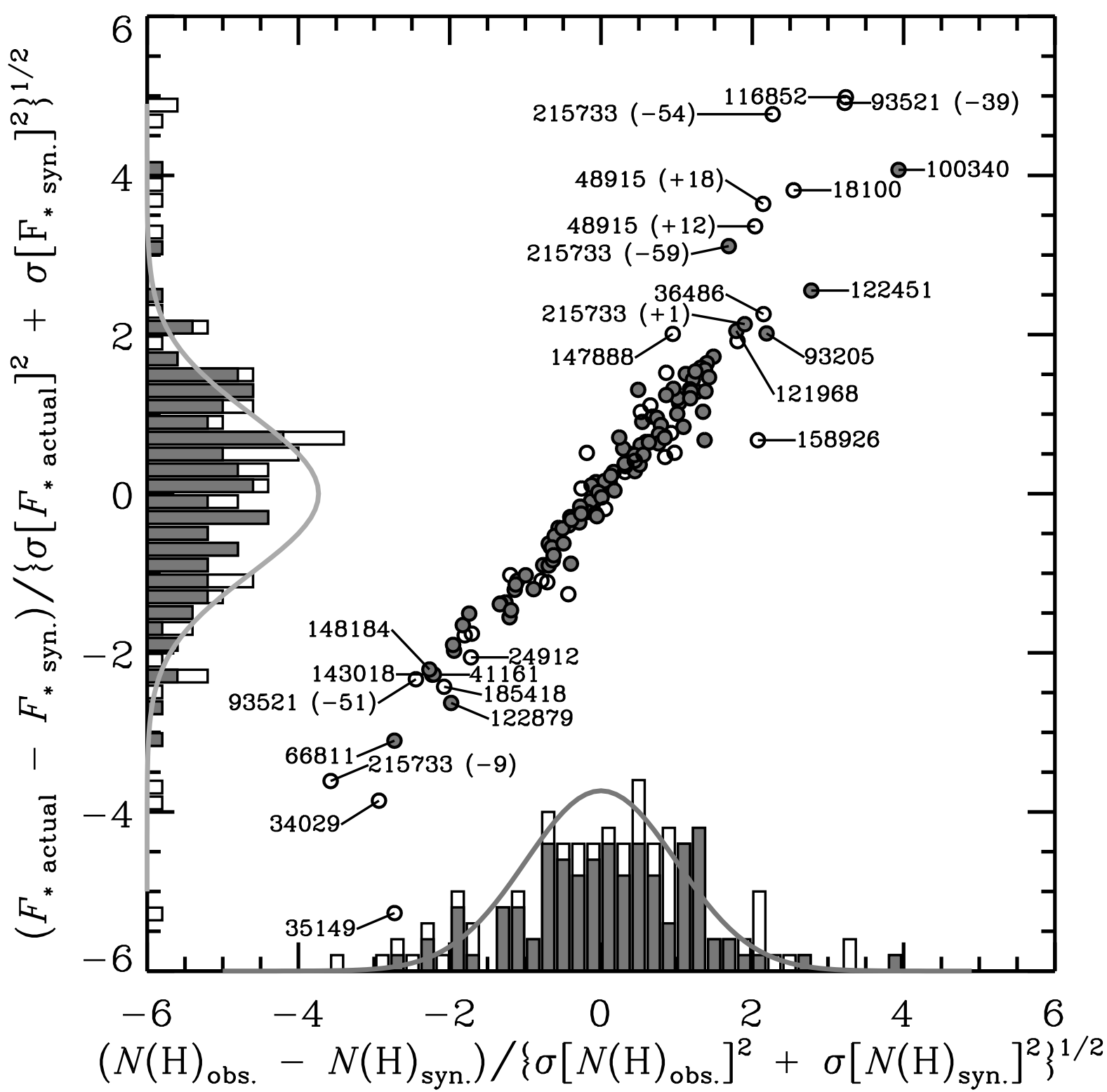

Fig. 12.- Deviations of $N(\mathrm{H})$ and $F_{*}$ (shown in Columns (3-6) of Table 5) from their synthetic counterparts derived from Eq. 24a (Columns 7 and 8 of the same table), divided by the respective uncertainties for the differences of the two quantities as defined by denominators shown in the $x$ and $y$ axis labels, for all cases where $N(\mathrm{H})$ is known from observations. Points that are filled in have probabilities of worse fit (see Column (9) of Table 5) greater than 0.05, while open points are below this threshold. The HD numbers of stars (and the velocity components in parentheses, if appropriate) are labeled for outlier points that have deviations for either case that are more than $2 \sigma$ away from zero. Histograms showing the distributions of all deviations are shown next to the $x$ and $y$ axes, with an overlay of a Gaussian distribution with a zero mean and standard deviation of 1 for comparison purposes. Solid and open portions of the bars are coded in the same manner as the points. 
In making judgments on how well the applications of Eq. 24a are working, we can examine all cases where $N(\mathrm{H})_{\text {obs }}$ is known and for which the right combination of elements were measured, and then simply compare the observed and synthetic values of $N(\mathrm{H})$. We can also do the same for the two methods for determining $F_{*}$. Figures 10 and 11 show these comparisons. For both variables, a vast majority of stars show a good agreement between the two methods.

We can also examine the overall behavior of differences in the two ways of deriving both variables divided by the expected errors of such differences. This is shown in Figure 12, It is clear that the errors are highly correlated, which comes as no surprise if one imagines how errors in the slopes of the lines can have a large leverage in creating deviations for the locations of the $y$-intercepts at $x=0$ (toward the far right-hand sides in the plots shown in Fig. 9), especially if there is no representation by elements with small depletions. (If one examines the errors in the synthetic $N(\mathrm{H})$ values listed in Table 5, it is clear that they are generally larger than average if $\mathrm{C}$, $\mathrm{N}$, O or $\mathrm{Kr}$ are not represented in the list of elements shown in the last column.) Histograms on the sides of the plot box in the figure show how the deviations are distributed, with a Gaussian curve having a unit standard deviation and zero mean overlaid for comparison. While the distribution of the bars of these histograms seem generally consistent with this Gaussian curve, it is clear that the number of outliers beyond $2 \sigma$ is larger than expected. Those cases are identified by their HD numbers (and velocities, if distinct). For both the histogram bars and the circle points in the diagram, the filled-in cases have probabilities of a worse fit that are larger than 0.05, while those that are open have lower probabilities.

\section{Depletions toward White Dwarf Stars in the Local Bubble}

It is clear from Fig. 3 that our coverage of distances exhibits an abrupt lower limit at about 100 pc. The volume of space out to about 100 pc from the Sun has an uncharacteristically low density; it is a region known as the Local Bubble (Cox \& Reynolds 1987; Breitschwerdt et al. 1996; Vallerga 1996; Ferlet 1999; Lallement et al. 2003; Frisch 2007), and it contains a collection of isolated, warm clouds (Redfield \& Linsky 2004a, b) embedded within and confined by a hot plasma (Breitschwerdt \& de Avillez 2006; Savage \& Lehner 2006). It was probably created by a series of supernova explosions that arose from an association of early-type stars that passed through our vicinity about 14 Myr ago (Maíz-Appelániz 2001; Berghöfer \& Breitschwerdt 2002; Fuchs et al. 2006). Many white dwarf stars embedded in the Local Bubble were observed by the Far Ultraviolet Spectroscopic Explorer (FUSE) satellite. However, for all but a few of these targets, N(H I) was not observed. Thus, if we wish to obtain an understanding about the strength of the depletions toward these objects, we must rely on the analysis of synthetic $F_{*}$.

A large fraction of the sight lines studied in the Local Bubble probably have $\log N(\mathrm{H} \mathrm{I})<19.5$, and thus they violate the restriction that we imposed to lessen the chances that partial ionization effects could influence the outcomes (see rule nr. 3 in 4 .4.2). Indeed, along the sight lines to white dwarf stars in the Local Bubble, it is not unusual to find that $N(\mathrm{~N} \mathrm{II})>N(\mathrm{~N}$ I) (Kruk et al. 2002; 
Lehner et al. 2003). However, for the elements Si and Fe, we can see from Figs 5 and 7 that most measurements with $\log N(\mathrm{H} \mathrm{I})<19.5$ (shown as open circles in the figures) seem to lie reasonably close to the trend established by the higher column density cases (or an extrapolation of it for $F_{*}<0$ ), suggesting that, for these particular elements, our initial hesitation to include these low column density cases was more cautious than necessary. Moreover, ionization models of gas within the Local Bubble shown in Figure 6 of Lehner et al. (2003) indicate that for $\log N(\mathrm{H} \mathrm{I}) \gtrsim 18$, the influence of photoionization within the Local Bubble on the abundances of O I, P II, Si II and Fe II relative to $\mathrm{H}$ I is small. Comparisons of $\mathrm{O}$ I to $\mathrm{H}$ I are rather secure under almost all conditions because the ionizations of these two elements are coupled to each other by a strong charge exchange reaction (Field \& Steigman 1971; Chambaud et al. 1980; Stancil et al. 1999).

In light of the above statements, we bypass here the column density restriction and proceed with derivations of synthetic values of $N(\mathrm{H} \mathrm{I})$ and $F_{*}$ for sight lines toward white dwarf stars in the Local Bubble by using the prescription outlined in 97 . In order to obtain a satisfactory spread in $A_{X}$, we require that information is available for $\mathrm{O} \mathrm{I}$ and one or more of the species P II, Si II, and Fe II. Table 6 lists results for the stars that satisfy these conditions, based on observations reported by Oliveira et al (2003) and Lehner et al (2003). If errors in $y$ of Eq. 24a were set to their formal values, unreasonably large values of $\chi^{2}$ were obtained. This probably reflects the fact that the accuracy of the observations of $N(X)$, along with the formal errors in $A_{X}$ and $B_{X}$, are far better than the precision of the assumption that Eq. 24a truly applies for gas parcels in the Local Bubble. For this reason, errors in $y$ were artificially increased by 0.2 dex (added in quadrature to the original errors) to make the worse fit probabilities, as reflected by the values of $\chi^{2}$, evenly distributed over the interval 0 to 1.

Values of $\log N(\mathrm{H} \mathrm{I})_{\text {syn. }}$ listed in Table 6 range from 17.5 to 20.1. For three cases, observations of $N(\mathrm{H} \mathrm{I})$ are available for spot checks on the accuracy of the synthetic values: HZ 43A $\log N(\mathrm{H} \mathrm{I})_{\text {obs. }}=17.93 \pm 0.03$ (Kruk et al. 2002$)$ vs. $\log N(\mathrm{H} \mathrm{I})_{\text {syn. }}=17.82 \pm 0.25 ;$ Lan 23 $\log N(\mathrm{H} \mathrm{I})_{\text {obs. }}=19.89_{-0.04}^{+0.25}$ (Wolff, Koester, \& Lallement 1999) vs. $\log N(\mathrm{H} \mathrm{I})_{\text {syn. }}=20.11 \pm 0.33$; GD $246 \log N(\mathrm{H} \mathrm{I})_{\text {obs. }}=19.11 \pm 0.03$ (Oliveira et al. 2003) vs. $\log N(\mathrm{H} \mathrm{I})_{\text {syn. }}=18.94 \pm 0.25$. In all cases, the agreements are well within the estimated errors.

Figure 13 shows the distribution in the sky of the FUSE white dwarf observations along with the distances and derived values of $F_{* \text { syn. }}$. The construction of this figure is very similar to Fig. 1 of Lehner et al. (2003) so that one can easily compare their values of $\log N$ (O I) (which are not very different from $N(\mathrm{H} \mathrm{I})_{\text {syn. }}$ aside from a constant factor) with our values of $F_{* \text { syn. }}$. It is also similar to Figs 7-12 of Redfield \& Linsky (2004a), which show column densities of various species toward mostly late-type stars in the Local Bubble (these targets are generally much closer to us than the white dwarf stars). Our Fig. 13 indicates that there is a mild degree of coherence in the depletions: stars in the general direction of the south Galactic pole have light depletions, those toward the Galactic center have moderate depletions, and distant stars over a broad range of Galactic latitudes and at longitudes of around $90^{\circ}$ have the largest values of $F_{* \text { syn. }}$. Six of the stars have $F_{* \text { syn. }} \geq 0.30$ and yet their values of $N(\mathrm{H})_{\text {syn }}$. are below our fiducial lower limit of $10^{19.5} \mathrm{~cm}^{-2}$ for the general 
Table 6. Synthetic $\log N(\mathrm{H})$ and $F_{*}$ for Stars in the Local Bubble

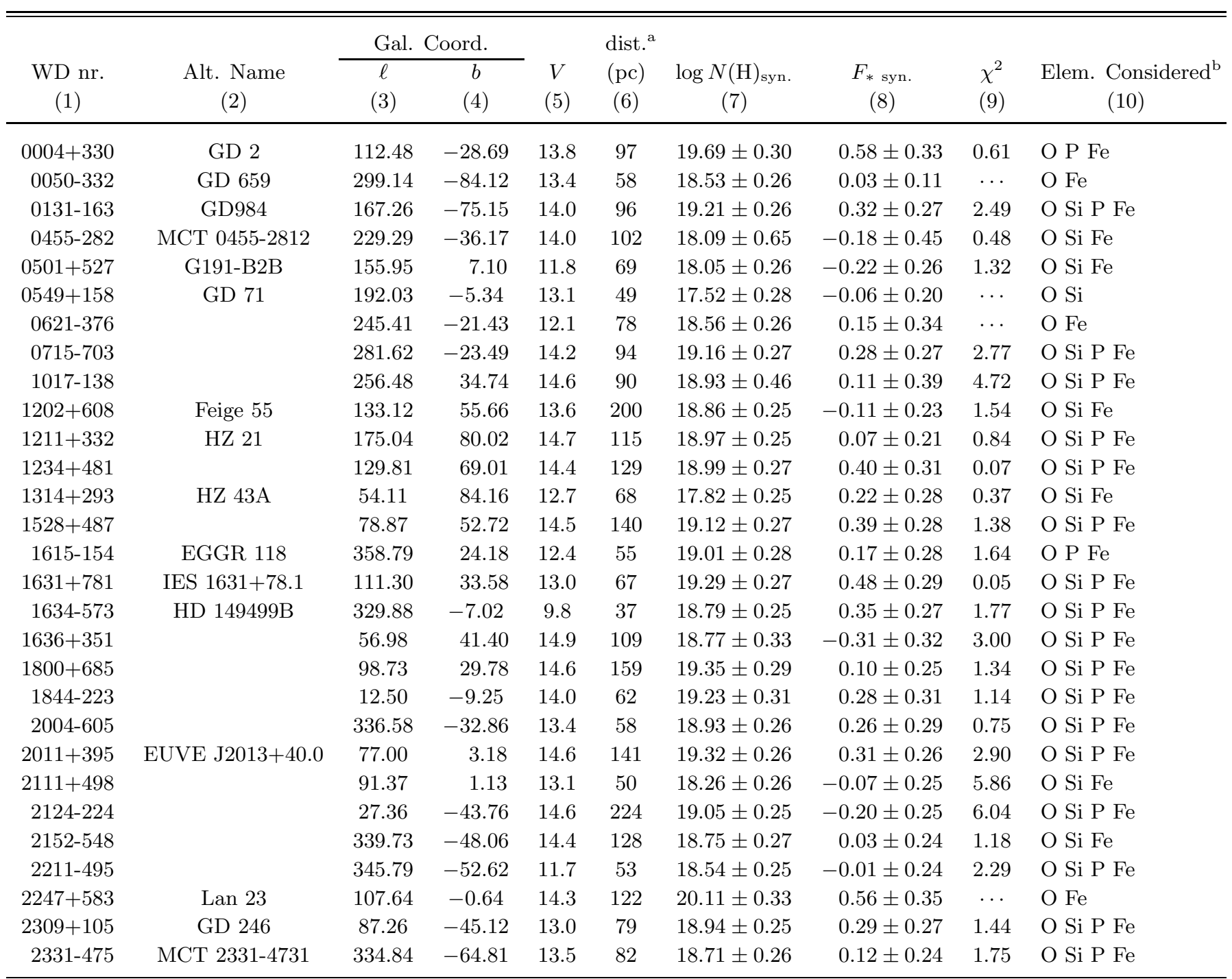

aTaken from the papers that described the FUSE observations.

${ }^{\mathrm{b}}$ All column density data from Lehner et al. (2003), except for HZ 21 (Oliveira et al. 2003). 


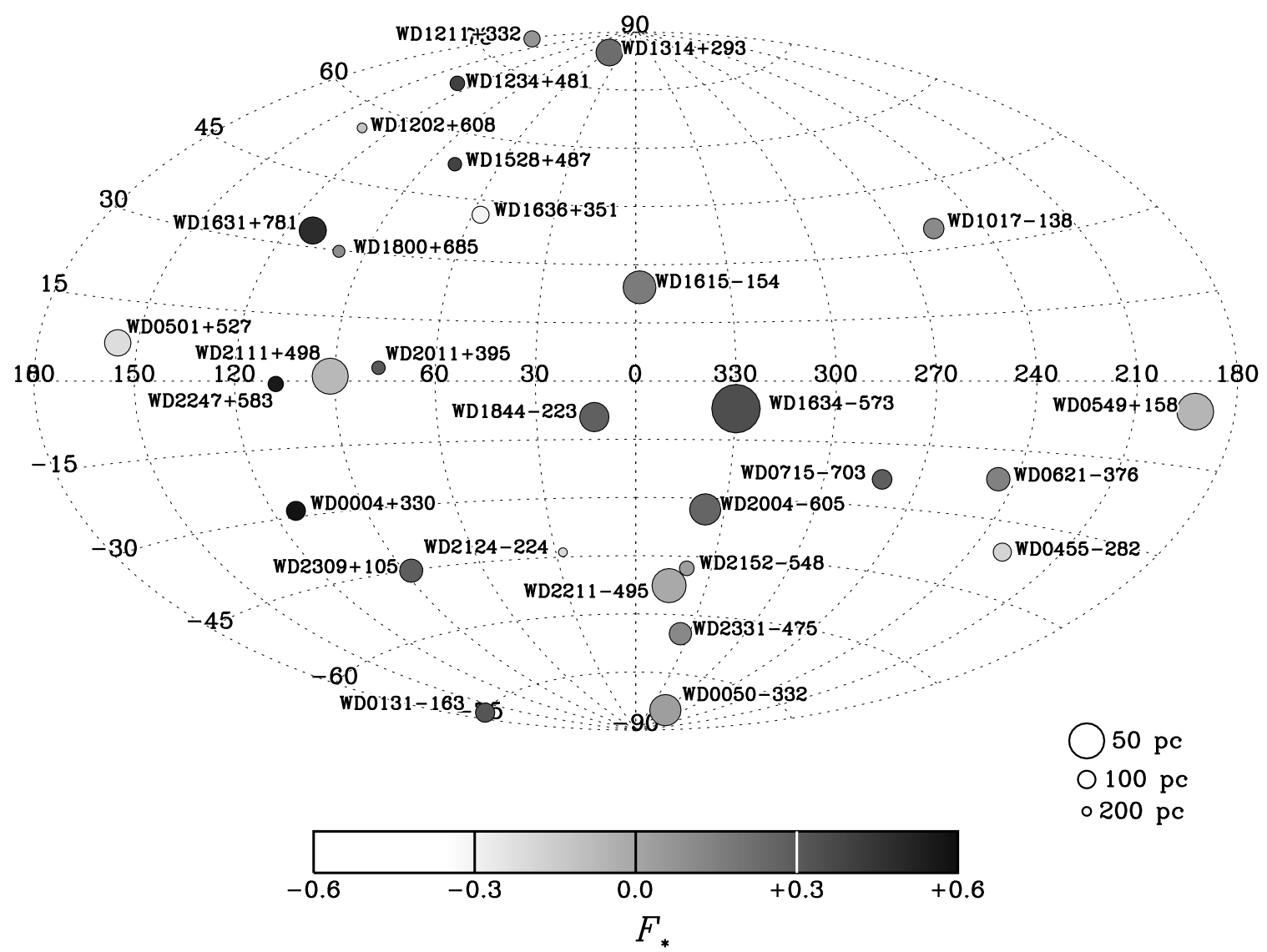

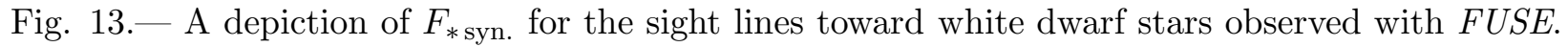
The positions of the circles indicate the Galactic coordinates $(\ell=0, b=0$ at the center) and their sizes indicate the distances to the stars, according to the legend shown in the lower right-hand portion of the figure. The darknesses of the filled in portions of the circles indicate the derived

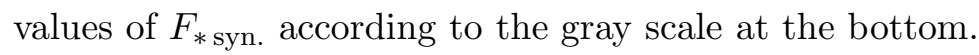


study, indicating that, provided we are not being misled by ionization effects, moderately strong depletions can be found in the Local Bubble. This conclusion is consistent with the findings of Kimura et al. (2003) for very local, warm gas that surrounds our heliosphere.

\section{Sulfur: A Troublesome Element}

Our consideration of sulfur has been deferred until now because this element presents difficulties that warrant special treatment. A study of the depletion behavior of sulfur is especially important, since many studies of gas in both our Galaxy and very distant systems have relied on this element as a standard for what should be virtually zero depletion. We need to re-examine whether or not this is true. For instance, Calura et al. (2009) have summarized some recent findings reported in the literature that may revise our understanding of the status of sulfur depletions or possible lack thereof.

The singly-ionized form of sulfur is detected only through a triplet with transitions at 1250.6, 1253.8 and $1259.5 \AA$, with $f$-values of $0.00543,0.0109$, and 0.0166, respectively (Morton 2003). Unfortunately, for many lines of sight that contain moderately large amounts of gas, even the weakest line is partly or strongly saturated. Observations taken at low resolution (e.g., with the G160M configuration of the GHRS instrument on HST) often exhibited ratios for the equivalent widths of the two weaker lines of less than 1.5, and thus they were deemed to be saturated enough to violate one of the censorship guidelines for this study (rule nr. 2 in 4.2 ). However, a small number of observations showed that the saturations were not so severe, or that the S II column densities could be extracted from moderately saturated features recorded at high resolution and analyzed through their apparent optical depths.

Prominent in the limited selection of S II measurements were the individual velocity components of the stars HD 93521 and HD 215733 analyzed by Spitzer \& Fitzpatrick (1993) and Fitzpatrick \& Spitzer (1997). In a few instances, the velocity separations of adjacent components were small, which could lead to errors in the assignments of column densities between them. An additional drawback of using the individual velocity components toward these stars is the reliance on 21-cm emission line measurements of $\mathrm{H}$ I instead of $\mathrm{L} \alpha$ absorption.

Table 13 in Appendix B shows the stars that had measurements of S II that were accumulated in the current study (but not all of which were suitable for determining depletion coefficients). Relative to the stars that could be used for other elements, they are few in number (12) and a substantial majority of them have hydrogen column densities that are either unknown or below the threshold

$N(\mathrm{H})=10^{19.5} \mathrm{~cm}^{-2}$ that qualifies them for consideration. As with the measurements of depletions of other elements, a reference abundance was adopted from Lodders $(2003), \log (\mathrm{S} / \mathrm{H})_{\odot}+12=$ $7.26 \pm 0.04$.

The left-hand panel of Fig. 14] shows the observed depletions as a function of $F_{*}$. A least-squares best fit to the observations with $\log N(\mathrm{H})>19.5$ (the 8 solid points) yields $A_{\mathrm{S}}=-1.261 \pm 0.165$, 

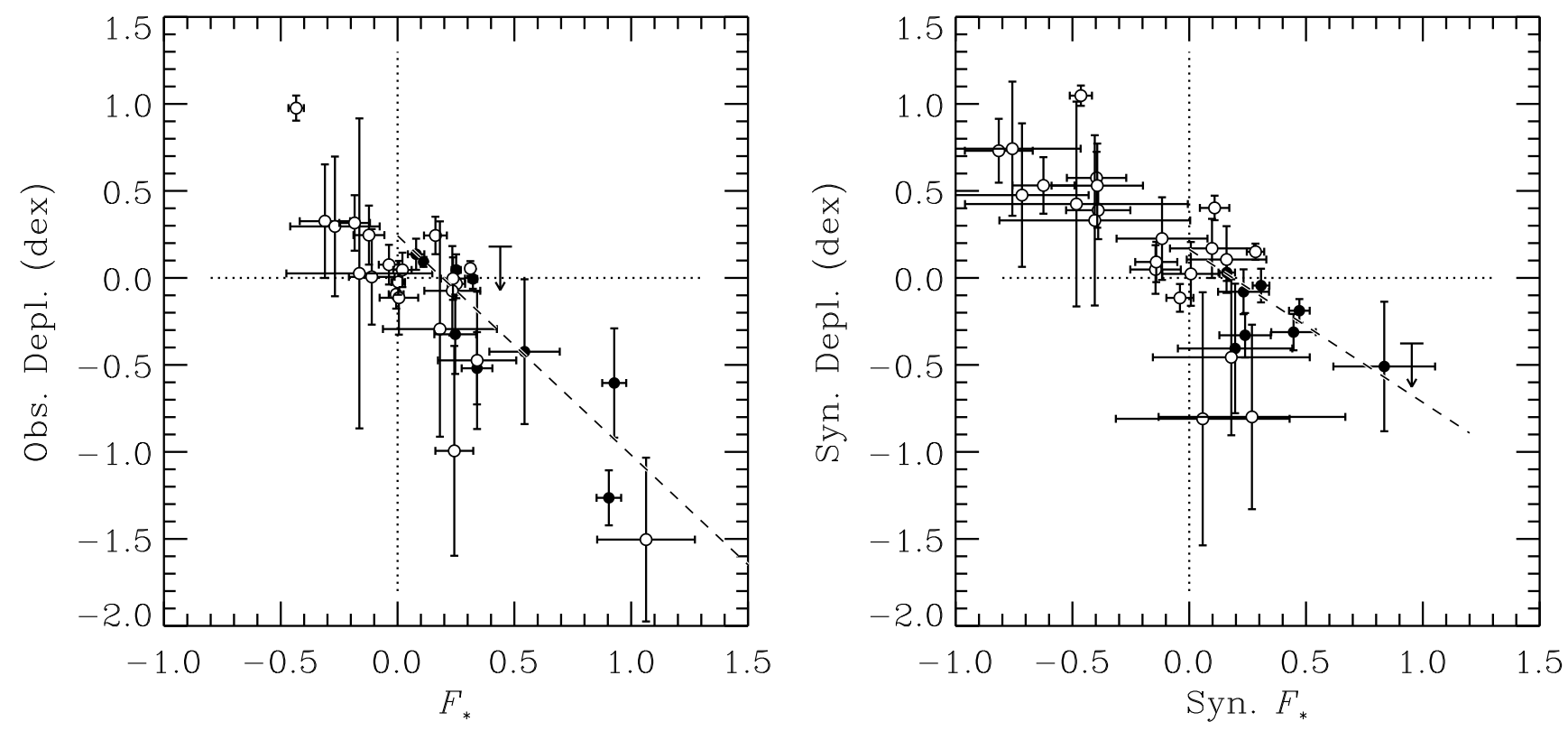

Fig. 14.- Left-hand panel: Observed depletions of $\mathrm{S}$ as a function of $F_{*}$. Cases with $N(\mathrm{H})<$ $10^{19.5} \mathrm{~cm}^{-2}$ are shown with open symbols, while cases with larger values of $N(\mathrm{H})$ have solid symbols. The dashed line shows the best least-squares fit to the solid points. Right-hand panel: Same as the left-hand panel, except that $N(\mathrm{H})_{\text {syn. }}$ was used to derive the depletions and $F_{*}$ derived from Eq. 4 was replaced by $F_{* \text { syn. }}$ calculated from the best fits to Eq. 24a, 
$B_{\mathrm{S}}=0.028 \pm 0.047$, and $z_{\mathrm{S}}=0.170$, whose linear equation is represented by the dashed line. However, the probability of a worse fit is exceptionally low: $p=0.005$.

There is a strong possibility that the 21-cm measurements that were used to set the $\mathrm{H}$ I column densities for the velocity components toward HD 93521 and HD 215733, which represent 26 of the points shown in the figure, are giving misleading outcomes. For instance, the beam width of the telescope was large $\left(21^{\prime}\right)$, and some $\mathrm{H}$ could be positioned inside the coverage of the beam but not in front of a star. Alternatively, some gas in front of the star that subtends a small solid angle in the sky could suffer severe beam dilution. Finally, some of the gas registered at $21 \mathrm{~cm}$ could be behind the star. (It was for these reasons that Fitzpatrick \& Spitzer (1997) chose to disregard the hydrogen measurements and instead determined the depletions of elements other than $\mathrm{S}$ by making comparisons to the respective determinations of $N(\mathrm{~S} \mathrm{II})$, on the presumption that $\mathrm{S}$ was always undepleted.)

To overcome the uncertainties in $N(\mathrm{H} \mathrm{I})$, we can resort to the tactic of deriving the synthetic versions of this quantity through the method outlined in $\$ 7$ that made use of the relative abundances of other species. Likewise, $F_{*}$ determinations that used $N(\mathrm{H})_{\text {obs. }}$ could be declared as suspect and instead we can use the synthetic values of $F_{*}$ derived in conjunction with the calculations of $N(\mathrm{H})$. The right-hand panel of Fig. 14 shows the outcomes with these different synthetic values of $N(\mathrm{H})$ and $F_{*}$ that were obtained from the fit to Eq. 24a. Here, we find that $A_{\mathrm{S}}=-0.879 \pm 0.284$, $B_{\mathrm{S}}=-0.091 \pm 0.042$, and $z_{\mathrm{S}}=0.290$. For the two fiducial points of $F_{*}$, we obtain from Eqs. 13 to 16 depletions $\left[\mathrm{S}_{\text {gas }} / \mathrm{H}\right]_{0}=0.163 \pm 0.092$ and $\left[\mathrm{S}_{\text {gas }} / \mathrm{H}\right]_{1}=-0.715 \pm 0.206$. The chance of obtaining a worse fit for the 8 valid points in this case is 0.482 (from $\chi^{2}=5.5$ with 6 degrees of freedom), a considerable improvement over the earlier value that used the conventional determination of $F_{*}$ and the observed values of $N(\mathrm{H})$. Based on misgivings about the $N(\mathrm{H})$ values derived from the 21-cm data and the improved fit using the synthetic values of $N(\mathrm{H})$ and $F_{*}$, the numbers given immediately above are probably more reliable than those that were listed earlier, which were based on $N(\mathrm{H})_{\text {obs }}$.

The ionization potential of $\mathrm{S}^{+}$is $23.4 \mathrm{eV}$; which, except for carbon, is the highest of the singly ionized species considered in this survey. For this reason, sulfur may be especially prone to the problem that its apparent abundance could be enhanced by its singly ionized form appearing in regions where the hydrogen is fully ionized by starlight photons (especially within H II regions created by stars with only moderately high effective temperatures, so that low energy photons that can ionize $\mathrm{H}$ are plentiful, while more energetic ones that are needed to ionize $\mathrm{S}^{+}$are not). One can therefore imagine that the appearance of readings of $\left[\mathrm{S}_{\text {gas }} / \mathrm{H}\right]>0$ shown in Fig. 14 for $\log N(\mathrm{H})<19.5$ (open circles) is caused by the invisibility of the accompanying hydrogen.

We could certainly benefit from some future, far more comprehensive survey of sulfur abundances. Not only do we find that the number of trustworthy determinations is small, but there may be a formidable selection bias that favors cases where $\left[\mathrm{S}_{\text {gas }} / \mathrm{H}\right]$ is lower than normal because we had to avoid cases where the sulfur absorption lines were not saturated and yet still satisfy our 
requirement that $\log N(\mathrm{H})>19.5$.

\section{Discussion}

\subsection{The Composition of Interstellar Dust}

\subsubsection{General Remarks}

The current study of depletions departs from most of the traditional ones that have emphasized the behavior of one or a few elements and how their abundance ratios change with such external factors as $\langle n(H)\rangle, f\left(\mathrm{H}_{2}\right)$, and location. Our new perspective ignores these factors (except for retrospective studies reported later in $\$ 10.2$ ) and recognizes that depletions change markedly from one sight line to the next but that among different elements they are well correlated. The objective now is to define how strongly each element participates in this collective behavior. In doing so, we can concentrate on only two properties of element depletions: (1) An initial depletion value $\left[X_{\text {gas }} / \mathrm{H}\right]_{0}$, which serves as a minimum strength for all sight lines and (2) an index $A_{X}$ that informs us about how rapidly individual elements deplete beyond this initial depletion compared to the others.

The existence of nonzero initial depletions $\left[X_{\text {gas }} / \mathrm{H}\right]_{0}$ is an effect that has been known for some time (Jenkins, Savage, \& Spitzer 1986; Joseph 1988; Fitzpatrick 1996), and it has commonly been identified with the gas phase abundances in a warm, low density medium (Spitzer 1985; Savage \& Sembach 1996a). We can surmise that these minimum depletions indicate the composition of grains (through Eq. 21) that either have not had a chance to grow in dense interstellar media or have been partially stripped of certain elements by the recent passage of a shock at some point after such a growth phase.

The correctness of the values for $\left[X_{\text {gas }} / \mathrm{H}\right]_{0}$ depend not only on the measured interstellar abundances, but also on the adopted values for the intrinsic abundance of the gas and dust put together, which in turn depend on the appropriateness and accuracy of the pre-solar abundance scale used in the current study. Also, it is important to remember that the definition of the zero point for $F_{*}$ is probably strongly driven by our having adopted $N(\mathrm{H})>10^{19.5} \mathrm{~cm}^{-2}$ as an artificial boundary condition in our assessment of the least severe levels of depletion. This requirement was imposed to minimize distortions in the abundance levels caused by the effects of ionization. As we look back to the open circles shown in the upper panels in Figs. 5 to 8 , it appears that for the most part this rule may have been too conservative. Many of these open circles seem to be close to the trend lines or extrapolations thereof to negative values of $F_{*}$.

In contrast to the stated values of $\left[X_{\text {gas }} / H\right]_{0}$, the derivations of the progressive amounts of depletion represented by the various slopes $A_{X}$ of elements $X$ multiplied by their respective actual interstellar abundances (see Eq. 21) have no sensitivity to the choices for the reference abundances; they depend only on the magnitude of the adopted scale factor for the index $F_{*}$, which is an 
index that we have created to define the collective depletion levels for the individual lines of sight. These differential rates for both the growth and destruction of grains allow us to determine the composition of the material that has been added to the cores responsible for the initial depletions. The elemental composition of this outer material (by number, not by mass) per unit change in the depletion index $F_{*}$, relative to the amount of hydrogen gas present, is represented by the lines and their error envelopes shown in the lower panels of Figs. 5 to 8 ,

Values of $A_{X}$ listed in column (3) of Table 4 range between the extremes of zero (for $A_{\mathrm{N}}$ ) to a large value for $A_{\mathrm{Ti}}$, which is equal to 2.4 times the median value for all elements of -0.85 . The strong variability of $A_{X}$ among the different elements allows us to rule out two explanations for the probable root cause of depletion differences in different sight lines: (1) errors in $N(\mathrm{H})$, which would cause all depletions in any given sight line to rise or fall in unison and (2) the dilution of elements in the gas within the Galactic disk caused by the infall and mixing of low metallicity material from the halo (Meyer et al. 1994; Meyer, Jura, \& Cardelli 1998), which likewise would cause the logarithms of all element abundances to decrease in lock step with each other.

In 4.6.2, we discussed the corrections to $N(\mathrm{H} \mathrm{I})_{\text {obs. }}$ to account for increases in the strengths of the L $\alpha$ absorption profiles caused by the stellar absorption features in stars of spectral type B1 and cooler. The median rank in $F_{*}$ for these stars was 137 , while for the hotter stars that did not need such a correction the median rank was 103. As a consequence, for elements that exhibited very mild progressive depletions (i.e., small absolute values of $A_{X}$ ), these corrections operated in a fashion to increase very slightly the numerical values of $A_{X}$ and thus decrease the apparent contributions to grain growth. These systematic shifts were always smaller than the random errors associated with the fitting processes to derive $A_{X}$, as stated in Table 4, and, except for Kr, were not of much importance (see the footnote in $\left.\$_{10.1 .7}\right)$.

In the following subsections, we discuss some noteworthy points about the depletions of a few specific elements.

\subsubsection{Carbon}

Carbon is a major constituent of grains, yet our knowledge of the actual differential consumption of $\mathrm{C}$ by grains still remains rudimentary, as is indicated by the large shaded region in Fig. 5 , The paucity of data for $\mathrm{C}$ in our survey toward distant stars can be traced to the need to observe a weak intersystem transition at $2325 \AA$ (Sofia et al. 2004) at a high S/N, since the allowed transitions at 1036 and $1335 \AA$ are always strongly saturated. The strong transitions reveal reliable C II column densities for only a modest fraction of stars that are much closer to the Sun, i.e., those that have very low values of $N(\mathrm{H})$ (Wood \& Linsky 1997; Lehner et al. 2003; Redfield \& Linsky 2004a). There has been some concern expressed in the literature that not enough carbon is depleted to explain the optical properties of dust (Kim \& Martin 1996; Mathis 1996; Dwek 1997). If we disregard the present large uncertainty in $A_{\mathrm{C}}$ and focus our attention on $B_{\mathrm{C}}$ to obtain a nominal 
carbon depletion (at $F_{*} \approx 0.8$ ), we infer that the amount of $\mathrm{C}$ that is available for interstellar dust (and small molecules) is only $10^{-4}$ times the amount of $\mathrm{H}$ by number. About twice this amount is needed to explain the dust extinction (Draine 2003a). However, a recent, preliminary study by Sofia \& Parvathi (2009) suggests that the strength of the intersystem line may be about twice as strong as that considered previously, which would lower the interstellar abundances by the same factor (and raise the dust carbon content by about $90 \%$ ).

\subsubsection{Nitrogen}

The abundance of nitrogen is $-0.109 \pm 0.111$ dex below its reference solar system abundance, regardless of the value of $F_{*}$, i.e., $A_{N}=0.00 \pm 0.08$. Knauth, et al. (2003) claimed to have detected progressively stronger depletions of nitrogen as $N(\mathrm{H})$ increased, but this effect may be indirectly related to an apparent enhancement of $\mathrm{N}_{\text {gas }} / \mathrm{O}_{\text {gas }}$ within $500 \mathrm{pc}$ of the Sun discussed by Knauth et al. (2006). The latter result highlights the possible influence of regional differences in relative proportions of outputs from different nucleosynthesis sources (Type II SNe vs. AGB stellar winds) coupled with incomplete mixing in the ISM. However, if an effect such as this one were influential for our findings for $\mathrm{N}$, it would probably have resulted in a poor outcome for the $\chi^{2}$ value of the fit, which appears not to be the case (see Table 4). The fact that $A_{N} \approx 0$ suggests that the negative value of $B_{N}$ might arise from the adopted value for $(\mathrm{N} / \mathrm{H})_{\odot}$ being too high, although the apparent deviation of $B_{N}$ from zero is only at the $1 \sigma$ level of significance.

Gail \& Sedlmayr (1986) have pointed out that the condensation of $\mathrm{N}$ into any sort of solid compound could be inhibited by the production of $\mathrm{N}_{2}$, which is very stable. The saturated bond of this molecule results in a high activation energy barrier for gas phase reactions to form other molecules. While this may be an important theoretical consideration, the fact remains that the abundance of $\mathrm{N}_{2}$ in the diffuse ISM is small (Knauth et al. 2004, 2006).

\subsubsection{Oxygen}

Cartledge et al. (2004) found that the abundance of oxygen exhibited a weak, but convincing downward trend of its abundance with respect to $\langle n(\mathrm{H})\rangle$. Thus, the fact that our value of $A_{\mathrm{O}}=$ $-0.225 \pm 0.053$ differs significantly from zero is not unexpected. However, what comes as a surprise is the finding that the extraction of oxygen from the gas phase seems, for the larger values of $F_{*}$, far out of proportion to the consumption of other, less abundant elements that can be thought to form solid compounds with oxygen. For instance, from Eq. 21 we find that when $F_{*}=0$, $d\left(\mathrm{O}_{\text {dust }} / \mathrm{H}\right) / d F_{*}$ is 1.6 times the sum of the solid phase accumulation rates (measured the same way) of $\mathrm{Mg}$, $\mathrm{Si}$ and Fe, i.e., $d\left(\mathrm{Mg}+\mathrm{Si}+\mathrm{Fe}_{\text {dust }} / \mathrm{H}\right) / d F_{*}$, and a factor of 16 greater when $F_{*}$ reaches 1.0. Yet the conventional view is that oxygen is mostly incorporated into such refractory compounds as metallic oxides and amorphous silicates. However, even the most oxygen-rich of these compounds, 
magnesium silicate (enstatite) $\mathrm{Mg} \mathrm{SiO}_{3}$, has only $3 / 2$ times as much $\mathrm{O}$ as the other elements. Considering the uncertainties in the $\mathrm{O}$ consumption at $F_{*}=0$, the $3 / 2$ ratio, or even a somewhat lesser amount, could be satisfied. However, the divergence between the $\mathrm{O}$ consumption and those of the other elements makes this equality rapidly vanish when $F_{*}$ becomes somewhat larger than 0 . At even the lower edge of $-2 \sigma$ error zone for the $\mathrm{O}$ consumption at $F_{*}=1$ shown in Fig. 5, we find that $\mathrm{O}$ atoms are taken out of the gas phase at a rate that is 6 times that of $\mathrm{Mg}+\mathrm{Si}+\mathrm{Fe}$.

If we now switch our attention to absolute depletions instead of differential ones (this now relies on the premise that the pre-solar abundances are correct), our calculation of the value of $\left(\mathrm{O}_{\text {dust }} / \mathrm{H}\right)$ at $F_{*}=1$ is $2.41_{-0.66}^{+0.74} \times 10^{-4}$; the nominal value here is larger than a limit of $1.8 \times 10^{-4}$ that is established by the total availability of other elements that can be incorporated into either the silicates, metallic oxides, or some combination of the two (Cardelli et al. 1996). However, the negative $(1 \sigma)$ error limit is consistent with this number. The uncertainty calculated for $\left(\mathrm{O}_{\text {dust }} / \mathrm{H}\right)$ includes the presumption that $(\mathrm{O} / \mathrm{H})_{\odot}$ has a possible error as large as 0.05 dex.

We are drawn to the conclusion that $\mathrm{O}$ must be locked up in either some carbon or hydrogen compound (or as $\mathrm{O}_{2}$ ), given that these are the only reactive elements with a sufficiently large cosmic abundance. (While it is abundant, the consumption of $\mathrm{N}$ during grain growth is nowhere near as much as O.) An initially attractive prospect was that $\mathrm{O}$ is incorporated in the form of amorphous $\mathrm{H}_{2} \mathrm{O}$ ice on the grain surfaces (Ioppolo et al. 2008). Slightly more than $5 \%$ of the available oxygen atoms are found in the form of water in the material (with large extinction values) toward young stellar objects (van Dishoeck 1998), but various surveys indicate that the strength of the $3.05 \mu \mathrm{m}$ ice band shows a linear trend that extrapolates to zero when $A_{V}$ decreases to values of around 2.6 to 5 (Whittet et al. 1988; Eiroa \& Hodapp 1989; Smith, Sellgren, \& Brooke 1993). The star Cygnus OB2 No. 1211 has an extinction $A_{V}=10.2 \pm 0.3$ but shows no detectable ice band in its spectrum $(\tau<0.02)$ (Gillett et al. 1975; Whittet et al. 1997). It may be possible that long term irradiation by cosmic ray particles and UV radiation modifies this ice layer in a way that inhibits the appearance of the infrared absorption feature (Greenberg 1982; Palumbo 2006). Other simple oxygen-bearing molecules in solid form, such as $\mathrm{CO}, \mathrm{CO}_{2}$ and $\mathrm{O}_{2}$ generally have smaller abundances than that of $\mathrm{H}_{2} \mathrm{O}$, but they are not entirely negligible (van Dishoeck 2004).

An entirely separate method of determining what fraction of the oxygen is locked up in compounds is to examine the structure of absorptions in the vicinity of the $\mathrm{K}$ absorption edge at $23 \AA$ in the spectra of x-ray binaries recorded by the grating spectrometers aboard Chandra and $X M M$-Newton. Molecular bonds shift the energies of bound-bound and bound-free transitions and create such complex structures, but unfortunately ionization of the atoms can play a similar role, which makes the analysis ambiguous (Costantini, Freyberg, \& Predehl 2005). As a result, different investigators have arrived at differing interpretations of the observations. For instance, Paerels et al. (2001), Schulz et al (2002), and Takei et al (2002) have viewed their results on the O-edge structures in terms of specific compounds in the ISM, but these conclusions were later criticized

\footnotetext{
${ }^{11}$ Sometimes called VI Cyg No. 12.
} 
by Juett, Schulz \& Chakrabarti (2004), who interpret the discrete features seen in a number of x-ray sources as arising simply from O I, O II, and O III. If their identification of absorption by compounds is correct, Takei et al. (2002) found that the amount of $\mathrm{O}$ in free atoms toward Cyg-X2 is $(8.6 \pm 2.8) \times 10^{17} \mathrm{~cm}^{-2}$, while $\mathrm{O}$ in bound form corresponds to $(5.2 \pm 2.2) \times 10^{17} \mathrm{~cm}^{-2}$, which is consistent with a depletion of atomic $\mathrm{O}$ of -0.205 dex. This amount of depletion is what we would expect for $F_{*}=0.86$. However, Cunningham, McCray \& Snow (2004) found that the total x-ray absorption by oxygen in all forms toward X Per (a sight line included here with $F_{*}=0.90 \pm 0.06$; see Table 9) is consistent with just the gas-phase measurement, leaving no room for an appreciable amount of additional $\mathrm{O}$ in solid form.

A different approach is to use the x-ray absorption results to compare the total abundance of $\mathrm{O}$ with those of other elements, on the premise that perhaps large amounts of oxygen are locked within dust grains that have diameters of order or greater than $1 \mu \mathrm{m}$. Grains this large have been detected in the local ISM by the dust sensors aboard the Galileo and Ulysses spacecrafts (Frisch et al. 1999; Landgraf et al. 2000; Krüger et al. 2006), and these measurements indicate that the large grains contribute a substantial portion of the total mass budget of material in solid form. The largest grains become optically thick to x-rays at energies near the K absorption edge. Takei et al (2002) found that $\log \left(\mathrm{Ne} / \mathrm{O}_{\text {gas }}+\right.$ dust $)=-0.84 \pm 0.18$ is consistent with the solar value of $-0.81 \pm 0.11$ dex (Lodders 2003), indicating that all of the $\mathrm{O}$ absorption was evident in the observed edge absorption. In contrast, higher values that appear to indicate that some of the $\mathrm{O}$ is hidden have been derived in other investigations: $\log (\mathrm{Ne} / \mathrm{O})=-0.52 \pm 0.21$ (Yao \& Wang 2006), $-0.66 \pm 0.08$ (Yao et al. 2009), and an outcome even as high as 0.1 (Paerels et al. 2001). Moreover, Ueda et al. (2005) found that $\mathrm{Si} / \mathrm{O}$ and $\mathrm{Mg} / \mathrm{O}$ were about 0.6 dex higher than their respective solar values (as adopted here, not as expressed in their article). The fact that the latter result is at variance with the UV absorption line data is consistent with the idea that while $\mathrm{Si}$ and $\mathrm{Mg}$ both reside mostly within small grains that individually have small optical depths for x-rays, significant amounts of $\mathrm{O}$ could be incorporated into grains or complexes thereof that are large enough to be fully opaque in x-rays.

Large dust grains having thick mantles of water ice should be extremely hard to detect by most astronomical methods. They contribute little to the extinction at visible and IR wavelengths, and their effectiveness in creating a distinctive $3.07 \mu \mathrm{m}$ ice band absorption feature would be limited if the grain diameters exceeded $1 \mu \mathrm{m}$ (B. T. Draine, private communication). About the only way to detect such large particles, if they are present, might be through very small angle scattering of x-rays from point sources (Smith \& Dwek 1998; Witt, Smith, \& Dwek 2001) or possibly even very faint scattering at larger angles at visible wavelengths for particles that are more than a few $\mu \mathrm{m}$ in diameter (Socrates \& Draine 2008). However, various interpretations of the x-ray observations so far seem to indicate that the small-angle x-ray scattering data are consistent with dust grain populations composed of refractory compounds over a distribution of sizes smaller than $0.25 \mu \mathrm{m}$ in diameter (Draine \& Tan 2003; Dwek et al. 2004; Costantini, Freyberg, \& Predehl 2005; Xiang, Zhang, \& Yao 2005; Smith et al. 2006; Ling et al. 2009; Smith 2008). 


\subsubsection{Phosphorous}

Phosphorous depletes more rapidly than oxygen, as is clear from the significant difference between the $A_{\mathrm{O}}$ and $A_{\mathrm{P}}$ values and their errors listed in Table 4. This finding is in conflict with the findings of Lebouteiller, Kuassivi \& Ferlet (2005), who claim that $N(\mathrm{P}$ II) $/ N(\mathrm{O}$ I) always appears to be consistent with the solar abundance ratio over a large range of O I column densities.

\subsubsection{Chlorine}

The abundance trend of $\mathrm{Cl}$ is not as regular as for the other elements, as is evident from the scatter of points shown in Fig. 6] and the larger than usual errors for the parameters of $\mathrm{Cl}$ in Table 4 . It should also be clear from the small dot sizes for $\mathrm{Cl}$ in Fig. 6 that the measurement errors are larger than usual. Some of the scatter in the $\mathrm{Cl}$ measurements may be due to the large fractions of $\mathrm{Cl}$ being in neutral form, compared to the singly ionized form. Jura (1974) has shown that chlorine ions can react with $\mathrm{H}_{2}$ to produce $\mathrm{HCl}^{+}+\mathrm{H}$ and eventually, through a chain of reactions that follow, revert to an amount of neutral chlorine that can even surpass the remaining concentration of chlorine ions. Indeed, there are a few lines of sight in the survey of JSS86 that indicate that $N(\mathrm{Cl} \mathrm{I})>N(\mathrm{Cl} \mathrm{II})$. If these cases are predominantly at the largest values of $F_{*}$ (which seems likely, since there will be a higher relative concentration of $\mathrm{H}_{2}$ ), the slope of the best-fit line may be too steep (i.e., $A_{X}$ is at too large a negative value), and this may be the dominant cause for our having found that $\left[\mathrm{Cl}_{\text {gas }} / \mathrm{H}\right]_{0}$ is positive.

\subsubsection{Krypton}

One apparently remarkable outcome is that $\mathrm{Kr}$ seems to show not only an offset below its solar system value, as indicated by the fact that $B_{\mathrm{Kr}}=-0.332 \pm 0.083$, but that also there is an indication, not an entirely conclusive one, that there is some progressive depletion as $F_{*}$ increases $\left(A_{\mathrm{Kr}}=-0.166 \pm 0.103\right)$. However it is clear that the nonzero value of this parameter is significant only at the $1.6 \sigma$ level of significance 12 A Pearson correlation coefficient of the 33 values $[\mathrm{Kr} / \mathrm{H}]_{\mathrm{obs}}$. vs. their respective $F_{*}$, which does not take into account the measurement errors, is only -0.225 . This value differs from zero correlation only at the $89.5 \%$ confidence level (we use a one-tail test here, since we reject the possibility that $A_{\mathrm{Kr}}>0$ ), which again supports the notion that this is a weak result. (Note that the determinations of $F_{*}$ included measurements of $\mathrm{Kr}$, but the weight factors $W_{X}$ for $\mathrm{Kr}$ given in Eq. 5 are extremely small compared those of other elements because the

\footnotetext{
${ }^{12}$ In an earlier phase of this investigation, corrections for stellar $\mathrm{L} \alpha$ absorption had not yet been implemented. The significance of the negative value for $A_{\mathrm{Kr}}$ was higher at that time. After the correction was added, a number of cases that supported stronger depletions of $\mathrm{Kr}$ at large $F_{*}$ vanished because the calculated values of $N(\mathrm{H} \mathrm{I})_{\text {stellar }}$ were about equal to the uncorrected $N(\mathrm{H} \mathrm{I})_{\text {obs. }}$.
} 
depletions have relatively large errors. Thus, there is a negligible influence of the Kr measurements on $F_{*}$, which in principle could have further weakened the conclusion on the significance of the correlation.)

The fact that the abundances of Kr seem to "pay attention to" the abundances of other elements with large values of $A_{X}$ may signify that $\mathrm{Kr}$ is truly depleting and not exhibiting chance deviations caused either by real abundance variations or errors in measurement (either for $\mathrm{Kr}$ or $\mathrm{H})$. This phenomenon was not evident in a conventional comparison of $\left(\mathrm{Kr}_{\text {gas }} / \mathrm{H}\right)$ vs. $\langle n(\mathrm{H})\rangle$ in the most recent compilation of $\mathrm{Kr}$ abundances (Cartledge et al. 2008), and it indicates that this noble gas might either be attached to grains via physisorption or could possibly be trapped in a water clathrate (recall from the discussion in 10.1 .4 that there might possibly be enough $\mathrm{H}_{2} \mathrm{O}$ ice on large grains in the ISM to explain the depletion of $\mathrm{O}$ ).

\subsubsection{Trends with Condensation Temperatures}

In trying to understand why different elements show different depletion strengths, a conventional approach is to compare them with their respective condensation temperatures. The condensation temperatures indicate the points at which the elements should show an appreciable deficit in the gaseous form as the result of forming compounds in a chemical equilibrium. However, apart from formation processes in stellar atmospheres and circumstellar envelopes, the formation and destruction of compounds within dust grains is not an equilibrium process. Even so, the condensation temperature may still be used as an approximate surrogate for the relative affinity of an element to form a solid compound and be resistant to destruction by shocks. As proposed by Dwek \& Scalo (1980), the relative ease for the destruction of different compounds in grains is related to their respective sublimation energies, which are reflected by their formation temperatures through the Clausius-Clapeyron relation.

The left-hand panel of Fig. [15] shows the magnitudes of the initial depletions $\left[X_{\text {gas }} / \mathrm{H}\right]_{0}$ as a function of the condensation temperatures $T_{c}$ computed by Lodders (2003). Her values of $T_{c}$ apply to a $50 \%$ decrease in the gas phase abundance at a pressure $10^{-4}$ bar with a pre-solar distribution of abundances. Values of $\left[X_{\text {gas }} / \mathrm{H}\right]_{0}$ probably give the closest representation of the composition of grains that emerge from the atmospheres of late-type stars, supernovae, and circumstellar shells or disks. The relationship between the elements seen in this figure is similar to that for the highly depleted component toward $\zeta$ Oph: most elements show a trend of increasing depletion toward higher $T_{c}$, with the exception of $\mathrm{P}, \mathrm{Cl}, \mathrm{Mg}$ and $\mathrm{Si}$, which seem to lie above the trend established by the other elements (Savage \& Sembach 1996a).

If we now examine the differential depletions, the picture is a bit different. Recall that from Eq. 21 that the differential depletion scales in proportion to $A_{X}\left(X_{\text {gas }} / \mathrm{H}\right)_{F_{*}}$. If we normalize this rate to the concentration of atoms that are present, i.e., $\left(X_{\text {gas }} / \mathrm{H}\right)_{F_{*}}$, we get simply $A_{X}$. In effect, $A_{X}$ represents a rate coefficient that applies to the quasiequilibrium state between the punctuated 

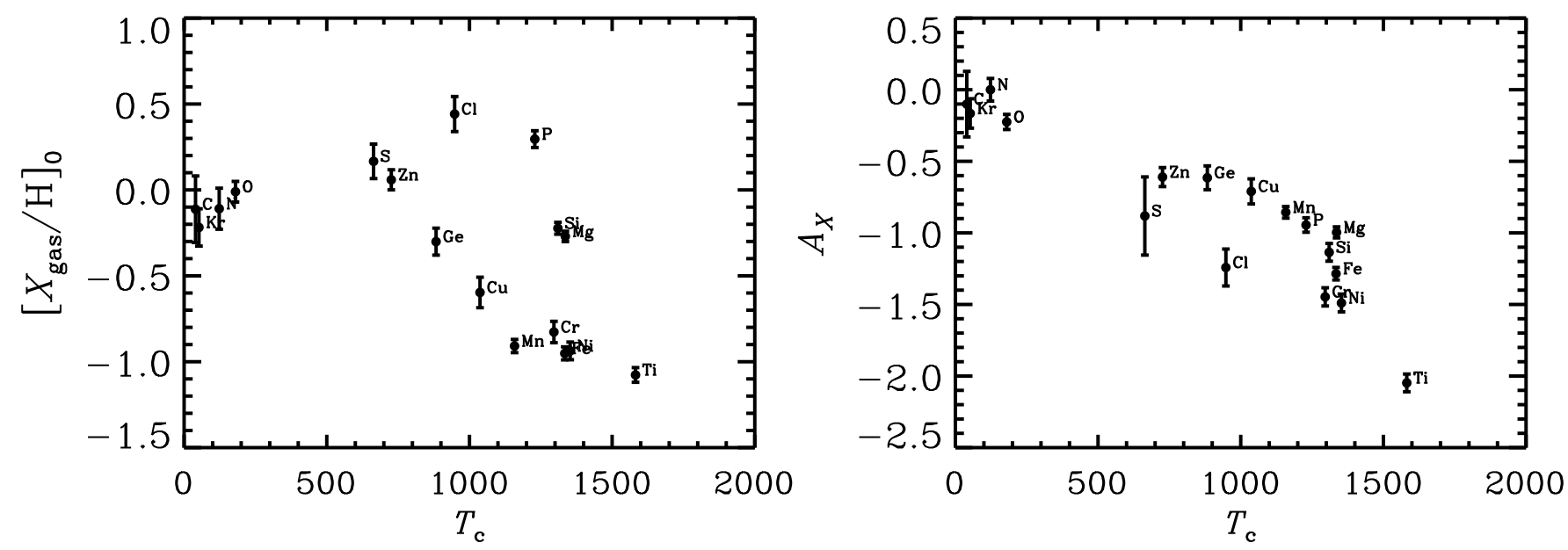

Fig. 15.- Left-hand panel: The trend of initial depletions as a function of the respective element condensation temperatures $T_{c}$ listed by Lodders (2003). Right-hand panel: Values of $A_{X}$ vs. $T_{c}$.

creation and destruction events of dust compounds (this is a loose concept because the condensation and destruction processes are physically different). The right-hand panel of Fig. 15 shows the values of $A_{X}$ as a function of $T_{c}$. The placement of the points in this diagram seems more regular than what was seen for $\left[X_{\text {gas }} / \mathrm{H}\right]_{0}$ (except for $\mathrm{Cl}$, which seems to have flipped its position relative to the other elements - but recall the remarks about $\mathrm{Cl}$ made in

\subsection{The Relationship of $F_{*}$ to Other Variables}

We are in a position to repeat some of the comparisons mentioned in $\$ 1.2$ using our generalized depletion index $F_{*}$ for each sightline instead of just concentrating on the depletions of a single element (or several elements, but in an individual fashion), as has been done in the past. Figure 16 shows the trends of $F_{*}$ against two popular extrinsic variables, the average density along the line of sight $\langle n(\mathrm{H})\rangle$ and the fraction of hydrogen atoms in molecular form $2 N\left(\mathrm{H}_{2}\right) /\left[N(\mathrm{H} \mathrm{I})+2 N\left(\mathrm{H}_{2}\right)\right]$. This figure shows that the relationship of $F_{*}$ with the former seems more well defined than with the latter. Snow, Rachford \& Figoski (2002) and Cartledge et al. (2006) arrived at a similar conclusion on the basis of their studies of the abundances of interstellar Fe, Ge, and $\mathrm{Mg}$. As one would expect, target stars at some distance from the Galactic plane have lower than usual values of $\langle n(H)\rangle$, but the color coding of the symbols indicates that their depletion indices do not seem to show any distinct differences from other sight lines with the same average density. In contrast, Sembach \& Savage (1996) found that gas identified with material in the lower halo of the Galaxy had smaller depletions than gas at comparable density in the disk [see also Savage \& Sembach (1996a)]. The appearance of such a difference probably results from the fact that they treated separately the abundances in velocity components whose kinematics were consistent with being at large distances 

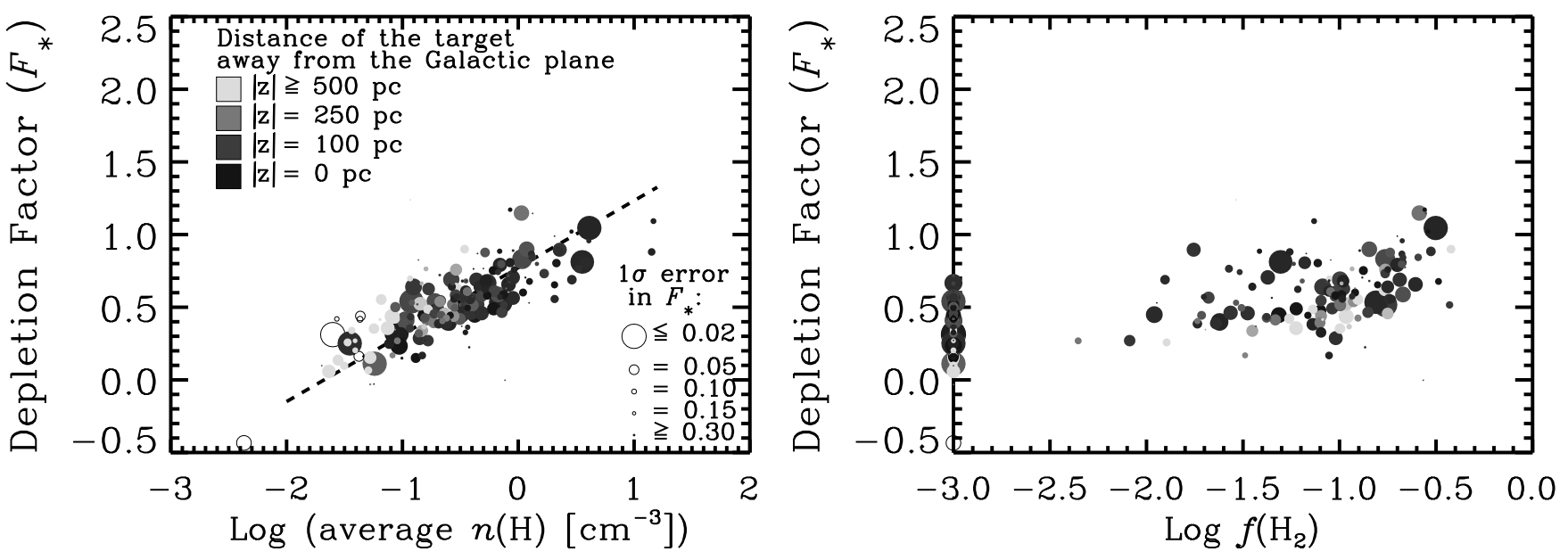

Fig. 16.- Left-hand panel: The trend of $F_{*}$ as a function of the logarithm of the average density along the respective sight lines $\langle n(\mathrm{H})\rangle$. As indicated by the legends, the sizes of the circles indicate the errors in $F_{*}$, and their shades of gray indicate the distances of the stars from the Galactic plane. Open circles indicate cases where $\log N(\mathrm{H})<19.5$. The least-squares best fit to the trend is indicated by the dashed line. Right-hand panel: The trend of $F_{*}$ against the logarithm of the fraction of hydrogen in molecular form $f\left(\mathrm{H}_{2}\right) \equiv 2 N\left(\mathrm{H}_{2}\right) /\left[N(\mathrm{H} \mathrm{I})+2 N\left(\mathrm{H}_{2}\right)\right]$. The sizes and gray levels of the points are the same as in the left-hand panel. Cases where $\log f\left(\mathrm{H}_{2}\right)<-3.0$ are all bunched together on the $y$ axis of the plot.

(i.e., far from the plane) instead of grouping all of the gas together, as in this study. An illustration of the importance of this distinction was shown earlier in Fig. 9 for the star HD 116852. Gas at progressively more negative velocities exhibited less depletion, and this material is farther from the Galactic plane (Sembach \& Savage 1996).

A linear least-squares best fit to the trend shown in the left-hand panel of Fig. 16 follows the formula $F_{*}=0.772+0.461 \log \langle n(\mathrm{H})\rangle$ indicated by the dashed line. This fit was evaluated in a way that minimized errors both in $F_{*}$ and $\log \langle n(\mathrm{H})\rangle$. For the former, we take the actual estimates for the uncertainties in $F_{*}$ [see column (6) of Table 5], and for the latter, we assume that the errors are dominated by the errors in the distances, which was assumed to be a uniform value of 0.2 dex (mostly from a $1 \mathrm{mag}$ error in $M_{V}$; see Appendix B3 of Bowen et al. (2008) for details on the probable errors in distances). In evaluating the fit, the protocol of accepting only sight lines where $N(\mathrm{H})>10^{19.5} \mathrm{~cm}^{-2}$ was followed (see rule $\mathrm{nr} .3 \mathrm{in} 4.2$ ). Such cases are indicated by the filled circles in the figure. The vertical dispersion of points on either side of the best fit line is 0.18. The $\chi^{2}$ value for the fit is 285 for 175 degrees of freedom, indicating that the natural dispersion is somewhat larger than that created by our errors in $F_{*}$ and $\log \langle n(\mathrm{H})\rangle$.

For the fit of $F_{*}$ vs. $\log \langle n(\mathrm{H})\rangle$, there seems to be no departure from a simple linear trend, which seems contrary to the assertion by Cartledge et al. $(2004,2006)$ that a more complex association 
between the two variables exists in the form of two plateaus with a transition between them at an intermediate value of $\log \langle n(\mathrm{H})\rangle$ (they used a Boltzmann function to express this behavior). In their study of several different elements, the value of $\log \langle n(\mathrm{H})\rangle$ for the transition region seemed to change somewhat from one element to the next, so the structure of this functional relationship may be lost when the generalized depletions based on many different elements are evaluated. Another alternative is that the extra parameters needed to define the Boltzmann function are not fully justified by the data, given the uncertainties present. The same remarks apply to the nonlinear forms shown by Jenkins, Savage \& Spitzer (1986), who showed functions that fitted within the theoretical interpretation published earlier by Spitzer (1985).

We can repeat the comparison of $F_{*}$ against the average of $n(\mathrm{H})$ along sight lines for the white dwarf star sight lines that were analyzed in 98 . Figure 17 shows this comparison and how it relates to the trend line shown in the left-hand panel of Fig. 16 for the early-type stars at greater distances. The correlation between $F_{* \text { syn. }}$ and $n(\mathrm{H})_{\text {syn. }}$ is clear, and most of the points lie above the trend that was found for the more distant stars. Again, we express the caution that this difference could arise from the effects of photoionization.

Finally, a definition of our $F_{*}$ parameter in the context of the summary of abundances given by Savage \& Sembach (1996a) is presented in Appendix C.1. This comparison is presented to allow one to place later works that made use of these generalized abundance patterns into the framework of the present study.

\subsection{Regional Differences in Total Abundances}

In $₫ 4.2$, we expressed reservations about using data from stars located at Galactocentric distances much different from that of the Sun. It is of interest to see if this concern was warranted, now that we have determined the coefficients $F_{*}$ for all sight lines, but used only stars inside the range $7<R_{\mathrm{GC}}<10 \mathrm{kpc}$ for determining the element parameters $A_{X}$ and $B_{X}$. In essence, we wish to see if the interstellar line data show any hint of the gradient of overall abundances that have been detected for stars, planetary nebulae and H II regions [see the references cited within rule nr. 7 in 4.2 and also Table 1 of Rolleston et al. (2000)].

It also would be interesting to see if there are metallicity changes that mimic in any way the more specific abundance deviations reported in the literature for certain elements, such as an apparent enhancement of $\mathrm{N}_{\text {gas }} / \mathrm{O}_{\text {gas }}$ within 500 pc of the Sun reported by Knauth et al. (2006) or the increase in $\mathrm{Kr}_{\text {gas }} / \mathrm{H}$ within an annulus $600<r<2500$ pc discussed by Cartledge et al. (2008).

A method for determining the overall metallicity of the gas that should be independent of the amount of depletion in a line of sight is to compare the synthetic determinations of hydrogen $N(\mathrm{H})_{\text {syn. }}$, calculated on the basis of only the values of $N(X)$ in conjunction with their respective $A_{X}$ and $B_{X}$ in 97 , with the observed counterparts $N(\mathrm{H})_{\text {obs. }}$. The ratio of the two should indicate

the relative excess or deficiency of the total heavy element abundances (gas + dust), compared to 


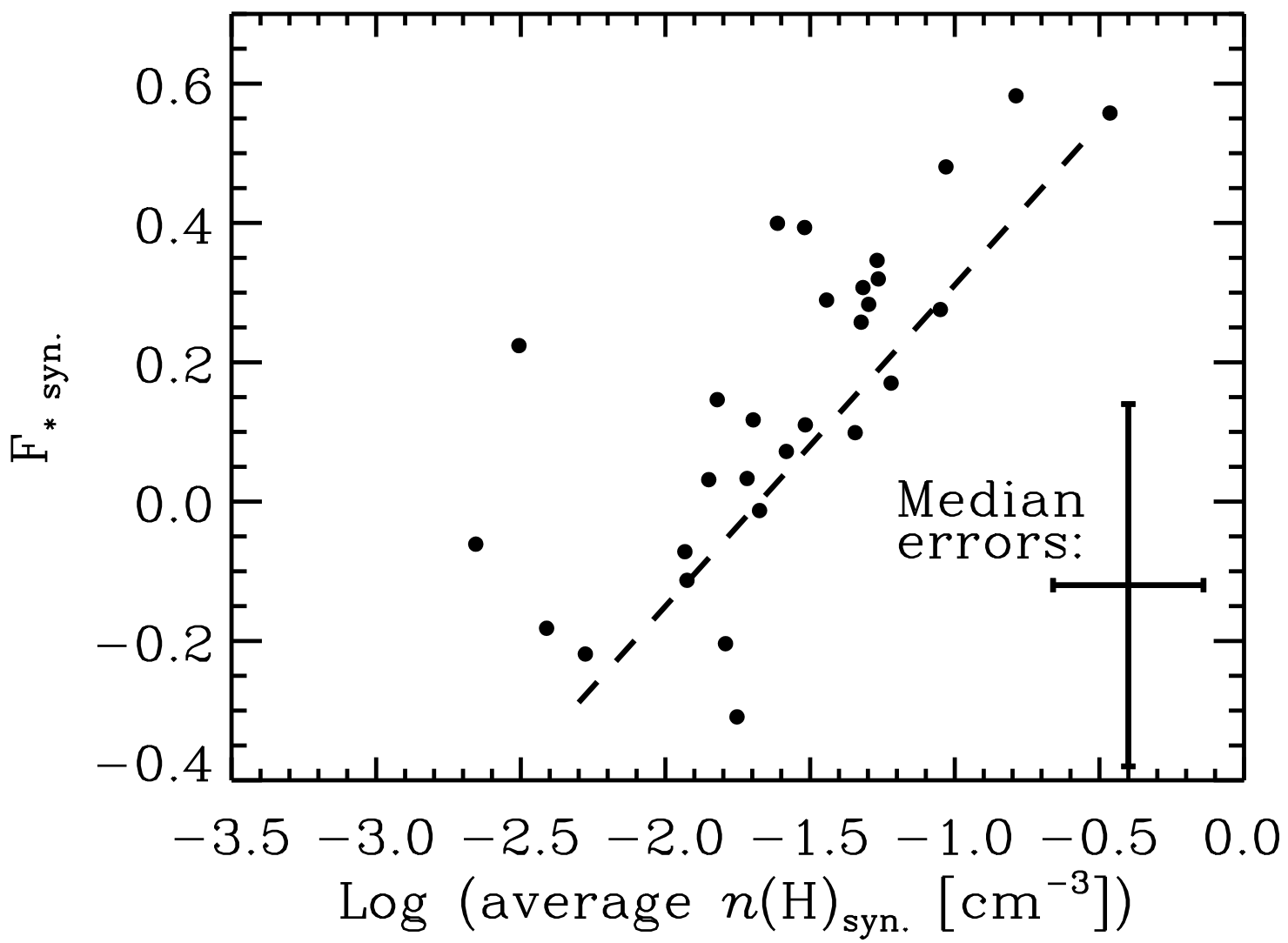

Fig. 17.- The relationship between $F_{* \text { syn. }}$ and the average sight line density (determined from $N(\mathrm{H})_{\text {syn. }}$ ) for the white dwarf stars in the Local Bubble, whose locations and distances are indicated in Fig. 13. Most of the estimated errors for the points in this figure have a size about equal to the bars shown in the lower right-hand portion of the plot. The diagonal dashed line indicates the location of the fit to the points shown in left-hand panel of Fig. 16. 


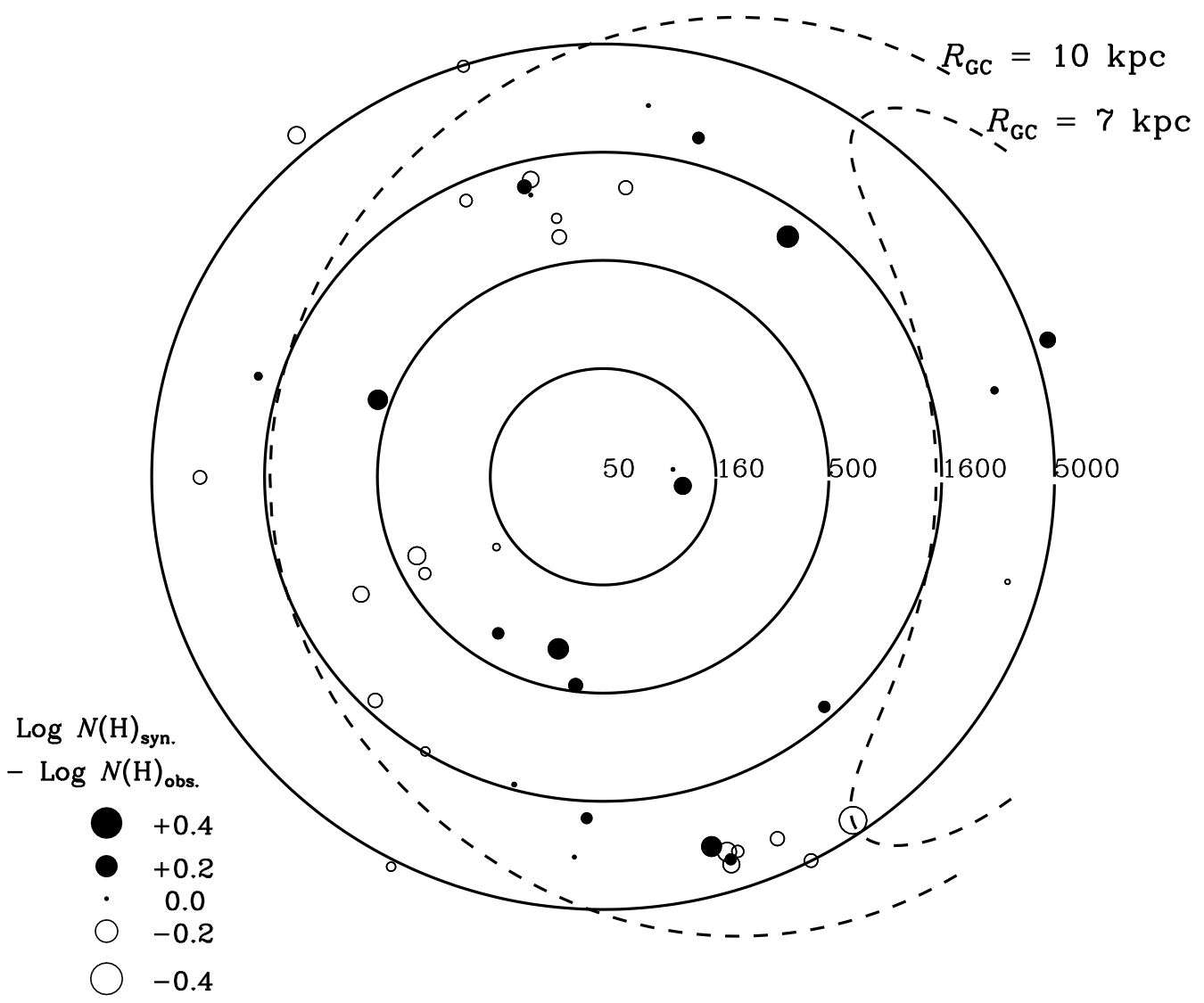

Fig. 18. - Differences in overall metallicity (gas + dust) with respect to locations relative to the Sun, as indicated by the quantity $\log N(\mathrm{H})_{\text {syn. }}-\log N(\mathrm{H})_{\text {obs. }}$. The only points that are shown are those with $N(\mathrm{H})_{\text {obs. }}>10^{19.5} \mathrm{~cm}^{-2}$ and where the ratio of the two values of $N(\mathrm{H})$ is known to an accuracy of $<0.1 \mathrm{dex}$. Solid circles indicate gas that is metal rich, and open ones indicate the opposite condition. The Galactic center is to the right, and this polar representation has the distance from the Sun represented in a logarithmic fashion. The dashed lines indicate locations that are 7 and $10 \mathrm{kpc}$ from the Galactic center. 
their pre-solar values. That is, if $N(\mathrm{H})_{\text {syn. }}<N(\mathrm{H})_{\text {obs. }}$, we would conclude that the gas is metal poor.

Figure 18 shows a depiction of excesses and deficiencies of $\log N(\mathrm{H})_{\text {syn. }}-\log N(\mathrm{H})_{\text {obs. }}$ in a polar coordinate system that is logarithmic in radius and centered on the Sun. The points shown in this diagram are restricted to cases where both $N(\mathrm{H})_{\text {syn. }}$ and $N(\mathrm{H})_{\text {obs. }}$ are known, the error of their difference is less than $0.1 \mathrm{dex}$, and $N(\mathrm{H})_{\text {obs. }}>10^{19.5} \mathrm{~cm}^{-2}$. The locations of the solid and open circles appear to be random, indicating that no coherent changes in metallicity appear to be detected in different, readily identifiable locations. Of course, real differences may be masked by the averaging effect over the sight line that extends from the location of the Sun to that of the star. Unfortunately, there are too few sight lines that extend outside the zone $7<R_{\mathrm{GC}}<10 \mathrm{kpc}$ and that satisfy the restrictions given above to offer a good test of the metallicity gradient with galactocentric distance.

\subsection{Applications for Abundances in Quasar and GRB Absorption Line Systems}

\subsubsection{Introductory Remarks}

There have been many contemporary studies of element abundances in the Damped Lyman Alpha (DLA) and sub-DLA gas systems in front of quasars (Lu et al. 1996; Prochaska \& Wolfe 2002; Pettini 2003; Prochaska, Howk, \& Wolfe 2003; Dessauges-Zavadsky et al. 2004; Wolfe, Gawiser, \& Prochaska 2005), as well as gases within or in front of the host galaxies of gamma-ray burst (GRB) sources that had bright afterglows in the visible part of the spectrum (Prochaska et al. 2007; Calura et al. 2009). A persistent problem with attempts to derive the intrinsic abundances of the elements has been the need to correct for the effect of depletion on the column density results. Early work on the abundances of these systems concentrated on the elements zinc and chromium (Meyer \& Roth 1990; Pettini, Boksenberg, \& Hunstead 1990), whose lines were easily accessible in the visible for low- $z$ systems (Pettini 2003). Since it was known that the depletion of zinc is usually small and chromium large, approximate depletion corrections could be made by comparing the abundances of these elements to their solar abundance ratios.

Advances with larger, more sensitive telescopes and spectrographs led to studies of a wider range of elements, since transitions with short wavelengths in the rest frame could be viewed in systems at large redshifts in front of faint quasars. While opening up more elements for study has led to significant progress in chemical evolution studies of distant systems, investigators have still been hampered by a near degeneracy between the effects of dust depletion and those arising from shifts in the ratio of elements arising from $\alpha$-capture processes compared to those associated with the iron peak (chiefly coming from Type 1a supernovae), since many of the iron peak elements are strongly susceptible to depletion while the $\alpha$-process elements are usually much less so (DessaugesZavadsky, Prochaska, \& D'Odorico 2002; Prochaska \& Wolfe 2002). One can bypass the issue of dust by focusing on very mildly depleted elements such as C, N, O, Ar and Zn to measure the 
overall metallicity of the gas, but except possibly for $\mathrm{Zn}$, there is little leverage in learning about the $\alpha /$ Fe ratio, which is important for our understanding of the stellar initial mass functions and formation histories of the DLAs. Likewise, one may study systems that are known to contain very little dust, but this selection can introduce a sample bias that could lead to false conclusions on the chemical evolution of systems in general. Finally, one can take a broader approach by correcting for the effects of dust depletion, using information based on the empirical evidence on how element abundances change with the formation of dust in our Galaxy. We explain how to do this here.

\subsubsection{The Current Proposal to Correct for Dust Depletions}

As a way to interpret the abundances observed in an absorption system with an unknown overall metallicity and level of dust depletion, we can start with an initial guess that the intrinsic abundance pattern is not much different from that of our Galaxy, aside from an overall elevation

or depression of all elemental abundances with respect to hydrogen. We then employ the method outlined in $\$ 7$ to determine the severity of depletion, as represented by $F_{*}$ (the slope of the trend of $y$ vs. $x$ ). If $N(\mathrm{H} \mathrm{I})$ can be determined by observing the L $\alpha$ absorption (either from a space observatory for low- $z$ absorption systems or from the ground for high- $z$ systems), the difference between the synthetic $N(\mathrm{H})$ and the real one indicates the metallicity of the system relative to that of the Galaxy. Next, we can examine the validity of the assumption that the pattern is not much different from that of our Galaxy by examining how well the element abundances conform to a straight line in $y$ vs. $x$, as exemplified by Fig. 9 for two sight lines in our Galaxy (but recall that these two panels show special demonstrations of poor fits). Certain patterns of deviations from a straight line could serve as a warning that alternate intrinsic abundance patterns must be considered. (While this may be true, one must be watchful that one is not being deceived by effects of seeing mixtures of regions with different values of $F_{*}$, as exemplified by the lower panel of Fig. 9 , It is noteworthy that on the one hand Prochaska (2003) found that abundance variations from all possible causes for different velocity components in 13 different DLA systems were less than 0.2 dex. On the other hand, Dessauges-Zavadsky et al. (2006) found that for some DLAs there were pronounced variations in some abundance ratios, sometimes $>0.3 \mathrm{dex}$, which they interpreted to arise from changes in the depletion levels from one cloud to the next.)

As we move on to gas systems that we have good reason to believe to have intrinsic abundance patterns that are different from that of our Galaxy, we must rely on a more general approach, but one that still makes use of information provided by the current study. It is clear from the differences of the slopes of the trends shown in lower panels of Figs. 5 to 8 that the progressively increasing scarcity of certain elements starts to modify the composition of added material on the grains as they become larger or more numerous (i.e., as $F_{*}$ increases). In such circumstances, it seems sensible to imagine that different atoms have their own proclivities to attach themselves to dust grains and form compounds, which forces the grain compositions to be regulated by the effective reaction rate constants of the elements (i.e., in a regime of only grain growth, we may 
think of such rate constants in terms of the atomic sticking efficiencies times their mean velocities) multiplied by their respective concentrations at any given time. As we pointed out near the end of 10.1.8, the $A_{X}$ terms derived here represent just such a collection of rate constants.

\subsubsection{Possible Complications}

A few cautionary remarks are in order for gas systems whose initial compositions differ appreciably from those in our Galaxy. In the following paragraphs, these cautions will be expressed, and it is important to emphasize that they apply to any dust correction scheme for abundances - not only the one proposed here.

One could imagine that for any arbitrary mixtures of gas-phase elements, one could simply integrate the equations for the condensations as a function of time (or grain growth), using the $A_{X}$ values as rate constants. However, such an approach invokes the assumption that the retention of atoms after an initial sticking is in no way driven by the composition of the existing grain material. This may not be correct. Most elements probably depend on the presence of others to form chemically stable compounds that are durable enough to remain in solid form for long periods of time. For instance, Lodders (2003) presented examples where the elements $\mathrm{Ni}$ and Ge depend on the presence of a host element Fe to create an alloy. Likewise, $\mathrm{Mg}, \mathrm{Si}$ and $\mathrm{O}$ are needed to form the host minerals forsterite and enstatite that are pathways to synthesize the most refractory compounds of $\mathrm{Zn}\left(\mathrm{Zn}_{2} \mathrm{SiO}_{4}\right.$ and $\left.\mathrm{ZnSiO}_{3}\right)$ and $\mathrm{Mn},\left(\mathrm{Mn}_{2} \mathrm{SiO}_{4}\right.$ and $\left.\mathrm{MnSiO}_{3}\right)$. Thus, while we may note from Table 4 that $A_{\mathrm{Zn}}$ is about the same as $A_{\mathrm{Ge}}$, in an environment where the $\alpha / \mathrm{Fe}$ ratio differs appreciably from that of our Galaxy, one or the other of these two elements could be more starved for its respective host element(s) and could thus would probably behave differently from what we have observed here.

Another complication is the possibility that there could be large differences in dust-to-gas ratios and grain compositions in the ejecta of various kinds of sources that enrich a galaxy throughout its lifetime, such as evolved stars or different varieties of supernovae (Dwek 1998; Kozasa et al. 2009). It is well known that contributions of differing proportions from these sources throughout the history of a system's chemical evolution will change the intrinsic mix of elements with time (Calura, Pipino, \& Matteucci 2008), but they might also induce changes in the populations of either the primitive grains or the resilient cores of mature grains that do not normally grow or decline in the ISM. These primitive grains (or grain cores) are probably major contributors to the depletions seen at $F_{*}=0$. Thus, while values of $A_{X}$ might accurately describe how elements accrete onto grains as they grow in the ISM, the overall offsets represented by $B_{X}$ could be influenced by the amounts and compositions of grains ejected by the sources.

As a simple illustration of how differing properties of grains in the ejecta of metal sources might create misleading conclusions, we can consider some comparisons of Si and Fe seen in the absorption spectra of DLAs. From entries in Table 4, we note that $A_{\mathrm{Si}} \approx A_{\mathrm{Fe}}$, so that differences in 
the depletions of these two elements do not change much with differing values of $F_{*}$. The minimum separation between $\left[\mathrm{Si}_{\text {gas }} / \mathrm{H}\right]$ and $\left[\mathrm{Fe}_{\text {gas }} / \mathrm{H}\right]$ occurs at $F_{*}=0$ and has a value of 0.73 dex. (A small decrease in this number could be realized by extrapolating the depletion trends to negative values of $F_{*}$, but not beyond that which makes $\left[\mathrm{Si}_{\text {gas }} / \mathrm{H}\right]>0$.) Wolfe, Gawiser \& Prochaska (Wolfe, Gawiser, \& Prochaska 2005) show measurements of [Si/Fe] in the gas phase (i.e., without any dust correction) as a function of $[\mathrm{Si} / \mathrm{H}]$ for a collection of high quality observations of DLAs (see their Fig. 8). Their plot shows that $[\mathrm{Si} / \mathrm{Fe}] \approx 0.3$ for $[\mathrm{Si} / \mathrm{H}] \lesssim-1.0$, and it increases somewhat for systems that have $\mathrm{Si}$ abundances that approach that of our Galaxy. On the one hand, if we simplistically apply our minimum correction for differences in dust depletion, we arrive at an intrinsic $[\mathrm{Si} / \mathrm{Fe}] \approx-0.4$. Correction factors of about the same magnitude were shown by Calura, Matteucci \& Vladilo (2003), but their corrected [Si/Fe] are not as low because their observed values of $[\mathrm{Si} / \mathrm{Fe}]$ started out at values that were generally higher than +0.3 dex. Of course, in this context it is possible that long, quiet periods between bursts of star formation could produce $[\alpha / \mathrm{Fe}]<0$ (Gilmore \& Wyse 1991), and indeed the sequence of $[\alpha / \mathrm{Fe}]$ as a function of $[\mathrm{Fe} / \mathrm{H}]$ for dwarf galaxies and the LMC is $\sim 0.1-0.3$ dex below that seen for stars in our Galaxy (Venn et al. 2004). On the other hand, it is quite possible that we could be misled in our interpretation if all of the following conditions apply: (1) Type Ia supernovae eject most of their Fe-peak elements eventually in the form of dust - a prospect that seems to have no observational support (Draine 2009), (2) this material is not significantly reprocessed through subsequent generations of stars and (3) core collapse supernovae do not form nearly as much dust in their ejecta as the Type Ia supernovae. In such circumstances, the depletion corrections could be distorted by the differing proportions of primitive grain production sites, compared to those in the present-day Galaxy (where the effects Type Ia supernovae are more influential than in the more primitive proto-disk galaxy systems), leading to corrected abundances that do not properly reflect the intrinsic gas + dust compositions of these other systems.

A strategy for checking on the complications discussed above is to examine many different elements simultaneously. For example, one might supplement the Si and Fe determinations discussed in the above paragraph with measurements of Ti (Dessauges-Zavadsky, Prochaska, \& D'Odorico 2002; Ledoux, Bergeron, \& Petitjean 2002), which is an $\alpha$-process element that has large depletion parameters, even larger than those of $\mathrm{Fe}$. If the depletion of $\mathrm{Ti}$ seems to be in the correct proportion to that of $\mathrm{Fe}$, after correcting for a different intrinsic $[\alpha / \mathrm{Fe}]$, then our misgivings about the effects of vastly different grain productions in different sources may be unwarranted.

Again, we suggest that to obtain the best general understanding of the complex processes that may influence the observed abundances in DLAs, the most productive insights may arise from examinations of the plots of $y$ vs. $x$ for individual absorbing systems. Such plots may be far more instructive than a battery of correlation plots that compare for many systems the various combinations of element abundance ratios. 


\subsubsection{Other Dust Correction Methods}

In the recent past, investigations of DLA system abundances have relied on different schemes for correcting for dust depletion. For instance, Vladilo (2002b) devised a method to account for dust depletion in DLAs, using information on dust grain compositions derived from the summary of interstellar abundances under different conditions in our Galaxy given by Savage \& Sembach (Savage \& Sembach 1996a) (see Appendix C.1). Vladilo's abundance corrections worked with parameters linked to the amounts of elements within the dust grains, with some recognition that these processes might change with different overall metallicities. Since this approach has been used to correct the observed abundances in a number of recent studies (Calura, Matteucci, \& Vladilo 2003; Centurión et al. 2003; Dessauges-Zavadsky et al. 2004, 2007; Vladilo 2004; Vladilo et al. 2006; Quast, Reimers, \& Baade 2008), it may be helpful re-express his abundance compensation parameters in the light of the parameters in the current study, so that we have a clearer understanding of what changes were made in the previous investigations. This is done in Appendix C.2.

In Appendix C.3 there is a similar cross calibration for two depletion parameters $\kappa^{\mathrm{Zn}}$ and $\kappa^{\mathrm{Si}}$ defined by Prochaska \& Wolfe (2002) in their study of elements seen in their collection of DLAs. It is important to realize that there is no fundamental reason why distant DLAs could not have values of $F_{*}$ less than zero, since their intrinsic metallicities $[\mathrm{M} / \mathrm{H}]$ range from about -2.5 to -0.5 dex (Wolfe, Gawiser, \& Prochaska 2005). Our condition $F_{*}=0$ applies to the arbitrary condition (but a practical one in our case) that the logarithm of the metallicity $[\mathrm{M} / \mathrm{H}]=0$ and $N(\mathrm{H}) \approx 10^{19.5} \mathrm{~cm}^{-2}$. While $F_{*}<0$ might seem to be a reasonable outcome for such systems with very low concentrations of metals, especially those at the lower limit of $N(\mathrm{H} \mathrm{I})=10^{20.3} \mathrm{~cm}^{-2}$ for the standard definition of a DLA, in practice a comparison of our Fig. 21 with Fig. 22 of Prochaska \& Wolfe (2002) indicates that $F_{*}$ is always greater than zero.

\section{Summary}

The principal aim of this study has been to arrive at a simple, generalized description of the depletions of atoms in the interstellar medium of our Galaxy. The objective is not only to help us understand the elemental composition of dust grains, and how it changes as depletions increase, but also to provide the necessary guidance on how to correct for deviations in elemental abundances caused by dust grain depletions in distant gas systems that can be studied via their absorption lines in the spectra of quasars or GRB afterglows.

It has been known for some time that the strengths of depletions vary from one region to the next. However, to a remarkable degree of uniformity, we find that as these general depletion strengths vary, the logarithms of the depletion factors of different elements $\left[X_{\text {gas }} / H\right]$ are related to each other in a linear fashion that can be described by an equation

$$
\left[X_{\text {gas }} / \mathrm{H}\right]=B_{X}+A_{X}\left(F_{*}-z_{X}\right)
$$


where $B_{X}$ and $A_{X}$ are empirically determined constants that apply to each element $X$, and $F_{*}$ is a generalized depletion strength parameter that applies to the line of sight through the ISM that is under study. The zero-point offset for any element $z_{X}$ that applies to $F_{*}$ is added to the equation simply to make the measurement errors in $B_{X}$ and $A_{X}$ independent of each other (and its value is governed only by the distribution of $F_{*}$ values and their errors in the sample).

A large accumulation of interstellar column densities gathered from the literature has been used to establish the validity of this simple model for depletions, as well as to provide the most likely values for the $F_{*}$ line-of-sight parameters and the two constants $B_{X}$ and $A_{X}$ for 17 different elements. The data were screened to eliminate determinations that may have been compromised by uncertain corrections for line saturation, and in many cases the column densities were corrected in a manner to make them conform to a modern compilation of transition $f$-values. For all of the elements except sulfur, which was handled separately, the two constants are listed in Table 4, In establishing these constants, we considered only those sight lines that had $N(\mathrm{H})>10^{19.5} \mathrm{~cm}^{-2}$, in order to decrease the chances that we could have been misled by unseen ionization stages, either for the element in question or hydrogen. Values of $F_{*}$ and/or $F_{* \text { syn }}$ for 239 separate regions are listed in Table 5 (these include, for a few cases, some separate velocity components exhibited for some single sight lines and also sight lines that had $N(\mathrm{H})$ below our established column density threshold). In a separate exercise, indirectly determined (synthetic) values of $N(\mathrm{H})$ and $F_{*}$ were evaluated for 29 white dwarf stars in the Local Bubble and listed in Table 6.

In conventional investigations of the elemental composition of dust grains, one compares the observed values of $N(\mathrm{X})$ to those expected from some adopted standard for the total abundance, most often taken from either a solar or meteoritic abundance (or the abundances of nearby B-type stars). The difference between a total abundance $(X / \mathrm{H})_{\odot}$ and $(X / \mathrm{H})_{\text {ISM }}$ indicates the quantity of the element that is locked up in solid form. One can apply this method to the measurements reported here, but the accuracy of the outcome is strongly driven by how well the adopted total abundance $(X / H) \odot$ conforms to reality. While this approach is needed to obtain the total makeup of the grains, another useful tactic is to study differences in specific elemental depletions as the overall levels of depletion increase. The outcome here is entirely independent of whatever one adopts for the total abundances. For any given value of $F_{*}$, the differential dust composition scales in proportion to $A_{X}\left(X_{\text {gas }} / \mathrm{H}\right)_{F_{*}}$.

For any sight line where $N(\mathrm{H})$ has not been observed, one does not have explicit measurements of any depletions. Nevertheless, by making use of the information on how elements deplete in a collective manner, we can derive reasonably accurate (synthetic) values of $F_{*}$ and $N(\mathrm{H})$ if we have column density measurements $N(X)$ for several elements that have large differences in $A_{X}$ and perform a least-squares fit of the quantities $\log N(X)-\log (X / \mathrm{H})_{\odot}-B_{X}+A_{X} z_{X}$ against their respective values of $A_{X}$. While this is a useful tool for overcoming our inability to measure directly $N(\mathrm{H})$ for any of several possible reasons, its greatest utility should be an application to the study of intrinsic element abundances in absorption-line systems seen in the spectra of distant quasars or the optical afterglows of GRBs. Specifically, one can compare the measured value of $N(\mathrm{H})$, 
obtained through an observation of the $\mathrm{L} \alpha$ absorption, to the synthetic value of $N(\mathrm{H})$ derived from the pattern of element column densities. The ratio of $N(\mathrm{H})_{\text {syn. }}$ to $N(\mathrm{H})_{\text {obs. }}$ yields the metallicity of the system relative to that of our Galaxy. The value of $F_{* \text { syn. }}$ indicates the dust content of the system. However, caution is advised for systems that are suspected to have a pattern of intrinsic abundances that differs appreciably from that of our Galaxy. For systems outside our Galaxy that are not too distant (e.g. the Magellanic Clouds), one should be able to validate the concept of using $N(\mathrm{H})_{\text {syn. }} / N(\mathrm{H})_{\text {obs. }}$ to obtain a metallicity by comparing the outcome to the average metallicity of the embedded stars.

The above paragraphs outline the basic themes contained in this paper. Some additional, more specific insights that came from this investigation are as follows:

1. Except for the elements $\mathrm{C}, \mathrm{N}, \mathrm{O}, \mathrm{P}, \mathrm{Cl}, \mathrm{S}$, and $\mathrm{Zn}$, all elements show some measurable depletion at $F_{*}=0$. For the elements $\mathrm{Ti}, \mathrm{Cr}, \mathrm{Mn}, \mathrm{Fe}$, and $\mathrm{Ni}$, these base depletions $\left[X_{\text {gas }} / \mathrm{H}\right]_{0}$ are of order -1 dex. They correlate moderately well with their respective condensation temperatures $T_{c}$, but the correlation of the depletion slopes $A_{X}$ with $T_{c}$ is even better.

2. Nitrogen appears to be the only element that does not show progressively stronger depletions as $F_{*}$ approaches 1 . There are too few measurements of carbon to establish whether or not the apparent strengthening of its depletion with $F_{*}$ is real. For both of these elements, the errors are large enough to permit the progressive incorporation of these atoms (by number) to still exceed the accumulations of $\mathrm{P}, \mathrm{Cl}, \mathrm{Cr}, \mathrm{Mn}, \mathrm{Fe}, \mathrm{Ni}, \mathrm{Zn}, \mathrm{Ti}, \mathrm{Cu}, \mathrm{Ge}$ or $\mathrm{Kr}$ when $F_{*} \approx 0$ and also $\mathrm{Mg}$ or Si when $F_{*}=1$.

3. Until now, the observed small variations of $\left[\mathrm{Kr}_{\text {gas }} / \mathrm{H}\right]$ seemed random (and possibly driven either by changes in intrinsic abundances of this element from one place to the next or by observational uncertainties). The apparent correlation of this quantity with $F_{*}$ in the current investigation suggests that the relative gas-phase abundance of this chemically inert element is coupled to those of other elements, but at a very low level. A possible means for depleting $\mathrm{Kr}$ is either physisorption on the surfaces of dust grains or locking within water ice clathrates.

4. For chlorine, there might be a mild misrepresentation of the relationship for its gas-phase abundance with respect to $F_{*}$. In part, the observational errors for $N(\mathrm{Cl}$ II) are larger than for other elements, but a more important effect is reversion of some of the atoms to a neutral form through a series of reactions with $\mathrm{H}_{2}$. This could be especially important at large values of $F_{*}$, where the fractional abundances of $\mathrm{H}_{2}$ are large. There are some known cases where $N(\mathrm{Cl} \mathrm{I})>N(\mathrm{Cl} \mathrm{II})$, according to JSS86.

5. The differential depletion of oxygen at low levels of $F_{*}$ is just barely consistent with the consumption of $\mathrm{O}$ in the form of oxides and silicates. For $F_{*} \approx 1$ this is no longer true: the loss of $\mathrm{O}$ atoms from the gas phase far outstrips the production of silicates and oxides, suggesting that the formation of compounds involving abundant partner elements such as $\mathrm{H}$ or C may play an important role. While $\mathrm{N}$ is abundant, it does not have differential depletions 
that are large enough to help explain the consumption of $\mathrm{O}$. The large loss of oxygen atoms from the gas phase found in the present study is very difficult to reconcile with current models of interstellar grains.

6. Even though the average density $\left\langle n_{\mathrm{H}}\right\rangle=N(\mathrm{H}) / d$ is a crude representation for the true local densities experienced by most of the atoms, we find that this quantity still exhibits a tight correlation with $F_{*}$. This same correlation is seen for both the distant stars and for sight lines within a regime of generally low space densities within the Local Bubble. The surprisingly good relationship between average density and depletion strength supports the notion that either the lines of sight exhibiting high $\left\langle n_{\mathrm{H}}\right\rangle$ have gas that is contained within, or has recently evolved from, very dense regions where rapid grain growth can occur or that these regions of space are better shielded from destructive, high velocity shocks, or both. The fraction of hydrogen in molecular form does not show a correlation that is probably any better than a secondary one that should arise from the correlation between $f\left(\mathrm{H}_{2}\right)$ and $\left\langle n_{\mathrm{H}}\right\rangle$.

7. By comparing synthetic values of $N(\mathrm{H})$ with the observed ones, we see no evidence for changes in the intrinsic abundances of heavy elements in different regions around the Sun. The pattern of observed deviations seems random.

8. More needs to be done: additional data of good quality are needed to define better the differential depletion relationships of $\mathrm{C}, \mathrm{S}$ and $\mathrm{Kr}$, to see if their values of $A_{X}$ are truly nonzero. Also, with the increase in sensitivity provided by the Cosmic Origins Spectrograph that will be installed on the forthcoming $H S T$ servicing mission, we should have an opportunity to observe lines of sight with greater extinctions (and hence probably much higher $F_{*}$ ), so that we can obtain extend our reach to denser clouds and obtain a better understanding of chemically active environments that are better protected from uv dissociation.

This research was supported by Program number HST-AR-10279.01-A which was provided by NASA through a grant from the Space Telescope Science Institute, which is operated by the Association of Universities for Research in Astronomy, Incorporated, under NASA contract NAS526555. The author acknowledges the great utility of the SIMBAD and VizieR catalog databases, operated at CDS, Strasbourg, France, which provided critically important information on the target stars included in this survey. The author thanks B. T. Draine, J. X. Prochaska, B. D. Savage, U. J. Sofia and G. Wallerstein for providing helpful comments after reading a draft version of this article.

Facilities: HST(STIS), FUSE, Copernicus, IUE 


\section{A. Errors in Quotients}

For several equations in 93 , we must evaluate the uncertainties of quotients of two terms, each of which have their own errors. In order to do so, we make use of Geary's (1930) approximation for the frequency distribution of the quotient of two quantities that each have normally distributed errors. According to Geary, for a quotient

$$
z=\frac{b+y}{a+x}
$$

involving a denominator $a$ and numerator $b$ that have respective normally distributed errors $x$ with a standard deviation $\alpha$ and $y$ with a standard deviation $\beta$, the quantity

$$
t(z)=\frac{a z-b}{\sqrt{\alpha^{2} z^{2}-2 r \alpha \beta z+\beta^{2}}}
$$

has a normal distribution with a mean of zero and standard deviation of unity, provided that $a+x$ is unlikely to be negative (i.e., $a / \alpha \gtrsim 3$ ). (The quantity $r$ in Eq. A2 is the correlation coefficient of $x$ and $y$, which in our applications within $\$ 3$ is always assumed to be zero.) After squaring both sides of Eq. A2 and collecting terms in $z$ and $z^{2}$, we have a quadratic equation,

$$
\left(t^{2} \alpha^{2}-a^{2}\right) z^{2}+\left(2 a b-2 t^{2} r \alpha \beta\right) z+\left(t^{2} \beta^{2}-\beta^{2}\right)=0
$$

whose roots give the extreme values of $z$ that bound the possible combinations of $b / a$ at the " $t \sigma$ level of significance." For the errors that appear in Eqs. 5] and 9, we evaluate half of the difference between the two roots for $t=1$.

\section{B. A Compilation of the Basic Data and Sight-Line Depletion Factors}

Tables 7 through $2 \sqrt{13}^{13}$ show the basic measurements of column densities (columns (3)-(5)) for each of the elements considered in this study, with the codes that signify the sources in the literature [column (6)] that are linked to references shown in column (2) in Table 1, All of the logarithms of the column densities have been corrected for changes in $f$-values (44.4) by adding the factors expressed in dex for the appropriate elements given in Table 1. Column (7) of the element tables shows the value of the depletion index $F_{*}$ and its error for the star in question, determined from Eqs. 4 and 6 , respectively. This column is followed one that shows the expected depletion of the element $\left[X_{\text {gas }} / \mathrm{H}\right]_{\text {fit }}$, calculated from Eq. 10 with the coefficients shown in Table 4, The error in this term,

$$
\sigma\left(\left[X_{\text {gas }} / \mathrm{H}\right]_{\text {fit }}\right)=\sqrt{\sigma\left(B_{X}\right)^{2}+\left[\left(F_{*}-z_{X}\right) \sigma\left(A_{X}\right)\right]^{2}+\left[A_{X} \sigma\left(F_{*}\right)\right]^{2}}
$$

\footnotetext{
13 These tables are placed at the end of this article, immediately after the references. When this article is published in the Astrophysical Journal, all of the tables will appear as a single, long table only in the electronic edition in the form of a machine-readable table.
} 
combines in quadrature the various sources of errors arising from either the best-fit coefficients $A_{X}$ and $B_{X}$ of element $X$ or the determination of $F_{*}$. (Recall from the discussion in 3.2 that $\sigma\left(B_{X}\right.$ ) here does not include the systematic error $\sigma(X / \mathrm{H})_{\odot}$.) Column (9) shows the amount by which the observed depletion $\left[X_{\text {gas }} / \mathrm{H}\right]_{\text {obs }}$ differs from $\left[X_{\text {gas }} / \mathrm{H}\right]_{\text {fit }}$, and column (10) shows this number divided by the combined uncertainty of $\left[X_{\text {gas }} / H\right]_{\text {obs }}$ and $\left[X_{\text {gas }} / H\right]_{\text {fit }}$ (with the two added together in quadrature), so that one can easily recognize deviations that seem to be unacceptably large. Values of $\left[X_{\text {gas }} / H\right]_{\text {obs }}$ can be obtained by adding together the numbers in columns (8) and (9), but asymmetrical error bars in the original data are not evident. To reconstruct the errors in $\left[X_{\text {gas }} / \mathrm{H}\right]_{\text {obs }}$ one must take into account the uncertainties of both $N(X)$ and $N(\mathrm{H})$; for the latter, see Table 5. For each element, one can sense how well the calculated values $\left[X_{\text {gas }} / \mathrm{H}\right]_{\text {fit }}$ agree with the observed ones by examining either individual deviations shown in the last two columns of the element tables or by inspecting the collective statistical information presented in Table 4 that was explained in \$5. Missing entries in columns (7)-(10) are caused by a lack of information needed to calculate $N(\mathrm{H})$ (see Table 2).

\section{Retrospectives on Earlier Characterizations}

Many studies of gas abundances and dust compositions have made use of earlier descriptions of the depletion process. In order to recast these previous investigations in the light of the present work, we present in the subsections below the outcomes of the earlier depletion studies in terms of the parameters defined in $₫ 3$. This should be useful in obtaining a better understanding of the earlier abundance works in the present context.

\section{C.1. A Comparison with the Results of Savage \& Sembach (1996a)}

After the publication of the review paper by Savage \& Sembach (1996a) on interstellar abundances from absorption line measurements using the Hubble Space Telescope, many investigations compared their own results with the generic depletions discussed in that review. We now offer a cross calibration between our $F_{*}$ and the environments discussed by Savage \& Sembach (1996a). We can do this through the application of Eq. 24a to their results, with mean values of the numbers given in their Table 6 replacing the expression $\log N(X)-\log (X / \mathrm{H})_{\odot}$ in our equation and by pinning $N(\mathrm{H})$ to a value of zero. Figure 19 shows this comparison for the four different representative environments specified by Savage \& Sembach.

In order to obtain the values of $F_{*}$ in each case, we evaluated a least-squares linear fit to the points, but without any weight factors to account for differing errors. For reasons given 99 , sulfur was not included in the fit (but it is shown at the appropriate locations in the panels of the figure). Since depletions are known with respect to hydrogen, it is appropriate to add this element to the fit at the location $(x, y)=0$. In order to make the comparison accurate, we made adjustments 


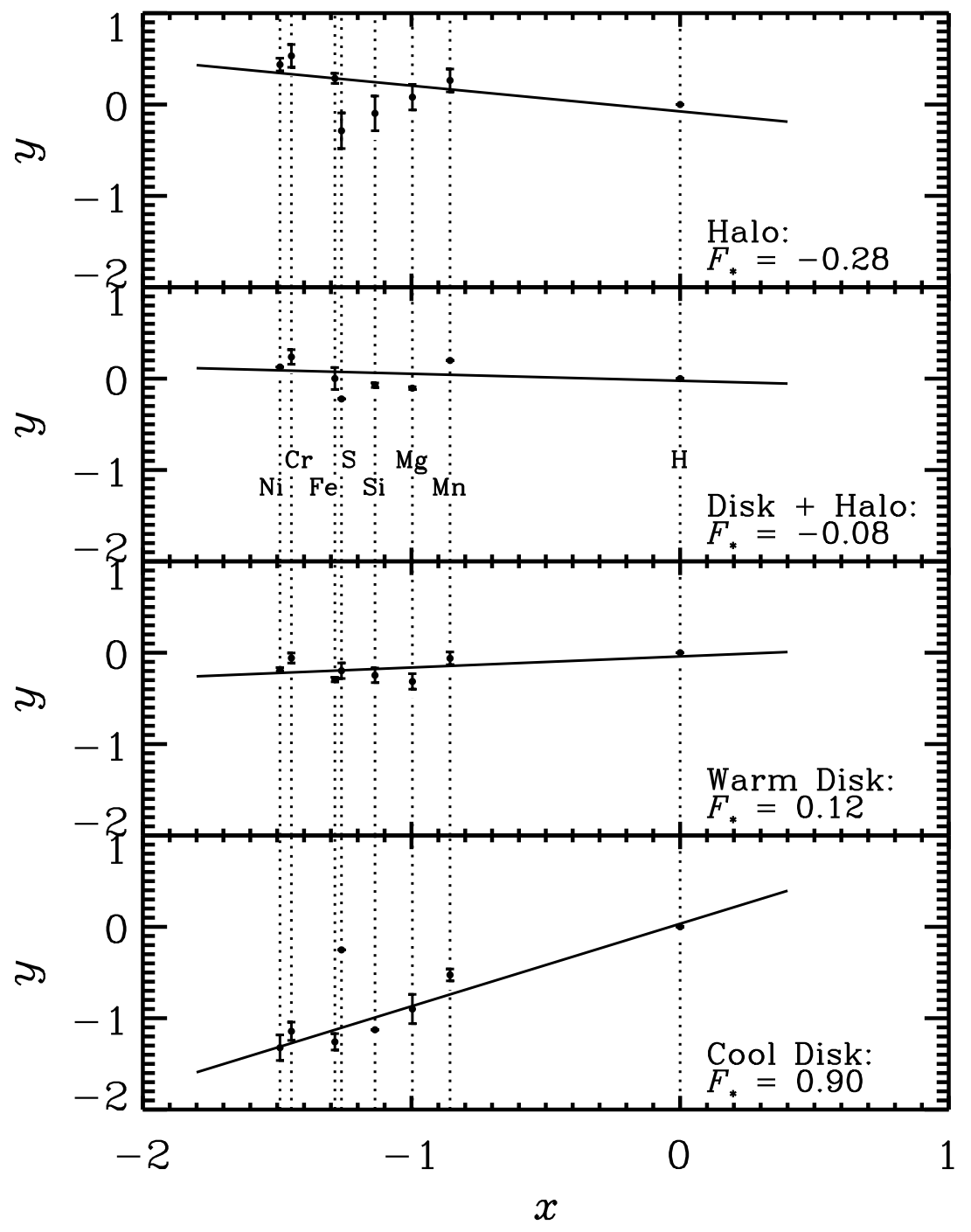

Fig. 19.- An application of Eq. 24a to the results shown in Table 6 of Savage \& Sembach (1996a), so that their results for different environments can be calibrated to the $F_{*}$ index of the present work. The values of $x$ for each element are identified in the panel second from the top, with vertical dotted lines linking them across the remaining panels. In each case an unweighted least-squares linear fit to the points is shown by a slanted line whose slope yields the value of $F_{*}$ listed in the respective panel. Error bars attached to some of the points do not represent uncertainties; instead they show the range of values that Savage \& Sembach found for the respective elements in each environment. 
to the numbers specified by Savage \& Sembach, so that we can account for (1) small differences between their adopted reference abundances and the ones given by Lodders (2003), as listed in column (2) of our Table 4, and (2) the differences between the $f$-values that seemed appropriate in 1996 to the more recent ones published by Morton (2003) and Jenkins \& Tripp (2006); see \$4.4 for some considerations that applied to the $f$-value adjustments. The net changes are given by the

following terms (expressed in dex) that were added to the original depletion values listed by Savage \& Sembach: $\mathrm{Mg}=0.23, \mathrm{Si}=-0.04, \mathrm{~S}=-0.01, \mathrm{Mn}=-0.05, \mathrm{Cr}=0.21, \mathrm{Fe}=-0.03$, and $\mathrm{Ni}=0.34$. The values of $F_{*}$ that apply to each environment are given in the respective panels of Figure 19, As one would expect, there is a regular progression in $F_{*}$ from the least dense environments to the most dense ones.

\section{C.2. Dust Corrections of Vladilo (2002a, b)}

Vladilo (2002b) used the summaries of element abundances in different environments given by Savage \& Sembach (1996a) to characterize changes in $\left(X_{\text {dust }} / \mathrm{H}\right)$ (which he calls $\left.p_{X}\right)$ in terms of $\left(\mathrm{Fe}_{\text {dust }} / \mathrm{H}\right.$ ) (which he calls $r$ ) by evaluating the derivatives of their logarithms and defining a parameter $\eta_{X} \equiv d \log p / d \log r$. We can evaluate the differentials of these two quantities with respect to $F_{*}$ to obtain

$$
\begin{aligned}
\eta_{X} & =\frac{r}{p_{X}} \frac{d p_{X} / d F_{*}}{d r / d F_{*}} \\
& =(X / \mathrm{H})_{\odot} \frac{\left(\mathrm{Fe}_{\text {dust }} / \mathrm{H}\right) 10^{[X / \mathrm{H}]} A_{X}(\mathrm{Fe} / \mathrm{H})_{\odot}^{-1}-\left(X_{\text {dust }} / \mathrm{H}\right) 10^{[\mathrm{Fe} / \mathrm{H}]} A_{\mathrm{Fe}}(X / \mathrm{H})_{\odot}^{-1}}{\left(X_{\text {dust }} / \mathrm{H}\right) 10^{[\mathrm{Fe} / \mathrm{H}]} A_{\mathrm{Fe}}} .
\end{aligned}
$$

Figure 20 shows how $\eta_{X}$ varies as a function of $F_{*}$ for the elements that Vladilo (2002a) chose to work with in his investigation of DLA abundances. It is clear from the figure that these quantities change with $F_{*}$, which makes it difficult to arrive at generalized dust correction factors for the DLA abundances using his method.

\section{C.3. Dust Corrections of Prochaska \& Wolfe (Prochaska \& Wolfe 2002)}

In their investigation of the relative amounts of dust as a function of $N(\mathrm{H})$ in the DLA systems that they studied, Prochaska \& Wolfe (2002) defined two dust parameters, $\kappa^{X} \equiv(1-$ $\left.10^{[X / \mathrm{Fe}]}\right) 10^{[X / \mathrm{H}]}$ for $X=\mathrm{Zn}$ and $X=\mathrm{Si}$, to characterize the dust-to-gas ratios in relation to those in our Galaxy. Figure 21 shows how these two parameters behave as a function of $F_{*}$, and these trends allow one to evaluate their findings in the context of the present study. 


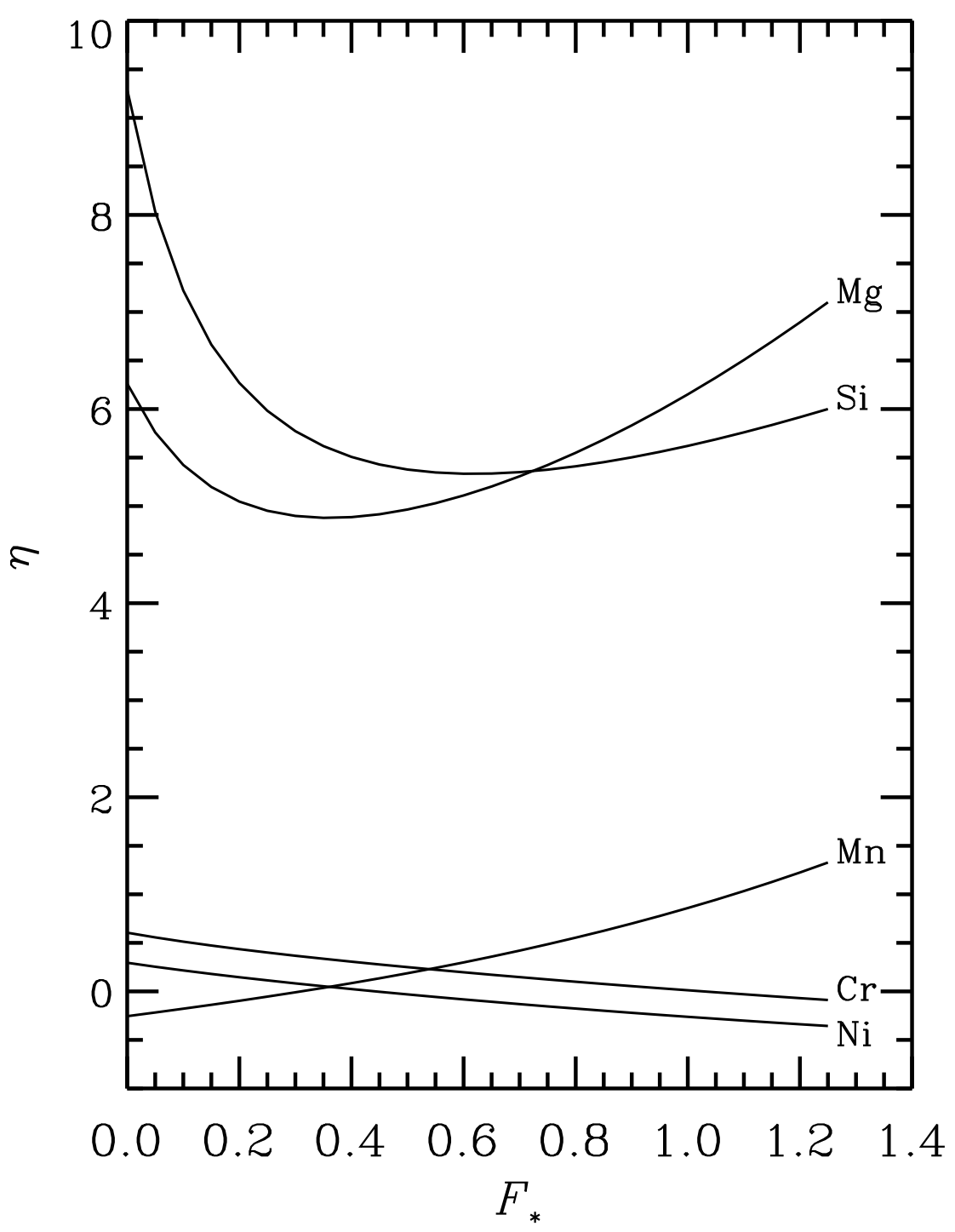

Fig. 20. - Values of the parameter $\eta_{X}$ for various elements in the dust correction scheme of Vladilo (2002b), expressed in terms of our parameter $F_{*} \cdot \eta_{\mathrm{Zn}}$ is off scale in this plot at values of around 20. 


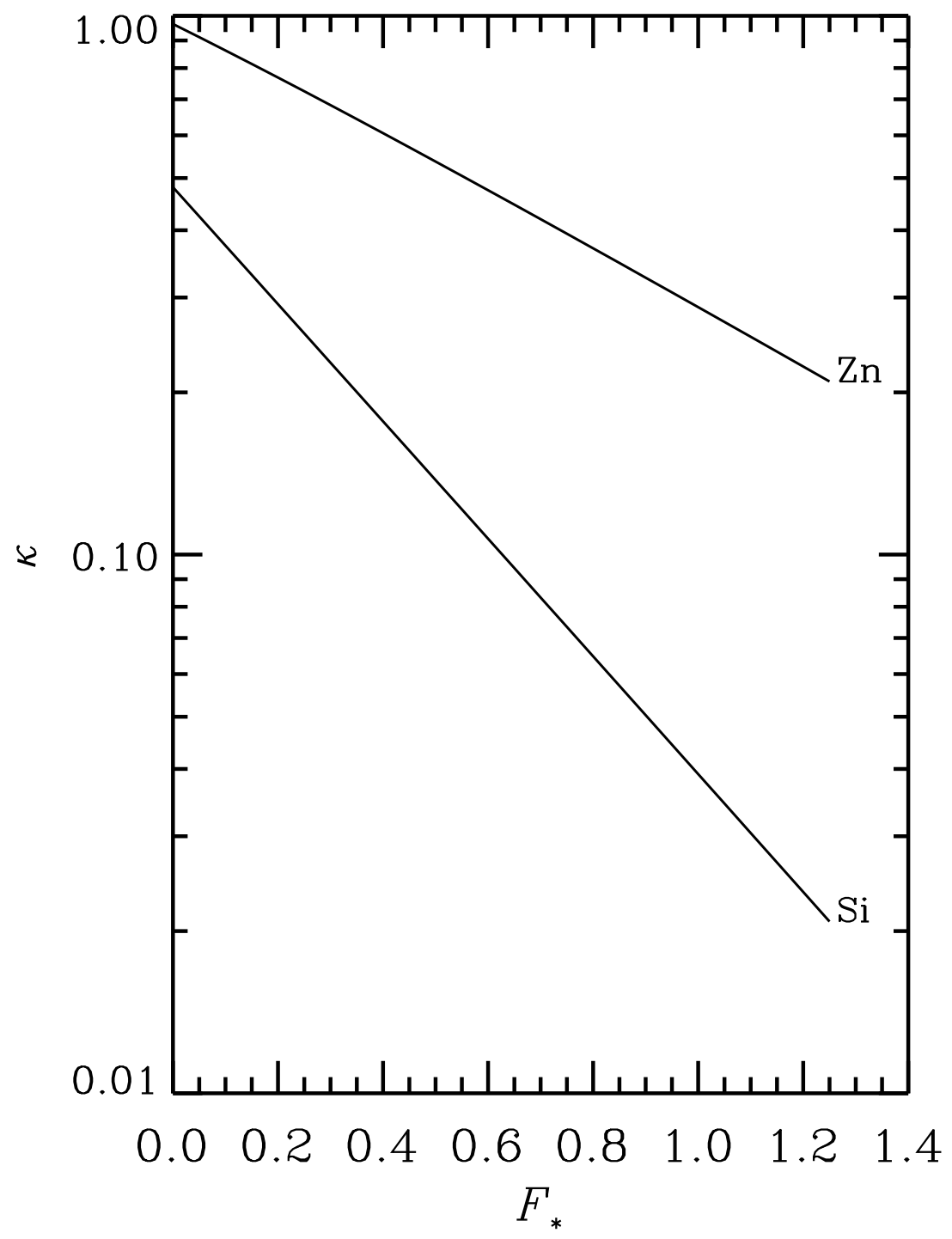

Fig. 21. - Trends with respect to $F_{*}$ for the parameters $\kappa^{\mathrm{Zn}}$ (upper line) and $\kappa^{\mathrm{Si}}$ (lower line) used by Prochaska \& Wolfe (2002) to exemplify the dust-to-gas ratios of different DLAs included in their investigation. 


\section{REFERENCES}

Abt, H. A. 1981, ApJS, 45, 437

Adams, W. S. 1949, ApJ, 109, 354

Afflerbach, A., Churchwell, E., \& Werner, M. W. 1997, ApJ, 478, 190

Albert, C. E., Blades, J. C., Morton, D. C., Lockman, F. J., Proulx, M., \& Ferrarese, L. 1993, ApJS, 88, 81

Allen, M. M., Jenkins, E. B., \& Snow, T. P. 1992, ApJS, 83, 261

Allende Prieto, C. 2008, in 14th Cambridge Workshop on Cool Stars, Stellar Systems, and the Sun, ed. G. T. van Belle (San Francisco: Astr. Soc. Pacific), p. 39

Allende Prieto, C., Lambert, D. L., \& Asplund, M. 2002, ApJ, 573, L137

Aloisi, A., Savaglio, S., Heckman, T. M., Hoopes, C. G., Leitherer, C., \& Sembach, K. R. 2003, ApJ, 595, 760

Andersen, J., Clausen, J. V., Nordstrom, B., \& Popper, D. M. 1985, A\&A, 151, 329

André, M., Oliveira, C., Howk, J. C., Ferlet, R., Désert, J. M., Hébrard, G., Lacour, S., Lecavelier des Étangs, A., Vidal-Madjar, A., \& Moos, H. W. 2003, ApJ, 591, 1000

Antia, H. M., \& Basu, S. 2005, ApJ, 620, L129

-. 2006, ApJ, 644, 1292

Asplund, M., Grevesse, N., Sauval, A. J., Allende Prieto, C., \& Blomme, R. 2005, A\&A, 431, 693

Asplund, M., Grevesse, N., Sauval, A. J., Allende Prieto, C., \& Kiselman, D. 2004b, A\&A, 417, 751

Badnell, N. R., Bautista, M. A., Butler, K., Delahaye, F., Mendoza, C., Palmeri, P., Zeippen, C. J., \& Seaton, M. J. 2005, MNRAS, 360, 458

Bahcall, J. N., Basu, S., Pinsonneault, M., \& Serenelli, A. M. 2005a, ApJ, 618, 1049

Bahcall, J. N., Serenelli, A. M., \& Basu, S. 2005b, ApJ, 621, L85

Barker, E. S., Lugger, P. M., Weiler, E. J., \& York, D. G. 1984, ApJ, 280, 600

Berghöfer, T. W., \& Breitschwerdt, D. 2002, A\&A, 390, 299

Bertiau, F. C. 1958, ApJ, 128, 533

Bidelman, W. P. 1954, PASP, 66, 249

Boesgaard, A. M. 1985, PASP, 97, 37

Bohlin, R. C., Savage, B. D., \& Drake, J. F. 1978, ApJ, 224, 132

Bohlin, R. C., Hill, J. K., Jenkins, E. B., Savage, B. D., Snow, T. P., Spitzer, L., \& York, D. G. 1983, ApJS, 51, 277

Bowen, D. V., Jenkins, E. B., Pettini, M., \& Tripp, T. M. 2005, ApJ, 635, 880 
Bowen, D. V., Jenkins, E. B., Tripp, T. M., Sembach, K. R., Savage, B. D., Moos, H. W., Oegerle, W. R., Friedman, S. D., Gry, C., Kruk, J. W., Murphy, E., Sankrit, R., Shull, J. M., Sonneborn, G., \& York, D. G. 2008, ApJS, 176, 59

Breitschwerdt, D., \& de Avillez, M. A. 2006, A\&A, 452, L1

Breitschwerdt, D., Egger, R., Freyberg, M. J., Frisch, P. C., \& Vallerga, J. V. 1996, Space Sci. Rev., 78,183

Burgh, E. B., France, K., \& McCandliss, S. R. 2007, ApJ, 658, 446

Caffau, E., Maiorca, E., Bonifacio, P., Faraggiana, R., Steffen, M., Ludwig, H.-G., Kamp, I., \& Busso, M. 2009, 0903.3406,

Calura, F., Matteucci, F., \& Vladilo, G. 2003, MNRAS, 340, 59

Calura, F., Pipino, A., \& Matteucci, F. 2008, A\&A, 479, 669

Calura, F., Dessauges-Zavadsky, M., Prochaska, J. X., \& Matteucci, F. 2009, ApJ, 693, 1236

Cannon, J. M., Skillman, E. D., Sembach, K. R., \& Bomans, D. J. 2005, ApJ, 618, 247

Cardelli, J. A. 1994, Sci, 265, 209

Cardelli, J. A., \& Meyer, D. M. 1997, ApJ, 477, L57

Cardelli, J. A., Sembach, K. R., \& Savage, B. D. 1995, ApJ, 440, 241

Cardelli, J. A., Savage, B. D., Bruhweiler, F. C., Smith, A. M., Ebbets, D. C., Sembach, K. R., \& Sofia, U. J. 1991, ApJ, 377, L57

Cardelli, J. A., Mathis, J. S., Ebbets, D. C., \& Savage, B. D. 1993, ApJ, 402, L17

Cardelli, J. A., Sofia, U. J., Savage, B. D., Keenan, F. P., \& Dufton, P. L. 1994, ApJ, 420, L29

Cardelli, J. A., Meyer, D. M., Jura, M., \& Savage, B. D. 1996, ApJ, 467, 334

Cartledge, S. I. B., Meyer, D. M., \& Lauroesch, J. T. 2003, ApJ, 597, 408

Cartledge, S. I. B., Meyer, D. M., Lauroesch, J. T., \& Sofia, U. J. 2001, ApJ, 562, 394

Cartledge, S. I. B., Lauroesch, J. T., Meyer, D. M., \& Sofia, U. J. 2004, ApJ, 613, 1037

- 2006, ApJ, 641, 327

Cartledge, S. I. B., Lauroesch, J. T., Meyer, D. M., Sofia, U. J., \& Clayton, G. C. 2008, ApJ, 687, 1043

Cassinelli, J. P., Cohen, D. H., MacFarlane, J. J., Drew, J. E., Lynas-Gray, A. E., Hoare, M. G., Vallerga, J. V., Welsh, B. Y., Vedder, P. W., Hubeny, I., \& Lanz, T. 1995, ApJ, 438, 932

Cassinelli, J. P., Cohen, D. H., MacFarlane, J. J., Drew, J. E., Lynas-Gray, A. E., Hubeny, I., Vallerga, J. V., Welsh, B. Y., \& Hoare, M. G. 1996, ApJ, 460, 949

Centeno, R., \& Socas-Navarro, H. 2008, ApJ, 682, L61

Centurión, M., Molaro, P., Vladilo, G., Péroux, C., Levshakov, S. A., \& D’Odorico, V. 2003, A\&A, 403, 55 
Chambaud, G., Launay, J. M., Levy, B., Millie, P., Roueff, E., \& Tran Minh, F. 1980, J. Phys. B, 13,4205

Collins, J. A., Shull, J. M., \& Giroux, M. L. 2003, ApJ, 585, 336

Costantini, E., Freyberg, M. J., \& Predehl, P. 2005, A\&A, 444, 187

Cox, D. P., \& Reynolds, R. J. 1987, ARA\&A, 25, 303

Crinklaw, G., Federman, S. R., \& Joseph, C. L. 1994, ApJ, 424, 748

Cunningham, N. J., McCray, R., \& Snow, T. P. 2004, ApJ, 611, 353

Daflon, S., Cunha, K., Smith, V. V., \& Butler, K. 2003, A\&A, 399, 525

de Boer, K. S., Lenhart, H., Van Der Hucht, K. A., Kamperman, T. M., Kondo, Y., \& Bruhweiler, F. C. 1986, A\&A, 157, 119

Deharveng, L., Peña, M., Caplan, J., \& Costero, R. 2000, MNRAS, 311, 329

Dessauges-Zavadsky, M., Prochaska, J. X., \& D’Odorico, S. 2002, A\&A, 391, 801

Dessauges-Zavadsky, M., Calura, F., Prochaska, J. X., D’Odorico, S., \& Matteucci, F. 2004, A\&A, 416,79

Dessauges-Zavadsky, M., Prochaska, J. X., D’Odorico, S., Calura, F., \& Matteucci, F. 2006, A\&A, 445,93

Dessauges-Zavadsky, M., Calura, F., Prochaska, J. X., D’Odorico, S., \& Matteucci, F. 2007, A\&A, 470,431

Diplas, A., \& Savage, B. D. 1994, ApJS, 93, 211

Draine, B. T. 2003a, ARA\&A, 41, 241

— 2003b, ApJ, 598, 1017

- 2003c, ApJ, 598, 1026

- 2004, in Origin and Evolution of the Elements, ed. A. Mc William \& M. Rauch (Cambridge: Cambridge Univ. Press), p. 317

- 2009, in Cosmic Dust, Near and Far, ed. T. Henning, E. Grün \& J. Steinacker (San Francisco: Ast. Soc. Pacific), in press (also arXiv 0903.1658)

Draine, B. T., \& Tan, J. C. 2003, ApJ, 594, 347

Dufton, P. L., Smartt, S. J., Lee, J. K., Ryans, R. S. I., Hunter, L., Evans, C. J., Herrero, A., Trundle, C., Lennon, D. J., Irwin, M. J., \& Daufer, A. 2006, A\&A, 457, 265

Dunham, T. 1939, proc am phil soc, 81, 277

Dupin, O., \& Gry, C. 1998, A\&A, 335, 661

Dwek, E. 1997, ApJ, 484, 779

— 1998, ApJ, 501, 643 
Dwek, E., \& Scalo, J. M. 1980, ApJ, 239, 193

Dwek, E., Zubko, V., Arendt, R. G., \& Smith, R. K. 2004, in Astrophysics of Dust, ed. A. N. Witt, G. C. Clayton \& B. T. Draine (San Francisco: Astr. Soc. Pacific), p. 499

Eiroa, C., \& Hodapp, K.-W. 1989, A\&A, 210, 345

Ellison, S. L., Prochaska, J. X., \& Lopez, S. 2007, MNRAS, 380, 1245

Feast, M. W. 1958, MNRAS, 118, 618

Feast, M. W., Thackeray, A. D., \& Wesselink, A. J. 1955, MmRAS, 67, 51

Federman, S. R., Brown, M., Torok, S., Cheng, S., Irving, R. E., Schectman, R. M., \& Curtis, L. J. 2007, ApJ, 660, 919

Ferlet, R. 1999, A\&A Rev., 9, 153

Field, G. B. 1974, ApJ, 187, 453

Field, G. B., \& Steigman, G. 1971, ApJ, 166, 59

Fitzpatrick, E. L. 1996, ApJ, 473, L55

Fitzpatrick, E. L., \& Massa, D. 1990, ApJS, 72, 163

Fitzpatrick, E. L., \& Spitzer, L. 1994, ApJ, 427, 232

- 1997, ApJ, 475, 623

Friedman, S. D., Howk, J. C., Chayer, P., Tripp, T. M., Hébrard, G., André, M., Oliveira, C., Jenkins, E. B., Moos, H. W., Oegerle, W. R., Sonneborn, G., Lamontagne, R., Sembach, K. R., \& Vidal- Madjar, A. 2002, ApJS, 140, 37

Frisch, P. C. 2007, Space Sci. Rev., 130, 355

Frisch, P. C., Dorschner, J. M., Geiss, J., Greenberg, J. M., Grün, E., Landgraf, M., Hoppe, P., Jones, A. P., Krätschmer, W., Linde, T. J., Morfill, G. E., Reach, W., Slavin, J. D., Svestka, J., Witt, A. N., \& Zank, G. P. 1999, ApJ, 525, 492

Fuchs, B., Breitschwerdt, D., de Avillez, M. A., Dettbarn, C., \& Flynn, C. 2006, MNRAS, 373, 993

Gail, H.-P., \& Sedlmayr, E. 1986, A\&A, 166, 225

Garrison, R. F., \& Gray, R. O. 1994, AJ, 107, 1556

Garrison, R. F., \& Kormendy, J. 1976, PASP, 88, 865

Geary, R. C. 1930, J. Royal Stat. Soc., 93, 442

Gibson, B. K., Giroux, M. L., Penton, S. V., Stocke, J. T., Shull, J. M., \& Tumlinson, J. 2001, AJ, 122,3280

Gillett, F. C., Jones, T. W., Merrill, K. M., \& Stein, W. A. 1975, A\&A, 45, 77

Gilmore, G., \& Wyse, R. F. G. 1991, ApJ, 367, L55

Giveon, U., Sternberg, A., Lutz, D., Feuchtgruber, H., \& Pauldrach, A. W. A. 2002, ApJ, 566, 880 
Golay, M., Mandwewala, N., \& Bartholdi, P. 1977, A\&A, 60, 181

Greenberg, J. M. 1982, in Comets, ed. L. L. Wilkening (Tucson: Univ. Arizona Press), p. 131

- 1989, in Interstellar Dust, ed. L. J. Allamandola \& A. G. G. M. Tielens (Dordrecht: Kluwer), p. 345

Grevesse, N., \& Sauval, A. J. 1998, Space Sci. Rev., 85, 161

Gummershach, C. A., Kaufer, A., Schäfer, D. R., Szeifert, T., \& Wolf, B. 1998, A\&A, 338, 881

Habing, H. 1969, Bull. Astron. Inst. Netherlands, 20, 177

Harris, A. W., Gry, C., \& Bromage, G. E. 1984, ApJ, 284, 157

Hauck, B., \& Mermilliod, M. 1998, A\&AS, 129, 431

Hébrard, G., Lemoine, M., Ferlet, R., \& Vidal-Madjar, A. 1997, A\&A, 324, 1145

Hébrard, G., Mallouris, C., Ferlet, R., Koester, D., Lemoine, M., Vidal-Madjar, A., \& York, D. 1999, A\&A, 350, 643

Herbig, G. H. 1968, ZAp, 68, 243

Hill, P. W. 1970, MNRAS, 150, 23

Hiltner, W. A. 1956, ApJS, 2, 389

Hiltner, W. A., Garrison, R. F., \& Schild, R. E. 1969, ApJ, 157, 313

Hobbs, L. M., York, D. G., \& Oegerle, W. 1982, ApJ, 252, L21

Hobbs, L. M., Welty, D. E., Morton, D. C., Spitzer, L., \& York, D. G. 1993, ApJ, 411, 750

Hoffleit, D. 1956, ApJ, 124, 61

Holweger, H. 2001, in Solar and Galactic Composition, A Joint SOHO/ACE Workshop, ed. R. F. Wimmer-Schweingruber (New York: AIP), p. 23

Hoopes, C. G., Sembach, K. R., Hébrard, G., Moos, H. W., \& Knauth, D. C. 2003, ApJ, 586, 1094

Howk, J. C., \& Savage, B. D. 1999, ApJ, 517, 746

Howk, J. C., Savage, B. D., \& Fabian, D. 1999, ApJ, 525, 253

Howk, J. C., \& Sembach, K. R. 1999, ApJ, 523, L141

Howk, J. C., Sembach, K. R., \& Savage, B. D. 2003, ApJ, 586, 249

- 2006, ApJ, 637, 333

Ioppolo, S., Cuppen, H. M., Romanzin, C., van Dishoeck, E. F., \& Linnartz, H. 2008, ApJ, 686, 1474

Jaschek, C., \& Jaschek, M. 1992, A\&AS, 95, 535

Jenkins, E. B. 1970, in Ultraviolet Stellar Spectra and Related Ground-Based Observations, ed. L. Houziaux \& H. Butler (Dordrecht: Reidel), p. 281

- 1971, ApJ, 169, 25 
— 1986, ApJ, 304, 739

- 1987, in Interstellar Processes, ed. D. J. Hollenbach \& H. A. Thronson Jr. (Dordrecht: Reidel), p. 533

— 1996, ApJ, 471, 292

- 2004, in Origin and Evolution of the Elements, ed. A. Mc William \& W. Rauch (Cambridge: Cambridge Univ. Press), p. 336

- 2009, Physica Scripta, in press.

Jenkins, E. B., Gry, C., \& Dupin, O. 2000, A\&A, 354, 253

Jenkins, E. B., \& Savage, B. D. 1974, ApJ, 187, 243

Jenkins, E. B., Savage, B. D., \& Spitzer, L. 1986, ApJ, 301, 355

Jenkins, E. B., Silk, J., \& Wallerstein, G. 1976, ApJS, 32, 681

Jenkins, E. B., \& Tripp, T. M. 2006, ApJ, 637, 548

Jenkins, E. B., \& Wallerstein, G. 1996, ApJ, 462, 758

Jenkins, E. B., Drake, J. F., Morton, D. C., Rogerson, J. B., Spitzer, L., \& York, D. G. 1973, ApJ, 181, L122

Jenkins, E. B., Tripp, T. M., Fitzpatrick, E. L., Lindler, D., Danks, A. C., Beck, T. L., Bowers, C. W., Joseph, C. L., Kaiser, M. E., Kimble, R. A., Kraemer, S. B., Robinson, R. D., Timothy, J. G., Valenti, J. A., \& Woodgate, B. E. 1998, ApJ, 492, L147

Jenkins, E. B., Tripp, T. M., Wozniak, P. R., Sofia, U. J., \& Sonneborn, G. 1999, ApJ, 520, 182

Jensen, A. G., Rachford, B. L., \& Snow, T. P. 2005, ApJ, 619, 891

- 2007, ApJ, 654, 955

Jensen, A. G., \& Snow, T. P. 2007a, ApJ, 669, 378

- 2007b, ApJ, 669, 401

Jensen, K. S. 1981, A\&AS, 45, 455

Johnson, H. L., \& Morgan, W. W. 1953, ApJ, 117, 313

Johnson, H. L., Mitchell, R. I., Iriarte, B., \& Wisniewski, W. Z. 1966, Comm. Lunar and Planetary Lab., 4, 99

Jones, A. P., Duley, W. W., \& Williams, D. A. 1990, QJRAS, 31, 567

Joseph, C. L. 1988, ApJ, 335, 157

Joseph, C. L., \& Jenkins, E. B. 1991, ApJ, 368, 201

Juett, A. M., Schulz, N. S., \& Chakrabarty, D. 2004, ApJ, 612, 308

Jura, M. 1974, ApJ, 190, L33

Jura, M., \& York, D. G. 1978, ApJ, 219, 861 
Kaltcheva, N., \& Knude, J. 2002, A\&A, 385, 1107

Khare, P., Kulkarni, V. P., Lauroesch, J. T., York, D. G., Crotts, A. P. S., \& Nakamura, O. 2004, ApJ, 616, 86

Kilkenny, D., \& Muller, S. 1989, South African. Astr. Obs. Circ, 13, 69

Kim, S. H., \& Martin, P. G. 1996, ApJ, 462, 296

Kimura, H., Mann, I., \& Jessberger, E. K. 2003, ApJ, 582, 846

Knauth, D. C., Meyer, D. M., \& Lauroesch, J. T. 2006, ApJ, 647, L115

Knauth, D., Andersson, B.-G., McCandliss, S., \& Moos, H. W. 2003, ApJ, 596, L51

Knauth, D. C., Andersson, B.-G., McCandliss, S. R., \& Moos, H. W. 2004, Nature, 429, 636

- 2006, in Astrophysics in the Far Ultraviolet, Five Years of Discovery with FUSE, ed. G. Sonneborn, H. W. Moos \& B.-G. Andersson (San Francisco: Ast. Soc. Pacific), p. 421

Kohoutek, L., \& Wehmeyer, R. 1999, A\&AS, 134, 255

Kozasa, T., Nozawa, T., Tominaga, N., Umeda, H., Maeda, K., \& Nomoto, K. 2009, arXiv 0903.0217

Krüger, H. et al. 2006, Planet. Space Sci., 54, 932

Kruk, J. W., Howk, J. C., André, M., Moos, H. W., Oegerle, W. R., Oliveira, C., Sembach, K. R., Chayer, P., Linsky, J. L., Wood, B. E., Ferlet, R., Hébrard, G., Lemoine, M., Vidal-Madjar, A., \& Sonneborn, G. 2002, ApJS, 140, 19

Kulkarni, V. P., Fall, S. M., Lauroesch, J. T., York, D. G., Welty, D. E., Khare, P., \& Truran, J. W. 2005, ApJ, 618, 68

Lallement, R., Hébrard, G., \& Welsh, B. Y. 2008, A\&A, 481, 381

Lallement, R., Welsh, B. Y., Vergely, J. L., Crifo, F., \& Sfeir, D. 2003, A\&A, 411, 447

Landgraf, M., Baggaley, W. J., Grün, E., Krüger, H., \& Linkert, G. 2000, J. Geophys. Res., 105, 10343

Laurent, C., Vidal-Madjar, A., \& York, D. G. 1979, ApJ, 229, 923

Lebouteiller, V., Kuassivi, \& Ferlet, R. 2005, A\&A, 443, 509

Ledoux, C., Bergeron, J., \& Petitjean, P. 2002, A\&A, 385, 802

Lehner, N., Jenkins, E. B., Gry, C., Moos, H. W., Chayer, P., \& Lacour, S. 2003, ApJ, 595, 858

Lesh, J. R. 1968, ApJS, 17, 371

Levato, H. 1972, PASP, 84, 584

Levato, H., \& Abt, H. A. 1976, PASP, 88, 712

Li, A. 2005, ApJ, 622, 965

Ling, Z., Zhang, S. N., Xiang, J., \& Tang, S. 2009, ApJ, 690, 224 
Linsky, J. L., Diplas, A., Wood, B. E., Brown, A., Ayres, T. R., \& Savage, B. D. 1995, ApJ, 451, 335

Lipman, K., \& Pettini, M. 1995, ApJ, 442, 628

Lodders, K. 2003, ApJ, 591, 1220

Lu, L., Sargent, W. L. W., Barlow, T. A., Churchill, C. W., \& Vogt, S. S. 1996, ApJS, 107, 475

Luck, R. E., Kovtyukh, V. V., \& Andrievsky, S. M. 2006, AJ, 132, 902

Lugger, P. M., York, D. G., Blanchard, T., \& Morton, D. C. 1978, ApJ, 224, 1059

Maíz-Apellániz, J. 2001, ApJ, 560, L83

Mallouris, C. 2003, ApJS, 147, 265

Martin, E. R., \& York, D. G. 1982, ApJ, 257, 135

Martín-Hernández, N. L., Peeters, E., Morisset, C., Tielens, A. G. G. M., Cox, P., Roelfsema, P. R., Baluteau, J.-P., Schaerer, D., Mathis, J. S., Damour, F., Churchwell, E., \& Kessler, M. F. 2002, A\&A, 381, 606

Martins, L. P., \& Viegas, S. M. M. 2000, A\&A, 361, 1121

Massa, D., Van Steenberg, M. E., Oliversen, N., \& Lawton, P. 1998, in Ultraviolet Astrophysics Beyond the IUE Final Archive, ed. W. Wamsteker \& R. Gonzalez Riestra (Noordwijk: ESA), p. 723

Mathis, J. S. 1990, ARA\&A, 28, 37

- 1996, ApJ, 472, 643

Meléndez, J., \& Asplund, M. 2008, A\&A, 490, 817

Merrill, P. W., Sanford, R. F., Wilson, O. C., \& Burwell, C. G. 1937, ApJ, 86, 274

Meyer, D. M., Cardelli, J. A., \& Sofia, U. J. 1997, ApJ, 490, L103

Meyer, D. M., Jura, M., \& Cardelli, J. A. 1998, ApJ, 493, 222

Meyer, D. M., \& Roth, K. C. 1990, ApJ, 363, 57

Meyer, D. M., Jura, M., Hawkins, I., \& Cardelli, J. A. 1994, ApJ, 437, L59

Miller, A., Lauroesch, J. T., Sofia, U. J., Cartledge, S. I. B., \& Meyer, D. M. 2007, ApJ, 659, 441

Morgan, W. W., Code, A. D., \& Whitford, A. E. 1955, ApJS, 2, 41

Morgan, W. W., Hiltner, W. A., \& Garrison, R. F. 1971, AJ, 76, 242

Morgan, W. W., \& Roman, N. G. 1950, ApJ, 112, 362

Morris, P. M. 1961, MNRAS, 122, 325

Morton, D. C. 1978, ApJ, 222, 863

- 1991, ApJS, 77, 119

- 2003, ApJS, 149, 205 
Morton, D. C., \& Dinerstein, H. L. 1976, ApJ, 204, 1

Morton, D. C., Jenkins, E. B., \& Bohlin, R. C. 1968, ApJ, 154, 661

Morton, D. C., \& Spitzer, L. 1966, ApJ, 144, 1

Morton, D. C., Drake, J. F., Jenkins, E. B., Rogerson, J. B., Spitzer, L., \& York, D. G. 1973, ApJ, 181, L103

Münch, G. 1957, ApJ, 125, 42

Münch, G., \& Zirin, H. 1961, ApJ, 133, 11

Murphy, E. M., Sembach, K. R., Gibson, B. K., Shull, J. M., Savage, B. D., Roth, K. C., Moos, H. W., Green, J. C., York, D. G., \& Wakker, B. P. 2000, ApJ, 538, L35

Nieva, M. F., \& Przybilla, N. 2008a, A\&A, 481, 199

- 2008b, Rev. Mexicana Astron. Astrofis., 33, 35

Oegerle, W. R., \& Polidan, R. S. 1984, ApJ, 285, 648

Oliveira, C. M., \& Hébrard, G. 2006, ApJ, 653, 345

Oliveira, C. M., Hébrard, G., Howk, J. C., Kruk, J. W., Chayer, P., \& Moos, H. W. 2003, ApJ, 587,235

Paerels, F., Brinkman, A. C., van der Meer, R. L. J., Kaastra, J. S., Kuulkers, E., den Boggende, A. J. F., Predehl, P., Drake, J. J., Kahn, S. M., Savin, D. W., \& McLaughlin, B. M. 2001, ApJ, 546, 338

Palumbo, M. E. 2006, A\&A, 453, 903

Péroux, C., Kulkarni, V. P., Meiring, J., Ferlet, R., Khare, P., Lauroesch, J. T., Vladilo, G., \& York, D. G. 2006a, A\&A, 450, 53

Péroux, C., Meirling, J. D., Kulkarni, V. P., Ferlet, R., Khare, P., Lauroesch, J. T., Vladilo, G., \& York, D. G. 2006b, MNRAS, 372, 369

Péroux, C., Meiring, J. D., Kulkarni, V. P., Khare, P., Lauroesch, J. T., Vladilo, G., \& York, D. G. 2008, MNRAS, 386, 2209

Pettini, M. 2003, in Cosmochemistry: The Melting Pot of the Elements, ed. C. Esteban, R. J. Garci, A. H. López \& F. Sánchez (Cambridge: Cambridge Univ.), p. 257

Pettini, M., Boksenberg, A., \& Hunstead, R. W. 1990, ApJ, 348, 48

Pettini, M., Smith, L. J., Hunstead, R. W., \& King, D. L. 1994, ApJ, 426, 79

Pettini, M., King, D. L., Smith, L. J., \& Hunstead, R. W. 1997, ApJ, 478, 536

Pettini, M., Ellison, S. L., Steidel, C. C., \& Bowen, D. V. 1999, ApJ, 510, 576

Pettini, M., Ellison, S. L., Bergeron, J., \& Petitjean, P. 2002, A\&A, 391, 21

Popper, D. M. 1943, ApJ, 97, 394 
Press, W. H., Teukolsky, S. A., Vetterling, W. T., \& Flannery, B. P. 2007, Numerical Recipes, The Art of Scientific Computing, 3rd ed., (Cambridge: Cambridge Univ. Press)

Prochaska, J. X. 2003, ApJ, 582, 49

- 2004, in Origin and Evolution of the Elements, ed. A. McWilliam \& M. Rauch (Cambridge: Cambridge Univ. Press), p. 455

Prochaska, J. X., Howk, J. C., \& Wolfe, A. M. 2003, Nature, 423, 57

Prochaska, J. X., Tripp, T. M., \& Howk, J. C. 2005, ApJ, 620, L39

Prochaska, J. X., \& Wolfe, A. M. 2002, ApJ, 566, 68

Prochaska, J. X., Howk, J. C., O’Meara, J. M., Tytler, D., Wolfe, A. M., Kirkman, D., Lubin, D., \& Suzuki, N. 2002, ApJ, 571, 693

Prochaska, J. X., Chen, H.-W., Desauges-Zavadsky, M., \& Bloom, J. S. 2007, ApJ, 666, 267

Przybilla, N., Nieva, M.-F., \& Butler, K. 2008, ApJ, 688, L103

Quast, R., Reimers, D., \& Baade, R. 2008, A\&A, 477, 443

Rachford, B., Snow, T. P., Tumlinson, J., Shull, J. M., Blair, W. P., Ferlet, R., Friedman, S. D., Gry, C., Jenkins, E. B., Morton, D. C., Savage, B. D., Sonnentrucker, P., Vidal-Madjar, A., Welty, D. E., \& York, D. G. 2002, ApJ, 577, 221

Rachford, B. L., Snow, T. P., Tumlinson, J., Shull, J. M., Roueff, E., Andre, M., Desert, J.-M., Ferlet, R., Vidal-Madjar, A., \& York, D. G. 2001, ApJ, 555, 839

Rachford, B. L., Snow, T. P., Destree, J. D., Ross, T. L., Ferlet, R., Friedman, S. D., Gry, C., Jenkins, E. B., Morton, D. C., Savage, B. D., Shull, J. M., Sonnentrucker, P., Tumlinson, J., Vidal-Madjar, A., Welty, D. E., \& York, D. G. 2009, ApJS, 180, 125

Redfield, S., \& Linsky, J. L. 2004a, ApJ, 602, 776

- 2004b, ApJ, 613, 1004

Richter, P., Sembach, K. R., Wakker, B. P., Savage, B. D., Tripp, T. M., Murphy, E. M., Kalberla, P. M. W., \& Jenkins, E. B. 2001, ApJ, 559, 318

Rogerson, J. B., Spitzer, L., Drake, J. F., Dressler, K., Jenkins, E. B., Morton, D. C., \& York, D. G. 1973a, ApJ, 181, L97

Rogerson, J. B., York, D. G., Drake, J. F., Jenkins, E. B., Morton, D. C., \& Spitzer, L. 1973b, ApJ, 181, L110

Rolleston, W. R. J., Smartt, S. J., Dufton, P. L., \& Ryans, R. S. I. 2000, A\&A, 363, 537

Roth, K. C., \& Blades, J. C. 1995, ApJ, 445, L95

- 1997, ApJ, 474, L95

Routly, P. M., \& Spitzer, L. 1952, ApJ, 115, 227

Ryu, K. S., Dixon, W. V., Hurwitz, M., Seon, K. I., Min, K. W., \& Edelstein, J. 2000, ApJ, 529, 251 
Sahu, M. S., \& Blades, J. C. 1997, ApJ, 484, L125

Sarlin, S. P. 1998, Ph.D. Thesis, University of Colorado, Boulder.

Savage, B. D., \& Bohlin, R. C. 1979, ApJ, 229, 136

Savage, B. D., Cardelli, J. A., \& Sofia, U. J. 1992, ApJ, 401, 706

Savage, B. D., \& Jenkins, E. B. 1972, ApJ, 172, 491

Savage, B. D., \& Lehner, N. 2006, ApJS, 162, 134

Savage, B. D., Massa, D., \& Meade, M. 1985, ApJS, 59, 397

Savage, B. D., Meade, M. R., \& Sembach, K. R. 2001, ApJS, 136, 631

Savage, B. D., \& Panek, R. J. 1974, ApJ, 191, 659

Savage, B. D., \& Sembach, K. R. 1991, ApJ, 379, 245

- 1996a, ARA\&A, 34, 279

- 1996b, ApJ, 470, 893

Savage, B. D., Bohlin, R. C., Drake, J. F., \& Budich, W. 1977, ApJ, 216, 291

Schrijver, H. 1997, The Hipparcos and Tycho Catalogues, (ESA Publications, SP-1200), (Noordwijk: European Space Agency)

Schulz, N. S., Cui, W., Canizares, C. R., Marshall, H. L., Lee, J. C., Miller, J. M., \& Lewin, W. H. G. 2002, ApJ, 565, 1141

Sembach, K. R., \& Savage, B. D. 1996, ApJ, 457, 211

Sembach, K. R., Savage, B. D., \& Tripp, T. M. 1997, ApJ, 480, 216

Shaver, P. A., McGee, R. X., Newton, L. M., Danks, A. C., \& Pottasch, S. R. 1983, MNRAS, 204, 53

Sheffer, Y., Rogers, M., Federman, S. R., Lambert, D. L., \& Gredel, R. 2007, ApJ, 667, 1002

Sheffer, Y., Rogers, M., Federman, S. R., Abel, N. P., Gredel, R., Lambert, D. L., \& Shaw, G. 2008, ApJ, 687, 1075

Shull, J. M., \& McKee, C. F. 1979, ApJ, 227, 131

Shull, J. M., \& Van Steenberg, M. E. 1985, ApJ, 294, 599

Shull, J. M., \& York, D. G. 1977, ApJ, 211, 803

Simonson, S. C. 1968, ApJ, 154, 923

Slettebak, A. 1982, ApJS, 50, 55

Smith, R. G., Sellgren, K., \& Brooke, T. Y. 1993, MNRAS, 263, 749

Smith, R. K. 2008, ApJ, 681, 343

Smith, R. K., \& Dwek, E. 1998, ApJ, 503, 831 
Smith, R. K., Dame, T. M., Costantini, E., \& Predehl, P. 2006, ApJ, 648, 452

Snow, T. P. 1976, ApJ, 204, 759

- 1977, ApJ, 216, 724

Snow, T. P., Peters, G. J., \& Mathieu, R. D. 1979, ApJS, 39, 359

Snow, T. P., Rachford, B. L., \& Figoski, L. 2002, ApJ, 573, 662

Snow, T. P., \& Witt, A. N. 1996, ApJ, 468, L65

Snow, T. P., Black, J. H., van Dishoeck, E. F., Burks, G., Crutcher, R. M., Lutz, B. L., Hanson, M. M., \& Shuping, R. Y. 1996, ApJ, 465, 245

Snow, T. P., Rachford, B. L., Tumlinson, J., Shull, J. M., Welty, D. E., Blair, W. P., Ferlet, R., Friedman, S. D., Gry, C., Jenkins, E. B., Lecavelier, A., Lemoine, M., Morton, D. C., Savage, B. D., Sembach, K. R., Vidal-Madjar, A., York, D. G., Andersson, B.-G., Feldman, P. D., \& Moos, H. W. 2000, ApJ, 538, L65

Socas-Navarro, H., \& Norton, A. A. 2007, ApJ, 660, L153

Socrates, A., \& Draine, B. T. 2008, arXiv, 0812.3913,

Sofia, U. J., Cardelli, J. A., \& Savage, B. D. 1994, ApJ, 430, 650

Sofia, U. J., Fitzpatrick, E. L., \& Meyer, D. M. 1998, ApJ, 504, L47

Sofia, U. J., \& Jenkins, E. B. 1998, ApJ, 499, 951

Sofia, U. J., \& Meyer, D. M. 2001, ApJ, 554, L221

Sofia, U. J., \& Parvathi, V. S. 2009, in Cosmic Dust - Near and Far, ed. T. Henning, E. Grün \& J. Steinacker (San Francisco: Ast. Soc. Pacific), in press.

Sofia, U. J., Cardelli, J. A., Guerin, K. P., \& Meyer, D. M. 1997, ApJ, 482, L105

Sofia, U. J., Lauroesch, J. T., Meyer, D. M., \& Cartledge, S. I. B. 2004, ApJ, 605, 272

Sofia, U. J., Gordon, K. D., Clayton, G. C., Misselt, K., Wolff, M. J., Cox, N. L. J., \& Ehrenfreund, P. 2006, ApJ, 636, 753

Sonneborn, G., Tripp, T. M., Ferlet, R., Jenkins, E. B., Sofia, U. J., Vidal-Madjar, A., \& Wozniak, P. R. 2000, ApJ, 545, 277

Sonnentrucker, P., Friedman, S. D., Welty, D. E., York, D. G., \& Snow, T. P. 2003, ApJ, 596, 350

Spitzer, L. 1985, ApJ, 290, L21

Spitzer, L., Cochran, W. D., \& Hirshfeld, A. 1974, ApJS, 28, 373

Spitzer, L., \& Field, G. B. 1955, ApJ, 121, 300

Spitzer, L., \& Fitzpatrick, E. L. 1993, ApJ, 409, 299

- 1995, ApJ, 445, 196

Spitzer, L., \& Jenkins, E. B. 1975, ARA\&A, 13, 133 
Spitzer, L., Drake, J. F., Jenkins, E. B., Morton, D. C., Rogerson, J. B., \& York, D. G. 1973, ApJ, 181, L116

Stancil, P. C., Schultz, D. R., Kimura, M., Gu, J.-P., Hirsch, G., \& Buenker, R. J. 1999, A\&AS, 140,225

Stokes, G. M. 1978, ApJS, 36, 115

Strassmeier, K. G., \& Fekel, F. C. 1990, A\&A, 230, 389

Strömgren, B. 1948, ApJ, 108, 242

Sudzius, J., \& Bobinas, V. 1992, Bull. Vilnius Astr. Obs., 86, 59

Takei, Y., Fujimoto, R., Mitsuda, K., \& Onaka, T. 2002, ApJ, 581, 307

Thackeray, A. D. 1971, MNRAS, 154, 103

Tielens, A. G. G. M. 1998, ApJ, 499, 267

Tobin, W. 1985, A\&A, 142, 189

Tobin, W., \& Kaufmann, J. P. 1984, MNRAS, 207, 369

Tobin, W., Viton, M., \& Sivan, J.-P. 1994, A\&AS, 107, 385

Tripp, T. M., Wakker, B. P., Jenkins, E. B., Bowers, C. W., Danks, A. C., Green, R. F., Heap, S. R., Joseph, C. L., Kaiser, M. E., Linsky, J. L., \& Woodgate, B. E. 2003, AJ, 125, 3122

Ueda, Y., Mitsuda, K., Murakami, H., \& Matsushita, K. 2005, ApJ, 620, 274

Vallerga, J. 1996, Space Sci. Rev., 78, 277

van Dishoeck, E. F. 1998, Faraday Disc., 109, 31

- 2004, ARA\&A, 42, 119

van Leeuwen, F. 2007, A\&A, 474, 653

Van Steenberg, M. E., \& Shull, J. M. 1988, ApJS, 67, 225

Venn, K. A., Krwin, M., Shetrone, M. D., Tout, C. A., Hill, V., \& Tolstoy, E. 2004, AJ, 128, 1177

Vidal-Madjar, A., \& Ferlet, R. 2002, ApJ, 571, L169

Vidal-Madjar, A., Ferlet, R., Laurent, C., \& York, D. G. 1982, ApJ, 260, 128

Vladilo, G. 2002a, A\&A, 391, 407

- 2002b, ApJ, 569, 295

- 2004, A\&A, 421, 479

Vladilo, G., Centurión, M., Levshakov, S. A., Péroux, C., Khare, P., Kulkarni, V. P., \& York, D. G. 2006, A\&A, 454, 151

Vladilo, J. 2008, in Pathways through an Exlectic Universe, ed. J. H. Knapen, T. J. Mahoney, and A. Vazdakis, (San Francisco: Ast. Soc. Pacific), p. 562

Wakker, B. P. 2001, ApJS, 136, 463 
Wakker, B. P., \& Mathis, J. S. 2000, ApJ, 544, L107

Wakker, B. P., Howk, J. C., Savage, B. D., van Woerden, H., Tufte, S. L., Schwarz, U. J., Benjamin, R., Reynolds, R. J., Peletier, R. F., \& Kalberla, P. M. W. 1999, Nature, 402, 388

Walborn, N. R. 1971, ApJS, 23, 257

- 1972, AJ, 77, 312

Wallerstein, G., \& Gilroy, K. K. 1992, AJ, 103, 1346

Wallerstein, G., \& Goldsmith, D. 1974, ApJ, 187, 237

Wegner, W. 1994, MNRAS, 270, 229

Welsh, B. Y., Sasseen, T., Craig, N., Jelinsky, S., \& Albert, C. E. 1997, ApJS, 112, 507

Welty, D. E., Lauroesch, J. T., Blades, J. C., Hobbs, L. M., \& York, D. G. 1997, ApJ, 489, 672

Welty, D. E., Hobbs, L. M., Lauroesch, J. T., Morton, D. C., Spitzer, L., \& York, D. G. 1999, ApJS, 124, 465

Welty, D. E., Lauroesch, J. T., Blades, J. C., Hobbs, L. M., \& York, D. G. 2001, ApJ, 554, L75

Whittet, D. C. B., Bode, M. F., Longmore, A. J., Adamson, A. J., McFadzean, A. D., Aitken, D. K., \& Roche, P. F. 1988, MNRAS, 233, 321

Whittet, D. C. B., Boogert, A. C. A., Gerakines, P. A., Schutte, W., Tielens, A. G. G. M., de Graauw, T., Prusti, T., van Dishoeck, E. F., Wesselius, P. R., \& Wright, C. M. 1997, ApJ, 490, 729

Witt, A. N., Smith, R. K., \& Dwek, E. 2001, ApJ, 550, L201

Wolfe, A. M., Gawiser, E., \& Prochaska, J. X. 2005, ARA\&A, 43, 861

Wolff, B., Koester, D., \& Lallement, R. 1999, A\&A, 346, 969

Wood, B. E., \& Linsky, J. L. 1997, ApJ, 474, L39

Wood, B. E., Redfield, S., Linsky, J. L., \& Sahu, M. S. 2002, ApJ, 581, 1169

Xiang, J., Zhang, S. N., \& Yao, Y. 2005, ApJ, 628, 769

Yao, Y., \& Wang, Q. D. 2006, ApJ, 641, 930

Yao, Y., Schulz, N. S., Gu, M. F., Nowak, M. A., \& Canizares, C. R. 2009, arXiv 0902.2778

York, D. G. 1976, ApJ, 204, 750

- 1983, ApJ, 264, 172

York, D. G., \& Kinahan, B. F. 1979, ApJ, 228, 127

York, D. G., \& Rogerson, J. B. 1976, ApJ, 203, 378

York, D. G., Spitzer, L., Bohlin, R. C., Hill, J., Jenkins, E. B., Savage, B. D., \& Snow, T. P. 1983, ApJ, 266, L55 
Table 7. Observations and Fits for Carbon

\begin{tabular}{|c|c|c|c|c|c|c|c|c|c|}
\hline \multirow[b]{2}{*}{$\begin{array}{c}\text { HD Number } \\
\text { (1) }\end{array}$} & \multirow[b]{2}{*}{$\begin{array}{l}\text { Name } \\
(2)\end{array}$} & \multicolumn{4}{|c|}{ Observed $\log N(\mathrm{C}$ II $)$} & \multirow[b]{2}{*}{$\begin{array}{l}F_{*} \\
(7)\end{array}$} & \multirow[b]{2}{*}{$\begin{array}{c}{\left[\mathrm{C}_{\text {gas }} / \mathrm{H}\right]_{\mathrm{fit}}{ }^{\mathrm{c}}} \\
(8)\end{array}$} & \multirow[b]{2}{*}{$\begin{array}{l}\text { Residual }^{\mathrm{d}} \\
\quad(9)\end{array}$} & \multirow{2}{*}{$\begin{array}{l}\text { Deviation } \\
\text { e } \\
\quad(10)\end{array}$} \\
\hline & & $\begin{array}{l}1.1 . \\
(3)\end{array}$ & $\begin{array}{l}\text { best } \\
(4)\end{array}$ & $\begin{array}{l}\text { u.l. } \\
(5)\end{array}$ & $\begin{array}{c}\text { Source }^{\mathrm{b}} \\
(6)\end{array}$ & & & & \\
\hline 24398 & $\zeta$ Per & 17.26 & 17.34 & 17.41 & CMJS96 & $0.88 \pm 0.05$ & $-0.201 \pm 0.049$ & -0.111 & -0.79 \\
\hline 24534 & X Per & 17.35 & 17.51 & 17.62 & SFM98 & $0.90 \pm 0.06$ & $-0.203 \pm 0.050$ & -0.085 & -0.58 \\
\hline 24912 & $\xi$ Per & 17.64 & 17.78 & 17.89 & $\mathrm{C}++91$ & $0.83 \pm 0.02$ & $-0.196 \pm 0.046$ & 0.225 & 1.47 \\
\hline 27778 & 62 Tau & $\cdots$ & $\ldots$ & 17.34 & SLMC04 & $\ldots$ & $\cdots$ & $\ldots$ & $\ldots$ \\
\hline 34029 & $\alpha$ Aur & 14.65 & 14.80 & 14.95 & WRLS02 & $0.44 \pm 0.05$ & $-0.157 \pm 0.095$ & 0.257 & 1.27 \\
\hline 35149 & 23 Ori & 16.90 & 16.98 & 17.04 & $\mathrm{~W}++99$ & $0.54 \pm 0.04$ & $-0.167 \pm 0.076$ & 0.055 & 0.32 \\
\hline 36861 & $\lambda$ Ori A & 16.79 & 17.00 & 17.14 & CMJS96 & $0.57 \pm 0.04$ & $-0.169 \pm 0.071$ & -0.085 & -0.39 \\
\hline 37021 & $\theta^{1}$ Ori & 17.64 & 17.82 & 17.94 & SLMC04 & $\cdots$ & $\cdots$ & $\cdots$ & $\cdots$ \\
\hline 37061 & $\nu$ Ori & 18.07 & 18.13 & 18.17 & SLMC04 & $\cdots$ & $\ldots$ & $\cdots$ & $\ldots$ \\
\hline 38771 & $\kappa$ Ori & $\cdots$ & $\cdots$ & 16.89 & CMJS96 & $0.67 \pm 0.03$ & $-0.180 \pm 0.055$ & $\cdots$ & $\cdots$ \\
\hline 57061 & $\tau \mathrm{CMa}$ & 16.78 & 16.96 & 17.08 & SCGM97 & $0.39 \pm 0.04$ & $-0.151 \pm 0.106$ & -0.045 & -0.24 \\
\hline 143275 & $\delta \mathrm{Sco}$ & 17.14 & 17.42 & 17.62 & HYO82 & $0.90 \pm 0.03$ & $-0.203 \pm 0.050$ & -0.006 & -0.02 \\
\hline 144217 & $\beta^{1}$ Sco & 17.27 & 17.37 & 17.45 & CMJS96 & $0.81 \pm 0.02$ & $-0.194 \pm 0.045$ & -0.027 & -0.25 \\
\hline 147888 & $\rho$ Oph D & 17.91 & 18.00 & 18.07 & SLMC04 & $0.88 \pm 0.06$ & $-0.201 \pm 0.049$ & 0.003 & 0.02 \\
\hline $149757(-15)$ & $\zeta \mathrm{Oph}$ & 17.24 & 17.36 & 17.45 & CMES93 & $1.05 \pm 0.02$ & $-0.218 \pm 0.071$ & -0.033 & -0.24 \\
\hline 152590 & HD 152590 & 18.11 & 18.21 & 18.29 & SLMC04 & $0.69 \pm 0.03$ & $-0.182 \pm 0.052$ & 0.464 & 4.03 \\
\hline 154368 & V1074 Sco & 17.30 & 17.68 & 17.88 & $\mathrm{~S}++96$ & $0.52 \pm 0.07$ & $-0.164 \pm 0.080$ & -0.202 & -0.66 \\
\hline 207198 & HD 207198 & 17.84 & 17.98 & 18.09 & SLMC04 & $0.90 \pm 0.03$ & $-0.203 \pm 0.050$ & 0.047 & 0.33 \\
\hline
\end{tabular}

${ }^{a}$ Terms in parentheses indicate separate velocity components, if they are explicitly identified and not grouped together; see 94.3

${ }^{\mathrm{b}}$ Codes in this column are linked to references listed in Table 1

${ }^{c}$ The expected depletion $\left[\mathrm{C}_{\text {gas }} / \mathrm{H}\right]$ computed using Eq. 10 . The listed errors do not include an overall systematic uncertainty of 0.04 in the solar abundance $\sigma(\mathrm{C} / \mathrm{H})_{\odot}$ in order to show just the formal error that arises from the uncertainties in location of line of best fit and the value of $F_{*}$.

${ }^{\mathrm{d}}$ The observed $\left[\mathrm{C}_{\text {gas }} / \mathrm{H}\right]$ minus that computed using Eq. 10$]$

e The difference shown in the previous column divided by the expected difference due to the uncertainties in both the measured column density and the coefficients that appear in Eq. 10 .

Note. - Tables 8 through 23 are published in the electronic edition of the Astrophysical Journal. This table illustrates the content and format of these tables. 
Table 8. Observations and Fits for Nitrogen

\begin{tabular}{|c|c|c|c|c|c|c|c|c|c|}
\hline \multirow[b]{2}{*}{$\begin{array}{c}\text { HD Number } \\
\text { (1) }\end{array}$} & \multirow[b]{2}{*}{$\begin{array}{l}\text { Name } \\
(2)\end{array}$} & \multicolumn{4}{|c|}{ Observed $\log N(\mathrm{~N}$ I $)$} & \multirow[b]{2}{*}{$\begin{array}{l}F_{*} \\
(7)\end{array}$} & \multirow[b]{2}{*}{$\begin{array}{c}{\left[\mathrm{N}_{\text {gas }} / \mathrm{H}\right]_{\mathrm{fit}}{ }^{\mathrm{c}}} \\
(8)\end{array}$} & \multirow[b]{2}{*}{$\begin{array}{l}\text { Residual }^{\mathrm{d}} \\
\quad(9)\end{array}$} & \multirow{2}{*}{$\begin{array}{l}\text { Deviation } \\
\quad \text { in } \sigma) \\
\quad(10)\end{array}$} \\
\hline & & $\begin{array}{l}1.1 . \\
(3)\end{array}$ & $\begin{array}{l}\text { best } \\
(4)\end{array}$ & $\begin{array}{l}\text { u.l. } \\
(5)\end{array}$ & $\begin{array}{c}\text { Source }^{b} \\
(6)\end{array}$ & & & & \\
\hline 5394 & $\gamma$ Cas & 15.96 & 16.00 & 16.04 & MCS97 & $0.52 \pm 0.04$ & $-0.109 \pm 0.017$ & 0.046 & 0.46 \\
\hline 22928 & $\delta$ Per & 15.18 & 15.30 & 15.39 & MY82 & $\cdots$ & $\cdots$ & $\cdots$ & $\cdots$ \\
\hline 23180 & o Per & 16.87 & 17.02 & 17.17 & $\mathrm{Y}++83$ & $0.84 \pm 0.06$ & $-0.109 \pm 0.029$ & 0.039 & 0.21 \\
\hline 24534 & X Per & 17.14 & 17.22 & 17.30 & JRS07 & $0.90 \pm 0.06$ & $-0.109 \pm 0.032$ & 0.087 & 0.94 \\
\hline 24760 & $\epsilon$ Per & 16.22 & 16.28 & 16.35 & MY82 & $0.68 \pm 0.04$ & $-0.109 \pm 0.020$ & -0.007 & -0.06 \\
\hline 27778 & $62 \mathrm{Tau}$ & 16.95 & 17.11 & 17.27 & JRS07 & $\cdots$ & $\cdots$ & $\cdots$ & $\cdots$ \\
\hline 34029 & $\alpha$ Aur & 13.78 & 13.87 & 13.96 & WRLS02 & $0.44 \pm 0.05$ & $-0.109 \pm 0.019$ & -0.164 & -1.24 \\
\hline 35149 & 23 Ori & 16.47 & 16.57 & 16.65 & $\mathrm{~W}++99$ & $0.54 \pm 0.04$ & $-0.109 \pm 0.017$ & 0.150 & 0.92 \\
\hline 36486 & $\delta$ Ori A & 15.81 & 15.85 & 15.89 & $\mathrm{~J}++99$ & $0.54 \pm 0.02$ & $-0.109 \pm 0.017$ & -0.127 & -2.15 \\
\hline 36861 & $\lambda$ Ori A & 16.63 & 16.65 & 16.68 & MCS97 & $0.57 \pm 0.04$ & $-0.109 \pm 0.017$ & 0.058 & 0.51 \\
\hline 37043 & $\iota$ Ori & 15.86 & 15.93 & 15.99 & MCS97 & $0.41 \pm 0.03$ & $-0.109 \pm 0.020$ & -0.014 & -0.15 \\
\hline 37903 & HD 37903 & 16.54 & 16.89 & 17.27 & JRS07 & $1.15 \pm 0.03$ & $-0.109 \pm 0.050$ & -0.337 & -0.90 \\
\hline 38771 & $\kappa$ Ori & 16.32 & 16.34 & 16.37 & MCS97 & $0.67 \pm 0.03$ & $-0.109 \pm 0.019$ & 0.026 & 0.48 \\
\hline 41161 & HD 41161 & 16.94 & 17.00 & 17.06 & $\mathrm{OH} 06$ & $0.44 \pm 0.04$ & $-0.109 \pm 0.019$ & 0.133 & 1.27 \\
\hline 44743 & $\beta \mathrm{CMa}$ & 14.04 & 14.06 & 14.08 & JGD00 & $-0.43 \pm 0.03$ & $-0.109 \pm 0.080$ & -0.028 & -0.27 \\
\hline $48915(+12)$ & $\alpha \mathrm{CMa}$ & 12.92 & 12.97 & 13.06 & $\mathrm{H}++99$ & $0.42 \pm 0.11$ & $-0.109 \pm 0.020$ & -0.224 & -1.05 \\
\hline$(+18)$ & & 13.05 & 13.12 & 13.09 & $\mathrm{H}++99$ & $0.42 \pm 0.08$ & $-0.109 \pm 0.020$ & -0.274 & -1.79 \\
\hline 53975 & HD 53975 & 16.72 & 16.80 & 16.88 & OH06 & $0.45 \pm 0.03$ & $-0.109 \pm 0.019$ & -0.130 & -1.29 \\
\hline 66811 & $\zeta$ Pup & 15.80 & 15.85 & 15.90 & $\mathrm{ST}++00$ & $0.32 \pm 0.02$ & $-0.109 \pm 0.025$ & 0.100 & 1.46 \\
\hline 68273 & $\gamma^{2} \mathrm{Vel}$ & 15.55 & 15.58 & 15.62 & $\mathrm{ST}++00$ & $0.25 \pm 0.02$ & $-0.109 \pm 0.029$ & 0.080 & 1.33 \\
\hline 73882 & HD 73882 & 17.25 & 17.36 & 17.47 & JRS07 & $0.68 \pm 0.07$ & $-0.109 \pm 0.020$ & 0.002 & 0.02 \\
\hline 75309 & HD 75309 & 16.74 & 16.86 & 16.96 & KAMM03 & $0.63 \pm 0.04$ & $-0.109 \pm 0.018$ & -0.111 & -0.82 \\
\hline 88115 & HD 88115 & 16.50 & 16.67 & 16.79 & KAMM03 & $0.35 \pm 0.45$ & $-0.109 \pm 0.023$ & -0.118 & -0.67 \\
\hline 94493 & HD 94493 & 16.69 & 16.82 & 16.92 & KAMM03 & $0.29 \pm 0.03$ & $-0.109 \pm 0.027$ & -0.143 & -1.15 \\
\hline 99857 & HD 99857 & 17.13 & 17.19 & 17.25 & KAMM03 & $0.54 \pm 0.04$ & $-0.109 \pm 0.017$ & 0.039 & 0.46 \\
\hline 108248 & $\alpha^{1} \mathrm{Cru}$ & 15.39 & 15.49 & 15.59 & $\mathrm{Y}++83$ & $0.15 \pm 0.05$ & $-0.109 \pm 0.036$ & 0.095 & 0.65 \\
\hline 110432 & BZ Cru & 17.02 & 17.09 & 17.15 & KAMM03 & $1.17 \pm 0.11$ & $-0.109 \pm 0.052$ & 0.098 & 0.89 \\
\hline 116658 & $\alpha$ Vir & 14.57 & 14.63 & 14.67 & YK79 & $0.16 \pm 0.05$ & $-0.109 \pm 0.035$ & -0.158 & -1.35 \\
\hline 118716 & $\epsilon$ Cen & 15.34 & 15.42 & 15.59 & $\mathrm{Y}++83$ & $0.15 \pm 0.16$ & $-0.109 \pm 0.036$ & 0.023 & 0.06 \\
\hline 121263 & $\zeta$ Cen & 15.49 & 15.64 & 15.79 & $\mathrm{Y}++83$ & $\cdots$ & $\cdots$ & $\cdots$ & $\cdots$ \\
\hline 122451 & $\beta$ Cen & 15.04 & 15.19 & 15.34 & LYBM78 & $0.23 \pm 0.03$ & $-0.109 \pm 0.030$ & -0.145 & -0.90 \\
\hline 124314 & HD 124314 & 17.23 & 17.28 & 17.33 & KAMM03 & $0.59 \pm 0.05$ & $-0.109 \pm 0.017$ & -0.023 & -0.26 \\
\hline 127972 & $\eta$ Cen & 16.01 & 16.08 & 16.16 & $\mathrm{Y}++83$ & $\ldots$ & $\ldots$ & $\ldots$ & $\cdots$ \\
\hline 143275 & $\delta$ Sco & 16.99 & 17.01 & 17.03 & MCS97 & $0.90 \pm 0.03$ & $-0.109 \pm 0.032$ & 0.051 & 0.54 \\
\hline 144217 & $\beta^{1}$ Sco & 16.97 & 17.10 & 17.22 & $\mathrm{Y}++83$ & $0.81 \pm 0.02$ & $-0.109 \pm 0.027$ & 0.176 & 1.32 \\
\hline 147888 & $\rho$ Oph D & 16.91 & 17.38 & 17.72 & JRS07 & $0.88 \pm 0.06$ & $-0.109 \pm 0.031$ & -0.148 & -0.34 \\
\hline $149757(-15)$ & $\zeta \mathrm{Oph}$ & 16.90 & 16.96 & 17.01 & SCS92 & $1.05 \pm 0.02$ & $-0.109 \pm 0.043$ & 0.015 & 0.17 \\
\hline 158926 & $\lambda \mathrm{Sco}$ & 14.83 & 14.85 & 14.87 & Y83 & $0.31 \pm 0.02$ & $-0.109 \pm 0.025$ & -0.167 & -3.79 \\
\hline 160578 & $\kappa \mathrm{Sco}$ & 15.92 & 15.99 & 16.04 & MCS97 & $0.50 \pm 0.07$ & $-0.109 \pm 0.017$ & -0.026 & -0.16 \\
\hline
\end{tabular}


Table 8-Continued

\begin{tabular}{|c|c|c|c|c|c|c|c|c|c|}
\hline \multirow[b]{2}{*}{$\begin{array}{l}\text { HD Number } \\
\text { (1) }\end{array}$} & \multirow[b]{2}{*}{$\begin{array}{l}\text { Name } \\
(2)\end{array}$} & \multicolumn{4}{|c|}{ Observed $\log N(\mathrm{~N} \mathrm{I})$} & \multirow[b]{2}{*}{$\begin{array}{l}F_{*} \\
(7)\end{array}$} & \multirow[b]{2}{*}{$\begin{array}{c}{\left[\mathrm{N}_{\text {gas }} / \mathrm{H}\right]_{\mathrm{fit}}{ }^{\mathrm{c}}} \\
(8)\end{array}$} & \multirow[b]{2}{*}{$\begin{array}{l}\text { Residual }^{\mathrm{d}} \\
(9)\end{array}$} & \multirow{2}{*}{$\begin{array}{l}\text { Deviation }^{\mathrm{e}} \\
\quad(\text { in } \sigma) \\
\quad(10)\end{array}$} \\
\hline & & $\begin{array}{l}1.1 . \\
(3)\end{array}$ & $\begin{array}{l}\text { best } \\
(4)\end{array}$ & $\begin{array}{l}\text { u.l. } \\
(5)\end{array}$ & $\begin{array}{c}\text { Source }^{b} \\
(6)\end{array}$ & & & & \\
\hline 179406 & $20 \mathrm{Aql}$ & 16.91 & 17.04 & 17.13 & KAMM03 & $\cdots$ & $\cdots$ & $\cdots$ & $\cdots$ \\
\hline 185418 & HD 185418 & 17.15 & 17.24 & 17.33 & $\mathrm{~S}++03$ & $0.79 \pm 0.03$ & $-0.109 \pm 0.025$ & 0.036 & 0.30 \\
\hline 191877 & HD 191877 & 16.70 & 16.80 & 16.88 & $\mathrm{H}++03$ & $0.39 \pm 0.04$ & $-0.109 \pm 0.021$ & -0.110 & -0.88 \\
\hline 192639 & HD 192639 & 16.78 & 17.18 & 17.66 & JRS07 & $0.64 \pm 0.04$ & $-0.109 \pm 0.018$ & -0.091 & -0.20 \\
\hline 195965 & HD 195965 & 16.73 & 16.79 & 16.86 & $\mathrm{H}++03$ & $0.52 \pm 0.02$ & $-0.109 \pm 0.017$ & -0.137 & -1.94 \\
\hline 199579 & HD 199579 & 17.06 & 17.16 & 17.26 & JRS07 & $0.76 \pm 0.27$ & $-0.109 \pm 0.024$ & 0.120 & 0.97 \\
\hline 206267 & HD 206267 & 16.87 & 17.16 & 17.43 & JRS07 & $0.87 \pm 0.07$ & $-0.109 \pm 0.030$ & -0.168 & -0.57 \\
\hline 207198 & HD 207198 & 17.22 & 17.41 & 17.59 & JRS07 & $0.90 \pm 0.03$ & $-0.109 \pm 0.032$ & -0.056 & -0.29 \\
\hline 210839 & $\lambda$ Cep & 17.07 & 17.19 & 17.32 & JRS07 & $0.66 \pm 0.03$ & $-0.109 \pm 0.019$ & -0.047 & -0.33 \\
\hline 218915 & HD 218915 & 16.86 & 16.97 & 17.05 & KAMM03 & $0.70 \pm 0.08$ & $-0.109 \pm 0.020$ & -0.078 & -0.76 \\
\hline 219188 & HD 219188 & 16.74 & 16.88 & 16.99 & KAMM03 & $1.24 \pm 0.57$ & $-0.109 \pm 0.057$ & 0.210 & 0.95 \\
\hline 220057 & HD 220057 & 17.00 & 17.04 & 17.07 & KML06 & $0.75 \pm 0.05$ & $-0.109 \pm 0.023$ & 0.093 & 0.75 \\
\hline 224151 & V373 Cas & 17.16 & 17.19 & 17.22 & KML06 & $0.46 \pm 0.04$ & $-0.109 \pm 0.018$ & -0.064 & -0.95 \\
\hline
\end{tabular}

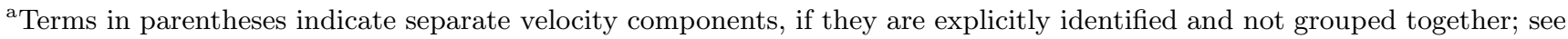
4.3

${ }^{\mathrm{b}}$ Codes in this column are linked to references listed in Table 1

${ }^{\mathrm{c}}$ The expected depletion $\left[\mathrm{N}_{\text {gas }} / \mathrm{H}\right]$ computed using Eq. 10 The listed errors do not include an overall systematic uncertainty of 0.11 in the solar abundance $\sigma(\mathrm{N} / \mathrm{H}) \odot$ in order to show just the formal error that arises from the uncertainties in location of line of best fit and the value of $F_{*}$.

${ }^{\mathrm{d}}$ The observed $\left[\mathrm{N}_{\text {gas }} / \mathrm{H}\right]$ minus that computed using Eq. 10 .

eThe difference shown in the previous column divided by the expected difference due to the uncertainties in both the measured column density and the coefficients that appear in Eq. 10. 
Table 9. Observations and Fits for Oxygen

\begin{tabular}{|c|c|c|c|c|c|c|c|c|c|}
\hline \multirow[b]{2}{*}{$\begin{array}{c}\text { HD Number } \\
\text { (1) }\end{array}$} & \multirow[b]{2}{*}{$\begin{array}{l}\text { Name } \\
(2)\end{array}$} & \multicolumn{4}{|c|}{ Observed $\log N(\mathrm{O} \mathrm{I})$} & \multirow[b]{2}{*}{$\begin{array}{l}F_{*} \\
(7)\end{array}$} & \multirow[b]{2}{*}{$\begin{array}{c}{\left[\mathrm{O}_{\text {gas }} / \mathrm{H}\right]_{\mathrm{fit}}{ }^{\mathrm{c}}} \\
(8)\end{array}$} & \multirow[b]{2}{*}{$\begin{array}{c}\text { Residual }^{\mathrm{d}} \\
\quad(9)\end{array}$} & \multirow{2}{*}{$\begin{array}{c}\text { Deviation } \\
\quad \text { (in } \sigma) \\
(10)\end{array}$} \\
\hline & & $\begin{array}{l}1.1 . \\
(3)\end{array}$ & $\begin{array}{l}\text { best } \\
(4)\end{array}$ & $\begin{array}{l}\text { u.l. } \\
(5)\end{array}$ & $\begin{array}{l}\text { Source }^{b} \\
(6)\end{array}$ & & & & \\
\hline 1383 & HD 1383 & 18.09 & 18.15 & 18.21 & CLMS04 & $0.61 \pm 0.04$ & $-0.148 \pm 0.014$ & 0.034 & 0.35 \\
\hline 5394 & $\gamma$ Cas & 16.72 & 16.76 & 16.80 & MJC98 & $0.52 \pm 0.04$ & $-0.127 \pm 0.015$ & -0.032 & -0.32 \\
\hline 12323 & HD 12323 & 17.96 & 18.02 & 18.08 & CLMS04 & $0.52 \pm 0.04$ & $-0.128 \pm 0.014$ & 0.103 & 1.08 \\
\hline 13268 & HD 13268 & 18.07 & 18.13 & 18.19 & CLMS04 & $0.51 \pm 0.04$ & $-0.126 \pm 0.015$ & 0.079 & 0.82 \\
\hline 14434 & HD 14434 & 18.10 & 18.18 & 18.26 & CLMS04 & $0.52 \pm 0.04$ & $-0.127 \pm 0.015$ & 0.080 & 0.73 \\
\hline 22586 & HD 22586 & 15.45 & $\infty$ & $\infty$ & JW96 & $0.34 \pm 0.07$ & $-0.087 \pm 0.023$ & $\cdots$ & $\cdots$ \\
\hline 23180 & o Per & 17.82 & 17.93 & 18.02 & MJC98 & $0.84 \pm 0.06$ & $-0.200 \pm 0.022$ & 0.180 & 1.24 \\
\hline 23478 & HD 23478 & 17.70 & 17.79 & 17.88 & $\mathrm{C}++08$ & $-0.00 \pm 0.50$ & $-0.010 \pm 0.116$ & -0.006 & -0.03 \\
\hline 24190 & HD 24190 & 17.86 & 17.91 & 17.96 & $\mathrm{C}++08$ & $0.63 \pm 0.24$ & $-0.152 \pm 0.056$ & 0.003 & 0.03 \\
\hline 24398 & $\zeta$ Per & 17.65 & 17.71 & 17.76 & MJC98 & $0.88 \pm 0.05$ & $-0.210 \pm 0.022$ & -0.035 & -0.28 \\
\hline 24534 & X Per & 17.85 & 17.87 & 17.89 & KAMM03 & $0.90 \pm 0.06$ & $-0.213 \pm 0.023$ & -0.019 & -0.43 \\
\hline 24760 & $\epsilon$ Per & 16.98 & 17.03 & 17.07 & MJC98 & $0.68 \pm 0.04$ & $-0.163 \pm 0.015$ & -0.066 & -0.65 \\
\hline 24912 & $\xi$ Per & 17.75 & 17.81 & 17.86 & $\mathrm{C}++91$ & $0.83 \pm 0.02$ & $-0.198 \pm 0.017$ & -0.043 & -0.45 \\
\hline 27778 & 62 Tau & 17.79 & 17.83 & 17.87 & CMLS01 & $\ldots$ & $\cdots$ & $\ldots$ & $\ldots$ \\
\hline 30614 & $\alpha \mathrm{Cam}$ & 17.86 & 17.98 & 18.07 & MJC98 & $0.46 \pm 0.04$ & $-0.113 \pm 0.016$ & 0.245 & 1.87 \\
\hline 34029 & $\alpha$ Aur & 14.85 & 15.01 & 15.37 & WRLS02 & $0.44 \pm 0.05$ & $-0.109 \pm 0.018$ & 0.116 & 0.42 \\
\hline 35149 & 23 Ori & 17.22 & 17.32 & 17.42 & CLMS04 & $0.54 \pm 0.04$ & $-0.132 \pm 0.014$ & 0.060 & 0.36 \\
\hline 36486 & $\delta$ Ori A & 16.62 & 16.67 & 16.72 & MJC98 & $0.54 \pm 0.02$ & $-0.132 \pm 0.012$ & -0.146 & -2.24 \\
\hline 36861 & $\lambda$ Ori A & 17.26 & 17.33 & 17.39 & MJC98 & $0.57 \pm 0.04$ & $-0.138 \pm 0.014$ & -0.089 & -0.69 \\
\hline 37021 & $\theta^{1}$ Ori & 18.06 & 18.09 & 18.12 & CMLS01 & $\ldots$ & $\ldots$ & $\ldots$ & $\ldots$ \\
\hline 37043 & $\iota$ Ori & 16.67 & 16.76 & 16.84 & MJHC94 & $0.41 \pm 0.03$ & $-0.103 \pm 0.016$ & -0.044 & -0.41 \\
\hline 37061 & $\nu$ Ori & 18.21 & 18.23 & 18.25 & CMLS01 & $\ldots$ & $\cdots$ & $\ldots$ & $\ldots$ \\
\hline 37128 & $\epsilon$ Ori & 16.93 & 16.98 & 17.03 & MJC98 & $0.54 \pm 0.03$ & $-0.132 \pm 0.013$ & -0.096 & -0.93 \\
\hline 37367 & HD 37367 & 17.98 & 18.06 & 18.14 & CLMS04 & $0.65 \pm 0.07$ & $-0.158 \pm 0.019$ & 0.125 & 0.99 \\
\hline 37903 & HD 37903 & 17.86 & 17.88 & 17.90 & CMLS01 & $1.15 \pm 0.03$ & $-0.269 \pm 0.032$ & -0.048 & -0.67 \\
\hline 38666 & $\mu \mathrm{Col}$ & $\ldots$ & $\ldots$ & 17.01 & HSF99 & $0.11 \pm 0.01$ & $-0.036 \pm 0.028$ & $\ldots$ & $\ldots$ \\
\hline 38771 & $\kappa$ Ori & 16.98 & 17.03 & 17.07 & MJHC94 & $0.67 \pm 0.03$ & $-0.161 \pm 0.013$ & -0.086 & -1.33 \\
\hline 40893 & HD 40893 & 18.04 & 18.07 & 18.10 & $\mathrm{C}++08$ & $0.61 \pm 0.05$ & $-0.147 \pm 0.016$ & -0.079 & -0.96 \\
\hline 41161 & HD 41161 & 17.99 & 18.04 & 18.09 & OH06 & $0.44 \pm 0.04$ & $-0.109 \pm 0.016$ & 0.314 & 3.17 \\
\hline 43818 & LU Gem & 18.19 & 18.22 & 18.25 & CLMS04 & $\ldots$ & $\ldots$ & $\ldots$ & $\ldots$ \\
\hline 44743 & $\beta \mathrm{CMa}$ & 14.98 & 15.00 & 15.02 & JGD00 & $-0.43 \pm 0.03$ & $0.087 \pm 0.056$ & -0.151 & -1.79 \\
\hline 47839 & 15 Mon & 16.72 & 16.84 & 16.93 & MJC98 & $0.25 \pm 0.05$ & $-0.066 \pm 0.024$ & -0.162 & -1.10 \\
\hline $48915(+12)$ & $\alpha \mathrm{CMa}$ & 13.61 & 13.71 & 13.82 & $\mathrm{H}++99$ & $0.42 \pm 0.11$ & $-0.105 \pm 0.028$ & -0.347 & -1.52 \\
\hline$(+18)$ & & 14.39 & 14.54 & 14.70 & $\mathrm{H}++99$ & $0.42 \pm 0.08$ & $-0.104 \pm 0.023$ & 0.282 & 1.30 \\
\hline 49798 & HD 49798 & 15.70 & $\infty$ & $\infty$ & JW96 & $\cdots$ & $\cdots$ & $\cdots$ & $\cdots$ \\
\hline 53975 & HD 53975 & 17.79 & 17.87 & 17.95 & OH06 & $0.45 \pm 0.03$ & $-0.112 \pm 0.015$ & 0.082 & 0.82 \\
\hline 57061 & $\tau \mathrm{CMa}$ & 17.29 & 17.33 & 17.37 & MJC98 & $0.39 \pm 0.04$ & $-0.097 \pm 0.018$ & -0.031 & -0.49 \\
\hline 63005 & HD 63005 & 17.91 & 17.95 & 17.99 & CLMS04 & $0.64 \pm 0.03$ & $-0.155 \pm 0.013$ & 0.027 & 0.40 \\
\hline 69106 & HD 69106 & 17.64 & 17.69 & 17.74 & $\mathrm{C}++08$ & $0.64 \pm 0.06$ & $-0.155 \pm 0.017$ & -0.007 & -0.09 \\
\hline
\end{tabular}


Table 9-Continued

\begin{tabular}{|c|c|c|c|c|c|c|c|c|c|}
\hline \multirow[b]{2}{*}{$\begin{array}{c}\text { HD Number }{ }^{\mathrm{a}} \\
\text { (1) }\end{array}$} & \multirow[b]{2}{*}{$\begin{array}{l}\text { Name } \\
(2)\end{array}$} & \multicolumn{4}{|c|}{ Observed $\log N(\mathrm{O} \mathrm{I})$} & \multirow[b]{2}{*}{$\begin{array}{l}F_{*} \\
(7)\end{array}$} & \multirow[b]{2}{*}{$\begin{array}{c}{\left[\mathrm{O}_{\text {gas }} / \mathrm{H}\right]_{\mathrm{fit}}{ }^{\mathrm{c}}} \\
(8)\end{array}$} & \multirow[b]{2}{*}{$\begin{array}{l}\text { Residual }^{\mathrm{d}} \\
\quad(9)\end{array}$} & \multirow{2}{*}{$\begin{array}{c}\text { Deviation }^{\mathrm{e}} \\
\quad(\text { in } \sigma) \\
(10)\end{array}$} \\
\hline & & $\begin{array}{l}1.1 . \\
(3)\end{array}$ & $\begin{array}{c}\text { best } \\
(4)\end{array}$ & $\begin{array}{l}\text { u.l. } \\
(5)\end{array}$ & $\begin{array}{c}\text { Source }^{b} \\
(6)\end{array}$ & & & & \\
\hline $72089(+5)$ & HD 72089 & 16.30 & $\infty$ & $\infty$ & JW96 & $\cdots$ & $\cdots$ & $\cdots$ & $\cdots$ \\
\hline 72754 & FY Vel & 17.68 & 17.74 & 17.80 & CLMS04 & $0.76 \pm 0.10$ & $-0.182 \pm 0.026$ & -0.123 & -1.04 \\
\hline 75309 & HD 75309 & 17.68 & 17.73 & 17.78 & CMLS01 & $0.63 \pm 0.04$ & $-0.151 \pm 0.014$ & -0.056 & -0.61 \\
\hline 79186 & GX Vel & 18.00 & 18.04 & 18.08 & CLMS04 & $0.69 \pm 0.03$ & $-0.166 \pm 0.014$ & 0.038 & 0.47 \\
\hline 88115 & HD 88115 & 17.61 & 17.67 & 17.72 & $\mathrm{~A}++03$ & $0.35 \pm 0.45$ & $-0.088 \pm 0.103$ & 0.004 & 0.03 \\
\hline 91824 & HD 91824 & 17.95 & 18.00 & 18.05 & CLMS04 & $0.45 \pm 0.03$ & $-0.111 \pm 0.015$ & 0.187 & 2.47 \\
\hline 91983 & HD 91983 & 17.92 & 17.96 & 18.00 & CLMS04 & $0.48 \pm 0.04$ & $-0.118 \pm 0.015$ & 0.078 & 0.88 \\
\hline 93030 & $\theta$ Car & 16.18 & 16.39 & 16.59 & AJS92 & $0.45 \pm 0.03$ & $-0.111 \pm 0.015$ & -0.524 & -2.43 \\
\hline 93205 & V560 Car & 17.92 & 17.95 & 17.98 & $\mathrm{~A}++03$ & $0.40 \pm 0.03$ & $-0.100 \pm 0.016$ & -0.111 & -2.17 \\
\hline 93222 & HD 93222 & 18.11 & 18.13 & 18.15 & $\mathrm{~A}++03$ & $0.39 \pm 0.04$ & $-0.098 \pm 0.018$ & 0.048 & 0.71 \\
\hline 94493 & HD 94493 & 17.81 & 17.85 & 17.88 & $\mathrm{~A}++03$ & $0.29 \pm 0.03$ & $-0.075 \pm 0.021$ & -0.004 & -0.08 \\
\hline 94454 & HD 94454 & 17.79 & 17.83 & 17.87 & $\mathrm{C}++08$ & $\cdots$ & $\cdots$ & $\cdots$ & $\cdots$ \\
\hline 99857 & HD 99857 & 17.86 & 17.89 & 17.92 & $\mathrm{~A}++03$ & $0.54 \pm 0.04$ & $-0.132 \pm 0.015$ & -0.095 & -1.40 \\
\hline 99872 & HD 99872 & 17.73 & 17.78 & 17.83 & $\mathrm{C}++08$ & $\cdots$ & $\cdots$ & $\cdots$ & $\cdots$ \\
\hline 102065 & HD 102065 & 17.63 & 17.70 & 17.77 & $\mathrm{C}++08$ & $\cdots$ & $\cdots$ & $\cdots$ & $\cdots$ \\
\hline 104705 & DF Cru & 17.79 & 17.81 & 17.83 & $\mathrm{~A}++03$ & $0.33 \pm 0.05$ & $-0.084 \pm 0.021$ & -0.042 & -0.52 \\
\hline 108639 & HD 108639 & 18.03 & 18.09 & 18.15 & $\mathrm{C}++08$ & $0.37 \pm 0.37$ & $-0.094 \pm 0.085$ & 0.040 & 0.30 \\
\hline 112999 & V946 Cen & 17.68 & 17.75 & 17.82 & $\mathrm{C}++08$ & $\cdots$ & $\cdots$ & $\cdots$ & $\cdots$ \\
\hline 114886 & HD 114886 & 17.89 & 17.95 & 18.01 & $\mathrm{C}++08$ & $0.87 \pm 0.31$ & $-0.206 \pm 0.072$ & -0.006 & -0.06 \\
\hline 115071 & V961 Cen & 18.17 & 18.20 & 18.23 & $\mathrm{C}++08$ & $0.22 \pm 0.21$ & $-0.061 \pm 0.052$ & 0.004 & 0.05 \\
\hline 116658 & $\alpha \mathrm{Vir}$ & 15.44 & 15.54 & 15.64 & YK79 & $0.16 \pm 0.05$ & $-0.047 \pm 0.028$ & -0.169 & -1.17 \\
\hline 116852 & HD 116852 & 17.52 & 17.56 & 17.60 & $\mathrm{C}++08$ & $0.36 \pm 0.04$ & $-0.091 \pm 0.018$ & -0.124 & -1.36 \\
\hline 120086 & HD 120086 & 16.20 & $\infty$ & $\infty$ & JW96 & $\cdots$ & $\cdots$ & $\cdots$ & $\cdots$ \\
\hline 121968 & HD 121968 & 16.99 & 17.10 & 17.21 & LKF05 & $0.26 \pm 0.06$ & $-0.069 \pm 0.025$ & -0.187 & -1.09 \\
\hline 122879 & HD 122879 & 18.08 & 18.14 & 18.20 & CLMS04 & $0.55 \pm 0.04$ & $-0.133 \pm 0.015$ & 0.177 & 1.49 \\
\hline 124314 & HD 124314 & 18.16 & 18.18 & 18.20 & $\mathrm{~A}++03$ & $0.59 \pm 0.05$ & $-0.142 \pm 0.016$ & 0.053 & 0.69 \\
\hline 137595 & HD 137595 & 17.72 & 17.76 & 17.80 & $\mathrm{C}++08$ & $0.77 \pm 0.22$ & $-0.185 \pm 0.053$ & -0.036 & -0.45 \\
\hline 141637 & $1 \mathrm{Sco}$ & 17.85 & 17.95 & 18.03 & MJC98 & $0.69 \pm 0.05$ & $-0.166 \pm 0.016$ & 0.224 & 1.57 \\
\hline 143275 & $\delta \mathrm{Sco}$ & 17.67 & 17.74 & 17.79 & MJC98 & $0.90 \pm 0.03$ & $-0.212 \pm 0.021$ & 0.029 & 0.27 \\
\hline 144217 & $\beta^{1} \mathrm{Sco}$ & 17.60 & 17.67 & 17.74 & MJC98 & $0.81 \pm 0.02$ & $-0.193 \pm 0.016$ & -0.030 & -0.37 \\
\hline 144470 & $\mathrm{o}^{1} \mathrm{Sco}$ & 17.82 & 17.88 & 17.95 & MJC98 & $0.81 \pm 0.04$ & $-0.192 \pm 0.018$ & 0.084 & 0.79 \\
\hline 144965 & HD 144965 & 17.74 & 17.80 & 17.86 & $\mathrm{C}++08$ & $1.15 \pm 0.35$ & $-0.268 \pm 0.084$ & -0.015 & -0.12 \\
\hline 147165 & $\sigma \mathrm{Sco}$ & 17.93 & 18.07 & 18.18 & MJC98 & $0.76 \pm 0.06$ & $-0.183 \pm 0.020$ & 0.132 & 0.61 \\
\hline 147683 & V760 Sco & 17.95 & 18.00 & 18.05 & $\mathrm{C}++08$ & $0.56 \pm 0.47$ & $-0.136 \pm 0.107$ & -0.029 & -0.17 \\
\hline 147888 & $\rho$ Oph D & 18.16 & 18.18 & 18.20 & CMLS01 & $0.88 \pm 0.06$ & $-0.209 \pm 0.023$ & -0.109 & -0.73 \\
\hline 147933 & $\rho \mathrm{Oph} \mathrm{A}$ & 17.98 & 18.18 & 18.31 & MJC98 & $1.09 \pm 0.08$ & $-0.256 \pm 0.034$ & -0.023 & -0.12 \\
\hline 148184 & $\chi \mathrm{Oph}$ & 18.07 & 18.26 & 18.39 & MJC98 & $0.96 \pm 0.09$ & $-0.226 \pm 0.030$ & 0.423 & 2.10 \\
\hline 148594 & HD 148594 & 17.83 & 17.86 & 17.89 & CLMS04 & $\cdots$ & $\cdots$ & $\cdots$ & $\cdots$ \\
\hline $149757(-27)$ & $\zeta \mathrm{Oph}$ & 16.39 & 16.70 & 16.88 & SCS92 & $\cdots$ & $\cdots$ & $\cdots$ & $\cdots$ \\
\hline
\end{tabular}


Table 9 -Continued

\begin{tabular}{|c|c|c|c|c|c|c|c|c|c|}
\hline \multirow[b]{2}{*}{$\begin{array}{l}\text { HD Number }{ }^{\mathrm{a}} \\
\text { (1) }\end{array}$} & \multirow[b]{2}{*}{$\begin{array}{c}\text { Name } \\
(2)\end{array}$} & \multicolumn{4}{|c|}{ Observed $\log N(\mathrm{O} \mathrm{I})$} & \multirow[b]{2}{*}{$\begin{array}{l}F_{*} \\
(7)\end{array}$} & \multirow[b]{2}{*}{$\begin{array}{c}{\left[\mathrm{O}_{\text {gas }} / \mathrm{H}\right]_{\mathrm{fit}}{ }^{\mathrm{c}}} \\
(8)\end{array}$} & \multirow[b]{2}{*}{$\begin{array}{l}\text { Residual }^{\mathrm{d}} \\
\quad(9)\end{array}$} & \multirow{2}{*}{$\begin{array}{l}\text { Deviation }^{\mathrm{e}} \\
\quad(\text { in } \sigma) \\
\quad(10)\end{array}$} \\
\hline & & $\begin{array}{l}1.1 . \\
(3)\end{array}$ & $\begin{array}{l}\text { best } \\
(4)\end{array}$ & $\begin{array}{l}\text { u.l. } \\
(5)\end{array}$ & $\begin{array}{c}\text { Source }^{b} \\
(6)\end{array}$ & & & & \\
\hline$(-15)$ & & 17.59 & 17.63 & 17.67 & SCS92 & $1.05 \pm 0.02$ & $-0.246 \pm 0.026$ & -0.033 & -0.47 \\
\hline 151805 & HD 151805 & 17.85 & 17.98 & 18.05 & $\mathrm{C}++08$ & $0.83 \pm 0.36$ & $-0.196 \pm 0.083$ & 0.011 & 0.08 \\
\hline 152590 & HD 152590 & 17.98 & 18.01 & 18.04 & $\mathrm{C}++08$ & $0.69 \pm 0.03$ & $-0.166 \pm 0.014$ & -0.052 & -0.86 \\
\hline 154368 & V1074 Sco & 17.88 & 18.11 & 18.21 & $\mathrm{~S}++96$ & $0.52 \pm 0.07$ & $-0.127 \pm 0.019$ & -0.111 & -0.64 \\
\hline 157246 & $\gamma$ Ara & 17.29 & 17.33 & 17.37 & MJC98 & $0.46 \pm 0.03$ & $-0.114 \pm 0.015$ & -0.020 & -0.21 \\
\hline 157857 & HD 157857 & 18.07 & 18.11 & 18.15 & CLMS04 & $0.62 \pm 0.04$ & $-0.151 \pm 0.014$ & 0.057 & 0.71 \\
\hline 158926 & $\lambda$ Sco & 15.87 & 15.88 & 15.90 & Y83 & $0.31 \pm 0.02$ & $-0.081 \pm 0.019$ & -0.034 & -0.89 \\
\hline 165246 & HD 165246 & 17.96 & 18.00 & 18.04 & $\mathrm{C}++08$ & $0.77 \pm 1.39$ & $-0.183 \pm 0.312$ & -0.032 & -0.06 \\
\hline 165955 & HD 165955 & 17.70 & 17.79 & 17.88 & CLMS04 & $0.42 \pm 0.04$ & $-0.105 \pm 0.017$ & 0.036 & 0.33 \\
\hline 167264 & $15 \mathrm{Sgr}$ & 17.98 & 18.14 & 18.26 & MJC98 & $0.68 \pm 0.16$ & $-0.164 \pm 0.037$ & 0.292 & 1.62 \\
\hline 175360 & HD 175360 & 17.53 & 17.59 & 17.65 & CMLS01 & $\cdots$ & $\cdots$ & $\cdots$ & $\cdots$ \\
\hline 177989 & HD 177989 & 17.76 & 17.79 & 17.81 & $\mathrm{~A}++03$ & $0.55 \pm 0.05$ & $-0.135 \pm 0.015$ & 0.081 & 1.08 \\
\hline 185418 & HD 185418 & 18.01 & 18.06 & 18.11 & CMLS01 & $0.79 \pm 0.03$ & $-0.189 \pm 0.017$ & 0.078 & 0.87 \\
\hline 190918 & V1676 Cyg & 18.04 & 18.12 & 18.20 & CLMS04 & $0.46 \pm 0.03$ & $-0.114 \pm 0.015$ & 0.070 & 0.71 \\
\hline 192035 & RX Cyg & 17.97 & 18.01 & 18.05 & CLMS04 & $0.76 \pm 0.04$ & $-0.181 \pm 0.016$ & 0.048 & 0.62 \\
\hline 192639 & HD 192639 & 18.10 & 18.14 & 18.18 & CLMS04 & $0.64 \pm 0.04$ & $-0.155 \pm 0.014$ & 0.054 & 0.67 \\
\hline 195965 & HD 195965 & 17.71 & 17.77 & 17.81 & $\mathrm{H}++03$ & $0.52 \pm 0.02$ & $-0.127 \pm 0.012$ & 0.005 & 0.10 \\
\hline 198478 & 55 Cyg & 17.97 & 18.02 & 18.07 & CLMS04 & $0.81 \pm 0.05$ & $-0.192 \pm 0.019$ & -0.094 & -0.78 \\
\hline 198781 & HD 198781 & 17.71 & 17.77 & 17.83 & CLMS04 & $0.59 \pm 0.03$ & $-0.143 \pm 0.013$ & 0.002 & 0.02 \\
\hline 201345 & HD 201345 & 17.60 & 17.66 & 17.72 & CLMS04 & $0.34 \pm 0.04$ & $-0.086 \pm 0.020$ & -0.015 & -0.15 \\
\hline 202347 & HD 202347 & 17.51 & 17.58 & 17.64 & $\mathrm{~A}++03$ & $0.56 \pm 0.06$ & $-0.136 \pm 0.018$ & 0.020 & 0.16 \\
\hline 203374 & HD 203374 & 17.98 & 18.02 & 18.06 & $\mathrm{C}++08$ & $0.56 \pm 0.06$ & $-0.136 \pm 0.017$ & 0.066 & 0.67 \\
\hline 203532 & HD 203532 & 17.83 & 17.85 & 17.87 & CMLS01 & $\cdots$ & $\cdots$ & $\cdots$ & $\cdots$ \\
\hline 206267 & HD 206267 & 18.07 & 18.14 & 18.21 & JRS05 & $0.87 \pm 0.07$ & $-0.206 \pm 0.024$ & 0.048 & 0.42 \\
\hline 206773 & HD 206773 & 17.85 & 17.90 & 17.95 & CLMS04 & $0.53 \pm 0.02$ & $-0.131 \pm 0.012$ & 0.020 & 0.28 \\
\hline 207198 & HD 207198 & 18.09 & 18.13 & 18.17 & CMLS01 & $0.90 \pm 0.03$ & $-0.213 \pm 0.020$ & -0.093 & -1.36 \\
\hline 207538 & HD 207538 & 18.29 & 18.32 & 18.35 & JRS05 & $0.84 \pm 0.07$ & $-0.200 \pm 0.023$ & 0.179 & 2.16 \\
\hline 208440 & HD 208440 & 17.89 & 17.96 & 18.03 & CLMS04 & $0.61 \pm 0.04$ & $-0.148 \pm 0.014$ & 0.041 & 0.39 \\
\hline 208947 & HD 208947 & 17.65 & 17.68 & 17.71 & $\mathrm{C}++08$ & $\cdots$ & $\cdots$ & $\cdots$ & $\cdots$ \\
\hline 209339 & HD 209339 & 17.92 & 17.96 & 18.00 & $\mathrm{C}++08$ & $0.58 \pm 0.04$ & $-0.140 \pm 0.014$ & 0.079 & 1.09 \\
\hline 210809 & HD 210809 & 17.92 & 17.99 & 18.06 & CLMS04 & $0.41 \pm 0.04$ & $-0.103 \pm 0.018$ & 0.001 & 0.01 \\
\hline 210839 & $\lambda$ Cep & 18.09 & 18.11 & 18.13 & $\mathrm{~A}++03$ & $0.66 \pm 0.03$ & $-0.158 \pm 0.013$ & 0.062 & 0.91 \\
\hline 212791 & V408 Lac & 17.77 & 17.83 & 17.89 & CLMS04 & $0.57 \pm 0.08$ & $-0.139 \pm 0.022$ & 0.086 & 0.44 \\
\hline 218915 & HD 218915 & 17.79 & 17.82 & 17.85 & $\mathrm{~A}++03$ & $0.70 \pm 0.08$ & $-0.168 \pm 0.022$ & -0.027 & -0.53 \\
\hline 219188 & HD 219188 & 17.19 & 17.28 & 17.34 & KAMM03 & $1.24 \pm 0.57$ & $-0.289 \pm 0.134$ & -0.067 & -0.29 \\
\hline 220057 & HD 220057 & 17.73 & 17.79 & 17.85 & CLMS04 & $0.75 \pm 0.05$ & $-0.180 \pm 0.018$ & 0.053 & 0.40 \\
\hline 224151 & V373 Cas & 18.03 & 18.06 & 18.09 & $\mathrm{~A}++03$ & $0.46 \pm 0.04$ & $-0.115 \pm 0.016$ & -0.048 & -0.72 \\
\hline 232522 & HDE 232522 & 17.70 & 17.78 & 17.86 & CLMS04 & $0.44 \pm 0.03$ & $-0.109 \pm 0.016$ & -0.057 & -0.59 \\
\hline 303308 & HDE 303308 & 18.06 & 18.09 & 18.11 & $\mathrm{~A}++03$ & $0.38 \pm 0.04$ & $-0.097 \pm 0.018$ & -0.052 & -0.72 \\
\hline
\end{tabular}


Table 9-Continued

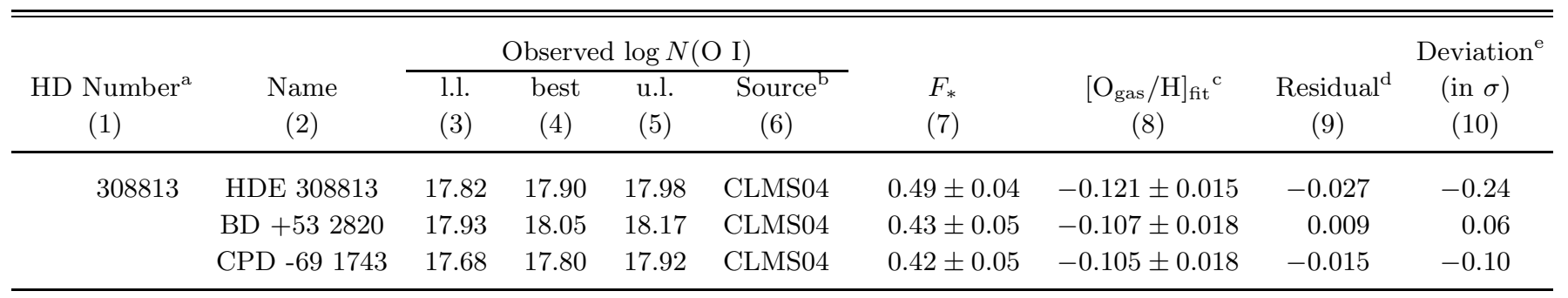

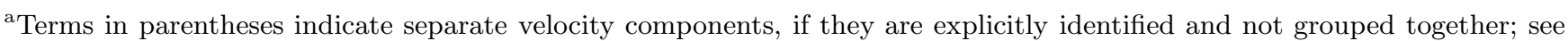
4.3

${ }^{\mathrm{b}}$ Codes in this column are linked to references listed in Table 1

${ }^{c}$ The expected depletion $\left[\mathrm{O}_{\text {gas }} / \mathrm{H}\right]$ computed using Eq. 10 The listed errors do not include an overall systematic uncertainty of 0.05 in the solar abundance $\sigma(\mathrm{O} / \mathrm{H})_{\odot}$ in order to show just the formal error that arises from the uncertainties in location of line of best fit and the value of $F_{*}$.

${ }^{\mathrm{d}}$ The observed $\left[\mathrm{O}_{\text {gas }} / \mathrm{H}\right]$ minus that computed using Eq. 10

${ }^{\text {e }}$ The difference shown in the previous column divided by the expected difference due to the uncertainties in both the measured column density and the coefficients that appear in Eq. 10. 
Table 10. Observations and Fits for Magnesium

\begin{tabular}{|c|c|c|c|c|c|c|c|c|c|}
\hline \multirow[b]{2}{*}{$\begin{array}{c}\text { HD Number } \\
\text { (1) }\end{array}$} & \multirow[b]{2}{*}{$\begin{array}{c}\text { Name } \\
(2)\end{array}$} & \multicolumn{4}{|c|}{ Observed $\log N(\mathrm{Mg}$ II $)$} & \multirow[b]{2}{*}{$\begin{array}{l}F_{*} \\
(7)\end{array}$} & \multirow[b]{2}{*}{$\begin{array}{c}{\left[\mathrm{Mg}_{\text {gas }} / \mathrm{H}\right]_{\mathrm{fit}}{ }^{\mathrm{c}}} \\
(8)\end{array}$} & \multirow[b]{2}{*}{$\begin{array}{l}\text { Residual }^{\mathrm{d}} \\
\quad(9)\end{array}$} & \multirow{2}{*}{$\begin{array}{l}\text { Deviation } \\
\text { (in } \sigma) \\
\quad(10)\end{array}$} \\
\hline & & $\begin{array}{l}1.1 . \\
(3)\end{array}$ & $\begin{array}{c}\text { best } \\
(4)\end{array}$ & $\begin{array}{l}\text { u.l. } \\
(5)\end{array}$ & $\begin{array}{c}\text { Source }^{b} \\
(6)\end{array}$ & & & & \\
\hline 1383 & HD 1383 & 16.27 & 16.36 & 16.45 & CLMS06 & $0.61 \pm 0.04$ & $-0.880 \pm 0.044$ & 0.115 & 0.92 \\
\hline 2905 & $\kappa$ Cas & 15.93 & 16.00 & 16.42 & JSS86 & $0.58 \pm 0.06$ & $-0.849 \pm 0.059$ & -0.060 & -0.21 \\
\hline 5394 & $\gamma$ Cas & 14.86 & 14.91 & 14.96 & JSS86 & $0.52 \pm 0.04$ & $-0.784 \pm 0.043$ & -0.085 & -0.76 \\
\hline 12323 & HD 12323 & 15.99 & 16.04 & 16.09 & CLMS06 & $0.52 \pm 0.04$ & $-0.792 \pm 0.037$ & -0.074 & -0.77 \\
\hline 13268 & HD 13268 & 16.19 & 16.24 & 16.29 & CLMS06 & $0.51 \pm 0.04$ & $-0.783 \pm 0.041$ & -0.015 & -0.15 \\
\hline 13745 & HD 13745 & 16.11 & 16.18 & 16.24 & JS07b & $0.43 \pm 0.07$ & $-0.694 \pm 0.069$ & -0.120 & -0.99 \\
\hline 14434 & HD 14434 & 16.22 & 16.27 & 16.32 & CLMS06 & $0.52 \pm 0.04$ & $-0.787 \pm 0.043$ & -0.031 & -0.31 \\
\hline 15137 & HD 15137 & 16.13 & 16.15 & 16.17 & JS07b & $0.37 \pm 0.09$ & $-0.636 \pm 0.089$ & -0.055 & -0.36 \\
\hline 18100 & HD 18100 & 15.15 & 15.18 & 15.21 & SS96b & $0.14 \pm 0.04$ & $-0.406 \pm 0.048$ & -0.187 & -1.29 \\
\hline 21278 & HD 21278 & 15.39 & 15.66 & $\infty$ & JSS86 & $\ldots$ & $\ldots$ & $\ldots$ & $\ldots$ \\
\hline 21856 & HD 21856 & 15.48 & 15.78 & 16.30 & JSS86 & $0.67 \pm 0.39$ & $-0.941 \pm 0.388$ & -0.002 & -0.00 \\
\hline 22586 & HD 22586 & $\cdots$ & $\cdots$ & 14.82 & JW96 & $0.34 \pm 0.07$ & $-0.609 \pm 0.067$ & $\cdots$ & $\cdots$ \\
\hline 22928 & $\delta$ Per & 14.64 & 14.86 & 15.02 & JSS86 & $\cdots$ & $\cdots$ & $\cdots$ & $\cdots$ \\
\hline 22951 & 40 Per & 15.31 & 15.44 & 15.54 & JSS86 & $0.73 \pm 0.05$ & $-0.999 \pm 0.052$ & -0.401 & -2.42 \\
\hline 23180 & o Per & 15.42 & 15.51 & 15.63 & JSS86 & $0.84 \pm 0.06$ & $-1.111 \pm 0.067$ & -0.189 & -1.17 \\
\hline 23480 & 23 Tau & 14.42 & 14.89 & 15.46 & JSS86 & $\cdots$ & $\ldots$ & $\ldots$ & $\ldots$ \\
\hline 24398 & $\zeta$ Per & 15.67 & 15.71 & 15.75 & $\mathrm{~S} 77$ & $0.88 \pm 0.05$ & $-1.152 \pm 0.053$ & 0.044 & 0.35 \\
\hline 24760 & $\epsilon$ Per & 15.09 & 15.13 & 15.16 & JSS86 & $0.68 \pm 0.04$ & $-0.948 \pm 0.040$ & -0.043 & -0.41 \\
\hline 24912 & $\xi$ Per & 15.88 & 15.92 & 15.96 & $\mathrm{C}++91$ & $0.83 \pm 0.02$ & $-1.099 \pm 0.029$ & 0.106 & 1.17 \\
\hline 27778 & 62 Tau & 15.46 & 15.48 & 15.50 & CLMS06 & $\cdots$ & $\cdots$ & $\cdots$ & $\cdots$ \\
\hline 29248 & $\nu$ Eri & 14.96 & 15.07 & 14.37 & JSS86 & $\cdots$ & $\cdots$ & $\cdots$ & $\cdots$ \\
\hline 30614 & $\alpha \mathrm{Cam}$ & 15.86 & 15.92 & 15.99 & JSS86 & $0.46 \pm 0.04$ & $-0.725 \pm 0.042$ & -0.062 & -0.58 \\
\hline 31237 & $\pi^{5}$ Ori & 15.10 & 15.19 & 15.31 & JSS86 & $0.52 \pm 0.21$ & $-0.788 \pm 0.207$ & 0.200 & 0.46 \\
\hline 34029 & $\alpha$ Aur & 12.80 & 12.81 & 12.82 & $\mathrm{~L}++95$ & $0.44 \pm 0.05$ & $-0.708 \pm 0.051$ & -0.342 & -3.15 \\
\hline 34816 & $\lambda$ Lep & 14.97 & 15.04 & 15.15 & JSS86 & $0.45 \pm 0.05$ & $-0.723 \pm 0.053$ & -0.036 & -0.26 \\
\hline 35149 & 23 Ori & 15.60 & 15.64 & 15.68 & $\mathrm{~W}++99$ & $0.54 \pm 0.04$ & $-0.807 \pm 0.039$ & 0.196 & 1.34 \\
\hline 35439 & 25 Ori & 15.27 & 15.39 & 15.79 & JSS86 & $0.72 \pm 0.18$ & $-0.989 \pm 0.177$ & 0.405 & 1.07 \\
\hline 35715 & $\psi$ Ori & 15.52 & 15.60 & 15.95 & JSS86 & $0.66 \pm 0.11$ & $-0.931 \pm 0.113$ & 0.421 & 1.36 \\
\hline 36166 & HD 36166 & 15.22 & 15.55 & $\infty$ & JSS86 & $\cdots$ & $\cdots$ & $\cdots$ & $\cdots$ \\
\hline 36486 & $\delta$ Ori A & 15.06 & 15.09 & 15.13 & JSS86 & $0.54 \pm 0.02$ & $-0.809 \pm 0.022$ & 0.090 & 1.52 \\
\hline 36822 & $\phi^{1}$ Ori & 15.56 & 15.59 & 15.76 & JSS86 & $0.74 \pm 0.08$ & $-1.009 \pm 0.081$ & 0.143 & 0.93 \\
\hline 36841 & HD 36841 & 15.38 & 15.45 & 15.52 & CLMS06 & $\cdots$ & $\ldots$ & $\cdots$ & $\cdots$ \\
\hline 36861 & $\lambda$ Ori A & 15.67 & 15.69 & 15.75 & JSS86 & $0.57 \pm 0.04$ & $-0.834 \pm 0.041$ & 0.107 & 0.86 \\
\hline 37021 & $\theta^{1}$ Ori & 15.87 & 15.90 & 15.93 & CLMS06 & $\cdots$ & $\cdots$ & $\cdots$ & $\cdots$ \\
\hline 37043 & $\iota$ Ori & 15.01 & 15.04 & 15.07 & JSS86 & $0.41 \pm 0.03$ & $-0.679 \pm 0.029$ & -0.050 & -0.64 \\
\hline 37061 & $\nu$ Ori & 15.75 & 15.80 & 15.85 & CLMS06 & $\ldots$ & $\ldots$ & $\ldots$ & $\ldots$ \\
\hline 37128 & $\epsilon$ Ori & 15.25 & 15.27 & 15.29 & JSS86 & $0.54 \pm 0.03$ & $-0.809 \pm 0.031$ & 0.010 & 0.10 \\
\hline 37367 & HD 37367 & 15.96 & 16.00 & 16.04 & CLMS06 & $0.65 \pm 0.07$ & $-0.922 \pm 0.068$ & -0.030 & -0.24 \\
\hline 37468 & $\sigma$ Ori & 15.50 & 15.53 & 15.57 & JSS86 & $0.58 \pm 0.04$ & $-0.851 \pm 0.043$ & 0.242 & 2.29 \\
\hline
\end{tabular}


Table 10 - Continued

\begin{tabular}{|c|c|c|c|c|c|c|c|c|c|}
\hline \multirow[b]{2}{*}{$\begin{array}{c}\text { HD Number } \\
\text { (1) }\end{array}$} & \multirow[b]{2}{*}{$\begin{array}{c}\text { Name } \\
(2)\end{array}$} & \multicolumn{4}{|c|}{ Observed $\log N(\mathrm{Mg} \mathrm{II})$} & \multirow[b]{2}{*}{$\begin{array}{l}F_{*} \\
(7)\end{array}$} & \multirow[b]{2}{*}{$\begin{array}{c}{\left[\mathrm{Mg}_{\text {gas }} / \mathrm{H}\right]_{\mathrm{fit}}{ }^{\mathrm{c}}} \\
(8)\end{array}$} & \multirow[b]{2}{*}{$\begin{array}{l}\text { Residual }^{\mathrm{d}} \\
\quad(9)\end{array}$} & \multirow{2}{*}{$\begin{array}{l}\text { Deviation } \\
\quad \text { (in } \sigma) \\
\quad(10)\end{array}$} \\
\hline & & $\begin{array}{l}1.1 . \\
(3)\end{array}$ & $\begin{array}{l}\text { best } \\
(4)\end{array}$ & $\begin{array}{l}\text { u.l. } \\
(5)\end{array}$ & $\begin{array}{c}\text { Source }^{b} \\
(6)\end{array}$ & & & & \\
\hline 37903 & HD 37903 & 15.56 & 15.62 & 15.68 & CLMS06 & $1.15 \pm 0.03$ & $-1.414 \pm 0.040$ & -0.023 & -0.24 \\
\hline 38666 & $\mu \mathrm{Col}$ & 15.10 & 15.12 & 15.14 & HSF99 & $0.11 \pm 0.01$ & $-0.381 \pm 0.020$ & 0.021 & 0.60 \\
\hline 38771 & $\kappa$ Ori & 15.35 & 15.35 & 15.41 & JSS86 & $0.67 \pm 0.03$ & $-0.935 \pm 0.029$ & 0.146 & 2.33 \\
\hline 40111 & 139 Tau & 15.78 & 15.84 & 15.92 & JSS86 & $0.49 \pm 0.04$ & $-0.758 \pm 0.038$ & 0.027 & 0.24 \\
\hline 40893 & HD 40893 & 16.30 & 16.33 & 16.36 & JS07b & $0.61 \pm 0.05$ & $-0.876 \pm 0.055$ & 0.050 & 0.51 \\
\hline 43818 & LU Gem & 16.44 & 16.48 & 16.52 & CLMS06 & $\cdots$ & $\cdots$ & $\cdots$ & $\cdots$ \\
\hline 44506 & HD 44506 & 15.11 & 15.32 & 15.45 & JSS86 & $-0.03 \pm 0.23$ & $-0.239 \pm 0.227$ & -0.146 & -0.29 \\
\hline $48915(+12)$ & $\alpha \mathrm{CMa}$ & 11.95 & 12.00 & 12.04 & $\mathrm{H}++99$ & $0.42 \pm 0.11$ & $-0.688 \pm 0.108$ & -0.333 & -1.44 \\
\hline$(+18)$ & & 12.20 & 12.23 & 12.26 & $\mathrm{H}++99$ & $0.42 \pm 0.08$ & $-0.686 \pm 0.082$ & -0.305 & -1.76 \\
\hline 52266 & HD 52266 & 16.07 & 16.09 & 16.11 & CLMS06 & $\cdots$ & $\cdots$ & $\cdots$ & $\cdots$ \\
\hline 52918 & 19 Mon & 15.11 & 15.25 & 15.39 & JSS86 & $0.44 \pm 0.24$ & $-0.712 \pm 0.242$ & 0.147 & 0.36 \\
\hline 53975 & HD 53975 & 16.05 & 16.10 & 16.15 & OH06 & $0.45 \pm 0.03$ & $-0.718 \pm 0.031$ & 0.058 & 0.70 \\
\hline 54662 & HD 54662 & 15.71 & 15.90 & 16.06 & JSS86 & $0.89 \pm 0.09$ & $-1.153 \pm 0.093$ & 0.021 & 0.09 \\
\hline 55879 & HD 55879 & 15.40 & 15.73 & $\infty$ & JSS86 & $\cdots$ & $\cdots$ & $\cdots$ & $\cdots$ \\
\hline 57060 & $29 \mathrm{CMa}$ & 15.57 & 15.70 & 15.79 & JSS86 & $0.50 \pm 0.05$ & $-0.769 \pm 0.048$ & 0.152 & 1.02 \\
\hline 57061 & $\tau \mathrm{CMa}$ & 15.79 & 15.86 & 15.97 & JSS86 & $0.39 \pm 0.04$ & $-0.655 \pm 0.044$ & 0.198 & 1.80 \\
\hline 63005 & HD 63005 & 16.00 & 16.03 & 16.06 & CLMS06 & $0.64 \pm 0.03$ & $-0.908 \pm 0.031$ & 0.001 & 0.01 \\
\hline 64740 & HD 64740 & $\cdots$ & 14.46 & 14.77 & JSS86 & $0.27 \pm 0.30$ & $-0.541 \pm 0.301$ & $\cdots$ & $\cdots$ \\
\hline 64760 & HD 64760 & 15.19 & 15.24 & 15.29 & JSS86 & $0.35 \pm 0.06$ & $-0.624 \pm 0.059$ & -0.015 & -0.11 \\
\hline 65575 & $\chi$ Car & $\cdots$ & $\cdots$ & 14.29 & JSS86 & $\cdots$ & $\cdots$ & $\cdots$ & $\cdots$ \\
\hline 65818 & V Pup & 15.32 & 15.43 & 15.54 & JSS86 & $0.36 \pm 0.09$ & $-0.631 \pm 0.090$ & -0.078 & -0.39 \\
\hline 66788 & HD 66788 & 16.01 & 16.11 & 16.19 & JS07b & $0.53 \pm 0.08$ & $-0.799 \pm 0.079$ & 0.033 & 0.22 \\
\hline 66811 & $\zeta$ Pup & 15.03 & 15.07 & 15.11 & M78 & $0.32 \pm 0.02$ & $-0.592 \pm 0.023$ & 0.081 & 1.32 \\
\hline 68273 & $\gamma^{2} \mathrm{Vel}$ & 14.55 & 14.67 & 14.85 & FS94 & $0.25 \pm 0.02$ & $-0.520 \pm 0.024$ & -0.139 & -0.88 \\
\hline 69106 & HD 69106 & 15.78 & 15.81 & 15.83 & JS07b & $0.64 \pm 0.06$ & $-0.909 \pm 0.061$ & 0.008 & 0.09 \\
\hline 71634 & HD 71634 & 15.75 & 15.79 & 15.83 & CLMS06 & $\cdots$ & $\ldots$ & $\cdots$ & $\ldots$ \\
\hline $72089(+5)$ & HD 72089 & 15.07 & 15.12 & 15.22 & JW96 & $\cdots$ & $\cdots$ & $\cdots$ & $\cdots$ \\
\hline 75309 & HD 75309 & 15.90 & 15.95 & 16.00 & CLMS06 & $0.63 \pm 0.04$ & $-0.894 \pm 0.040$ & 0.047 & 0.47 \\
\hline 79186 & GX Vel & 16.07 & 16.11 & 16.15 & CLMS06 & $0.69 \pm 0.03$ & $-0.957 \pm 0.036$ & 0.039 & 0.46 \\
\hline 79351 & a Car & $\cdots$ & $\cdots$ & 15.20 & JSS86 & $\cdots$ & $\ldots$ & $\cdots$ & $\ldots$ \\
\hline 81188 & $\kappa \mathrm{Vel}$ & 14.99 & 15.04 & 15.10 & JSS86 & $\cdots$ & $\cdots$ & $\cdots$ & $\cdots$ \\
\hline 91597 & HD 91597 & 16.20 & 16.25 & 16.30 & JS07b & $0.44 \pm 0.05$ & $-0.713 \pm 0.056$ & -0.072 & -0.76 \\
\hline 91651 & HD 91651 & 16.22 & 16.26 & 16.29 & JS07b & $0.27 \pm 0.04$ & $-0.540 \pm 0.044$ & 0.023 & 0.28 \\
\hline 91824 & HD 91824 & 16.11 & 16.14 & 16.17 & CLMS06 & $0.45 \pm 0.03$ & $-0.715 \pm 0.032$ & 0.070 & 1.00 \\
\hline 91983 & HD 91983 & 16.13 & 16.19 & 16.25 & CLMS06 & $0.48 \pm 0.04$ & $-0.745 \pm 0.041$ & 0.075 & 0.71 \\
\hline 92554 & HD 92554 & 16.32 & 16.37 & 16.41 & JS07b & $0.27 \pm 0.07$ & $-0.538 \pm 0.071$ & 0.004 & 0.03 \\
\hline 93030 & $\theta$ Car & 15.09 & 15.19 & 15.25 & AJS92 & $0.45 \pm 0.03$ & $-0.714 \pm 0.034$ & 0.028 & 0.24 \\
\hline 93205 & V560 Car & 16.29 & 16.32 & 16.34 & JS07b & $0.40 \pm 0.03$ & $-0.668 \pm 0.030$ & -0.034 & -0.62 \\
\hline 93222 & HD 93222 & 16.39 & 16.41 & 16.42 & JS07b & $0.39 \pm 0.04$ & $-0.658 \pm 0.042$ & 0.028 & 0.37 \\
\hline
\end{tabular}


Table 10-Continued

\begin{tabular}{|c|c|c|c|c|c|c|c|c|c|}
\hline \multirow[b]{2}{*}{$\begin{array}{c}\text { HD Number }{ }^{\mathrm{a}} \\
(1)\end{array}$} & \multirow[b]{2}{*}{$\begin{array}{l}\text { Name } \\
(2)\end{array}$} & \multicolumn{4}{|c|}{ Observed $\log N(\mathrm{Mg}$ II $)$} & \multirow[b]{2}{*}{$\begin{array}{l}F_{*} \\
(7)\end{array}$} & \multirow[b]{2}{*}{$\begin{array}{c}{\left[\mathrm{Mg}_{\text {gas }} / \mathrm{H}\right]_{\mathrm{fit}}{ }^{\mathrm{c}}} \\
(8)\end{array}$} & \multirow[b]{2}{*}{$\begin{array}{l}\text { Residual }^{\mathrm{d}} \\
(9)\end{array}$} & \multirow{2}{*}{$\begin{array}{l}\text { Deviation }^{\mathrm{e}} \\
\quad(\text { in } \sigma) \\
\quad(10)\end{array}$} \\
\hline & & $\begin{array}{l}\text { l.l. } \\
(3)\end{array}$ & $\begin{array}{c}\text { best } \\
(4)\end{array}$ & $\begin{array}{l}\text { u.l. } \\
(5)\end{array}$ & $\begin{array}{c}\text { Source }^{b} \\
(6)\end{array}$ & & & & \\
\hline $93521(-66)$ & HD 93521 & 14.06 & 14.24 & 14.42 & SF93 & $-0.31 \pm 0.11$ & $0.040 \pm 0.113$ & 0.071 & 0.18 \\
\hline$(-58)$ & & 14.27 & 14.43 & 14.59 & SF93 & $-0.01 \pm 0.03$ & $-0.264 \pm 0.039$ & -0.265 & -1.44 \\
\hline$(-51)$ & & 14.38 & 14.50 & 14.65 & SF93 & $-0.04 \pm 0.04$ & $-0.234 \pm 0.050$ & -0.085 & -0.47 \\
\hline$(-39)$ & & 14.06 & 14.32 & 14.58 & SF93 & $0.01 \pm 0.08$ & $-0.276 \pm 0.085$ & 0.097 & 0.29 \\
\hline$(-18)$ & & 14.21 & 14.40 & 14.59 & SF93 & $0.00 \pm 0.03$ & $-0.273 \pm 0.037$ & -0.226 & -1.10 \\
\hline$(-10)$ & & 14.31 & 14.53 & 14.65 & SF93 & $0.02 \pm 0.04$ & $-0.291 \pm 0.045$ & -0.158 & -0.83 \\
\hline$(+3)$ & & 14.13 & 14.32 & 14.51 & SF93 & $0.25 \pm 0.04$ & $-0.521 \pm 0.040$ & -0.078 & -0.37 \\
\hline (total) & & 15.06 & 15.25 & 15.42 & SF93 & $0.06 \pm 0.04$ & $-0.328 \pm 0.041$ & -0.143 & -0.73 \\
\hline 93843 & HD 93843 & 16.23 & 16.25 & 16.27 & JS07b & $0.39 \pm 0.05$ & $-0.655 \pm 0.052$ & -0.061 & -0.64 \\
\hline 94493 & HD 94493 & 16.14 & 16.16 & 16.18 & JS07b & $0.29 \pm 0.03$ & $-0.557 \pm 0.037$ & -0.073 & -1.28 \\
\hline 99857 & HD 99857 & 16.08 & 16.21 & 16.24 & JS07b & $0.54 \pm 0.04$ & $-0.807 \pm 0.044$ & 0.040 & 0.37 \\
\hline 99890 & HD 99890 & 16.15 & 16.18 & 16.21 & JS07b & $0.17 \pm 0.08$ & $-0.439 \pm 0.082$ & 0.040 & 0.26 \\
\hline 100340 & HD 100340 & 15.41 & 15.48 & 15.55 & SS96b & $0.10 \pm 0.06$ & $-0.368 \pm 0.061$ & -0.236 & -1.74 \\
\hline 103779 & HD 103779 & 16.15 & 16.17 & 16.19 & JS07b & $0.43 \pm 0.06$ & $-0.703 \pm 0.065$ & 0.055 & 0.48 \\
\hline 104705 & DF Cru & 16.17 & 16.19 & 16.21 & JS07b & $0.33 \pm 0.05$ & $-0.596 \pm 0.047$ & -0.010 & -0.11 \\
\hline 106490 & $\delta \mathrm{Cru}$ & 14.54 & 14.60 & 14.67 & JSS86 & $\cdots$ & $\cdots$ & $\cdots$ & $\cdots$ \\
\hline 108248 & $\alpha^{1} \mathrm{Cru}$ & 14.83 & 14.85 & 14.88 & JSS86 & $0.15 \pm 0.05$ & $-0.421 \pm 0.051$ & 0.052 & 0.45 \\
\hline 109399 & HD 109399 & 15.90 & 15.95 & 16.00 & JS07b & $0.48 \pm 0.05$ & $-0.754 \pm 0.051$ & -0.095 & -1.02 \\
\hline 111934 & BU Cru & 16.26 & 16.28 & 16.30 & CLMS06 & $\cdots$ & $\cdots$ & $\cdots$ & $\cdots$ \\
\hline 113904 & $\theta$ Mus & 15.67 & 15.80 & 15.96 & JSS86 & $\cdots$ & $\cdots$ & $\cdots$ & $\cdots$ \\
\hline 116781 & V967 Cen & 16.11 & 16.14 & 16.17 & JS07b & $0.44 \pm 0.07$ & $-0.713 \pm 0.067$ & -0.011 & -0.10 \\
\hline 116852 & HD 116852 & 15.87 & 15.91 & 15.95 & CLMS06 & $0.36 \pm 0.04$ & $-0.625 \pm 0.037$ & -0.100 & -1.03 \\
\hline 118716 & $\epsilon$ Cen & 14.79 & 14.84 & 14.89 & JSS86 & $0.15 \pm 0.16$ & $-0.419 \pm 0.165$ & 0.038 & 0.10 \\
\hline 119608 & HD 119608 & 15.83 & 15.88 & 15.93 & SST97 & $\cdots$ & $\cdots$ & $\cdots$ & $\cdots$ \\
\hline 120086 & HD 120086 & 15.32 & 15.37 & 15.47 & JW96 & $\cdots$ & $\cdots$ & $\cdots$ & $\cdots$ \\
\hline 120324 & $\mu$ Cen & 14.69 & 14.91 & 15.03 & JSS86 & $-0.81 \pm 3.74$ & $0.536 \pm 3.725$ & -0.002 & -0.00 \\
\hline 121263 & $\zeta$ Cen & 14.61 & 14.67 & 14.73 & JSS86 & $\cdots$ & $\cdots$ & $\cdots$ & $\cdots$ \\
\hline 122879 & HD 122879 & 16.21 & 16.23 & 16.25 & CLMS06 & $0.55 \pm 0.04$ & $-0.813 \pm 0.044$ & 0.088 & 0.78 \\
\hline 124314 & HD 124314 & 16.30 & 16.32 & 16.34 & JS07b & $0.59 \pm 0.05$ & $-0.854 \pm 0.053$ & 0.045 & 0.49 \\
\hline 127972 & $\eta$ Cen & 14.62 & 14.67 & 14.73 & JSS86 & $\cdots$ & $\ldots$ & $\cdots$ & $\cdots$ \\
\hline 135591 & HD 135591 & 15.65 & 15.82 & 16.35 & JSS86 & $0.56 \pm 0.22$ & $-0.833 \pm 0.220$ & -0.085 & -0.20 \\
\hline 136298 & $\delta$ Lup & 14.88 & 14.93 & 14.99 & JSS86 & $\cdots$ & $\cdots$ & $\cdots$ & $\cdots$ \\
\hline 138690 & $\gamma \operatorname{Lup}$ & 14.70 & 14.83 & 14.90 & JSS86 & $\cdots$ & $\cdots$ & $\cdots$ & $\cdots$ \\
\hline 141637 & $1 \mathrm{Sco}$ & 15.78 & 15.84 & 15.91 & JSS86 & $0.69 \pm 0.05$ & $-0.957 \pm 0.052$ & 0.046 & 0.34 \\
\hline 143018 & $\pi \mathrm{Sco}$ & 14.94 & 15.14 & 15.34 & JJ91 & $0.71 \pm 0.03$ & $-0.973 \pm 0.035$ & -0.195 & -0.92 \\
\hline 143118 & $\eta \operatorname{Lup} \mathrm{A}$ & 14.42 & 14.54 & 14.63 & JSS86 & $\cdots$ & $\cdots$ & $\cdots$ & $\cdots$ \\
\hline 143275 & $\delta$ Sco & 15.72 & 15.74 & 15.76 & JSS86 & $0.90 \pm 0.03$ & $-1.163 \pm 0.038$ & 0.121 & 1.23 \\
\hline 144217 & $\beta^{1}$ Sco & 15.70 & 15.72 & 15.75 & JSS86 & $0.81 \pm 0.02$ & $-1.079 \pm 0.025$ & 0.047 & 0.93 \\
\hline 144470 & $\mathrm{o}^{1} \mathrm{Sco}$ & 15.78 & 15.82 & 15.87 & JSS86 & $0.81 \pm 0.04$ & $-1.074 \pm 0.041$ & 0.047 & 0.45 \\
\hline
\end{tabular}


Table 10-Continued

\begin{tabular}{|c|c|c|c|c|c|c|c|c|c|}
\hline \multirow[b]{2}{*}{$\begin{array}{c}\text { HD Number } \\
\text { (1) }\end{array}$} & \multirow[b]{2}{*}{$\begin{array}{l}\text { Name } \\
(2)\end{array}$} & \multicolumn{4}{|c|}{ Observed $\log N(\mathrm{Mg}$ II $)$} & \multirow[b]{2}{*}{$\begin{array}{l}F_{*} \\
(7)\end{array}$} & \multirow[b]{2}{*}{$\begin{array}{c}{\left[\mathrm{Mg}_{\text {gas }} / \mathrm{H}\right]_{\mathrm{fit}}{ }^{\mathrm{c}}} \\
(8)\end{array}$} & \multirow[b]{2}{*}{$\begin{array}{l}\text { Residual }^{\mathrm{d}} \\
\quad(9)\end{array}$} & \multirow{2}{*}{$\begin{array}{l}\text { Deviation }^{\mathrm{e}} \\
\quad(\text { in } \sigma) \\
(10)\end{array}$} \\
\hline & & $\begin{array}{l}1.1 . \\
(3)\end{array}$ & $\begin{array}{c}\text { best } \\
(4)\end{array}$ & $\begin{array}{l}\text { u.l. } \\
(5)\end{array}$ & $\begin{array}{c}\text { Source }^{b} \\
(6)\end{array}$ & & & & \\
\hline 145502 & $\nu \mathrm{Sco}$ & 15.68 & 15.94 & 16.60 & JSS86 & $0.80 \pm 0.11$ & $-1.066 \pm 0.114$ & 0.262 & 0.51 \\
\hline 147165 & $\sigma \mathrm{Sco}$ & 15.87 & 15.93 & 16.10 & JSS86 & $0.76 \pm 0.06$ & $-1.033 \pm 0.062$ & -0.017 & -0.08 \\
\hline 147888 & $\rho \mathrm{Oph} \mathrm{D}$ & 15.99 & 16.03 & 16.07 & CLMS06 & $0.88 \pm 0.06$ & $-1.148 \pm 0.066$ & -0.180 & -1.09 \\
\hline 147933 & $\rho$ Oph A & 15.63 & 15.74 & 16.08 & JSS86 & $1.09 \pm 0.08$ & $-1.359 \pm 0.086$ & -0.220 & -0.86 \\
\hline 148184 & $\chi \mathrm{Oph}$ & 15.51 & 15.62 & 15.72 & JSS86 & $0.96 \pm 0.09$ & $-1.224 \pm 0.096$ & -0.078 & -0.42 \\
\hline 148594 & HD 148594 & 15.57 & 15.61 & 15.65 & CLMS06 & $\cdots$ & $\cdots$ & $\cdots$ & $\cdots$ \\
\hline 148605 & 22 Sco & $\cdots$ & 15.13 & 16.12 & JSS86 & $0.53 \pm 0.39$ & $-0.798 \pm 0.393$ & $\cdots$ & $\cdots$ \\
\hline 149038 & $\mu$ Nor & 15.94 & 16.20 & $\infty$ & JSS86 & $0.56 \pm 0.05$ & $-0.825 \pm 0.048$ & $\cdots$ & $\cdots$ \\
\hline $149757(-27)$ & $\zeta \mathrm{Oph}$ & 14.65 & 14.70 & 14.75 & SCS92 & $\cdots$ & $\cdots$ & $\cdots$ & $\cdots$ \\
\hline$(-15)$ & & 15.39 & 15.42 & 15.44 & SCS92 & $1.05 \pm 0.02$ & $-1.312 \pm 0.029$ & -0.039 & -0.60 \\
\hline 151804 & V973 Sco & 15.90 & 16.00 & 16.11 & JSS86 & $0.57 \pm 0.08$ & $-0.843 \pm 0.076$ & 0.031 & 0.18 \\
\hline 151890 & $\mu^{1} \mathrm{Sco}$ & 14.99 & 15.03 & 15.08 & JSS86 & $-0.03 \pm 3.47$ & $-0.242 \pm 3.462$ & 0.067 & 0.01 \\
\hline 152590 & HD 152590 & 16.11 & 16.20 & 16.29 & CLMS06 & $0.69 \pm 0.03$ & $-0.958 \pm 0.032$ & 0.071 & 0.66 \\
\hline 154368 & V1074 Sco & 15.91 & 16.21 & 16.51 & $\mathrm{~S}++96$ & $0.52 \pm 0.07$ & $-0.785 \pm 0.066$ & -0.215 & -0.69 \\
\hline 155806 & V1075 Sco & 15.92 & 15.97 & 16.03 & JSS86 & $0.62 \pm 0.07$ & $-0.892 \pm 0.067$ & 0.108 & 0.74 \\
\hline 156110 & HD 156110 & 15.10 & 15.14 & 15.18 & CLMS06 & $\cdots$ & $\cdots$ & $\cdots$ & $\cdots$ \\
\hline 157246 & $\gamma$ Ara & 15.51 & 15.55 & 15.60 & JSS86 & $0.46 \pm 0.03$ & $-0.728 \pm 0.035$ & -0.047 & -0.46 \\
\hline 157857 & HD 157857 & 16.13 & 16.19 & 16.25 & CLMS06 & $0.62 \pm 0.04$ & $-0.890 \pm 0.038$ & 0.017 & 0.17 \\
\hline 160578 & $\kappa \mathrm{Sco}$ & 15.08 & 15.13 & 15.17 & JSS86 & $0.50 \pm 0.07$ & $-0.764 \pm 0.074$ & 0.053 & 0.30 \\
\hline 164284 & $66 \mathrm{Oph}$ & 15.24 & 15.34 & 15.44 & JSS86 & $0.89 \pm 0.18$ & $-1.157 \pm 0.179$ & 0.134 & 0.34 \\
\hline 165024 & $\theta$ Ara & 15.58 & 15.61 & 15.67 & JSS86 & $0.56 \pm 0.03$ & $-0.832 \pm 0.036$ & -0.017 & -0.16 \\
\hline 165955 & HD 165955 & 15.97 & 16.02 & 16.07 & CLMS06 & $0.42 \pm 0.04$ & $-0.688 \pm 0.042$ & -0.010 & -0.12 \\
\hline 167264 & $15 \mathrm{Sgr}$ & 15.62 & 15.82 & 15.93 & JSS86 & $0.68 \pm 0.16$ & $-0.948 \pm 0.156$ & -0.102 & -0.42 \\
\hline 167756 & HD 167756 & 15.70 & 15.72 & 15.74 & CSS95 & $\cdots$ & $\cdots$ & $\cdots$ & $\cdots$ \\
\hline 168941 & HD 168941 & 15.77 & 15.87 & 15.95 & JS07b & $0.42 \pm 0.17$ & $-0.685 \pm 0.165$ & -0.253 & -0.81 \\
\hline 175360 & HD 175360 & 15.55 & 15.60 & 15.65 & CLMS06 & $\cdots$ & $\cdots$ & $\cdots$ & $\cdots$ \\
\hline 177989 & HD 177989 & 15.80 & 15.83 & 15.86 & JS07b & $0.55 \pm 0.05$ & $-0.822 \pm 0.046$ & -0.053 & -0.60 \\
\hline 184915 & $\kappa \mathrm{Aql}$ & 15.38 & 15.57 & 15.71 & JSS86 & $0.88 \pm 0.05$ & $-1.144 \pm 0.052$ & 0.049 & 0.26 \\
\hline 185418 & HD 185418 & 15.94 & 15.96 & 15.98 & CLMS06 & $0.79 \pm 0.03$ & $-1.059 \pm 0.037$ & -0.012 & -0.14 \\
\hline 188209 & HD 188209 & 15.18 & 15.55 & 15.70 & JSS86 & $0.66 \pm 0.12$ & $-0.932 \pm 0.122$ & -0.135 & -0.44 \\
\hline 190918 & V1676 Cyg & 16.30 & 16.34 & 16.38 & CLMS06 & $0.46 \pm 0.03$ & $-0.731 \pm 0.035$ & 0.046 & 0.59 \\
\hline 192035 & RX Cyg & 15.89 & 15.93 & 15.97 & CLMS06 & $0.76 \pm 0.04$ & $-1.026 \pm 0.042$ & -0.047 & -0.55 \\
\hline 192639 & HD 192639 & 16.18 & 16.21 & 16.24 & CLMS06 & $0.64 \pm 0.04$ & $-0.908 \pm 0.039$ & 0.018 & 0.21 \\
\hline 193322 & HD 193322 & $\cdots$ & 15.76 & $\infty$ & JSS86 & $\cdots$ & $\cdots$ & $\cdots$ & $\cdots$ \\
\hline 195965 & HD 195965 & 15.84 & 15.89 & 15.93 & JS07b & $0.52 \pm 0.02$ & $-0.786 \pm 0.018$ & -0.078 & -1.46 \\
\hline 198478 & 55 Cyg & 15.91 & 15.95 & 15.99 & CLMS06 & $0.81 \pm 0.05$ & $-1.075 \pm 0.055$ & -0.142 & -1.11 \\
\hline 198781 & HD 198781 & 15.72 & 15.76 & 15.80 & CLMS06 & $0.59 \pm 0.03$ & $-0.856 \pm 0.032$ & -0.155 & -1.97 \\
\hline 200120 & 59 Cyg & 14.61 & 14.98 & 15.17 & JSS86 & $\cdots$ & $\cdots$ & $\cdots$ & $\cdots$ \\
\hline 201345 & HD 201345 & 15.93 & 15.96 & 15.99 & CLMS06 & $0.34 \pm 0.04$ & $-0.607 \pm 0.042$ & -0.055 & -0.56 \\
\hline
\end{tabular}


Table 10-Continued

\begin{tabular}{|c|c|c|c|c|c|c|c|c|c|}
\hline \multirow[b]{2}{*}{$\begin{array}{c}\text { HD Number } \\
\text { (1) }\end{array}$} & \multirow[b]{2}{*}{$\begin{array}{l}\text { Name } \\
(2)\end{array}$} & \multicolumn{4}{|c|}{ Observed $\log N(\mathrm{Mg} \mathrm{II})$} & \multirow[b]{2}{*}{$\begin{array}{l}F_{*} \\
(7)\end{array}$} & \multirow[b]{2}{*}{$\begin{array}{c}{\left[\mathrm{Mg}_{\text {gas }} / \mathrm{H}\right]_{\mathrm{fit}^{\mathrm{c}}}} \\
(8)\end{array}$} & \multirow[b]{2}{*}{$\begin{array}{l}\text { Residual }^{\mathrm{d}} \\
\quad(9)\end{array}$} & \multirow{2}{*}{$\begin{array}{c}\text { Deviation } \\
\quad \text { (in } \sigma) \\
(10)\end{array}$} \\
\hline & & $\begin{array}{l}1.1 . \\
(3)\end{array}$ & $\begin{array}{c}\text { best } \\
(4)\end{array}$ & $\begin{array}{l}\text { u.l. } \\
(5)\end{array}$ & $\begin{array}{c}\text { Source }^{b} \\
(6)\end{array}$ & & & & \\
\hline 202347 & HD 202347 & 15.57 & 15.62 & 15.66 & $\mathrm{JS} 07 \mathrm{~b}$ & $0.56 \pm 0.06$ & $-0.826 \pm 0.064$ & -0.110 & -0.84 \\
\hline 202904 & $v$ Cyg & 15.22 & 15.29 & 15.37 & JSS86 & $\cdots$ & $\cdots$ & $\cdots$ & $\cdots$ \\
\hline 203064 & $68 \mathrm{Cyg}$ & 15.70 & 15.87 & 16.27 & JSS86 & $0.68 \pm 0.20$ & $-0.949 \pm 0.204$ & 0.056 & 0.15 \\
\hline 203374 & HD 203374 & 16.05 & 16.07 & 16.09 & JS07b & $0.56 \pm 0.06$ & $-0.825 \pm 0.060$ & -0.054 & -0.50 \\
\hline 203532 & HD 203532 & 15.56 & 15.58 & 15.60 & CLMS06 & $\cdots$ & $\cdots$ & $\cdots$ & $\cdots$ \\
\hline 206267 & HD 206267 & 16.01 & 16.05 & 16.09 & JS07b & $0.87 \pm 0.07$ & $-1.134 \pm 0.072$ & 0.027 & 0.22 \\
\hline 206773 & HD 206773 & 15.97 & 15.99 & 16.01 & CLMS06 & $0.53 \pm 0.02$ & $-0.803 \pm 0.023$ & -0.078 & -1.30 \\
\hline 207198 & HD 207198 & 16.06 & 16.08 & 16.10 & CLMS06 & $0.90 \pm 0.03$ & $-1.166 \pm 0.035$ & -0.049 & -0.76 \\
\hline 207308 & HD 207308 & 15.88 & 15.93 & 15.98 & JS07b & $0.80 \pm 0.06$ & $-1.065 \pm 0.061$ & -0.062 & -0.62 \\
\hline 207538 & HD 207538 & 16.03 & 16.07 & 16.10 & JS07b & $0.84 \pm 0.07$ & $-1.109 \pm 0.073$ & -0.022 & -0.20 \\
\hline 208440 & HD 208440 & 16.00 & 16.05 & 16.10 & CLMS06 & $0.61 \pm 0.04$ & $-0.878 \pm 0.042$ & 0.001 & 0.01 \\
\hline 209339 & HD 209339 & 16.02 & 16.04 & 16.06 & JS07b & $0.58 \pm 0.04$ & $-0.845 \pm 0.043$ & 0.003 & 0.04 \\
\hline 209975 & 19 Cep & 16.10 & 16.33 & 16.69 & JSS86 & $0.57 \pm 0.26$ & $-0.841 \pm 0.262$ & 0.370 & 0.90 \\
\hline 210809 & HD 210809 & 16.17 & 16.23 & 16.29 & CLMS06 & $0.41 \pm 0.04$ & $-0.682 \pm 0.044$ & -0.041 & -0.37 \\
\hline 210839 & $\lambda$ Cep & 16.02 & 16.05 & 16.08 & JS07b & $0.66 \pm 0.03$ & $-0.925 \pm 0.035$ & -0.091 & -1.16 \\
\hline 212791 & V408 Lac & 15.80 & 15.87 & 15.94 & CLMS06 & $0.57 \pm 0.08$ & $-0.840 \pm 0.083$ & -0.034 & -0.16 \\
\hline 214080 & HD 214080 & 14.91 & 15.27 & 15.78 & JSS86 & $0.27 \pm 0.10$ & $-0.539 \pm 0.102$ & -0.425 & -0.86 \\
\hline 214680 & $10 \mathrm{Lac}$ & 15.66 & 15.69 & 15.73 & JSS86 & $0.50 \pm 0.06$ & $-0.765 \pm 0.064$ & 0.108 & 0.74 \\
\hline 214993 & $12 \mathrm{Lac}$ & 15.43 & 15.50 & 15.58 & JSS86 & $0.68 \pm 0.10$ & $-0.948 \pm 0.096$ & 0.006 & 0.04 \\
\hline $215733(-59)$ & HD 215733 & 14.34 & 14.43 & 14.52 & FS97 & $-0.11 \pm 0.10$ & $-0.160 \pm 0.101$ & 0.017 & 0.06 \\
\hline$(-54)$ & & 13.55 & 13.86 & 14.17 & FS97 & $0.54 \pm 0.15$ & $-0.812 \pm 0.150$ & -0.581 & -1.08 \\
\hline$(-47)$ & & 14.10 & 14.32 & 14.54 & FS97 & $\cdots$ & $\cdots$ & $\cdots$ & $\cdots$ \\
\hline$(-45)$ & & 13.66 & 13.97 & 14.28 & FS97 & $-0.40 \pm 0.28$ & $0.133 \pm 0.279$ & 0.154 & 0.23 \\
\hline$(-42)$ & & 13.22 & 13.67 & 14.12 & FS97 & $-0.16 \pm 0.31$ & $-0.107 \pm 0.313$ & -0.376 & -0.37 \\
\hline$(-32)$ & & 14.41 & 14.63 & 14.85 & FS97 & $0.25 \pm 0.09$ & $-0.516 \pm 0.090$ & -0.117 & -0.42 \\
\hline$(-31)$ & & 13.07 & 13.68 & 14.29 & FS97 & $\cdots$ & $\ldots$ & $\cdots$ & $\cdots$ \\
\hline$(-28)$ & & 14.13 & 14.32 & 14.51 & FS97 & $-0.18 \pm 0.07$ & $-0.087 \pm 0.072$ & -0.126 & -0.55 \\
\hline$(-26)$ & & 14.31 & 14.48 & 14.65 & FS97 & $-0.12 \pm 0.07$ & $-0.148 \pm 0.071$ & -0.105 & -0.48 \\
\hline$(-23)$ & & 13.18 & 13.72 & 14.26 & FS97 & $0.24 \pm 0.08$ & $-0.512 \pm 0.082$ & -0.641 & -1.17 \\
\hline$(-21)$ & & 14.38 & 14.49 & 14.60 & FS97 & $0.24 \pm 0.05$ & $-0.507 \pm 0.053$ & 0.004 & 0.03 \\
\hline$(-16)$ & & 14.60 & 14.68 & 14.76 & FS97 & $0.93 \pm 0.05$ & $-1.195 \pm 0.054$ & 0.142 & 1.30 \\
\hline$(-11)$ & & 14.79 & 14.91 & 15.03 & FS97 & $-0.01 \pm 0.07$ & $-0.263 \pm 0.075$ & -0.050 & -0.33 \\
\hline$(-9)$ & & 15.00 & 15.12 & 15.24 & FS97 & $0.08 \pm 0.04$ & $-0.349 \pm 0.040$ & -0.224 & -1.49 \\
\hline$(-5)$ & & 14.07 & 14.31 & 14.55 & FS97 & $0.77 \pm 0.18$ & $-1.040 \pm 0.179$ & 0.147 & 0.46 \\
\hline$(+1)$ & & 13.97 & 14.16 & 14.35 & FS97 & $0.90 \pm 0.05$ & $-1.172 \pm 0.055$ & -0.001 & -0.01 \\
\hline (total) & & 15.55 & 15.70 & 15.86 & FS97 & $\cdots$ & $\cdots$ & $\cdots$ & $\cdots$ \\
\hline 217675 & o And & 15.10 & 15.27 & 15.81 & JSS86 & $\cdots$ & $\cdots$ & $\ldots$ & $\cdots$ \\
\hline 218376 & 1 Cas & 15.66 & 15.77 & 16.02 & JSS86 & $0.60 \pm 0.06$ & $-0.869 \pm 0.061$ & -0.047 & -0.21 \\
\hline 219188 & HD 219188 & 15.53 & 15.69 & $\infty$ & JSS86 & $1.24 \pm 0.57$ & $-1.505 \pm 0.571$ & $\cdots$ & $\cdots$ \\
\hline
\end{tabular}


Table 10-Continued

\begin{tabular}{|c|c|c|c|c|c|c|c|c|c|}
\hline $\begin{array}{l}\text { HD Number }{ }^{\mathrm{a}} \\
\text { (1) }\end{array}$ & $\begin{array}{l}\text { Name } \\
(2)\end{array}$ & \multicolumn{4}{|c|}{ Observed $\log N(\mathrm{Mg} \mathrm{II})$} & $\begin{array}{l}F_{*} \\
(7)\end{array}$ & $\begin{array}{c}{\left[\mathrm{Mg}_{\text {gas }} / \mathrm{H}\right]_{\mathrm{fit}}{ }^{\mathrm{c}}} \\
(8)\end{array}$ & $\begin{array}{l}\text { Residual }^{\mathrm{d}} \\
(9)\end{array}$ & $\begin{array}{l}\text { Deviation }^{\mathrm{e}} \\
\quad \text { (in } \sigma) \\
(10)\end{array}$ \\
\hline 220057 & HD 220057 & 15.63 & 15.66 & 15.69 & CLMS06 & $0.75 \pm 0.05$ & $-1.020 \pm 0.055$ & -0.096 & -0.72 \\
\hline 224151 & V373 Cas & 16.27 & 16.30 & 16.33 & JS07b & $0.46 \pm 0.04$ & $-0.734 \pm 0.044$ & -0.049 & -0.64 \\
\hline 224572 & $\sigma$ Cas & 15.48 & 15.56 & 15.63 & JSS86 & $0.76 \pm 0.07$ & $-1.027 \pm 0.072$ & -0.010 & -0.07 \\
\hline 303308 & HDE 303308 & 16.29 & 16.34 & 16.38 & JS07b & $0.38 \pm 0.04$ & $-0.652 \pm 0.040$ & -0.107 & -1.20 \\
\hline \multirow[t]{3}{*}{308813} & HDE 308813 & 16.12 & 16.15 & 16.18 & CLMS06 & $0.49 \pm 0.04$ & $-0.760 \pm 0.041$ & 0.003 & 0.03 \\
\hline & $\mathrm{BD}+354258$ & 16.07 & 16.15 & 16.21 & JS07b & $0.40 \pm 0.08$ & $-0.674 \pm 0.079$ & -0.092 & -0.65 \\
\hline & CPD -59 2603 & 16.32 & 16.35 & 16.38 & JS07b & $0.17 \pm 0.06$ & $-0.438 \pm 0.065$ & -0.037 & -0.31 \\
\hline
\end{tabular}

a Terms in parentheses indicate separate velocity components, if they are explicitly identified and not grouped together; see 4.3

${ }^{\mathrm{b}}$ Codes in this column are linked to references listed in Table 1

${ }^{\mathrm{c}}$ The expected depletion $\left[\mathrm{Mg}_{\text {gas }} / \mathrm{H}\right]$ computed using Eq. 10. The listed errors do not include an overall systematic uncertainty of 0.02 in the solar abundance $\sigma(\mathrm{Mg} / \mathrm{H}) \odot$ in order to show just the formal error that arises from the uncertainties in location of line of best fit and the value of $F_{*}$.

${ }^{\mathrm{d}}$ The observed $\left[\mathrm{Mg}_{\text {gas }} / \mathrm{H}\right]$ minus that computed using Eq. 10 ,

eThe difference shown in the previous column divided by the expected difference due to the uncertainties in both the measured column density and the coefficients that appear in Eq. 10. 
Table 11. Observations and Fits for Silicon

\begin{tabular}{|c|c|c|c|c|c|c|c|c|c|}
\hline \multirow[b]{2}{*}{$\begin{array}{c}\text { HD Number }{ }^{\mathrm{a}} \\
(1)\end{array}$} & \multirow[b]{2}{*}{$\begin{array}{l}\text { Name } \\
(2)\end{array}$} & \multicolumn{4}{|c|}{ Observed $\log N(\mathrm{Si} I \mathrm{I})$} & \multirow[b]{2}{*}{$\begin{array}{l}F_{*} \\
(7)\end{array}$} & \multirow[b]{2}{*}{$\begin{array}{c}{\left[\mathrm{Si}_{\text {gas }} / \mathrm{H}\right]_{\mathrm{fit}}{ }^{\mathrm{c}}} \\
(8)\end{array}$} & \multirow[b]{2}{*}{$\begin{array}{c}\text { Residual }^{\mathrm{d}} \\
(9)\end{array}$} & \multirow{2}{*}{$\begin{array}{l}\text { Deviation }^{\mathrm{e}} \\
\quad(\text { in } \sigma) \\
\quad(10)\end{array}$} \\
\hline & & $\begin{array}{l}1.1 . \\
(3)\end{array}$ & $\begin{array}{l}\text { best } \\
(4)\end{array}$ & $\begin{array}{l}\text { u.l. } \\
(5)\end{array}$ & $\begin{array}{c}\text { Source }^{b} \\
(6)\end{array}$ & & & & \\
\hline 18100 & HD 18100 & 15.31 & 15.34 & 15.37 & SS96b & $0.14 \pm 0.04$ & $-0.378 \pm 0.056$ & -0.046 & -0.31 \\
\hline 22586 & HD 22586 & 15.26 & 15.31 & 15.51 & JW96 & $0.34 \pm 0.07$ & $-0.610 \pm 0.078$ & -0.053 & -0.24 \\
\hline 27778 & 62 Tau & $\cdots$ & $\ldots$ & 15.94 & $\mathrm{M}++07$ & $\cdots$ & $\cdots$ & $\cdots$ & $\ldots$ \\
\hline 34029 & $\alpha$ Aur & 13.16 & 13.20 & 13.24 & WRLS02 & $0.44 \pm 0.05$ & $-0.722 \pm 0.062$ & 0.076 & 0.64 \\
\hline 35149 & 23 Ori & 15.36 & 15.44 & 15.51 & $\mathrm{~W}++99$ & $0.54 \pm 0.04$ & $-0.835 \pm 0.050$ & 0.034 & 0.21 \\
\hline 37021 & $\theta^{1}$ Ori & 16.04 & 16.16 & 16.24 & $\mathrm{M}++07$ & $\ldots$ & $\ldots$ & $\ldots$ & $\ldots$ \\
\hline 37061 & $\nu$ Ori & 16.10 & 16.16 & 16.21 & $\mathrm{M}++07$ & $\cdots$ & $\cdots$ & $\cdots$ & $\cdots$ \\
\hline 38666 & $\mu \mathrm{Col}$ & 15.14 & 15.16 & 15.18 & HSF99 & $0.11 \pm 0.01$ & $-0.349 \pm 0.026$ & 0.040 & 1.05 \\
\hline 44743 & $\beta \mathrm{CMa}$ & 14.08 & 14.10 & 14.12 & DG98 & $-0.43 \pm 0.03$ & $0.270 \pm 0.063$ & -0.077 & -0.86 \\
\hline $48915(+12)$ & $\alpha \mathrm{CMa}$ & 12.27 & 12.36 & 12.50 & $\mathrm{H}++99$ & $0.42 \pm 0.11$ & $-0.700 \pm 0.125$ & 0.053 & 0.20 \\
\hline$(+18)$ & & 12.33 & 12.41 & 12.53 & $\mathrm{H}++99$ & $0.42 \pm 0.08$ & $-0.697 \pm 0.096$ & -0.100 & -0.49 \\
\hline 49798 & HD 49798 & 15.15 & 15.20 & 15.40 & JW96 & $\cdots$ & $\cdots$ & $\cdots$ & $\cdots$ \\
\hline 66811 & $\zeta$ Pup & 15.13 & 15.23 & 15.43 & M78 & $0.32 \pm 0.02$ & $-0.589 \pm 0.030$ & 0.250 & 1.58 \\
\hline 68273 & $\gamma^{2}$ Vel & 14.67 & 14.75 & 14.84 & FS94 & $0.25 \pm 0.02$ & $-0.508 \pm 0.031$ & -0.059 & -0.60 \\
\hline $93521(-66)$ & HD 93521 & 13.94 & 14.01 & 14.08 & SF93 & $-0.31 \pm 0.11$ & $0.130 \pm 0.130$ & -0.237 & -0.66 \\
\hline$(-58)$ & & 14.59 & 14.62 & 14.65 & SF93 & $-0.01 \pm 0.03$ & $-0.216 \pm 0.046$ & -0.111 & -1.14 \\
\hline$(-51)$ & & 14.52 & 14.57 & 14.62 & SF93 & $-0.04 \pm 0.04$ & $-0.181 \pm 0.058$ & -0.056 & -0.42 \\
\hline$(-39)$ & & 14.07 & 14.10 & 14.13 & SF93 & $0.01 \pm 0.08$ & $-0.230 \pm 0.098$ & -0.157 & -0.70 \\
\hline$(-29)$ & & 13.16 & 13.23 & 13.30 & SF93 & $0.34 \pm 0.17$ & $-0.610 \pm 0.192$ & -0.147 & -0.37 \\
\hline$(-18)$ & & 14.48 & 14.52 & 14.56 & SF93 & $0.00 \pm 0.03$ & $-0.226 \pm 0.044$ & -0.141 & -1.54 \\
\hline$(-10)$ & & 14.51 & 14.65 & 14.69 & SF93 & $0.02 \pm 0.04$ & $-0.247 \pm 0.052$ & -0.070 & -0.56 \\
\hline$(+3)$ & & 14.28 & 14.34 & 14.40 & SF93 & $0.25 \pm 0.04$ & $-0.509 \pm 0.047$ & -0.058 & -0.52 \\
\hline$(+7)$ & & 13.75 & 13.86 & 13.97 & SF93 & $0.23 \pm 0.12$ & $-0.489 \pm 0.138$ & -0.048 & -0.16 \\
\hline (total) & & 15.26 & 15.33 & 15.37 & SF93 & $0.06 \pm 0.04$ & $-0.289 \pm 0.048$ & -0.095 & -0.94 \\
\hline 100340 & HD 100340 & 15.13 & $\infty$ & $\infty$ & SS96b & $0.10 \pm 0.06$ & $-0.334 \pm 0.071$ & $\cdots$ & $\cdots$ \\
\hline 116658 & $\alpha$ Vir & 13.96 & 14.11 & 14.26 & YK79 & $0.16 \pm 0.05$ & $-0.407 \pm 0.060$ & -0.097 & -0.51 \\
\hline 120086 & HD 120086 & 15.26 & 15.31 & 15.51 & JW96 & $\cdots$ & $\cdots$ & $\cdots$ & $\cdots$ \\
\hline 122451 & $\beta$ Cen & 14.47 & 14.51 & 14.55 & BLWY84 & $0.23 \pm 0.03$ & $-0.488 \pm 0.038$ & -0.151 & -2.03 \\
\hline 147933 & $\rho \mathrm{Oph} \mathrm{A}$ & 16.03 & 16.12 & 16.19 & $\mathrm{M}++07$ & $1.09 \pm 0.08$ & $-1.464 \pm 0.108$ & 0.272 & 1.74 \\
\hline $149757(-27)$ & $\zeta \mathrm{Oph}$ & 14.73 & 14.74 & 14.75 & SCS94 & $\cdots$ & $\cdots$ & $\cdots$ & $\cdots$ \\
\hline$(-15)$ & & 15.31 & 15.34 & 15.37 & $\mathrm{C}++94$ & $1.05 \pm 0.02$ & $-1.410 \pm 0.055$ & -0.010 & -0.13 \\
\hline 149881 & V600 Her & 15.70 & 15.80 & 15.90 & SF95 & $0.07 \pm 0.06$ & $-0.298 \pm 0.076$ & -0.159 & -0.71 \\
\hline 152590 & HD 152590 & 15.75 & 15.92 & 16.04 & $\mathrm{M}++07$ & $0.69 \pm 0.03$ & $-1.007 \pm 0.047$ & -0.150 & -0.94 \\
\hline 154368 & V1074 Sco & 16.04 & 16.34 & 16.64 & $\mathrm{~S}++96$ & $0.52 \pm 0.07$ & $-0.809 \pm 0.079$ & -0.051 & -0.16 \\
\hline 158926 & $\lambda \mathrm{Sco}$ & 14.06 & 14.09 & 14.11 & Y83 & $0.31 \pm 0.02$ & $-0.577 \pm 0.029$ & -0.175 & -3.58 \\
\hline 167756 & HD 167756 & 15.83 & 15.88 & 15.95 & CSS95 & $\cdots$ & $\cdots$ & $\cdots$ & $\cdots$ \\
\hline 207198 & HD 207198 & 15.55 & 15.84 & 16.01 & $\mathrm{M}++07$ & $0.90 \pm 0.03$ & $-1.244 \pm 0.055$ & -0.201 & -0.83 \\
\hline $215733(-93)$ & HD 215733 & 12.92 & 12.95 & 12.98 & FS97 & $-0.27 \pm 0.19$ & $0.081 \pm 0.221$ & -0.128 & -0.29 \\
\hline$(-83)$ & & 12.12 & 12.24 & 12.36 & FS97 & $0.99 \pm 0.30$ & $-1.345 \pm 0.341$ & -0.422 & -0.69 \\
\hline
\end{tabular}


Table 11-Continued

\begin{tabular}{|c|c|c|c|c|c|c|c|c|c|}
\hline \multirow[b]{2}{*}{$\begin{array}{c}\text { HD Number }{ }^{\mathrm{a}} \\
\text { (1) }\end{array}$} & \multirow[b]{2}{*}{$\begin{array}{l}\text { Name } \\
(2)\end{array}$} & \multicolumn{4}{|c|}{ Observed $\log N(\mathrm{Si} \mathrm{II})$} & \multirow[b]{2}{*}{$\begin{array}{l}F_{*} \\
(7)\end{array}$} & \multirow[b]{2}{*}{$\begin{array}{c}{\left[\mathrm{Si}_{\text {gas }} / \mathrm{H}\right]_{\mathrm{fit}}{ }^{\mathrm{c}}} \\
(8)\end{array}$} & \multirow[b]{2}{*}{$\begin{array}{c}\text { Residual }^{\mathrm{d}} \\
(9)\end{array}$} & \multirow{2}{*}{$\begin{array}{l}\text { Deviation } \\
\quad \text { (in } \sigma) \\
\quad(10)\end{array}$} \\
\hline & & $\begin{array}{l}1.1 . \\
(3)\end{array}$ & $\begin{array}{l}\text { best } \\
(4)\end{array}$ & $\begin{array}{l}\text { u.l. } \\
(5)\end{array}$ & $\begin{array}{c}\text { Source }^{b} \\
(6)\end{array}$ & & & & \\
\hline$(-61)$ & & 13.34 & 13.61 & 13.88 & FS97 & $1.06 \pm 0.21$ & $-1.431 \pm 0.243$ & -0.006 & -0.01 \\
\hline$(-59)$ & & 14.31 & 14.37 & 14.43 & FS97 & $-0.11 \pm 0.10$ & $-0.098 \pm 0.116$ & -0.089 & -0.30 \\
\hline$(-54)$ & & 14.22 & 14.28 & 14.34 & FS97 & $0.54 \pm 0.15$ & $-0.841 \pm 0.173$ & -0.116 & -0.26 \\
\hline$(-47)$ & & 14.47 & 14.55 & 14.63 & FS97 & $\ldots$ & $\ldots$ & $\ldots$ & $\ldots$ \\
\hline$(-45)$ & & 13.00 & 13.41 & 13.82 & FS97 & $-0.40 \pm 0.28$ & $0.237 \pm 0.319$ & -0.494 & -0.67 \\
\hline$(-42)$ & & 13.60 & 13.86 & 14.12 & FS97 & $-0.16 \pm 0.31$ & $-0.037 \pm 0.357$ & -0.240 & -0.25 \\
\hline$(-40)$ & & 13.57 & 13.77 & 13.97 & FS97 & $0.18 \pm 0.24$ & $-0.429 \pm 0.278$ & -0.218 & -0.31 \\
\hline$(-32)$ & & 14.58 & 14.76 & 14.94 & FS97 & $0.25 \pm 0.09$ & $-0.504 \pm 0.104$ & 0.017 & 0.07 \\
\hline$(-31)$ & & 13.74 & 14.00 & 14.26 & FS97 & $\ldots$ & $\ldots$ & $\ldots$ & $\ldots$ \\
\hline$(-28)$ & & 14.25 & 14.39 & 14.53 & FS97 & $-0.18 \pm 0.07$ & $-0.014 \pm 0.083$ & -0.113 & -0.58 \\
\hline$(-26)$ & & 14.19 & 14.38 & 14.57 & FS97 & $-0.12 \pm 0.07$ & $-0.084 \pm 0.082$ & -0.253 & -1.06 \\
\hline$(-23)$ & & 14.10 & 14.30 & 14.50 & FS97 & $0.24 \pm 0.08$ & $-0.499 \pm 0.095$ & -0.058 & -0.25 \\
\hline$(-21)$ & & 13.98 & 14.15 & 14.32 & FS97 & $0.24 \pm 0.05$ & $-0.493 \pm 0.062$ & -0.334 & -1.72 \\
\hline$(-19)$ & & 14.20 & 14.31 & 14.42 & FS97 & $\ldots$ & $\ldots$ & $\ldots$ & $\ldots$ \\
\hline$(-16)$ & & 14.45 & 14.55 & 14.65 & FS97 & $0.93 \pm 0.05$ & $-1.277 \pm 0.073$ & 0.110 & 0.82 \\
\hline$(-11)$ & & 14.86 & 14.99 & 15.12 & FS97 & $-0.01 \pm 0.07$ & $-0.215 \pm 0.086$ & -0.002 & -0.01 \\
\hline$(-9)$ & & 15.18 & 15.24 & 15.30 & FS97 & $0.08 \pm 0.04$ & $-0.313 \pm 0.047$ & -0.124 & -1.12 \\
\hline$(-5)$ & & 13.19 & 13.73 & 14.27 & FS97 & $0.77 \pm 0.18$ & $-1.100 \pm 0.207$ & -0.357 & -0.61 \\
\hline$(+1)$ & & 13.68 & 13.82 & 13.96 & FS97 & $0.90 \pm 0.05$ & $-1.250 \pm 0.074$ & -0.247 & -1.49 \\
\hline$(+9)$ & & 12.69 & 12.77 & 12.85 & FS97 & $\ldots$ & $\ldots$ & $\ldots$ & $\ldots$ \\
\hline$(+15)$ & & 12.47 & 12.58 & 12.69 & FS97 & $0.96 \pm 0.08$ & $-1.312 \pm 0.103$ & -0.135 & -0.77 \\
\hline (total) & & 15.66 & 15.77 & 15.90 & FS97 & $\ldots$ & $\ldots$ & $\ldots$ & $\ldots$ \\
\hline
\end{tabular}

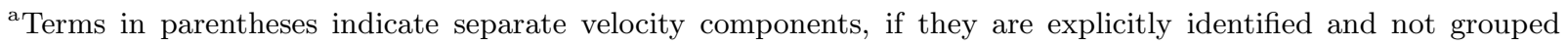
together; see 4.3

${ }^{\mathrm{b}}$ Codes in this column are linked to references listed in Table 1

${ }^{\mathrm{c}}$ The expected depletion [Sigas $\left./ \mathrm{H}\right]$ computed using Eq. 10] The listed errors do not include an overall systematic uncertainty of 0.02 in the solar abundance $\sigma(\mathrm{Si} / \mathrm{H})_{\odot}$ in order to show just the formal error that arises from the uncertainties in location of line of best fit and the value of $F_{*}$.

${ }^{\mathrm{d}}$ The observed $\left[\mathrm{Si}_{\text {gas }} / \mathrm{H}\right]$ minus that computed using Eq. 10

${ }^{\text {e}}$ The difference shown in the previous column divided by the expected difference due to the uncertainties in both the measured column density and the coefficients that appear in Eq. 10 
Table 12. Observations and Fits for Phosphorus

\begin{tabular}{|c|c|c|c|c|c|c|c|c|c|}
\hline \multirow[b]{2}{*}{$\begin{array}{l}\text { HD Number }{ }^{\mathrm{a}} \\
\text { (1) }\end{array}$} & \multirow[b]{2}{*}{$\begin{array}{l}\text { Name } \\
(2)\end{array}$} & \multicolumn{4}{|c|}{ Observed $\log N(\mathrm{P}$ II $)$} & \multirow[b]{2}{*}{$\begin{array}{l}F_{*} \\
(7)\end{array}$} & \multirow[b]{2}{*}{$\begin{array}{c}{\left[\mathrm{P}_{\text {gas }} / \mathrm{H}\right]_{\mathrm{fit}}{ }^{\mathrm{c}}} \\
(8)\end{array}$} & \multirow[b]{2}{*}{$\begin{array}{l}\text { Residual }^{\mathrm{d}} \\
(9)\end{array}$} & \multirow{2}{*}{$\begin{array}{l}\text { Deviation }^{\mathrm{e}} \\
\quad \text { (in } \sigma) \\
\quad(10)\end{array}$} \\
\hline & & $\begin{array}{l}1.1 . \\
(3)\end{array}$ & $\begin{array}{l}\text { best } \\
(4)\end{array}$ & $\begin{array}{l}\text { u.l. } \\
(5)\end{array}$ & $\begin{array}{c}\text { Source }^{b} \\
(6)\end{array}$ & & & & \\
\hline 2905 & $\kappa$ Cas & 14.43 & 14.78 & $\infty$ & JSS86 & $0.58 \pm 0.06$ & $-0.253 \pm 0.057$ & $\ldots$ & $\ldots$ \\
\hline 5394 & $\gamma \mathrm{Cas}$ & 13.33 & 13.41 & 13.51 & JSS86 & $0.52 \pm 0.04$ & $-0.192 \pm 0.042$ & -0.100 & -0.75 \\
\hline 18100 & HD 18100 & 13.65 & 13.72 & 13.79 & SS96b & $0.14 \pm 0.04$ & $0.167 \pm 0.047$ & -0.138 & -0.88 \\
\hline 21278 & HD 21278 & 13.29 & 13.54 & $\infty$ & JSS86 & $\cdots$ & $\cdots$ & $\cdots$ & $\cdots$ \\
\hline 21856 & HD 21856 & 14.08 & 14.38 & $\infty$ & JSS86 & $0.67 \pm 0.39$ & $-0.340 \pm 0.368$ & $\cdots$ & $\cdots$ \\
\hline 22928 & $\delta$ Per & 13.31 & 13.61 & 13.78 & JSS86 & $\cdots$ & $\cdots$ & $\cdots$ & $\cdots$ \\
\hline 22951 & 40 Per & 13.85 & 14.03 & 14.15 & JSS86 & $0.73 \pm 0.05$ & $-0.396 \pm 0.051$ & -0.341 & -1.78 \\
\hline 23180 & o Per & 14.22 & 14.43 & 14.64 & S76 & $0.84 \pm 0.06$ & $-0.501 \pm 0.065$ & 0.199 & 0.82 \\
\hline 23408 & 20 Tau & 14.08 & 14.33 & $\infty$ & JSS86 & $\cdots$ & $\cdots$ & $\cdots$ & $\cdots$ \\
\hline 23480 & 23 Tau & 13.09 & 13.24 & 13.64 & JSS86 & $\cdots$ & $\cdots$ & $\cdots$ & $\cdots$ \\
\hline 23630 & $\eta \mathrm{Tau}$ & 12.88 & 13.26 & $\infty$ & JSS86 & $\ldots$ & $\ldots$ & $\ldots$ & $\ldots$ \\
\hline 24398 & $\zeta$ Per & 14.44 & 14.58 & 14.72 & $\mathrm{~S} 77$ & $0.88 \pm 0.05$ & $-0.540 \pm 0.053$ & 0.383 & 2.07 \\
\hline 24534 & X Per & 14.37 & 14.42 & 14.47 & LKF05 & $0.90 \pm 0.06$ & $-0.554 \pm 0.058$ & 0.092 & 1.10 \\
\hline 24760 & $\epsilon$ Per & 13.43 & 13.56 & 13.63 & JSS86 & $0.68 \pm 0.04$ & $-0.346 \pm 0.040$ & -0.136 & -0.97 \\
\hline 24912 & $\xi$ Per & 14.50 & 14.53 & 14.55 & $\mathrm{C}++91$ & $0.83 \pm 0.02$ & $-0.490 \pm 0.032$ & 0.182 & 2.12 \\
\hline 27778 & $62 \mathrm{Tau}$ & 14.19 & 14.21 & 14.23 & CLMS06 & $\cdots$ & $\cdots$ & $\cdots$ & $\cdots$ \\
\hline 28497 & 228 Eri & 13.60 & 13.91 & 14.20 & SY77 & $\cdots$ & $\cdots$ & $\cdots$ & $\cdots$ \\
\hline 29248 & $\nu$ Eri & 13.73 & 14.06 & $\infty$ & JSS86 & $\cdots$ & $\cdots$ & $\cdots$ & $\cdots$ \\
\hline 30614 & $\alpha \mathrm{Cam}$ & 14.00 & 14.20 & 14.40 & JY78 & $0.46 \pm 0.04$ & $-0.136 \pm 0.041$ & -0.299 & -1.37 \\
\hline 31237 & $\pi^{5}$ Ori & 13.14 & 13.24 & 13.42 & JSS86 & $0.52 \pm 0.21$ & $-0.195 \pm 0.197$ & -0.263 & -0.60 \\
\hline 34816 & $\lambda$ Lep & 13.22 & 13.39 & 13.54 & JSS86 & $0.45 \pm 0.05$ & $-0.134 \pm 0.051$ & -0.195 & -1.01 \\
\hline 35149 & 23 Ori & 14.27 & 14.31 & 14.35 & $\mathrm{~W}++99$ & $0.54 \pm 0.04$ & $-0.214 \pm 0.038$ & 0.348 & 2.39 \\
\hline 35439 & 25 Ori & 13.07 & 13.14 & 13.29 & JSS86 & $0.72 \pm 0.18$ & $-0.386 \pm 0.168$ & -0.369 & -1.25 \\
\hline 35715 & $\psi$ Ori & 13.27 & 13.34 & 13.62 & JSS86 & $0.66 \pm 0.11$ & $-0.331 \pm 0.108$ & -0.359 & -1.28 \\
\hline 36166 & HD 36166 & 13.19 & 13.59 & $\infty$ & JSS86 & $\cdots$ & $\cdots$ & $\cdots$ & $\cdots$ \\
\hline 36486 & $\delta$ Ori A & 13.13 & 13.33 & 13.53 & JY78 & $0.54 \pm 0.02$ & $-0.215 \pm 0.023$ & -0.184 & -0.90 \\
\hline 36822 & $\phi^{1}$ Ori & 14.00 & 14.08 & 14.18 & JSS86 & $0.74 \pm 0.08$ & $-0.405 \pm 0.078$ & 0.105 & 0.74 \\
\hline 36841 & HD 36841 & 13.87 & 13.93 & 13.99 & CLMS06 & $\cdots$ & $\cdots$ & $\cdots$ & $\cdots$ \\
\hline 36861 & $\lambda$ Ori A & 13.98 & 14.03 & 14.08 & JSS86 & $0.57 \pm 0.04$ & $-0.239 \pm 0.040$ & -0.072 & -0.57 \\
\hline 37021 & $\theta^{1}$ Ori & 14.44 & 14.47 & 14.50 & CLMS06 & $\cdots$ & $\ldots$ & $\ldots$ & $\ldots$ \\
\hline 37043 & $\iota$ Ori & 13.43 & 13.48 & 13.55 & JSS86 & $0.41 \pm 0.03$ & $-0.092 \pm 0.029$ & -0.121 & -1.28 \\
\hline 37128 & $\epsilon$ Ori & 13.70 & 13.78 & 13.85 & JSS86 & $0.54 \pm 0.03$ & $-0.215 \pm 0.031$ & 0.002 & 0.01 \\
\hline 37468 & $\sigma$ Ori & 13.65 & 13.73 & 13.78 & JSS86 & $0.58 \pm 0.04$ & $-0.255 \pm 0.042$ & -0.078 & -0.66 \\
\hline 37903 & HD 37903 & 14.05 & 14.09 & 14.13 & CLMS06 & $1.15 \pm 0.03$ & $-0.789 \pm 0.047$ & -0.095 & -1.10 \\
\hline 38666 & $\mu \mathrm{Col}$ & 13.59 & 13.61 & 13.63 & HSF99 & $0.11 \pm 0.01$ & $0.191 \pm 0.024$ & 0.021 & 0.57 \\
\hline 38771 & $\kappa$ Ori & 13.80 & 13.88 & 13.93 & JSS86 & $0.67 \pm 0.03$ & $-0.334 \pm 0.030$ & 0.151 & 1.83 \\
\hline 40111 & 139 Tau & 14.13 & 14.23 & 14.30 & JSS86 & $0.49 \pm 0.04$ & $-0.167 \pm 0.037$ & -0.101 & -0.81 \\
\hline 41161 & HD 41161 & 13.63 & $\infty$ & $\infty$ & OH06 & $0.44 \pm 0.04$ & $-0.120 \pm 0.041$ & $\cdots$ & $\cdots$ \\
\hline 44506 & HD 44506 & 12.94 & 13.19 & $\infty$ & JSS86 & $-0.03 \pm 0.23$ & $0.325 \pm 0.216$ & $\ldots$ & $\ldots$ \\
\hline
\end{tabular}


Table 12-Continued

\begin{tabular}{|c|c|c|c|c|c|c|c|c|c|}
\hline \multirow[b]{2}{*}{$\begin{array}{c}\text { HD Number }{ }^{\mathrm{a}} \\
\text { (1) }\end{array}$} & \multirow[b]{2}{*}{$\begin{array}{l}\text { Name } \\
(2)\end{array}$} & \multicolumn{4}{|c|}{ Observed $\log N(\mathrm{P}$ II $)$} & \multirow[b]{2}{*}{$\begin{array}{l}F_{*} \\
(7)\end{array}$} & \multirow[b]{2}{*}{$\begin{array}{c}{\left[\mathrm{P}_{\text {gas }} / \mathrm{H}\right]_{\mathrm{fit}}{ }^{\mathrm{c}}} \\
(8)\end{array}$} & \multirow[b]{2}{*}{$\begin{array}{c}\text { Residual }^{\mathrm{d}} \\
(9)\end{array}$} & \multirow{2}{*}{$\begin{array}{l}\text { Deviation }^{\mathrm{e}} \\
\quad(\text { in } \sigma) \\
\quad(10)\end{array}$} \\
\hline & & $\begin{array}{l}1.1 . \\
(3)\end{array}$ & $\begin{array}{l}\text { best } \\
(4)\end{array}$ & $\begin{array}{l}\text { u.l. } \\
(5)\end{array}$ & $\begin{array}{c}\text { Source }^{b} \\
(6)\end{array}$ & & & & \\
\hline 47839 & 15 Mon & 13.33 & 13.63 & 13.83 & JY78 & $0.25 \pm 0.05$ & $0.061 \pm 0.048$ & -0.285 & -1.04 \\
\hline 52918 & 19 Mon & 13.37 & 13.49 & 13.72 & JSS86 & $0.44 \pm 0.24$ & $-0.123 \pm 0.230$ & -0.122 & -0.29 \\
\hline 53975 & HD 53975 & 13.62 & $\infty$ & $\infty$ & OH06 & $0.45 \pm 0.03$ & $-0.129 \pm 0.030$ & $\cdots$ & $\cdots$ \\
\hline 54662 & HD 54662 & 14.15 & 14.43 & $\infty$ & JSS86 & $0.89 \pm 0.09$ & $-0.541 \pm 0.090$ & $\cdots$ & $\cdots$ \\
\hline 55879 & HD 55879 & 13.75 & 14.28 & $\infty$ & JSS86 & $\cdots$ & $\cdots$ & $\cdots$ & $\cdots$ \\
\hline 57060 & $29 \mathrm{CMa}$ & 13.85 & 13.93 & 14.00 & JSS86 & $0.50 \pm 0.05$ & $-0.178 \pm 0.047$ & -0.135 & -1.07 \\
\hline 64740 & HD 64740 & 12.94 & 13.19 & $\infty$ & JSS86 & $0.27 \pm 0.30$ & $0.039 \pm 0.286$ & $\cdots$ & $\cdots$ \\
\hline 64760 & HD 64760 & 13.70 & 13.78 & 13.85 & JSS86 & $0.35 \pm 0.06$ & $-0.040 \pm 0.057$ & 0.017 & 0.12 \\
\hline 65575 & $\chi$ Car & 12.82 & 12.89 & 13.04 & JSS86 & $\cdots$ & $\cdots$ & $\cdots$ & $\cdots$ \\
\hline 65818 & V Pup & 14.00 & 14.13 & 14.25 & JSS86 & $0.36 \pm 0.09$ & $-0.047 \pm 0.086$ & 0.113 & 0.54 \\
\hline 66811 & $\zeta$ Pup & 13.46 & 13.51 & 13.56 & M78 & $0.32 \pm 0.02$ & $-0.009 \pm 0.024$ & 0.023 & 0.34 \\
\hline 68273 & $\gamma^{2}$ Vel & 12.97 & 13.13 & 13.38 & FS94 & $0.25 \pm 0.02$ & $0.059 \pm 0.026$ & -0.182 & -0.86 \\
\hline 71634 & HD 71634 & 14.29 & 14.32 & 14.35 & CLMS06 & $\cdots$ & $\cdots$ & $\cdots$ & $\cdots$ \\
\hline 72754 & FY Vel & 14.41 & 14.45 & 14.49 & CLMS06 & $0.76 \pm 0.10$ & $-0.426 \pm 0.096$ & 0.054 & 0.38 \\
\hline 75309 & HD 75309 & 14.52 & 14.55 & 14.58 & CLMS06 & $0.63 \pm 0.04$ & $-0.296 \pm 0.039$ & 0.131 & 1.44 \\
\hline 79186 & GX Vel & 14.67 & 14.73 & 14.79 & CLMS06 & $0.69 \pm 0.03$ & $-0.356 \pm 0.036$ & 0.141 & 1.45 \\
\hline 79351 & a Car & 12.34 & 12.69 & 13.02 & JSS86 & $\cdots$ & $\cdots$ & $\cdots$ & $\cdots$ \\
\hline 81188 & $\kappa \mathrm{Vel}$ & 13.48 & 13.71 & 13.88 & JSS86 & $\cdots$ & $\cdots$ & $\cdots$ & $\cdots$ \\
\hline 91824 & HD 91824 & 14.53 & 14.56 & 14.59 & CLMS06 & $0.45 \pm 0.03$ & $-0.126 \pm 0.032$ & -0.016 & -0.22 \\
\hline 91983 & HD 91983 & 14.58 & 14.62 & 14.66 & CLMS06 & $0.48 \pm 0.04$ & $-0.154 \pm 0.040$ & -0.002 & -0.02 \\
\hline 93030 & $\theta$ Car & 13.47 & 13.64 & 13.70 & AJS92 & $0.45 \pm 0.03$ & $-0.125 \pm 0.033$ & -0.031 & -0.22 \\
\hline 93222 & HD 93222 & 14.81 & 14.81 & 14.83 & LKF05 & $0.39 \pm 0.04$ & $-0.072 \pm 0.041$ & -0.078 & -1.04 \\
\hline 99857 & HD 99857 & 14.62 & 14.64 & 14.66 & LKF05 & $0.54 \pm 0.04$ & $-0.213 \pm 0.043$ & -0.044 & -0.58 \\
\hline 104705 & DF Cru & 14.62 & 14.65 & 14.68 & LKF05 & $0.33 \pm 0.05$ & $-0.013 \pm 0.046$ & -0.053 & -0.57 \\
\hline 106490 & $\delta \mathrm{Cru}$ & 12.87 & 12.94 & 13.09 & JSS86 & $\cdots$ & $\cdots$ & $\cdots$ & $\cdots$ \\
\hline 108248 & $\alpha^{1} \mathrm{Cru}$ & 13.17 & 13.24 & 13.32 & JSS86 & $0.15 \pm 0.05$ & $0.153 \pm 0.051$ & -0.052 & -0.39 \\
\hline 111934 & BU Cru & 14.68 & 14.73 & 14.78 & CLMS06 & $\cdots$ & $\cdots$ & $\cdots$ & $\cdots$ \\
\hline 116658 & $\alpha \operatorname{Vir}$ & 12.19 & 12.39 & 12.49 & YK79 & $0.16 \pm 0.05$ & $0.142 \pm 0.051$ & -0.291 & -1.56 \\
\hline 118716 & $\epsilon$ Cen & 13.24 & 13.34 & 13.44 & JSS86 & $0.15 \pm 0.16$ & $0.154 \pm 0.157$ & 0.044 & 0.11 \\
\hline 120324 & $\mu$ Cen & 13.17 & 13.39 & 13.62 & JSS86 & $-0.81 \pm 3.74$ & $1.060 \pm 3.532$ & 0.034 & 0.00 \\
\hline 121263 & $\zeta$ Cen & 12.87 & 12.99 & 13.17 & JSS86 & $\cdots$ & $\cdots$ & $\cdots$ & $\cdots$ \\
\hline 121968 & HD 121968 & 13.97 & 14.03 & 14.09 & LKF05 & $0.26 \pm 0.06$ & $0.052 \pm 0.060$ & -0.158 & -1.02 \\
\hline 124314 & HD 124314 & 13.77 & 14.81 & 14.85 & LKF05 & $0.59 \pm 0.05$ & $-0.258 \pm 0.051$ & 0.018 & 0.03 \\
\hline 127972 & $\eta$ Cen & 12.89 & 12.94 & 13.04 & JSS86 & $\cdots$ & $\cdots$ & $\cdots$ & $\cdots$ \\
\hline 135591 & HD 135591 & 14.28 & 14.43 & $\infty$ & JSS86 & $0.56 \pm 0.22$ & $-0.238 \pm 0.209$ & $\cdots$ & $\cdots$ \\
\hline 136298 & $\delta$ Lup & 13.07 & 13.19 & 13.34 & JSS86 & $\cdots$ & $\cdots$ & $\cdots$ & $\cdots$ \\
\hline 138690 & $\gamma$ Lup & 12.84 & 13.19 & $\infty$ & JSS86 & $\ldots$ & $\ldots$ & $\cdots$ & $\cdots$ \\
\hline 141637 & $1 \mathrm{Sco}$ & 14.10 & 14.23 & 14.35 & JSS86 & $0.69 \pm 0.05$ & $-0.356 \pm 0.051$ & -0.091 & -0.52 \\
\hline 143018 & $\pi$ Sco & 13.70 & 13.90 & 14.10 & JJ91 & $0.71 \pm 0.03$ & $-0.371 \pm 0.036$ & 0.036 & 0.17 \\
\hline
\end{tabular}


Table 12-Continued

\begin{tabular}{|c|c|c|c|c|c|c|c|c|c|}
\hline \multirow[b]{2}{*}{$\begin{array}{c}\text { HD Number } \\
\text { (1) }\end{array}$} & \multirow[b]{2}{*}{$\begin{array}{l}\text { Name } \\
(2)\end{array}$} & \multicolumn{4}{|c|}{ Observed $\log N(\mathrm{P}$ II $)$} & \multirow[b]{2}{*}{$\begin{array}{l}F_{*} \\
(7)\end{array}$} & \multirow[b]{2}{*}{$\begin{array}{c}{\left[\mathrm{P}_{\text {gas }} / \mathrm{H}\right]_{\mathrm{fit}}{ }^{\mathrm{c}}} \\
(8)\end{array}$} & \multirow[b]{2}{*}{$\begin{array}{l}\text { Residual }^{\mathrm{d}} \\
\quad(9)\end{array}$} & \multirow{2}{*}{$\begin{array}{c}\text { Deviation }^{\mathrm{e}} \\
\quad(\text { in } \sigma) \\
(10)\end{array}$} \\
\hline & & $\begin{array}{l}1.1 . \\
(3)\end{array}$ & $\begin{array}{c}\text { best } \\
(4)\end{array}$ & $\begin{array}{l}\text { u.l. } \\
(5)\end{array}$ & $\begin{array}{c}\text { Source }^{b} \\
(6)\end{array}$ & & & & \\
\hline 143118 & $\eta \operatorname{Lup} \mathrm{A}$ & 12.79 & 12.84 & 12.99 & JSS86 & $\cdots$ & $\cdots$ & $\cdots$ & $\cdots$ \\
\hline 143275 & $\delta$ Sco & 14.18 & 14.23 & 14.30 & JSS86 & $0.90 \pm 0.03$ & $-0.551 \pm 0.041$ & 0.072 & 0.63 \\
\hline 144217 & $\beta^{1} \mathrm{Sco}$ & 14.15 & 14.23 & 14.30 & JSS86 & $0.81 \pm 0.02$ & $-0.471 \pm 0.029$ & 0.023 & 0.26 \\
\hline 144470 & $\mathrm{o}^{1} \mathrm{Sco}$ & 14.20 & 14.28 & 14.35 & JSS86 & $0.81 \pm 0.04$ & $-0.466 \pm 0.042$ & -0.027 & -0.23 \\
\hline 145502 & $\nu \mathrm{Sco}$ & 14.18 & 14.48 & $\infty$ & JSS86 & $0.80 \pm 0.11$ & $-0.459 \pm 0.109$ & $\cdots$ & $\cdots$ \\
\hline 147165 & $\sigma \mathrm{Sco}$ & 14.20 & 14.28 & 14.35 & JSS86 & $0.76 \pm 0.06$ & $-0.427 \pm 0.061$ & -0.199 & -1.00 \\
\hline 147933 & $\rho \mathrm{Oph} \mathrm{A}$ & 13.48 & 13.63 & 13.93 & JSS86 & $1.09 \pm 0.08$ & $-0.737 \pm 0.085$ & -0.878 & -3.46 \\
\hline 148184 & $\chi \mathrm{Oph}$ & 14.03 & 14.18 & 14.30 & JSS86 & $0.96 \pm 0.09$ & $-0.609 \pm 0.093$ & -0.060 & -0.29 \\
\hline 148594 & HD 148594 & 14.23 & 14.26 & 14.29 & CLMS06 & $\cdots$ & $\cdots$ & $\cdots$ & $\cdots$ \\
\hline 148605 & $22 \mathrm{Sco}$ & 14.05 & 14.38 & $\infty$ & JSS86 & $0.53 \pm 0.39$ & $-0.205 \pm 0.373$ & $\cdots$ & $\cdots$ \\
\hline 149038 & $\mu$ Nor & 14.15 & 14.48 & $\infty$ & JSS86 & $0.56 \pm 0.05$ & $-0.230 \pm 0.047$ & $\cdots$ & $\cdots$ \\
\hline $149757(-27)$ & $\zeta \mathrm{Oph}$ & 13.04 & 13.06 & 13.08 & SCS92 & $\cdots$ & $\cdots$ & $\cdots$ & $\cdots$ \\
\hline$(-15)$ & & 13.67 & $\infty$ & $\infty$ & SCS92 & $1.05 \pm 0.02$ & $-0.692 \pm 0.036$ & $\cdots$ & $\cdots$ \\
\hline 151804 & V973 Sco & 57.32 & $\infty$ & $\infty$ & JSS86 & $0.57 \pm 0.08$ & $-0.247 \pm 0.073$ & $\cdots$ & $\cdots$ \\
\hline 151890 & $\mu^{1} \mathrm{Sco}$ & 13.31 & 13.41 & 13.51 & JSS86 & $-0.03 \pm 3.47$ & $0.323 \pm 3.282$ & -0.039 & -0.00 \\
\hline 152590 & HD 152590 & 14.62 & 14.64 & 14.66 & CLMS06 & $0.69 \pm 0.03$ & $-0.357 \pm 0.033$ & -0.008 & -0.12 \\
\hline 154368 & V1074 Sco & 14.69 & 14.99 & 15.29 & $\mathrm{~S}++96$ & $0.52 \pm 0.07$ & $-0.192 \pm 0.064$ & 0.048 & 0.15 \\
\hline 155806 & V1075 Sco & 57.35 & $\infty$ & $\infty$ & JSS86 & $0.62 \pm 0.07$ & $-0.293 \pm 0.064$ & $\cdots$ & $\cdots$ \\
\hline 156110 & HD 156110 & 13.68 & 13.72 & 13.76 & CLMS06 & $\cdots$ & $\cdots$ & $\cdots$ & $\cdots$ \\
\hline 157246 & $\gamma$ Ara & 13.98 & 14.08 & 14.18 & JSS86 & $0.46 \pm 0.03$ & $-0.138 \pm 0.035$ & -0.031 & -0.23 \\
\hline 157857 & HD 157857 & 14.57 & 14.61 & 14.65 & CLMS06 & $0.62 \pm 0.04$ & $-0.292 \pm 0.037$ & -0.078 & -0.90 \\
\hline 158926 & $\lambda \mathrm{Sco}$ & 12.55 & 12.59 & 12.64 & Y83 & $0.31 \pm 0.02$ & $0.001 \pm 0.023$ & -0.177 & -3.01 \\
\hline 160578 & $\kappa \mathrm{Sco}$ & 13.14 & 13.24 & 13.34 & JSS86 & $0.50 \pm 0.07$ & $-0.173 \pm 0.071$ & -0.349 & -1.77 \\
\hline 164284 & $66 \mathrm{Oph}$ & 13.38 & 13.48 & 13.65 & JSS86 & $0.89 \pm 0.18$ & $-0.545 \pm 0.171$ & -0.264 & -0.66 \\
\hline 165024 & $\theta$ Ara & 14.03 & 14.13 & 14.23 & JSS86 & $0.56 \pm 0.03$ & $-0.237 \pm 0.036$ & -0.016 & -0.11 \\
\hline 167264 & $15 \mathrm{Sgr}$ & 14.73 & 14.83 & $\infty$ & JSS86 & $0.68 \pm 0.16$ & $-0.347 \pm 0.149$ & $\cdots$ & $\cdots$ \\
\hline 175360 & HD 175360 & 14.11 & 14.20 & 14.29 & CLMS06 & $\cdots$ & $\cdots$ & $\cdots$ & $\cdots$ \\
\hline 177989 & HD 177989 & 14.40 & 14.44 & 14.48 & LKF05 & $0.55 \pm 0.05$ & $-0.227 \pm 0.045$ & 0.043 & 0.47 \\
\hline 184915 & $\kappa \mathrm{Aql}$ & 14.08 & 14.33 & $\infty$ & JSS86 & $0.88 \pm 0.05$ & $-0.533 \pm 0.053$ & $\cdots$ & $\cdots$ \\
\hline 185418 & HD 185418 & 14.60 & 14.63 & 14.66 & CLMS06 & $0.79 \pm 0.03$ & $-0.452 \pm 0.038$ & 0.134 & 1.55 \\
\hline 188209 & HD 188209 & 14.05 & 14.18 & 14.28 & JSS86 & $0.66 \pm 0.12$ & $-0.332 \pm 0.116$ & -0.031 & -0.16 \\
\hline 193322 & HD 193322 & 13.43 & 13.73 & $\infty$ & JSS86 & $\cdots$ & $\cdots$ & $\cdots$ & $\cdots$ \\
\hline 198478 & 55 Cyg & 14.65 & 14.68 & 14.71 & CLMS06 & $0.81 \pm 0.05$ & $-0.467 \pm 0.054$ & 0.063 & 0.51 \\
\hline 198781 & HD 198781 & 14.38 & 14.42 & 14.46 & CLMS06 & $0.59 \pm 0.03$ & $-0.260 \pm 0.032$ & -0.008 & -0.11 \\
\hline 200120 & 59 Cyg & 13.60 & 13.78 & 13.98 & JSS86 & $\cdots$ & $\cdots$ & $\cdots$ & $\cdots$ \\
\hline 201345 & HD 201345 & 14.35 & 14.41 & 14.47 & CLMS06 & $0.34 \pm 0.04$ & $-0.023 \pm 0.041$ & -0.106 & -0.95 \\
\hline 202347 & HD 202347 & 14.26 & 14.33 & 14.40 & LKF05 & $0.56 \pm 0.06$ & $-0.231 \pm 0.061$ & 0.085 & 0.61 \\
\hline 202904 & $v$ Cyg & 13.39 & 13.49 & 13.67 & JSS86 & $\cdots$ & $\cdots$ & $\cdots$ & $\cdots$ \\
\hline 203064 & 68 Cyg & 14.00 & 14.23 & $\infty$ & JSS86 & $0.68 \pm 0.20$ & $-0.348 \pm 0.194$ & $\cdots$ & $\cdots$ \\
\hline
\end{tabular}


Table 12-Continued

\begin{tabular}{|c|c|c|c|c|c|c|c|c|c|}
\hline \multirow[b]{2}{*}{$\begin{array}{c}\text { HD Number } \\
\text { (1) }\end{array}$} & \multirow[b]{2}{*}{$\begin{array}{l}\text { Name } \\
(2)\end{array}$} & \multicolumn{4}{|c|}{ Observed $\log N(\mathrm{P}$ II $)$} & \multirow[b]{2}{*}{$\begin{array}{l}F_{*} \\
(7)\end{array}$} & \multirow[b]{2}{*}{$\begin{array}{c}{\left[\mathrm{P}_{\text {gas }} / \mathrm{H}\right]_{\mathrm{fit}}{ }^{\mathrm{c}}} \\
(8)\end{array}$} & \multirow[b]{2}{*}{$\begin{array}{l}\text { Residual }^{\mathrm{d}} \\
(9)\end{array}$} & \multirow{2}{*}{$\begin{array}{l}\text { Deviation } \\
\quad \text { in } \sigma) \\
\quad(10)\end{array}$} \\
\hline & & $\begin{array}{l}1.1 . \\
(3)\end{array}$ & $\begin{array}{c}\text { best } \\
(4)\end{array}$ & $\begin{array}{l}\text { u.l. } \\
(5)\end{array}$ & $\begin{array}{c}\text { Source }^{b} \\
(6)\end{array}$ & & & & \\
\hline 203532 & HD 203532 & 14.18 & 14.21 & 14.24 & CLMS06 & $\cdots$ & $\cdots$ & $\cdots$ & $\cdots$ \\
\hline 206773 & HD 206773 & 14.56 & 14.60 & 14.64 & CLMS06 & $0.53 \pm 0.02$ & $-0.209 \pm 0.024$ & 0.022 & 0.31 \\
\hline 208440 & HD 208440 & 14.54 & 14.61 & 14.68 & CLMS06 & $0.61 \pm 0.04$ & $-0.281 \pm 0.041$ & 0.047 & 0.42 \\
\hline 209975 & 19 Cep & 14.23 & 14.43 & $\infty$ & JSS86 & $0.57 \pm 0.26$ & $-0.246 \pm 0.248$ & $\cdots$ & $\cdots$ \\
\hline 212791 & V408 Lac & 14.31 & 14.34 & 14.37 & CLMS06 & $0.57 \pm 0.08$ & $-0.244 \pm 0.079$ & -0.076 & -0.38 \\
\hline 214080 & HD 214080 & 13.67 & 13.99 & $\infty$ & JSS86 & $0.27 \pm 0.10$ & $0.041 \pm 0.097$ & $\cdots$ & $\cdots$ \\
\hline 214680 & $10 \mathrm{Lac}$ & 13.83 & 13.88 & 13.93 & JSS86 & $0.50 \pm 0.06$ & $-0.173 \pm 0.062$ & -0.218 & -1.46 \\
\hline 214993 & $12 \mathrm{Lac}$ & 13.78 & 13.88 & 14.08 & JSS86 & $0.68 \pm 0.10$ & $-0.347 \pm 0.092$ & -0.139 & -0.64 \\
\hline 217675 & o And & 13.53 & 13.91 & $\infty$ & JSS86 & $\cdots$ & $\cdots$ & $\cdots$ & $\cdots$ \\
\hline 218376 & 1 Cas & 14.30 & 14.48 & $\infty$ & JSS86 & $0.60 \pm 0.06$ & $-0.272 \pm 0.059$ & $\cdots$ & $\cdots$ \\
\hline 218915 & HD 218915 & 14.39 & 14.46 & 14.53 & LKF05 & $0.70 \pm 0.08$ & $-0.364 \pm 0.078$ & 0.029 & 0.27 \\
\hline 219188 & HD 219188 & 13.29 & 13.44 & $\infty$ & JSS86 & $1.24 \pm 0.57$ & $-0.875 \pm 0.543$ & $\cdots$ & $\cdots$ \\
\hline 220057 & HD 220057 & 14.30 & 14.33 & 14.36 & CLMS06 & $0.75 \pm 0.05$ & $-0.415 \pm 0.054$ & 0.052 & 0.39 \\
\hline 224151 & V373 Cas & 14.78 & 14.87 & 14.96 & LKF05 & $0.46 \pm 0.04$ & $-0.144 \pm 0.043$ & 0.010 & 0.09 \\
\hline 224572 & $\sigma$ Cas & 13.95 & 14.08 & 14.18 & JSS86 & $0.76 \pm 0.07$ & $-0.422 \pm 0.070$ & -0.021 & -0.13 \\
\hline
\end{tabular}

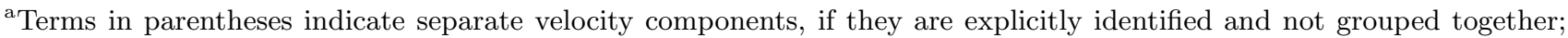
see 4.3

${ }^{\mathrm{b}}$ Codes in this column are linked to references listed in Table 1

${ }^{\mathrm{c}}$ The expected depletion $\left[\mathrm{P}_{\text {gas }} / \mathrm{H}\right]$ computed using Eq. 10. The listed errors do not include an overall systematic uncertainty of 0.04 in the solar abundance $\sigma(\mathrm{P} / \mathrm{H})_{\odot}$ in order to show just the formal error that arises from the uncertainties in location of line of best fit and the value of $F_{*}$.

${ }^{\mathrm{d}}$ The observed $\left[\mathrm{P}_{\text {gas }} / \mathrm{H}\right]$ minus that computed using Eq. 10 .

'The difference shown in the previous column divided by the expected difference due to the uncertainties in both the measured column density and the coefficients that appear in Eq. 10. 
Table 13. Observations and Fits for Sulfur

\begin{tabular}{|c|c|c|c|c|c|c|c|c|c|}
\hline \multirow[b]{2}{*}{$\begin{array}{c}\text { HD Number }{ }^{\mathrm{a}} \\
(1)\end{array}$} & \multirow[b]{2}{*}{$\begin{array}{c}\text { Name } \\
(2)\end{array}$} & \multicolumn{4}{|c|}{ Observed $\log N(\mathrm{~S}$ II $)$} & \multirow[b]{2}{*}{$\begin{array}{l}F_{*} \\
(7)\end{array}$} & \multirow[b]{2}{*}{$\begin{array}{c}{\left[\mathrm{S}_{\text {gas }} / \mathrm{H}\right]_{\mathrm{fit}}{ }^{\mathrm{c}}} \\
(8)\end{array}$} & \multirow[b]{2}{*}{$\begin{array}{l}\text { Residual }^{\mathrm{d}} \\
\quad(9)\end{array}$} & \multirow{2}{*}{$\begin{array}{l}\text { Deviation } \\
\quad \text { in } \sigma) \\
(10)\end{array}$} \\
\hline & & $\begin{array}{l}1.1 . \\
(3)\end{array}$ & $\begin{array}{l}\text { best } \\
(4)\end{array}$ & $\begin{array}{l}\text { u.l. } \\
(5)\end{array}$ & $\begin{array}{c}\text { Source }^{b} \\
(6)\end{array}$ & & & & \\
\hline 22586 & HD 22586 & 15.05 & 15.10 & 15.30 & JW96 & $0.34 \pm 0.07$ & $-0.186 \pm 0.091$ & -0.333 & -1.47 \\
\hline 22928 & $\delta$ Per & 14.75 & 14.82 & 14.88 & MY82 & $\cdots$ & $\cdots$ & $\cdots$ & $\cdots$ \\
\hline 34029 & $\alpha$ Aur & $\cdots$ & $\cdots$ & 13.59 & WRLS02 & $0.44 \pm 0.05$ & $-0.312 \pm 0.081$ & $\cdots$ & $\cdots$ \\
\hline 38666 & $\mu \mathrm{Col}$ & 15.19 & 15.21 & 15.23 & HSF99 & $0.11 \pm 0.01$ & $0.102 \pm 0.028$ & -0.010 & -0.26 \\
\hline 44743 & $\beta \mathrm{CMa}$ & 14.50 & 14.54 & 14.58 & DG98 & $-0.43 \pm 0.03$ & $0.790 \pm 0.111$ & 0.186 & 1.41 \\
\hline 49798 & HD 49798 & 15.25 & 15.30 & 15.50 & JW96 & $\cdots$ & $\cdots$ & $\cdots$ & $\cdots$ \\
\hline 66811 & $\zeta$ Pup & 15.17 & 15.21 & 15.25 & M78 & $0.32 \pm 0.02$ & $-0.164 \pm 0.042$ & 0.158 & 2.24 \\
\hline 68273 & $\gamma^{2} \mathrm{Vel}$ & 14.95 & 15.02 & 15.11 & FS94 & $0.25 \pm 0.02$ & $-0.074 \pm 0.037$ & 0.120 & 1.24 \\
\hline $93521(-66)$ & HD 93521 & 14.07 & 14.10 & 14.13 & SF93 & $-0.31 \pm 0.11$ & $0.634 \pm 0.159$ & -0.308 & -0.85 \\
\hline$(-58)$ & & 14.49 & 14.51 & 14.53 & SF93 & $-0.01 \pm 0.03$ & $0.250 \pm 0.055$ & -0.344 & -3.47 \\
\hline$(-51)$ & & 14.51 & 14.54 & 14.57 & SF93 & $-0.04 \pm 0.04$ & $0.289 \pm 0.069$ & -0.213 & -1.60 \\
\hline$(-39)$ & & 13.96 & 14.03 & 14.10 & SF93 & $0.01 \pm 0.08$ & $0.235 \pm 0.110$ & -0.349 & -1.46 \\
\hline$(-29)$ & & 12.97 & 13.17 & 13.37 & SF93 & $0.34 \pm 0.17$ & $-0.187 \pm 0.214$ & -0.287 & -0.64 \\
\hline$(-18)$ & & 14.50 & 14.52 & 14.54 & SF93 & $0.00 \pm 0.03$ & $0.239 \pm 0.052$ & -0.263 & -2.94 \\
\hline$(-10)$ & & 14.55 & 14.67 & 14.69 & SF93 & $0.02 \pm 0.04$ & $0.216 \pm 0.060$ & -0.170 & -1.47 \\
\hline$(+3)$ & & 14.51 & 14.53 & 14.55 & SF93 & $0.25 \pm 0.04$ & $-0.075 \pm 0.054$ & 0.041 & 0.42 \\
\hline$(+7)$ & & 13.92 & 13.98 & 14.04 & SF93 & $0.23 \pm 0.12$ & $-0.053 \pm 0.153$ & -0.021 & -0.07 \\
\hline (total) & & 15.28 & 15.33 & 15.36 & SF93 & $0.06 \pm 0.04$ & $0.169 \pm 0.054$ & -0.200 & -2.08 \\
\hline 116658 & $\alpha \mathrm{Vir}$ & 14.46 & 14.50 & 14.54 & YK79 & $0.16 \pm 0.05$ & $0.038 \pm 0.066$ & 0.206 & 1.63 \\
\hline 158926 & $\lambda \mathrm{Sco}$ & 14.51 & 14.54 & 14.57 & Y83 & $0.31 \pm 0.02$ & $-0.150 \pm 0.040$ & 0.204 & 3.49 \\
\hline $215733(-93)$ & HD 215733 & 12.82 & 12.95 & 13.08 & FS97 & $-0.27 \pm 0.19$ & $0.580 \pm 0.253$ & -0.284 & -0.60 \\
\hline$(-61)$ & & 12.88 & 13.20 & 13.52 & FS97 & $1.06 \pm 0.21$ & $-1.098 \pm 0.303$ & -0.406 & -0.72 \\
\hline$(-59)$ & & 14.17 & 14.22 & 14.27 & FS97 & $-0.11 \pm 0.10$ & $0.382 \pm 0.134$ & -0.376 & -1.23 \\
\hline$(-54)$ & & 14.44 & 14.47 & 14.50 & FS97 & $0.54 \pm 0.15$ & $-0.443 \pm 0.201$ & 0.019 & 0.04 \\
\hline$(-47)$ & & 14.44 & 14.50 & 14.56 & FS97 & $\cdots$ & $\cdots$ & $\cdots$ & $\cdots$ \\
\hline$(-42)$ & & 13.57 & 13.82 & 14.07 & FS97 & $-0.16 \pm 0.31$ & $0.448 \pm 0.398$ & -0.422 & -0.43 \\
\hline$(-40)$ & & 13.65 & 13.78 & 13.91 & FS97 & $0.18 \pm 0.24$ & $0.014 \pm 0.308$ & -0.308 & -0.45 \\
\hline$(-32)$ & & 14.40 & 14.58 & 14.76 & FS97 & $0.25 \pm 0.09$ & $-0.069 \pm 0.116$ & -0.255 & -1.00 \\
\hline$(-31)$ & & 13.98 & 14.15 & 14.32 & FS97 & $\cdots$ & $\cdots$ & $\cdots$ & $\cdots$ \\
\hline$(-28)$ & & 14.37 & 14.49 & 14.61 & FS97 & $-0.18 \pm 0.07$ & $0.474 \pm 0.104$ & -0.158 & -0.83 \\
\hline$(-26)$ & & 14.50 & 14.62 & 14.74 & FS97 & $-0.12 \pm 0.07$ & $0.397 \pm 0.099$ & -0.151 & -0.77 \\
\hline$(-23)$ & & 12.92 & 13.52 & 14.12 & FS97 & $0.24 \pm 0.08$ & $-0.064 \pm 0.106$ & -0.930 & -1.52 \\
\hline$(-21)$ & & 14.53 & 14.63 & 14.73 & FS97 & $0.24 \pm 0.05$ & $-0.057 \pm 0.070$ & 0.053 & 0.37 \\
\hline$(-19)$ & & 13.35 & 13.69 & 14.03 & FS97 & $\cdots$ & $\cdots$ & $\cdots$ & $\cdots$ \\
\hline$(-16)$ & & 14.46 & 14.77 & 15.08 & FS97 & $0.93 \pm 0.05$ & $-0.927 \pm 0.143$ & 0.323 & 0.94 \\
\hline$(-9)$ & & 15.43 & 15.47 & 15.51 & FS97 & $0.08 \pm 0.04$ & $0.142 \pm 0.053$ & -0.006 & -0.06 \\
\hline$(+1)$ & & 13.56 & 13.71 & 13.86 & FS97 & $0.90 \pm 0.05$ & $-0.898 \pm 0.140$ & -0.366 & -1.73 \\
\hline (total) & & 15.71 & 15.80 & 15.91 & FS97 & $\cdots$ & $\cdots$ & $\cdots$ & $\cdots$ \\
\hline
\end{tabular}




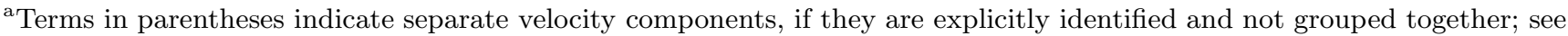
$\$ 4.3$

${ }^{\mathrm{b}}$ Codes in this column are linked to references listed in Table 1

${ }^{\mathrm{c}}$ The expected depletion $\left[\mathrm{S}_{\text {gas }} / \mathrm{H}\right]$ computed using Eq. 10 The listed errors do not include an overall systematic uncertainty of 0.04 in the solar abundance $\sigma(\mathrm{S} / \mathrm{H})_{\odot}$ in order to show just the formal error that arises from the uncertainties in location of line of best fit and the value of $F_{*}$.

${ }^{\mathrm{d}}$ The observed $\left[\mathrm{S}_{\text {gas }} / \mathrm{H}\right]$ minus that computed using Eq. 10.

'The difference shown in the previous column divided by the expected difference due to the uncertainties in both the measured column density and the coefficients that appear in Eq. 10. 
Table 14. Observations and Fits for Chlorine

\begin{tabular}{|c|c|c|c|c|c|c|c|c|c|}
\hline \multirow[b]{2}{*}{$\begin{array}{c}\text { HD Number }{ }^{\mathrm{a}} \\
\text { (1) }\end{array}$} & \multirow[b]{2}{*}{$\begin{array}{l}\text { Name } \\
(2)\end{array}$} & \multicolumn{4}{|c|}{ Observed $\log N(\mathrm{Cl} \mathrm{II})$} & \multirow[b]{2}{*}{$\begin{array}{l}F_{*} \\
(7)\end{array}$} & \multirow[b]{2}{*}{$\begin{array}{c}{\left[\mathrm{Cl}_{\text {gas }} / \mathrm{H}\right]_{\mathrm{fit}}{ }^{\mathrm{c}}} \\
(8)\end{array}$} & \multirow[b]{2}{*}{$\begin{array}{c}\text { Residual }^{\mathrm{d}} \\
(9)\end{array}$} & \multirow{2}{*}{$\begin{array}{l}\text { Deviation } \\
\quad(\text { in } \sigma) \\
\quad(10)\end{array}$} \\
\hline & & $\begin{array}{l}1.1 . \\
(3)\end{array}$ & $\begin{array}{c}\text { best } \\
(4)\end{array}$ & $\begin{array}{l}\text { u.l. } \\
(5)\end{array}$ & $\begin{array}{c}\text { Source }^{b} \\
(6)\end{array}$ & & & & \\
\hline 2905 & $\kappa$ Cas & 13.85 & 14.21 & 15.11 & JSS86 & $0.58 \pm 0.06$ & $-0.280 \pm 0.076$ & -0.134 & -0.21 \\
\hline 5394 & $\gamma$ Cas & 12.62 & 13.05 & 13.25 & JSS86 & $0.52 \pm 0.04$ & $-0.199 \pm 0.059$ & -0.243 & -0.73 \\
\hline 21278 & HD 21278 & 14.25 & 14.55 & $\infty$ & JSS86 & $\cdots$ & $\cdots$ & $\cdots$ & $\cdots$ \\
\hline 21856 & HD 21856 & $\cdots$ & 13.48 & 13.95 & JSS86 & $0.67 \pm 0.39$ & $-0.394 \pm 0.484$ & $\cdots$ & $\cdots$ \\
\hline 22928 & $\delta$ Per & $\cdots$ & $\cdots$ & 12.73 & JSS86 & $\cdots$ & $\cdots$ & $\cdots$ & $\cdots$ \\
\hline 22951 & 40 Per & 14.24 & 14.33 & 14.54 & JSS86 & $0.73 \pm 0.05$ & $-0.467 \pm 0.070$ & 0.241 & 1.23 \\
\hline 23180 & o Per & $\cdots$ & 13.41 & 13.73 & JSS86 & $0.84 \pm 0.06$ & $-0.606 \pm 0.090$ & $\ldots$ & $\ldots$ \\
\hline 23408 & 20 Tau & 12.76 & 14.06 & 15.14 & JSS86 & $\cdots$ & $\cdots$ & $\cdots$ & $\cdots$ \\
\hline 23480 & $23 \mathrm{Tau}$ & 13.23 & 13.68 & 14.55 & JSS86 & $\cdots$ & $\cdots$ & $\cdots$ & $\cdots$ \\
\hline 23630 & $\eta \mathrm{Tau}$ & $\cdots$ & $\cdots$ & $\infty$ & JSS86 & $\cdots$ & $\cdots$ & $\cdots$ & $\cdots$ \\
\hline 24398 & $\zeta$ Per & $\cdots$ & $\cdots$ & 13.15 & $\mathrm{~S} 77$ & $0.88 \pm 0.05$ & $-0.657 \pm 0.076$ & $\cdots$ & $\cdots$ \\
\hline 24760 & $\epsilon$ Per & 13.00 & 13.19 & 13.30 & JSS86 & $0.68 \pm 0.04$ & $-0.402 \pm 0.055$ & -0.241 & -1.33 \\
\hline 24912 & $\xi$ Per & 14.30 & 14.54 & 15.11 & JSS86 & $0.83 \pm 0.02$ & $-0.591 \pm 0.049$ & 0.505 & 1.23 \\
\hline 29248 & $\nu$ Eri & 13.50 & 13.64 & 13.79 & JSS86 & $\cdots$ & $\cdots$ & $\cdots$ & $\cdots$ \\
\hline 30614 & $\alpha \mathrm{Cam}$ & 13.46 & 13.92 & 14.08 & JSS86 & $0.46 \pm 0.04$ & $-0.125 \pm 0.060$ & -0.377 & -1.16 \\
\hline 34816 & $\lambda$ Lep & 12.03 & 12.90 & 13.16 & JSS86 & $0.45 \pm 0.05$ & $-0.123 \pm 0.072$ & -0.490 & -0.85 \\
\hline 35149 & 23 Ori & 12.86 & 13.57 & 14.22 & JSS86 & $0.54 \pm 0.04$ & $-0.228 \pm 0.054$ & -0.166 & -0.24 \\
\hline 35439 & 25 Ori & 13.22 & 13.67 & 14.22 & JSS86 & $0.72 \pm 0.18$ & $-0.454 \pm 0.222$ & 0.437 & 0.75 \\
\hline 35715 & $\psi$ Ori & 13.22 & 13.62 & 13.79 & JSS86 & $0.66 \pm 0.11$ & $-0.382 \pm 0.142$ & 0.179 & 0.48 \\
\hline 36166 & HD 36166 & 12.91 & 13.71 & $\infty$ & JSS86 & $\cdots$ & $\cdots$ & $\cdots$ & $\ldots$ \\
\hline 36486 & $\delta$ Ori A & 13.11 & 13.23 & 13.32 & JSS86 & $0.54 \pm 0.02$ & $-0.230 \pm 0.036$ & -0.062 & -0.53 \\
\hline 36822 & $\phi^{1}$ Ori & 13.27 & 13.49 & 13.61 & JSS86 & $0.74 \pm 0.08$ & $-0.479 \pm 0.105$ & -0.200 & -0.93 \\
\hline 36861 & $\lambda$ Ori A & 13.67 & 13.74 & 13.80 & JSS86 & $0.57 \pm 0.04$ & $-0.261 \pm 0.056$ & -0.129 & -0.92 \\
\hline 37043 & $\iota$ Ori & 12.96 & 13.10 & 13.19 & JSS86 & $0.41 \pm 0.03$ & $-0.067 \pm 0.049$ & -0.315 & -2.20 \\
\hline 37128 & $\epsilon$ Ori & 13.44 & 13.51 & 13.56 & JSS86 & $0.54 \pm 0.03$ & $-0.229 \pm 0.045$ & -0.043 & -0.37 \\
\hline 37468 & $\sigma$ Ori & 13.64 & 13.72 & 13.78 & JSS86 & $0.58 \pm 0.04$ & $-0.282 \pm 0.058$ & 0.150 & 1.19 \\
\hline 38771 & $\kappa$ Ori & 13.37 & 13.47 & 13.54 & JSS86 & $0.67 \pm 0.03$ & $-0.386 \pm 0.042$ & 0.004 & 0.04 \\
\hline 40111 & 139 Tau & 13.86 & 13.97 & 14.06 & JSS86 & $0.49 \pm 0.04$ & $-0.166 \pm 0.054$ & -0.150 & -1.09 \\
\hline 41161 & HD 41161 & 14.02 & $\infty$ & $\infty$ & OH06 & $0.44 \pm 0.04$ & $-0.104 \pm 0.060$ & $\cdots$ & $\ldots$ \\
\hline 44506 & HD 44506 & 13.78 & 14.12 & 14.28 & JSS86 & $-0.03 \pm 0.23$ & $0.480 \pm 0.294$ & 0.221 & 0.39 \\
\hline 47839 & 15 Mon & 13.38 & 13.57 & 13.77 & JY78 & $0.25 \pm 0.05$ & $0.133 \pm 0.078$ & -0.198 & -0.84 \\
\hline 52918 & 19 Mon & $\cdots$ & 12.52 & 13.32 & JSS86 & $0.44 \pm 0.24$ & $-0.109 \pm 0.304$ & $\cdots$ & $\cdots$ \\
\hline 54662 & HD 54662 & 13.71 & 14.03 & 14.23 & JSS86 & $0.89 \pm 0.09$ & $-0.658 \pm 0.122$ & -0.059 & -0.19 \\
\hline 55879 & HD 55879 & $\cdots$ & $\cdots$ & 14.56 & JSS86 & $\cdots$ & $\cdots$ & $\cdots$ & $\cdots$ \\
\hline 57060 & $29 \mathrm{CMa}$ & 13.81 & 14.08 & 14.21 & JSS86 & $0.50 \pm 0.05$ & $-0.180 \pm 0.065$ & 0.228 & 1.01 \\
\hline 57061 & $\tau \mathrm{CMa}$ & 13.88 & 14.03 & 14.14 & JSS86 & $0.39 \pm 0.04$ & $-0.038 \pm 0.066$ & 0.036 & 0.24 \\
\hline 64740 & HD 64740 & 13.58 & 13.89 & 14.96 & JSS86 & $0.27 \pm 0.30$ & $0.104 \pm 0.378$ & 0.402 & 0.48 \\
\hline 64760 & HD 64760 & 13.41 & 13.55 & 13.64 & JSS86 & $0.35 \pm 0.06$ & $0.001 \pm 0.083$ & -0.043 & -0.24 \\
\hline 65575 & $\chi \mathrm{Car}$ & 12.55 & 13.05 & 13.27 & JSS86 & $\cdots$ & $\cdots$ & $\cdots$ & $\cdots$ \\
\hline
\end{tabular}


Table 14-Continued

\begin{tabular}{|c|c|c|c|c|c|c|c|c|c|}
\hline \multirow[b]{2}{*}{$\begin{array}{l}\text { HD Number } \\
\text { (1) }\end{array}$} & \multirow[b]{2}{*}{$\begin{array}{c}\text { Name } \\
(2)\end{array}$} & \multicolumn{4}{|c|}{ Observed $\log N(\mathrm{Cl} \mathrm{II})$} & \multirow[b]{2}{*}{$\begin{array}{l}F_{*} \\
(7)\end{array}$} & \multirow[b]{2}{*}{$\begin{array}{c}{\left[\mathrm{Cl}_{\text {gas }} / \mathrm{H}\right]_{\mathrm{fit}}{ }^{\mathrm{c}}} \\
(8)\end{array}$} & \multirow[b]{2}{*}{$\begin{array}{l}\text { Residual }^{\mathrm{d}} \\
\quad(9)\end{array}$} & \multirow{2}{*}{$\begin{array}{l}\text { Deviation } \\
\quad \text { in } \sigma) \\
\quad(10)\end{array}$} \\
\hline & & $\begin{array}{l}1.1 . \\
(3)\end{array}$ & $\begin{array}{l}\text { best } \\
(4)\end{array}$ & $\begin{array}{l}\text { u.l. } \\
(5)\end{array}$ & $\begin{array}{c}\text { Source }^{\mathrm{b}} \\
(6)\end{array}$ & & & & \\
\hline 65818 & V Pup & 13.84 & 14.01 & 14.13 & JSS86 & $0.36 \pm 0.09$ & $-0.008 \pm 0.119$ & 0.165 & 0.70 \\
\hline 66811 & $\zeta$ Pup & 13.30 & 13.45 & 13.60 & M78 & $0.32 \pm 0.02$ & $0.041 \pm 0.050$ & 0.124 & 0.76 \\
\hline 68273 & $\gamma^{2} \mathrm{Vel}$ & $\cdots$ & 12.86 & 13.24 & JSS86 & $0.25 \pm 0.02$ & $0.130 \pm 0.058$ & $\cdots$ & $\cdots$ \\
\hline 81188 & $\kappa \mathrm{Vel}$ & 12.41 & 13.00 & 13.16 & JSS86 & $\cdots$ & $\cdots$ & $\cdots$ & $\cdots$ \\
\hline 93030 & $\theta$ Car & 13.34 & 13.48 & 13.56 & AJS92 & $0.45 \pm 0.03$ & $-0.111 \pm 0.052$ & 0.006 & 0.04 \\
\hline 106490 & $\delta \mathrm{Cru}$ & 12.89 & 13.07 & 13.19 & JSS86 & $\cdots$ & $\cdots$ & $\cdots$ & $\cdots$ \\
\hline 108248 & $\alpha^{1} \mathrm{Cru}$ & 12.96 & 13.02 & 13.08 & JSS86 & $0.15 \pm 0.05$ & $0.254 \pm 0.088$ & -0.166 & -1.13 \\
\hline 113904 & $\theta$ Mus & $\cdots$ & 13.31 & 13.70 & JSS86 & $\cdots$ & $\cdots$ & $\cdots$ & $\cdots$ \\
\hline 116658 & $\alpha \operatorname{Vir}$ & 12.52 & 12.78 & 12.94 & YK79 & $0.16 \pm 0.05$ & $0.240 \pm 0.087$ & 0.206 & 0.83 \\
\hline 118716 & $\epsilon$ Cen & 12.92 & 13.07 & 13.17 & JSS86 & $0.15 \pm 0.16$ & $0.256 \pm 0.214$ & -0.120 & -0.28 \\
\hline 120324 & $\mu$ Cen & 13.22 & 13.57 & 13.80 & JSS86 & $-0.81 \pm 3.74$ & $1.446 \pm 4.645$ & 0.034 & 0.00 \\
\hline 121263 & $\zeta$ Cen & $\ldots$ & 12.42 & 12.76 & JSS86 & $\cdots$ & $\cdots$ & $\cdots$ & $\cdots$ \\
\hline 127972 & $\eta$ Cen & $\ldots$ & 12.12 & 12.59 & JSS86 & $\cdots$ & $\cdots$ & $\cdots$ & $\cdots$ \\
\hline 135591 & HD 135591 & 14.32 & 14.47 & 15.32 & JSS86 & $0.56 \pm 0.22$ & $-0.259 \pm 0.275$ & 0.277 & 0.47 \\
\hline 136298 & $\delta$ Lup & 13.15 & 13.29 & 13.39 & JSS86 & $\cdots$ & $\cdots$ & $\cdots$ & $\cdots$ \\
\hline 138690 & $\gamma$ Lup & 12.85 & 13.23 & 13.41 & JSS86 & $\cdots$ & $\cdots$ & $\cdots$ & $\cdots$ \\
\hline 141637 & $1 \mathrm{Sco}$ & 13.85 & 14.13 & 14.30 & JSS86 & $0.69 \pm 0.05$ & $-0.415 \pm 0.068$ & 0.079 & 0.30 \\
\hline 143118 & $\eta \operatorname{Lup} \mathrm{A}$ & 12.99 & 13.16 & 13.27 & JSS86 & $\cdots$ & $\cdots$ & $\cdots$ & $\cdots$ \\
\hline 143275 & $\delta \mathrm{Sco}$ & 13.88 & 13.91 & 13.93 & JSS86 & $0.90 \pm 0.03$ & $-0.671 \pm 0.062$ & 0.083 & 0.76 \\
\hline 144217 & $\beta^{1}$ Sco & 13.81 & 13.85 & 13.89 & JSS86 & $0.81 \pm 0.02$ & $-0.567 \pm 0.044$ & -0.051 & -0.72 \\
\hline 144470 & $\mathrm{o}^{1} \mathrm{Sco}$ & 14.03 & 14.10 & 14.17 & JSS86 & $0.81 \pm 0.04$ & $-0.560 \pm 0.059$ & 0.097 & 0.80 \\
\hline 145502 & $\nu \mathrm{Sco}$ & 12.94 & 13.79 & 14.46 & JSS86 & $0.80 \pm 0.11$ & $-0.550 \pm 0.145$ & -0.119 & -0.15 \\
\hline 147165 & $\sigma \mathrm{Sco}$ & 14.19 & 14.28 & 14.38 & JSS86 & $0.76 \pm 0.06$ & $-0.508 \pm 0.082$ & 0.093 & 0.44 \\
\hline 147933 & $\rho \mathrm{Oph} \mathrm{A}$ & 13.86 & 14.08 & 14.51 & JSS86 & $1.09 \pm 0.08$ & $-0.915 \pm 0.123$ & -0.039 & -0.11 \\
\hline 148184 & $\chi \mathrm{Oph}$ & 13.44 & 13.77 & 13.96 & JSS86 & $0.96 \pm 0.09$ & $-0.747 \pm 0.128$ & -0.120 & -0.38 \\
\hline 148605 & $22 \mathrm{Sco}$ & 13.45 & 13.79 & 14.32 & JSS86 & $0.53 \pm 0.39$ & $-0.216 \pm 0.491$ & -0.012 & -0.02 \\
\hline 149038 & $\mu$ Nor & 14.69 & 15.51 & $\infty$ & JSS86 & $0.56 \pm 0.05$ & $-0.249 \pm 0.064$ & $\cdots$ & $\cdots$ \\
\hline 151804 & V973 Sco & 13.81 & 14.29 & 14.49 & JSS86 & $0.57 \pm 0.08$ & $-0.272 \pm 0.097$ & 0.035 & 0.10 \\
\hline 151890 & $\mu^{1}$ Sco & 12.95 & 13.18 & 13.30 & JSS86 & $-0.03 \pm 3.47$ & $0.478 \pm 4.315$ & -0.215 & -0.02 \\
\hline 155806 & V1075 Sco & 13.80 & 13.93 & 14.02 & JSS86 & $0.62 \pm 0.07$ & $-0.332 \pm 0.086$ & -0.206 & -1.12 \\
\hline 157246 & $\gamma$ Ara & 14.23 & 14.29 & 14.34 & JSS86 & $0.46 \pm 0.03$ & $-0.128 \pm 0.053$ & 0.380 & 3.34 \\
\hline 158926 & $\lambda \mathrm{Sco}$ & 12.90 & 13.00 & 13.09 & Y83 & $0.31 \pm 0.02$ & $0.055 \pm 0.051$ & 0.390 & 3.49 \\
\hline 160578 & $\kappa \mathrm{Sco}$ & 13.40 & 13.48 & 13.53 & JSS86 & $0.50 \pm 0.07$ & $-0.174 \pm 0.096$ & 0.099 & 0.51 \\
\hline 164284 & $66 \mathrm{Oph}$ & 13.01 & 13.34 & 13.52 & JSS86 & $0.89 \pm 0.18$ & $-0.663 \pm 0.227$ & -0.074 & -0.16 \\
\hline 165024 & $\theta$ Ara & 13.88 & 13.93 & 13.99 & JSS86 & $0.56 \pm 0.03$ & $-0.259 \pm 0.050$ & 0.017 & 0.15 \\
\hline 167264 & $15 \mathrm{Sgr}$ & $\cdots$ & $\cdots$ & 13.98 & JSS86 & $0.68 \pm 0.16$ & $-0.403 \pm 0.196$ & $\cdots$ & $\cdots$ \\
\hline 184915 & $\kappa \mathrm{Aql}$ & 13.42 & 13.89 & 14.47 & JSS86 & $0.88 \pm 0.05$ & $-0.647 \pm 0.075$ & 0.158 & 0.29 \\
\hline 188209 & HD 188209 & $\cdots$ & $\cdots$ & 13.83 & JSS86 & $0.66 \pm 0.12$ & $-0.383 \pm 0.154$ & $\cdots$ & $\cdots$ \\
\hline 193322 & HD 193322 & $\cdots$ & 14.04 & $\infty$ & JSS86 & $\cdots$ & $\cdots$ & $\cdots$ & $\cdots$ \\
\hline
\end{tabular}


Table 14-Continued

\begin{tabular}{|c|c|c|c|c|c|c|c|c|c|}
\hline \multirow[b]{2}{*}{$\begin{array}{l}\text { HD Number }{ }^{\mathrm{a}} \\
\text { (1) }\end{array}$} & \multirow[b]{2}{*}{$\begin{array}{l}\text { Name } \\
(2)\end{array}$} & \multicolumn{4}{|c|}{ Observed $\log N(\mathrm{Cl} \mathrm{II})$} & \multirow[b]{2}{*}{$\begin{array}{l}F_{*} \\
(7)\end{array}$} & \multirow[b]{2}{*}{$\begin{array}{c}{\left[\mathrm{Cl}_{\text {gas }} / \mathrm{H}\right]_{\mathrm{fit}}{ }^{\mathrm{c}}} \\
(8)\end{array}$} & \multirow[b]{2}{*}{$\begin{array}{l}\text { Residual }^{\mathrm{d}} \\
\quad(9)\end{array}$} & \multirow{2}{*}{$\begin{array}{l}\text { Deviation } \\
\quad \text { (in } \sigma) \\
(10)\end{array}$} \\
\hline & & $\begin{array}{l}1.1 . \\
(3)\end{array}$ & $\begin{array}{l}\text { best } \\
(4)\end{array}$ & $\begin{array}{l}\text { u.l. } \\
(5)\end{array}$ & $\begin{array}{c}\text { Source }^{b} \\
(6)\end{array}$ & & & & \\
\hline 200120 & $59 \mathrm{Cyg}$ & 11.52 & 13.26 & 13.84 & JSS86 & $\cdots$ & $\cdots$ & $\cdots$ & $\cdots$ \\
\hline 202904 & $v$ Cyg & 13.14 & 13.49 & 13.67 & JSS86 & $\cdots$ & $\cdots$ & $\cdots$ & $\cdots$ \\
\hline 203064 & $68 \mathrm{Cyg}$ & 13.71 & 14.03 & 14.53 & JSS86 & $0.68 \pm 0.20$ & $-0.404 \pm 0.255$ & -0.044 & -0.09 \\
\hline 209975 & 19 Cep & 13.93 & 14.29 & 15.13 & JSS86 & $0.57 \pm 0.26$ & $-0.270 \pm 0.327$ & 0.043 & 0.06 \\
\hline 214080 & HD 214080 & $\cdots$ & $\cdots$ & 13.99 & JSS86 & $0.27 \pm 0.10$ & $0.107 \pm 0.135$ & $\cdots$ & $\cdots$ \\
\hline 214680 & $10 \mathrm{Lac}$ & 13.36 & 13.55 & 13.65 & JSS86 & $0.50 \pm 0.06$ & $-0.174 \pm 0.084$ & -0.336 & -1.60 \\
\hline 214993 & $12 \mathrm{Lac}$ & 13.33 & 13.71 & 13.91 & JSS86 & $0.68 \pm 0.10$ & $-0.403 \pm 0.122$ & -0.042 & -0.12 \\
\hline 217675 & o And & $\cdots$ & 12.82 & 14.93 & JSS86 & $\ldots$ & $\ldots$ & $\ldots$ & $\ldots$ \\
\hline 218376 & 1 Cas & 13.47 & 13.90 & 14.36 & JSS86 & $0.60 \pm 0.06$ & $-0.305 \pm 0.080$ & -0.197 & -0.42 \\
\hline 219188 & HD 219188 & $\cdots$ & $\cdots$ & 15.01 & JSS86 & $1.24 \pm 0.57$ & $-1.097 \pm 0.716$ & $\cdots$ & $\cdots$ \\
\hline 224572 & $\sigma$ Cas & 12.96 & 13.37 & 13.56 & JSS86 & $0.76 \pm 0.07$ & $-0.501 \pm 0.094$ & -0.441 & -1.33 \\
\hline
\end{tabular}

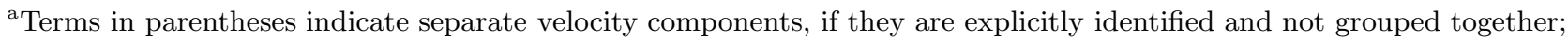
see 4.3

${ }^{\mathrm{b}}$ Codes in this column are linked to references listed in Table 1

${ }^{\mathrm{c}}$ The expected depletion $\left[\mathrm{Cl}_{\text {gas }} / \mathrm{H}\right]$ computed using Eq. 10 The listed errors do not include an overall systematic uncertainty of 0.06 in the solar abundance $\sigma(\mathrm{Cl} / \mathrm{H})_{\odot}$ in order to show just the formal error that arises from the uncertainties in location of line of best fit and the value of $F_{*}$.

${ }^{\mathrm{d}}$ The observed $\left[\mathrm{Cl}_{\text {gas }} / \mathrm{H}\right]$ minus that computed using Eq. 10

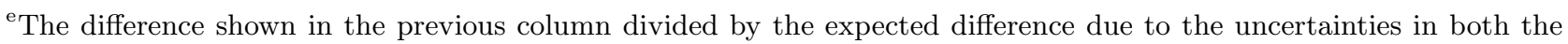
measured column density and the coefficients that appear in Eq. 10. 
Table 15. Observations and Fits for Titanium

\begin{tabular}{|c|c|c|c|c|c|c|c|c|c|}
\hline \multirow[b]{2}{*}{$\begin{array}{c}\text { HD Number } \\
\text { (1) }\end{array}$} & \multirow[b]{2}{*}{$\begin{array}{l}\text { Name } \\
(2)\end{array}$} & \multicolumn{4}{|c|}{ Observed $\log N(\mathrm{Ti}$ II $)$} & \multirow[b]{2}{*}{$\begin{array}{l}F_{*} \\
(7)\end{array}$} & \multirow[b]{2}{*}{$\begin{array}{c}{\left[\mathrm{Ti}_{\text {gas }} / \mathrm{H}\right]_{\mathrm{fit}}{ }^{\mathrm{c}}} \\
(8)\end{array}$} & \multirow[b]{2}{*}{$\begin{array}{l}\text { Residual }^{\mathrm{d}} \\
(9)\end{array}$} & \multirow{2}{*}{$\begin{array}{l}\text { Deviation } \\
\quad \text { (in } \sigma) \\
(10)\end{array}$} \\
\hline & & $\begin{array}{l}1.1 . \\
(3)\end{array}$ & $\begin{array}{l}\text { best } \\
(4)\end{array}$ & $\begin{array}{l}\text { u.l. } \\
(5)\end{array}$ & $\begin{array}{c}\text { Source }^{b} \\
(6)\end{array}$ & & & & \\
\hline 2905 & $\kappa$ Cas & 12.03 & 12.09 & 12.15 & S78 & $0.58 \pm 0.06$ & $-2.266 \pm 0.120$ & 0.069 & 0.39 \\
\hline 5394 & $\gamma$ Cas & 11.01 & 11.09 & 11.17 & $\mathrm{~S} 78$ & $0.52 \pm 0.04$ & $-2.133 \pm 0.087$ & 0.067 & 0.45 \\
\hline 18100 & HD 18100 & $\cdots$ & $\ldots$ & 10.93 & $\mathrm{~A}++93$ & $0.14 \pm 0.04$ & $-1.356 \pm 0.094$ & $\ldots$ & $\ldots$ \\
\hline 22586 & HD 22586 & 11.38 & 11.58 & 11.78 & JW96* & $0.34 \pm 0.07$ & $-1.773 \pm 0.136$ & -0.006 & -0.02 \\
\hline 22928 & $\delta$ Per & 10.45 & 10.62 & 10.89 & S78 & $\cdots$ & $\cdots$ & $\cdots$ & $\cdots$ \\
\hline 22951 & 40 Per & 11.70 & 11.77 & 11.84 & $\mathrm{~S} 78$ & $0.73 \pm 0.05$ & $-2.575 \pm 0.107$ & 0.126 & 0.75 \\
\hline 23180 & o Per & 11.30 & 11.43 & 11.56 & S78 & $0.84 \pm 0.06$ & $-2.804 \pm 0.136$ & 0.045 & 0.21 \\
\hline 23630 & $\eta \mathrm{Tau}$ & 10.69 & 10.84 & 10.99 & $\mathrm{~S} 78$ & $\cdots$ & & $\cdots$ & $\cdots$ \\
\hline 24398 & $\zeta$ Per & 11.15 & 11.24 & 11.33 & $\mathrm{~S} 78$ & $0.88 \pm 0.05$ & $-2.888 \pm 0.108$ & -0.065 & -0.36 \\
\hline 24760 & $\epsilon$ Per & 11.04 & 11.11 & 11.18 & $\mathrm{~S} 78$ & $0.68 \pm 0.04$ & $-2.469 \pm 0.082$ & 0.081 & 0.57 \\
\hline 24912 & $\xi$ Per & 11.52 & 11.57 & 11.62 & S78 & $0.83 \pm 0.02$ & $-2.780 \pm 0.058$ & 0.060 & 0.56 \\
\hline 30614 & $\alpha \mathrm{Cam}$ & 12.13 & 12.19 & 12.25 & S78 & $0.46 \pm 0.04$ & $-2.012 \pm 0.086$ & 0.115 & 0.89 \\
\hline 34816 & $\lambda$ Lep & 11.13 & 11.18 & 11.23 & $\mathrm{~W}++97$ & $0.45 \pm 0.05$ & $-2.007 \pm 0.107$ & 0.004 & 0.03 \\
\hline 35149 & 23 Ori & 11.18 & 11.21 & 11.24 & $\mathrm{~W}++99$ & $0.54 \pm 0.04$ & $-2.181 \pm 0.079$ & -0.244 & -1.53 \\
\hline 36486 & $\delta$ Ori A & 11.11 & 11.15 & 11.19 & PTH05 & $0.54 \pm 0.02$ & $-2.184 \pm 0.044$ & 0.144 & 2.01 \\
\hline 36861 & $\lambda$ Ori A & 11.63 & 11.68 & 11.73 & $\mathrm{~S} 78$ & $0.57 \pm 0.04$ & $-2.236 \pm 0.084$ & 0.121 & 0.82 \\
\hline 37043 & $\iota$ Ori & 11.28 & 11.31 & 11.34 & PTH05 & $0.41 \pm 0.03$ & $-1.916 \pm 0.057$ & 0.076 & 0.83 \\
\hline 37128 & $\epsilon$ Ori & 11.37 & 11.40 & 11.43 & РTH05 & $0.54 \pm 0.03$ & $-2.183 \pm 0.062$ & 0.133 & 1.17 \\
\hline 37468 & $\sigma$ Ori & 11.01 & 11.10 & 11.19 & $\mathrm{~S} 78$ & $0.58 \pm 0.04$ & $-2.271 \pm 0.087$ & -0.145 & -0.94 \\
\hline 37742 & $\zeta$ Ori A & 11.12 & 11.18 & 11.24 & $\mathrm{~S} 78$ & $0.57 \pm 0.05$ & $-2.235 \pm 0.109$ & 0.009 & 0.06 \\
\hline 38666 & $\mu \mathrm{Col}$ & 11.48 & 11.50 & 11.52 & LHW08 & $0.11 \pm 0.01$ & $-1.304 \pm 0.029$ & -0.056 & -1.36 \\
\hline 38771 & $\kappa$ Ori & 10.96 & 11.06 & 11.16 & S78 & $0.67 \pm 0.03$ & $-2.442 \pm 0.059$ & -0.014 & -0.11 \\
\hline 40111 & 139 Таu & 11.95 & 12.02 & 12.09 & $\mathrm{~S} 78$ & $0.49 \pm 0.04$ & $-2.079 \pm 0.077$ & 0.148 & 1.14 \\
\hline 41161 & HD 41161 & 12.09 & 12.13 & 12.17 & EPL07 & $0.44 \pm 0.04$ & $-1.977 \pm 0.084$ & 0.031 & 0.25 \\
\hline 42933 & $\delta \mathrm{Pic}$ & 11.44 & 11.50 & 11.56 & $\mathrm{~W}++97$ & $0.32 \pm 0.06$ & $-1.731 \pm 0.121$ & -0.002 & -0.01 \\
\hline 44743 & $\beta \mathrm{CMa}$ & $\cdots$ & $\cdots$ & 10.50 & $\mathrm{~W}++97$ & $-0.43 \pm 0.03$ & $-0.188 \pm 0.088$ & $\ldots$ & $\cdots$ \\
\hline 47839 & 15 Mon & 11.73 & 11.82 & 11.91 & $\mathrm{~S} 78$ & $0.25 \pm 0.05$ & $-1.586 \pm 0.097$ & 0.100 & 0.60 \\
\hline 52089 & $\epsilon \mathrm{CMa}$ & $\cdots$ & $\cdots$ & 10.36 & $\mathrm{~W}++97$ & $\cdots$ & $\cdots$ & $\cdots$ & $\ldots$ \\
\hline 53138 & $\mathrm{o}^{2} \mathrm{Cma}$ & 11.44 & 11.50 & 11.56 & $\mathrm{~W}++97$ & $0.10 \pm 0.53$ & $-1.277 \pm 1.090$ & -0.011 & -0.01 \\
\hline 53975 & HD 53975 & 12.24 & 12.28 & 12.32 & EPL07 & $0.45 \pm 0.03$ & $-1.997 \pm 0.061$ & 0.137 & 1.46 \\
\hline 57060 & $29 \mathrm{CMa}$ & 11.34 & 11.45 & 11.56 & $\mathrm{~S} 78$ & $0.50 \pm 0.05$ & $-2.103 \pm 0.098$ & -0.143 & -0.83 \\
\hline 66811 & $\zeta$ Pup & 11.03 & 11.07 & 11.11 & EPL07 & $0.32 \pm 0.02$ & $-1.737 \pm 0.042$ & -0.153 & -2.17 \\
\hline 68273 & $\gamma^{2} \mathrm{Vel}$ & 11.08 & 11.10 & 11.12 & EPL07 & $0.25 \pm 0.02$ & $-1.591 \pm 0.045$ & -0.019 & -0.31 \\
\hline $72089(+5)$ & HD 72089 & 11.32 & 11.42 & 11.52 & WG92 & $\cdots$ & & $\cdots$ & $\cdots$ \\
\hline 72127 & HD 72127 & 11.43 & 11.53 & 11.63 & WG92 & $\cdots$ & $\cdots$ & $\cdots$ & $\cdots$ \\
\hline 74575 & $\alpha \mathrm{Pyx}$ & 11.65 & 11.72 & 11.79 & $\mathrm{~W}++97$ & $0.33 \pm 0.09$ & $-1.746 \pm 0.178$ & -0.001 & -0.01 \\
\hline 91316 & $\rho$ Leo & 11.84 & 11.88 & 11.92 & $\mathrm{~S} 78$ & $0.15 \pm 0.04$ & $-1.390 \pm 0.083$ & 0.026 & 0.20 \\
\hline 93030 & $\theta$ Car & 11.30 & 11.31 & 11.32 & EPL07 & $0.45 \pm 0.03$ & $-1.988 \pm 0.067$ & 0.038 & 0.37 \\
\hline 93205 & V560 Car & 12.51 & 12.61 & 12.71 & WG92 & $0.40 \pm 0.03$ & $-1.893 \pm 0.058$ & 0.106 & 0.87 \\
\hline
\end{tabular}


Table 15-Continued

\begin{tabular}{|c|c|c|c|c|c|c|c|c|c|}
\hline \multirow[b]{2}{*}{$\begin{array}{c}\text { HD Number }{ }^{\mathrm{a}} \\
\text { (1) }\end{array}$} & \multirow[b]{2}{*}{$\begin{array}{l}\text { Name } \\
(2)\end{array}$} & \multicolumn{4}{|c|}{ Observed $\log N(\mathrm{Ti}$ II $)$} & \multirow[b]{2}{*}{$\begin{array}{l}F_{*} \\
(7)\end{array}$} & \multirow[b]{2}{*}{$\begin{array}{c}{\left[\mathrm{Ti}_{\text {gas }} / \mathrm{H}\right]_{\mathrm{fit}}{ }^{\mathrm{c}}} \\
(8)\end{array}$} & \multirow[b]{2}{*}{$\begin{array}{l}\text { Residual }^{\mathrm{d}} \\
\quad(9)\end{array}$} & \multirow{2}{*}{$\begin{array}{l}\text { Deviation }^{\mathrm{e}} \\
\quad \text { (in } \sigma) \\
\quad(10)\end{array}$} \\
\hline & & $\begin{array}{l}1.1 . \\
(3)\end{array}$ & $\begin{array}{c}\text { best } \\
(4)\end{array}$ & $\begin{array}{l}\text { u.l. } \\
(5)\end{array}$ & $\begin{array}{c}\text { Source }^{b} \\
(6)\end{array}$ & & & & \\
\hline $93521(-66)$ & HD 93521 & 10.98 & 11.08 & 11.18 & SF93 & $-0.31 \pm 0.11$ & $-0.440 \pm 0.226$ & 0.008 & 0.02 \\
\hline$(-58)$ & & 11.40 & 11.42 & 11.48 & SF93 & $-0.01 \pm 0.03$ & $-1.065 \pm 0.072$ & 0.143 & 1.24 \\
\hline$(-51)$ & & 11.04 & 11.17 & 11.30 & SF93 & $-0.04 \pm 0.04$ & $-1.001 \pm 0.095$ & -0.031 & -0.16 \\
\hline$(-39)$ & & 10.34 & 10.68 & 11.02 & SF93 & $0.01 \pm 0.08$ & $-1.088 \pm 0.172$ & -0.114 & -0.26 \\
\hline$(-18)$ & & 11.28 & 11.36 & 11.44 & SF93 & $0.00 \pm 0.03$ & $-1.082 \pm 0.067$ & 0.160 & 1.28 \\
\hline$(-10)$ & & 11.12 & 11.30 & 11.38 & SF93 & $0.02 \pm 0.04$ & $-1.119 \pm 0.086$ & 0.057 & 0.34 \\
\hline$(+3)$ & & 10.68 & 10.85 & 11.02 & SF93 & $0.25 \pm 0.04$ & $-1.593 \pm 0.078$ & 0.141 & 0.69 \\
\hline (total) & & 11.93 & 12.03 & 12.14 & SF93 & $0.06 \pm 0.04$ & $-1.196 \pm 0.078$ & 0.127 & 0.85 \\
\hline 116658 & $\alpha \mathrm{Vir}$ & 10.36 & 10.49 & 10.62 & LHW08 & $0.16 \pm 0.05$ & $-1.409 \pm 0.103$ & -0.101 & -0.52 \\
\hline 119608 & HD 119608 & 12.30 & 12.34 & 12.38 & $\mathrm{~A}++93$ & $\cdots$ & $\cdots$ & $\cdots$ & $\cdots$ \\
\hline 120086 & HD 120086 & 11.68 & 11.88 & 12.08 & JW96 & $\cdots$ & $\cdots$ & $\cdots$ & $\cdots$ \\
\hline 121968 & HD 121968 & 12.03 & 12.06 & 12.09 & LP95 & $0.26 \pm 0.06$ & $-1.605 \pm 0.127$ & 0.067 & 0.37 \\
\hline 122451 & $\beta$ Cen & 11.01 & 11.05 & 11.09 & EPL07 & $0.23 \pm 0.03$ & $-1.554 \pm 0.061$ & 0.064 & 0.72 \\
\hline 125924 & HD 125924 & 12.08 & 12.13 & 12.18 & LP95 & $0.20 \pm 0.08$ & $-1.493 \pm 0.171$ & -0.007 & -0.03 \\
\hline 143018 & $\pi \mathrm{Sco}$ & 10.75 & 10.85 & 10.95 & $\mathrm{~S} 78$ & $0.71 \pm 0.03$ & $-2.522 \pm 0.072$ & -0.316 & -2.30 \\
\hline 143275 & $\delta \mathrm{Sco}$ & 10.90 & 10.97 & 11.04 & $\mathrm{~S} 78$ & $0.90 \pm 0.03$ & $-2.912 \pm 0.078$ & -0.280 & -2.06 \\
\hline 144217 & $\beta^{1}$ Sco & 11.11 & 11.18 & 11.25 & S78 & $0.81 \pm 0.02$ & $-2.739 \pm 0.051$ & -0.212 & -2.26 \\
\hline 144470 & $\mathrm{o}^{1} \mathrm{Sco}$ & 11.29 & 11.39 & 11.49 & $\mathrm{~S} 78$ & $0.81 \pm 0.04$ & $-2.728 \pm 0.083$ & -0.108 & -0.71 \\
\hline 145502 & $\nu \mathrm{Sco}$ & 11.29 & 11.41 & 11.53 & $\mathrm{~S} 78$ & $0.80 \pm 0.11$ & $-2.712 \pm 0.234$ & -0.001 & -0.00 \\
\hline 147165 & $\sigma \mathrm{Sco}$ & 11.39 & 11.47 & 11.55 & S78 & $0.76 \pm 0.06$ & $-2.643 \pm 0.127$ & -0.245 & -1.07 \\
\hline 149038 & $\mu$ Nor & 11.94 & 11.99 & 12.04 & $\mathrm{~W}++97$ & $0.56 \pm 0.05$ & $-2.216 \pm 0.098$ & 0.008 & 0.06 \\
\hline $149757(-27)$ & $\zeta \mathrm{Oph}$ & 11.23 & 11.28 & 11.33 & $\mathrm{~W}++97$ & $\cdots$ & $\cdots$ & $\cdots$ & $\cdots$ \\
\hline$(-15)$ & & 10.92 & 11.02 & 11.12 & $\mathrm{~W}++97$ & $1.05 \pm 0.02$ & $-3.218 \pm 0.057$ & 0.083 & 0.66 \\
\hline 149881 & V600 Her & 12.40 & 12.48 & 12.54 & $\mathrm{~A}++03$ & $0.07 \pm 0.06$ & $-1.212 \pm 0.131$ & 0.040 & 0.17 \\
\hline 152236 & $\zeta^{1} \mathrm{Sco}$ & 12.17 & 12.24 & 12.31 & $\mathrm{~W}++97$ & $0.80 \pm 0.06$ & $-2.723 \pm 0.120$ & 0.117 & 0.66 \\
\hline 154368 & V1074 Sco & 11.85 & 12.15 & 12.45 & $\mathrm{~S}++96$ & $0.52 \pm 0.07$ & $-2.133 \pm 0.136$ & -0.302 & -0.90 \\
\hline 157246 & $\gamma$ Ara & 11.49 & 11.54 & 11.59 & $\mathrm{~W}++97$ & $0.46 \pm 0.03$ & $-2.017 \pm 0.071$ & -0.152 & -1.24 \\
\hline 158243 & V861 Ara & 12.45 & 12.47 & 12.49 & LP95 & $\cdots$ & $\cdots$ & $\cdots$ & $\cdots$ \\
\hline 158408 & $v \mathrm{Sco}$ & $\cdots$ & $\cdots$ & 10.74 & $\mathrm{~S} 78$ & $\cdots$ & $\cdots$ & $\cdots$ & $\cdots$ \\
\hline 158926 & $\lambda \mathrm{Sco}$ & $\cdots$ & $\cdots$ & 10.74 & $\mathrm{~S} 78$ & $0.31 \pm 0.02$ & $-1.715 \pm 0.040$ & $\cdots$ & $\cdots$ \\
\hline 163522 & HD 163522 & 12.74 & 12.76 & 12.78 & LP95 & $\cdots$ & $\cdots$ & $\cdots$ & $\cdots$ \\
\hline 164794 & $9 \mathrm{Sgr}$ & 11.76 & 11.83 & 11.90 & $\mathrm{~W}++97$ & $\cdots$ & $\ldots$ & $\ldots$ & $\ldots$ \\
\hline 165024 & $\theta$ Ara & 11.58 & 11.63 & 11.68 & $\mathrm{~W}++97$ & $0.56 \pm 0.03$ & $-2.232 \pm 0.073$ & 0.019 & 0.15 \\
\hline 179406 & $20 \mathrm{Aql}$ & 12.83 & 12.93 & 13.03 & $\mathrm{~W}++97$ & $\cdots$ & $\cdots$ & $\cdots$ & $\cdots$ \\
\hline 179407 & HD 179407 & 12.39 & 12.41 & 12.44 & LP95 & $0.35 \pm 0.05$ & $-1.799 \pm 0.096$ & -0.000 & -0.00 \\
\hline 184915 & $\kappa \mathrm{Aql}$ & 11.11 & 11.18 & 11.25 & $\mathrm{~W}++97$ & $0.88 \pm 0.05$ & $-2.873 \pm 0.107$ & 0.002 & 0.01 \\
\hline 191877 & HD 191877 & 12.22 & 12.24 & 12.26 & PTH05 & $0.39 \pm 0.04$ & $-1.883 \pm 0.091$ & 0.001 & 0.01 \\
\hline 195455 & HD 195455 & 12.14 & 12.16 & 12.19 & LP95 & $\cdots$ & $\cdots$ & $\cdots$ & $\cdots$ \\
\hline 195965 & HD 195965 & 12.00 & 12.02 & 12.04 & РTH05 & $0.52 \pm 0.02$ & $-2.136 \pm 0.036$ & 0.022 & 0.47 \\
\hline
\end{tabular}


Table 15-Continued

\begin{tabular}{|c|c|c|c|c|c|c|c|c|c|}
\hline \multirow[b]{2}{*}{$\begin{array}{l}\text { HD Number }{ }^{\mathrm{a}} \\
\text { (1) }\end{array}$} & \multirow[b]{2}{*}{$\begin{array}{l}\text { Name } \\
(2)\end{array}$} & \multicolumn{4}{|c|}{ Observed $\log N(\mathrm{Ti} \mathrm{II})$} & \multirow[b]{2}{*}{$\begin{array}{l}F_{*} \\
(7)\end{array}$} & \multirow[b]{2}{*}{$\begin{array}{c}{\left[\mathrm{Ti}_{\text {gas }} / \mathrm{H}\right]_{\mathrm{fit}}{ }^{\mathrm{c}}} \\
(8)\end{array}$} & \multirow[b]{2}{*}{$\begin{array}{l}\text { Residual }^{\mathrm{d}} \\
\quad(9)\end{array}$} & \multirow{2}{*}{$\begin{array}{l}\text { Deviation } \\
\quad \text { (in } \sigma) \\
\quad(10)\end{array}$} \\
\hline & & $\begin{array}{l}1.1 . \\
(3)\end{array}$ & $\begin{array}{l}\text { best } \\
(4)\end{array}$ & $\begin{array}{l}\text { u.l. } \\
(5)\end{array}$ & $\begin{array}{c}\text { Source }^{b} \\
(6)\end{array}$ & & & & \\
\hline 200120 & 59 Cyg & 11.41 & 11.52 & 11.63 & $\mathrm{~S} 78$ & $\cdots$ & $\cdots$ & $\cdots$ & $\cdots$ \\
\hline 202904 & $v$ Cyg & 11.26 & 11.35 & 11.44 & $\mathrm{~S} 78$ & $\cdots$ & $\cdots$ & $\cdots$ & $\cdots$ \\
\hline 206144 & HD 206144 & 12.16 & 12.20 & 12.23 & LP95 & $\ldots$ & $\cdots$ & $\cdots$ & $\ldots$ \\
\hline 206773 & HD 206773 & 12.14 & 12.16 & 12.18 & EPL07 & $0.53 \pm 0.02$ & $-2.172 \pm 0.045$ & 0.081 & 1.13 \\
\hline 210839 & $\lambda$ Cep & 12.08 & 12.14 & 12.20 & $\mathrm{~S} 78$ & $0.66 \pm 0.03$ & $-2.423 \pm 0.071$ & 0.120 & 1.07 \\
\hline 214080 & HD 214080 & 11.96 & 12.04 & 12.10 & $\mathrm{~A}++93$ & $0.27 \pm 0.10$ & $-1.628 \pm 0.208$ & 0.052 & 0.17 \\
\hline 214680 & $10 \mathrm{Lac}$ & 11.68 & 11.74 & 11.80 & $\mathrm{~S} 78$ & $0.50 \pm 0.06$ & $-2.092 \pm 0.131$ & 0.109 & 0.57 \\
\hline 217675 & o And & 11.06 & 11.14 & 11.22 & $\mathrm{~S} 78$ & $\cdots$ & $\cdots$ & $\cdots$ & $\cdots$ \\
\hline 218376 & 1 Cas & 11.76 & 11.83 & 11.90 & $\mathrm{~S} 78$ & $0.60 \pm 0.06$ & $-2.308 \pm 0.126$ & 0.072 & 0.40 \\
\hline 303308 & HDE 303308 & 12.63 & 12.73 & 12.83 & WG92 & $0.38 \pm 0.04$ & $-1.861 \pm 0.080$ & 0.116 & 0.81 \\
\hline
\end{tabular}

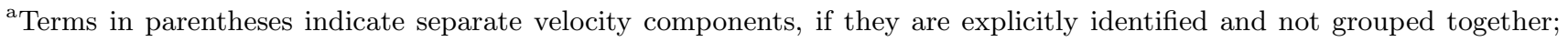
see 4.3

${ }^{\mathrm{b}}$ Codes in this column are linked to references listed in Table 1

${ }^{\mathrm{c}}$ The expected depletion $\left[\mathrm{Ti}_{\text {gas }} / \mathrm{H}\right]$ computed using Eq. 10, The listed errors do not include an overall systematic uncertainty of 0.03 in the solar abundance $\sigma(\mathrm{Ti} / \mathrm{H}) \odot$ in order to show just the formal error that arises from the uncertainties in location of line of best fit and the value of $F_{*}$.

${ }^{\mathrm{d}}$ The observed $\left[\mathrm{Ti}_{\text {gas }} / \mathrm{H}\right]$ minus that computed using Eq. 10

${ }^{\text {e}}$ The difference shown in the previous column divided by the expected difference due to the uncertainties in both the measured column density and the coefficients that appear in Eq. 10. 
Table 16. Observations and Fits for Chromium

\begin{tabular}{|c|c|c|c|c|c|c|c|c|c|}
\hline \multirow[b]{2}{*}{$\begin{array}{c}\text { HD Number } \\
\text { (1) }\end{array}$} & \multirow[b]{2}{*}{$\begin{array}{l}\text { Name } \\
(2)\end{array}$} & \multicolumn{4}{|c|}{ Observed $\log N(\mathrm{Cr}$ II $)$} & \multirow[b]{2}{*}{$\begin{array}{l}F_{*} \\
(7)\end{array}$} & \multirow[b]{2}{*}{$\begin{array}{c}{\left[\mathrm{Cr}_{\text {gas }} / \mathrm{H}\right]_{\mathrm{fit}}{ }^{\mathrm{c}}} \\
(8)\end{array}$} & \multirow[b]{2}{*}{$\begin{array}{l}\text { Residual }^{\mathrm{d}} \\
(9)\end{array}$} & \multirow{2}{*}{$\begin{array}{l}\text { Deviation }^{\mathrm{e}} \\
\quad \text { (in } \sigma) \\
\quad(10)\end{array}$} \\
\hline & & $\begin{array}{l}1.1 . \\
(3)\end{array}$ & $\begin{array}{c}\text { best } \\
(4)\end{array}$ & $\begin{array}{l}\text { u.l. } \\
(5)\end{array}$ & $\begin{array}{c}\text { Source }^{b} \\
(6)\end{array}$ & & & & \\
\hline 18100 & HD 18100 & 12.87 & 12.91 & 12.95 & SS96b & $0.14 \pm 0.04$ & $-1.024 \pm 0.071$ & 0.061 & 0.39 \\
\hline 23630 & $\eta$ Tau & 11.81 & 11.86 & 11.91 & RB95 & $\cdots$ & $\cdots$ & $\cdots$ & $\cdots$ \\
\hline 24912 & $\xi$ Per & 12.88 & 12.90 & 12.91 & $\mathrm{C}++91$ & $0.83 \pm 0.02$ & $-2.030 \pm 0.047$ & -0.080 & -0.88 \\
\hline 35149 & 23 Ori & 12.73 & 12.74 & 12.75 & $\mathrm{~W}++99$ & $0.54 \pm 0.04$ & $-1.607 \pm 0.059$ & -0.004 & -0.02 \\
\hline 36486 & $\delta$ Ori A & 12.04 & 12.09 & 12.14 & RB95 & $0.54 \pm 0.02$ & $-1.609 \pm 0.036$ & -0.213 & -2.89 \\
\hline 37128 & $\epsilon$ Ori & 12.40 & 12.45 & 12.50 & RB95 & $0.54 \pm 0.03$ & $-1.609 \pm 0.048$ & -0.113 & -1.00 \\
\hline 38666 & $\mu \mathrm{Col}$ & 12.60 & 12.63 & 12.66 & HSF99 & $0.11 \pm 0.01$ & $-0.988 \pm 0.034$ & 0.036 & 0.73 \\
\hline 47839 & 15 Mon & 12.81 & 12.86 & 12.91 & RB95 & $0.25 \pm 0.05$ & $-1.187 \pm 0.072$ & 0.015 & 0.11 \\
\hline 57061 & $\tau \mathrm{CMa}$ & 11.87 & 12.92 & 12.97 & RB95 & $0.39 \pm 0.04$ & $-1.386 \pm 0.066$ & -0.116 & -0.21 \\
\hline 66811 & $\zeta$ Pup & 12.04 & 12.24 & 12.44 & M78 & $0.32 \pm 0.02$ & $-1.294 \pm 0.036$ & -0.149 & -0.72 \\
\hline 72127 & HD 72127 & 12.42 & 12.47 & 12.52 & RB95 & $\cdots$ & $\cdots$ & $\cdots$ & $\cdots$ \\
\hline 91316 & $\rho$ Leo & 12.82 & 12.87 & 12.92 & RB95 & $0.15 \pm 0.04$ & $-1.048 \pm 0.064$ & -0.052 & -0.43 \\
\hline 116658 & $\alpha \mathrm{Vir}$ & $\cdots$ & $\cdots$ & 12.32 & YK79 & $0.16 \pm 0.05$ & $-1.062 \pm 0.077$ & $\cdots$ & $\cdots$ \\
\hline 141637 & $1 \mathrm{Sco}$ & 13.00 & 13.05 & 13.10 & RB95 & $0.69 \pm 0.05$ & $-1.825 \pm 0.078$ & 0.019 & 0.13 \\
\hline 143018 & $\pi \mathrm{Sco}$ & 12.59 & 12.64 & 12.69 & RB95 & $0.71 \pm 0.03$ & $-1.848 \pm 0.055$ & 0.074 & 0.77 \\
\hline 144217 & $\beta^{1} \mathrm{Sco}$ & 12.93 & 12.98 & 13.03 & RB95 & $0.81 \pm 0.02$ & $-2.002 \pm 0.043$ & 0.125 & 1.65 \\
\hline 147165 & $\sigma \mathrm{Sco}$ & 13.45 & 13.50 & 13.55 & RB95 & $0.76 \pm 0.06$ & $-1.934 \pm 0.093$ & 0.349 & 1.71 \\
\hline $149757(-27)$ & $\zeta \mathrm{Oph}$ & 12.32 & 12.36 & 12.40 & SCS92 & $\cdots$ & $\cdots$ & $\cdots$ & $\cdots$ \\
\hline$(-15)$ & & 12.50 & 12.53 & 12.56 & SCS92 & $1.05 \pm 0.02$ & $-2.340 \pm 0.051$ & 0.001 & 0.01 \\
\hline 149881 & V600 Her & 13.39 & 13.44 & 13.49 & RB95 & $0.07 \pm 0.06$ & $-0.922 \pm 0.097$ & -0.010 & -0.04 \\
\hline 158926 & $\lambda$ Sco & 11.71 & 11.76 & 11.81 & RB95 & $0.31 \pm 0.02$ & $-1.278 \pm 0.035$ & 0.086 & 1.26 \\
\hline 167756 & HD 167756 & 13.26 & 13.29 & 13.32 & CSS95 & $\cdots$ & $\cdots$ & $\cdots$ & $\cdots$ \\
\hline 212571 & $\pi \mathrm{Aqr}$ & 12.74 & 12.79 & 12.84 & RB95 & $\cdots$ & $\cdots$ & $\cdots$ & $\cdots$ \\
\hline $215733(-59)$ & HD 215733 & 12.11 & 12.18 & 12.25 & FS97 & $-0.11 \pm 0.10$ & $-0.667 \pm 0.148$ & 0.177 & 0.56 \\
\hline$(-54)$ & & 12.04 & 12.12 & 12.20 & FS97 & $0.54 \pm 0.15$ & $-1.614 \pm 0.219$ & 0.384 & 0.81 \\
\hline$(-47)$ & & 12.22 & 12.31 & 12.40 & FS97 & $\cdots$ & $\cdots$ & $\cdots$ & $\cdots$ \\
\hline$(-42)$ & & 11.71 & 11.93 & 12.15 & FS97 & $-0.16 \pm 0.31$ & $-0.591 \pm 0.454$ & 0.271 & 0.27 \\
\hline$(-40)$ & & 11.69 & 11.89 & 12.09 & FS97 & $0.18 \pm 0.24$ & $-1.089 \pm 0.354$ & 0.449 & 0.62 \\
\hline$(-32)$ & & 11.81 & 12.10 & 12.39 & FS97 & $0.25 \pm 0.09$ & $-1.184 \pm 0.132$ & -0.076 & -0.22 \\
\hline$(-31)$ & & 12.09 & 12.23 & 12.37 & FS97 & $\cdots$ & $\cdots$ & $\cdots$ & $\cdots$ \\
\hline$(-28)$ & & 11.84 & 12.05 & 12.26 & FS97 & $-0.18 \pm 0.07$ & $-0.561 \pm 0.106$ & -0.019 & -0.07 \\
\hline$(-26)$ & & 12.21 & 12.33 & 12.45 & FS97 & $-0.12 \pm 0.07$ & $-0.650 \pm 0.105$ & 0.150 & 0.75 \\
\hline$(-23)$ & & 11.76 & 11.99 & 12.22 & FS97 & $0.24 \pm 0.08$ & $-1.179 \pm 0.120$ & 0.199 & 0.75 \\
\hline$(-21)$ & & 11.62 & 11.87 & 12.12 & FS97 & $0.24 \pm 0.05$ & $-1.170 \pm 0.079$ & -0.050 & -0.18 \\
\hline$(-19)$ & & 11.39 & 11.69 & 11.99 & FS97 & $\cdots$ & $\cdots$ & $\cdots$ & $\cdots$ \\
\hline$(-16)$ & & 9.08 & 10.48 & 11.88 & FS97 & $0.93 \pm 0.05$ & $-2.169 \pm 0.083$ & -1.181 & -0.84 \\
\hline$(-11)$ & & 11.91 & 12.18 & 12.45 & FS97 & $-0.01 \pm 0.07$ & $-0.817 \pm 0.110$ & -0.323 & -1.09 \\
\hline$(-9)$ & & 12.67 & 12.79 & 12.91 & FS97 & $0.08 \pm 0.04$ & $-0.942 \pm 0.061$ & -0.058 & -0.37 \\
\hline$(-5)$ & & 11.03 & 11.55 & 12.07 & FS97 & $0.77 \pm 0.18$ & $-1.944 \pm 0.261$ & 0.194 & 0.33 \\
\hline
\end{tabular}


Table 16-Continued

\begin{tabular}{|c|c|c|c|c|c|c|c|c|c|}
\hline \multirow[b]{2}{*}{$\begin{array}{c}\text { HD Number }{ }^{\mathrm{a}} \\
\text { (1) }\end{array}$} & \multirow[b]{2}{*}{$\begin{array}{l}\text { Name } \\
(2)\end{array}$} & \multicolumn{4}{|c|}{ Observed $\log N(\mathrm{Cr}$ II $)$} & \multirow[b]{2}{*}{$\begin{array}{l}F_{*} \\
(7)\end{array}$} & \multirow[b]{2}{*}{$\begin{array}{c}{\left[\mathrm{Cr}_{\text {gas }} / \mathrm{H}\right]_{\mathrm{fit}}{ }^{\mathrm{c}}} \\
(8)\end{array}$} & \multirow[b]{2}{*}{$\begin{array}{c}\text { Residual }^{\mathrm{d}} \\
(9)\end{array}$} & \multirow{2}{*}{$\begin{array}{l}\text { Deviation }^{\mathrm{e}} \\
\quad \text { (in } \sigma) \\
\quad(10)\end{array}$} \\
\hline & & $\begin{array}{l}1.1 . \\
(3)\end{array}$ & $\begin{array}{c}\text { best } \\
(4)\end{array}$ & $\begin{array}{l}\text { u.l. } \\
(5)\end{array}$ & $\begin{array}{c}\text { Source }^{b} \\
(6)\end{array}$ & & & & \\
\hline$(+1)$ & & 11.35 & 11.67 & 11.99 & FS97 & $0.90 \pm 0.05$ & $-2.136 \pm 0.084$ & 0.376 & 1.12 \\
\hline (total) & & 13.21 & 13.37 & 13.55 & FS97 & $\ldots$ & $\ldots$ & $\ldots$ & $\ldots$ \\
\hline
\end{tabular}

${ }^{a}$ Terms in parentheses indicate separate velocity components, if they are explicitly identified and not grouped together; see 4.3

${ }^{\mathrm{b}}$ Codes in this column are linked to references listed in Table 1

${ }^{\mathrm{c}}$ The expected depletion $\left[\mathrm{Cr}_{\text {gas }} / \mathrm{H}\right]$ computed using Eq. 10, The listed errors do not include an overall systematic uncertainty of 0.05 in the solar abundance $\sigma(\mathrm{Cr} / \mathrm{H})_{\odot}$ in order to show just the formal error that arises from the uncertainties in location of line of best fit and the value of $F_{*}$.

d The observed $\left[\mathrm{Cr}_{\text {gas }} / \mathrm{H}\right]$ minus that computed using Eq. 10 .

${ }^{\text {e}}$ The difference shown in the previous column divided by the expected difference due to the uncertainties in both the measured column density and the coefficients that appear in Eq. 10. 
Table 17. Observations and Fits for Manganese

\begin{tabular}{|c|c|c|c|c|c|c|c|c|c|}
\hline \multirow[b]{2}{*}{$\begin{array}{l}\text { HD Number }{ }^{\mathrm{a}} \\
\text { (1) }\end{array}$} & \multirow[b]{2}{*}{$\begin{array}{l}\text { Name } \\
(2)\end{array}$} & \multicolumn{4}{|c|}{ Observed $\log N(\mathrm{Mn}$ II $)$} & \multirow[b]{2}{*}{$\begin{array}{l}F_{*} \\
(7)\end{array}$} & \multirow[b]{2}{*}{$\begin{array}{c}{\left[\mathrm{Mn}_{\text {gas }} / \mathrm{H}\right]_{\mathrm{fit}}{ }^{\mathrm{c}}} \\
(8)\end{array}$} & \multirow[b]{2}{*}{$\begin{array}{c}\text { Residual }^{\mathrm{d}} \\
(9)\end{array}$} & \multirow{2}{*}{$\begin{array}{l}\text { Deviation } \\
\quad \text { in } \sigma) \\
\quad(10)\end{array}$} \\
\hline & & $\begin{array}{l}1.1 . \\
(3)\end{array}$ & $\begin{array}{l}\text { best } \\
(4)\end{array}$ & $\begin{array}{l}\text { u.l. } \\
(5)\end{array}$ & $\begin{array}{c}\text { Source }^{b} \\
(6)\end{array}$ & & & & \\
\hline 1383 & HD 1383 & 13.54 & 13.60 & 13.66 & CLMS06 & $0.61 \pm 0.04$ & $-1.432 \pm 0.039$ & -0.054 & -0.52 \\
\hline 2905 & $\kappa$ Cas & 13.36 & 13.41 & 13.85 & JSS86 & $0.58 \pm 0.06$ & $-1.406 \pm 0.051$ & -0.058 & -0.21 \\
\hline 5394 & $\gamma$ Cas & 12.44 & 12.50 & 12.57 & JSS86 & $0.52 \pm 0.04$ & $-1.350 \pm 0.037$ & 0.108 & 0.92 \\
\hline 12323 & HD 12323 & 13.45 & 13.53 & 13.61 & CLMS06 & $0.52 \pm 0.04$ & $-1.357 \pm 0.033$ & 0.019 & 0.17 \\
\hline 13268 & HD 13268 & 13.55 & 13.59 & 13.63 & CLMS06 & $0.51 \pm 0.04$ & $-1.349 \pm 0.036$ & -0.060 & -0.66 \\
\hline 14434 & HD 14434 & 13.53 & 13.60 & 13.67 & CLMS06 & $0.52 \pm 0.04$ & $-1.352 \pm 0.038$ & -0.097 & -0.90 \\
\hline 18100 & HD 18100 & 12.71 & 12.74 & 12.77 & SS96b & $0.14 \pm 0.04$ & $-1.025 \pm 0.043$ & 0.036 & 0.25 \\
\hline 21278 & HD 21278 & $\cdots$ & 11.90 & 14.15 & JSS86 & $\cdots$ & $\cdots$ & $\cdots$ & $\cdots$ \\
\hline 21856 & HD 21856 & 12.57 & 13.22 & 14.07 & JSS86 & $0.67 \pm 0.39$ & $-1.485 \pm 0.334$ & 0.017 & 0.02 \\
\hline 22928 & $\delta$ Per & 12.31 & 12.52 & 12.90 & JSS86 & $\cdots$ & $\cdots$ & $\cdots$ & $\cdots$ \\
\hline 22951 & 40 Per & 13.23 & 13.33 & 13.63 & JSS86 & $0.73 \pm 0.05$ & $-1.535 \pm 0.046$ & 0.060 & 0.26 \\
\hline 23180 & o Per & 13.06 & 13.18 & 13.30 & S76 & $0.84 \pm 0.06$ & $-1.631 \pm 0.058$ & 0.038 & 0.23 \\
\hline 23408 & 20 Tau & $\cdots$ & 13.08 & $\infty$ & JSS86 & $\cdots$ & $\cdots$ & $\ldots$ & $\cdots$ \\
\hline 23480 & $23 \mathrm{Tau}$ & $\cdots$ & 12.60 & $\infty$ & JSS86 & $\ldots$ & $\ldots$ & $\ldots$ & $\ldots$ \\
\hline 23630 & $\eta \mathrm{Tau}$ & $\ldots$ & $\ldots$ & $\infty$ & JSS86 & $\ldots$ & $\ldots$ & $\ldots$ & $\ldots$ \\
\hline 24398 & $\zeta$ Per & 13.12 & 13.26 & 13.40 & $\mathrm{~S} 77$ & $0.88 \pm 0.05$ & $-1.666 \pm 0.047$ & 0.149 & 0.81 \\
\hline 24760 & $\epsilon$ Per & 12.62 & 12.67 & 12.72 & JSS86 & $0.68 \pm 0.04$ & $-1.491 \pm 0.036$ & 0.077 & 0.71 \\
\hline 24912 & $\xi$ Per & 13.49 & 13.52 & 13.54 & $\mathrm{C}++91$ & $0.83 \pm 0.02$ & $-1.621 \pm 0.027$ & 0.268 & 3.17 \\
\hline 27778 & $62 \mathrm{Tau}$ & 12.98 & 13.04 & 13.10 & CLMS06 & $\cdots$ & $\ldots$ & $\ldots$ & $\cdots$ \\
\hline 29248 & $\nu$ Eri & $\ldots$ & 11.17 & 11.56 & JSS86 & $\ldots$ & $\ldots$ & $\ldots$ & $\ldots$ \\
\hline 30614 & $\alpha \mathrm{Cam}$ & 13.01 & 13.11 & 13.20 & JSS86 & $0.46 \pm 0.04$ & $-1.300 \pm 0.037$ & -0.263 & -2.06 \\
\hline 31237 & $\pi^{5}$ Ori & 12.07 & 12.40 & 12.65 & JSS86 & $0.52 \pm 0.21$ & $-1.354 \pm 0.178$ & 0.012 & 0.02 \\
\hline 35149 & 23 Ori & 12.97 & 13.01 & 13.04 & $\mathrm{~W}++99$ & $0.54 \pm 0.04$ & $-1.370 \pm 0.034$ & 0.169 & 1.18 \\
\hline 35439 & 25 Ori & 12.11 & 12.52 & 12.72 & JSS86 & $0.72 \pm 0.18$ & $-1.526 \pm 0.152$ & 0.109 & 0.27 \\
\hline 35715 & $\psi$ Ori & 12.27 & 12.51 & 12.65 & JSS86 & $0.66 \pm 0.11$ & $-1.477 \pm 0.097$ & -0.086 & -0.30 \\
\hline 36166 & HD 36166 & $\ldots$ & 12.46 & $\infty$ & JSS86 & $\ldots$ & $\ldots$ & $\ldots$ & $\ldots$ \\
\hline 36486 & $\delta$ Ori A & 12.22 & 12.27 & 12.33 & JSS86 & $0.54 \pm 0.02$ & $-1.372 \pm 0.020$ & -0.130 & -1.79 \\
\hline 36822 & $\phi^{1}$ Ori & 12.49 & 12.60 & 12.69 & JSS86 & $0.74 \pm 0.08$ & $-1.544 \pm 0.071$ & -0.275 & -1.86 \\
\hline 36841 & HD 36841 & 12.83 & 12.92 & 13.01 & CLMS06 & $\cdots$ & $\cdots$ & $\cdots$ & $\cdots$ \\
\hline 36861 & $\lambda$ Ori A & 12.90 & 12.94 & 13.00 & JSS86 & $0.57 \pm 0.04$ & $-1.393 \pm 0.036$ & -0.047 & -0.37 \\
\hline 37043 & $\iota$ Ori & 12.52 & 12.58 & 12.62 & JSS86 & $0.41 \pm 0.03$ & $-1.260 \pm 0.026$ & 0.108 & 1.25 \\
\hline 37128 & $\epsilon$ Ori & 12.68 & 12.72 & 12.76 & JSS86 & $0.54 \pm 0.03$ & $-1.371 \pm 0.028$ & 0.059 & 0.58 \\
\hline 37367 & HD 37367 & 13.38 & 13.42 & 13.46 & CLMS06 & $0.65 \pm 0.07$ & $-1.469 \pm 0.059$ & -0.026 & -0.21 \\
\hline 37468 & $\sigma$ Ori & 12.43 & 12.50 & 12.55 & JSS86 & $0.58 \pm 0.04$ & $-1.408 \pm 0.038$ & -0.194 & -1.67 \\
\hline 37903 & HD 37903 & 13.14 & 13.20 & 13.26 & CLMS06 & $1.15 \pm 0.03$ & $-1.892 \pm 0.039$ & 0.073 & 0.78 \\
\hline 38666 & $\mu \mathrm{Col}$ & 12.39 & 12.41 & 12.43 & HSF99 & $0.11 \pm 0.01$ & $-1.004 \pm 0.021$ & -0.027 & -0.77 \\
\hline 38771 & $\kappa$ Ori & 12.37 & 12.40 & 12.44 & JSS86 & $0.67 \pm 0.03$ & $-1.480 \pm 0.026$ & -0.222 & -3.54 \\
\hline 40111 & 139 Tau & 13.13 & 13.16 & 13.22 & JSS86 & $0.49 \pm 0.04$ & $-1.328 \pm 0.034$ & -0.049 & -0.50 \\
\hline 43818 & LU Gem & 13.63 & 13.68 & 13.73 & CLMS06 & $\ldots$ & $\ldots$ & $\ldots$ & $\ldots$ \\
\hline
\end{tabular}


Table 17-Continued

\begin{tabular}{|c|c|c|c|c|c|c|c|c|c|}
\hline \multirow[b]{2}{*}{$\begin{array}{c}\text { HD Number }{ }^{\mathrm{a}} \\
(1)\end{array}$} & \multirow[b]{2}{*}{$\begin{array}{l}\text { Name } \\
(2)\end{array}$} & \multicolumn{4}{|c|}{ Observed $\log N(\mathrm{Mn} \mathrm{II})$} & \multirow[b]{2}{*}{$\begin{array}{l}F_{*} \\
(7)\end{array}$} & \multirow[b]{2}{*}{$\begin{array}{c}{\left[\mathrm{Mn}_{\text {gas }} / \mathrm{H}\right]_{\mathrm{fit}}{ }^{\mathrm{c}}} \\
(8)\end{array}$} & \multirow[b]{2}{*}{$\begin{array}{l}\text { Residual }^{\mathrm{d}} \\
\quad(9)\end{array}$} & \multirow{2}{*}{$\begin{array}{c}\text { Deviation }^{\mathrm{e}} \\
\quad(\text { in } \sigma) \\
\quad(10)\end{array}$} \\
\hline & & $\begin{array}{l}\text { l.l. } \\
(3)\end{array}$ & $\begin{array}{l}\text { best } \\
(4)\end{array}$ & $\begin{array}{l}\text { u.l. } \\
(5)\end{array}$ & $\begin{array}{c}\text { Source }^{b} \\
(6)\end{array}$ & & & & \\
\hline 44506 & HD 44506 & $\cdots$ & $\cdots$ & 12.45 & JSS86 & $-0.03 \pm 0.23$ & $-0.882 \pm 0.196$ & $\cdots$ & $\cdots$ \\
\hline 44743 & $\beta \mathrm{CMa}$ & 11.55 & 11.59 & 11.63 & DG98 & $-0.43 \pm 0.03$ & $-0.537 \pm 0.049$ & 0.244 & 2.79 \\
\hline 52266 & HD 52266 & 13.38 & 13.42 & 13.46 & CLMS06 & $\cdots$ & $\cdots$ & $\cdots$ & $\cdots$ \\
\hline 52918 & 19 Mon & 11.34 & 12.27 & 12.48 & JSS86 & $0.44 \pm 0.24$ & $-1.288 \pm 0.209$ & -0.220 & -0.32 \\
\hline 54662 & HD 54662 & 12.91 & 13.18 & 13.55 & JSS86 & $0.89 \pm 0.09$ & $-1.667 \pm 0.081$ & -0.150 & -0.43 \\
\hline 55879 & HD 55879 & $\cdots$ & 12.52 & $\infty$ & JSS86 & $\cdots$ & $\cdots$ & $\cdots$ & $\cdots$ \\
\hline 57060 & $29 \mathrm{CMa}$ & 12.74 & 12.92 & 13.00 & JSS86 & $0.50 \pm 0.05$ & $-1.338 \pm 0.042$ & -0.024 & -0.15 \\
\hline 57061 & $\tau \mathrm{CMa}$ & 12.82 & 12.88 & 12.96 & JSS86 & $0.39 \pm 0.04$ & $-1.239 \pm 0.039$ & -0.163 & -1.77 \\
\hline 63005 & HD 63005 & 13.25 & 13.31 & 13.37 & CLMS06 & $0.64 \pm 0.03$ & $-1.457 \pm 0.028$ & -0.133 & -1.58 \\
\hline 64740 & HD 64740 & $\cdots$ & 12.09 & 12.88 & JSS86 & $0.27 \pm 0.30$ & $-1.142 \pm 0.259$ & $\cdots$ & $\cdots$ \\
\hline 64760 & HD 64760 & 12.63 & 12.68 & 12.72 & JSS86 & $0.35 \pm 0.06$ & $-1.213 \pm 0.052$ & 0.051 & 0.39 \\
\hline 65575 & $\chi \mathrm{Car}$ & $\cdots$ & $\cdots$ & 11.45 & JSS86 & $\cdots$ & $\cdots$ & $\cdots$ & $\cdots$ \\
\hline 65818 & V Pup & 12.58 & 12.75 & 12.87 & JSS86 & $0.36 \pm 0.09$ & $-1.219 \pm 0.078$ & -0.134 & -0.62 \\
\hline 66811 & $\zeta$ Pup & 12.40 & 12.44 & 12.48 & M78 & $0.32 \pm 0.02$ & $-1.185 \pm 0.021$ & 0.086 & 1.42 \\
\hline 68273 & $\gamma^{2} \mathrm{Vel}$ & 12.31 & 12.39 & 12.47 & FS94 & $0.25 \pm 0.02$ & $-1.123 \pm 0.023$ & 0.222 & 2.41 \\
\hline 71634 & HD 71634 & 13.28 & 13.34 & 13.40 & CLMS06 & $\cdots$ & $\cdots$ & $\cdots$ & $\cdots$ \\
\hline 75309 & HD 75309 & 13.27 & 13.31 & 13.35 & CLMS06 & $0.63 \pm 0.04$ & $-1.445 \pm 0.035$ & -0.005 & -0.05 \\
\hline 79186 & GX Vel & 13.41 & 13.48 & 13.55 & CLMS06 & $0.69 \pm 0.03$ & $-1.499 \pm 0.032$ & -0.011 & -0.11 \\
\hline 79351 & a Car & 12.72 & 12.81 & $\infty$ & JSS86 & $\cdots$ & $\cdots$ & $\cdots$ & $\cdots$ \\
\hline 81188 & $\kappa \mathrm{Vel}$ & 12.19 & 12.29 & 12.37 & JSS86 & $\cdots$ & $\cdots$ & $\cdots$ & $\cdots$ \\
\hline 91824 & HD 91824 & 13.36 & 13.42 & 13.48 & CLMS06 & $0.45 \pm 0.03$ & $-1.290 \pm 0.029$ & -0.036 & -0.42 \\
\hline 91983 & HD 91983 & 13.41 & 13.47 & 13.53 & CLMS06 & $0.48 \pm 0.04$ & $-1.316 \pm 0.036$ & -0.035 & -0.34 \\
\hline 93030 & $\theta$ Car & 12.40 & 12.54 & 12.63 & AJS92 & $0.45 \pm 0.03$ & $-1.290 \pm 0.030$ & -0.007 & -0.05 \\
\hline $93521(-66)$ & HD 93521 & 11.68 & 11.74 & 11.80 & SF93 & $-0.31 \pm 0.11$ & $-0.642 \pm 0.099$ & 0.291 & 0.84 \\
\hline$(-58)$ & & 12.18 & 12.22 & 12.25 & SF93 & $-0.01 \pm 0.03$ & $-0.904 \pm 0.036$ & 0.203 & 2.14 \\
\hline$(-51)$ & & 12.10 & 12.14 & 12.18 & SF93 & $-0.04 \pm 0.04$ & $-0.877 \pm 0.045$ & 0.236 & 1.88 \\
\hline$(-39)$ & & 11.67 & 11.76 & 11.85 & SF93 & $0.01 \pm 0.08$ & $-0.913 \pm 0.075$ & 0.212 & 0.92 \\
\hline$(-29)$ & & 10.99 & 11.18 & 11.37 & SF93 & $0.34 \pm 0.17$ & $-1.200 \pm 0.144$ & 0.419 & 1.01 \\
\hline$(-18)$ & & 12.02 & 12.07 & 12.12 & SF93 & $0.00 \pm 0.03$ & $-0.911 \pm 0.035$ & 0.120 & 1.29 \\
\hline$(-10)$ & & 11.99 & 12.13 & 12.17 & SF93 & $0.02 \pm 0.04$ & $-0.926 \pm 0.041$ & 0.115 & 0.95 \\
\hline$(+3)$ & & 11.64 & 11.71 & 11.78 & SF93 & $0.25 \pm 0.04$ & $-1.124 \pm 0.036$ & -0.047 & -0.42 \\
\hline$(+7)$ & & 11.41 & 11.52 & 11.63 & SF93 & $0.23 \pm 0.12$ & $-1.109 \pm 0.104$ & 0.258 & 0.88 \\
\hline (total) & & 12.81 & 12.88 & 12.94 & SF93 & $0.06 \pm 0.04$ & $-0.958 \pm 0.038$ & 0.163 & 1.62 \\
\hline 100340 & HD 100340 & 12.81 & 12.89 & 12.97 & SS96b & $0.10 \pm 0.06$ & $-0.992 \pm 0.054$ & -0.157 & -1.14 \\
\hline 106490 & $\delta \mathrm{Cru}$ & 11.72 & 11.93 & 12.06 & JSS86 & $\cdots$ & $\cdots$ & $\cdots$ & $\cdots$ \\
\hline 108248 & $\alpha^{1} \mathrm{Cru}$ & 12.21 & 12.25 & 12.29 & JSS86 & $0.15 \pm 0.05$ & $-1.038 \pm 0.045$ & 0.106 & 0.91 \\
\hline 111934 & BU Cru & 13.58 & 13.63 & 13.68 & CLMS06 & $\cdots$ & $\cdots$ & $\cdots$ & $\cdots$ \\
\hline 113904 & $\theta$ Mus & 13.01 & 13.14 & 13.29 & JSS86 & $\cdots$ & $\cdots$ & $\cdots$ & $\cdots$ \\
\hline 116658 & $\alpha \mathrm{Vir}$ & 11.36 & 11.55 & 11.68 & YK79 & $0.16 \pm 0.05$ & $-1.048 \pm 0.046$ & 0.020 & 0.10 \\
\hline
\end{tabular}


Table 17-Continued

\begin{tabular}{|c|c|c|c|c|c|c|c|c|c|}
\hline \multirow[b]{2}{*}{$\begin{array}{c}\text { HD Number } \\
\text { (1) }\end{array}$} & \multirow[b]{2}{*}{$\begin{array}{l}\text { Name } \\
(2)\end{array}$} & \multicolumn{4}{|c|}{ Observed $\log N(\mathrm{Mn} \mathrm{II})$} & \multirow[b]{2}{*}{$\begin{array}{l}F_{*} \\
(7)\end{array}$} & \multirow[b]{2}{*}{$\begin{array}{c}{\left[\mathrm{Mn}_{\text {gas }} / \mathrm{H}\right]_{\mathrm{fit}}{ }^{\mathrm{c}}} \\
(8)\end{array}$} & \multirow[b]{2}{*}{$\begin{array}{l}\text { Residual }^{\mathrm{d}} \\
\quad(9)\end{array}$} & \multirow{2}{*}{$\begin{array}{c}\text { Deviation }^{\mathrm{e}} \\
\quad(\text { in } \sigma) \\
(10)\end{array}$} \\
\hline & & $\begin{array}{l}1.1 . \\
(3)\end{array}$ & $\begin{array}{c}\text { best } \\
(4)\end{array}$ & $\begin{array}{l}\text { u.l. } \\
(5)\end{array}$ & $\begin{array}{c}\text { Source }^{b} \\
(6)\end{array}$ & & & & \\
\hline 116852 & HD 116852 & 13.38 & 13.44 & 13.50 & CLMS06 & $0.36 \pm 0.04$ & $-1.213 \pm 0.033$ & 0.056 & 0.53 \\
\hline 120324 & $\mu$ Cen & $\cdots$ & 11.98 & 12.28 & JSS86 & $-0.81 \pm 3.74$ & $-0.216 \pm 3.201$ & $\cdots$ & $\cdots$ \\
\hline 121263 & $\zeta$ Cen & 12.10 & 12.20 & 12.29 & JSS86 & $\cdots$ & $\cdots$ & $\cdots$ & $\cdots$ \\
\hline 122879 & HD 122879 & 13.54 & 13.58 & 13.62 & CLMS06 & $0.55 \pm 0.04$ & $-1.375 \pm 0.039$ & 0.038 & 0.32 \\
\hline 127972 & $\eta$ Cen & 12.16 & 12.24 & 12.31 & JSS86 & $\cdots$ & $\cdots$ & $\cdots$ & $\cdots$ \\
\hline 135591 & HD 135591 & 13.12 & 13.25 & 13.65 & JSS86 & $0.56 \pm 0.22$ & $-1.392 \pm 0.189$ & -0.060 & -0.17 \\
\hline 136298 & $\delta$ Lup & 12.03 & 12.15 & 12.24 & JSS86 & $\cdots$ & $\cdots$ & $\cdots$ & $\cdots$ \\
\hline 138690 & $\gamma \operatorname{Lup}$ & 11.87 & 12.19 & 12.32 & JSS86 & $\cdots$ & $\cdots$ & $\cdots$ & $\cdots$ \\
\hline 141637 & $1 \mathrm{Sco}$ & 13.12 & 13.20 & 13.27 & JSS86 & $0.69 \pm 0.05$ & $-1.499 \pm 0.045$ & -0.017 & -0.12 \\
\hline 143018 & $\pi \mathrm{Sco}$ & 12.68 & 12.88 & 13.08 & JJ91 & $0.71 \pm 0.03$ & $-1.513 \pm 0.032$ & 0.119 & 0.56 \\
\hline 143118 & $\eta \operatorname{Lup} \mathrm{A}$ & 11.80 & 11.96 & 12.07 & JSS86 & $\cdots$ & $\cdots$ & $\cdots$ & $\cdots$ \\
\hline 143275 & $\delta \mathrm{Sco}$ & 13.20 & 13.22 & 13.24 & JSS86 & $0.90 \pm 0.03$ & $-1.676 \pm 0.035$ & 0.148 & 1.55 \\
\hline 144217 & $\beta^{1}$ Sco & 13.12 & 13.15 & 13.18 & JSS86 & $0.81 \pm 0.02$ & $-1.604 \pm 0.024$ & 0.037 & 0.71 \\
\hline 144470 & $\mathrm{o}^{1} \mathrm{Sco}$ & 13.23 & 13.29 & 13.35 & JSS86 & $0.81 \pm 0.04$ & $-1.599 \pm 0.037$ & 0.077 & 0.72 \\
\hline 145502 & $\nu \mathrm{Sco}$ & 12.87 & 12.98 & 13.36 & JSS86 & $0.80 \pm 0.11$ & $-1.593 \pm 0.098$ & -0.137 & -0.41 \\
\hline 147165 & $\sigma \mathrm{Sco}$ & 13.41 & 13.50 & 13.75 & JSS86 & $0.76 \pm 0.06$ & $-1.564 \pm 0.054$ & 0.119 & 0.48 \\
\hline 147888 & $\rho$ Oph D & 13.37 & 13.44 & 13.51 & CLMS06 & $0.88 \pm 0.06$ & $-1.663 \pm 0.058$ & -0.217 & -1.26 \\
\hline 147933 & $\rho \mathrm{Oph} \mathrm{A}$ & 13.24 & 13.29 & 13.80 & JSS86 & $1.09 \pm 0.08$ & $-1.844 \pm 0.075$ & -0.149 & -0.50 \\
\hline 148184 & $\chi \mathrm{Oph}$ & 13.22 & 13.32 & 13.41 & JSS86 & $0.96 \pm 0.09$ & $-1.728 \pm 0.084$ & 0.161 & 0.93 \\
\hline 148594 & HD 148594 & 13.06 & 13.14 & 13.22 & CLMS06 & $\cdots$ & $\cdots$ & $\cdots$ & $\cdots$ \\
\hline 148605 & 22 Sco & 12.51 & 12.94 & 13.88 & JSS86 & $0.53 \pm 0.39$ & $-1.362 \pm 0.338$ & 0.034 & 0.04 \\
\hline $149757(-27)$ & $\zeta \mathrm{Oph}$ & 12.16 & 12.21 & 12.26 & SCS92 & $\cdots$ & $\cdots$ & $\cdots$ & $\cdots$ \\
\hline$(-15)$ & & 13.01 & 13.04 & 13.07 & SCS92 & $1.05 \pm 0.02$ & $-1.804 \pm 0.029$ & 0.111 & 1.68 \\
\hline 149881 & V600 Her & 13.30 & 13.36 & 13.42 & SF95 & $0.07 \pm 0.06$ & $-0.965 \pm 0.058$ & 0.097 & 0.48 \\
\hline 151804 & V973 Sco & 13.08 & 13.28 & 13.64 & JSS86 & $0.57 \pm 0.08$ & $-1.401 \pm 0.066$ & -0.096 & -0.32 \\
\hline 151890 & $\mu^{1} \mathrm{Sco}$ & 12.19 & 12.29 & 12.36 & JSS86 & $-0.03 \pm 3.47$ & $-0.884 \pm 2.975$ & 0.006 & 0.00 \\
\hline 152590 & HD 152590 & 13.47 & 13.56 & 13.65 & CLMS06 & $0.69 \pm 0.03$ & $-1.500 \pm 0.029$ & 0.010 & 0.10 \\
\hline 154368 & V1074 Sco & 14.11 & 14.23 & 14.33 & $\mathrm{~S}++96$ & $0.52 \pm 0.07$ & $-1.351 \pm 0.057$ & 0.412 & 3.06 \\
\hline 155806 & V1075 Sco & 13.26 & 13.30 & 13.35 & JSS86 & $0.62 \pm 0.07$ & $-1.442 \pm 0.058$ & 0.024 & 0.17 \\
\hline 157246 & $\gamma$ Ara & 12.93 & 12.96 & 12.99 & JSS86 & $0.46 \pm 0.03$ & $-1.302 \pm 0.031$ & -0.026 & -0.27 \\
\hline 157857 & HD 157857 & 13.50 & 13.57 & 13.64 & CLMS06 & $0.62 \pm 0.04$ & $-1.441 \pm 0.033$ & -0.014 & -0.14 \\
\hline 160578 & $\kappa \mathrm{Sco}$ & 12.61 & 12.67 & 12.72 & JSS86 & $0.50 \pm 0.07$ & $-1.333 \pm 0.064$ & 0.199 & 1.13 \\
\hline 164284 & $66 \mathrm{Oph}$ & 12.72 & 12.86 & 12.95 & JSS86 & $0.89 \pm 0.18$ & $-1.671 \pm 0.155$ & 0.203 & 0.53 \\
\hline 165024 & $\theta$ Ara & 12.98 & 13.02 & 13.08 & JSS86 & $0.56 \pm 0.03$ & $-1.392 \pm 0.032$ & -0.010 & -0.10 \\
\hline 165955 & HD 165955 & 13.29 & 13.33 & 13.37 & CLMS06 & $0.42 \pm 0.04$ & $-1.268 \pm 0.037$ & -0.083 & -1.01 \\
\hline 167264 & $15 \mathrm{Sgr}$ & 13.11 & 13.38 & 13.53 & JSS86 & $0.68 \pm 0.16$ & $-1.491 \pm 0.135$ & 0.036 & 0.13 \\
\hline 175360 & HD 175360 & 13.18 & 13.26 & 13.34 & CLMS06 & $\cdots$ & $\cdots$ & $\cdots$ & $\cdots$ \\
\hline 184915 & $\kappa$ Aql & 13.02 & 13.22 & 13.68 & JSS86 & $0.88 \pm 0.05$ & $-1.660 \pm 0.047$ & 0.250 & 0.73 \\
\hline 185418 & HD 185418 & 13.54 & 13.59 & 13.64 & CLMS06 & $0.79 \pm 0.03$ & $-1.586 \pm 0.033$ & 0.184 & 1.96 \\
\hline
\end{tabular}


Table 17-Continued

\begin{tabular}{|c|c|c|c|c|c|c|c|c|c|}
\hline \multirow[b]{2}{*}{$\begin{array}{c}\text { HD Number } \\
\text { (1) }\end{array}$} & \multirow[b]{2}{*}{$\begin{array}{l}\text { Name } \\
(2)\end{array}$} & \multicolumn{4}{|c|}{ Observed $\log N(\mathrm{Mn} \mathrm{II})$} & \multirow[b]{2}{*}{$\begin{array}{l}F_{*} \\
(7)\end{array}$} & \multirow[b]{2}{*}{$\begin{array}{c}{\left[\mathrm{Mn}_{\text {gas }} / \mathrm{H}\right]_{\mathrm{fit}}{ }^{\mathrm{c}}} \\
(8)\end{array}$} & \multirow[b]{2}{*}{$\begin{array}{l}\text { Residual }^{\mathrm{d}} \\
\quad(9)\end{array}$} & \multirow{2}{*}{$\begin{array}{c}\text { Deviation }^{\mathrm{e}} \\
\quad(\text { in } \sigma) \\
(10)\end{array}$} \\
\hline & & $\begin{array}{l}1.1 . \\
(3)\end{array}$ & $\begin{array}{c}\text { best } \\
(4)\end{array}$ & $\begin{array}{l}\text { u.l. } \\
(5)\end{array}$ & $\begin{array}{c}\text { Source }^{b} \\
(6)\end{array}$ & & & & \\
\hline 188209 & HD 188209 & 13.08 & 13.22 & 13.36 & JSS86 & $0.66 \pm 0.12$ & $-1.477 \pm 0.105$ & 0.116 & 0.56 \\
\hline 190918 & V1676 Cyg & 13.56 & 13.62 & 13.68 & CLMS06 & $0.46 \pm 0.03$ & $-1.304 \pm 0.031$ & -0.062 & -0.70 \\
\hline 192035 & RX Cyg & 13.17 & 13.24 & 13.31 & CLMS06 & $0.76 \pm 0.04$ & $-1.558 \pm 0.037$ & -0.167 & -1.64 \\
\hline 192639 & HD 192639 & 13.51 & 13.59 & 13.67 & CLMS06 & $0.64 \pm 0.04$ & $-1.457 \pm 0.035$ & -0.016 & -0.14 \\
\hline 193322 & HD 193322 & 13.35 & 13.58 & $\infty$ & JSS86 & $\cdots$ & $\cdots$ & $\cdots$ & $\cdots$ \\
\hline 198478 & $55 \mathrm{Cyg}$ & 13.51 & 13.60 & 13.69 & CLMS06 & $0.81 \pm 0.05$ & $-1.600 \pm 0.048$ & 0.071 & 0.48 \\
\hline 198781 & HD 198781 & 13.23 & 13.28 & 13.33 & CLMS06 & $0.59 \pm 0.03$ & $-1.412 \pm 0.029$ & -0.041 & -0.50 \\
\hline 200120 & 59 Cyg & 12.52 & 12.71 & 12.87 & JSS86 & $\cdots$ & $\cdots$ & $\cdots$ & $\cdots$ \\
\hline 201345 & HD 201345 & 13.35 & 13.38 & 13.41 & CLMS06 & $0.34 \pm 0.04$ & $-1.198 \pm 0.037$ & -0.006 & -0.06 \\
\hline 202904 & $v$ Cyg & 12.33 & 12.52 & 12.64 & JSS86 & $\cdots$ & $\cdots$ & $\cdots$ & $\cdots$ \\
\hline 203064 & 68 Cyg & 12.98 & 13.21 & 13.64 & JSS86 & $0.68 \pm 0.20$ & $-1.492 \pm 0.175$ & -0.026 & -0.07 \\
\hline 203532 & HD 203532 & 13.00 & 13.05 & 13.10 & CLMS06 & $\cdots$ & $\cdots$ & $\cdots$ & $\cdots$ \\
\hline 206773 & HD 206773 & 13.45 & 13.50 & 13.55 & CLMS06 & $0.53 \pm 0.02$ & $-1.366 \pm 0.021$ & 0.034 & 0.45 \\
\hline 207198 & HD 207198 & 13.50 & 13.57 & 13.64 & CLMS06 & $0.90 \pm 0.03$ & $-1.679 \pm 0.033$ & -0.009 & -0.10 \\
\hline 208440 & HD 208440 & 13.36 & 13.42 & 13.48 & CLMS06 & $0.61 \pm 0.04$ & $-1.431 \pm 0.037$ & -0.038 & -0.36 \\
\hline 209975 & 19 Cep & 13.15 & 13.36 & 13.62 & JSS86 & $0.57 \pm 0.26$ & $-1.399 \pm 0.225$ & -0.007 & -0.02 \\
\hline 210809 & HD 210809 & 13.55 & 13.59 & 13.63 & CLMS06 & $0.41 \pm 0.04$ & $-1.262 \pm 0.039$ & -0.062 & -0.63 \\
\hline 212791 & V408 Lac & 13.24 & 13.28 & 13.32 & CLMS06 & $0.57 \pm 0.08$ & $-1.398 \pm 0.072$ & -0.027 & -0.14 \\
\hline 214080 & HD 214080 & 12.54 & 12.88 & 13.36 & JSS86 & $0.27 \pm 0.10$ & $-1.139 \pm 0.088$ & -0.177 & -0.38 \\
\hline 214993 & $12 \mathrm{Lac}$ & 12.94 & 13.02 & 13.11 & JSS86 & $0.68 \pm 0.10$ & $-1.491 \pm 0.083$ & 0.106 & 0.61 \\
\hline $215733(-61)$ & HD 215733 & 10.89 & 11.25 & 11.61 & FS97 & $1.06 \pm 0.21$ & $-1.820 \pm 0.181$ & 0.052 & 0.10 \\
\hline$(-59)$ & & 11.65 & 11.76 & 11.87 & FS97 & $-0.11 \pm 0.10$ & $-0.814 \pm 0.088$ & 0.046 & 0.15 \\
\hline$(-54)$ & & 11.68 & 11.75 & 11.82 & FS97 & $0.54 \pm 0.15$ & $-1.374 \pm 0.130$ & -0.084 & -0.19 \\
\hline$(-47)$ & & 11.90 & 11.99 & 12.08 & FS97 & $\cdots$ & $\cdots$ & $\cdots$ & $\cdots$ \\
\hline$(-45)$ & & 11.01 & 11.24 & 11.47 & FS97 & $-0.40 \pm 0.28$ & $-0.562 \pm 0.241$ & 0.164 & 0.26 \\
\hline$(-42)$ & & 11.23 & 11.45 & 11.67 & FS97 & $-0.16 \pm 0.31$ & $-0.769 \pm 0.269$ & 0.111 & 0.12 \\
\hline$(-40)$ & & 11.15 & 11.35 & 11.55 & FS97 & $0.18 \pm 0.24$ & $-1.064 \pm 0.210$ & 0.026 & 0.04 \\
\hline$(-32)$ & & 12.14 & 12.32 & 12.50 & FS97 & $0.25 \pm 0.09$ & $-1.120 \pm 0.078$ & 0.222 & 0.92 \\
\hline$(-31)$ & & 11.43 & 11.64 & 11.85 & FS97 & $\cdots$ & $\cdots$ & $\cdots$ & $\cdots$ \\
\hline$(-28)$ & & 11.61 & 11.79 & 11.97 & FS97 & $-0.18 \pm 0.07$ & $-0.751 \pm 0.064$ & 0.053 & 0.24 \\
\hline$(-26)$ & & 11.89 & 12.04 & 12.19 & FS97 & $-0.12 \pm 0.07$ & $-0.804 \pm 0.063$ & 0.156 & 0.77 \\
\hline$(-23)$ & & 11.64 & 11.76 & 11.88 & FS97 & $0.24 \pm 0.08$ & $-1.117 \pm 0.071$ & 0.049 & 0.32 \\
\hline$(-21)$ & & 11.77 & 11.88 & 11.99 & FS97 & $0.24 \pm 0.05$ & $-1.112 \pm 0.047$ & 0.044 & 0.32 \\
\hline$(-19)$ & & 11.54 & 11.66 & 11.78 & FS97 & $\cdots$ & $\cdots$ & $\cdots$ & $\cdots$ \\
\hline$(-16)$ & & 11.49 & 11.61 & 11.73 & FS97 & $0.93 \pm 0.05$ & $-1.703 \pm 0.048$ & -0.375 & -2.70 \\
\hline$(-9)$ & & 12.88 & 12.89 & 12.90 & FS97 & $0.08 \pm 0.04$ & $-0.977 \pm 0.037$ & 0.219 & 2.47 \\
\hline$(+1)$ & & 11.34 & 11.48 & 11.62 & FS97 & $0.90 \pm 0.05$ & $-1.683 \pm 0.049$ & -0.125 & -0.80 \\
\hline (total) & & 13.16 & 13.24 & 13.34 & FS97 & $\cdots$ & $\cdots$ & $\cdots$ & $\cdots$ \\
\hline 217675 & o And & 12.92 & 13.19 & $\infty$ & JSS86 & $\ldots$ & $\ldots$ & $\ldots$ & $\ldots$ \\
\hline
\end{tabular}


Table 17-Continued

\begin{tabular}{|c|c|c|c|c|c|c|c|c|c|}
\hline $\begin{array}{l}\text { HD Number }{ }^{\mathrm{a}} \\
\text { (1) }\end{array}$ & $\begin{array}{l}\text { Name } \\
(2)\end{array}$ & \multicolumn{4}{|c|}{ Observed $\log N(\mathrm{Mn} \mathrm{II})$} & $\begin{array}{l}F_{*} \\
(7)\end{array}$ & $\begin{array}{c}{\left[\mathrm{Mn}_{\text {gas }} / \mathrm{H}\right]_{\mathrm{fit}}{ }^{\mathrm{c}}} \\
(8)\end{array}$ & $\begin{array}{l}\text { Residual }^{\mathrm{d}} \\
(9)\end{array}$ & $\begin{array}{l}\text { Deviation }^{\mathrm{e}} \\
\quad \text { (in } \sigma) \\
(10)\end{array}$ \\
\hline 218376 & $1 \mathrm{Cas}$ & 12.53 & 12.86 & 12.99 & JSS86 & $0.60 \pm 0.06$ & $-1.423 \pm 0.053$ & -0.368 & -1.43 \\
\hline 219188 & HD 219188 & 12.05 & 12.76 & 13.47 & JSS86 & $1.24 \pm 0.57$ & $-1.970 \pm 0.491$ & 0.272 & 0.31 \\
\hline 220057 & HD 220057 & 12.98 & 13.04 & 13.10 & CLMS06 & $0.75 \pm 0.05$ & $-1.553 \pm 0.049$ & -0.145 & -1.03 \\
\hline 232522 & HDE 232522 & 13.35 & 13.41 & 13.47 & CLMS06 & $0.44 \pm 0.03$ & $-1.283 \pm 0.030$ & -0.075 & -0.89 \\
\hline \multirow[t]{3}{*}{308813} & HDE 308813 & 13.42 & 13.46 & 13.50 & CLMS06 & $0.49 \pm 0.04$ & $-1.330 \pm 0.036$ & -0.080 & -0.87 \\
\hline & $\mathrm{BD}+532820$ & 13.65 & 13.71 & 13.77 & CLMS06 & $0.43 \pm 0.05$ & $-1.274 \pm 0.045$ & 0.014 & 0.13 \\
\hline & CPD -69 1743 & 13.28 & 13.33 & 13.38 & CLMS06 & $0.42 \pm 0.05$ & $-1.269 \pm 0.043$ & -0.143 & -1.37 \\
\hline
\end{tabular}

${ }^{\text {a }}$ Terms in parentheses indicate separate velocity components, if they are explicitly identified and not grouped together; see 4.3

${ }^{\mathrm{b}}$ Codes in this column are linked to references listed in Table 1

${ }^{\mathrm{c}}$ The expected depletion $\left[\mathrm{Mn}_{\text {gas }} / \mathrm{H}\right]$ computed using Eq. 10 The listed errors do not include an overall systematic uncertainty of 0.03 in the solar abundance $\sigma(\mathrm{Mn} / \mathrm{H}) \odot$ in order to show just the formal error that arises from the uncertainties in location of line of best fit and the value of $F_{*}$.

${ }^{\mathrm{d}}$ The observed $\left[\mathrm{Mn}_{\text {gas }} / \mathrm{H}\right]$ minus that computed using Eq. 10]

eThe difference shown in the previous column divided by the expected difference due to the uncertainties in both the measured column density and the coefficients that appear in Eq. 10. 
Table 18. Observations and Fits for Iron

\begin{tabular}{|c|c|c|c|c|c|c|c|c|c|}
\hline \multirow[b]{2}{*}{$\begin{array}{c}\text { HD Number } \\
\text { (1) }\end{array}$} & \multirow[b]{2}{*}{$\begin{array}{l}\text { Name } \\
(2)\end{array}$} & \multicolumn{4}{|c|}{ Observed $\log N(\mathrm{Fe} \mathrm{II})$} & \multirow[b]{2}{*}{$\begin{array}{l}F_{*} \\
(7)\end{array}$} & \multirow[b]{2}{*}{$\begin{array}{c}{\left[\mathrm{Fe}_{\text {gas }} / \mathrm{H}\right]_{\mathrm{fit}}{ }^{\mathrm{c}}} \\
(8)\end{array}$} & \multirow[b]{2}{*}{$\begin{array}{c}\text { Residual }^{\mathrm{d}} \\
(9)\end{array}$} & \multirow{2}{*}{$\begin{array}{l}\text { Deviation } \\
\quad \text { in } \sigma) \\
\quad(10)\end{array}$} \\
\hline & & $\begin{array}{l}1.1 . \\
(3)\end{array}$ & $\begin{array}{l}\text { best } \\
(4)\end{array}$ & $\begin{array}{l}\text { u.l. } \\
(5)\end{array}$ & $\begin{array}{c}\text { Source }^{b} \\
(6)\end{array}$ & & & & \\
\hline 2905 & $\kappa$ Cas & 14.93 & 15.01 & 15.46 & JSS86 & $0.58 \pm 0.06$ & $-1.698 \pm 0.076$ & -0.126 & -0.43 \\
\hline 5394 & $\gamma$ Cas & 14.01 & 14.11 & 14.21 & JSS86 & $0.52 \pm 0.04$ & $-1.614 \pm 0.055$ & 0.022 & 0.15 \\
\hline 12323 & HD 12323 & 15.09 & 15.16 & 15.23 & JS07a & $0.52 \pm 0.04$ & $-1.624 \pm 0.048$ & -0.039 & -0.35 \\
\hline 13745 & HD 13745 & 15.45 & 15.53 & 15.62 & JS07a & $0.43 \pm 0.07$ & $-1.498 \pm 0.089$ & 0.115 & 0.80 \\
\hline 15137 & HD 15137 & 15.31 & 15.39 & 15.49 & JS07a & $0.37 \pm 0.09$ & $-1.422 \pm 0.115$ & 0.054 & 0.28 \\
\hline 18100 & HD 18100 & 14.63 & 14.67 & 14.71 & SS96b & $0.14 \pm 0.04$ & $-1.126 \pm 0.060$ & 0.102 & 0.67 \\
\hline 21278 & HD 21278 & 14.36 & 15.01 & $\infty$ & JSS86 & $\cdots$ & $\cdots$ & $\cdots$ & $\cdots$ \\
\hline 21856 & HD 21856 & 14.88 & 15.06 & $\infty$ & JSS86 & $0.67 \pm 0.39$ & $-1.816 \pm 0.501$ & $\cdots$ & $\cdots$ \\
\hline 22586 & HD 22586 & 14.51 & 14.56 & 14.66 & JW96 & $0.34 \pm 0.07$ & $-1.388 \pm 0.086$ & 0.054 & 0.27 \\
\hline 22928 & $\delta$ Per & 13.93 & 14.11 & 14.28 & JSS86 & $\cdots$ & $\cdots$ & $\cdots$ & $\cdots$ \\
\hline 22951 & 40 Per & 14.53 & 14.61 & 15.11 & JSS86 & $0.73 \pm 0.05$ & $-1.892 \pm 0.068$ & -0.264 & -0.84 \\
\hline 23180 & o Per & 14.61 & 14.76 & $\infty$ & JSS86 & $0.84 \pm 0.06$ & $-2.035 \pm 0.086$ & $\cdots$ & $\cdots$ \\
\hline 23408 & 20 Tau & 15.46 & 15.71 & $\infty$ & JSS86 & $\cdots$ & $\cdots$ & $\cdots$ & $\cdots$ \\
\hline 23480 & 23 Tau & 13.76 & 14.01 & $\infty$ & JSS86 & $\cdots$ & $\cdots$ & $\cdots$ & $\cdots$ \\
\hline 24398 & $\zeta$ Per & 14.28 & 14.43 & 14.58 & $\mathrm{~S} 77$ & $0.88 \pm 0.05$ & $-2.088 \pm 0.069$ & -0.219 & -1.11 \\
\hline 24534 & X Per & 14.43 & 14.56 & 14.70 & SRF02 & $0.90 \pm 0.06$ & $-2.108 \pm 0.076$ & -0.212 & -1.34 \\
\hline 24760 & $\epsilon$ Per & 14.23 & 14.31 & 14.38 & JSS86 & $0.68 \pm 0.04$ & $-1.825 \pm 0.052$ & 0.091 & 0.71 \\
\hline 24912 & $\xi$ Per & 14.69 & 14.72 & 14.75 & $\mathrm{C}++91$ & $0.83 \pm 0.02$ & $-2.020 \pm 0.038$ & -0.093 & -1.03 \\
\hline 27778 & 62 Tau & 14.41 & 14.42 & 14.43 & $\mathrm{M}++07$ & $\cdots$ & $\cdots$ & $\cdots$ & $\cdots$ \\
\hline 28497 & 228 Eri & 14.11 & 14.31 & 14.51 & SY77 & $\cdots$ & $\cdots$ & $\cdots$ & $\cdots$ \\
\hline 29248 & $\nu$ Eri & 13.86 & 14.06 & $\infty$ & JSS86 & $\cdots$ & $\cdots$ & $\cdots$ & $\cdots$ \\
\hline 30614 & $\alpha \mathrm{Cam}$ & 14.98 & 15.11 & $\infty$ & JSS86 & $0.46 \pm 0.04$ & $-1.538 \pm 0.055$ & $\cdots$ & $\cdots$ \\
\hline 31237 & $\pi^{5}$ Ori & 13.98 & 14.11 & 14.51 & JSS86 & $0.52 \pm 0.21$ & $-1.619 \pm 0.267$ & 0.028 & 0.05 \\
\hline 34029 & $\alpha$ Aur & 12.45 & 12.46 & 12.47 & $\mathrm{~L}++95$ & $0.44 \pm 0.05$ & $-1.516 \pm 0.066$ & 0.198 & 1.71 \\
\hline 34816 & $\lambda$ Lep & 14.44 & 14.74 & $\infty$ & JSS86 & $0.45 \pm 0.05$ & $-1.535 \pm 0.068$ & $\cdots$ & $\cdots$ \\
\hline 34989 & HD 34989 & 14.57 & 14.77 & 14.97 & SB79 & $0.72 \pm 0.17$ & $-1.872 \pm 0.224$ & 0.008 & 0.02 \\
\hline 35149 & 23 Ori & 14.36 & 14.38 & 14.41 & $\mathrm{~W}++99$ & $0.54 \pm 0.04$ & $-1.644 \pm 0.050$ & -0.148 & -1.01 \\
\hline 35439 & 25 Ori & 13.53 & 13.81 & $\infty$ & JSS86 & $0.72 \pm 0.18$ & $-1.878 \pm 0.228$ & $\cdots$ & $\cdots$ \\
\hline 35715 & $\psi$ Ori & 14.13 & 14.21 & 14.33 & JSS86 & $0.66 \pm 0.11$ & $-1.804 \pm 0.146$ & -0.019 & -0.07 \\
\hline 36166 & HD 36166 & 14.06 & 14.46 & $\infty$ & JSS86 & $\cdots$ & $\cdots$ & $\ldots$ & $\cdots$ \\
\hline 36486 & $\delta$ Ori A & 14.01 & 14.06 & 14.13 & JSS86 & $0.54 \pm 0.02$ & $-1.646 \pm 0.029$ & -0.026 & -0.33 \\
\hline 36822 & $\phi^{1}$ Ori & 14.36 & 14.46 & 14.61 & JSS86 & $0.74 \pm 0.08$ & $-1.905 \pm 0.105$ & -0.015 & -0.08 \\
\hline 36861 & $\lambda$ Ori A & 14.56 & 14.61 & 14.68 & JSS86 & $0.57 \pm 0.04$ & $-1.679 \pm 0.053$ & -0.052 & -0.38 \\
\hline 37021 & $\theta^{1}$ Ori & 15.42 & 15.44 & 15.46 & $\mathrm{M}++07$ & $\cdots$ & $\cdots$ & $\cdots$ & $\cdots$ \\
\hline 37043 & $\iota$ Ori & 14.13 & 14.21 & 14.31 & JSS86 & $0.41 \pm 0.03$ & $-1.478 \pm 0.037$ & -0.004 & -0.03 \\
\hline 37061 & $\nu$ Ori & 15.42 & 15.44 & 15.46 & $\mathrm{M}++07$ & $\cdots$ & $\cdots$ & $\cdots$ & $\ldots$ \\
\hline 37128 & $\epsilon$ Ori & 14.16 & 14.21 & 14.26 & JSS86 & $0.54 \pm 0.03$ & $-1.646 \pm 0.040$ & -0.137 & -1.24 \\
\hline 37468 & $\sigma$ Ori & 14.41 & 14.56 & $\infty$ & JSS86 & $0.58 \pm 0.04$ & $-1.701 \pm 0.055$ & $\cdots$ & $\cdots$ \\
\hline 37903 & HD 37903 & 14.77 & 14.87 & 14.99 & JS07a & $1.15 \pm 0.03$ & $-2.427 \pm 0.053$ & 0.322 & 2.36 \\
\hline
\end{tabular}


Table 18-Continued

\begin{tabular}{|c|c|c|c|c|c|c|c|c|c|}
\hline \multirow[b]{2}{*}{$\begin{array}{c}\text { HD Number } \\
\text { (1) }\end{array}$} & \multirow[b]{2}{*}{$\begin{array}{c}\text { Name } \\
(2)\end{array}$} & \multicolumn{4}{|c|}{ Observed $\log N(\mathrm{Fe}$ II $)$} & \multirow[b]{2}{*}{$\begin{array}{l}F_{*} \\
(7)\end{array}$} & \multirow[b]{2}{*}{$\begin{array}{c}{\left[\mathrm{Fe}_{\mathrm{gas}} / \mathrm{H}\right]_{\mathrm{fit}}{ }^{\mathrm{c}}} \\
(8)\end{array}$} & \multirow[b]{2}{*}{$\begin{array}{c}\text { Residual }^{\mathrm{d}} \\
(9)\end{array}$} & \multirow{2}{*}{$\begin{array}{c}\text { Deviation } \\
\quad \text { (in } \sigma) \\
\quad(10)\end{array}$} \\
\hline & & $\begin{array}{l}1.1 . \\
(3)\end{array}$ & $\begin{array}{c}\text { best } \\
(4)\end{array}$ & $\begin{array}{l}\text { u.l. } \\
(5)\end{array}$ & $\begin{array}{c}\text { Source }^{b} \\
(6)\end{array}$ & & & & \\
\hline 38666 & $\mu \mathrm{Col}$ & 14.30 & 14.31 & 14.32 & HSF99 & $0.11 \pm 0.01$ & $-1.094 \pm 0.022$ & 0.004 & 0.13 \\
\hline 38771 & $\kappa$ Ori & 14.21 & 14.26 & 14.33 & JSS86 & $0.67 \pm 0.03$ & $-1.808 \pm 0.038$ & 0.006 & 0.07 \\
\hline 40111 & $139 \mathrm{Tau}$ & 14.81 & 14.86 & 15.16 & JSS86 & $0.49 \pm 0.04$ & $-1.580 \pm 0.049$ & -0.056 & -0.28 \\
\hline 40893 & HD 40893 & 15.27 & 15.32 & 15.38 & JS07a & $0.61 \pm 0.05$ & $-1.732 \pm 0.072$ & -0.022 & -0.19 \\
\hline 41161 & HD 41161 & 14.92 & 14.98 & 15.04 & $\mathrm{OH} 06$ & $0.44 \pm 0.04$ & $-1.516 \pm 0.054$ & -0.119 & -1.03 \\
\hline 44506 & HD 44506 & 14.53 & 14.61 & 14.66 & JSS86 & $-0.03 \pm 0.23$ & $-0.911 \pm 0.292$ & -0.107 & -0.21 \\
\hline 44743 & $\beta \mathrm{CMa}$ & 13.26 & 13.29 & 13.32 & DG98 & $-0.43 \pm 0.03$ & $-0.394 \pm 0.059$ & -0.154 & -1.73 \\
\hline $48915(+12)$ & $\alpha \mathrm{CMa}$ & 11.68 & 11.71 & 11.74 & $\mathrm{H}++99$ & $0.42 \pm 0.11$ & $-1.490 \pm 0.139$ & 0.262 & 1.07 \\
\hline$(+18)$ & & 11.89 & 11.91 & 11.92 & $\mathrm{H}++99$ & $0.42 \pm 0.08$ & $-1.487 \pm 0.106$ & 0.259 & 1.41 \\
\hline 52918 & 19 Mon & 13.98 & 14.11 & $\infty$ & JSS86 & $0.44 \pm 0.24$ & $-1.521 \pm 0.313$ & $\cdots$ & $\cdots$ \\
\hline 53975 & HD 53975 & 14.79 & 14.84 & 14.89 & OH06 & $0.45 \pm 0.03$ & $-1.528 \pm 0.039$ & -0.311 & -3.60 \\
\hline 54662 & HD 54662 & 14.81 & 14.91 & 14.98 & JSS86 & $0.89 \pm 0.09$ & $-2.089 \pm 0.120$ & 0.042 & 0.22 \\
\hline 55879 & HD 55879 & 14.03 & 14.41 & $\infty$ & JSS86 & $\cdots$ & $\cdots$ & $\cdots$ & $\cdots$ \\
\hline 57060 & $29 \mathrm{CMa}$ & 14.71 & 14.81 & 14.91 & JSS86 & $0.50 \pm 0.05$ & $-1.595 \pm 0.062$ & 0.163 & 1.10 \\
\hline 57061 & $\tau \mathrm{CMa}$ & 14.68 & 14.76 & 14.86 & JSS86 & $0.39 \pm 0.04$ & $-1.448 \pm 0.057$ & -0.034 & -0.30 \\
\hline 64740 & HD 64740 & 13.98 & 14.16 & 14.61 & JSS86 & $0.27 \pm 0.30$ & $-1.301 \pm 0.388$ & -0.133 & -0.23 \\
\hline 64760 & HD 64760 & 14.28 & 14.36 & 14.46 & JSS86 & $0.35 \pm 0.06$ & $-1.407 \pm 0.076$ & -0.035 & -0.22 \\
\hline 65575 & $\chi \mathrm{Car}$ & 13.78 & 13.86 & $\infty$ & JSS86 & $\cdots$ & $\cdots$ & $\cdots$ & $\cdots$ \\
\hline 65818 & V Pup & 14.28 & 14.46 & 14.76 & JSS86 & $0.36 \pm 0.09$ & $-1.417 \pm 0.116$ & -0.186 & -0.62 \\
\hline 66788 & HD 66788 & 15.07 & 15.14 & 15.22 & JS07a & $0.53 \pm 0.08$ & $-1.634 \pm 0.101$ & -0.020 & -0.13 \\
\hline 66811 & $\zeta$ Pup & 14.06 & 14.08 & 14.16 & M78 & $0.32 \pm 0.02$ & $-1.366 \pm 0.028$ & -0.050 & -0.72 \\
\hline 68273 & $\gamma^{2}$ Vel & 13.86 & 13.95 & 14.04 & FS94 & $0.25 \pm 0.02$ & $-1.274 \pm 0.030$ & -0.024 & -0.24 \\
\hline 69106 & HD 69106 & 14.49 & 14.74 & 15.03 & JS07a & $0.64 \pm 0.06$ & $-1.776 \pm 0.079$ & -0.114 & -0.40 \\
\hline 73882 & HD 73882 & 15.25 & 15.29 & 15.35 & JS07a & $0.68 \pm 0.07$ & $-1.822 \pm 0.093$ & 0.007 & 0.05 \\
\hline 74375 & HD 74375 & 14.39 & 14.59 & 14.79 & SB79 & $0.61 \pm 0.18$ & $-1.738 \pm 0.229$ & 0.005 & 0.02 \\
\hline 91597 & HD 91597 & 15.44 & 15.51 & 15.59 & JS07a & $0.44 \pm 0.05$ & $-1.522 \pm 0.072$ & 0.080 & 0.67 \\
\hline 91651 & HD 91651 & 15.34 & 15.37 & 15.40 & JS07a & $0.27 \pm 0.04$ & $-1.299 \pm 0.056$ & -0.027 & -0.30 \\
\hline 92554 & HD 92554 & 15.46 & 15.51 & 15.57 & JS07a & $0.27 \pm 0.07$ & $-1.297 \pm 0.092$ & -0.015 & -0.10 \\
\hline 93030 & $\theta$ Car & 14.13 & 14.20 & 14.26 & AJS92 & $0.45 \pm 0.03$ & $-1.523 \pm 0.043$ & -0.078 & -0.69 \\
\hline 93205 & V560 Car & 15.45 & 15.49 & 15.53 & JS07a & $0.40 \pm 0.03$ & $-1.464 \pm 0.038$ & 0.015 & 0.22 \\
\hline 93222 & HD 93222 & 15.48 & 15.55 & 15.63 & JS07a & $0.39 \pm 0.04$ & $-1.452 \pm 0.054$ & 0.043 & 0.39 \\
\hline $93521(-66)$ & HD 93521 & 13.55 & 13.59 & 13.63 & SF93 & $-0.31 \pm 0.11$ & $-0.552 \pm 0.143$ & 0.094 & 0.26 \\
\hline$(-58)$ & & 14.22 & 14.36 & 14.70 & SF93 & $-0.01 \pm 0.03$ & $-0.944 \pm 0.047$ & 0.426 & 1.65 \\
\hline$(-51)$ & & 13.88 & 13.91 & 13.94 & SF93 & $-0.04 \pm 0.04$ & $-0.904 \pm 0.061$ & 0.076 & 0.59 \\
\hline$(-39)$ & & 13.71 & 13.73 & 13.75 & SF93 & $0.01 \pm 0.08$ & $-0.959 \pm 0.109$ & 0.271 & 1.18 \\
\hline$(-29)$ & & 12.55 & 12.65 & 12.75 & SF93 & $0.34 \pm 0.17$ & $-1.389 \pm 0.216$ & 0.121 & 0.29 \\
\hline$(-18)$ & & 13.96 & 13.98 & 14.00 & SF93 & $0.00 \pm 0.03$ & $-0.955 \pm 0.044$ & 0.117 & 1.37 \\
\hline$(-10)$ & & 13.89 & 14.01 & 14.03 & SF93 & $0.02 \pm 0.04$ & $-0.978 \pm 0.055$ & 0.090 & 0.79 \\
\hline$(+3)$ & & 13.54 & 13.56 & 13.58 & SF93 & $0.25 \pm 0.04$ & $-1.275 \pm 0.050$ & -0.003 & -0.03 \\
\hline
\end{tabular}


Table 18-Continued

\begin{tabular}{|c|c|c|c|c|c|c|c|c|c|}
\hline \multirow[b]{2}{*}{$\begin{array}{c}\text { HD Number }{ }^{\mathrm{a}} \\
\text { (1) }\end{array}$} & \multirow[b]{2}{*}{$\begin{array}{c}\text { Name } \\
(2)\end{array}$} & \multicolumn{4}{|c|}{ Observed $\log N(\mathrm{Fe}$ II $)$} & \multirow[b]{2}{*}{$\begin{array}{l}F_{*} \\
(7)\end{array}$} & \multirow[b]{2}{*}{$\begin{array}{c}{\left[\mathrm{Fe}_{\text {gas }} / \mathrm{H}\right]_{\mathrm{fit}}{ }^{\mathrm{c}}} \\
(8)\end{array}$} & \multirow[b]{2}{*}{$\begin{array}{l}\text { Residual }^{\mathrm{d}} \\
(9)\end{array}$} & \multirow{2}{*}{$\begin{array}{c}\text { Deviation } \\
\quad \text { (in } \sigma) \\
\quad(10)\end{array}$} \\
\hline & & $\begin{array}{l}1.1 . \\
(3)\end{array}$ & $\begin{array}{l}\text { best } \\
(4)\end{array}$ & $\begin{array}{l}\text { u.l. } \\
(5)\end{array}$ & $\begin{array}{c}\text { Source }^{b} \\
(6)\end{array}$ & & & & \\
\hline$(+7)$ & & 12.95 & 12.99 & 13.03 & SF93 & $0.23 \pm 0.12$ & $-1.253 \pm 0.155$ & -0.085 & -0.29 \\
\hline (total) & & 14.74 & 14.82 & 14.98 & SF93 & $0.06 \pm 0.04$ & $-1.026 \pm 0.051$ & 0.202 & 1.36 \\
\hline 93843 & HD 93843 & 15.45 & 15.48 & 15.50 & JS07a & $0.39 \pm 0.05$ & $-1.448 \pm 0.067$ & 0.043 & 0.41 \\
\hline 94493 & HD 94493 & 15.46 & 15.52 & 15.58 & JS07a & $0.29 \pm 0.03$ & $-1.320 \pm 0.047$ & 0.133 & 1.56 \\
\hline 99171 & HD 99171 & 14.44 & 14.64 & 14.84 & SB79 & $\cdots$ & $\cdots$ & $\cdots$ & $\cdots$ \\
\hline 99857 & HD 99857 & 15.27 & 15.33 & 15.39 & JS07a & $0.54 \pm 0.04$ & $-1.644 \pm 0.058$ & 0.079 & 0.77 \\
\hline 99890 & HD 99890 & 15.24 & 15.28 & 15.33 & JS07a & $0.17 \pm 0.08$ & $-1.168 \pm 0.105$ & -0.049 & -0.29 \\
\hline 100340 & HD 100340 & 14.94 & $\infty$ & $\infty$ & SS96b & $0.10 \pm 0.06$ & $-1.077 \pm 0.077$ & $\cdots$ & $\cdots$ \\
\hline 103779 & HD 103779 & 15.12 & 15.17 & 15.22 & JS07a & $0.43 \pm 0.06$ & $-1.510 \pm 0.084$ & -0.056 & -0.42 \\
\hline 104705 & DF Cru & 15.32 & 15.40 & 15.42 & JS07a & $0.33 \pm 0.05$ & $-1.371 \pm 0.060$ & 0.057 & 0.53 \\
\hline 106490 & $\delta \mathrm{Cru}$ & 13.79 & 13.84 & 13.92 & JSS86 & $\cdots$ & . & $\cdots$ & $\cdots$ \\
\hline 108248 & $\alpha^{1} \mathrm{Cru}$ & 13.94 & 13.99 & 14.04 & JSS86 & $0.15 \pm 0.05$ & $-1.145 \pm 0.065$ & -0.004 & -0.03 \\
\hline 109399 & HD 109399 & 15.17 & 15.22 & 15.28 & JS07a & $0.48 \pm 0.05$ & $-1.575 \pm 0.066$ & 0.078 & 0.75 \\
\hline 110432 & BZ Cru & 14.20 & 14.30 & 14.43 & SRF02 & $1.17 \pm 0.11$ & $-2.457 \pm 0.144$ & 0.021 & 0.10 \\
\hline 113904 & $\theta$ Mus & 14.93 & 15.06 & 15.46 & JSS86 & $\cdots$ & & $\cdots$ & $\ldots$ \\
\hline 116658 & $\alpha$ Vir & 13.14 & 13.34 & 13.45 & YK79 & $0.16 \pm 0.05$ & $-1.160 \pm 0.065$ & -0.042 & -0.22 \\
\hline 116781 & V967 Cen & 15.20 & 15.27 & 15.36 & JS07a & $0.44 \pm 0.07$ & $-1.522 \pm 0.087$ & 0.010 & 0.07 \\
\hline 116852 & HD 116852 & 15.22 & 15.24 & 15.26 & SS96a & $0.36 \pm 0.04$ & $-1.409 \pm 0.047$ & 0.094 & 0.98 \\
\hline 118716 & $\epsilon$ Cen & 13.94 & 13.99 & 14.07 & JSS86 & $0.15 \pm 0.16$ & $-1.143 \pm 0.212$ & -0.008 & -0.02 \\
\hline 120086 & HD 120086 & 14.41 & 14.46 & 14.56 & JW96 & $\cdots$ & $\cdots$ & $\cdots$ & $\cdots$ \\
\hline 120324 & $\mu$ Cen & 13.94 & 14.14 & 14.59 & JSS86 & $-0.81 \pm 3.74$ & $0.088 \pm 4.803$ & -0.245 & -0.03 \\
\hline 121263 & $\zeta$ Cen & 13.79 & 13.84 & 13.94 & JSS86 & $\cdots$ & $\cdots$ & $\ldots$ & $\ldots$ \\
\hline 122879 & HD 122879 & 15.20 & 15.25 & 15.31 & JS07a & $0.55 \pm 0.04$ & $-1.652 \pm 0.057$ & 0.028 & 0.22 \\
\hline 124314 & HD 124314 & 15.22 & 15.27 & 15.33 & JS07a & $0.59 \pm 0.05$ & $-1.704 \pm 0.068$ & -0.073 & -0.65 \\
\hline 127972 & $\eta$ Cen & 13.81 & 13.86 & 13.91 & JSS86 & $\ldots$ & $\cdots$ & $\ldots$ & $\ldots$ \\
\hline 135591 & HD 135591 & 14.56 & 14.76 & $\infty$ & JSS86 & $0.56 \pm 0.22$ & $-1.677 \pm 0.284$ & $\cdots$ & $\cdots$ \\
\hline 136298 & $\delta$ Lup & 13.92 & 13.99 & 14.07 & JSS86 & $\cdots$ & $\cdots$ & $\cdots$ & $\cdots$ \\
\hline 138690 & $\gamma \operatorname{Lup}$ & 13.89 & 13.94 & 14.02 & JSS86 & $\cdots$ & $\cdots$ & $\cdots$ & $\cdots$ \\
\hline 141637 & $1 \mathrm{Sco}$ & 14.71 & 14.81 & 15.11 & JSS86 & $0.69 \pm 0.05$ & $-1.837 \pm 0.067$ & -0.029 & -0.12 \\
\hline 143018 & $\pi \mathrm{Sco}$ & 14.36 & 14.46 & 14.56 & JJ91 & $0.71 \pm 0.03$ & $-1.858 \pm 0.046$ & 0.090 & 0.72 \\
\hline 143118 & $\eta \operatorname{Lup} \mathrm{A}$ & 14.13 & 14.21 & 14.28 & JSS86 & $\cdots$ & $\cdots$ & $\cdots$ & $\cdots$ \\
\hline 143275 & $\delta \mathrm{Sco}$ & 14.66 & 14.76 & 14.86 & JSS86 & $0.90 \pm 0.03$ & $-2.103 \pm 0.050$ & 0.155 & 1.09 \\
\hline 144217 & $\beta^{1} \mathrm{Sco}$ & 14.73 & 14.81 & 15.16 & JSS86 & $0.81 \pm 0.02$ & $-1.995 \pm 0.034$ & 0.127 & 0.58 \\
\hline 144470 & $\mathrm{o}^{1} \mathrm{Sco}$ & 14.68 & 14.76 & 14.88 & JSS86 & $0.81 \pm 0.04$ & $-1.987 \pm 0.053$ & -0.025 & -0.18 \\
\hline 145502 & $\nu \mathrm{Sco}$ & 14.46 & 14.86 & $\infty$ & JSS86 & $0.80 \pm 0.11$ & $-1.977 \pm 0.147$ & $\ldots$ & $\ldots$ \\
\hline 147165 & $\sigma \mathrm{Sco}$ & 14.96 & 15.11 & $\infty$ & JSS86 & $0.76 \pm 0.06$ & $-1.934 \pm 0.081$ & $\cdots$ & $\cdots$ \\
\hline 147888 & $\rho$ Oph D & 15.48 & 15.50 & 15.53 & JS07a & $0.88 \pm 0.06$ & $-2.083 \pm 0.086$ & 0.307 & 1.79 \\
\hline 147933 & $\rho \mathrm{Oph} \mathrm{A}$ & 14.65 & 14.90 & $\infty$ & $\mathrm{M}++07$ & $1.09 \pm 0.08$ & $-2.355 \pm 0.111$ & $\cdots$ & $\cdots$ \\
\hline 148184 & $\chi \mathrm{Oph}$ & 14.71 & 14.81 & $\infty$ & JSS86 & $0.96 \pm 0.09$ & $-2.181 \pm 0.124$ & $\ldots$ & $\ldots$ \\
\hline
\end{tabular}


Table 18-Continued

\begin{tabular}{|c|c|c|c|c|c|c|c|c|c|}
\hline \multirow[b]{2}{*}{$\begin{array}{c}\text { HD Number }{ }^{\mathrm{a}} \\
\text { (1) }\end{array}$} & \multirow[b]{2}{*}{$\begin{array}{l}\text { Name } \\
(2)\end{array}$} & \multicolumn{4}{|c|}{ Observed $\log N(\mathrm{Fe} \mathrm{II})$} & \multirow[b]{2}{*}{$\begin{array}{l}F_{*} \\
(7)\end{array}$} & \multirow[b]{2}{*}{$\begin{array}{c}{\left[\mathrm{Fe}_{\text {gas }} / \mathrm{H}\right]_{\mathrm{fit}}{ }^{\mathrm{c}}} \\
(8)\end{array}$} & \multirow[b]{2}{*}{$\begin{array}{l}\text { Residual }^{\mathrm{d}} \\
\quad(9)\end{array}$} & \multirow{2}{*}{$\begin{array}{l}\text { Deviation } \\
\quad \text { in } \sigma) \\
(10)\end{array}$} \\
\hline & & $\begin{array}{l}1.1 . \\
(3)\end{array}$ & $\begin{array}{l}\text { best } \\
(4)\end{array}$ & $\begin{array}{l}\text { u.l. } \\
(5)\end{array}$ & $\begin{array}{c}\text { Source }^{b} \\
(6)\end{array}$ & & & & \\
\hline 148605 & $22 \mathrm{Sco}$ & 14.31 & 14.71 & $\infty$ & JSS86 & $0.53 \pm 0.39$ & $-1.632 \pm 0.507$ & 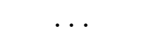 & $\cdots$ \\
\hline 149038 & $\mu$ Nor & 14.68 & 15.01 & $\infty$ & JSS86 & $0.56 \pm 0.05$ & $-1.666 \pm 0.062$ & & $\ldots$ \\
\hline $149757(-27)$ & $\zeta \mathrm{Oph}$ & 13.99 & 14.03 & 14.06 & SCS92 & $\cdots$ & $\cdots$ & $\cdots$ & $\cdots$ \\
\hline$(-15)$ & & 14.36 & 14.39 & 14.41 & SCS92 & $1.05 \pm 0.02$ & $-2.295 \pm 0.039$ & -0.007 & -0.10 \\
\hline 149881 & V600 Her & 15.14 & 15.20 & 15.26 & SF95 & $0.07 \pm 0.06$ & $-1.036 \pm 0.083$ & 0.049 & 0.23 \\
\hline 151804 & V973 Sco & 15.06 & 15.11 & 15.23 & JSS86 & $0.57 \pm 0.08$ & $-1.690 \pm 0.098$ & 0.063 & 0.37 \\
\hline 151890 & $\mu^{1} \mathrm{Sco}$ & 14.23 & 14.31 & 14.33 & JSS86 & $-0.03 \pm 3.47$ & $-0.914 \pm 4.464$ & 0.097 & 0.01 \\
\hline 152236 & $\zeta^{1} \mathrm{Sco}$ & 15.15 & 15.23 & 15.32 & JS07a & $0.80 \pm 0.06$ & $-1.984 \pm 0.076$ & -0.166 & -1.04 \\
\hline 152590 & HD 152590 & 15.17 & 15.19 & 15.20 & $\mathrm{M}++07$ & $0.69 \pm 0.03$ & $-1.839 \pm 0.042$ & 0.021 & 0.32 \\
\hline 154368 & V1074 Sco & 15.20 & 15.31 & 15.46 & SRF02 & $0.52 \pm 0.07$ & $-1.614 \pm 0.086$ & -0.203 & -1.23 \\
\hline 155806 & V1075 Sco & 14.88 & 14.96 & 15.21 & JSS86 & $0.62 \pm 0.07$ & $-1.752 \pm 0.086$ & 0.034 & 0.16 \\
\hline 157246 & $\gamma$ Ara & 14.56 & 14.66 & 14.73 & JSS86 & $0.46 \pm 0.03$ & $-1.541 \pm 0.045$ & -0.047 & -0.36 \\
\hline 158926 & $\lambda \mathrm{Sco}$ & 13.35 & 13.39 & 13.42 & Y83 & $0.31 \pm 0.02$ & $-1.352 \pm 0.027$ & -0.026 & -0.49 \\
\hline 160578 & $\kappa \mathrm{Sco}$ & 13.99 & 14.09 & 14.17 & JSS86 & $0.50 \pm 0.07$ & $-1.588 \pm 0.095$ & -0.083 & -0.41 \\
\hline 164284 & $66 \mathrm{Oph}$ & 14.38 & 14.51 & 14.61 & JSS86 & $0.89 \pm 0.18$ & $-2.095 \pm 0.231$ & 0.317 & 0.76 \\
\hline 165024 & $\theta$ Ara & 14.63 & 14.71 & 14.81 & JSS86 & $0.56 \pm 0.03$ & $-1.676 \pm 0.047$ & 0.004 & 0.03 \\
\hline 167264 & $15 \mathrm{Sgr}$ & 14.73 & 15.01 & $\infty$ & JSS86 & $0.68 \pm 0.16$ & $-1.826 \pm 0.202$ & $\cdots$ & $\cdots$ \\
\hline 167756 & HD 167756 & 14.90 & $\infty$ & $\infty$ & CSS95 & $\cdots$ & $\cdots$ & $\cdots$ & $\cdots$ \\
\hline 167971 & MY Ser & 15.26 & 15.42 & 15.62 & SRF02 & $0.70 \pm 0.23$ & $-1.857 \pm 0.292$ & 0.007 & 0.02 \\
\hline 168076 & HD 168076 & 15.35 & 15.45 & 15.55 & SRF02 & $0.68 \pm 0.17$ & $-1.828 \pm 0.219$ & 0.007 & 0.02 \\
\hline 168941 & HD 168941 & 15.36 & 15.42 & 15.49 & JS07a & $0.42 \pm 0.17$ & $-1.486 \pm 0.213$ & 0.180 & 0.54 \\
\hline 170740 & HD 170740 & 14.59 & 14.69 & 14.79 & SRF02 & $1.02 \pm 0.11$ & $-2.263 \pm 0.150$ & 0.015 & 0.07 \\
\hline 177989 & HD 177989 & 14.89 & 14.95 & 15.01 & JS07a & $0.55 \pm 0.05$ & $-1.662 \pm 0.060$ & -0.010 & -0.09 \\
\hline 179406 & $20 \mathrm{Aql}$ & 14.57 & 14.72 & 14.89 & JS07a & $\cdots$ & $\cdots$ & $\cdots$ & $\cdots$ \\
\hline 184915 & $\kappa \mathrm{Aql}$ & 14.61 & 14.86 & $\infty$ & JSS86 & $0.88 \pm 0.05$ & $-2.078 \pm 0.068$ & $\cdots$ & $\cdots$ \\
\hline 185418 & HD 185418 & 14.90 & 15.00 & 15.12 & SRF02 & $0.79 \pm 0.03$ & $-1.968 \pm 0.048$ & 0.021 & 0.15 \\
\hline 188209 & HD 188209 & 14.88 & 15.01 & $\infty$ & JSS86 & $0.66 \pm 0.12$ & $-1.804 \pm 0.157$ & $\cdots$ & $\cdots$ \\
\hline 192639 & HD 192639 & 15.06 & 15.14 & 15.24 & SRF02 & $0.64 \pm 0.04$ & $-1.774 \pm 0.051$ & -0.104 & -0.84 \\
\hline 193322 & HD 193322 & 14.61 & 14.86 & $\infty$ & JSS86 & $\cdots$ & $\cdots$ & $\cdots$ & $\cdots$ \\
\hline 197512 & HD 197512 & 14.94 & 15.06 & 15.21 & SRF02 & $\cdots$ & $\cdots$ & $\cdots$ & $\cdots$ \\
\hline 199579 & HD 199579 & 14.80 & 14.87 & 14.14 & SRF02 & $0.76 \pm 0.27$ & $-1.933 \pm 0.345$ & 0.017 & 0.04 \\
\hline 200120 & 59 Cyg & 13.98 & 14.11 & 14.36 & JSS86 & $\cdots$ & $\cdots$ & $\cdots$ & $\ldots$ \\
\hline 202347 & HD 202347 & 14.80 & 14.84 & 14.87 & JS07a & $0.56 \pm 0.06$ & $-1.668 \pm 0.082$ & 0.034 & 0.25 \\
\hline 202904 & $v$ Cyg & 14.26 & 14.31 & 14.36 & JSS86 & $\cdots$ & $\cdots$ & $\cdots$ & $\cdots$ \\
\hline 203064 & $68 \mathrm{Cyg}$ & 14.68 & 14.96 & $\infty$ & JSS86 & $0.68 \pm 0.20$ & $-1.826 \pm 0.263$ & $\cdots$ & $\cdots$ \\
\hline 203374 & HD 203374 & 15.18 & 15.22 & 15.25 & JS07a & $0.56 \pm 0.06$ & $-1.667 \pm 0.077$ & 0.019 & 0.16 \\
\hline 203938 & HD 203938 & 14.84 & 15.03 & 16.43 & SRF02 & $0.99 \pm 0.64$ & $-2.222 \pm 0.818$ & 0.015 & 0.01 \\
\hline 206267 & HD 206267 & 14.89 & 14.97 & 15.07 & SRF02 & $0.87 \pm 0.07$ & $-2.065 \pm 0.093$ & -0.039 & -0.25 \\
\hline 207198 & HD 207198 & 15.06 & 15.13 & 15.19 & $\mathrm{M}++07$ & $0.90 \pm 0.03$ & $-2.107 \pm 0.047$ & 0.021 & 0.22 \\
\hline
\end{tabular}


Table 18-Continued

\begin{tabular}{|c|c|c|c|c|c|c|c|c|c|}
\hline \multirow[b]{2}{*}{$\begin{array}{l}\text { HD Number } \\
\text { (1) }\end{array}$} & \multirow[b]{2}{*}{$\begin{array}{l}\text { Name } \\
(2)\end{array}$} & \multicolumn{4}{|c|}{ Observed $\log N($ Fe II $)$} & \multirow[b]{2}{*}{$\begin{array}{l}F_{*} \\
(7)\end{array}$} & \multirow[b]{2}{*}{$\begin{array}{c}{\left[\mathrm{Fe}_{\text {gas }} / \mathrm{H}\right]_{\mathrm{fit}}{ }^{\mathrm{c}}} \\
(8)\end{array}$} & \multirow[b]{2}{*}{$\begin{array}{l}\text { Residual }^{\mathrm{d}} \\
\quad(9)\end{array}$} & \multirow{2}{*}{$\begin{array}{l}\text { Deviation } \\
\text { (in } \sigma) \\
(10)\end{array}$} \\
\hline & & $\begin{array}{l}1.1 . \\
(3)\end{array}$ & $\begin{array}{l}\text { best } \\
(4)\end{array}$ & $\begin{array}{l}\text { u.l. } \\
(5)\end{array}$ & $\begin{array}{c}\text { Source }^{b} \\
(6)\end{array}$ & & & & \\
\hline 207308 & HD 207308 & 15.02 & 15.10 & 15.19 & JS07a & $0.80 \pm 0.06$ & $-1.976 \pm 0.079$ & 0.101 & 0.77 \\
\hline 207538 & HD 207538 & 14.91 & 15.02 & 15.24 & SRF02 & $0.84 \pm 0.07$ & $-2.033 \pm 0.094$ & -0.065 & -0.32 \\
\hline 209339 & HD 209339 & 15.05 & 15.09 & 15.13 & JS07a & $0.58 \pm 0.04$ & $-1.692 \pm 0.056$ & -0.018 & -0.19 \\
\hline 209975 & 19 Cep & 15.06 & 15.46 & $\infty$ & JSS86 & $0.57 \pm 0.26$ & $-1.688 \pm 0.337$ & $\cdots$ & $\cdots$ \\
\hline 210839 & $\lambda$ Cep & 15.07 & 15.12 & 15.18 & SRF02 & $0.66 \pm 0.03$ & $-1.796 \pm 0.045$ & -0.068 & -0.71 \\
\hline 214080 & HD 214080 & 14.73 & 15.21 & $\infty$ & JSS86 & $0.27 \pm 0.10$ & $-1.297 \pm 0.131$ & $\ldots$ & $\cdots$ \\
\hline 214680 & $10 \mathrm{Lac}$ & 14.18 & 14.31 & 14.51 & JSS86 & $0.50 \pm 0.06$ & $-1.589 \pm 0.083$ & -0.371 & -1.67 \\
\hline 214993 & $12 \mathrm{Lac}$ & 14.88 & 15.01 & $\infty$ & JSS86 & $0.68 \pm 0.10$ & $-1.826 \pm 0.124$ & $\cdots$ & $\cdots$ \\
\hline $215733(-93)$ & HD 215733 & 12.58 & 12.59 & 12.60 & FS97 & $-0.27 \pm 0.19$ & $-0.607 \pm 0.248$ & 0.270 & 0.59 \\
\hline$(-83)$ & & 12.06 & 12.09 & 12.12 & FS97 & $0.99 \pm 0.30$ & $-2.221 \pm 0.384$ & 0.374 & 0.60 \\
\hline$(-61)$ & & 12.76 & 13.02 & 13.28 & FS97 & $1.06 \pm 0.21$ & $-2.318 \pm 0.270$ & 0.361 & 0.71 \\
\hline$(-59)$ & & 13.82 & 13.86 & 13.90 & FS97 & $-0.11 \pm 0.10$ & $-0.810 \pm 0.129$ & 0.183 & 0.60 \\
\hline$(-54)$ & & 13.73 & 13.77 & 13.81 & FS97 & $0.54 \pm 0.15$ & $-1.650 \pm 0.194$ & 0.253 & 0.55 \\
\hline$(-47)$ & & 13.91 & 13.97 & 14.03 & FS97 & $\cdots$ & $\cdots$ & $\cdots$ & $\ldots$ \\
\hline$(-45)$ & & 13.08 & 13.23 & 13.38 & FS97 & $-0.40 \pm 0.28$ & $-0.431 \pm 0.359$ & 0.064 & 0.10 \\
\hline$(-42)$ & & 13.57 & 13.68 & 13.79 & FS97 & $-0.16 \pm 0.31$ & $-0.741 \pm 0.403$ & 0.354 & 0.37 \\
\hline$(-40)$ & & 12.88 & 13.12 & 13.36 & FS97 & $0.18 \pm 0.24$ & $-1.184 \pm 0.314$ & -0.043 & -0.06 \\
\hline$(-32)$ & & 14.06 & 14.25 & 14.44 & FS97 & $0.25 \pm 0.09$ & $-1.269 \pm 0.116$ & 0.342 & 1.30 \\
\hline$(-31)$ & & 13.37 & 13.60 & 13.83 & FS97 & $\cdots$ & $\cdots$ & $\cdots$ & $\cdots$ \\
\hline$(-28)$ & & 13.74 & 13.88 & 14.02 & FS97 & $-0.18 \pm 0.07$ & $-0.715 \pm 0.090$ & 0.148 & 0.75 \\
\hline$(-26)$ & & 13.77 & 13.94 & 14.11 & FS97 & $-0.12 \pm 0.07$ & $-0.794 \pm 0.089$ & 0.087 & 0.38 \\
\hline$(-23)$ & & 13.33 & 13.52 & 13.71 & FS97 & $0.24 \pm 0.08$ & $-1.264 \pm 0.105$ & -0.003 & -0.02 \\
\hline$(-21)$ & & 13.65 & 13.76 & 13.87 & FS97 & $0.24 \pm 0.05$ & $-1.256 \pm 0.068$ & 0.109 & 0.74 \\
\hline$(-19)$ & & 13.36 & 13.47 & 13.58 & FS97 & $\cdots$ & $\cdots$ & $\cdots$ & $\cdots$ \\
\hline$(-16)$ & & 13.30 & 13.43 & 13.56 & FS97 & $0.93 \pm 0.05$ & $-2.143 \pm 0.071$ & -0.074 & -0.47 \\
\hline$(-9)$ & & 14.54 & 14.56 & 14.58 & FS97 & $0.08 \pm 0.04$ & $-1.053 \pm 0.050$ & 0.006 & 0.07 \\
\hline$(+1)$ & & 13.22 & 13.29 & 13.36 & FS97 & $0.90 \pm 0.05$ & $-2.114 \pm 0.072$ & 0.157 & 1.40 \\
\hline$(+9)$ & & 12.13 & 12.20 & 12.27 & FS97 & $\cdots$ & $\cdots$ & $\cdots$ & $\cdots$ \\
\hline$(+15)$ & & 11.79 & 11.88 & 11.97 & FS97 & $0.96 \pm 0.08$ & $-2.184 \pm 0.107$ & 0.107 & 0.64 \\
\hline (total) & & 15.00 & 15.09 & 15.19 & FS97 & $\cdots$ & $\ldots$ & $\cdots$ & $\ldots$ \\
\hline 217675 & o And & 13.23 & 14.01 & $\infty$ & JSS86 & $\cdots$ & $\cdots$ & $\cdots$ & $\cdots$ \\
\hline 218376 & 1 Cas & 14.81 & 15.01 & $\infty$ & JSS86 & $0.60 \pm 0.06$ & $-1.724 \pm 0.080$ & $\cdots$ & $\cdots$ \\
\hline 219188 & HD 219188 & 14.21 & 14.46 & $\infty$ & JSS86 & $1.24 \pm 0.57$ & $-2.544 \pm 0.737$ & $\cdots$ & $\cdots$ \\
\hline 224151 & V373 Cas & 15.47 & 15.52 & 15.59 & JS07a & $0.46 \pm 0.04$ & $-1.549 \pm 0.057$ & 0.068 & 0.67 \\
\hline 224572 & $\sigma$ Cas & 14.66 & 14.76 & 15.01 & JSS86 & $0.76 \pm 0.07$ & $-1.927 \pm 0.094$ & 0.165 & 0.74 \\
\hline \multirow[t]{3}{*}{303308} & HDE 303308 & 15.55 & 15.60 & 15.65 & JS07a & $0.38 \pm 0.04$ & $-1.443 \pm 0.051$ & 0.027 & 0.28 \\
\hline & $\mathrm{BD}+354258$ & 15.36 & 15.44 & 15.53 & JS07a & $0.40 \pm 0.08$ & $-1.472 \pm 0.102$ & 0.078 & 0.47 \\
\hline & CPD -59 2603 & 15.55 & 15.59 & 15.64 & JS07a & $0.17 \pm 0.06$ & $-1.167 \pm 0.083$ & 0.015 & 0.11 \\
\hline
\end{tabular}


aTerms in parentheses indicate separate velocity components, if they are explicitly identified and not grouped together; see 4.3

${ }^{\mathrm{b}}$ Codes in this column are linked to references listed in Table 1

${ }^{\mathrm{c}}$ The expected depletion $\left[\mathrm{Fe}_{\text {gas }} / \mathrm{H}\right]$ computed using Eq. 10. The listed errors do not include an overall systematic uncertainty of 0.03 in the solar abundance $\sigma(\mathrm{Fe} / \mathrm{H})_{\odot}$ in order to show just the formal error that arises from the uncertainties in location of line of best fit and the value of $F_{*}$.

d The observed $\left[\mathrm{Fe}_{\text {gas }} / \mathrm{H}\right]$ minus that computed using Eq. 10 ,

'The difference shown in the previous column divided by the expected difference due to the uncertainties in both the measured column density and the coefficients that appear in Eq. 10. 
Table 19. Observations and Fits for Nickel

\begin{tabular}{|c|c|c|c|c|c|c|c|c|c|}
\hline \multirow[b]{2}{*}{$\begin{array}{c}\text { HD Number } \\
\text { (1) }\end{array}$} & \multirow[b]{2}{*}{$\begin{array}{l}\text { Name } \\
(2)\end{array}$} & \multicolumn{4}{|c|}{ Observed $\log N(\mathrm{Ni}$ II $)$} & \multirow[b]{2}{*}{$\begin{array}{l}F_{*} \\
(7)\end{array}$} & \multirow[b]{2}{*}{$\begin{array}{c}{\left[\mathrm{Ni}_{\text {gas }} / \mathrm{H}\right]_{\mathrm{fit}}{ }^{\mathrm{c}}} \\
(8)\end{array}$} & \multirow[b]{2}{*}{$\begin{array}{l}\text { Residual }^{\mathrm{d}} \\
\quad(9)\end{array}$} & \multirow{2}{*}{$\begin{array}{l}\text { Deviation } \\
\text { (in } \sigma) \\
\quad(10)\end{array}$} \\
\hline & & $\begin{array}{l}1.1 . \\
(3)\end{array}$ & $\begin{array}{c}\text { best } \\
(4)\end{array}$ & $\begin{array}{l}\text { u.l. } \\
(5)\end{array}$ & $\begin{array}{c}\text { Source }^{b} \\
(6)\end{array}$ & & & & \\
\hline 1383 & HD 1383 & 13.95 & 13.98 & 14.01 & CLMS06 & $0.61 \pm 0.04$ & $-1.848 \pm 0.066$ & 0.030 & 0.28 \\
\hline 2905 & $\kappa$ Cas & 13.27 & 13.51 & 14.21 & JSS86 & $0.58 \pm 0.06$ & $-1.802 \pm 0.088$ & -0.266 & -0.54 \\
\hline 12323 & HD 12323 & 13.97 & 14.00 & 14.03 & CLMS06 & $0.52 \pm 0.04$ & $-1.717 \pm 0.056$ & 0.137 & 1.42 \\
\hline 13268 & HD 13268 & 14.07 & 14.11 & 14.15 & CLMS06 & $0.51 \pm 0.04$ & $-1.703 \pm 0.062$ & 0.102 & 0.98 \\
\hline 14434 & HD 14434 & 14.08 & 14.12 & 14.16 & CLMS06 & $0.52 \pm 0.04$ & $-1.709 \pm 0.066$ & 0.067 & 0.63 \\
\hline 18100 & HD 18100 & 13.41 & 13.46 & 13.51 & SS96b & $0.14 \pm 0.04$ & $-1.140 \pm 0.074$ & 0.154 & 0.96 \\
\hline 22586 & HD 22586 & 13.35 & 13.40 & 13.50 & JW96 & $0.34 \pm 0.07$ & $-1.444 \pm 0.101$ & 0.200 & 0.96 \\
\hline 22951 & 40 Per & 13.22 & 13.44 & 13.83 & JSS86 & $0.73 \pm 0.05$ & $-2.027 \pm 0.079$ & -0.043 & -0.13 \\
\hline 23180 & o Per & $\cdots$ & $\cdots$ & 12.63 & S76 & $0.84 \pm 0.06$ & $-2.193 \pm 0.100$ & $\cdots$ & $\cdots$ \\
\hline 24912 & $\xi$ Per & 13.27 & 13.32 & 13.36 & $\mathrm{C}++91$ & $0.83 \pm 0.02$ & $-2.176 \pm 0.043$ & -0.087 & -0.88 \\
\hline 27778 & $62 \mathrm{Tau}$ & 13.00 & 13.04 & 13.08 & CLMS06 & $\cdots$ & $\cdots$ & $\cdots$ & $\cdots$ \\
\hline 35149 & 23 Ori & 12.85 & 12.98 & 13.08 & $\mathrm{~W}++99$ & $0.54 \pm 0.04$ & $-1.740 \pm 0.059$ & -0.205 & -1.10 \\
\hline 36841 & HD 36841 & 12.98 & 13.05 & 13.12 & CLMS06 & $\cdots$ & $\cdots$ & $\cdots$ & $\cdots$ \\
\hline 37021 & $\theta^{1}$ Ori & 13.78 & 13.80 & 13.82 & CLMS06 & $\cdots$ & $\cdots$ & $\cdots$ & $\cdots$ \\
\hline 37903 & HD 37903 & 13.10 & 13.13 & 13.16 & CLMS06 & $1.15 \pm 0.03$ & $-2.647 \pm 0.061$ & 0.046 & 0.51 \\
\hline 38666 & $\mu \mathrm{Col}$ & 12.92 & 12.96 & 13.02 & HSF99 & $0.11 \pm 0.01$ & $-1.103 \pm 0.038$ & -0.087 & -1.33 \\
\hline 40111 & 139 Tau & 12.89 & 13.30 & 13.51 & JSS86 & $0.49 \pm 0.04$ & $-1.666 \pm 0.058$ & -0.275 & -0.84 \\
\hline 43818 & LU Gem & 13.92 & 13.95 & 13.98 & CLMS06 & $\cdots$ & $\cdots$ & $\cdots$ & $\cdots$ \\
\hline 52266 & HD 52266 & 13.73 & 13.75 & 13.77 & CLMS06 & $\cdots$ & $\cdots$ & $\cdots$ & $\cdots$ \\
\hline 54662 & HD 54662 & 13.10 & 13.53 & 14.37 & JSS86 & $0.89 \pm 0.09$ & $-2.256 \pm 0.139$ & 0.085 & 0.13 \\
\hline 63005 & HD 63005 & 13.77 & 13.79 & 13.81 & CLMS06 & $0.64 \pm 0.03$ & $-1.890 \pm 0.047$ & 0.069 & 0.94 \\
\hline 66811 & $\zeta$ Pup & 12.30 & 12.70 & 13.10 & M78 & $0.32 \pm 0.02$ & $-1.417 \pm 0.038$ & -0.131 & -0.32 \\
\hline 71634 & HD 71634 & 13.25 & 13.32 & 13.39 & CLMS06 & $\cdots$ & $\cdots$ & $\cdots$ & $\cdots$ \\
\hline 75309 & HD 75309 & 13.44 & 13.49 & 13.54 & CLMS06 & $0.63 \pm 0.04$ & $-1.869 \pm 0.060$ & -0.112 & -1.03 \\
\hline 79186 & GX Vel & 13.68 & 13.70 & 13.72 & CLMS06 & $0.69 \pm 0.03$ & $-1.964 \pm 0.054$ & -0.038 & -0.43 \\
\hline 91824 & HD 91824 & 13.77 & 13.82 & 13.87 & CLMS06 & $0.45 \pm 0.03$ & $-1.601 \pm 0.050$ & -0.037 & -0.42 \\
\hline 91983 & HD 91983 & 13.81 & 13.86 & 13.91 & CLMS06 & $0.48 \pm 0.04$ & $-1.646 \pm 0.063$ & -0.027 & -0.24 \\
\hline 100340 & HD 100340 & 13.85 & 13.90 & 13.95 & SS96b & $0.10 \pm 0.06$ & $-1.083 \pm 0.094$ & 0.226 & 1.55 \\
\hline 111934 & BU Cru & 13.89 & 14.00 & 14.11 & CLMS06 & $\cdots$ & $\ldots$ & $\ldots$ & $\ldots$ \\
\hline 116658 & $\alpha$ Vir & $\cdots$ & $\cdots$ & 12.17 & YK79 & $0.16 \pm 0.05$ & $-1.179 \pm 0.080$ & $\cdots$ & $\cdots$ \\
\hline 116852 & HD 116852 & $14.01^{\mathrm{f}}$ & $14.05^{\mathrm{f}}$ & $14.09^{\mathrm{f}}$ & CLMS06 & $0.36 \pm 0.04$ & $-1.467 \pm 0.057$ & 0.208 & 1.95 \\
\hline 120086 & HD 120086 & 13.85 & 13.90 & 14.00 & JW96 & $\cdots$ & $\cdots$ & $\cdots$ & $\cdots$ \\
\hline 122879 & HD 122879 & 13.74 & 13.75 & 13.76 & CLMS06 & $0.55 \pm 0.04$ & $-1.749 \pm 0.067$ & -0.131 & -1.07 \\
\hline 143275 & $\delta$ Sco & 13.01 & 13.09 & 13.15 & JSS86 & $0.90 \pm 0.03$ & $-2.271 \pm 0.058$ & -0.090 & -0.72 \\
\hline 147888 & $\rho$ Oph D & 13.77 & 13.83 & 13.89 & CLMS06 & $0.88 \pm 0.06$ & $-2.248 \pm 0.099$ & 0.047 & 0.25 \\
\hline 147933 & $\rho \mathrm{Oph} \mathrm{A}$ & 12.09 & 12.95 & 13.78 & JSS86 & $1.09 \pm 0.08$ & $-2.564 \pm 0.128$ & -0.473 & -0.55 \\
\hline 148184 & $\chi \mathrm{Oph}$ & $\cdots$ & 12.68 & 13.07 & JSS86 & $0.96 \pm 0.09$ & $-2.363 \pm 0.144$ & $\cdots$ & $\cdots$ \\
\hline 148594 & HD 148594 & 13.35 & 13.38 & 13.41 & CLMS06 & $\cdots$ & $\cdots$ & $\cdots$ & $\cdots$ \\
\hline $149757(-27)$ & $\zeta \mathrm{Oph}$ & 12.76 & 12.79 & 12.82 & SCS92 & $\cdots$ & $\cdots$ & $\cdots$ & $\cdots$ \\
\hline
\end{tabular}


Table 19-Continued

\begin{tabular}{|c|c|c|c|c|c|c|c|c|c|}
\hline \multirow[b]{2}{*}{$\begin{array}{c}\text { HD Number }{ }^{\mathrm{a}} \\
(1)\end{array}$} & \multirow[b]{2}{*}{$\begin{array}{c}\text { Name } \\
(2)\end{array}$} & \multicolumn{4}{|c|}{ Observed $\log N(\mathrm{Ni}$ II $)$} & \multirow[b]{2}{*}{$\begin{array}{l}F_{*} \\
(7)\end{array}$} & \multirow[b]{2}{*}{$\begin{array}{c}{\left[\mathrm{Ni}_{\text {gas }} / \mathrm{H}\right]_{\mathrm{fit}}{ }^{\mathrm{c}}} \\
(8)\end{array}$} & \multirow[b]{2}{*}{$\begin{array}{c}\text { Residual }^{\mathrm{d}} \\
(9)\end{array}$} & \multirow{2}{*}{$\begin{array}{l}\text { Deviation }^{\mathrm{e}} \\
\quad \text { (in } \sigma) \\
\quad(10)\end{array}$} \\
\hline & & $\begin{array}{l}1.1 . \\
(3)\end{array}$ & $\begin{array}{l}\text { best } \\
(4)\end{array}$ & $\begin{array}{l}\text { u.l. } \\
(5)\end{array}$ & $\begin{array}{c}\text { Source }^{b} \\
(6)\end{array}$ & & & & \\
\hline$(-15)$ & & 12.92 & 12.94 & 12.96 & SCS92 & $1.05 \pm 0.02$ & $-2.494 \pm 0.044$ & -0.004 & -0.05 \\
\hline 151804 & V973 Sco & 13.14 & 13.45 & 13.69 & JSS86 & $0.57 \pm 0.08$ & $-1.793 \pm 0.114$ & -0.238 & -0.75 \\
\hline 154368 & V1074 Sco & 13.87 & 14.17 & 14.47 & $\mathrm{~S}++96$ & $0.52 \pm 0.07$ & $-1.706 \pm 0.100$ & -0.008 & -0.02 \\
\hline 155806 & V1075 Sco & 13.49 & 13.65 & 13.91 & JSS86 & $0.62 \pm 0.07$ & $-1.865 \pm 0.100$ & 0.093 & 0.36 \\
\hline 157857 & HD 157857 & 13.89 & 13.93 & 13.97 & CLMS06 & $0.62 \pm 0.04$ & $-1.864 \pm 0.057$ & 0.056 & 0.57 \\
\hline 164284 & $66 \mathrm{Oph}$ & 10.53 & 12.57 & 12.91 & JSS86 & $0.89 \pm 0.18$ & $-2.262 \pm 0.268$ & -0.199 & -0.16 \\
\hline 165955 & HD 165955 & 13.84 & 13.92 & 14.00 & CLMS06 & $0.42 \pm 0.04$ & $-1.562 \pm 0.064$ & 0.089 & 0.75 \\
\hline 175360 & HD 175360 & 13.27 & 13.32 & 13.37 & CLMS06 & $\ldots$ & $\cdots$ & $\ldots$ & $\ldots$ \\
\hline 185418 & HD 185418 & 13.27 & 13.32 & 13.37 & CLMS06 & $0.79 \pm 0.03$ & $-2.116 \pm 0.055$ & -0.269 & -2.59 \\
\hline 190918 & V1676 Cyg & 14.06 & 14.09 & 14.12 & CLMS06 & $0.46 \pm 0.03$ & $-1.625 \pm 0.054$ & 0.016 & 0.20 \\
\hline 192035 & RX Cyg & 13.66 & 13.72 & 13.78 & CLMS06 & $0.76 \pm 0.04$ & $-2.067 \pm 0.063$ & 0.109 & 1.01 \\
\hline 192639 & HD 192639 & 13.85 & 13.91 & 13.97 & CLMS06 & $0.64 \pm 0.04$ & $-1.890 \pm 0.059$ & 0.026 & 0.24 \\
\hline 198478 & $55 \mathrm{Cyg}$ & 13.67 & 13.74 & 13.81 & CLMS06 & $0.81 \pm 0.05$ & $-2.139 \pm 0.082$ & 0.039 & 0.25 \\
\hline 198781 & HD 198781 & 13.73 & 13.75 & 13.77 & CLMS06 & $0.59 \pm 0.03$ & $-1.813 \pm 0.050$ & 0.117 & 1.47 \\
\hline 201345 & HD 201345 & 13.94 & 13.98 & 14.02 & CLMS06 & $0.34 \pm 0.04$ & $-1.440 \pm 0.065$ & 0.124 & 1.09 \\
\hline 203532 & HD 203532 & 12.87 & 12.95 & 13.03 & CLMS06 & $\cdots$ & $\cdots$ & $\cdots$ & $\cdots$ \\
\hline 206773 & HD 206773 & 13.66 & 13.71 & 13.76 & CLMS06 & $0.53 \pm 0.02$ & $-1.733 \pm 0.036$ & -0.102 & -1.26 \\
\hline 207198 & HD 207198 & 13.78 & 13.84 & 13.90 & CLMS06 & $0.90 \pm 0.03$ & $-2.276 \pm 0.053$ & 0.146 & 1.54 \\
\hline 208440 & HD 208440 & 13.67 & 13.72 & 13.77 & CLMS06 & $0.61 \pm 0.04$ & $-1.846 \pm 0.063$ & -0.035 & -0.31 \\
\hline 210809 & HD 210809 & 14.11 & 14.14 & 14.17 & CLMS06 & $0.41 \pm 0.04$ & $-1.552 \pm 0.068$ & 0.065 & 0.59 \\
\hline 212791 & V408 Lac & 13.69 & 13.77 & 13.85 & CLMS06 & $0.57 \pm 0.08$ & $-1.788 \pm 0.125$ & 0.141 & 0.60 \\
\hline 220057 & HD 220057 & 13.44 & 13.49 & 13.54 & CLMS06 & $0.75 \pm 0.05$ & $-2.058 \pm 0.083$ & 0.097 & 0.64 \\
\hline 224572 & $\sigma$ Cas & $\cdots$ & 12.61 & 13.06 & JSS86 & $0.76 \pm 0.07$ & $-2.068 \pm 0.109$ & $\ldots$ & $\cdots$ \\
\hline 232522 & HDE 232522 & 13.91 & 13.95 & 13.99 & CLMS06 & $0.44 \pm 0.03$ & $-1.588 \pm 0.053$ & 0.058 & 0.70 \\
\hline 308813 & HDE 308813 & 13.91 & 13.96 & 14.01 & CLMS06 & $0.49 \pm 0.04$ & $-1.670 \pm 0.063$ & 0.048 & 0.43 \\
\hline & $\mathrm{BD}+532820$ & 14.16 & 14.20 & 14.24 & CLMS06 & $0.43 \pm 0.05$ & $-1.573 \pm 0.079$ & 0.091 & 0.75 \\
\hline & CPD -69 1743 & 13.93 & 13.97 & 14.01 & CLMS06 & $0.42 \pm 0.05$ & $-1.565 \pm 0.075$ & 0.080 & 0.68 \\
\hline
\end{tabular}

${ }^{\mathrm{a}}$ Terms in parentheses indicate separate velocity components, if they are explicitly identified and not grouped together; see 4.3

${ }^{\mathrm{b}}$ Codes in this column are linked to references listed in Table 1

${ }^{\mathrm{c}}$ The expected depletion $\left[\mathrm{Ni}_{\text {gas }} / \mathrm{H}\right]$ computed using Eq. 10, The listed errors do not include an overall systematic uncertainty of 0.03 in the solar abundance $\sigma(\mathrm{Ni} / \mathrm{H})_{\odot}$ in order to show just the formal error that arises from the uncertainties in location of line of best fit and the value of $F_{*}$.

d The observed $\left[\mathrm{Ni}_{\text {gas }} / \mathrm{H}\right]$ minus that computed using Eq. 10

'The difference shown in the previous column divided by the expected difference due to the uncertainties in both the measured column density and the coefficients that appear in Eq. 10 
${ }^{\mathrm{f}}$ The entry 13.44 for the adopted value of $N(\mathrm{Ni}$ II) stated by CLMS06 is incorrect; this number should be 13.94 , as confirmed by Cartledge (private communication). The value listed here includes a correction for a change in the transition $f$-value by -0.106 dex - see Table 1 
Table 20. Observations and Fits for Copper

\begin{tabular}{|c|c|c|c|c|c|c|c|c|c|}
\hline \multirow[b]{2}{*}{$\begin{array}{l}\text { HD Number }{ }^{\mathrm{a}} \\
\text { (1) }\end{array}$} & \multirow[b]{2}{*}{$\begin{array}{c}\text { Name } \\
(2)\end{array}$} & \multicolumn{4}{|c|}{ Observed $\log N(\mathrm{Cu} \mathrm{II})$} & \multirow[b]{2}{*}{$\begin{array}{l}F_{*} \\
(7)\end{array}$} & \multirow[b]{2}{*}{$\begin{array}{c}{\left[\mathrm{Cu}_{\text {gas }} / \mathrm{H}\right]_{\mathrm{fit}}{ }^{\mathrm{c}}} \\
(8)\end{array}$} & \multirow[b]{2}{*}{$\begin{array}{l}\text { Residual }^{\mathrm{d}} \\
\quad(9)\end{array}$} & \multirow{2}{*}{$\begin{array}{l}\text { Deviation } \\
\quad \text { in } \sigma) \\
\quad(10)\end{array}$} \\
\hline & & $\begin{array}{l}1.1 . \\
(3)\end{array}$ & $\begin{array}{c}\text { best } \\
(4)\end{array}$ & $\begin{array}{l}\text { u.l. } \\
(5)\end{array}$ & $\begin{array}{c}\text { Source }^{b} \\
(6)\end{array}$ & & & & \\
\hline 1383 & HD 1383 & 12.65 & 12.73 & 12.81 & CLMS06 & $0.61 \pm 0.04$ & $-1.031 \pm 0.037$ & -0.083 & -0.72 \\
\hline 2905 & $\kappa$ Cas & 11.95 & 12.34 & 12.61 & JSS86 & $0.58 \pm 0.06$ & $-1.009 \pm 0.047$ & -0.279 & -0.79 \\
\hline 12323 & HD 12323 & 12.50 & 12.55 & 12.60 & CLMS06 & $0.52 \pm 0.04$ & $-0.969 \pm 0.036$ & -0.107 & -1.12 \\
\hline 13268 & HD 13268 & 12.62 & 12.67 & 12.72 & CLMS06 & $0.51 \pm 0.04$ & $-0.962 \pm 0.038$ & -0.125 & -1.30 \\
\hline 14434 & HD 14434 & 12.76 & 12.83 & 12.90 & CLMS06 & $0.52 \pm 0.04$ & $-0.965 \pm 0.040$ & -0.013 & -0.12 \\
\hline 22951 & 40 Per & 12.46 & 12.65 & 12.79 & JSS86 & $0.73 \pm 0.05$ & $-1.117 \pm 0.041$ & 0.206 & 1.02 \\
\hline 23180 & o Per & 12.12 & 12.42 & 12.72 & $\mathrm{~S} 76$ & $0.84 \pm 0.06$ & $-1.196 \pm 0.051$ & 0.085 & 0.27 \\
\hline 24398 & $\zeta$ Per & 12.27 & 12.32 & 12.37 & $\mathrm{~S} 77$ & $0.88 \pm 0.05$ & $-1.225 \pm 0.044$ & 0.010 & 0.08 \\
\hline 24912 & $\xi$ Per & 12.13 & 12.20 & 12.26 & $\mathrm{C}++91$ & $0.83 \pm 0.02$ & $-1.187 \pm 0.028$ & -0.248 & -2.39 \\
\hline 27778 & $62 \mathrm{Tau}$ & 12.21 & 12.26 & 12.31 & CLMS06 & $\cdots$ & $\cdots$ & $\cdots$ & $\cdots$ \\
\hline 35149 & 23 Ori & 11.99 & 12.02 & 12.05 & $\mathrm{~W}++99$ & $0.54 \pm 0.04$ & $-0.980 \pm 0.036$ & 0.028 & 0.20 \\
\hline 36841 & HD 36841 & 11.95 & 12.05 & 12.15 & CLMS06 & $\cdots$ & $\cdots$ & $\cdots$ & $\cdots$ \\
\hline 37021 & $\theta^{1}$ Ori & 12.78 & 12.81 & 12.84 & CLMS06 & $\cdots$ & $\ldots$ & $\cdots$ & $\ldots$ \\
\hline 37061 & $\nu$ Ori & 12.93 & 12.95 & 12.97 & CLMS06 & $\cdots$ & $\ldots$ & $\cdots$ & $\ldots$ \\
\hline 37367 & HD 37367 & 12.54 & 12.59 & 12.64 & CLMS06 & $0.65 \pm 0.07$ & $-1.062 \pm 0.052$ & -0.021 & -0.18 \\
\hline 37903 & HD 37903 & 12.31 & 12.35 & 12.39 & CLMS06 & $1.15 \pm 0.03$ & $-1.412 \pm 0.048$ & -0.015 & -0.17 \\
\hline 38666 & $\mu \mathrm{Col}$ & $\cdots$ & $\cdots$ & 11.66 & HSF99 & $0.11 \pm 0.01$ & $-0.676 \pm 0.056$ & $\cdots$ & $\cdots$ \\
\hline 40111 & 139 Tau & 11.83 & 12.38 & 12.55 & JSS86 & $0.49 \pm 0.04$ & $-0.944 \pm 0.038$ & 0.033 & 0.09 \\
\hline 43818 & LU Gem & 12.87 & 12.89 & 12.91 & CLMS06 & $\cdots$ & $\cdots$ & $\cdots$ & $\cdots$ \\
\hline 47839 & 15 Mon & $\cdots$ & $\cdots$ & 11.54 & $\mathrm{H}++93$ & $0.25 \pm 0.05$ & $-0.773 \pm 0.056$ & $\cdots$ & $\cdots$ \\
\hline 52266 & HD 52266 & 12.58 & 12.61 & 12.64 & CLMS06 & $\cdots$ & $\cdots$ & $\cdots$ & $\cdots$ \\
\hline 54662 & HD 54662 & $\cdots$ & 12.37 & 12.82 & JSS86 & $0.89 \pm 0.09$ & $-1.226 \pm 0.070$ & $\cdots$ & $\cdots$ \\
\hline 63005 & HD 63005 & 12.49 & 12.54 & 12.59 & CLMS06 & $0.64 \pm 0.03$ & $-1.051 \pm 0.029$ & -0.066 & -0.85 \\
\hline 66811 & $\zeta$ Pup & $\cdots$ & $\cdots$ & 11.39 & M78 & $0.32 \pm 0.02$ & $-0.826 \pm 0.042$ & $\cdots$ & $\cdots$ \\
\hline 71634 & HD 71634 & 12.35 & 12.40 & 12.45 & CLMS06 & $\cdots$ & $\cdots$ & $\cdots$ & $\cdots$ \\
\hline 75309 & HD 75309 & 12.43 & 12.48 & 12.53 & CLMS06 & $0.63 \pm 0.04$ & $-1.041 \pm 0.034$ & 0.004 & 0.04 \\
\hline 79186 & GX Vel & 12.59 & 12.63 & 12.67 & CLMS06 & $0.69 \pm 0.03$ & $-1.086 \pm 0.031$ & -0.032 & -0.38 \\
\hline 91824 & HD 91824 & 12.42 & 12.49 & 12.56 & CLMS06 & $0.45 \pm 0.03$ & $-0.914 \pm 0.037$ & -0.101 & -1.05 \\
\hline 91983 & HD 91983 & 12.50 & 12.59 & 12.68 & CLMS06 & $0.48 \pm 0.04$ & $-0.935 \pm 0.040$ & -0.054 & -0.43 \\
\hline 111934 & BU Cru & 12.77 & 12.82 & 12.87 & CLMS06 & $\cdots$ & $\ldots$ & $\cdots$ & $\cdots$ \\
\hline 116658 & $\alpha \operatorname{Vir}$ & $\cdots$ & $\cdots$ & 12.41 & YK79 & $0.16 \pm 0.05$ & $-0.712 \pm 0.062$ & $\cdots$ & $\cdots$ \\
\hline 116852 & HD 116852 & 12.18 & 12.26 & 12.34 & CLMS06 & $0.36 \pm 0.04$ & $-0.850 \pm 0.044$ & -0.245 & -2.02 \\
\hline 122879 & HD 122879 & 12.65 & 12.70 & 12.75 & CLMS06 & $0.55 \pm 0.04$ & $-0.984 \pm 0.039$ & 0.008 & 0.07 \\
\hline 141637 & $1 \mathrm{Sco}$ & 12.28 & 12.33 & 12.38 & $\mathrm{H}++93$ & $0.69 \pm 0.05$ & $-1.087 \pm 0.041$ & -0.057 & -0.45 \\
\hline 143018 & $\pi \mathrm{Sco}$ & 11.93 & 12.01 & 12.07 & $\mathrm{H}++93$ & $0.71 \pm 0.03$ & $-1.098 \pm 0.031$ & 0.076 & 0.78 \\
\hline 143275 & $\delta$ Sco & 12.05 & 12.14 & 12.21 & JSS86 & $0.90 \pm 0.03$ & $-1.233 \pm 0.035$ & -0.129 & -1.06 \\
\hline 147933 & $\rho \mathrm{Oph} \mathrm{A}$ & 12.50 & 12.75 & 13.24 & JSS86 & $1.09 \pm 0.08$ & $-1.373 \pm 0.070$ & 0.084 & 0.22 \\
\hline 148184 & $\chi \mathrm{Oph}$ & 11.51 & 12.09 & 12.39 & JSS86 & $0.96 \pm 0.09$ & $-1.277 \pm 0.073$ & -0.276 & -0.60 \\
\hline 148594 & HD 148594 & 12.39 & 12.42 & 12.45 & CLMS06 & $\ldots$ & $\ldots$ & $\ldots$ & $\ldots$ \\
\hline
\end{tabular}


Table 20-Continued

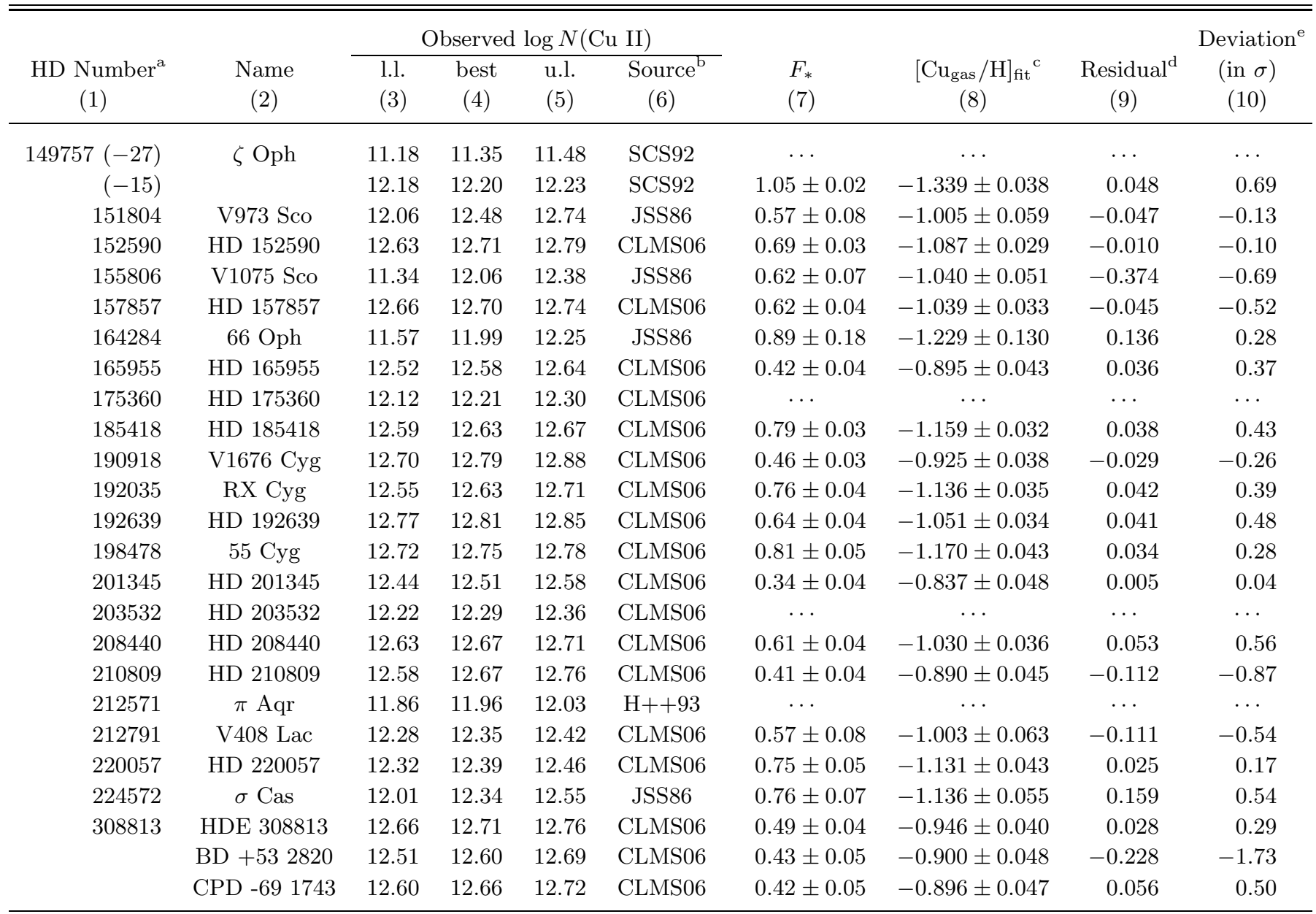

${ }^{a}$ Terms in parentheses indicate separate velocity components, if they are explicitly identified and not grouped together; see $\$ 4.3$

${ }^{\mathrm{b}}$ Codes in this column are linked to references listed in Table 1

${ }^{c}$ The expected depletion $\left[\mathrm{Cu}_{\text {gas }} / \mathrm{H}\right]$ computed using Eq. 10. The listed errors do not include an overall systematic uncertainty of 0.06 in the solar abundance $\sigma(\mathrm{Cu} / \mathrm{H})_{\odot}$ in order to show just the formal error that arises from the uncertainties in location of line of best fit and the value of $F_{*}$.

${ }^{\mathrm{d}}$ The observed $\left[\mathrm{Cu}_{\text {gas }} / \mathrm{H}\right]$ minus that computed using Eq. 10 ,

'The difference shown in the previous column divided by the expected difference due to the uncertainties in both the measured column density and the coefficients that appear in Eq. 10. 
Table 21. Observations and Fits for Zinc

\begin{tabular}{|c|c|c|c|c|c|c|c|c|c|}
\hline \multirow[b]{2}{*}{$\begin{array}{c}\text { HD Number }{ }^{\mathrm{a}} \\
(1)\end{array}$} & \multirow[b]{2}{*}{$\begin{array}{l}\text { Name } \\
(2)\end{array}$} & \multicolumn{4}{|c|}{ Observed $\log N(\mathrm{Zn} \mathrm{II})$} & \multirow[b]{2}{*}{$\begin{array}{l}F_{*} \\
(7)\end{array}$} & \multirow[b]{2}{*}{$\begin{array}{c}{\left[\mathrm{Zn}_{\text {gas }} / \mathrm{H}\right]_{\mathrm{fit}}{ }^{\mathrm{c}}} \\
(8)\end{array}$} & \multirow[b]{2}{*}{$\begin{array}{l}\text { Residual }^{\mathrm{d}} \\
(9)\end{array}$} & \multirow{2}{*}{$\begin{array}{l}\text { Deviation }^{\mathrm{e}} \\
\quad(\text { in } \sigma) \\
\quad(10)\end{array}$} \\
\hline & & $\begin{array}{l}1.1 . \\
(3)\end{array}$ & $\begin{array}{l}\text { best } \\
(4)\end{array}$ & $\begin{array}{l}\text { u.l. } \\
(5)\end{array}$ & $\begin{array}{c}\text { Source }^{b} \\
(6)\end{array}$ & & & & \\
\hline 18100 & HD 18100 & 12.57 & 12.62 & 12.67 & SS96b & $0.14 \pm 0.04$ & $-0.024 \pm 0.044$ & -0.212 & -1.42 \\
\hline 23630 & $\eta$ Tau & 12.62 & 12.66 & 12.72 & RB95 & $\cdots$ & $\cdots$ & $\cdots$ & $\cdots$ \\
\hline 24912 & $\xi$ Per & 13.38 & 13.39 & 13.41 & $\mathrm{C}++91$ & $0.83 \pm 0.02$ & $-0.448 \pm 0.032$ & -0.154 & -1.84 \\
\hline 35149 & 23 Ori & 13.20 & 13.28 & 13.34 & $\mathrm{~W}++99$ & $0.54 \pm 0.04$ & $-0.270 \pm 0.031$ & 0.219 & 1.41 \\
\hline 36486 & $\delta$ Ori A & 12.57 & 12.62 & 12.66 & RB95 & $0.54 \pm 0.02$ & $-0.271 \pm 0.025$ & -0.004 & -0.06 \\
\hline 37128 & $\epsilon$ Ori & 12.91 & 12.97 & 13.02 & RB95 & $0.54 \pm 0.03$ & $-0.271 \pm 0.028$ & 0.085 & 0.80 \\
\hline 38666 & $\mu \mathrm{Col}$ & 12.51 & 12.59 & 12.67 & HSF99 & $0.11 \pm 0.01$ & $-0.009 \pm 0.037$ & 0.036 & 0.40 \\
\hline 47839 & 15 Mon & 12.81 & 12.86 & 12.91 & RB95 & $0.25 \pm 0.05$ & $-0.093 \pm 0.041$ & -0.062 & -0.52 \\
\hline 57061 & $\tau \mathrm{CMa}$ & 13.20 & 13.24 & 13.30 & RB95 & $0.39 \pm 0.04$ & $-0.177 \pm 0.036$ & 0.022 & 0.28 \\
\hline 66811 & $\zeta$ Pup & 12.24 & 12.44 & 12.64 & M78 & $0.32 \pm 0.02$ & $-0.138 \pm 0.029$ & -0.078 & -0.38 \\
\hline 72127 & HD 72127 & 12.77 & 12.82 & 12.87 & RB95 & $\cdots$ & $\cdots$ & $\cdots$ & $\cdots$ \\
\hline 91316 & $\rho$ Leo & 12.83 & 12.88 & 12.93 & RB95 & $0.15 \pm 0.04$ & $-0.034 \pm 0.042$ & -0.039 & -0.36 \\
\hline 116658 & $\alpha$ Vir & $\cdots$ & $\cdots$ & 11.61 & YK79 & $0.16 \pm 0.05$ & $-0.040 \pm 0.045$ & $\cdots$ & $\cdots$ \\
\hline 116852 & HD 116852 & 13.20 & 13.23 & 13.25 & SS96a & $0.36 \pm 0.04$ & $-0.158 \pm 0.033$ & -0.325 & -3.60 \\
\hline 141637 & $1 \mathrm{Sco}$ & 13.44 & 13.49 & 13.54 & RB95 & $0.69 \pm 0.05$ & $-0.362 \pm 0.039$ & 0.013 & 0.10 \\
\hline 143018 & $\pi \mathrm{Sco}$ & 13.11 & 13.14 & 13.16 & RB95 & $0.71 \pm 0.03$ & $-0.371 \pm 0.031$ & 0.115 & 1.53 \\
\hline 144217 & $\beta^{1} \mathrm{Sco}$ & 13.47 & 13.52 & 13.57 & RB95 & $0.81 \pm 0.02$ & $-0.436 \pm 0.030$ & 0.116 & 1.69 \\
\hline 147165 & $\sigma$ Sco & 13.62 & 13.66 & 13.72 & RB95 & $0.76 \pm 0.06$ & $-0.408 \pm 0.045$ & 0.010 & 0.05 \\
\hline $149757(-27)$ & $\zeta \mathrm{Oph}$ & 12.37 & 12.38 & 12.40 & SCS92 & $\cdots$ & $\cdots$ & $\cdots$ & $\cdots$ \\
\hline$(-15)$ & & 13.14 & 13.19 & 13.24 & RB95 & $1.05 \pm 0.02$ & $-0.579 \pm 0.041$ & -0.088 & -1.07 \\
\hline 149881 & V600 Her & 13.14 & 13.19 & 13.24 & RB95 & $0.07 \pm 0.06$ & $0.019 \pm 0.054$ & -0.184 & -0.92 \\
\hline 158926 & $\lambda$ Sco & 11.70 & 11.76 & 11.81 & RB95 & $0.31 \pm 0.02$ & $-0.131 \pm 0.029$ & -0.044 & -0.68 \\
\hline 167756 & HD 167756 & 13.26 & 13.27 & 13.28 & CSS95 & $\cdots$ & $\cdots$ & $\cdots$ & $\cdots$ \\
\hline 212571 & $\pi$ Aqr & 13.14 & 13.19 & 13.24 & RB95 & $\cdots$ & $\cdots$ & $\cdots$ & $\cdots$ \\
\hline $215733(-59)$ & HD 215733 & 11.48 & 11.56 & 11.64 & FS97 & $-0.11 \pm 0.10$ & $0.126 \pm 0.077$ & -0.219 & -0.75 \\
\hline$(-54)$ & & 11.58 & 11.66 & 11.74 & FS97 & $0.54 \pm 0.15$ & $-0.273 \pm 0.094$ & -0.400 & -0.92 \\
\hline$(-47)$ & & 11.74 & 11.82 & 11.90 & FS97 & $\cdots$ & $\cdots$ & $\cdots$ & $\cdots$ \\
\hline$(-42)$ & & 11.14 & 11.32 & 11.50 & FS97 & $-0.16 \pm 0.31$ & $0.159 \pm 0.198$ & -0.072 & -0.08 \\
\hline$(-32)$ & & 11.01 & 11.35 & 11.69 & FS97 & $0.25 \pm 0.09$ & $-0.092 \pm 0.062$ & -0.901 & -2.42 \\
\hline$(-31)$ & & 11.18 & 11.40 & 11.62 & FS97 & $\cdots$ & $\cdots$ & $\cdots$ & $\ldots$ \\
\hline$(-28)$ & & 11.77 & 11.86 & 11.95 & FS97 & $-0.18 \pm 0.07$ & $0.171 \pm 0.067$ & 0.076 & 0.49 \\
\hline$(-26)$ & & 11.69 & 11.80 & 11.91 & FS97 & $-0.12 \pm 0.07$ & $0.134 \pm 0.064$ & -0.147 & -0.84 \\
\hline$(-23)$ & & 9.22 & 10.31 & 11.40 & FS97 & $0.24 \pm 0.08$ & $-0.089 \pm 0.058$ & -1.554 & -1.42 \\
\hline$(-21)$ & & 11.87 & 11.93 & 11.99 & FS97 & $0.24 \pm 0.05$ & $-0.086 \pm 0.043$ & -0.057 & -0.56 \\
\hline$(-16)$ & & 12.23 & 12.29 & 12.35 & FS97 & $0.93 \pm 0.05$ & $-0.507 \pm 0.045$ & -0.016 & -0.18 \\
\hline$(-11)$ & & 12.36 & 12.43 & 12.50 & FS97 & $-0.01 \pm 0.07$ & $0.063 \pm 0.061$ & 0.064 & 0.60 \\
\hline$(-9)$ & & 12.64 & 12.69 & 12.74 & FS97 & $0.08 \pm 0.04$ & $0.011 \pm 0.044$ & -0.094 & -0.90 \\
\hline$(-5)$ & & 11.47 & 11.69 & 11.91 & FS97 & $0.77 \pm 0.18$ & $-0.412 \pm 0.113$ & -0.181 & -0.68 \\
\hline (total) & & 13.08 & 13.16 & 13.25 & FS97 & $\ldots$ & $\ldots$ & $\ldots$ & $\ldots$ \\
\hline
\end{tabular}


Table 21-Continued

\begin{tabular}{|c|c|c|c|c|c|c|c|c|c|}
\hline \multirow[b]{2}{*}{$\begin{array}{l}\text { HD Number } \\
\text { (1) }\end{array}$} & \multirow[b]{2}{*}{$\begin{array}{c}\text { Name } \\
(2)\end{array}$} & \multicolumn{4}{|c|}{ Observed $\log N(\mathrm{Zn} \mathrm{II})$} & \multirow[b]{2}{*}{$\begin{array}{l}F_{*} \\
(7)\end{array}$} & \multirow[b]{2}{*}{$\begin{array}{c}{\left[\mathrm{Zn}_{\text {gas }} / \mathrm{H}\right]_{\mathrm{fit}}{ }^{\mathrm{c}}} \\
(8)\end{array}$} & \multirow[b]{2}{*}{$\begin{array}{l}\text { Residual }^{\mathrm{d}} \\
(9)\end{array}$} & \multirow{2}{*}{$\begin{array}{l}\text { Deviation } \\
\text { (in } \sigma) \\
(10)\end{array}$} \\
\hline & & $\begin{array}{l}1.1 . \\
(3)\end{array}$ & $\begin{array}{c}\text { best } \\
(4)\end{array}$ & $\begin{array}{l}\text { u.l. } \\
(5)\end{array}$ & $\begin{array}{c}\text { Source }^{b} \\
(6)\end{array}$ & & & & \\
\hline
\end{tabular}

a Terms in parentheses indicate separate velocity components, if they are explicitly identified and not grouped together; see $\$ 4.3$

${ }^{\mathrm{b}}$ Codes in this column are linked to references listed in Table 1

${ }^{\mathrm{c}}$ The expected depletion $\left[\mathrm{Zn}_{\text {gas }} / \mathrm{H}\right]$ computed using Eq. 10. The listed errors do not include an overall systematic uncertainty of 0.04 in the solar abundance $\sigma(\mathrm{Zn} / \mathrm{H})_{\odot}$ in order to show just the formal error that arises from the uncertainties in location of line of best fit and the value of $F_{*}$.

${ }^{\mathrm{d}}$ The observed $\left[\mathrm{Zn}_{\text {gas }} / \mathrm{H}\right]$ minus that computed using Eq. 10

${ }^{\text {e }}$ The difference shown in the previous column divided by the expected difference due to the uncertainties in both the measured column density and the coefficients that appear in Eq. 10. 
Table 22. Observations and Fits for Germanium

\begin{tabular}{|c|c|c|c|c|c|c|c|c|c|}
\hline \multirow[b]{2}{*}{$\begin{array}{c}\text { HD Number } \\
\text { (1) }\end{array}$} & \multirow[b]{2}{*}{$\begin{array}{l}\text { Name } \\
(2)\end{array}$} & \multicolumn{4}{|c|}{ Observed $\log N(\mathrm{Ge}$ II $)$} & \multirow[b]{2}{*}{$\begin{array}{l}F_{*} \\
(7)\end{array}$} & \multirow[b]{2}{*}{$\begin{array}{c}{\left[\mathrm{Ge}_{\mathrm{gas}} / \mathrm{H}\right]_{\mathrm{fit}}{ }^{\mathrm{c}}} \\
(8)\end{array}$} & \multirow[b]{2}{*}{$\begin{array}{l}\text { Residual }^{\mathrm{d}} \\
\quad(9)\end{array}$} & \multirow{2}{*}{$\begin{array}{l}\text { Deviation }^{\mathrm{e}} \\
\quad(\text { in } \sigma) \\
(10)\end{array}$} \\
\hline & & $\begin{array}{l}1.1 . \\
(3)\end{array}$ & $\begin{array}{c}\text { best } \\
(4)\end{array}$ & $\begin{array}{l}\text { u.l. } \\
(5)\end{array}$ & $\begin{array}{c}\text { Source }^{b} \\
(6)\end{array}$ & & & & \\
\hline 1383 & HD 1383 & 12.36 & 12.45 & 12.54 & CLMS06 & $0.61 \pm 0.04$ & $-0.677 \pm 0.033$ & -0.077 & -0.63 \\
\hline 12323 & HD 12323 & 12.09 & 12.15 & 12.21 & CLMS06 & $0.52 \pm 0.04$ & $-0.623 \pm 0.032$ & -0.213 & -2.14 \\
\hline 13268 & HD 13268 & 12.37 & 12.44 & 12.51 & CLMS06 & $0.51 \pm 0.04$ & $-0.617 \pm 0.034$ & -0.060 & -0.56 \\
\hline 27778 & $62 \mathrm{Tau}$ & 12.10 & 12.14 & 12.18 & CLMS06 & $\cdots$ & $\cdots$ & $\cdots$ & $\cdots$ \\
\hline 35149 & 23 Ori & 11.85 & 11.89 & 11.93 & $\mathrm{~W}++99$ & $0.54 \pm 0.04$ & $-0.633 \pm 0.033$ & 0.191 & 1.32 \\
\hline 37021 & $\theta^{1}$ Ori & 12.28 & 12.32 & 12.36 & CLMS06 & $\ldots$ & $\ldots$ & $\ldots$ & $\ldots$ \\
\hline 37061 & $\nu$ Ori & 12.46 & 12.51 & 12.56 & CLMS06 & $\cdots$ & $\cdots$ & $\cdots$ & $\cdots$ \\
\hline 37367 & HD 37367 & 12.30 & 12.34 & 12.38 & CLMS06 & $0.65 \pm 0.07$ & $-0.703 \pm 0.046$ & 0.011 & 0.09 \\
\hline 37903 & HD 37903 & 11.99 & 12.02 & 12.05 & CLMS06 & $1.15 \pm 0.03$ & $-1.007 \pm 0.047$ & -0.110 & -1.33 \\
\hline 43818 & LU Gem & 12.52 & 12.58 & 12.64 & CLMS06 & $\cdots$ & $\cdots$ & $\cdots$ & $\cdots$ \\
\hline 47839 & 15 Mon & 11.25 & 11.41 & 11.51 & $\mathrm{H}++93$ & $0.25 \pm 0.05$ & $-0.454 \pm 0.050$ & -0.143 & -0.83 \\
\hline 52266 & HD 52266 & 12.39 & 12.43 & 12.47 & CLMS06 & $\cdots$ & $\cdots$ & $\cdots$ & $\cdots$ \\
\hline 63005 & HD 63005 & 12.27 & 12.31 & 12.35 & CLMS06 & $0.64 \pm 0.03$ & $-0.695 \pm 0.026$ & -0.013 & -0.18 \\
\hline 71634 & HD 71634 & 11.96 & 12.02 & 12.08 & CLMS06 & $\cdots$ & $\cdots$ & $\cdots$ & $\cdots$ \\
\hline 72754 & FY Vel & 12.15 & 12.20 & 12.25 & CLMS06 & $0.76 \pm 0.10$ & $-0.771 \pm 0.064$ & -0.014 & -0.11 \\
\hline 75309 & HD 75309 & 12.16 & 12.22 & 12.28 & CLMS06 & $0.63 \pm 0.04$ & $-0.686 \pm 0.031$ & 0.028 & 0.28 \\
\hline 79186 & GX Vel & 12.28 & 12.34 & 12.40 & CLMS06 & $0.69 \pm 0.03$ & $-0.725 \pm 0.028$ & -0.043 & -0.46 \\
\hline 91824 & HD 91824 & 12.25 & 12.33 & 12.41 & CLMS06 & $0.45 \pm 0.03$ & $-0.575 \pm 0.034$ & 0.041 & 0.40 \\
\hline 91983 & HD 91983 & 12.33 & 12.37 & 12.41 & CLMS06 & $0.48 \pm 0.04$ & $-0.594 \pm 0.036$ & 0.024 & 0.26 \\
\hline 111934 & BU Cru & 12.52 & 12.56 & 12.60 & CLMS06 & $\cdots$ & $\cdots$ & $\cdots$ & $\cdots$ \\
\hline 116852 & HD 116852 & 11.93 & 12.00 & 12.07 & CLMS06 & $0.36 \pm 0.04$ & $-0.520 \pm 0.040$ & -0.195 & -1.72 \\
\hline 122879 & HD 122879 & 12.40 & 12.47 & 12.54 & CLMS06 & $0.55 \pm 0.04$ & $-0.636 \pm 0.035$ & 0.070 & 0.55 \\
\hline 141637 & $1 \mathrm{Sco}$ & 12.01 & 12.04 & 12.06 & $\mathrm{H}++93$ & $0.69 \pm 0.05$ & $-0.725 \pm 0.036$ & -0.066 & -0.56 \\
\hline 143018 & $\pi \mathrm{Sco}$ & 11.64 & 11.72 & 11.78 & $\mathrm{H}++93$ & $0.71 \pm 0.03$ & $-0.735 \pm 0.028$ & 0.066 & 0.68 \\
\hline 147888 & $\rho \mathrm{Oph} \mathrm{D}$ & 12.42 & 12.48 & 12.54 & CLMS06 & $0.88 \pm 0.06$ & $-0.843 \pm 0.047$ & -0.115 & -0.70 \\
\hline 148594 & HD 148594 & 12.09 & 12.15 & 12.21 & CLMS06 & $\cdots$ & $\cdots$ & $\cdots$ & $\cdots$ \\
\hline $149757(-15)$ & $\zeta \mathrm{Oph}$ & 11.94 & 11.98 & 12.02 & SCS92 & $1.05 \pm 0.02$ & $-0.944 \pm 0.037$ & 0.074 & 0.99 \\
\hline 152590 & HD 152590 & 12.39 & 12.44 & 12.49 & CLMS06 & $0.69 \pm 0.03$ & $-0.726 \pm 0.026$ & -0.002 & -0.02 \\
\hline 156110 & HD 156110 & 11.30 & 11.37 & 11.44 & CLMS06 & $\cdots$ & $\cdots$ & $\cdots$ & $\cdots$ \\
\hline 157857 & HD 157857 & 12.43 & 12.52 & 12.61 & CLMS06 & $0.62 \pm 0.04$ & $-0.684 \pm 0.030$ & 0.060 & 0.51 \\
\hline 165955 & HD 165955 & 12.15 & 12.19 & 12.23 & CLMS06 & $0.42 \pm 0.04$ & $-0.559 \pm 0.038$ & -0.050 & -0.60 \\
\hline 175360 & HD 175360 & 11.85 & 11.91 & 11.97 & CLMS06 & $\cdots$ & $\cdots$ & $\cdots$ & $\cdots$ \\
\hline 185418 & HD 185418 & 12.40 & 12.44 & 12.48 & CLMS06 & $0.79 \pm 0.03$ & $-0.788 \pm 0.030$ & 0.117 & 1.34 \\
\hline 192035 & RX Cyg & 12.28 & 12.33 & 12.38 & CLMS06 & $0.76 \pm 0.04$ & $-0.767 \pm 0.032$ & 0.014 & 0.16 \\
\hline 198478 & 55 Cyg & 12.44 & 12.48 & 12.52 & CLMS06 & $0.81 \pm 0.05$ & $-0.797 \pm 0.039$ & 0.031 & 0.25 \\
\hline 198781 & HD 198781 & 12.14 & 12.20 & 12.26 & CLMS06 & $0.59 \pm 0.03$ & $-0.663 \pm 0.028$ & 0.011 & 0.13 \\
\hline 201345 & HD 201345 & 12.03 & 12.09 & 12.15 & CLMS06 & $0.34 \pm 0.04$ & $-0.509 \pm 0.043$ & -0.103 & -0.92 \\
\hline 203532 & HD 203532 & 12.02 & 12.07 & 12.12 & CLMS06 & $\cdots$ & $\cdots$ & $\cdots$ & $\cdots$ \\
\hline 206773 & HD 206773 & 12.29 & 12.34 & 12.39 & CLMS06 & $0.53 \pm 0.02$ & $-0.630 \pm 0.026$ & 0.019 & 0.25 \\
\hline
\end{tabular}


Table 22-Continued

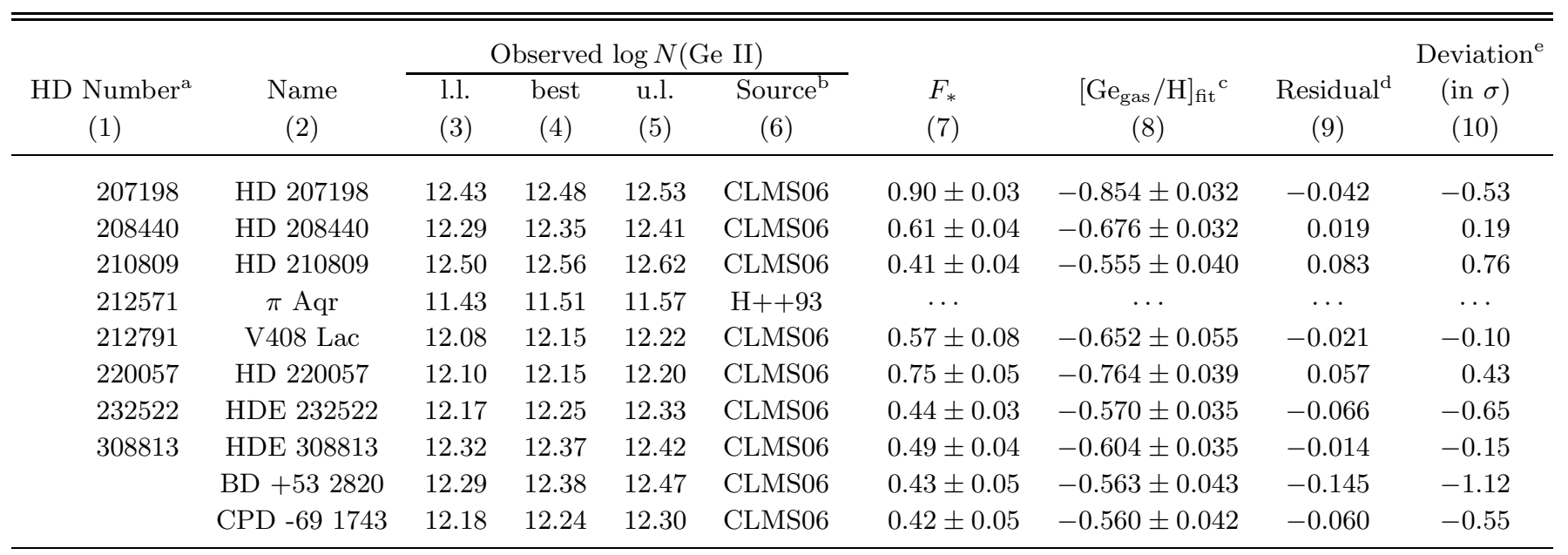

aTerms in parentheses indicate separate velocity components, if they are explicitly identified and not grouped together; see 4.3

${ }^{\mathrm{b}}$ Codes in this column are linked to references listed in Table 1

${ }^{\mathrm{c}}$ The expected depletion $\left[\mathrm{Ge}_{\text {gas }} / \mathrm{H}\right]$ computed using Eq. 10. The listed errors do not include an overall systematic uncertainty of 0.05 in the solar abundance $\sigma(\mathrm{Ge} / \mathrm{H}) \odot$ in order to show just the formal error that arises from the uncertainties in location of line of best fit and the value of $F_{*}$.

d The observed $\left[\mathrm{Ge}_{\text {gas }} / \mathrm{H}\right]$ minus that computed using Eq. 10.

eThe difference shown in the previous column divided by the expected difference due to the uncertainties in both the measured column density and the coefficients that appear in Eq. 10. 
Table 23. Observations and Fits for Krypton

\begin{tabular}{|c|c|c|c|c|c|c|c|c|c|}
\hline \multirow[b]{2}{*}{$\begin{array}{c}\text { HD Number } \\
\text { (1) }\end{array}$} & \multirow[b]{2}{*}{$\begin{array}{l}\text { Name } \\
(2)\end{array}$} & \multicolumn{4}{|c|}{ Observed $\log N($ Kr I $)$} & \multirow[b]{2}{*}{$\begin{array}{l}F_{*} \\
(7)\end{array}$} & \multirow[b]{2}{*}{$\begin{array}{c}{\left[\mathrm{Kr}_{\text {gas }} / \mathrm{H}\right]_{\mathrm{fit}}{ }^{\mathrm{c}}} \\
(8)\end{array}$} & \multirow[b]{2}{*}{$\begin{array}{l}\text { Residual }^{\mathrm{d}} \\
(9)\end{array}$} & \multirow{2}{*}{$\begin{array}{l}\text { Deviation }^{\mathrm{e}} \\
\quad(\text { in } \sigma) \\
\quad(10)\end{array}$} \\
\hline & & $\begin{array}{l}1.1 . \\
(3)\end{array}$ & $\begin{array}{l}\text { best } \\
(4)\end{array}$ & $\begin{array}{l}\text { u.l. } \\
(5)\end{array}$ & $\begin{array}{c}\text { Source }^{b} \\
(6)\end{array}$ & & & & \\
\hline 23478 & HD 23478 & 12.18 & 12.23 & 12.28 & $\mathrm{C}++08$ & $-0.00 \pm 0.50$ & $-0.218 \pm 0.110$ & 0.042 & 0.24 \\
\hline 24190 & HD 24190 & 12.29 & 12.35 & 12.41 & $\mathrm{C}++08$ & $0.63 \pm 0.24$ & $-0.323 \pm 0.046$ & 0.013 & 0.15 \\
\hline 24398 & $\zeta$ Per & 12.15 & 12.18 & 12.20 & CM97 & $0.88 \pm 0.05$ & $-0.365 \pm 0.031$ & -0.011 & -0.09 \\
\hline 24760 & $\epsilon$ Per & 11.38 & 11.46 & 11.53 & CM97 & $0.68 \pm 0.04$ & $-0.331 \pm 0.022$ & -0.070 & -0.58 \\
\hline 27778 & $62 \mathrm{Tau}$ & 12.31 & 12.37 & 12.41 & CMLS01 & $\cdots$ & $\cdots$ & $\cdots$ & $\cdots$ \\
\hline 35149 & 23 Ori & $\cdots$ & $\cdots$ & 11.72 & $\mathrm{~W}++99$ & $0.54 \pm 0.04$ & $-0.308 \pm 0.027$ & $\cdots$ & $\cdots$ \\
\hline 36861 & $\lambda$ Ori A & 11.74 & 11.80 & 11.85 & CM97 & $0.57 \pm 0.04$ & $-0.312 \pm 0.026$ & -0.045 & -0.36 \\
\hline 37021 & $\theta^{1}$ Ori & 12.59 & 12.63 & 12.67 & CMLS01 & $\cdots$ & $\cdots$ & $\cdots$ & $\cdots$ \\
\hline 37061 & $\nu$ Ori & 12.68 & 12.72 & 12.74 & CMLS01 & $\cdots$ & $\cdots$ & $\ldots$ & $\cdots$ \\
\hline 37128 & $\epsilon$ Ori & 11.30 & 11.40 & 11.48 & CM97 & $0.54 \pm 0.03$ & $-0.308 \pm 0.026$ & -0.101 & -0.78 \\
\hline 37367 & HD 37367 & 12.46 & 12.51 & 12.56 & CML03 & $0.65 \pm 0.07$ & $-0.327 \pm 0.024$ & 0.144 & 1.30 \\
\hline 37903 & HD 37903 & 12.25 & 12.31 & 12.37 & CMLS01 & $1.15 \pm 0.03$ & $-0.409 \pm 0.053$ & -0.078 & -0.78 \\
\hline 38771 & $\kappa$ Ori & 11.41 & 11.50 & 11.58 & CM97 & $0.67 \pm 0.03$ & $-0.329 \pm 0.022$ & -0.050 & -0.51 \\
\hline 40893 & HD 40893 & 12.49 & 12.56 & 12.63 & $\mathrm{C}++08$ & $0.61 \pm 0.05$ & $-0.319 \pm 0.025$ & -0.017 & -0.16 \\
\hline 57061 & $\tau \mathrm{CMa}$ & 11.69 & 11.75 & 11.80 & CM97 & $0.39 \pm 0.04$ & $-0.282 \pm 0.038$ & -0.027 & -0.33 \\
\hline 69106 & HD 69106 & 12.10 & 12.19 & 12.28 & $\mathrm{C}++08$ & $0.64 \pm 0.06$ & $-0.325 \pm 0.024$ & 0.063 & 0.58 \\
\hline 72754 & FY Vel & 12.13 & 12.23 & 12.33 & CML03 & $0.76 \pm 0.10$ & $-0.345 \pm 0.028$ & -0.070 & -0.49 \\
\hline 75309 & HD 75309 & 12.09 & 12.21 & 12.30 & CMLS01 & $0.63 \pm 0.04$ & $-0.322 \pm 0.023$ & -0.005 & -0.04 \\
\hline 94454 & HD 94454 & 12.28 & 12.36 & 12.44 & $\mathrm{C}++08$ & $\cdots$ & $\ldots$ & $\cdots$ & $\cdots$ \\
\hline 99857 & HD 99857 & 12.19 & 12.29 & 12.37 & $\mathrm{~A}++03$ & $0.54 \pm 0.04$ & $-0.308 \pm 0.027$ & -0.120 & -1.08 \\
\hline 99872 & HD 99872 & 12.18 & 12.25 & 12.32 & $\mathrm{C}++08$ & $\cdots$ & $\cdots$ & $\cdots$ & $\cdots$ \\
\hline 102065 & HD 102065 & 12.05 & 12.16 & 12.27 & $\mathrm{C}++08$ & $\cdots$ & $\cdots$ & $\cdots$ & $\cdots$ \\
\hline 104705 & DF Cru & 11.92 & 12.12 & 12.26 & $\mathrm{~A}++03$ & $0.33 \pm 0.05$ & $-0.272 \pm 0.043$ & -0.143 & -0.75 \\
\hline 108639 & HD 108639 & 12.30 & 12.40 & 12.50 & $\mathrm{C}++08$ & $0.37 \pm 0.37$ & $-0.279 \pm 0.073$ & -0.064 & -0.43 \\
\hline 112999 & V946 Cen & 12.18 & 12.27 & 12.36 & $\mathrm{C}++08$ & $\cdots$ & $\cdots$ & $\cdots$ & $\cdots$ \\
\hline 114886 & HD 114886 & 12.29 & 12.43 & 12.57 & $\mathrm{C}++08$ & $0.87 \pm 0.31$ & $-0.363 \pm 0.059$ & 0.030 & 0.19 \\
\hline 115071 & V961 Cen & 12.57 & 12.64 & 12.71 & $\mathrm{C}++08$ & $0.22 \pm 0.21$ & $-0.255 \pm 0.063$ & 0.038 & 0.36 \\
\hline 116852 & HD 116852 & 12.00 & 12.06 & 12.12 & $\mathrm{C}++08$ & $0.36 \pm 0.04$ & $-0.277 \pm 0.040$ & -0.038 & -0.35 \\
\hline 122879 & HD 122879 & 12.47 & 12.60 & 12.73 & $\mathrm{C}++08$ & $0.55 \pm 0.04$ & $-0.309 \pm 0.027$ & 0.213 & 1.27 \\
\hline 124314 & HD 124314 & 12.61 & 12.70 & 12.79 & $\mathrm{C}++08$ & $0.59 \pm 0.05$ & $-0.315 \pm 0.025$ & 0.146 & 1.24 \\
\hline 137595 & HD 137595 & 12.27 & 12.34 & 12.41 & $\mathrm{C}++08$ & $0.77 \pm 0.22$ & $-0.347 \pm 0.044$ & 0.106 & 1.12 \\
\hline 141637 & $1 \mathrm{Sco}$ & 12.09 & 12.24 & 12.30 & $\mathrm{H}++93$ & $0.69 \pm 0.05$ & $-0.333 \pm 0.023$ & 0.080 & 0.52 \\
\hline 143018 & $\pi \mathrm{Sco}$ & $\cdots$ & $\cdots$ & 11.44 & $\mathrm{H}++93$ & $0.71 \pm 0.03$ & $-0.335 \pm 0.022$ & $\cdots$ & $\cdots$ \\
\hline 144965 & HD 144965 & 12.22 & 12.30 & 12.38 & $\mathrm{C}++08$ & $1.15 \pm 0.35$ & $-0.408 \pm 0.078$ & 0.025 & 0.18 \\
\hline 147165 & $\sigma \mathrm{Sco}$ & 12.40 & 12.45 & 12.50 & $\mathrm{C}++08$ & $0.76 \pm 0.06$ & $-0.345 \pm 0.025$ & 0.072 & 0.39 \\
\hline 147683 & V760 Sco & 12.46 & 12.52 & 12.58 & $\mathrm{C}++08$ & $0.56 \pm 0.47$ & $-0.311 \pm 0.082$ & 0.065 & 0.40 \\
\hline 147888 & $\rho \mathrm{Oph} \mathrm{D}$ & 12.70 & 12.73 & 12.76 & CMLS01 & $0.88 \pm 0.06$ & $-0.364 \pm 0.031$ & -0.004 & -0.02 \\
\hline 148594 & HD 148594 & 12.29 & 12.37 & 12.45 & CML03 & $\ldots$ & $\ldots$ & $\ldots$ & $\cdots$ \\
\hline $149757(-15)$ & $\zeta \mathrm{Oph}$ & 11.95 & 12.04 & 12.11 & CM97 & $1.05 \pm 0.02$ & $-0.392 \pm 0.043$ & -0.079 & -0.76 \\
\hline
\end{tabular}


Table 23-Continued

\begin{tabular}{|c|c|c|c|c|c|c|c|c|c|}
\hline \multirow[b]{2}{*}{$\begin{array}{c}\text { HD Number }{ }^{\mathrm{a}} \\
\text { (1) }\end{array}$} & \multirow[b]{2}{*}{$\begin{array}{l}\text { Name } \\
(2)\end{array}$} & \multicolumn{4}{|c|}{ Observed $\log N(\mathrm{Kr} \mathrm{I})$} & \multirow[b]{2}{*}{$\begin{array}{l}F_{*} \\
(7)\end{array}$} & \multirow[b]{2}{*}{$\begin{array}{c}{\left[\mathrm{Kr}_{\text {gas }} / \mathrm{H}\right]_{\mathrm{fit}}{ }^{\mathrm{c}}} \\
(8)\end{array}$} & \multirow[b]{2}{*}{$\begin{array}{c}\text { Residual }^{\mathrm{d}} \\
(9)\end{array}$} & \multirow{2}{*}{$\begin{array}{l}\text { Deviation } \\
\quad(\text { in } \sigma) \\
\quad(10)\end{array}$} \\
\hline & & $\begin{array}{l}1.1 . \\
(3)\end{array}$ & $\begin{array}{c}\text { best } \\
(4)\end{array}$ & $\begin{array}{l}\text { u.l. } \\
(5)\end{array}$ & $\begin{array}{c}\text { Source }^{b} \\
(6)\end{array}$ & & & & \\
\hline 151805 & HD 151805 & 12.33 & 12.41 & 12.49 & $\mathrm{C}++08$ & $0.83 \pm 0.36$ & $-0.355 \pm 0.065$ & -0.000 & -0.00 \\
\hline 152590 & HD 152590 & 12.49 & 12.54 & 12.59 & $\mathrm{C}++08$ & $0.69 \pm 0.03$ & $-0.333 \pm 0.022$ & 0.045 & 0.61 \\
\hline 165246 & HD 165246 & 12.47 & 12.53 & 12.59 & $\mathrm{C}++08$ & $0.77 \pm 1.39$ & $-0.345 \pm 0.231$ & 0.060 & 0.13 \\
\hline 175360 & HD 175360 & 11.91 & 12.01 & 12.09 & CMLS01 & $\cdots$ & $\cdots$ & $\cdots$ & $\cdots$ \\
\hline 177989 & HD 177989 & 12.18 & 12.25 & 12.32 & $\mathrm{C}++08$ & $0.55 \pm 0.05$ & $-0.310 \pm 0.026$ & 0.116 & 1.14 \\
\hline 185418 & HD 185418 & 12.43 & 12.50 & 12.56 & CMLS01 & $0.79 \pm 0.03$ & $-0.350 \pm 0.025$ & 0.079 & 0.79 \\
\hline 198478 & $55 \mathrm{Cyg}$ & 12.52 & 12.60 & 12.68 & CML03 & $0.81 \pm 0.05$ & $-0.352 \pm 0.026$ & 0.046 & 0.33 \\
\hline 203374 & HD 203374 & 12.50 & 12.56 & 12.62 & $\mathrm{C}++08$ & $0.56 \pm 0.06$ & $-0.311 \pm 0.027$ & 0.181 & 1.63 \\
\hline 203532 & HD 203532 & 12.15 & 12.26 & 12.34 & CMLS01 & $\cdots$ & $\cdots$ & $\cdots$ & $\cdots$ \\
\hline 206267 & HD 206267 & 12.55 & 12.65 & 12.75 & $\mathrm{C}++08$ & $0.87 \pm 0.07$ & $-0.362 \pm 0.031$ & 0.115 & 0.84 \\
\hline 207198 & HD 207198 & 12.58 & 12.68 & 12.77 & CMLS01 & $0.90 \pm 0.03$ & $-0.367 \pm 0.031$ & 0.012 & 0.10 \\
\hline 208440 & HD 208440 & 12.33 & 12.43 & 12.53 & CML03 & $0.61 \pm 0.04$ & $-0.319 \pm 0.024$ & 0.083 & 0.64 \\
\hline 208947 & HD 208947 & 11.91 & 11.99 & 12.07 & $\mathrm{C}++08$ & $\cdots$ & $\cdots$ & $\cdots$ & $\cdots$ \\
\hline 209339 & HD 209339 & 12.29 & 12.35 & 12.41 & $\mathrm{C}++08$ & $0.58 \pm 0.04$ & $-0.314 \pm 0.025$ & 0.042 & 0.48 \\
\hline 212571 & $\pi$ Aqr & $\cdots$ & $\ldots$ & 11.70 & $\mathrm{H}++93$ & $\cdots$ & $\cdots$ & $\ldots$ & $\cdots$ \\
\hline 220057 & HD 220057 & 12.11 & 12.19 & 12.27 & CML03 & $0.75 \pm 0.05$ & $-0.343 \pm 0.024$ & 0.017 & 0.12 \\
\hline 224151 & V373 Cas & 12.46 & 12.58 & 12.70 & $\mathrm{C}++08$ & $0.46 \pm 0.04$ & $-0.295 \pm 0.032$ & 0.052 & 0.38 \\
\hline 303308 & HDE 303308 & 12.23 & 12.32 & 12.41 & $\mathrm{C}++08$ & $0.38 \pm 0.04$ & $-0.282 \pm 0.038$ & -0.237 & -2.02 \\
\hline
\end{tabular}

aTerms in parentheses indicate separate velocity components, if they are explicitly identified and not grouped together; see 4.3

${ }^{\mathrm{b}}$ Codes in this column are linked to references listed in Table 1

${ }^{\mathrm{c}}$ The expected depletion $\left[\mathrm{Kr}_{\text {gas }} / \mathrm{H}\right]$ computed using Eq. 10, The listed errors do not include an overall systematic uncertainty of 0.08 in the solar abundance $\sigma(\mathrm{Kr} / \mathrm{H})_{\odot}$ in order to show just the formal error that arises from the uncertainties in location of line of best fit and the value of $F_{*}$.

${ }^{\mathrm{d}}$ The observed $\left[\mathrm{Kr}_{\text {gas }} / \mathrm{H}\right]$ minus that computed using Eq. 10 .

eThe difference shown in the previous column divided by the expected difference due to the uncertainties in both the measured column density and the coefficients that appear in Eq. 10. 